\title{
FרR REFERENCE
}


atin ialage

Dept..? Entmology

PROPERTY OF

Z. P. METCALF

LIBRARY OF

Dr: Z P M

1885-1956 




\section{New York State Education Department}

\section{New York State Nuseum}

Johx .I. ('Lakke. l)irector

Ephrain Porter Fel state Entomologist

\section{Memoir 8}

\section{INSECTS AFFECTING PARK AND WOODLAND TREES}

$\mathrm{BY}$

EPHRAIM PORTER FELT D.Sic.

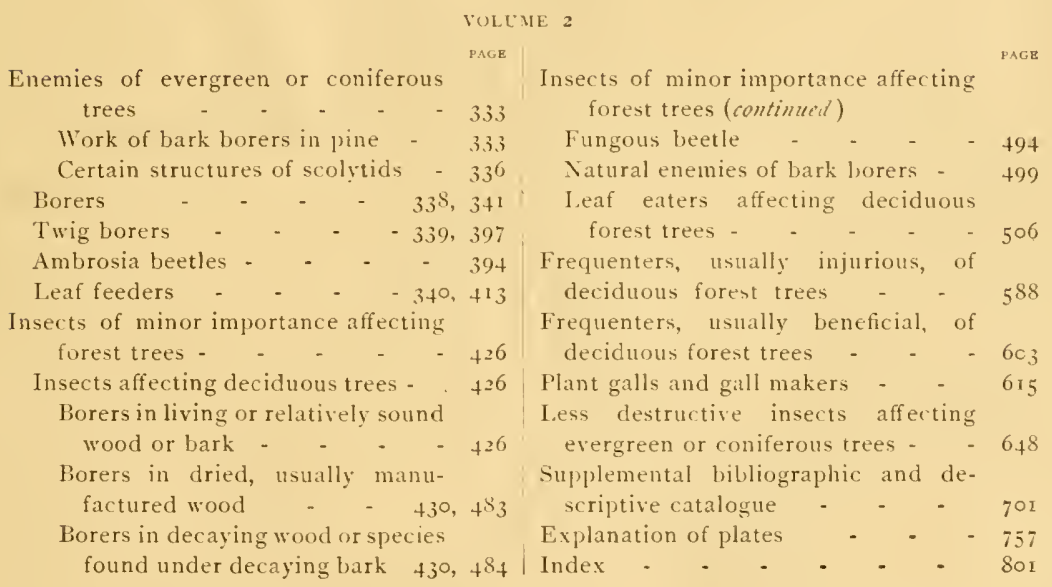

\section{ALBA NY}

NEW YORK STATE EDUCATION DEPARTMENT

1906 


\section{STATE OF NEW IORK \\ EDUCATION DEPARTMENT}

Regents of the University

With years when terms expire

1913 WhintelaW ReI1 M.A. LL.D. Chancellor - - - New York I917 St (indk Mckelway M.A. L.H.I. LL.D). D.C.L. Vice Chancellor Brooklyn

go8 Danel Beach Ph.D. LL.D. - - - - - - Watkins I91+ Pline T. Sexton LL.B. L.L.D. - - - - Palmyra 1912 T. Gunfokn Smitn M.A. C.E. LL.D. - - - - Buffalo 1907 Whlma Nottmgham M.A. Pl.D. LL.D. - - Syracuse 3910 Charles A. Garniner Ph.D. L.H.D. LL.D. D.C.L. - New York 1915 Albert Taxper Veer M.D. M.A. Ph.D. L.L.D. - Albany 191 E Emard Lauterbaci M.A. LL.D. - - - - New York 1909 Eugene A. Philin LL.B. LL.D. - - - - New York igr6 Lucian L. Sireduen LL.B. - - - - - - Plattsburg

\section{Commissioner of Education}

ANDREW S. Draper LL.B. LL.D.

Assistant Commissioners

Howarn) J. Rogers M.A. LL.D. First Assistant

Einward J. Goomwin Lit.D. L.H.D. Second Assistant

Augustus S. Downing M.A. Pd.D. LL.D. Third Assistant

Secretary to the Commissioner

Harlan H. Horner B.A.

Dinector of State Library

Enwin H. AnDerson M.A.

Director of Science and State Museum John M. Clarke Ph.D. LL.D

Accounts, Willian Mason

Chiefs of Divisions

Attendance, James D. Sullivan

Educational Extension

Examinations, Charles I?. Wheelock B.S. LL.D.

Inspections, FraNk H. WoOn M.A.

Law, Tiromas E. Finegan M.A.

School Libraries, Charles E. Fitcu L.H.D.

Statistics, Hiran C. Case

Visual Instruction, DeLaxcey M. Elis 


\section{ENEMIES OF EVERGREEN OR CONIFEROUS TREES}

WORK OF JMKK HORERS IN PINE

It is difficult for the average reader to gain a just conception of the injurious character of these insects by a perusal of a number of detached notices of the work of associated species. It is therefore proposed to give at the outset a brief resume of the conditions we have found in the Hudson valley. The white pines in this section have suffered seriously during the last three or four years and a considerable proportion of the damage is due to the work of bark borers and their associates. The extremely injurious character of their operations is well illustrated on plates 52, 53 and the rapid progress these pests may make is shown in figures I and 2 of plate 53. Figure I was taken Sep, 28, 1901 and figure 2 of the same trees was taken April 1902. It will be seen that these pines have been practically killed within a year and if a close examination is made we will find conditions substantially as follows:

At the very base of the trees there are a number of irregular, rather large masses of pitch and on removing these it will be found that they cover the entrance to a gallery about $1 / 4$ inch in diameter. The condition within is well represented on plate 58 , figure 4 , which shows the preservation of the walls by the infiltration of pitch and is thus incontrovertible evidence of living tissues having been attacked. This borer, known as Dendroctonus terebrans Oliv., is a very common species in New York State where it may be met with in small numbers in almost any pine grove. It can hardly be regarded as a dangerous form though it works in living tissues. Farther up the same trees a much more serious injury is evidenced by the numerous pitch tubes on the bark [pl. 54, fig. 2]. Plate 54 , figure 4 , represents one in profile. The removal of a piece of bark will show the condition of affairs under the pitch tube. Plate 54 , figure 3, illustrates the large central chamber underneath with five longitudinal galleries leading therefrom. Small notches may be observed on the sides of these galleries, particularly near the extremities, and these lead into 
diverging somewhat sinuous larval galleries which run approximately trans. versely of the woot fibers. This is the work of a large borer known as Tomicus calligraphus Germ., an insect that occurs in the thicker bark of trunks and larger limbs of both hard and soft pines. It normally does not cause very much injury bus under exceptional conditions it may become so abundant as to kill a tree very rapidly, so much so that the writer has known young pines, in apparently excellent condition, killed in ro weeks' time. These borers sometimes become so abundant. as to eat away practically all of the inner bark, a condition represented at plate 56 , figure 3 .

Farther up on the tree in the thinner bark of the trunk and the medium thick bark of the larger limbs, a smaller species may be found at work in some pines and its method of operation is well shown in plate 60, figure 3 . which represents the longitudinal burrows and the larval galleries of this smaller species, Tomicus cacographus Lec. This is a very badly. infestei piece of bark and plate 6o, figure 2, illustrates the work of this insect on limbs of hard pine which it had entered in the fall of Igoo. It will be observed that these galleries are very irregular and anastomose with out apparent reason. These are evidently galleries which the beetles have made for feeding purposes and in which they pass the winter.

Higher up on a white pine in the still thinner bark of the smooth trunk, a smalier form, the pine bark beetle, Tom ic us p in i Say, may be obsersed at work. This species operates not only in the trunk but also in the medium thick bark of the smaller limbs and not infrequently attacks living tissues. Plate 59, figure 1 , which is from a photograph taken with a light background, represents the numerous exit holes which this species may make in a badly infested section of a trunk and also a number of small pitch tubes and plate 59 , figure 2 , shows the inside of the same piece of bark photographed in a similar manner. The method of operation of this snecies is well illustrated, the central chambers, the primary galleries and the dilatıng mines of the young together with larger flat tortuous mines of another species known as the pine sawyer, Monoham $\mathrm{mus}$ con- 
fus or Kirby: The parent of this latter insect is represented at plate $6_{3}$, figure 1 , and its operations are familiar to many lumbermen because its coarse white sawdustlike chips may be frequently observed dropping from logs piled in mill yards and its large galleries are not uncommon defects in timber. The sawyer is rarely found attaching living trees. It prefers to breed in those which are dying or nearly dead and therefore is a follower of the above noted barkborers. ()ther species have a similar habit, notably the ribbed rhagrum. Rhagium lineat um Olis., a species which is frequently destructive to the bark of trees previously kilied by other insects. Its broad flattened grub delights to revel in moist decaying tissues and its very characteristic cells [pl. 64, fig. 7,8, 10] are walled by long white splinters torn from the rood forming a portion of its oval pupal cell. Another species, l'ytho americanus Kirby, is also associated with the preceding in this work of reducing decaying tissues to a still finer condition. It may be easily recognized by its oval cells which instead of being borlered by linear chips torn from the surface of the wood are lined with nearly decayed debris from the bark [sec pl. 64, fig. 6, 9].

These two species in conjunction with the bark borers soon reduce the inner tissues of an attacked tree to a mass of decayed regetable matter and render the stripping of the bark an easy matter. Plate 56 , figure 2 , illustrates the secrecy of these operations very nicely. Apparently the trunk of the tree has suffered little or no injury, but on removing the bark its inner layers are found to be a mass of corruption, as shown at plate 56 , figure 3 . The bark loosens and soon drops in large patches, exposing the wood to other enemies such as ambrosia beetles.

The condition of such a tree which scarcel: two years before it was photographed was in full vigor, is well shown at plate 54 , figure 1 . The small black holes in the bare wood are entrances to galleries of wood borers known as ambrosia beetles and these lead into lateral galleries from which in turn there are series of perpendicular chambers. This latter insect, Xyloterus bivittatus Kirby, is common in soft woods and is 
injurious on account of its making small black walled galleries which materially lower the market value of infested lumber.

CHRTAIX STRLCTIRES OF SCOLTTID

Scolytid beetles are so small and present such slight differences in general form, that a study of minor structural details is absolutely necessary for the adequate separation of species, unless we rely largely on food habits, something which is not always practical. Color has very little value and as a consequence we have felt obliged to give some attention to structural details, in spite of the fact that a distinguished authority on this group is engaged in a comprehensive study of these beetles.

The classificatory value of the antennae has long been recognized. They vary widely in character, as has been pointed out by earlier writers, though to our knowledge no one has figured these organs in many of our native species. The exceeding variability in structure is well illustrated by reference to plate 67 , figure 1 , showing the single jointed funicle of II onarthrum mali Fitch, inique in this extremely interesting group. The strongly flattened and enormously dilated club or terminal segment of Chramesus hicoriae Lec. is extremely characteristic. The two antennae of Scolytus, S. rugulosus Ratz. and S. quadrispinosus Say [pl. 67, fig. 10 and 15] are peculiar on account of the dark colored, triangular, clitinous structure in the club. The lamellate antennae of Phloeotribus liminaris Harr. and P. frontalis Oliv. [pl. 66, fig. I and 3 respectively $]$ are very different from those of other scolytids. The disposition of the sensory areas on the expanded club of the various species of Tomicus, is of considerable specific value [pl. 66, fig. 4-9 inclusive], while the greneral structure of the antennae of Dendroctonus [pl. 66, fig. 10] appears to be very characteristic of this genus.

The tibiae of various species also present characters which are of considerable value in the separation of different forms, though we should expect to find more or less variation in the number and development of the minor chitinous tubercles or processes. The closely allied species of Dryocoetes, D. e i ch hoff i i Hopk, and D. a utographus Ratz. vary sufficiently; so that they can be recognized by this character alone. Chramesus hicoriae Lec. has a very peculiar middle tibia, and the two species of Scolytus are remarkable for the development of a large terminal process opposite the attachment of the first tarsal segment [fig. 47]. V'arious specie: of Tomicus may be recognized by tibial characteristics, and Xyloclepte: possesses a very peculiar femur and tarsus. Phloeosinus dentatus 
Say may be instantly recognized by the distal margin of the hind tibia being thickly set with stout, chitinous processes.

The structure of the so called gizzard or proventriculus is exceedingly interesting in this group, most of the species differing markedly in this respect from their allies. The employment of this organ in systematic work is not new. It has been used by myrmecologists and Dr J. B. Smith, in a report issued a few years ago, calls attention to the fact that various species of katydids present recognizable differences in this organ. The structure of the Scolytid proventriculus is exceedingly interesting. It consists of a series of eight double, rectangular plates, the posterior extremities of which are provided with a series of long, chitinous, hairlike processes, undoubtedly serving as strainers to prevent the entry into the true or chyle stomach, of untriturated material. An end view of this organ is given on plate 68 , figure 5 , and plate 69 , figures 2 , 5, each of which shows the octagonal structure and the first named, the strainerlike hairs probably in the normal position. There are several well marked types of proventriculi. That of Tomicus, shown on plate 68 , illustrates a higlnly developed form in which the anterior portion consists of a series of plain, chitinous basal plates interlocked more or less perfectly by a series of marginal teeth, while the posterior part is narrower, strongly ribbed with chitinous bars and in addition, provided with a series of long, slender, chitinous processes, which undoubtedly serve as strainers as stated above. This type is also found in l'ityogenes and Dryocoetes. Dendroctonus [pl. 68, fig. 7$]$ has a simpler form of proventriculus, consisting of a series of eight double plates, in the walls of which are numerous chitinous points placed in more or less irregular rows. The posterior portion is provided with a series of stout, chitinous rods which terminate at the free margin in tufted processes and long, slender, chitinous rods, which latter evidently serve as strainers. A modification is seen in the proventriculus of Phloeosinus dentatus Say [pl. 69, fig. 4]. Another type, intermediate perhaps between that of Tomicus and Dendroctonus or Phloeosinus, is found in Nyleborus, Nyloterus and some other genera. It consists of the usual double plates, each provided along its length with a series of stout, chitinous bars terminating in a stout, dense structure composed apparently of fused ends and at the posterior extremity there are a number of long, slender, chitinous processes which unite to form a strainer. The differences in this organ between closely allied forms, are very nicely shown on plate 68 , figures $2,3,6$ and 8 , and plate 69 , figure 10 , which illustrate portions of the proventriculus of certain species of Tomicus. It will be seen that no two are alike, though all present a general resemblance one to another. The illustrations of the proventriculus of I) ryocoetes a utographus Ratz., and D. eich ho f i i Hopk. [pl. 69, fig. 9 and 11$]$ also bring out this point nicely; there being a marked difference in the toothing of the anterior portion of the plates. 


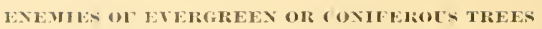

\section{Borers in trunk and wood}

Large, brownish pitch masses on pine trunks

Pitch mass borer, Parharmonia pin i, P. 34 I

\section{True bark borers}

Masses of pitch at the base of large pines, usually indicate the presence of a stout, brownish beetle about ${ }^{3}{ }_{16}$ to $1 / 4$ inch in length which, with its grub, bores the inner bark.......... Turpentine bark beetle, le ndroctonus terebrans, $p .3\}^{2}$ A rather stout, brownish or black, cylindric beetle, about $1 / 4$ inch in length, makes more or less longitudinal burrows in the thicker bark of the trunk and larger limbs of various pines .......... Coarse writing lark beetle, Tomicus calligraphus, p. 345 A light brown or nearly !lack beetle about " ${ }_{32}$ inch in length, bores the thicker pine bark near the middle portion of the trunk and that of the larger limbs

Pine bark beetle, To micus pin i, p. 351

A brown or nearly black, cylindric beetle about $1 / 6$ inch in length, works in the inner layers of thicker pine bark, particularly about the middle part of the trunk and on the underside of the limbs of larger trees......... Tom ic us caelat us, p. $35+$

A small, brown or blackish, cylindric beetle about $1 / 6$ inch long, bores the thicker bark of smaller pines and that of the limbs of larger trees

Southern Tomicus, Tom icus c a cographus, p. 356

A minute, dark bark beetle about $1 / 16$ inch long, makes short, sinuous mines in the bark of spruce and pine........ Minute spruce bark beetle, Crypturgus a to m us, p. 359

A rather stout, brownish or black beetle, ahout $3 / 16$ inch long, makes longitudinal galleries in the inner bark and outer sapwood of living spruce.

Spruce destroying beetle, I) en droct on us pice a perd a, p. 379

A light brown or black, rather stout beetle about $3^{\prime}{ }_{32}$ inch in length, makes somewhat irregular, transverse galleries in inner spruce bark, from which diverge smaller dilating larsal galleries........ Spruce bark beetle, Polygraphus rufipennis, p. 386

Balsam trees with red tips may be infested by a small, brownish or black beetle about : $3_{2}^{2}$ inch in length which, with its larvae, runs numerous galleries in the inner bark and sapwood.............. Balsam hark borer, Tomicus bals a me us, p. 375

A light brown or black beetle about $1 / 36$ inch long, makes peculiar, clubbed, longitudinal galleries under the bark of red cedar

Red cedar bark beetle, Phloe osinus dentat us, p. 39r 


\section{Large bark and wood borers, sawyers and their associates}

Large, white, fleshy, legless grubs from about t/2 to I inches long, may be frequently found working in the inner bark and sapwood of dead and dying pines, spruces, balsams and also in cut logs from these trees, produce the following:

A magnificent grayish beetie finely mottled with light brown and ranging in length from $3 / 4$ to $1 / 2$ inches.......... Sawyer. II onoham m s confusor, 1 . 360

A uniformly black beetle mottled with white and with a white scutellum, about $5 / 8$ inch in length.. White spotted sawyer, Monoh a m m s scutellatus, p. 364

A brownisł, mottled, cylindric beetle about $1 / 2$ inch in length and with very long, slender antennae............ Tickler, II on oh a m m us titillat or, p. $3^{65}$

A large beetle about.$/ 3 \mathrm{inch}$ long, with light grayish wing covers mottled with brown and dark spots..... Marbled sawyer, Monoh am mus marmoratus, p. 366 Smaller white grubs working in decaying bark, never entering the wood.

A white, broad headed, flattened grub occurs in considerable numbers on the bark of dead pines, transforming to a gray. black marked beetle with conspicuous ridges on its wing covers......... Ribbed pine borer, $\mathrm{R} h$ a g i u m $\mathrm{line}$ a $\mathrm{t} u \mathrm{~m}, \mathrm{p} .366$ A smaller, less flattened grub producing a small beetle with a black head and thin, dark bluish wing covers ................. Py tho american us, p. 368 Flattened, white or yellowish spotted beetles about $3 / 8$ inch in length, occur on spruce and hemlock in July, and are the parents of a destructive flat headed borer

Spotted buprestid, Melanophila fulvoguttata, p. 390

\section{Smaller wood borers}

A rather stout, brownish black beetle about I/. inch long, attacks exposed wood of rarious coniferous treees........ Spruce timber beetle, Xy loterus bivittat us: $1.3^{69}$ A brownish black, rather slender beetle about Is inch long, enters the sapwood of dying and dead white pine, making cylindric galleries, with black stained walls.

Eastern pine wood stainer, Gnathotrichus materiarius, p. 37 I

Small bark and wood borers working in the inner bark and outer sapwood and forming rather irregular galleries in dead limbs

Pityophthorus and Pityogenes(several species of each), 1). $372-375$

\section{Twig borers}

An oblong, oval weevil about $1 / 4$ inch long, frequently deposits eggs in the leading shoots of pine or other evergreen trees. The grubs work in the shoots and kill them, causing an irregular, deformed tree of little commercial value

White pine weevil, Pis sodes strobi, p. 397 
Two larger forms occasionally taken with the above, are much rarer

Pissodes dubius and P. affinis, p. for, foz

Two small, jet black weevils not over ${ }^{3}{ }_{16}$ inch in length, are occasionally abundant in association with the white pine weeril

II agdalis perforat a and M. a lutacea, p. 402 Short brown needles on the tops of hard pine, specially if there be a small pitch mass near the base of the tree, is an indication of the work of this insect

Pine tip moth, Pinipestis zimmermani, p. 403 Small yeltowish larvae infest the new growth of several pines, spinning a delicate web around the bud and mining both the twig and bases of the leaves

Nantucket pine moth, Evetria frustran a, 1) 405

An associated similar species is much rarer

Pitch pine Retinia, Evetria rigid a na, p. 407

Masses of pitch usually on the upper side of the smaller limbs and wigs of hard pine. cover the entrance of a burrow made by a small, yellowish white caterpillar about ${ }^{12}$ inch in length............ Pitch twig moth, Evetria comstockiana, p. 407

Fontless orange gruls occur in colored or whitish pitch masses on the underside of pitch pine branches............. Pitch midge, Cecidomyia resinicola, p. 4 to

\section{Insects affecting the leaves}

l)irty, yellowish, red headed, hlack spotted false caterpillars feed in clusters on the outer branches of pines from which they strip the leaves

LeConte's sawfly, Loph y rus lecontei, p. +i3

Yellowish, black headed, black spotted, false caterpillars nearly an inch in length, defoliate whice and hard pines from midsummer till late fall

Abbott's pine sawfy, Lophyrus abboti i, p. 4 It

Clusters of black headed, dark green, dark striped false caterpillars about ${ }^{1} 2$ inch long defoliate fir, spruce and pitch pine........ Fir sawfly, Lophy rus a lite tis, 1\% 4 is spruces dying in masses or clumps of greater or less extent are very likely affected by this species................. Spruce bud worm, Tortrix $f u$ m if eran $a, p .416$

A greenisn yellow saw fly caterpillar frequently defoliates larches in midsummer

Iarch sawfly, Lygaeonematus erichsonii, p. 4is Shortened, deformed needtes of pitch pine having a basal enlargement occupied by a thick, orange colored larva

Pine needle gall fly, Cecidom yia pini-rigidae, p. +23 


\section{Pitch-mass borer Parharmonia pini Kellicott}

Large brownish pitch masses on pine trunks may be caused by this borer.

This species is one of the more common pine borers and evidences of its work are by no means rare in the vicinity of Albany. Its recorded distribution is given as Canada, New York, New Jersey and New Hampshire. The life history of this species has been worked out very fully by the late Dr Kellicott, its describer, and the following is taken largely from his account.

Description. Malc. Head, palpi, antennae, thorax, and legs wholly metallic blue or green black. Collar edged with orange in front. Abdomen blue black above, with the posterior half of the fourth segment orange; underside wholly orange. Anal tuft orange, blue black above in the middle. Fore wings opaque, metallic blue or green black with discal mark somewhat deeper in color. Hind wings thinly covered with blue black scales; outer border very narrow, blue black.

Femalc. Same as the male.

Expanse: male and female, 28-30 mm (Beutenmuller).

Life history. The larvae occur more frequently than elsewhere just below a branch, sometimes about the border of a wound made by the axe. or where a limb has been wrenched off by the wind, rarely in the axils of the branches. It appears to attack larger trees than Zimmerman's pine pest and more frequently occurs at a considerable hight, having been taken 30 to to feet from the ground. While the larvae as a rule probably take advantage of the broken cortex, Dr Kellicott found instances of where they had worked through the bark into the soft layers. Pupae are to be found the last of May and the moths appear from the middle to the end of June and possibly others come forth in July and August, for Dr Kellicott found seemingly fully grown larvae in July, though some apparently mature caterpillars taken July I $5^{\text {th }}$ remained in their pitch cells unchanged till the following November.

According to the observations of Dr Kellicott three years are required, in some instances, to complete the life cycle. The larvae run more or less 
transverse rather tortuous galleries in the inner bark and sapwood, thus causing a copious exudation of pitch which is the most tangible evidence of their presence in a tree. Pupation occurs within the mass of pitch and just prior to the emergence of the moth, the pupa wriggles itself partly out of this sticky medium and is thus in a position to release the adult so that it may not become smeared with the pitch [pl. 45, fig. 4.]. Dr Kellicott bred a dipterous parasite from this species and as the larva frequently moves through the pitch and is almost always within its pitchy burrows, it is somewhat difficult to unclerstand how a parasitic fly could get at such a host. The excrement of the larvae is mixed somewhat with pitch and the caterpillar apparently moves through this substance as easily as some others through water.

\section{Turpentine bark beetle}

\section{Dendroctonus tercbrans Oliv.}

Masses of pitch at the base of large pines usually indicate the presence of a stout brownish beetle about ${ }^{3} 16$ to $1 / 4$ inch in length which, with its grubs, bores the inner bark.

This species is very common in New York State judging from collections in various localities, and the masses of pitch occurring at the base of larger trees is a most characteristic sign of its presence. A number of grubs and larvae of this species were found working in the living tissues at the base of hard pines at Mlanor L. I., in 1900. The insect was observed in the vicinity of Albany the same year and in 1901 at Round Lake and other localities. Pitch may be found flowing slowly from the wounds the latter part of the summer and pitch tubes on adjacent parts of the tree give additional evidence to the liking of this beetle for living tissues. Tomicus cacographus Lec. was observed working in large numbers in hard pines infested by this borer on Long Island and in the Hudson river valley: Tomicus calligraphus Germ. and some smaller species were found working in the trunk and limbs of trees infested by this insect. In no instance has the writer been able to trace very serious injury to the work of this borer. The greater part of the damage appears to have been done by species of Tomicus.

Early history. This species was observed by Dr Harris and he states 
that its larvae are common under the thick bark of pine logs and stumps. Dr Fitch notices this insect briefly and evidently considered it one of the common species in New York State. Dr Packard records the occurrence of larvae and immature beetles in abundance at Brunswick Me., in the middle of March. Dr A. D. Hopkins states that this insect was very common in IVest Virginia from IS9o-94, when it attacked all the pines and Norway spruce, working near the base of living and dying trees and in stumps. He also observes that it is widely distributed.

Description. The adult is a rather stout brownish beetle from about $3 / 16$ to $1 / 4$ inch long. It is probable that in a large series there would be

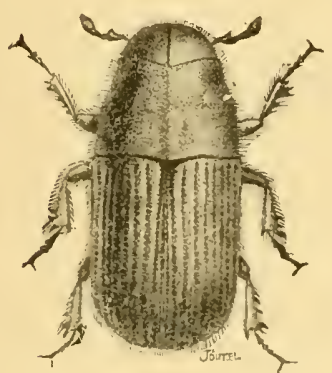

Fig. 64 Dendroctonus terebrans (author's illustration)

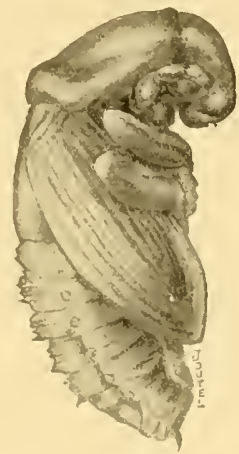

Fig, 65 Pupa of Den-

droctonus terebrans

(authur's illustration)

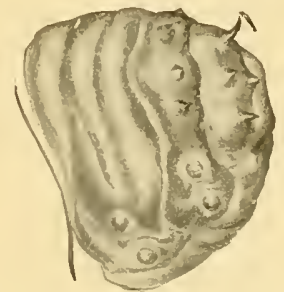

Fig. 66 Anal plate of larva of Dendroctonus terebrans (azthor's illustration)

considerable range in color, as is the case in many other bark beetles. The jaws are black, the eyes are finely granulated and the head and thorax thickly and somewhat coarsely punctured. The wing or elytra are striated and somewhat coarsely punctured. The general form of the beetle and certain structural details are shown in figure 64.

The pupa is white, quite stout and about $1 / t$ inch long. The lateral edges of the abdominal segments are each provided with a rather stout fleshy spine tipped with a dark chitinous point. A pair of similar spines are found on the last segment and smaller, scattering ones on the dorsal 
surface of the abdomen. Three segments project beyond the tips of the wing pacls.

The grub is a stout, brown headed, white larva about 3,8 inch long. The tips of the mouth parts and adjacent sutures are dark brown or black. The most prominent characteristic of this grub is the group of seven dark, chitinous spines on the horny anal plate. They are arranged as follows: an anterior transierse row of three, two wider apart behind and between these latter two, two others, one in front of the other [fig. 66].

Life history. The life history of this insect has received considerable attention at the hands of Dr Hopkins who states that hibernating adults commence to fly in the latitude of Morgantown $\mathrm{W}$. Va., as early as Ap. 20 and that all have emerged by May ro. Beetles from hibernating pupae and larvae emerge later. He records an instance when this beetle appeared in immense swarms soon after emerging from winter quarters and states that many were attracted by recently painted buildings and furniture shops, freshly sawed pine, lumber, etc., by the odor of turpentine.

1)r Hopkins states that this insect prefers to enter the bark of dying trees or the stumps of recently felled ones and that it will attack healthy trees only when it has no more favorable conditions. He finds that it shows a decided preference for the living bark at the base of trees and stumps and even the exposed roots, in which it excavates broad galleries.

It rarely breeds in the bark of logs. Dr Hopkins states that the primary gallery is usually extended longitudinally both above and below the main entrance, selelom in a lateral direction, though the secondary or drainage galleries may do so. Along the sides of the main or secondary galleries 20 to 40 eggs are placed in a mass and when the larvae emerge they proceed in a body to feed on the bark before them, working sicle by side. Plate 58 , figure 4 , illustrates a primary gallery of this species and shows how the walls have been preserved by the infiltrating pitch. The young grulos were working from one side of this gallery and had eaten out an irregular area of considerable size.

Dr Hopkins states that the first erg depositing period extends through 
the month of May and that larvae are found in abundance from the first of June to the beginning of winter. Pupae commence to appear early in July and may be found from then till winter. The adults of the first brood develop about the middle of July and emerge in August or possibly late in July since he has found young larvae by Aug. Io. Late in the fall all stages occur in the bark of infested trees and often in the bark of the roots as much as 6 inches below the surface of the ground.

These observations agree very closely with our own in this section as large numbers of eg'gs were found by us at Round Lake, Sep. 20, 1901. The observations of Dr Hopkins indicate that there are at least two broods in West Virginia and the same appears to be true for the latitude of Albany.

Dr Hopkins states that he has observed a clerid, Thanasimus dubius Fabr., attack and kill this large bark beetle, and he records finding large numbers of the beetles in the stomachs of brook trout caught in Randolph county, II. I'a. the latter part of May:

\section{Bibliography}

I $86 z$ Harris, $T$. W. Insects Injurious to Vegetation. p. 86.

1858 Fitch, Asa. Ins. X. I. 4th Rep't $1857,1.42^{2-43}$.

Is9o Packard, A. S. L. S. Ent. Com. 5th Rep't J. 721.

1899 Hopkins, A. D. W. Va. Agric. Exp. Sta. Bul. 56, p. $284,294,296,333,342,344$, $3+7,349,392,+15-20$.

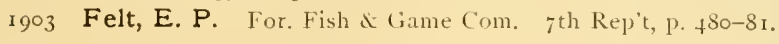

\section{Coarse writing bark beetle \\ Tomicus calligraphus Germ.}

A rather stout brownish or blackish cylindric beetle, about I/ inch in length, makes more or less longitudinal burrows in the thicker bark of the trunk and larger limbs of various pines.

This is one of the largest and commonest species of the genus found on or in the thick bark of our native pines. Its operations have been observed by the writer in many localities in and about Albany during the seasons of 1899-1902 and in some instances at least it appeared to be an active partner in causing very serious injuries to these trees. 
Early history. This species was noticed by Dr Fitch in his fourth report under the common name of fine writing bark beetle, but as this is hardly characteristic of the work of this borer, the writer has preferred to use the more pertinent common name employed by Dr Packard. Dr Fitch states that this beetle occurs mostly in the pitch pine in New York State and that he has also met with it in the limbs of aged white pines. Dr Packard records the work of this insect uncler the bark of the southern pitch pine at Houston. Tex., where it appeared to be abundant and Dr Hopkins in more recent years has taken the insect in various localities in the Western States. He finds that it is a common and widely distributed species over the greater part of the pine producing areas of the United States from the Atlantic coast to and including the Rocky mountain region.

He adds that it attacks all of the eastern and southern pines and doubtless several of the western species in addition to the rock pine in which he found it in large numbers in the Black Hill region.

Description. The beetle is about $1 / 4$ inch in length and varies in color from a light brown to nearly black. It is rather stout, cylindric and the

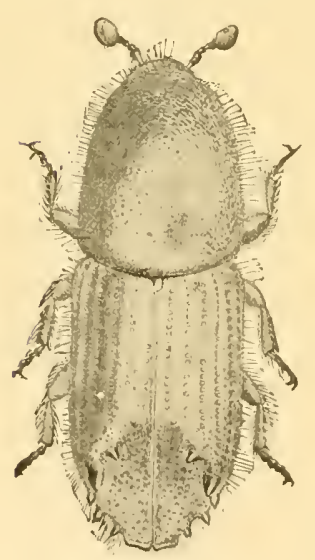

Fig. 67 Tomicus calligraphus (author's illustration) conspicuous excavation or declivity at the posterior end of the wing covers is bordered on each side by a row of six teeth or chitinized processes [fig. 67 ]. The teeth are arranged on each wing cover as follows: a minute tooth a little to one side of the median line, a dorsal subequal pair, a minute tooth between them and the two teeth of nearly uniform hight near the ventral margin of the declivity. The prothorax is thickly and rather finely granulated while the wing covers are marked with rows of closely set rather large punctures. The general form of the beetle and the sculpturing of the dorsal surface are shown in the accompanying figure. The antennale are represented on plate 66 , figure 8 .

The white pupae are found in oval cells in 
the bark. They are not quite so large as the beetle, having a smaller transverse diameter and tapering very much to the posterior extremity. Two or three of the abdominal segments usually project beyond the tip of the wing covers. As the pupa advances in age, the white becomes yellowish and the mandibles may be a dark brown.

The full grown larva is a brown headed grub about ${ }^{3}$ ro inch long when normally extended.

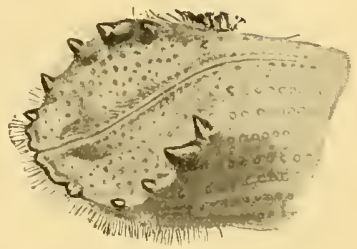
Fig. 68 Declivity of Tomicus calligraph us (author's illustration) It body is rather stout, usually slightly curled and there is frequently a considerable thickening in the thoracic segments. Portions of the inandibles and the borders of adjacent sutures are dark brown.

The galleries of this borer are very characteristic and frequently afford one of the readiest means of recognizing the insect. The exterior signs of its presence may be limited to numerous circular holes about I/8 inch in diameter or very few of these may be found. This latter occurs in cases where the beetles have entered the bark in large numbers but have not emerged. The entrance is usually effected under a projecting scale of bark and is therefore not conspicuous, while many of the exit holes [pl. 56, fig. I] occur on the prominent ridges and are therefore very easily detected. This species under certain conditions attacks living tissues and in that event the presence of the borers is indicated by brownish or whitish pitch tubes which may be nearly $1 / 2$ inch in diameter and almost that in hight. One of these structures is represented [pl. 54, fig. 4] and a close examination would show that it was built up with particles of pitch from the burrows. Plate 54, figure 2, shows a pine trunk with a number of pitch tubes indicating that the tree was alive when attacked. These pitch tubes are located, as a rule, over the entrance or nuptial chamber, from which the females make their galleries, usually following along the grain of the bark.

Plate 54, figure 3 , shows one of these nuptial chambers on the inner side of the bark and represents the seven female galleries, three extending 
down and four upwards. In the farther portions of the galleries are series of expanding larval burrows. It will be seen that these are placed at somewhat regular intervals and are due to the fact that the female gnaws small chambers at these points and places an egg in each. Sometimes eggs are deposited very largely on one side of the gallery and at others on both sides. The larval galleries dilate gradually, with the growth of the young, have a somewhat serpentine course and end in an oval pupal cell. They form perfect mazes of interlacing burrows when at all abun-
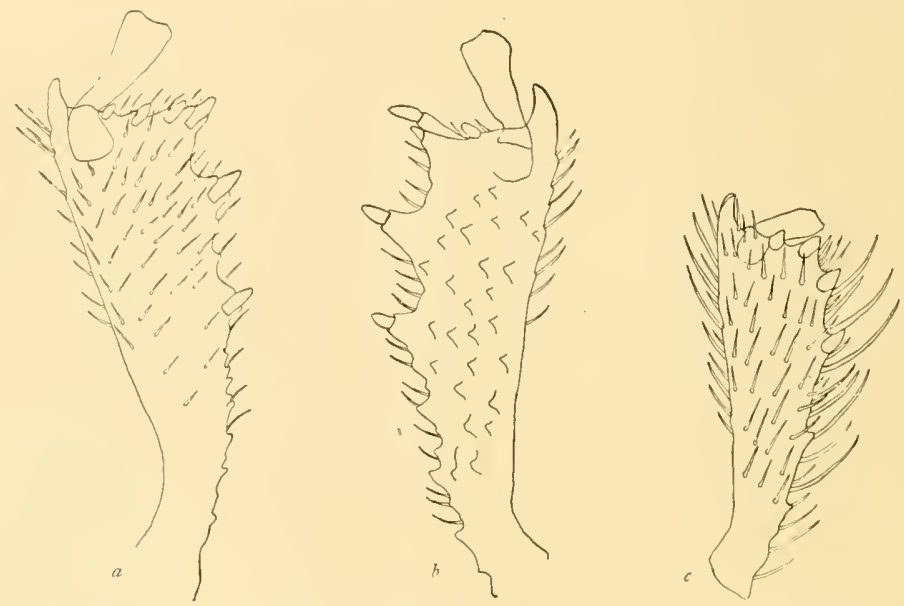

Fig. 60 Midule tibiae: $a, b=$ Dendrocton us terebrans, the former from Karner, the latter from Manor; $c=$ Tomicus calligraph us (original)

dant because the galleries of the young of different females may interfere more or less. It frequently happens that the beetles are so abundant as to eat away a considerable proportion of the bark and plate 55, figure 3 , shows this condition very nicely and figure 1 on the same plate represents the same thing in a more advanced stage. The condition of the trunk of the tree after it has harbored large numbers of these borers is shown on plate 54, figure 1. It will be seen that all of the bark has dropped from the trunk and that many very shallow grooves have been made in the surface 
of the wood, indicating that this species burrows very largely in the inner bark. The work of this insect is sometimes inconspicuous. Plate 56 , figure 2, shows the base of a tree, the inner bark of which has been thoroughly riddled by this borer, as shown on plate 56 , figure 3 , while it will be seen that nothing but decaying borings lies between the outer bark and the surface of the wood. The few exit holes on such a tree are shown on plate 56 , figure $\mathrm{I}$. The galleries of this insect are sometimes preserved for indefinite periods and constitute unimpeachable records of injury to living trees. Plate 55, figure t, shows an elongated piece of bark with a series of longitudinal well preserved burrows which have been kept from injury by insects usually following Tomicus because their walls were infiltrated with pitch, conclusive evidence that the tissues were living at the time this bark borer attacked the tree. The same thing is shown more plainly in plate 56 , figure 2. It will be observed that the burrows on either side of these preserved channels have been almost entirely obliterated by insects which follow the original invaders. Plate 60 , figure + shows how the Tomicus burrows may be obliterated by $R$ hag $\mathrm{i} u$ m line a $\mathrm{t} u$ m Oliv., a species living in decaying bark. The work of this scolytid in conjunction with other forms to be noticed later is well shown on plate 53 , figure I, which represent two pines photographed Sep. 28, r9or. It will be observed that the tip of one has very little foliage and as a matter of fact it was entirely dead at that time. The lower limbs, however, were thrifty and green and though insects were working in the trunk the tree still appeared to be rigorous. The other tree in the photograph bears rather abundant foliage and showed very little evidence of weakness, though it was somewhat injured at that time by the borers. The same trees are represented at figure 2, as they stood Ap. 2S, I902. It will be observed that the tree with a dead tip the preceding September has been entirely killed and that very few needles are to be seen on the other one, which showed comparatively little injury the preceding fall. Both are dead and are evidences of the rapidity with which this insect and its associates may work. Plate 52 shows a somewhat familiar condition in the ricinity of 
Albany where a considerable proportion of narrow strips of pine have been killed by this and related bark borers in recent years.

Life history. The development of this insect requires about ro weeks. Aug. 5, 1901 a slender pine was observed in which this species was entering in large numbers. The needles were somewhat thin at that time, pitch tubes were rather abundant and many small masses of pitch were to be found on the foliage of surrounding shrubs. The beetles were running their prinary galleries at this time, the bark of the tree was alive along practically its entire length, and many eggs were being laid by the beetles. About eight wecks later, or Sep. 26, two thirds of the needles were brown and the remainder were changing rapidly. Oct. is practically all the needles were brown and dead, the bark had been killed and its inner layers consisted of little else than borings. Practically all of the living Tomicids had forsaken this tree though some were found in those near by. 1) uring this short time the entire life cycle was completed as the inner bark had been entirely destroyed by the work of beetles and grubs. Dr Hopkins states that $\mathrm{H}$ ister cylindricus Payk is a common predaceous enemy of this species.

Habits. It is not intended by the above account to give the impression that this insect normally attacks living trees, but the evidence submitted above proves conclusively that, under certain conditions, it may and cloes cause serious injury. It is undoubtedly true, as stated by other writers, that this species, like some of its allies, attacks by preference diseased or dying trees and that only when it becomes exceptionally abundant is there danger of its injuring healthy pines. The writer has observed this insect in the vicinity of Albany where it has caused more injury to white pines than to the equally abundant, though smaller, hard or pitch pine. The latter occurs almost entirely on Long lsland and therefore this species can attack no other pine in that section.

Preventive measures. There is very little that can be done for trees which have been attacked by this and related borers other than cutting and burning the infested parts before the beetles have emerged. If this cutting 
is clone at the time the insects are all in the larval or grub state, it will be sufficient if the bark is stripped from the trees and allowed to dry. This will kill practically all the insects, but in case there are considerable numbers of beetles present, it would be wiser to destroy them at once by burning.

\section{Bibliography}

${ }_{1} 85^{8}$ Fitch, Asa. Ins. N. Y. 41 h Rej't 1857, p. $35^{-36}$

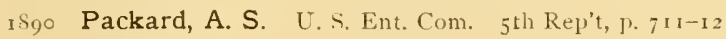

1899 Hopkins, A. D. W. Ta. Ayric. Exp. Sta. Bul. 56, ]. 284, 294, 342, 422, 445

1902 Felt, E. P. U. S. Dep't Agric. Div. Ent. Bul. 3r, n. s., P. $64-65$

1902 Hopkins, A. D. U. S. Dep’t Agrie. Div. Ent. Bul. 32, n. S. 1. $11-12$

1903 Felt, E. P. For. Fish \& Game Com. $7^{\text {th }}$ Rep't, 1\%. $4 S_{z-S_{5}}$

\section{Pine bark beetle \\ Tomicus pini Say}

A light brown or nearly black beetle about 532 inch in length bores the thinner pine bark near the middle portion of the trunk and that of the larger limbs.

This species is about the same size as Tomicus cacographus Lec. and similarly it is frequently associated with larger forms, specially with Tomicus calligraphus Germ. It appears to confine its attack largely to the white pine though it has been recorded from spruce and larch.

This borer was breeding in large numbers Aug. I8, Igor at Saranac Inn in a small dying white pine about 18 inches in diameter. The tree was abundantly infested about midway of its hight and a few beetles were found almost at the top and nearly to the base. This species occurred Sep. I5 in considerable numbers under the bark of the upper portion of the trunk and on the underside of the larger limbs of a large dying white pine at Lansingburg. This tree was also attacked by Tomicus calligraphus Germ. which was exceedingly abundant in the thick bark near the base of the trunk. Practically the same conditions as clescribed above were found at Bath-on-Hudson, across the river from Albany, except that the attack was more advanced. This form was also concerned in the death of a number of 
white pines at Round Lake N. Y. in the summer of I gor. The destructive work of this little borer was further evidenced by a complaint from Jeremiah Day, Catskill N. Y., December Igor, to the effect that 50 young white pines about 25 or 30 years old had been killed during the preceding summer and the examples of the injured bark proved that this species was the depredator. It is very evident that this little borer can seriously injure if it does not kill a tree outright. It was met with on pine and tamarack at Big Moose N. Y., July S, Igo3, evidently attracted to the recently burned trees.

Description. The beetle is slightly larger than Tomicus cacographus Lec., being about 5,32 inch long and usually a little stouter. It

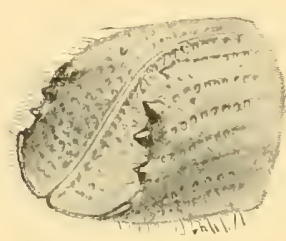

Fig. 7o Declivity of $\mathbf{T}$ omicus pi in i (author's illustration)

varies in color, like the preceling, from a light to a very dark brown. One of the most prominent characteristics of this species is the presence of but four teeth on each side of the conspicuous. posterior excavation or leclivity of the elytra. They are arranged as follows: the dorsal one near the median line is minute and sometimes wanting in the female; the second and third are larger, specially the latter, and touching at the base; the fourth is much smaller and independent. The prothorax is rather coarsely granulated and the elytra or wing covers are ornamented with lonsitudinal rows of rather small punctures. The antennal structure is shown on plate 66 , figure 7 and that of the tibia in figure 71 .

Life history and habits. The typical form of the burrows of this insect is well shown in plate $5 \%$, figure 3 , which represents the central or entrance chamber and an adult gallery. The latter is about ${ }^{2}{ }_{i 6}$ inch in diameter, and leading therefrom are somewhat tortuous expanding larval mines, rarely more than I $_{2}$ inch in length. The specimen of bark photographed shows also the work of what is probably a young Monohammus larva. It will be seen by an examination of this figure that, in this case at least, two females continued their work from the central chamber, one going up and the other down approximately parallel with the bark fibers. A more advanced 
stage of this insect's work is shown at plate 57 , figure 2 , which represents a portion of a female gallery together with a great many very irregular larral mines, several pupal cells and a few exit holes. This insect and its relatives may cause considerable injury to the inner bark without any very perceptible exterior signs. Plate 57 , figure 1 , represents a portion of pine bark, the inner surface of which has been badly mined by this borer. The early work of this species is shown on plate $5^{\delta}$, figure I, 2.

The work of this species in the thinner bark of the middle portion of a young pine is well shown on plate 59, figure 1,2 . The view of the inner aspect of the bark [fig. 2] shows the galleries of the Tomicus very plainly indeed and also the broader shallow workings of young Monohammus larvae. A great number of exit holes are represented in figure i by the light spots. Both of these illustrations were taken with a light background, consequently the exit holes appear as white spots.

Dr Fitch has noticed this insect and he states that the adult burrows have some resemblance to the fingers of a hand spread apart or to the track of a bird, in that they diverge from a common center and run up and down the tree. He states that this insect may be found under the bark of old white pines.
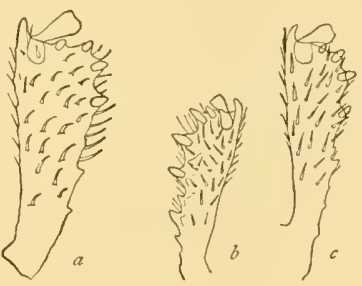

Prof. A. D. Hopkins records this species as exceedingly common in the bark of white pine Fig. 7 I Middle tibiae: $a-\mathrm{T}$ omicus pini; b-T. caelatus; $c=\mathrm{T}$. caco graphus (original) in West Virginia and observes that it attacks all other kinds of pine in that State. He has also found it in both the larch and black spruce, but not so commonly as in the pine. In May and June 1897 he found it quite common excavating egg gralleries in the living bark of black spruce and his observations led him to conclude that under favorable conditions it might prove a very destructive enemy of this tree.

Preventive measures. Methods of service in controlling the preceding species will also prove valuable in checking this borer. 


\section{Bibliography}

I858 Fitch, Asa. Ins. N. Y. 4th Rep't 1857, p. 36-37

I 890 Packard, A. S. U. S. Ent. Com. 5th Rep't, p. 7 r $3-15,858,903$

1 So9 Hopkins, A. D. W. Ta. Agric. Exp. Sta. Bul. 56, p. $253^{-5}+342,422,445$

Igoz Felt, E. P. For. Fish \& (rame Com. 7th Rep't, 1. $487-88$

\section{Tomicus caelatus Eich.}

A brownish or nearly black cylindric beetle about $2 / 6$ inch in length may be found working in the inner layers of thinner pine bark, particularly that of the middle portion of the trunk and on the underside of the limbs of larger trees.

This borer, like Tomicus cacographus Lec. and T. pin i Say is frequently associated with the larger and very common $T$. calli $\mathrm{i}$ graphus Germ. and like the other small forms prefers the thinner bark of smaller trees or that of the upper portions of the trunk of larger ones. This bark beetle has been characterized by Dr Fitch as one of the most pernicious of all the insects infesting our white pine forests and the yellow pine in the Southern States. He adds that while most of the larger borers may attack old and decaying or dead trees, this small insect is liable to invade those that are in full health and vigor and young trees as well as older ones.

This species is stated by Dr Hopkins to be very common in IVest Virginia in partly living bark, on living, dying and dead, standing and felled trees. He adds that it infests all of the pines and the native and introduced spruces and that it is widely distributed. He has found Hister cylindricus Payk in the galleries of this species.

This beetle was found at work in balsam in company with T o m ic us balsameus Lec, in hard pine with T. calligraphus Grem. and T. cacographus Lec, in white pine with T. calligraphus Germ. and T.pini Say and in spruce with l'olygraphus rufipennis Kirby: It was also taken on spruce and tamarack at Big Moose N. Y., Aug. 3, 1903, probably attracted to the recently burned trees.

Description. This is another medium sized Tomicus, being about I/s inch in length, cylindric, and varying in color from a light to a very dark 
brown. It is a little shorter and more slender than Tom icus c acographus Lec., the posterior, dorsal portion of the wing covers is more hairy and the declivity is not so well marked. There are three principal tubercles or chitinous teeth. A minute clorsal one near the median line and two larger, widely separated teeth on the flattened area of the declivity. Between the larger tubercles and farther from the median line there are two minute chitinous points marking the real margin of the declivity. The prothorax is rather finely granulated and the wing covers are marked with longitudinal rows

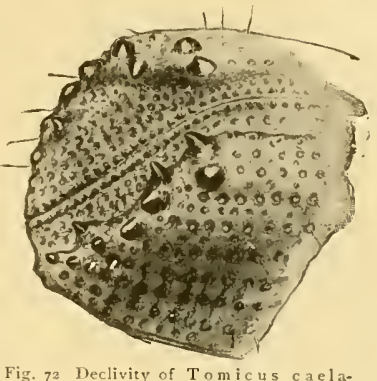
Fig. 72 Declivity of Tomicus caelatus (author's illustration) of rather fine punctures. The antennae are represented on plate 66 , figure 5 and the middle tibia at figure $7 \mathrm{I} b$.

The galleries of this species, judging from the few specimens collected are more irregular than are those of some other members of the grenus. The central or entrance chamber is well marked and from this three or more females may make their way in rather tortuous courses, sometimes parallel with and sometimes nearly across the bark fibers.

The eggs are deposited on both sides of the burrows and the grubs or larvae excavate very irregular galleries for a distance of about an inch and end their labors in a rather deep oval cell in the sapwood in which the grub transforms to the beetle.

Dr Fitch noticed this insect in his fourth report under the name of Tomicus xylographus Say and he comments as follows on the boring habits of this species. He states that a long slender cylindric gallery is formed which is excavated about equally in the outer surface of the wood and in the inner layers of the bark. In some cases two, three or even six galleries start from one point, running in opposite directions, but always lengthwise with the tree or limb. Little notches are excavated at intervals in the adult galleries while the work is in progress, one to four eggs being placed in each notch. The gnawings of the beetles are left 
strewn in the bark behind them, and as they travel backward and forward in the burrow from time to time, the little stiff hairs with which their bodies are provided serve as a brush to sweep this dust into the egg notches. Thus the mouths of these chambers are filled and the eggs therein covered and concealed. The female forms a burrow from 4 to 8 inches or more in length.

Life history. Dr Fitch states that the eggs probably hatch in 10 to 20 days according to the temperature. The young grub is found lying with its back towards the sawdust with which the cavity in which the egg is laid was filled, it thus being close to the soft innermost layer of bark at the extremity of the notch. This cavity is continued by the larvae to a clistance of from I to 3 inches at approximately right angles to the central gallery, which latter increases in size with the development of the grub. Those not overtaken by disaster excavate an oval cell in which the final transformation to the adult takes place. The small beetles escape from their retreats by boring directly to the surface of the bark.

\section{Bibliography}

1857 Fitch, Asa. Ins. N. Y. 4th Rej't 1857 , P. $30-35$

I 899 Hopkins, A. D. W. Va. Agric. Exp. Sta. Bull. 56, p. $258,34^{2}, 4^{2} 3$ and $+7^{6}$

I 903 Felt, E. P. For. lish \& Game Com. 7 th Rep't, 1\% $488-90$

\section{Southern tomicus}

\section{Tomicus carcograpluns Lec.}

A small brown or blackish cylindric beetle about ${ }^{\prime} 8$ inch long may frequently be found boring the thinner bark of smaller pines and that of the limbs of larger trees. It is usually associated in this work with one or more species belonging to this genus.

This bark borer is a medium sized form which was specially abundant in October 1900 at Manor L. 1., where it attacked the hard pines which are so abundant in that region. This beetle prefers the thinner bark of smaller trees and also attacks the middle portion of the trunk and the limbs of larger pines. It is frepuently associated in its destructive work with Tomicus calligraphus Germ.

This species was taken in August and September in considerable num- 
bers at Slingerlands and Karner. It was found working in a recently cut hard pine at Karner and in white pine limbs which had just been cut at Slingerlands. This beetle was common at Manor L. I., in I90o. It was taken from under the bark of the middle portion of the trunk of a pitch pine, which was attacked at the base by Dendroctonus terebrans Oliv. It appeared to be the primary offender in one case where it was boring in large numbers in a limb on which the needles were still green, though they dropped readily. It was found working in the living tissues at the base of another dying hard pine. This latter tree had thrown out sprouts in a last effort to sustain life and even these were dying. Another small tree was found badly infested with this bark borer. The leaves were just beginning to turn yellow and the attack was confined almost entirely to the upper portion of the trunk.

Description. This is one of the medium sized species of Tomicus. The beetle is a trifle over $1 / 8$ inch long, cylindric, rather slender in form and like other species of this genus, varies in color from a light to a dark brown. The posterior excavation or declivity of the wing covers is bordered by a series of five teeth. The one near the dorsal median line is very minute, the second and third are much larger and connected at the base and the fourth and fifth are Fig. 73 Deciivity of Tomicus smaller and distinct from each other. The prothorax illusiration) is rather coarsely granulated and the wing covers are marked with longitudinal rows of rather deep punctures. The antennal structure is illustrated on plate 66 , figure 8 and the tibia in figure $7 \mathrm{I} c$.

The soft white pupae may be found in their oval cells in the bark. The pupa is usually creamy white, about as long as the beetle and with a tapering abdomen with one or two segments isually extending beyond the tips of the wing covers.

The full grown larvae or grubs are a creamy white, about 3 ' is inch long and with the body slightly curved. The head is light brown with the tips of the mouth parts and adjacent sutures much darker. 
Life history. Aclults of this species were entering limbs in large numbers at Manor L. 1. Oct. 3, I900, the galleries evidently being both for hibernation and food. They were a little over ${ }^{1}$ in inch in diameter, exceedingly tortuous and apparently without plan. In one portion the beetles had just begun their operations and the curious manner in which they work in living bark is shown on plate 60, figure I. A more advanced stage is illustrated at plate 60, figure 2, and this shows how completely a limb may be girdled within a short time. The specimen from which this illustration was made was taken from a limb about so feet long which bore many green needles. The foliage dropped readily and as the tree had apparently been vigorous till within a short time, the primary injury was attributed to this insect. A central or entrance chamber will be seen in both of these illustrations, though most of the galleries are very irregular. The tendency of the adults to work largely with the grain of the bark is shown in plate 60 , figure 3 , which illustrates a very badly eaten piece of hard pine bark. There was very little or no evidence of the operations of the larva in this instance. Dr Packard states that the burrows of this species are much like those of T. calligraphus Germ. except that the main gallery is narrower, being about $I$ to inch in diameter and the exit holes to correspond with the smaller size of tine beetle.

So far as our observations go the galleries made by the beetles during the breeding period are more regular and are apt to run with the grain of the bark, the eggs being deposited on either side and the young making more or less oblique, serpentine galleries in the adjacent tissues. Later, the infested bark may become a mass of interlacing burrows partly filled with brown particles of decaying bark. A few of the adult galleries may remain comparatively untouched, but, as a rule, they are not so straight and sharply defined as are those of Tom icus calligraphus Germ. Dr Hopkins has observed that the beetles are attracted by turpentine.

Distribution. The distribution of this species has been given by Dr LeConte as the Southern and Western States and Dr Packard credits it with injuring the pines of North Carolina and southward even more than 
T. pin i Say in the north. Dr J. B. Smith records the insect as being present throughout New Jersey where it mines the green bark of dead or dying pines and spruces. Dr Hopkins states that it is very common in Wiest Virginia under partly living, dying and dead bark of living, dying and dead standing and fallen pines and spruces. He states that it infests all of the pines and the native and introduced spruces and that it is widely distributed.

Natural enemies. Dr A. D. Hopkins has reared several parasites from this species. Spathius canadensis (?) Ashm, was bred by him from cocoons found in the mines of this insect in white pine and S. pallidus Ashm. was reared by hin from cocoons occurring in the larval galleries under the bark of scrub pine. Hister parallelus Say and H. cylindricus Payk were taken by Dr Hopkins in the galleries of this species.

\section{Bibliography}

ISgo Packard, A. S. U. S. Ent. Com. 5th Rep't, p. i;

IS99 Hopkins, A. D. WV. Va. Agric. Exp. Sta, Bul. 56, p. $2 S_{4}-3+4,3+7,422,42 i$, $4=S$ and +45

1903 Felt, E. P. For. Fish it Game Com. ith Rep't, p. $+\$ 5-86$

\section{Minute spruce bark beetle \\ Crupturgus atomus Lec.}

A minute, dark bark beetle about $1 / 15$ inch in length. makes short sinuous mines in the bark of spruce and pine.

This is one of our smallest bark borers and in many instances is probably overlooked on this account. According to Dr Hopkins it enters the galleries of other bark beetles, from which it excavates numerous very small, irregular channels through the inner bark of dying and dead black and red spruce and white pine. The mine consists of a short, sinuous, primary gallery about $\mathrm{I}_{2}$ inch long from which arise on either side about io shorter secondary galleries. The beetles are sometimes extremely numerous, many mines occurring within a square inch of surface. Dr Packard records meeting larvae, pupae and beetles in great abundance at Brunswick 
Me., in August I880, where they occur in dead trees as well as spruce stumps, also in white pine stumps.

The following description of the beetle is given by Dr LeConte: Slender, dark, piceous, shining, prothorax distinctly longer than wide, sparsely and coarsely punctured ; elytra very finely not densely pubescent, striae composed of shallow punctures, interspaces as well as the striae without distinct punctulations. Length, I $\mathrm{mm}+$. Head with a broad short beak, slightly convex, finely not densely punctulate. Prothorax distinctly longer than wide, slightly rouncled on the sides, gradually narrowed from the middle to the tip; disk transversely convex, not polished, but very imperceptibly granulate, sparsely and strongly punctured. Elytra cylindrical, not wider than the prothorax, convexly declivous behind; sparsely clothed with very short and fine yellowish pubescence, striae composed of rather large, shallow punctures, interspaces not narrower than the striae, almost imperceptibly punctulate. Beneath nearly smooth, sides of metasternum with a row of punctures, sides of ventral segments feebly punctured. Legs piceous, front tibiae with five distinct acute teeth on the outer edge, which is also sparsely fringed with long yellowish hairs, with a fine apical spine at inner anyle; tarsi yellow, narrow, third joint not dilated. Antennae with the scape long, the first joint of the funicle large, rouncled; second indistinct, closely connected with the club, which is large oval, not pointed, solid, polished and corneous, except along the apical margin, where there is a spongy sensitive band.

This species probably has a wide distribution in the northeastern United States, as it is recorded from Canada and Maine south to WVest Virginia and westward to Ohio.

\section{Sawyer}

\section{Monohammus confusor Kirby}

Large white, fleshy, legless grub from $I_{1}^{\mathrm{T}}$ to 2 inches long may frequently work in the inner bark and sapwood of dead and dying pines, spruces and balsams, and also in logs cut from these trees.

This species is one of the more common borers found under the bark of logs and dead and dying trees belonging to the species mentioned above. The presence of the borers in piles of logs may easily be detected by the masses of white sawdustlike borings which collect on the ground beneath or which may be found under the bark.

Injuries. Grubs belonging presumably to this species have been met 
with by the writer in balsam, spruce, hard and white pines, and in not a few instances they were abundant enough to cause considerable injury and materially reduce the market value of the logs. This species, when numerous, also appears able to exist in living trees. The writer found a number of these grubs Oct. I6, 190 I at Bath-on-Hudson, working in living, apparently healthy bark and with the point of injury indicated by wormlike masses of pitch, showing conclusively that the grubs were operating in living tissues. The tree under observation was apparently not infested by any other insect and it appears probable that the beetles must have bred in large numbers in nearby decaying, dead or dying trees and then, because of the lack of more suitable conditions, attacked this living white pine. Another case was observed during the same summer where the grubs of this species were working in what appeared to be healthy pines and their operations were to be observed here and there over a considerable proportion of large trunks. It is remarkable how quickly this species infests a dying tree, and in not a few other cases have we been led to question whether the Monohammus larvae may not have followed the work of other species very closely, even if its attack was not coincident with theirs.

Early history. This species was noticed in some detail by Dr Fitch under the name of Monoham mis notatus Drury. He characterizes it, M. marmoratus Rand. ancl M. scutellatus Say as the most common and pernicious borers of pine timber in New York. He states that felled pine timber allowed to remain in the forest through the summer months is likely to suffer much injury from these borers, and adds that they invariably make their exit from the wood on its upper side, and, as the holes from which they issue admit water, the timber decays rapidly.

This insect was noticed in 1877 by Rev. C. J. S. Bethune who states that it is very generally destructive throughout Canada and the Northern states, often being excessively abundant in pine regions. He cites $\operatorname{Mr} \mathrm{E}$. Billings to the effect that he once saw a pine tree near Lake Clear, Renfrew county, on which he calculated there were at least 300 individuals of this species, while many others were flying about in all directions. Dr James 
Fletcher in 1887 includes this species and M. scutellatus Say as the two insects which probably commit the most serious ravages in Canada on felled pine timber or on standing pine trees after they have been injured by fire.

Description. The egg has been described by Dr Packard as follows : "Ovo-cylindrical, well rounded, but tapering somewhat at each end, of a dirty white color" and as about $1 / 6$ inch long.

The grub is a white, fleshy, cylindric larva, which when full grown may. attain a length of from $1 / 2$ to 2 inches. The mandibles are a very dark brown and the head varies in color from amber to rather dark brown, the deeper color occurring at the sutures. The thoracic shield is somewhat chitinized and bears a transverse, irregular, dark brown marking. This larva may be readily distinguished from that of Rhagium, which frequently occurs under similar conditions, by the entire absence of legs and by the head not being nearly so wide and flattened.

The adult insect is a magnificent grayish beetle, finely mottled with light brown and rather conspicuously dotted, specially on the wing covers, with dark brown or nearly black. The body length of the beetle varies from about $3 / t$ to $1 / 2$ inches. The insect is remarkable for its enormous antennae, which may measure from 2 to 3 or more inches in length [pl.63, fig. I].

Life history. The beetles are found in the vicinity of Albany from the latter part of June through July and into August and Dr Fletcher mentions taking an adult in September. This latter date is late for New York State. The beetles by preference frequent dying or dead trees and occasionally are found in considerable numbers.

The eggs of this species are deposited in conspicuous transverse gashes in the bark which are made by the female with her jaws. Dr Packard is of the opinion that the beetle prys up a portion of the gash and inserts the egg in the opening thus formed. The eggs are said to hatch in from two to three day's after deposition and the young grubs at once begin boring in the inner bark. The earlier work of the larva or grub is confined almost 
entirely to the inner bark, but as it increases in size the sapwood may be scored, and eventually the borer may go to some depth in the wood, particularly on the approach of winter.

This grub when near maturity is very strong and excavates large, irregular galleries in almost any direction in the wood, and has been frequently met with by the writer at the depth of 6 or 8 inches from the surface. He has seen small balsam trees, 6 inches in diameter, penetrated to the center by the grub, which subsequently completed its transformations and the beetle emerged on the opposite side. This borer works so rigorously that it may be heard at night gnawing in the wood.

The period required for the completion of the life cycle is unknown, though most writers are of the opinion that under ordinary circumstances three years are necessary. Dr James Fletcher calls attention to the finding of larva of all sizes in a pine which had been killed by fice the previous spring and from this he is inclined to believe that under certain conditions the life cycle may be completed in a year. It is known that this time may be enormously extended, since beetles have been bred out from wood which had been cut 10 to 15 or more years before.

Distribution. This insect, which appears to have a general distribution in pine, spruce and balsam regions, ranges from IV est Virginia into Canada and, according to published accounts, it appears to be much more abundant to the north.

Protective measures. Very little, or nothing can be done to protect standing trees from attack by this insect, other than the prompt cutting of dying and dead timber. Dr James Fletcher has pointed out that logs may be protected to a considerable extent by covering them with fir boughs so as to shade them from the sun. Probably any other shade would be nearly as effective. The removal of the bark would also aid materially in preventing the borers from entering the logs.

\section{Bibliography}

I 857 Fitch, Asa. Ins. N. Y. 4th Rep't, p. $21-24$

1890 Packard, A. S. U. S. Ent. Com. 5th Rep't, p. 686-95 


\section{White spotted sawyer}

\section{Monohammus scutcllatus Say}

This longicorn is much less abundant about Albany than its larger relative M. confusor Kirby. It measures about $5 / 8$ inch in length and may be recognized by its nearly uniform black color mottled with white.

The writer took a specimen on dying white pine at Bath-on-Hudson July 26, Igoi, and one on hard pine at Karner June $r_{3}$ of the same year. It appears to be numerous in the Adirondack region, and somewhat so at Pike. According to Dr Packard it is common, sometimes abundant, in Maine and northern New England and specially in the lumber regions of Lake Superior, from whence he had received it in large numbers. It also occurs, according to him, in pine forests of British America, and in Mashingron and Oregon along the Pacific coast. Dr A. 1). Hopkins records it as a common and destructive wood borer in dying and dead white pine in West Virginia. This species appears to be comparatively rare in New Jersey, since Dr Smith lists a single specimen from Newark and gives but one other locality where it is known to occur.

Rev. C. J. S. Bethune, writing of this insect in 1877 , states that the species is sometimes very abundant in Canada, and that he has occasionally found the insects swarming in great numbers on fallen pines. Rev. Thomas IV. Fyles records an instance where this species was extremely injurious to spruce in 1895 . He states that in the spring one of his neighbors planted an extensive hedge around his grounds and by the end of the summer nearly every scion had been girdled or partially so by this beetle. He adds that in a heary wind he has seen a large spruce tree snap off two feet from the ground, and on examination found that the stem was honey combed with the larval galleries of this insect. Dr James Fletcher states that shading cut logs with balsam boughs appears to be a very effective method of preventing injury by this species and $M$. confusor Kirby. 


\section{Tickler}

\section{Monohammus titillator Fabr.}

A brownish mottled cylindric beetle, about //2 inch long, and with very long slender antennae, may be found in small numbers on pine trees in midsummer. The larvae bore in the wood.

This beautiful little beetle was met with in very small numbers in 1901 on both white pine and hard pine. This species is evidently widely distributed, since its range has been given by $\mathrm{Dr}$ Horn as from Canada to the state of Washington and southward. It occurs on pines in June and July throughout the state of New Jersey as recorded by Dr Smith. This insect was noticed briefly by Dr Harris, but he was not aware of its habits. Mr F. C. Bowditch has ascertained some interesting facts regarding it.

Life history and description. Mr Bowditch records taking adults under the bark of yellow pines in June, at which time a number were nearly ready to emerge, and a week later he disccrered no less than so beetles in one tree in all stages of development, the largest being near the base. The larrae bore through the trunk, when it is less than 6 inches in diameter, instead of working here and there on the surface of the wood. He states that the larra feeds on the sapwood or inner bark till fall, when it turns and bores outward, leaving its passage filled with chips, and forms a hibernating cell about $1 / 2$ to ${ }^{1}$ ro inch beneath the bark, in which it completes its transformation during the winter or even as late as the last of June. The grub has been described by Mr Bowditch as follows:

The larra is a footless, yellowish, white grub, more or less hairy, cylindrical in shape, about $\mathrm{I}+$ io inches long, and $3 / 20$ of an inch in diameter. The body including the head is made up of $1+$ segments, the last eight of which have a kind of ridge on each side, covered with hairs longer than those which are found on the rest of the body and which doubtless assist it in locomotion, the second segment next the head is flattened on the upper side.

\section{Bibliography}

I 873 Bowditch, F, C. Am. Nat. $7: 498-500$ 


\section{Marbled sawyer}

Honohammus marmoratus Rand.

This insect is much rarer in New York State than the larger M. conf us or Kirby and the nearly equal sized M. scutellatus Say. The beetle is about 8 inch long and ma be recognized by its light grayish wing covers mottled with brown and dark brown spots.

The insect was taken in small numbers the latter part of June and in early July; 1901 at Albany and a few specimens have been received by the writer from Pike.

It presumably has about the same habits as M. scutellatus Say. It was brought to the attention of Dr Fitch in 1857 , who records the breeding of the beetle in July. Dr Packard states that it is not a particularly common insect.

\section{Bibliography}

1857 Fitch, Asa. Ins. N. Y. th Rep't, P. 24

\section{Ribbed pine borer \\ Rhagium lincatum Oliv.}

A white, broad headed flattened grub frequently occurs in considerable numbers under the bark of dead pines, and transforms to a gray, black marked beetle with conspicuous ridges on irs wing rovers.

This species has been met with by the writer in considerable abundance under the bark of dead white or hard pines in the vicinity of Albany. It can not be considered injurious to living trees so far as our experience goes, since it is one of the forms which revels in partly rotten tissues, and the operations of the grub and associated insects soon loosen the bark so that it falls off in large sheets. This beetle was so abundant Sep. 2, 1901, under the bark of a good sized white pine, at Lansingburg, that about 25 adults, numerous pupae and larvae were obtained in a few minutes. Oct. ro practically the same conditions obtained, though there may have been fewer larvae. It was taken Aug. 17, 1901, under spruce bark at Saranac Inn.

This species was noticed by Dr Rathvon in I86I, who found it very common in Pennsylvania and credited it with killing trees. It has been 
recorded by Dr Packard as occurring under the bark of pitch pine and balsam trees. He found this species abundant under the bark of a white pine $\log$ at Salem Mass., in October, and states that he has frequently detected it in the same situations in Maine. He obtained both the larvae and adults $A_{p}$. 2. . Dr Hopkins has recorded this species as mining under the bark of dying trees and states that it is common in Virginia. He records the presence of adults Ap. 8, May 5, 9, Oct. 17, Dec. 19, and pupa in October, and larvae July 14. He adds that it is a very common borer in decaying pine wherever the trees grow in IV'est Virginia.

Description. This beetle is a grayish insect, mottled with black, about 5,8 inch long. Its general forms and markings are well shown on plate 64 , figure I. The prothoracic spines and the two prominent ridges on each wing cover are the most characteristic features of this beetle.

The pupa is white, rather stout, and varies in length from about $1 / 2$ to nearly $3 / 4$ inch. The dorsum of the head, meso- and metathorax and each abdominal segment bear minute hairs or setae somewhat grouped on each side of the dorsal line. The brown abdominal spiracles are conspicuous [pl. 6., fig. +4].

The pupal cell is constructed just under the bark. It is oval, about $1 / 2$ by $3 / 4$ inches in diameter and is partly lined with somewhat decayed wood particles. The most characteristic feature is the mass of fibers torn from the wood at the bottom of the cell and incorporated in its walls [pl. 64, fig. 7]. The excavation in the wood is probably necessary to give requisite depth for the thicker pupa and beetle. This is in marked contrast to the pupal cells of Pytho americanus Kirby, a species frequently associated with Rhagium and which is noticed on page 368 .

The white flattened grub or larra ranges in length from $3 / 4$ to $11 / 4$ inches and is remarkable for its broad head which is amber colored and is fully as wide as the thoracic segments. The powerful jaws are tipped with black. The corneous prothoracic shield is yellowish, and the six true legs are poorly developed [pl. 64, fig. 11].

Life history. Some larvae, pupae and many beetles were found under 
the bark of one tree Sep. 21, I9or. The remaining pupae were nearly ready to assume the adult form and the beetles were to be found mostly within the pupal cells. Many of them had begun to burrow in an oblique direction up and out through the bark. Some had just started the work but in many cases the beetles had nearly penetrated the thick bark, though none had escaped, so far as was observed.

The grubs of this species evidently become full grown during the latter part of the summer, construct their pupal cells, and transform to beetles before the approach of cold weather. The adults winter very largely in the pupal cells or in the characteristic upward curving exit burrows which they begin soon after assuming the adult condition.

\section{Bibliography}

I861 Rathvon, S. S. L. S. Patent Office Rep't, p. 620

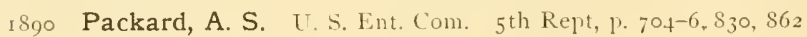

1893 Hopkins, A. D. II. Va. Agric. Exp. Sta. Bul. 32, p. 195

I 899 W. Va. Agric. Exp. Sta. Hul. 56, 1. 439

1903 Felt, E. P. For. Fish « Game Com. 7th Rep’t, 1) $492-93$

Pytho americanus Kirby

A small beetle with a black head and thin dark bluish green wing covers may be met with under decaying pine hark the latter part of the summer.

This species, like its associate, $\mathrm{R}$ hagium lineatum Oliv., occurs rather commonly in moist lecaying pine bark. The larrae, pupae and beetles of these two species may be found in large numbers under the bark of the same tree.

This insect appears to prefer the bark in an advanced state of decay and, like its associate, can be regarded as injurious only so far as it hastens the decay of dead trees, since it aids in loosening the bark and in exposing the wood to the elements. It has been recorded by $\mathrm{Mr}$ Harrington as occurring in Ontario, Can., in shallow cells under the bark of old logs and stumps. Dr Hopkins states that in West Virginia it commonly infests dying and dead bark in pine logs and stumps. He obtained adults in February. 
Description. The beetle is much flattened and is about 1/2 inch long, with the head and thorax black, and the striated wing covers a dark bluish green. The powerful jaws are rufous, tipped with black, and the antennae, legs and abdomen are similiarly colored. The insect is represented on plate 6.4 , figure 2.

The pupa is whitish, more slender than that of Rhagium, and may easily be recognized by its occurring in cells with walls composed entirely of nearly rotten particles of bark [pl. 64, fig. 3].

The pupal cell is nearly circular, about $3 / 4$ inch in diameter, and is constructed between the bark and the wood. There is no excavation in the wood and the walls are composed only of partly rotten borings [pl. 64, fig. 9]. The difference between the cells of Rhagium and Pytho is well brought out in the illustration.

Life history. The larva evidently becomes full grown the latter part of the season and transforms to the pupa and then to the beetle before the approach of cold weather. The species hibernates probably very largely in the pupal cells or under the bark.

\section{Bibliography}

I 893 Hopkins, A. D. W. Ta. Agric. Exp. Sta. Bul. 32, p. 204

I 899 W. Va. Agric. Exp. Sta. Bul, 56, p. 4 I r

I903 Felt, E. P. For. Fish \& Game Com. ;th Rep't, p. $49+$

\section{Spruce timber beetle Vyloterus bivitatus Kirby}

A rather stout, brownish black beetle, about is inch long, attacks the exposed wood of various coniferous trees.

The deserted galleries of this species were found by the writer in a spruce $\log$ at Floodwood in I9or. This beetle was breeding Aug. 23 at Axton in a stump of a balsamtree which had been cut the preceding April. It has been recorded by Dr Hopkins as infesting black spruce and hemlock in West Virginia, and Dr Packard states that the insect occurred, though not commonly, under the bark of a fir in the White mountains near the 
Glen House. Mr H. C. Hubbard states that this species is common in coniferous trees from Alaska to Maine and extending southward in the mountainous regions. He adds that it is equally common in northern Europe.

Description. This is a rather stout, brownish, black beetle, measuring

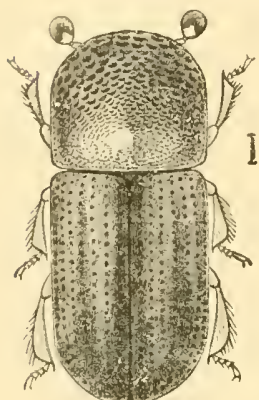

Fig. 7t Xyloterus bivitta this. (After Hubbard, $\mathrm{L}^{\circ}$ S. Dep't Agric, lliv. Fut. Bul, 7, n, s, 1897) but little over 's inch in length. The form of the antennae, the sculpturing of the prothorax and the markings on the wing covers are well shown at figure $7+$

The galleries of this species, like those of the following, penetrate the wood vertically for some distance and then branch. The brood chambers are arranged at nearly equal distances and extend above and below in a direction parallel with the wood fibers. They are usually farther apart than in the case of X. politus Say. The walls are stained black as in allied species. Natural enemies. Dr Hopkins has found I ps fasciatus Olir. associated with this form in spruce logs, and larva, probably of the same species, in its burrows. A predaceous form, Thancrocleris sanguineus Say, was found by Dr Hopkins on a hemlock stump with this borer. He also records an interesting instance where large numbers of this species were taken in the stomachs of brook trout in Randolph W. Ta. the latter part of May. The insects had evidently been flying in considerable numbers, dropped on the water and fallen a prey to the fisin.

\section{Bibliography}

1897 Hubbard, H. G. U. S. Dep't Igric. Div. Ent. I3ul. 7, n. s. p. 28

r 899 Hopkins, P. D. WI. Va. Agric. Exp. Sta. Bul. 56, I'. 349, +44 


\section{Eastern pine wood stainer}

\section{Guathotrichus matcriarius Fitch}

A brownish black, rather slender beetle about $1 / 8$ inch long, enters the sapwood of dying and dead white pine, making cylindric galleries, the walls of which are stained black.

This common wood-boring Ambrosia beetle lives on a fungus cultivated in its galleries. This species is common in dying and dead white pines in different sections of the State, entering the wood very shortly after the tree has been injured as a rule. It was met with on spruce at Big Moose N. Y., July 2, 1903, it being attracted to trees injured by recent fires in that

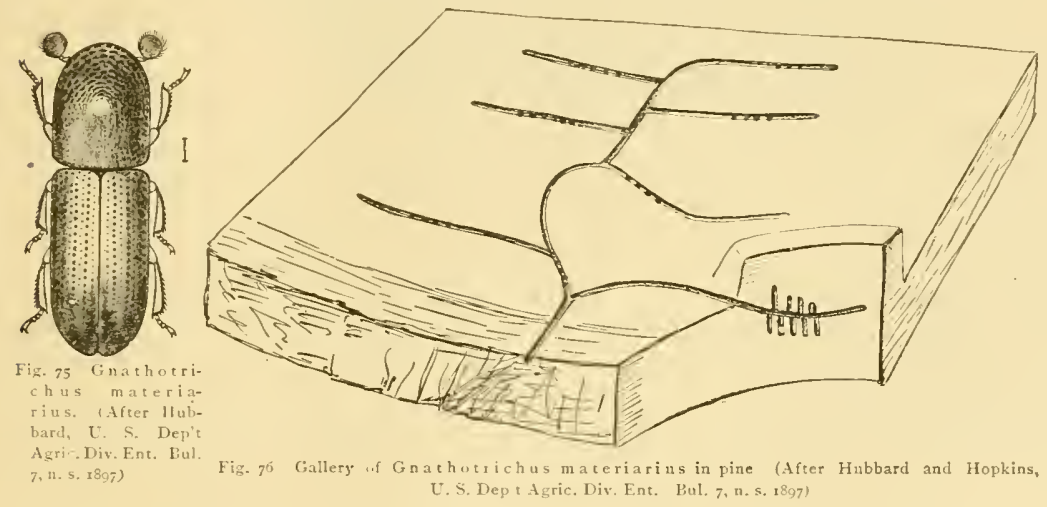

section. It has also been noticed by I) Fitch. This insect makes slender, cylindric burrows across the wood fibers and usually parallel with the lines of growth. Short, straight, lateral galleries or brood cells branch off from the main ones at right angles above and below. This species is attracted by the odor of turpentine, and Dr Hopkins records it as one of a number collected on a recently painted greenhouse. He states that this species, associated with others, is frequently found in the sapwood of spruce at IVilliams River Wr. Va., and adds that it is very common in that state in the sapwood of dead and dying pine and spruce trees, logs and stumps. He 
adds that it is widely distributed. A small beetle, $H$ ister parallelus Say occurs in the burrows of this insect and may possibly prey on it. The presence of this borer, as well as that of some others, may frequently be detected by the small piles of white sawdust on the bark or at the base of infested trees.

Description. This beetle is a rather slender, cylindric, brownish black insect, about I inch long, and with yellowish legs. The globular antennal club, the puncturing of the thorax, and the linear dotting of the wing covers are well shown in figure 75. The structure of the antennae is represented on plate 67 , figure 4 , and that of the middle tibia at figure $78 a$.

The burrows of this beetle extend into the wood vertically for a short distance, in a specimen at hand less than $1 / 2$ an inch. This main gallery has several branches diverging in a direction approximately parallel with the lines of growth, each of which leads into a series of vertical brood chambers. The illustration is typical of the complex system of galleries.

\section{Bibliography}

1858 Fitch, Asa. Ins, N. Y. th Rep't i 857, 1). $40-42$

$189 \circ$ Packard, A. S. U. S. Wint. Com. 5th Rej't, 1) 7r8-20

1897 Hubbard, H. G. U. S. Dep't Agric. Div. Ent. Bul. 7, n. s. p. 30

1899 Hopkins, A. D. W. Va. Agric, Exp. Sta. Bul. 56, 1. 344, 346, 347, 434, 442

1903 Felt, E. P. For. Fish i Game Com. 7th Rep't, 1. $495^{-96}$

\section{Pityophthorus sp.}

An insect belonging to this genus'was met with by the writer Aug. 22, 1900, at Axton, where it was working in small numbers under the bark of a young dying white pine. The central chamber of this species is somewhat circular and in the specimen figured has four primary galleries with a short fifth. The primary or egg galleries run longitudinally or obliquely to the wood fibers and cut into the wood a considerable proportion of their depth. The larval galleries are somewhat tortuous, expand very gradually, and also cut the sapwood for about $1 / 2$ their depth, and toward the extremities a greater proportion lies in the wood [fig. 77]. 


\section{Pityophthorus sp.}

A small species belonging to this genus was met with by the writer Sep. 8, I 900 at Karner, working under the bark of a dead hard pine limb.

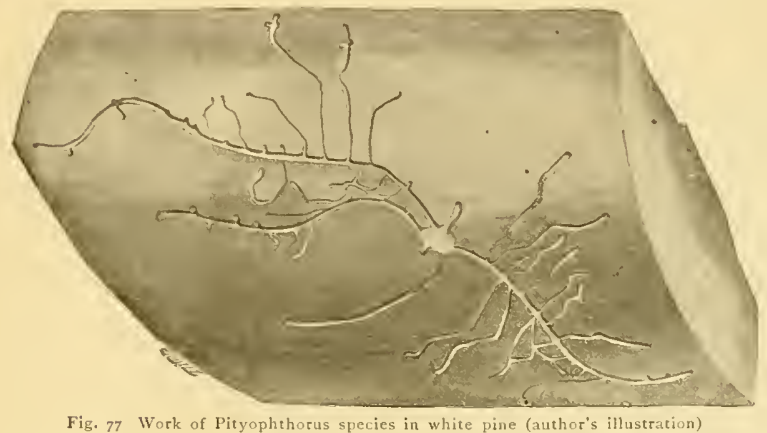

Recently transformed adults and a few pupae were observed in the galleries. The twig was also bored by a longicorn larva. The adult galleries of this insect are remarkable for their delicacy. They are well represented in plate 63 , figure 6 . It will be seen that the general design has been much marred by the work of the longicorn above mentioned, and the tortuous larval galleries may be seen branching from the primary ones at irregular and somewhat considerable distances. The larva as it attains maturity appears to make a very irregular excaration which sometimes doubles back on itself or is simply a very broad excaration.

\section{Pityophthorus sp.}

This species was taken Sep. 8, I900 at Karner from dead limbs of pitch pine. Its breeding season was evidently nearly at end as a very few pupae and some recently transformed adults were found.

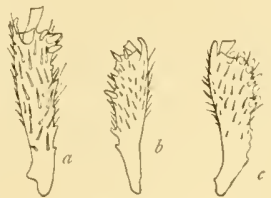
Fig. $7^{3}$ Middle tibiae: $a=$ Gnathotricus materia rius: $b=$ Pityugenes sp. a. ; $c=$ Pic yogenes sp. b. (original)

Description. This is a reddish brown or almost black, rather slender, cylindric beetle measuring but little over $1 / 16$ inch in length. 
The adult burrows, in the smaller limbs just beneath the bark, are usually nearly parallel with the grain of the wood and may extend a distance of 3 or more inches. The irregular, serpentine burrows of the young are $1 / 4$ inch or more apart, over $1 / 2$ inch long and usually alternating on each side of the parental gallery.

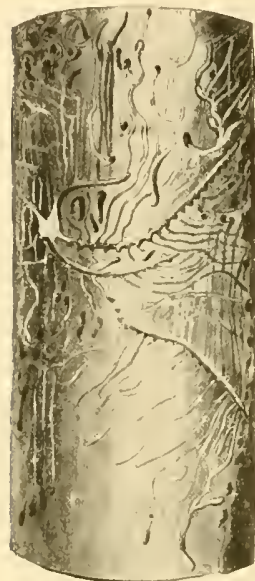

Fir. 70 Work of Pityogenes sp.ain white pine (original)

\section{Pityogenes sp. a}

Another species of this genus, stated by Dr Hopkins to be a new form, was met with by the writer at Saranac Inn in August I90o. It was working in a nearly dead young pine and its galleries are quite different from the following. The central chamber is not quite so large, the egg notches appear to be placed closer together, and the larval galleries do not groove the wood so deeply as a rule. The pupal cells are sunken much more deeply into the sapwood. Figure 79 illustrates the work of this species. Apparently the same insect was met with in another white pine where it was associated with Tomicus caelatus Lec., and also in balsam, where it occurred in company with the last named species and Tomicus balsame us lec. This latter tree was dying and had been abundantly infested by the bark borers.

\section{Pityogenes sp. b}

A small beetle, a little over ${ }_{32}$ inch in length, works in the bark of dead white pine limbs. The prothorax is dark brown, rather coarsely tuberculate, while the wing covers are a lighter brown, nearly smooth, and with two or three minute tubercles on the declivity of each.

This species was met with by the writer Aug. 5, I900, at Slingerlands N. Y., where it was working on pine limbs which had evidently been recently cut. Larvae and pupae were present and the insect had begun operations only a little while before. Tomicus cacographus Lec. was associated with this borer and also a species of Hypophloeus. This 
bark borer occurred in the limbs of a dying white pine at Saranac Inn, Aug. 19. All stages were present and though the tree was not excessively: infested, it may possibly have had a hand in its death, as its burrows were found along the entire length of the tree. It was associated with Tomicus balsameus Lec, another species of Pityogenes, Hypophloeus and a Chalcid. The two latter were not determined.

This insect was also met with Sep. I\$, 1900, at Bath-on-Hudson, where it was boring the dead limbs of white pine in which were found larvae, pupae and adults. This tree had also been attacked by Tomicus calligraphus Germ. The borings of this species form a rather large irregular central chamber with 3 to 4 or 5 primary or egg galleries diverging, sometimes obliquely and sometimes at right angles to the wood fibers. In one case noticed, several larval galleries originated from the central chamber, showing that the eggs in at least one instance, were deposited in little notches in its wall. The primary or egg galleries are from about I to $I_{1}^{\prime}$ ' inches in length, and? from them arise the siender, somewhat tortuous larval galleries, which latter may attain a length of about $1 \mathrm{r} / 2$ inches [pl. 63 , fig. 5]. Pupation occurs at the tip of the mine in a slightly enlarged cell which is sometimes excarated in the sapwood. The beetles emerge therefrom through vertical exit holes.

\section{Balsam bark borer \\ Tomicus balsamcus Lec.}

Balsam trees with red tops may frequently be observed in the Adirondack region and a close examination may show that a small brownish or nearly black beetle about $3 / 32$ inch in length is working in large numbers in the inner bark.

The balsam is one of the handsomest trees in the Adirondack region and forms a very characteristic feature of the landscape. It is not a specially valuable tree but as a subject of insect attack, it is of interest. Nany healthy balsamtrees have probably been killed by this borer though it also works in diseased or sickly trees and hastens their death by its operations. Affected balsams may easily be detected at a distance by their reddened tops though this sign does not invariably indicate the presence of borers. 
This species appears to be quite prevalent in the Adirondacks, judging both from olservations and reports and as it frequently concentrates its attack on one or two trees, the inner bark is soon repeatedly traversed with interlacing burrows of beetles and grubs.

This species appears to exist wherever its farorite tree, the balsam, grows, though it does not hesitate to attack spruce and white pine. It has been found in the Adirondacks in both of these latter trees several times, once in arbor vitae, and it has been reared from hemlock. There is little doubt of this insect's ability to kill healthy trees. A balsam to inches in diameter just beginning to die, as was shown by its reddening top), was cut down Aus. 14, I goo. This borer was found in ali stages and in large numbers from the base of the tree almost to its tip, some 50 feet high. The bark along much of this distance appeared to be healthy and the lower limbs had not begun to show any signs of weakness. No other insect had affected the vitality of this tree, so far as could be determined. Such balsams were to be met with here and there in the woods and it was stated that many of these trees had been affected in this way a few years earlicr. Numerous dead balsams here and there, attested the truth of this assertion.

This insect was associated with Tom ic us pin i Say and species of Pityogenes, in white pine. It was obtained with Cryphalus striatulatus Mann. and also with Polygraphus rufipennis Kirby

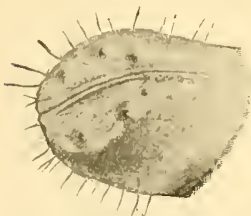

Fig. 80 Therlivity of $\mathrm{T}$ om $\mathrm{m}$ cus bulsumeus (author's illustration) from spruce. Tom icus caelat us Eich. was found with it in balsam. It was taken by the writer at Floodwood, at many places about Saranac Inn, at Axton and vicinity and at Ampersand pond.

Description. This is our smallest species of Tomicus, the adult beetle being only about $3 / 32$ inch long. It is rather slender in form and varies in color from light brown to almost black. The rather coarse, light brown hairs are quite conspicuous near the posterior end of the elytra and the possession of these enables one to separate it from the allied 
species. The excavation of the declivity is comparatively slight and is marked on each side by the three small independent, nearly equidistant tubercles, the lower two being larger and farther apart. There is also a very minute tubercle a little above and outside of the lowest tubercle but ordinarily it is not seen. The dorsal tubercle of the three is small and near the median line. The prothorax is coarsely granulated and the wing covers are marked with longitudinal rows of rather small punctures. The general form and structure of the antennae and tibia are shown on plate 66 , figure $t$ and at figure $90 a$.

The white pupa of this species is about the same size as the beetle.
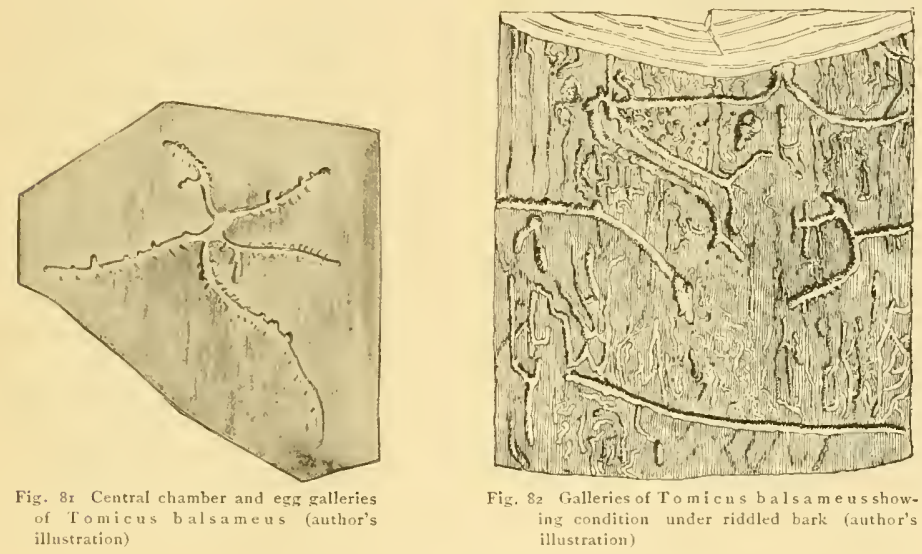

It tapers somewhat at the posterior extremity, which latter bears a pair of slencler pointed processes.

The partly curled grub or larva is ahmost $\mathrm{I} / \mathrm{s}$ inch long and has a brownish yellow head with dark mouth parts.

Habits. The operations of this species are best seen in a tree which the beetles have just entered. There will usually be found three to five branch burrows here and there under the bark. A very small one is shown on plate 62, and in figure 8 I $\quad$ it will be seen that there are five radiating 
adult galleries and that each one contains a number of minute notches, the egg chambers. Each branch represents the work of a female and all have origin in a central chamber near the entrance of which the male stands guard.

A more advanced stage of this insect's work is shown at plate 62 , figure 3 , which represents the work of three females liverging from a common chamber. It will be seen that a number of the eggs have hatched and that the larvae have worked to a considerable distance in a direction nearly par-
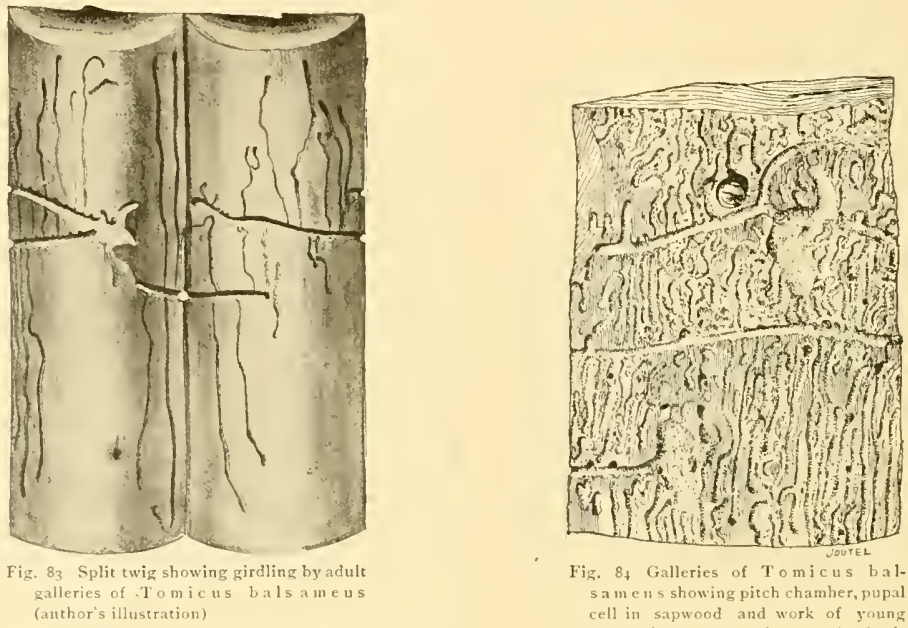

Fig. 8+ Galleries of Tomicus balsame us showing pitch chamher, pupal cell in sapwood and work of young Monoh ammus larva (author's illustration)

allel with the wood fibers The egg notches are also visible. The same gallery as it appears on the bark is represented at plate 62, figure 1 . It will be seen that in this instance at least, the larvae bored in the sapwood rather more than in the bark. A still more advanced stage is shown at plate 62, figure 5, which represents a portion of a trunk which had been injured by a large number of the beetles. The adult galleries, egg notches and the work of larvae or grubs can all be seen.

Plate 62, figure 4, represents a portion of a very badly infested trunk 
after the attack has practically ended. It will be observed that the inner bark is a mass of partially decayed tissues tunnelled by numerous larval and adult galleries. Figures $82,8+$ represent the condition after the decayed tissues have been removed. The adult galleries may be easily recognized where they score the surface of the wood and here and there are peculiar chambers a little to one side of an aclult gallery. These are not central or entrance chambers but are evidently little cavities hollowed out by the beetles for the reception of balsam and show conclusively that the tree must have been alive at the time of the initial attack. The hard, dried balsam can easily be found in such carities.

Figure 83 illustrates very nicely how thoroughly this insect may girdle twigs. It represents a small twig less than $1 / 2$ inch in diameter and shows the adult galleries of two females passing from a central chamber around the twig in opposite directions and overlapping each other on the farther side by about $1 / 2$ inch.

The larrae or grubs pursue a rather tortuous course at approxmately right angles to the parental galleries and end their operations in a slightly enlarged elliptic cell where the final transformations to the beetle occur

Natural enemies. The writer collected two parasites, Spathius tom ici Ashn., and Cosmophorus hopkinsi Ashm, in the burrows of this bark borer.

\section{Bibliography}

1903 Felt, E. P. For. Fish \& Game Com 7th Rep't, p. 519-22

\section{Spruce destroying beetle Dendroctouns piccaperda Hopk.}

A rather stout, brownish or black beetle about ${ }_{16}$ inch long, makes longitudinal galleries in the inner bark and outer sapwood of living spruce. These, in connection with the more or less transverse expanding larval galleries, frequently result in the destruction of trees.

This species, though only recently characterized, is an exceedingly destructive form, and its ravages have been known for some years, though the operations were usually attributed to another species. 
Early history. Dr Hopkins states that there is a record of this insect killing spruce in the neighborhood of Sherburne $V t$., in $1 \delta_{3} 1$ to $18_{33}$, and in 1840 , according to Henry Hough, there was serious injury to spruce in Newport, Sullivan co., N. H., probably by the same species. Prof. C. H. Peck, state botanist, when investigating the work of this insect in the Adirondacks in 1874 , learned that the greatest destruction of spruce in Lewis county occurred 1o or I 5 years before. The same trouble, according to him, was experienced in Rensselaer county about 1854 . "A lumber firm found that their spruce timber was rapidly dying, and to make their loss as light as possible, they made haste to open roads in the forest that they might draw out and work up as many dead spruces as practicable before decay should render them entirely worthless, but with all their promptness they suffered no inconsiderable loss, for these dead trees soon became too much decayed to make marketable lumber."

l'rofessor Peck's investigations are of exceptional interest, particularly as we have been fortunate enough to examine specimens collected by him at that time, and therefore can be certain regarding the identity of this insect. A portion of his observations for the year 1874 , follow :

In August a collecting trip was undertaken in the vicinity of Lake Pleasant, Hamilton county. While there it became apparent to me that I was in a region where the spruces were dying. Standing near the outlet of the lake and looking upon the distant mountain slopes toward the northeast, east and south, patches of brown appeared here and there mingled with the usual dark green hue of the forest. The inhabitants told me that these brown patches were groups of dead spruces; that the spruce trees were then rapidly dying, and had been for two or three years previous, and that in consequence the value of the woodland was greatly diminishing. One of the most conspicuous of these brown patches was on the slope of Speculator mountain, a little more than half way from the base to the summit. Preparations were therefore made to visit this locality. Once on the ground it needed but little observation to satisfy me that the destructive process was then in operation. The ground under some of the spruces was thickly strewn with their fallen leaves, yet green, and every agitating wind was bringing down more of them. The bark of these trees, and of others already dead, was perforated in many places with small round holes scarcely $\mathrm{I} / 8$ of an inch in diameter. Upon stripping a piece of bark from the trunk of one of the affected trees, the apparent cause of the mischief was at once 
revealed. The surface of the wood and the inner layers of the bark were abunclantly furrowed by the winding and branching galleries of a small bark-mining beetle.

Small trees are rarely attacked. In the localities visited, from one half to two thirds of the spruces with a basal diameter ranging from one to two feet, were either dead or dying. Trees of this size are the most suitable for lumber and consequently the most valuable. The smallest affected tree noticed, had an estimated basal diameter of about 10 inches. In this case the attack appeared to be a failure, for so much resin had oozed from the wound that the work was obstructed. The galleries were scattered and single and their authors were found dead, each in its furrow. . . When two trees of unequal size stand in close proximity the larger one seems to be most liable to be attacked. In one instance two trees stood scarcely more than three feet apart. The larger one had been attacked; the smaller one remained unharmed. In another similar instance the larger of the two trees was dead, having been attacked first; the other was dying.

Professor Pecks observations in 18,6 , are also given in part as follows:

The green slopes of Mt Emmons, commonly called I3lue Mountain, and of several mountains to the north of it had their bcauty, and their value too, greatly impaired by the abundant intermixture of the brown tops of dead spruces. The destruction was also visible along the road between Newcomb and Long Lake, and on the mountain slopes farther to the north of this road. Again, on the trail from Adirondack to Calamity pond, there was sad evidence that the little destroyer had invaded also the forests of Essex county. From what I have seen at Lake Pleasant, in the southern part, and in the vicinity of Long Lake, in the northern part, and from information concerning the Cedar river region, in the central part of Hamilton county, there is reason to believe that much of the spruce timber of this country has already been invaded by the beetle. How much farther this destructive work has extended, or will extend, it is impossible to say. But one thing is certain, it is still in progress.

There are other records of extensive injuries to spruce, presumably by this species, about this time. Dr Packard reports serious damage about Beede's hotel, Keene Flats in the Adirondacks, where the spruces had been dying for about 15 years. Serious injury was caused in Maine between I874 to 1881, extensive damage occurred about this time on the Allegash and other tributaries of the St John river, and dying spruce was met with in northern New Hampshire by Fiske in 1897 . The damage caused by 
this species has been estimated by various correspondents at IO, 50 and even as much as $90 \%$.

Description. The parent beetle is a small, rather thick, light or dark brown insect about $3 / 16$ inch in length. It presents no distinctive character

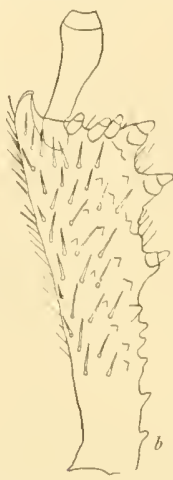

Fig. 85 Middle tibize: $a-\mathrm{Po} 1 \mathrm{y}$

graphus rufipennis; $b$

Dendroctonus picezperda (original) which will enable its separation from allies, and it is more easily identified by its work, as no other insect of its size causes so much injury to spruce. The middle tibia is illustrated at figure 85 .

Its attack is limited, as observed by Professor Peck, mostly to the larger trees, it rarely being found in those less than 10 inches in diameter. The most characteristic feature of injury is the browned tops, and an examination of the trunk usually results in finding tubes of pitch, which are pushed out from the wounds made by the beetles when excavating an entrance. The adult galleries are about $1 / 8$ inch in diameter and run longitudinally for a distance of several inches, egros being laid on either side and the larvae working more or less obliquely and very irregularly from this central gallery [pl. 6I, fig. 1]. Their burrows are . easily recognized by their irregular, more or less tortuous course and expanding character. Adult galleries preserved by infiltrated pitch are shown at plate 6 i, figure 2. These illustrations are specially valuable as they represent material taken by Professor Peck some 30 years ago.

The following more detailed account of this insect's work by Professor Peck, will also prove of service.

For the purpose of gaining more knowledge of the insect, 1 cut down at South Pond, a tree that had recently been attacked by it. It was about 20 inches in diameter at the base; the foliage was still fresh and green, and there was nothing, except the perforations in the bark, to indicate that it was at all affected. The bark peeled from the trunk without much difficulty; the sapwood was perfectly sound, and the heartwood also, except a small portion in which there was a slight appearance of incipient decay. Longitudinal furrows, varying from one to six inches in length, were found 
under the bark, and each furrow was occupied by one or two beetles. The furrows are excavated from below upwards. In the short ones but one beetle was found, and but one perforation communicating with the external air. In the longer ones two beetles (probably the two sexes), were usually found, and from two to four perforations afforded means of ingress and egress. The lowest perforation, which is the one by which the beetle first enters and commences its furrow, is often found closed or "blocked up " by the dust and debris thrown down by the excavator in the progress of the work. The second perforation is crenerally one or two inches above the first. I failed to discover whether it is made by the second beetle for the purpose of ingress or by the first beetle. The third and fourth perforations are in a nearly direct line abore the other two and are probably made from within outwardly, but for what purpose is uncertain. In one instance the two beetles were found at work making these perforations, boring throush from the inner surface of the bark. In one instance the third was less than half an inch above the second, so that there would seem to be no particular necessity for it. The eggs of the insect are deposited along both sides of the upper part of the furrow. They lie close together, almost or quite in contact with each other. When the larvae emerge from the egos they begin to feed upon the sof cambium and to work their way under the bark at right angles to the main furrow. They are, at first, so minute and work so close together that they make no distinct furrows but seem rather to devour entirely a very thin layer of the cambium. But as they increase in size they begin gradually to form distinct furrows and to take directions more divergent from each other and from their original course. In this way colonies from contiguous furrows at length run together and in time the whole trunk is surrounded by their multitudinous pathways, and the death of the tree is accomplished. Great care is taken by the parent beetles to keep their furrows separate. No instance was observed in which they ran together. In one instance the course of a furrow was changed to avoid running into the lateral furrows of a colony of larvae just above. No furrows were found in the tree more than 10 or 12 feet from its base, thus indicating that the attacks are made upon the lower part of the trunk. The attacks are not made simultaneously. Some of the furrows in this tree were scarcely more than an inch long, and evidently had been just commenced. ()thers were fully excarated and contained eggs, and in others still the larvae had hatched and commenced their work, but in none were they fully grown. In another tree, a few rods distant from the first, the attack had evidently been made earlier in the season, for the larvae were farther advanced in size and the bark, on one side of the tree was well loosened, though, strange to say; the other side of the trunk was comparatively unharmed. I was unable to discover why, in this instance, the attack was limited to one side of the trunk. It is pretty evident therefore that the trees are attacked all along during the months of June and July and possibly as late as August. 
Life history. The life history of this species has been carefully studied by Dr Hopkins, and the following is his summary :

These observations would also indicate that activity ceases in the fall by about the middle of October, when all stages of the insect may occur in the bark of infested trees where they, with the probable exception of the egrs and pupae, remain until the first week in June. Activity then commences, the mature larvae change to pupae, and by the middle of June those that pass the winter in the adult stage emerge and commence to excavate ralleries and deposit egss. The adults from the hibernating larvae of different stages, develop and continue to emerge possibly until the last of August. Therefore the eggs deposited by the late developing beetles produce larvae which do not complete their development until July or Aunust of the next year. Thus, the period of development may vary from about 70 days to about 12 months, but all broods from egers to matured and emerging adults remain in the bark about 12 months, of which they are dormant about seven and a half and active four and a half.

Natural enemies. This species is subject to attack by several natural enemies. The commonest parasite, according to Dr Hopkins, is Bracon simplex Cress, a well known species which lives at the expense of a number of wood borers. The antlike clerid beetle, Than a $\mathrm{i}$ m $\mathrm{us} \mathrm{n}$ ub $\mathrm{i}$ lus Kl, is said by 1) Hopkins to be a very efficient enemy of this species. He states that the adult emerges from the bark of infested trees somewhat earlier than the spruce destroying beetle and remains hidden thereon till the bark borers commence to emerge, when it pounces on and devours them. It also follows the beetles to other trees and continues to prey on them, and while it does not enter the galleries, it cleposits egrgs at their entrances, so that the active reddish larvae hatching therefrom can readily enter and feed on the bark beetle larvae. The clerid larvae on attaining full growth retire to the central Dendroctonus galleries, pupate and transform to the adults.

Woodpeckers are valuable checks on this species. Professor Peck states that many of the deacl trees in two groves observed by him, had their bark so chipped by woodpeckers, that the general hue of the trunk was a reddish brown instead of the usual greenish brown. Dr Hopkins states that he is quite confident that in many hundreds of infested trees examined, at least one half of the beetles and their young had been 
destroyed by birds, and in many cases a greater proportion had perished from this cause. He states that the arctic three-toed and banded threetoed woodpeckers render by far the greater service and probably do their principal feeding during winter on this bark borer.

Remedial measures. Dr Hopkins advises regulating winter cutting of trees so as to include as many of the infested, dying and dearl ones as possible and then placing the logs from the same in water before the first of June. He also advises arranging the summer cutting so that as many recently attacked trees as possible may be cut and the bark remored from their trunks and stumps. He suggests, in bally infested areas where logring operations will or can be conducted the following summer and winter, girdling a large number of trees early in June. These girdled trees are for the purpose of attracting the borers, and if felled later and either peeled or placed in the water before the furst of the succeeding June, a large proportion of the insects will be destroyed. His experiments in girdling indicate that the best time for this is when the flowers (catkins) are falling from the birch, and while the flowering or bird cherry and the hobblebush are in bloom. The girdled trees should be sound and healthy. and not less than 15 inches in cliameter. The best method of girdling seems to be hacking through the bark with an axe into the sapwood and around the trunk two or three feet above the base.

The dead spruce remains sound for some time and is valuable for pulp wood at least, for a considerable period. It should be cut and utilized as rapidly as possible, and the same is true of mature living timber in sections where the bectle is at all abundant.

\section{Bibliography}

1876 Peck, C. H. Alb. Ins. Trans. 8:29--30 I

$1879-$ X. Y. State Mis. Nat. Hist. 28 th Rep't, p. $32-3^{8}$

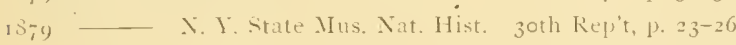

ISgo Packard, A. S. L. S. Ent. Com. 5th Rep't, p. 8ti-22 (P'ortions relate to this species)

Igor Hopkins, A. D. U S. I)ep't Agric. Div. Ent. Bul, 2S, p. I-łS 


\section{Spruce bark beetle \\ Polygraphus rufiponnis Kirby}

A light brown or black, rather stout beetle ahout $3 / 3^{2}$ inch in length makes somewhat irregular transverse galleries, from which diverge smaller dilating larval galleries, in the inner bark of spruce.

This very common species in the Adirondacks is a dangerous enemy of the spruce. It can usually be found $i n$ small numbers in this tree and it is frequently present in great abundance in the bark of cut logs or trimmings. This bark borer was taken by the writer in 1900 in several localities in the Adirondacks. It was found Aug. 14, 1900, in all stages in the bark of cut spruce logs and some nearby fallen spruce were badly infested by the insect. It was present Aug. 22 at Axton, breeding in large numbers in logs cut sometime during the preceding month. Old beetles were scarce at this time and there were numerous larvae and few pupae, indicating that the infestation was a comparatively recent one. This insect was also found at work in considerable numbers in spruce tops cut between September and Deccmber of the preceding year, and remains of this species were found under the bark of clead spruces standing on the edge of Little Clear pond at Saranac Inn. Large numbers of trees had been affected in in this manner and the primary cause of the trouble in this particular instance was probably the raising of the level of the pond, which had occurred several years earlier. This borer was found by the writer associated with species of Iryocoetes in spruce and with $\mathrm{Tomicus}$ ba lsameus Lec, in balsam, and Dr Hopkins records finding a single example in pine.

Early history. Very little has apparently been recorded concerning this borer aside from the facts made known by Dr $A$. D. Hopkins who bas made an exhaustive study of this insect in IV est Virginia, and writing of it in I 893 , states that it infests black spruce. His studies led him to believe that it was a very dangerous enemy of this tree and that it may have been the species to blame for the great destruction of spruce timber in VIest Virginia in $188_{3}$ to $188_{5}$. 
Description. The beetle varies from a light brown to a black. It is quite small, being about $3_{32}$ inch long and with a rather stout form. The head is thickly and finely punctured and nearly concealed by the overhanging prothorax. The mouth parts are tipped with black and the concolorous, coarsely granulated eyes are divided, the two portions being connected by a smooth strip of chitin. The prothorax is much narrowed in front, thickly and finely punctured and the wing covers or elytra are rough, finely punctured and almost striate. The structure of the antennae is shown on plate 67 , figure 8 , and that of the tibia in figure $85 a$.

The white pupa is about the same size as the beetle, rather stout and with a tapering abdomen terminated by a pair of fleshy spinelike processes.

The brown headed, white grubs or larvae are about 1/4 inch long when full grown. The mouth parts and adjacent sutures are a dark brown and the body is usually somewhat curved.

Life history. The life history of this borer in West Virginia has been given by Dr Hopkins as follows:

The adults emerge in May or June and are attracted to stumps, trunks and tops of recently fallen trees and those that are weakened by the attack of insects, such as the destructive pine bark beetle, Dendroctonus frontalis Zimm., or diseases of any kinds. The beetles commence to excavate entrance galleries through the outer bark, and their presence is indicated by the fine brownish borings in the crevices of the bark. This entrance is extended to the outer surface of the inner soft bark where the

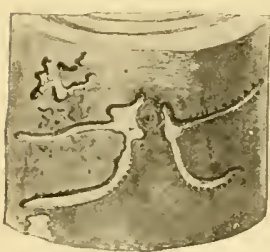

Fig. 86 Polveraphus rufipen $n$ is: early galleries and egg notches (author's illustration) central chamber is excavated. In the meantime, the female, which appears to do the greater part of the work, is joined by a male who stations himself in the outer gallery to keep out enemies and objectionable visitors and to render assistance in expelling the borings. The female excarates a gallery from one edge of the central chamber through the inner bark of the wood and then in the inner layer of the bark, usually at right angles to the bark fibers, and for a distance of one or two inches. Small notches are made along the sides of the brood gallery, in each of which pearly white egrs are deposited. One to three other females are admitted to this central chamber by the male and from it extend similar 
galleries in other directions from the central chamber. The egres begin to hatch before the galleries are finished and the grubs burrow in the inner bark on which they feed. The surrounding bark is filled with grubs of various sizes by the time all the egers are hatched and soon all of the inner part, for a raclius of from 2 to + inches, is completely honeycombed with burrows. The male suards the entrance in the meantime, and the females either rest in the central chamber or egs gallery, or emerese to make an entrance to the bark in another place and start a new brocid. The larvae on attaining their growth enlarge the end of their burow to form a cell in which they change to the pupa, thence to the adult, and then either
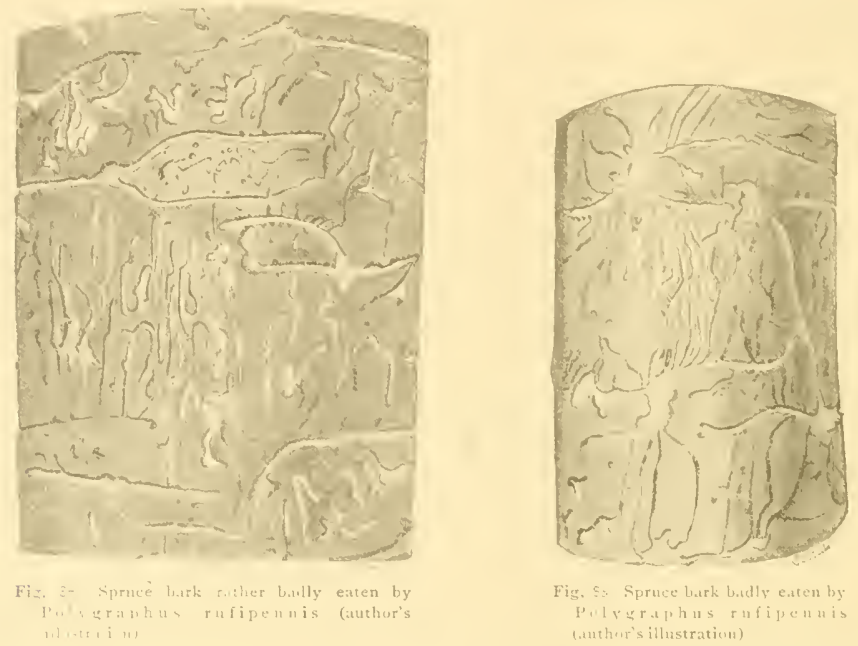

emerge from the bark and start a second brood or remain in this retreat till the following spring.

Dr Hopkins states that two or three broods may occur in one season and that his observations have lead him to believe that owing to the shortness of the season in the high elevations occupied by the spruce in his State there is generally only one generation. This species, as well as some of its allies, occasionally occurs in swarms since Mrs Slosson records hundreds of them in the air at $11 \mathrm{t} 11$ ashington in 1895. 
The galleries of this insect are very characteristic and may be distinguished from those of Tomicus balsameus Lec. which works in balsam, and may therefore be met with in the same forest, by the fact that the wood is rarely scored by the galleries of the spruce infesting species, while the balsam borer frequently cuts nearly half of the diameter of the primary gallery from the sapwood. The general character of these galleries is well shown in the accompanying illustration which represents the central chamber, the transverse primary or egg galleries diverging therefrom, together with a number of small dilating mines of the young. It will be observed that the larval mines begin as very slender borings which widen gradually and end in a somewhat broader pupal cell which is sometimes excavated partly in the sapwood. Several of the egg chambers may also be seen.

Distribution. Dr Hopkins states that this species is evidently widely distributed over North $\therefore$ merica and doubtless occurs where its food tree is indigenous. It has been recorded from New Hampshire to Alaska, and Georgia, and in West Virginia it appears to be confined to the Canadian life zone of the spruce area, since it has never been met with in cultivated spruce or in other life zones.

Associated insects. Dr llopkins records having found the following species associated with this insect in spruce: Homalot a species, Baptolinus longiceps Fabr., Paromalus bistriatus Er., P. difficilis Horn, Epuraea truncatella Mann., Hypophloeus parallelus Melsh, and H. thoracicus Melsh, and a Tenebrionid larra. He also obtained a Dipterous larrae from the galleries of this borer.

Natural enemies. The following predaceous insects were observed by Dr Hopkins either in association with this borer or preying on it: Th hanasimus trifasciatus Say, T. dubius Fabr., Phyllobaenus dislocatus Say, and a Clerid larva.

The following parasites were reared by Dr Hopkins from this species or collected by him from infested logs or trees: Spathius, claripennis Ashm., Caenophanes pityophthori Ashm., Cosmo- 
phorus hopkinsii Ashm., a common parasite of the adult, a species of Eurytoma, a species of Lochites, Cecidostiba polygraphi Ashm., C. dendroctoni Ashm., Decatomidea polygraphi Ashm. The value of these insects in controlling this borer is shown by the fact that Dr Hopkins believes them to be the principal natural agents in checking the injuries to spruce in West Virginia between the years I $8 S 2-$ I $S 89$.

\section{Bibliography}

1893 Hopkins, A. D. W. Va. Agric. Exp. Sta. Bul. 32, P. 9, r2, 40, 4r, 45, 98, 99, 10z, $107,205,206,209,293,349,359,373,379,3^{8} 4,398,399,407,492,493,494$

rög9 —- II. Va. Agric. Exp. Sta. Bul. 56, p. 235, 246, 25 I, 296, 299, 319, 346, 349, $427,428,429,447$

1903 Felt, E. P. For. Fish \& Game Com. 7th Rep't, p. 5 $13^{-15}$

\section{Spotted buprestid \\ Mclenophila fulvoguttato Harr.}

Flattened, white or yellowish spotted beetles about $3 / 8$ inch in length, occur on spruce and hemlock in July, and are the parents of an injurious flat-headed borer.

This destructive beetle is sometimes very abundant in hemlock and spruce. Specimens were taken on hemlock at Bigr Noose, July 6, 1903, and

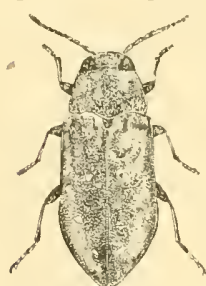
a larva, probably belonging to this species, was met with under somewhat moist spruce bark at Saranac Inn, Aug. $17,1900$.

Description. The beetle is about $3 \frac{8}{8}$ inch long, of a dark metallic color with greenish reflections above the mouth. The head, thorax and wing covers are marked with somewhat coarse, irregular, transverse punctures, Fig. sg Melanophila slightly resembling the graining of morocco leather. Each fulvoguttata, en- wing cover bears three nearly circular or lenticular shaped
larged (original) yellowish or white spots. The larva is of the ordinary buprestid shape with a wicle, flattened head.

Life history and habits. Dr Harris records taking this insect from the trunks of white pine in June, and Dr Hopkins states that in West Virginia 
it infests green bark on livingr injured and dying hemlocks, the beetles occurring the latter part of March and during May, June and July. He also adds that it has caused the death of a great number of hemlock trees in that State. Dr J. B. Smith records this insect on both spruce and hemlock in New Jersey:

Distribution. This species occurs throughout the middle and northern part of the United States, being very abundant about Lake Superior, according to Dr LeConte. It has been taken by Mrs Slosson on Mount Washington, and occurs in limited numbers in southwestern Pennsylvania.

Natural enemies. A single parasite, Bracon pectinat or Say, was bred by Messrs Riley and Howard from cocoons found in the larval mines of this insect.

\section{Red cedar bark beetle Phlocosinus dentatus Say}

A light brown or black beetle, about $1 / 1 \%$ inch long, makes peculiar clubbed, longitudinal galleries under the bark of red cedars.

This little beetle can hardly be classed as injurious in the Adirondacks, since it was found by the writer in comparatively small numbers only in dying or dead limbs. It was taken by him Aug. 21, Igoo, at Floodwood, from limbs cut the preceling June, as nearly as could be ascertained. The beetles were just beginning their operations at this time.

This insect was also found in small numbers in the dying red cedars at Axton, It is evidently a common species in northern New York, because almost all red cedar used in the construction of rustic summerhouses and similar structures is very prettily grooved by the characteristic burrows of this insect.

Early history. Dr Packard states that this is a common species on junipers about the city of Providence R. I., where its attacks are confined to sickly or dead trees. The beetles were found alive in their burrows May 12 and $I_{3}$, and also nearly full grown larvae but no pupae. He has found this insect in considerable numbers in northern Maine under the 
bark of cedar, Thuja occidentalis. He states that Mr Knaus considered this borer very destructive to junipers and arbor vitae in that State. It was first noticed at Salina Kan., in the summer and fall of ISS4, attacking the junipers on the grounds of many residents of that city. The beetles were present in great numbers and many trees were entirely destroyed and others batly injured. The damage was almost invariably. confined to the base of the lateral offshoots of the branches, the bectles burrowing under the bark and eating around the base of the twig causing its destruction. This attack, as characterized by Mr Knaus, is different from anything observed by the writer, unless the burrows passing around the twig are the work of larvae rather than adults

Description. The beetle varies in color from a light brown to black, is a very little over $1 / \mathrm{s}$, inch long and relatively stout. The mouth parts

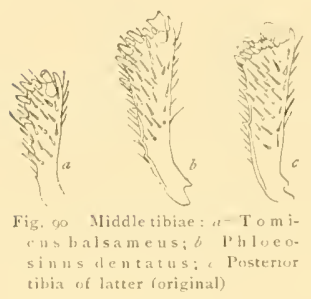
apically and the eyes are black. The latter are coarsely granulated, transversely elongated and partly divided near their midelle. The prothorax is rather coarsely and thickly punctured and tapers very much anteriorly. The wing covers or elytra are margined anteriorly, deeply striate and thickly clothed with short, yellowish hairs. Certain structural details of the antennae are shown on plate $6 \%$, figure 7 and that of the middle and posterior tibiae in figure go.

A pupa nearly ready to assume the adult form is yellowish white, about the length of the beetle and stouter. The eyes are brown and the mouth parts almost black. Four of the abdominal segments project beyond the wing pads.

The typical burrow $\mid$ fig. 91, 92, and pl. 63, fig. 4] has a very characteristic form. There runs from the three lobed primary or nuptial chamber nearly parallel with the wood fibers a broad burrow about $3 / 4$ inch long. Eggrs are laid in minute notches on both sides of the parental channel and the young work for a short distance at nearly right angles and then they are apt to oblique in either direction. The larval burrows score the sap- 
wood lightly at first but as the grubs increase in size the wood is entered more deeply, till nearly half the burrow may be therein

Natural enemies. This little insect appears to be kept well in check by natural enemies, of which a number have been recorded. Dr. Hopkins lists the predaceous Phymatodera bicolor Say as an associate and Clerus quadrisignatus Say var. nigripes Say has been observed under red cedar bark with this insect. Seseral small parasites also prey on this species. Spathius canadensis Ashm., a species

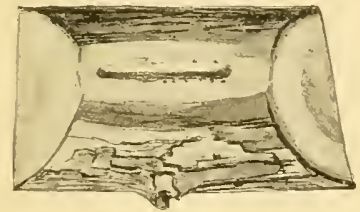

Fig. 9I Phloeosinus dentatus: adult gallery and egg notches (anthor's

illustration)

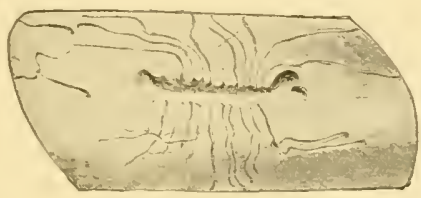

Fig. 92 Phloeosinus dentatus: small gallery and larval mines (auchor's illus(ration)

of Pteromalus and a species of Eurytoma have been observed by Dr Hopkins preying on this borer. The writer has reared another small parasite from this insect which has been kindly determined by Mr Ashmead as Caudonia pityophthori Ashm.

\section{Bibliography}

Is9o Packard, A. S. U. S. Ent. Com. 5th Rep't, p. 904-6

I $\$ 93$ Hopkins, A. D. W. Va, Igric. Sta. Bul, 32, p. i $\$_{5}$, I $\$ 6,213,222,224,226$

rg03 Felt, E. P. For. Fish and Game Com. 7th Rep't, p. $522-23$ 


\section{MIBROSIA BEETLES}

This small group of insects is remarkable because the different species live on various succulent fungi carefully grown in their galleries. These interesting forms have been closely studied by the late H. G. Hubbard of the Division of Entomology, United States Department of Agriculture, and the following account is based on his published observations. These little wood borers are easily recognized by their somewhat elongate, cylindric form and specially by their habit of making uniform sized galleries in the wood of various trees. The burrows usually penetrate to a considerable depth, have a well marked design, and their walls are stained a bluish or black color by the fungus. The exits of the galleries are circular and from them are ejected minute white chips, which may frequently be observed on the rough bark or the ground beneath. These little beetles are remarkable for the care bestowed on their young, and in this exhibit characteristics foreign to most Coleoptera, and such as we expect to find only among the social bees, ants and their allies, and Neuroptera, such as the well known white ants.

These borers require special conditions for the propagation of their food fungus, and consequently can inhabit only certain trees. This fungus does not appear by accident but is carefully propagated by the mother beetle on a packed bed or layer of chips, sometimes near the entrance in the bark though usually at the end of a branch gallery. The ambrosia of some species is grown only in certain brood chambers of a peculiar structure, and in others in beds near what Mr Hubbard considers larval cradles. The excrement of the young is used in some and probably in all species, to form new beds or layers for the propagation of the fungi, the types of which have been described by Mr Hubbard, as follows: one has erect stems with swollen cells at the tips [fig. I05]; and another forms tangled chains or cells resembling the piled up beads of a broken necklace [fig. 54]. The erect or stem forms occur among species whose larvae live in galleries, such as Platypus and Ayleborus, while the beadlike kinds appear to be peculiar to 
species whose young are reared in separate cells or cradles. All the growing parts of the fungus are extremely succulent and tender; the conidia specially are pellucid and glisten like pearls or drops of dew. These are produced in great abundance during active growth, sometimes appearing

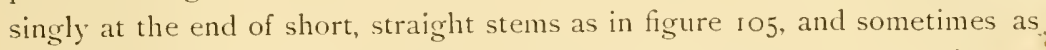
grapelike clusters among interlacing branches [fig. 54]. The fungus appears at such times like hoarfrost on the walls of the galleries, and the very young nip off the tender tips somewhat as calves eat heads of clover, while the older larvae and the beetles devour the whole structure which soon springs up again. Mr Hubbard compares the growth of these fungi to asparagus, which remains succulent and edible only when cropped, and when allowed to gro to seed is no longer useful for food. The ambrosia must be constantly fed on; otherwise it ripens, the cells burst and discharge their granules in such abundance as to fill the galleries, and the beetles may be overwhelmed and destroyed by the growth.

Disturbances in conditions necessary to growth are apt to promote the ripening of the fungus, a danger to which every colony of ambrosia beetles is exposed. Checking the natural increase of a populous colony of beetles also results in overproduction of fungus and disaster, because the superabundant growth chokes the galleries and often suffocates the remaining insects. The same untoward results may be brought about by closing the outlet of the galleries through the bark, or by spraying with kerosene or some other liquid. This throws the inmates of the galleries into a panic, and like other social insects, they gorge themselves with food and exhibit great concern at the threatened loss of this their most precious possession. They rush hither and thither, trampling on and crushing young, eggs and larvae, breaking down the delicate lining of the brood chambers and puddling it into a slush, which is pushed about and accumulates in the passage ways, completely blocking them. Breaking down of the fungus follows, and in a few days the galleries are filled with masses of spores or mycelium threads.

The limited conditions under which these fungi can be grown restricts 
the life of a colony, and as a rule only two or three generations occur in a large tree trunk, while in smaller ones there may be only one brood.

A typical life history of these insects is well illustrated by Mr Hubbard's account of Xyleborus pubescens Zimm. A solitary female starts the galleries similar to those illustrated in figure 104. The branches serve as brood galleries and in each, free to six oval, pearly egss are deposited. The young hatch within a week and begin feeding on the ambrosia at once. The pupae lie free in the galleries, and in somewhat over a month from the eggs perfect beetles appear. The colony, in time, contains beside the mother insect 15 or 20 adult offspring, most of which are females, only one or two males commonly being found. A second brood is started by this later generation, but the seasoning of the wood and threatening failure of food usually warn the young females to depart and seek fresher trees. This leaves the abandoned males in a sad condition, since they are unable to consume the ripened ambrosia, and they also wander forth, though wingless and weak, or are suffocated by the superabundant fungus. Sometimes they assemble in certain galleries and form bachelor colonies, where by united efforts they are able to check the fungus and prolong existence for a time. The watchful care of the mother for the young is well described in the notice of 11 on arthru mali Fitch, page 291.

These little insects are of economic importance, principally on account of their injury to timber. A few species are known to affect living trees, though as a general rule their attacks are confined to dying or dead timber. The defects in the wood caused by the galleries of these beetles, and the stains left by the fungus, probably entail more loss than the injury caused by attacks on living trees. The presence of their galleries seriously depreciates the value of timber used as cask heads, staves, shingles and the like. These defects may be repaired to some extent by plugging, but those made by some species cannot be thus treated. It is possible in some instances to take advantage of the habits of the insects, and by proper sawing the damage may be reduced to a minimum. The soft wood in the Adirondack region is seriously affected by these little borers, and the quality of much of it greatly impaired. 


\section{White pine weevil \\ Yissodes strobi Peck}

An oblong oral weevil, about if inch long, iretuently deposits eggs in the leacling shoots of pine or olher evergreen trees. The gruls work in the shouts and kill them, causing an irregularly deformed tree of very little commercial value.

This is one of the commonest enemies of pine trees in New lork State, and its work may be observed in practically erery locality where they occur.

Early history. It was brought to the attention of the public early in the last century; by Prof. IV. 1). Pech of Harrard ('niversity who macle a study of the insect and described it, and also ascertained a number of facts regarding its life history. It was studied later by I ) Harris who succeeded in adding to our knowledge of its habits, and who states that the beetles are found in wreat numbers in April and May; on fences, buildings and pine trees, and that they probably secrete themselves, during the winter, in the crevices of the bark, or about the roots of the trees. depositing their egss in the sprins. Dr Fitch studied the insect in New Jork, about $185 \pi$, presenting an account of it in his fourth report. He state's that this species selects thrifty growing vigorous pines whose topmost shoot has made the greatest advance the preceding year. He observed that the insects were so numerous that in one grove not only the topmost shoots of every tree, but many of the lateral ones were attacked and destroyed. The depredations of this insect were also brought to the attention of the late 1)r Lintner on several occasions, and $\mathrm{Mr}_{\mathrm{r}} \mathrm{M}$. C. Pierce of Richford, as recorded by I)r Lintner in his ninth report, states that I 50 Norway spruces which had been planted in a cemetery the preceding year, began to die at the top. Examination showed that small borers were working between the bark and the wood, in the topmost shoot and destroying the life of the trees. Dr A. I). Hopkins states that this insect infests the bark of logs and trunks of living and dying pines and spruce.

Description. The adult beetle is about ${ }^{{ }}+$inch long, reddish brown to a very dark brown, and with a somewhat peculiar whitish spot near the 
posterior third of each wing cover. The beetle is also somewhat mottled with white on the sides and legs. The snout is rather long and stout and the legs somewhat so, as represented at plate 19 , figure 7 .

The creamy white pupa is about the same length as the beetle and in recently transformed individuals is nearly uniform in color, except for the lark brown eyes and the brownish tips of the mandibles. As the pupa ages the coloration begins to appear, and in rather old pupae the snout may be reddish brown, and the legs show traces of color. The tip of the last abclominal segment is ornamented with a pair of rather slender, curved spines.

The grub is a white, footless creature, varying in size according to the stage of development. The bark of the infested twig may have all of the inner bark and a portion of the sapwood recluced to a decaying mass of borings. The pupal cells in the example before us are entirely within the wook, nearly ${ }_{+}$inch in length and set somewhat obliquciy to the axis of the twig. There is a channel which is packed with borings leading obliquely from the pupal cell to the cavity under the bark [pl. I9, fig. 6].

Life history. The life history of this insect has been studied by a number of entomologists, and it may be summarized as follows. The beetles occur most abundantly in early spring, and it is probable that most of the egrs are deposited in the leading shoots at this time. Dr Fitch states that the female places her eggs in the bark of the topmost shoots of the tree, dropping one in a place at irregular intervals throughout its length, and that the worm or grub after hatching, eats its way inward and obliquely downward till it reaches the pith in which it burrows for a short distance, the whole length of its track being about $1 / 2$ inch long.

It frequently happens that so many eggs are placed on a shoot as to limit very closely the portion occupied by each grub, and therefore some of them are compelled co burrow in the wood outside of the pith, in order to avoid interfering with those nearby. When they are so close to each other that the burrow cannot be continued to its normal length, the larvae feed on the walls of their galleries, and thus obtain the necessary nourishment. 
The attacked shoot continues its growth during the early part of the season, but soon the grubs cause so much injury that it begins to wilt and wither about the middle of July, and the tender parts above dry and perish. Examination of the affected shoot reveals small oval cells, about $1 / 3$ inch long, placed lengthwise in the center of the stem. They are so very close in some cases that their ends are nearly in contact, and in others they are more or less widely separated by masses of borings, and not infrequently small cells may be found in the sapwood just beneath the bark [pl. ig, fig. 6].

Each of these contains a white plump larva or grub, which later changes to a pupa and the adult insects appear abroad next spring. Pupal cells of this weevil may also be found under the bark of pine logs and stumps. Mr L. H. Joutel has recently called the writer's attention to the breeding of this insect in the bark of a tree 6 inches in diameter, a fact previously mentioned. Dr Fitch was quite confident that eggs deposited in the spring become mature beetles within a year. This weevil was observed by the writer to be very common and injurious to white pines at Karner in $190 \mathrm{r}$, and the following year he had an opportunity of studying recent work of the pest in small white pines at Salem N. Y. These observations indicate that the attack frequently begins just below the terminal whorl and is evidenced by the small irregular masses of pitch and the lighter color of the foliage above the point of injury. The larva or grub makes a longitudinal burrow in the inner bark, which is closely followed by a drying and shrinking of the tissues immediately above and adjacent to the wound, forming a darker, sunken area on the shoot. The work is extended downward under the bark to the next whorl and possibly below. The infested bark soon becomes a mass of burrows and decaying matter, eventually peeling off and revealing oval pupal cells in the wood. Its work was also observed here and there in other parts of the State. The record of captures by beating certain trees in 1901 may be of interest, as it shows the persistence of this species in small numbers, at least, throughout a long period. The record is as follows: June 4, 6; June 13,18 ; June 19, I ; June 26, 2 ; 
July 8, 1; July 19. 1; July 27. 5; Aug. 2, 1; Aug. 9, 6; Aug. 21, 11 ; Sep 6,$4 ;$ Sej. $18,2:$ Oet. 23 , 6. It was also taken in April and May 1902. It will be noted that in rgor no collecting was done in Nay, and it is the writer's impression that the insect was not very abundant, as was the case in 1902, in that locality prior to the beginning of our operations. A study of this record shows that the beetles were nuore abundant from the 13 th to the 26 th of June, and from the gth to the latter part of August. The tendency of this insect to breed more or less throughout the season is also indicated by the condition of a badly infested twig, reccived by the writer the last of August rgoz. This small piece, about 3 inches long, was almost honeycombed ly the insect and contained numerous pupal cells in each of which there was a pupa in a more or less adranced stage of development. One insect had emerged in transit, another oie was almost ready to appear and the remainder would probably have forsaken their retreats before the approach of cold wcather. It is interesting in this connection to note that Dr Hopkins found pupae in spruce bark June 27 , and in white pine July 13, in yellow pine July I 1 , showing that some of the insects must develop later than early. May. The later captures represent scattering individuals, and it would appear as though this insect bred more or less throushout the season, though as stated by the later writers, the principal brood may appear in May and early June.

Food plants. This weevil is well known as a serious enemy to most of our native pines and severe injury to spruces has been recorded by several writers.

Natural enemies. I) litch has stated that after the infested shoot becomes withered and dry in midsummer one may observe that the bark covering the cells bas leen broken and peeled off in spots and that all its lower parts are torn away. Newly perforated holes larger than the burrows of this insect may be observed, here and there, in the wood. These, he states, are the work of small birds which are rery efficient in clevouring the larvac and the pupac of this pest. Dr Riley in his report for $\mathrm{I}_{5} 5$ states that the grubs or larvac are exposed to many dangers from carniv- 
orous foes, particularly the young of beetles belonging to the family Tenebrionidae and records finding young Ichneumon or Chalcid flies in their burrows. Messrs Riley and Howard have recorded the rearing of Bracon pissodis Ashm. from specimens of this insect received from Wellesley Mass. Dr A. D. Hopkins has also obtained Spathius brachyrus Ashm. in Itest Virginia.

\section{Bibliography}

I8I 7 Peck, W. D. Mass. Agric. Jour. 4th Rep't, P. 207-II

1885 Riley, C. V. U. S. Dep't Agric. Rep't, p. 322-25

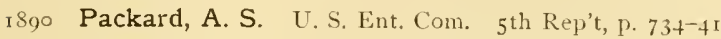

1903 Felt, E. P. For. Fish and Game Com. 7th Rep't, p. 497-500

\section{Pissodes dubius Rand.}

A small, brownish, yellowish, flattened, long snouted beetle about $3 / 16$ inch in length, may be met with on spruce in July.

A single specimen of this interesting insect was taken on spruce July 4 , I 903 , at Big Noose N. Y.

Description. The beetle is about $3 / 6$ inch in length, brownish, with the thorax and wing covers flaked with golden, creamy yellow scales, with here and there a bunch of variable size. The thorax is very coarsely; almost contiguously punctured, and the wing covers are closely striated with a series of nearly contiguous punctures. It may be separated from its ally, P. affinis Rand, according to Dr LeConte, by the sides of the thorax converging a little near the hind angles, which thus become somewhat obtuse. There is also some difference in the scales on the elytra, which, in well preserved specimens are more diffuse with the markings less definite.

Distribution. This species has been recorded from Lake Superior, Canada and New Hampshire, and Randall states that he found it on a wharf in Boston on pine wood brought from Maine. 


\section{Pissodes affinis Rand.}

'This species resembles the common white pine weevil, Pissodes strobi Peck, and may be recognized by its larger size, it measuring about $5 / 16$ inch in length, and by the less ronspicuous markings, specially the whitish spots on the posterior third of the wing covers

A single example of this insect was taken by the writer on white pine July 26, Igor at Bath-on-Hudson. 1)r LeConte records this species from Lake Superior, Canada and New Hampshire.

\section{Magdalis perforata $110 \mathrm{rn}^{\mathrm{x}}$}

A small, jet-black weevil, $3 / 15$ to If inch in length, may be met with on hard pine during June and July [pl. 20, fig 177 .

This species was specially abunclant near the tips of the central shoots of hard pines at Karner in the stmmer of 1901 , at which time it occurred in considerable numbers in association with the white pine weevil, P iss odes strobi Peck. It was taken at intervals during June and July, and was also met with in early June, I902. It probably breeds in the terminal shoots, though we have not detected the work of its larvae. Very little has been recorded concerning this species. It was described from Georgia by Dr Horn, and has been listed from New Jersey by Dr J. B. Smith, who states that it is generally distributed, though rare, on pine.

\section{Magdalis alutacea Lec. ${ }^{2}$}

This species resembles the preceding closely, though it is smaller, measuring as a rule not over $3 / 16$ inch in length. It may also be distinguished by the more highly polished wing covers [pl. 20, fig. 16].

It was associated with the preceding on the terminal shoots of hard pines at Karner, and like it, probably bred in company with the pine weevil, l'issodes strobi Peck. It was taken on pines in 1901 as follows: June 4, I; June I 3. 5; June 26, 2; July 8, 2, showing that the adults are apparently abroad during a somewhat limited period. It was described by

${ }^{2} 1873$ Horn, (i. H. An. Phil, Soc. Proc. 13: 453.

${ }^{2} 1878$ leConte, J L. Geol. \& Geog. Sur. Ter. Bul. 4, p. 463 (original description). 
Dr LeConte in 1878 , from specimens taken at an altitude of 9,000 to Io,ooo feet in the Leavenworth valley above Georgetown Col. These two widely separated localities would seem to indicate a general distribution over the United States, and that it probably ranges into southern Canada, at least.

\section{Pine tip moth \\ Pinipestis zimmcrmani Grote}

Shorl, brown, needles on tips of hard pine, specially if there be a small pitch mass near the base of the injured portion, is an indication of the work of 1 his insect.

This pernicious borer, kindly determined by Prof. C. H. Fernald from bred specimens, was met with on hard pines at Karner during June and July of both 1901 and 1902 . It invariably attacks the more slender growing tips, frequently the leader or the central shoot of a branch, and causes them to shrivel, curl slightly and later turn brown. The work of this borer is frequently indicated by a small, granular mass of brownish pitch pushed out by the borer near the base of the injured portion. The needles on the affected parts are much smaller than normal. The insect is occasionally so abundant as to kill a considerable proportion of the terminal shoots and thus seriously injure the development of the tree, practically ruining it for other than firewood purposes.

Description. The moth is a pretty, slate gray and white insect with a wing spread of about $3 /+$ inch [pl, 20, fig. I9]. The larva measures a little over 3f inch in length, with the head and thoracic shield black and the body varying from reddish brown to somewhat livid green. Its dark brown tubercles each bear a slender hair and the skin is further ornamented by linear series of dark brown, blackish chitinous points. The presence of these latter are characteristic of this caterpillar, and permit its ready separation from the borer operating on the smaller limbs, (Evetria comstockiana Fern.)

Life history. Dr I. S. Kellicott records taking the larvae of this insect at Hastings, and states that they were a dull white and not livid, though otherwise as described by Grote. He adds that the larvae were found in 
the vicinity of wounded areas on the trunk, and that they cannot penetrate the outer bark of other than tender trees or the branches of larger trees. He found galleries of the insect in both the trunk and branches above and below the whorls, and states that sometimes the borers completcly girlle the stem and kill the portion above. The work clescribed by Dr Kellicott was quite different from that observed by us at Karner and it may be that two species have become confused. A thin, papery cocoon is spun in July. as stated by Mr Grote, and the moth appears to to 14 days later. We have bred it the latter part of July.

Food plants. Mr Charles Zimmerman, for whom this species was named, records it on the following pines: Pinus strobus, P. rubra or P. resinosa, P. a ustriaca, P. sylvestris, P. cembra and on the Corsican, lofty Bothan and Russian pines. He states that $\mathrm{P}$ in us sylyestris seems to suffer most, as the limbs and even the main stems are constantly breaking off. The hard pine, Pinus resinosa, is the common species at Karner, and we have yet to find the insect appearing on any other and in a manner different from that described above. Consequently; we are at a loss to account for its wide range of food plants and very different method of work noted by earlier writers, unless there has been a change in food habit or two species are under consideration.

Injuries. 1)r Kellicott, writing of this insect in 1879 , states that many small pines at Hastings, Oswego co. were seriously infested, and Professor Grote expressed the belief the same year that this insect caused more injury to young white pines than any other species.

Distribution. Dr Kellicott found this species at Buffalo, Cheektowaga, Hamburg and Clarence, Erie co. and Hastings, Oswego co. He also found it common in both cultivated and forest pines at Corunna Mich., it being especially destructive to small ornamental pines and spruces in a cemetery. He took eight pupae from the trunk of a single spruce.

Parasites. A parasite was found by Mr Grote filling the cocoons of this insect, and Dr Kellicott records the presence of this heneficial species in localities where the moth is abundant. He also bred another parasite from this insect but has not recorded its name so far as known. 


\section{Bibliography}

${ }_{1} 877$ Grote, A. R. Can. Ent. 9: $161-63$

1878 Zimmerman, C. D. Can. Ent. 10:20

1879 Kellicott, D. S. Can. Ent. I $1: 114^{-16}$

1903 Felt, E. P. For. Fish \& Game Com. $7^{\text {th }}$ Rep't, p. 5 oI

\section{Nantucket pine moth \\ Eactria frustrena Scudd.}

Infesting the new growth of Pinus inops, P. rigida, and perhaps of other species, spinning a delicate web around the terminal bud, and mining both the twig and the bases of the leaves; one or several small yellowish larvae, which transform within grayish cocoons, either in their burrows or fastened to the twigs, and become small copper-colored moths, with wing expanse of nearly $\mathrm{I}_{2}^{\prime}$ inch.

The work of this species was met with on hard pine at Karner in Igor. The insect was not specially abundant, and though infested tips were collected, no adults were reared. This species is a very serious enemy of hard pines on Nantucket Island. Professor Scudder, writing of this species in $188_{3}$, states that the pines set out on Nantucket Island 20 or 30 years before were dying in large numbers. He adds that a great many have perished, and that most of the living trees appear sickly. Niss Mary Treat records this species as most destructive to hard pines in the vicinity of Vineland N. J. Professor Comstock also received twigs infested by this insect from Prof. S. H. Gage of Ithaca. Dr A. D. Hopkins records the work of this species as very common along Alleghany Front, Mineral co., IV. Va. He states that though the characteristic mines were found, scarcely any larvae or pupae were obtained.

Life history and habits. The following condensed account of the life history and habits of this insect is that given by Professor Comstock:

About the middle of May 1879 , the scrub pines ( $\mathrm{P}$ in us inops) in Virginia, near IVashington, were found to be greatly injured by small lepidopterous larvae. On many trees there was scarcely a new shoot to be found which was not infested at its tip by from one to four yellowish, black-headed caterpillars. They were so completely concealed while at work that their presence would scarcely be noticed, and the effect of their work was hardly visible, until the twig was almost completely destroyed. 
Upon close examination a delicate web was seen inclosing the base of the bud and the surrounding new leaflets, resembling much the nest of a small spider. When this web was removed, one or several little caterpillars were seen either retreating into a mine in the bud or into the bases of the leaves, which were also mined, or, not infrequently, they dropped from the twig, suspending themselves by a silken thread. The bud was often so hollowed that it dropped to pieces almost at a touch [sce pl. 2o, fig. 3].

At the time when they were first noticed larvae of almost all sizes were to be founcl. Some were apparently almost full grown, while others had evidently not been long hatched. The nearly full grown specimens measured $8 \mathrm{~mm}$ (.3 i inch) in length. The first pupae were obtained early in June. Most of the larvae transformed within the burrows which they had made, first spinning more or less of a silken envelop about themselves. Others, however, issued from their mines, and spun rather tough grayish cocoons between the leaves. The pupae were short, stout, and brown in color, with each segment furnished dorsally with two serrated lines, one consisting of large and the other of fine teeth.

The first moths issued June 13 , the pupae having previously worked their way, by means of the spines just mentioned, into such positions that they could give forth the moths without injury to the latter, and a few weeks later almost every shoot had one or more of the empty pupa skins protruding from it.

In the latter part of August, individuals of the second brood were very abundant in the scrub pine in the vicinity of Washington. As before, they were found in almost every stage of growth, and the differences were even more marked. In one instance five larvae of greatly differing sizes were found in one shoot. 'The smaller ones were boring into the bases of the leaves, and the larger ones into the twig proper. The largest of the five had made quite a long channel from the tip of the bud down into the heart of the twig. Pupae were also found at this time, which did not give forth the moth until late in the winter.

The usual mode of hibernation is in the pupa state. A thorough search in January in the field showed only pupae. The pupae collected in August and September did not begin to give forth the moths in the breeding cages before early January; February and March this was continued through intervals, and was greatly hastened without doubt by the heat of the room. On Fel, i5, however, a few twigs were collected, from one of which, on Feb. 28 , a full grown larva had emerged and was found crawling about the cage. This would seem to indicate occasional larval bibernation.

Parasites. Mr Scudder records the breeding of three hymenopterous parasites from this insect, one a species of 13 racon, another, a minute Peri- 
lampus, both of which he states to be undescribed. He adds that the latter is far more important.

Remedial measures. The only method of relieving the trouble, so far as Professor Comstock could suggest, was picking the infested tips in early winter and burning them, a measure practical only in the case of highly valued trees.

\section{Bibliography}

I88o Comstock, J. H. U. S. Dep't Agric. Rep't I87y, p. $23^{6-37}$

${ }_{1} 88_{3}$ Scudder, S. H. Nass. Soc. Promotion Agric. Pub., p. I-20

1890 Packard, A. S. U S Ent. Com. 5:745-54

I891 Treat, Mary. Garden and Forest. $4:$ I 4

I 903 Felt, E. P For. Fish \& Game Com, 7th Rep't, p. 501-3

\section{Pitch pine retinia Evatria rigidana Fern.}

Inhabiting terminal shoots of Pinus rigida, and of similar habits to the Nantucket pine moth, Evetria frustran a $S$ :udt., a gray, brown, or blackish larva? 3 inch long, becomes a small moth with dingy white wings, marked with dark red and silvery gray.

This species was received in the larval stage by Professor Comstock in I 879 , from Prof. S. H. Gage of Ithaca. The work of this species is stated to resemble that of Evetria frustrana Scudd, and the larva is described as differing in coloration, and being slightly larger. The moth possesses characters intermediate between E. frustrana Scudd. and E. comstockiania Fern.

\section{Bibliography}

I880 Comstock, J. H. U. S. Dej't Agric. Rep't is 879 p. 237

Is9o Packard, A. S. U. S. Ent. Com. 5:75+-55

Pitch twig moth

\section{Eactria constockiana Fern.}

Masses of pitch, usually on the lipper side of the smaller limbs and twigs of hard pine, cover the entrance of a burrow made by a small yellowish white caterpillar about $1 / 2$ inch in length.

The work of this insect was quite abundant on hard pine at Karner in 1901 , and its operations have also been observed on many hard pines in the 
eastern portion of the State. The work of this species is quite characteristic, in that the mass of pitch is on the upper side of the smaller limbs and twigs. Many of these pitch collections show two layers or masses of different age and this is specially true in the spring. The more recent layer is the record of the later activities of the caterpillar, which, boring in the center of the twig, carries the accumulating pitch out and deposits it around the entrance of its gallery [pl. 20, fig. I].

Early history. This species was described in i879 by Prof. C. H. Fernald, from examples sent him by Professor Comstock, whose attention had been attracted by its work. Professor Comstock records this borer as quite abundant in the vicinity of Ithaca N. Y. Dr Lugger has taken the moth at Baltimore Md., and Dr Hopkins states that this insect is common in West Virginia, on the living twigs of pitch pine near Kanawha Station, and adds that it is frequently observed wherever pitch pines grow. The writer has also observed the work of this insect in several localities in Massachusetts.

Life history. This species passes the winter in the larval or caterpillar stage, and at Karner, operations begin about Ap. I5. This is very nicely indicated by the fresh layers of pitch placed on the outside of masses exposed to the weather during the winter. The spring addition is frequently nearly equal to the accumulation of the previous season, and the demarcation between the old and the new is very evident. June 12, rgor, an empty pupal case was seen, but no adults were obtained in breeding cages till the 2oth. Though a considerable number of the infested twigs were collected at various times during 190r, we succeeded in breeding the moth only during the month of June. Professor Comstock expresses the opinion that this insect passes through two generations in one season, though our data hardly bear out this conclusion. The have been unable to make any observations on the duration of the period during which the moth flies, or on the method of oviposition. The preparation for hibernation has been described by Professor Comstock. He states that the larva lines its burrow with a delicate layer of white silk, which often forms a closed tube at the lower 
end. The larva remains in this case with its head toward its extremity, reversing its position before the transformation to the pupa occurs. Just before the disclosure of the moth, the pupa wriggles its way partly out of the burrow till it protrudes a short distance beyond the surface of the pitch mass, a procedure which enables the moth to escape without injury [pl. 20, fig. 1].

Description. The moth is a delicate, grayish brown mottled insect, having a wing spread of about $3 / 4$ inch [pl. 20, fig. 21].

The pupa is brownish, about $1 / 2$ inch in length, and the abdominal segments are each provided with two transverse rows of stout teeth. These are of great assistance to the pupa in wriggling out of its burrow.

The larva is about $1 / 2$ inch long when full grown, the head and thoracic shield are light brown, and the body a yellowish white. The labrum and tip of the mandibles are dark brown, the moderate tubercles are well chitinized and bear one or two setae. The spiracles or breathing pores are encircled by dark brown rings of chitin, and the anal shield is somewhat chitinized and ornamented with longer setae. This larva may be readily distinguished from the larger dark colored one of the pine tip moth, Pinipestis zimmermani Grote, by its not possessing linear series or dark brown, blackish, chitinized points on the body surface.

The egg is lemon yellow; elliptic-oral in form when deposited on the glass of the breeding jar, and nearly $\mathrm{r} / 25$ inch long.

The gallery or burrow of the caterpillar may be 2 or more inches in length. It is usually confined to the center of the twig, and may extend in one direction from the pitch mass or in both. The opening to the latter is kept clear, though usually there is a slight cover over the tip of the gallery at the surface of the pitch.

Parasites. It might be thought that a caterpillar having its burrow protected by a pitch mass would be safe from the attacks of parasitic insects. Such however is not the case, and this species is the host of at least two parasites which were bred by Professor Comstock; one is known as Ephialtes comstockii Cress., and the other is a species of 
Agathis. An Ichneumon, Cremastus retiniae Cress, was reared from this insect by Messrs Riley and Howard. The writer also succeeded in breeding from this insect an exceelingly small four winged fly which was determined by Dr Ashmead as a species of Stenomesius.

\section{Bibliography}

1880 Comstock, J. H. U. S. Dep't Agric. Rep't 1879, p. 233

188.4 Saunders, William. Ent. Soc. Ont. Rep't $188_{3}, \mathrm{p} \cdot 5^{8}$

1890 Packard, A. S. U. S. Ent. Com. 5: $74^{2-45}$

189 I Kellicott, D. S. Columbus Hort. Jour., p. 60-62

1898 Hopkins, A. D. W. Va. Agric. Exp. Sta. Bul. $5^{6}$, p. $45^{1}$

1903 Felt, E. P. For. Fish \& Game Com. 7th Rep'1, P. 503-5

\section{Pitch midge}

\section{Cecidomyia resinicola Osten-Sacken}

Footless orange grubs occur in clear or whitish pitch masses on the underside of pitch pine branches.

This interesting insect has been under general observation at Karner for several years, where it was present in considerable numbers on some trees. The species may be easily recognized by the peculiar, whitish masses of pitch illustrated on plate 20, figure 2. They hang from the underside of limbs and occasionally occur in numbers on the central stem. During warm weather drops of pitch may fall at times from the masses.

Life history. The eggs of this species have been olsserved by Miss Lida S. Eckel, who states that they are bright orange and arranged regularly, projecting radially about the equator of the spherical pitch drop. She states that in the case of specimens under observation, eggrs were deposited only on fresh pitch and never on old, hardened lumps or on twigs or leaves. No new masses of pitch appeared on the stems, as would have been the case had the insect punctured the bark for the purpose of starting an exudation. She therefore concludes that this insect takes advantage of fresh pitch masses, and as a rule there are plenty of them occurring under normal conditions. She states that the young larvae 
creep beneath the surface of the pitch and rapidly grow to twice their original size, gradually making their way toward the portion of the twig from which the pitch is exuding. This results in their collecting in a group with their mouths close together and their bodies extending toward the surface of the mass. The very young larvae have hooklike spines on the ventral surface of each segment. These disappear with growth, and the entire skin becomes covered with fine, backward curving spines. After 15 or 18 days the young attained a length of from $1 / 8$ to alout $1 / 4$ inch. Miss Eckel's observations demonstrate that the parent insects take advantage of normal exudations of resin on which to oviposit, and that the flow of this substance may be increased to some extent by the larvae rasping the living tissues. This latter is particularly liable to occur when the supply is somewhat deficient.

Adults have been bred by us during the latter part of June and in early October. They were also reared from material collected which was supposed to represent only the work of the pine twig moth, Evetria comstockiana Fern. It is not improbable that a few eggs may be deposited in pitch masses around the galleries of this borer and the larvae come to maturity under such conditions. The normal pitch mass inhabited by this little $\mathrm{fly}$, may contain from two to about 30 larvae which, when full grown, measure about $1 / 4$ inch in length. They are a pale orange while feeding, and on the approach of maturity become a bright orange color. The larvae are elongated, widest about the middle, and the underside of segments 1 to 7 are each provided with two transverse rows of black or brown spines which probably aid in locomotion. Professor Comstock states that while they burrow in the bark and resin, the anal tubercles are always at the surface, thus permitting the insect to breathe, and when the larva contracts to a pupa, the end of the body is drawn in, though an open channel is left for the passage of air. The pupa works its way partly out of the pitch mass before disclosing the little midge, which has a wing expanse of about $1 / 3$ inch, the thorax gray and the abdomen in living specimens, a dark red. 
Description. The original characterization of this insect by Baron C. R. Osten-Sacken is as follow's :

Length .12 to. I 4 of an inch. Male antennae not much shorter than the body, of dark color, except the scapus, which is reddish; $2 \times 24[14]$ jointed, flagellum with small, subglobular joints alternating with double, subcylindrical ones; pedicels between the joints about equal to the diameter of the shorter joints, somewhat longer towards the end of the antennae, joints verticillate, the length of the hairs of the verticils not exceeding the length of joints. Female antennae less than half as long as the body, $2 \times 12$ jointed; joints of flagellum subcylindrical, more than twice longer than they are broad, the basal ones being the longest; pedicels short: the hairs, clothing the antennae, are shorter than each single joint. Head strongly gibbous above, which cribbosity is very striking, when viewed in front or from the side; the black eyes being absolutely confluent, and covering the whole gibbosity, occupy nearly the whole surface of the head, except a small space round and below the antennae and a portion of the occiput, which are brownish red (the brown predominating in several specimens). The ground color of thorax is reddish; the dorsal portion however, including the scutellum are grayish brown; rows of yellowish hairs indicate the direction of the ordinary stripes (when rubbed off these hairs show gray stripes under them); the middle stripe is divided in two by a grayish longitudinal line; pleurae and sternum reddish, mixed with brownish gray; abdomen reddish, with grayish-yellow hairs, long and erect along the sides, short and appressed on the back; genitals pale. Feet brownish, with a yellowish gray, appressed pubescence; some longer hairs on the underside of the femora; halteres with dark knobs. W ings gray, second longitudinal vein arcuated in its latter portion, ending immediately beyond the apex of the wing.

He states that the species can be easily recognized by the extraordinary shape of the head.

Parasites. This little insect in spite of its passing a large portion of its existence within pitch masses, is subject to parasitic attack. Miss Eckel, referred to above, has succeeded in breeding three species, as follows: Syntasis diplosidis Eckel, polygnotus pinicola Ashm., and another belonging to the genus Eupelmus.

This insect can hardly be considered of much economic importance, yet we have observed trees which were seriously weakened by an excessive flow of pitch inhabited largely by the larvae of this species, and are therefore inclined to believe that in such cases some injury may be caused by 
the larvae increasing the flow to such an extent as to seriously weaken a tree unable to stand a severe drain.

\section{Bibliography}

1880 Comstock, J. H. U S. Dep't Agric. Rep't r879, p. 256-57

I 890 Packard, A. S. U. S. Ent. Com. 5th Rep't, p. 797-98

1903 Eckel, L. S. Ent. News, 14:279-84

\section{LeConte's sawfly \\ Lophyrus lecontio Fitch}

Dirty yellowish, red-headed, black spotted caterpillars feed in clusters on the outer branches of pines from which they strip the leaves.

This species is a rather common one although as a rule it is not injurious. It was first brought to notice by Dr Asa Fitch who characterized it in 1857 , and described its work and the adult female as follows:

When nearly matured these worms are so large that the end of a single leaf of the pine probably furnishes them a very insufficient mouthful, hence two worms often unite, standing face to face, and thus hold the five leaves which grow from each sheath on the white pine pressed together in a bundle as they eat it, commencing at the tip and gradually stepping backwards as the leaves become shorter. It is only the old leaves of the previous year's

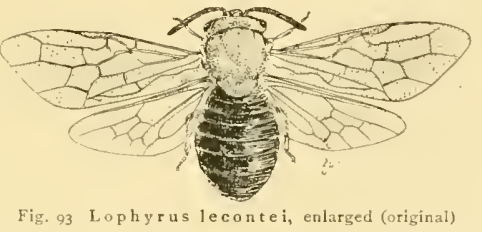
growth which these worms consume, never touching the new ones at the outer end of the limb; hence they injure the tree much less than they would were they to strip the limbs they invade of the whole of their foliage. At least two broods of these worms appear annually, the one in July, the other in September and October, the latter often remaining on the trees after the frosty nights have occurred. Having finished feeding, they leave the tree and inclose themselves in cocoons under fallen leaves or other shelter on the surface of the ground, in which they remain during their pupa state.

The female. Length, .38 inch to the tip of the abdomen, and .48 inch to the end of the wings. It may at once be distinguished from all our other described species by the joints of its antennae, which are 21 in number It is shining dull, tawny yellow, with the antennae black, and also the abdomen and base of the thorax. The underside is paler yellow, with two broad, black stripes on the abdomen. The wings are smoky hyaline, their veins black. Captured the middle of May. 
The full grown larva is about an inch long, the head red and the body pale yellowish with subdorsal and sublateral rows of triangular black spots, one on each segment. True legs black, prolegs pale yellowish [pl. 19, fig. 8].

This species, as stated by Dr Riley, has been observed feeding on Scotch and Austrian pines in New Jersey. There are several sawfly larvae having the same general appearance and habits as this species.

\section{Bibliography}

${ }_{1858}$ Fitch, Asa. Ins. N. Y. 4th Rep't, p. $5^{8}$

I $89 \circ$ Packard, A. S. U. S. Ent. Com. 5th Rep't, p. $75^{8}$

\section{Abbott's pine sawfly \\ Lophyrus abbotii Leach}

Yellowish, black headed, black spotted, false caterpillars nearly an inch in length, defoliate white and hard pines from midsummer till late fall.

This species is a common one in New York State and occasionally inflicts considerable injury, particularly on young trees, though as a rule it is present here and there in relatively small numbers. The caterpillars are gregarious and consequently their work is very apparent because entire branches are quickly defoliated. The ravages of this species are by no means confined to New York, it having been reported from a number of other states and Canada, and Dr Smith has recorded an outbreak in New Jersey, which resulted in the defoliation of about 50 acres. This is very exceptional. 1)r Packard states that the insect is so abundant on Cape Cod as to threaten the existence of plantations of young pines. There are probably two generations, the larvae of the first appearing in midsummer and those of the second in September and October. The larvae, when disturbed, throw lack the head and move the upper portion of the body in a manner very similar to that of species of Datana. Many can be clislodged by violent shaking. The larvae spin their brownish, oval cocoons among the leaves, and adults of the first generation appear about the middle 
of August. The adults of the second generation winter in the cocoons. The esgrs are deposited in little slits in the leaves. Dr Riley states that some of the flies appear early in the spring, while others do not issue till the latter part of June. A single parasite, Limneria lophyri Riley, has been reared from this species.

Description. The adults have been described by Mr Saunders practically as follows :

The male has a wing spread of about $\mathrm{x} / 2$ inch and the female of $2 / 3$ inch. The body of the male is black, excepting the yellowish underside and tip of the abdomen. The female is honey-yellow, with the head and thorax a little darker, the thorax with the abdomen being slightly marked with black. The wings are transparent with black veins.

The full grown sawfly larva has a black head, the body is yellowish white and is ornamented with two rows of oblong square black spots down the back. On each side there is another row of about 1 I black, nearly square spots, they being a little longer than broad.

\section{Fir sawfly}

\section{Lophy'rus abietis Harr.}

Clusters of black headed, dark green, dark striped caterpillars about 1/2 inch long, defoliate fir, spruce and pitch pine in midsummer and probably early fall.

This sawfly is one of the rarer species occurring on hard pine. It was taken by us in small numbers on hard pine at Karner in early June and again the latter part of July. It is probable that this species, like its allies, has two generations, the first produced by adults which hibernate in the cocoons and the second from sawflies emerging about midsummer. This species has been recorded from several northeastern states and Canada, and Dr Fletcher states that Mr Harrington obtained the larvae of this form from spruce and apparently the same thing occurred very abundantly on white cedar.

Description. The full grown larvae have the head yellowish or black and the body a dull green with a pale dorsal stripe; in some specimens the stripe is lighter on the posterior portions of each segment. There is also a subdorsal and stigmatal paler stripe. The true legs are black and the false 
or abdominal legs pale yellowish with dark green bases [pl. 20, fig. 6]. The cocoon is cylindric, oroid, silvery white and about 5,16 inch long. The adult has been characterized by Dr Harris substantially as follows:

The male is ' + inch long with a wing spread of about ${ }^{2}{ }_{5}$ inch. The body is black above, brown beneath and the wings are transparent with changeable tints of rose-red, green and yellow. The legs are a lirty leather yellow color. The antennae resemble short black feathers, wide at the end, narrowed to a point and are curled inward on each edge so as to appear hollow. The female is about $3 /$ ro inch long and with a wing spread of $1 / 2$ inch or more. She is yellowish brown above, with a short blackish stripe on each side of the middle of the thorax. The body beneath and her legs are paler, of a dirty yellow color, and her wings rescmble those of the male. The antennae are short, taper to a point, consist of 19 segments and are serrate on one side.

\section{Spruce bud worm}

\section{Tortrix fumifirana Clem.}

Trees dying in masses or clumps of greater or less extent are very likely affected by this species.

The spruce bud worm has been characterized by Dr Packard as the most destructive enemy of spruce in certain portions of Maine. He and others have placed on record a number of instances of severe injury resulting from this insect's work. This is due, as observed by Mr Kellogg, to the fact that there are in the spruce but a few buds, usually two or three at the end of a twig, and if they are destroyed the tree does not reproduce them till the following year. This makes it very easy for an insect feeding on these portions to inflict very serious damagre.

Description. Young larvae have been lescribed by Dr Packard as uniformly pale green with a yellowish tint. The head is dark brown, the thoracic shield amber, with two dots on the posterior margin; hairs about half the length of the body thickness. Length about $3 / 32$ inch. Just before the last molt they are uniformly rust-red brown with the tubercles duller, the head and thoracic shield black. The full grown larva has an unusually thick, stout body tapering gradually from the middle to the end and slightly flattened from above. The head is not quite so wide as the body, a very dark brown, though lighter than before the last molt. 
The pupa is very thick, the thorax being unusually swollen. The body, soon after changing, is a pale horn color, striped with brown; antennae and legs dark horn color or dull tan brown. The moth has been described by Clemens as follows:

Fore wings brown, varied with dark brown, short striae. The basal patch is indicated by dark brown striae, but the central fascia is not indicated. Following the basal patch is a grayish brown space having a shining luster; its exterior edge is irregular and it widens toward the dorsal margin, where it bears short, dark brown striae. About the middle of the costa is a round spot of the same hue and luster, and along the terminal margin is a stripe with irregular margins, of the same hue and luster bordered on each side with dark brown. Sometimes the grayish luster is absent on the markings, which are then simply of a paler brown than the general hue; hind wings dark fuscous.

Life history and habits. Dr Packard states that injured trees look as though a light fire had passed through them. The larva feeds on the leaves or needles of the terminal shoots of both the first and previous year's growth. It gnaws the base of the needles, separating them from the twig, meanwhile spinning a silken thread by which the needles and bud scales are loosely attached to the twig. The caterpillar moves about freely and does not live in a regular tube, though sometimes it draws together two adjacent shoots. Its presence is hardly noticeable till the caterpillars are abundant enough to partly defoliate trees. They are usually most numerous in June and early July, occurring on firs and hemlocks, in addition to spruce. The caterpillar attains full growth from about the zoth to the zoth of June, at which time it transforms to the pupa in its rude shelter or hiding place under the loose leaves of the infested shoots, and about six days later the parent insect appears. The pale green, scalelike, flat eggs are laid in patches, the eggs overlapping each other irregularly, leaving about a third or fourth of the surface of each exposed. Hatching occurs in about io days, and the young caterpillars feed for a while and pass the winter in a partly grown condition among the terminal shoots of the tree, completing their transformations the following June and July. Professor Fernald bred from this caterpillar a parasite, Pimpla 
conquisitor Say, though as a rule this insect appears to be remarkably free from the attacks of natural enemies.

Distribution. This species occurs in New York, New Jersey, and has been listed by Dyar from the northern United States.

\section{Bibliography}

1890 Packard, A. S. U. S. Ent. Con. 5th Rep't, p. $830-38$

\section{Larch sawfly}

\section{Lygaconematus erichsonii Hartig}

A greenish yellow sawtly larva frequently defoliates larches in midsummer.

This insect has been repeatedly brougint to the attention of the writer and also to that of his predecessor, Dr J. A. Lintner, on account of the serious injury inflicted in recent years on the larches or tamarack of the Adirondacks.

Early history. I) A. S. Packard states that his attention was first called to this species in August 1882 , when he saw the effects of its work at Brunswick Me. It at that time had partly or entirely stripped the larches in the very wet swamps on the banks of the Androscoggin river. He found that most of the trees, both large ones 6 to 10 inches in diameter, and small saplings 6 to 15 feet in hight, had been attacked and that some of the trees had been stripped, others partly defoliated, and still others had escaped injury, those in the middle of the swamp appearing to have suffered most. He also published several extracts from local papers of that year, all of which were to the effect that the larches had been very seriously injured by this imported insect. Its work was observed at Franconia $\mathrm{N}$. H., in the same year by Prof. IV. II. Bailey and it also attacked larches in various parts of Massachusetts. The work of this species was observed in New York State July 25 and early in August 1883 at Horicon and Pottersville, Warren co, and at Schroon Lake in Essex county, as stated by Dr Packard. The trees were defoliated by the first of August and the affected region was very extensive, covering many 
square miles in different swamps. It was reported "from Schroon Lake to North Elba and about Mount Marcy." The work of this sawfly was observed on larches during the years $188+$ to 1886 in several counties of northern New York by State Botanist Peck, who kindly reported the depredations to Dr Lintner. Agrain in 1887 , larvae of this insect were received by Dr E. L. Sturtevant of the State Agricultural Experiment Station from $\mathrm{Mr}$ E. Phelps of De Kalb Junction. The abundance and destructiveness of this pest is well described in the following notice from the St Lawrence Republican of July 27, is 87.

Mr David Page of Jerusalem Corners, in this town, has given us an account of a remarkable pest of worms which recently infested his premises. There are three larch or tamarack trees growing in his dooryard. About July 7 , very soon after the extremely hot weather set in, a few worms appeared upon them, feeding upon the leaves. The next day they had doubled in number, and in a day or two had become a countless host, completely covering the trees, so that the end of the finger could not be placed even on the trunk of one of them without touching one or more of the worms. They also covered apple and maple trees and shrubbery, and the grass beneath, but ate nothing, so far as could be discovered, except the leaves of the tamarack. They swarmed upon the house and piazza, and it became necessary to sweep them from the latter every few minutes. They accumulated in little windrows along the house. The countless hordes of worms became an object of great curiosity and interest to people of the neighborhood, and $M r$ Page and his family became really alarmed as to the result of this invasion; but in scarcely a week from the time of their appearance they disappeared as rapidly as they had come, and in a day or two none of them were to be found. The tamaracks were left as bare as in winter, but no other signs of damage were visible. Whether the worms had grone into the ground or what had become of them seems not to have been ascertained.

The work of this insect was also brought to Dr Lintner's attention the same year from Cherry Valley, Otsego co., by Rev. Henry U. Swinnerton, and a brief paragraph published in the Conntry Gontleman July it of that year doubtless refers to the work of this insect at Sharon. The following account of personal observations by Dr Lintner in the southern portions of Hamilton county, gives a very good idea of the seriousness of its attack. 
All of the larches within sigrht of the stage route from Newton's Corners, at the foot of Lake l'leasant, to Sageville at its head, a distance of 4 miles, had been almost entirely stripped at the earliest date above named. 'The trees of this species of which there are many, in some places' it being the prevailing growth, could be recognized at the greatest distance from which they could be seen by their nakedness, appearing as if lead, which undoubtedly some of them were, as the result of the previous defoliation. The elevation above tide of Lake l'leasant is r Soo feet. Not all of the larches in the vicinity had been wholly stripped. A large one of is inches in diameter at three feet from the ground and reaching upwards to a hight of at least 70 feet, standing alone in a pastured lot, and throwing out long and thick branches, had its foliage less than one half eaten. From a large number of larches of a moderate hight of 15 feet and under that were entirely free from harm, it appeared that the younger trees were not sought by the parent sawfly for oriposition. Whenever they had been eaten, they were in the immediate vicinity of larger trees, which, having been stripped, the migrants from them, in their search for food, may have been able to ascend with difficulty in small numbers, such of the smaller ones as chanced to be in their way. The tips of these small larches gave no evidence of oriposition in them.

He adds that this attack was also observed by him in the Lake Placid region cluring the summer of $188 S$. This insect continued its ravages and in 189 . Dr Lintner observed that many of the larches from the road passing through Wilmington, and the Mountain View in North Elba, Essex co., were nearly or entirely stripped of their leaves. Considerable numbers of dead larches were seen which he thought had been killed by the annual defoliations by this insect. This insect has been injurious in later years, and has undoubtedly killed a great many larches or tamaracks in the Adirondack region. It has also extended its ravages here and there to ornamental trees. The investigations of the writer in 1900 showed that the pest was present in numbers in the Saranac Lake region, and that many larches suffered from its work, and later observations in the vicinity of Boonville in 1902, showed that larches in that section were injured more or less by this pest.

Life history. The life history of this insect has been given by $\mathrm{Dr}$ Packard as follows:

The eggs are laid in the terminal young shoots of larch from about the 
middle of June in Massachusetts, to the early part of July in northern Maine, the larvae feeding on the leaves late in June and in July and early August. The young are nearly full grown by the last of July or first week in August, according to the latitude. Still a few occur on trees in Massachusetts, as late as the last week of August or early September.

Dr Packard states that it is rery doubtful if there are two broods. He observed at Brunswick Me., that all the eggs had hatched by June 23 or 28. They are placed in two rows, alternately, not exactly parallel, one being placed a little in adrance of the other, and are inserted at the base of the fresh young partly developed leaves of the new shoots, which are usually at this time only about 1 or $1 \mathrm{I} / 2$ inches in length. The presence of the eggs causes a deformation of the shoots, which curl over, the incisions being in all cases observed on the inner side of the shoot. Dr Packard has described the operations of egg laying as follows:

The sawing the slit in which the eggs are placed requires about 5 minutes. The two sets of serrated blades of the ovipositor were thrust obliquely into the shoot by a sawing movement, the lower set of blades being the most active, and sliding in and out alternately. After the incision is sufficiently deep, the egg is expelled through the inner blades of the ovipositor.

Dr Packard states that though the slit is at first closed, as soon as the embryo increases in size the twigs swell where they have been cut and the slit enlarges and gaps more or less, and thus affords ready egress for the newly hatched larva, which rarely eats the terminal shoots, but crawls on the leaves of the whorls next thereto. It first nibbles one side of the needle or leaf, leaving it half eaten and rough, serrate, and partly withered along the edge. The presence of the injured leaves is of great aid in detecting the young sawtly larvae, which collect on the verticils of the larches after they have shed their first skin and almost invariably begin to eat the needles one after another. In this way one verticil after another is devoured and when the larvae are half grown, they occasionally collect around the main stem of the twig in singular clusters, with the hinder part of the body curled over the back. Owing to the oblique position in reference one to another, they look much like a ball 
of worms when in this posture. "The larvae appear to attain their full size in about 5 to 7 days after hatching, certainly not more than Io days." There appear to be three molts. On gaining maturity, the larvae descend from the tree and spin oval elongated cocoons beneath the moss or other convenient shelter, where they remain unchanged during the winter, transforming to the pupa the next spring. The following characterization of the different stages is taken from Dr Packard's descriptions.

The ego is slender, cylindrical, tapering towards each end, slightly over $1 / 25$ of an inch in length.

The very young larvae have dusky or smoky green heads, and uniform pea-green bodies. After the first molt, the body is a pale green and without the glaucous pearly bloom of the latter two stages. The head and thoracic feet are black and the segments wrinkled as in the adult.

After the second molt, the larva has the peculiar bloom mentioned above. The body is a pale pea-green beneath, and on the lower portion of the sides. The black spines of the abdominal segments are as distinct as in the full grown caterpillar.

The fully developed larva may be recognized by its round jet-black head and the peculiar glaucous green color of the body which resembles that of the underside of the leaf. There are no lateral stripes or spots. The thoracic segments are unmarked, but around each abdominal segment, except the second, there are parallel double rows of minute dark dots or waits [pl. is, fig. 11 ].

The oval, brownish cocoon is $2 / 5$ of an inch in length and one half that in diameter.

The adult sawfly is a large thick black species, with the second and fifth and part of the sixth abdominal segments a bright resin-red.

Distribution. This insect appears to have become well established over a considerable proportion of Canada and the New England States, New York and l'ennsylvania, and it will probably thrive wherever the larch exists.

Introduction. Dr J. A. Lintner states that this species was observed at the Arnold Arboretum at Brookline Mass. in I 880 by Prof. C. S. Sargent, who discovered the larva feeding on some European larches. Specimens were submitted at this time to $1 \mathrm{r} \mathrm{H}$. Hagen who identified the species. This is the first record of the insect's occurrence in America.

Parasites. Dr A. S. Packard records the rearing of a number of 
minute Chalcids belonging to the genus Pteromalus and for which, in case the species proves undescribed, he proposed the name of $\mathrm{P}$. n e m a $\mathrm{t}$ i c i d a. He states that this beneficial species was so abundant as to infest nearly every cocoon transmitted to him by one correspondent. He also records several plant bugs, one similar to Podis us s p in os us Dallas, as preying on the sawfly larvae. Dr Lintner observed this plant bug feeding on the sawtly larvae. He states that the full grown caterpillars were fearlessly seized and firmly held till their fluids were extracted.

Remedial measures. There is very little that can be done in checking this insect in native swamps. Valued trees on lawns can be protected from injury by thorough spraying with an arsenical poison. It is very probable that one of the prepared forms of arsenate of lead would prove most effective.

\section{Bibliography}

${ }_{188}$ Fletcher, James. Ent. Soc. Ont. 15th Rep't, p. 72-77

1889 Lintner, J. A. State Ent., 5th Rep't, p. $164-73$

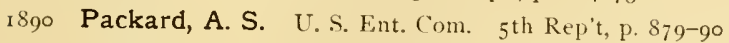

I 893 Lintner, J. A. Ins. N. Y. 8th Rep't is91, p. 168-69

\section{Pine needle gall fly \\ Cecidomyia pini-rigidae Pack.}

The basal enlargement of shortened, deformed pitch pine needles contain at certain seasons thick orange colored larvae.

The work of this interesting gall fly was met with at Karner during several years, though at no time was it excessively abundant. The attack was in most cases confined to one or two tips on the tree and a considerable proportion of the needles would be affected, indicating that the female probably remains on one branch and deposits a large proportion of the eggs at the base of adjacent developing needles [pl. 20, fig. 4]. This insect was observed by its describer, Dr Packard, at Brunswick Me., in 1862 or I 863. He found the larvae in September of that year and states that when fully developed it forsakes the gall, ascends to the terminal buds and 
pupates on one side exposed to the air. He adds that there are sometimes two larvae in a gall, one on each side of the leaf. The cocoons are described by him as pale, oval and covered with pitch which exudes from the buds of the tree. They were found May zo. At maturity the pupa wriggles partly out of the cocoon and through the adhering pitch, permitting the fly to emerge readily from the projecting case.

Life history. The life history of the species has been summarized by Dr Packard as follows:

The eggs are probably laid at the base of the needles early in May and possibly the preceding autumn or the larva may winter in this gall, though this does not appear probable. They pupate at the base of terminal buds, spin silken cocoons about the middle or the third week of Nay and the fly probably appears in the early part or the middle of June and deposits eggs which give rise to the brood we have found in September.

He finds that a large percentage of the insects are destroyed by a Chalcid parasite. The insect was under our observation during several years and July 27,1901 , very small larvae were met with in affected needles. On the 2 oth of the following June a few deformed needles were found among the old foliage, young larvae were to be seen and flies were bred July 23. These latter, however, were possibily adults of C e c i d o m y i a resinicola Osten-Sacken, to which this species has been referred by Kertész. The great difference in larval habits leads us to question the correctness of this synonymy and for the present we prefer to treat it as a . distinct species.

The work of this insect was again observed July 15, of the same year, at which time the malformation was well developed in new grown needles. It will be seen that our observations substantiate in a general way the life history as outlined by Dr. Packard.

Description. The following clescription of the larva and female is that given by Dr Packard:

Larva. Deep orange in color, with the "breast-ione" retractile. The lateral swollen region of the body is well marked, convex, and the segments are short, quite convex. 
Female described from life. Antennae 14-jointed, about half as long as the body, brown, with sparse, irregular verticils of gray hair, the 10 terminal joints twice as long as broad, and pedicellate. Clypeus and epicranium testaceous brown, the clypeus (hypostoma) having a few long gray hairs curving over and downward. Palpi concolorons with the ends of the antennae.

Thorax shining black, with four lines of white hairs, as in C. p in i DeGeer; the sides including the prothorax, reddish; scutellum reddish brown, while the trochanters are much darker, the first pair being nearly black, the two posterior pairs reddish brown. Legs brown, paler beneath, with gray hairs, the tarsal joints darker at the articulations, covered with fine silvery hairs.

Wings rather short and broad, with scarcely any pubescence; fringe long, veins dark brown; the subcostal (first longitudinal) vein terminates at the middle of the wing (in C. sali $\mathrm{c}$ is it terminates much beyond this point); the median vein terminates at or perhaps a little below the apex; it curves around rapidly, following the curve of the margin; cross vein very minute, very oblique, almost obsolete, situated a little below the middle of the first longitudinal vein; third longitudinal vein straight, but turning down to the inner margin as nearly a right angle. The venule which, in continuation of the main vein, is bent upward at its origin, thence goes straight to the outer edge, inclosing a triangular space. The halteres are pale flesh-colored.

Abdomen blood-red, with slight sparse hairs. The segments on the terminal half of the abdomen are edged with black, and the tip of the abdomen is blackish, while the genital armature is flesh-colored. Length . 10 inch.

\section{Bibliography}

1890 Packard, A. S. U. S. Ent. Com. $5^{\text {th }}$ Rep't, p. 798-800

1903 Felt, E. P. For. Fish and Game Com. 7th Rep't, p. 5 ro-II 


\section{INSECTS OF MINOR IMPORTANCE AFFECTING IOREST TREES}

This division is purely an arbitrary one and made as a matter of convenience because it enables the bringing together of accounts relating to species which are more or less injurious from year to year. Nany of the insects noticed in this latter section, are of considerable importance and occasionally may cause serious injury. This division is defective in that it involves looking in several places in order to learn about the insects affecting a tree, and this difficulty is remedied in part by indexing all the species under their food plants as well as under their generic and specific names.

\section{INSECTS AFFECTING DECIDUOUS TREES}

\section{Borers in living or relatively sound wood and bark}

A stout beetle about an inch long and beautifully marked with dark brown, silvery and reddish yellow, bores in hickory... Beautiful hickory borer. Go es pulch ra, p. 43r A brownish gray beetle about $3 / 16$ inch long, and with very long, slender antennae, occurs on oak.................................. pus pun ctat us, p. 432

A small, grayish, black-spotted beetle about if inch long, may be bred from dead twigs of oak and othertrees.................. II y perplatys maculat 11 s, p. 432

A narrow, triangular, blackish beetle $1 / 4$ inch long, marked with lines and spots of yellowish or orange, occurs on varions flowers in June

Mordella octopunctata, p. 433

A slender, flattened beetle with red prothorax and bluish wing covers, mines as a larva the inner bark of dead and dying trees; also injurious to tan bark

Variable oak borer, Phymatodes variabilis, p. 433

A stout, brownish, gray-spotted, long-horned beetle about an inch in length, may be bred from oak, walnut and hackbery

Dusty oak borer, Romaleum a tomarium, p. 434

A stout, brown, grayish mottled, long-horned beetle occurs in midsummer on oak and various trees, the larva is an oak and pine borer. Urog raph is f as c i a tus, p. 434

A black beetle about $1 / 2$ inch long, with brick-red wing covers marked with reddish yellow spots, occurs on scrub oak............ Ty pocerus velut in us, p. $43^{6}$

A small grayish weevil $1 / 8$ to $3 / x 6$ inch long occurs on oak foliage, the larva tunnelling the wood ................ Gray sided oak weevil, Pand elet ejus hilaris, p. 436

A black, clearwing moth with red-spotted wings and yellow-banded legs and abdomen, may be reared from oak galls................ Sesia rubristigma, p. 437 
A golden yellow and black wasplike, clearwing moth having a wing spread of $1 / 2$ inches, is very injurious to red oak................. Me my thrus simulans, p. 438

A brown-headed, greenish larva with rose-colored elevated points, about $1 / 2$ inches long, bores in black oak

Lesser oak carpenter worm, l'rion oxyst $\mathrm{s}$ macmurtrei, p. 439 A small, black, yellowish, gray-marked, long-horned beetle may be reared from dead limbs of hickory, oak and other trees............ Le pturges que re i, p. 439

A black beetle about $3 / 6$ inch long, variahly marked with dark orange red, occurs on scrub oak.............................................. u ra vans, p. 40

A grayish, narrow, triangular beetle from $3 / 8$ to $1 / 2$ inch long, may be met with on hickory in early June ........................ Tomoxia bidentata, p. $44^{\mathrm{I}}$

A narrow, triangular, brownish, gray-marked beetle about $3 / 26$ to $5 / 26$ inch long, occurs on decaying hickory in early June ............... Tomoxial lineella, p. $44^{\mathrm{I}}$

A small, cylindric, stout, black, red-shouldered beetle about $\% / 5$ inch long, makes short, curved galleries in the branches of a number of deciduous trees

Red-shouldered twig borer, sinoxylon basilare, p. 442

A flat-headed, yellowish white grub bores in the trunk and limls of pignut hickory, trans. forming to a flattened, hard-shelled, lurid, dull brassy colored beetle

Lurid Dicerca, Dicerca obscura var. li rida, 1). 442

A stout, black beetle with golden yellow spots and transverse bars on its wing covers, occurs on chestnut, oak and hickory in midsummer.. Callo ides nobilis, p. 443 A slender, blackish, gray-marked beetle about $5 / 8$ inch long, mines as a larva the inner bark and sapwood of chestnut and oak

Thunderbolt beetle, Arhopalus fulminans, p. 444

A black, slender, cylindric, long-horned beetle about $3 / 8$ inch long, is easily reared from hickory twigs...................... Dorcaschema nigrum, p. 444

A brownish black, red-bordered beetle about $1 / 2$ inch long, bores as a larva in hickory

Red-edged Saperda, Saperda lateralis, p. 445

A small, jet-black beetle about $1 / 4$ inch long and with an oblique white line on each side, works in hickory and chestnut branches.......... Eu derces picipes, p. 445

A cylindric, brownish beetle about $3 / \mathrm{r}$ inch long, makes holes of nearly uniform diameter in hickory and oak......... Hickory timber beetle, Xyle borus celsus, p. 446

A short, stout, black beetle about $1 / 16$ inch long, may be bred from hickory twigs

Hickory twig borer, Chramesus hicoriae, p. $44^{8}$

A slender, odd looking larva with a prominent hump on its neck, and leaflike, fleshy appendages at the end of its back, excavates extensive galleries in the heartwood and sapwood of living and dead chestnut and oak

Chestnut timber worm, L y mexylon serice u m, p. 449 
A brownish, flattened beetle about 1/2 inch long, occurs on chestnut, the larvae mining the inner bark ............................ c 11 idium a ere $u$ m, p. $45^{\circ}$

A heantiful, black, golden-marked beetle about 58 inch long, occurs on various trees in

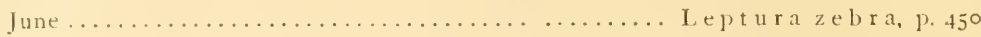
A blue black, clearwing moth about $3 / 4$ inch long, with yellow-banded legs and abdomen, bores as a larva under chestnut and dogwood bark........ Sesia scitula, p. 451 A minute, brownish, rather stout beetle about "1o inch long, runs transverse galleries in the inner bark of peach, plum and cherry

Peach bark beetle, Phloe otribus 1 im in a ris, $\mathrm{p} .452$ A blue black, clearwing moth having a wing spread of an inch and with narrow, yellow bands on the abdomen and legs, lives as a larva under the bark of plum and several

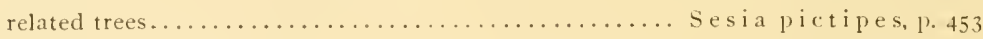

A red-horned, red-legged, black, brilliant greenish beetle about I 2 inch long, occurs on butternut, oak and birch................. (ia u rotes cy a in ipen nis, p. 454 A flattened, jet-black snout beetle about $3 / 4$ inch long, hores in butternut, poplar and other

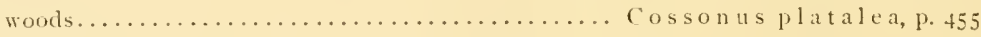

A slender, light brown beetle about $\mathrm{I}$ inch long, bores in butternut and beech Centrodera decolorata, p. $45^{6}$

A purplish, black, yellow-marked, red-tailed, clearwing moth with a wing spread of about $3 / 4$ inch, bores as a larva in maple.................. Sesia corn i, p. 456

A flat brassy beetle with divergent wing covers, works in peach, cherry, beech, maple and other deciduous trees....... Divaricated buprestis, Dicerca divaricat a, p. 457 A brilliant green, goldén yellow, flat beetle about $5 / 8$ inch long, bores in maple

Banded buprestid, Buprest is fasciat a, p. $45^{8}$

A slender blackish, wasplike insect bores as a larva in diseased maple

White-horned maple horer, Xy phidria albicarnis, p. 459

lark brown or black beetles about ${ }^{1}{ }_{32}$ inch long, make longitudinal burrows in partly decayed sugar maple limbs.................. Xy loc leptes species, p. 460

Small worms similar to young apple borers sometimes occur in multitudes under the bark of apple and maple trees. Prickly Leptostylus, I, e p tost ylus a culiferus, p. 46 i

A stout, black beetle $5 / 8$ inch long, with brownish wing covers ornamented with three lines, occurs on elm.................. Physocnemum brevilinenm, p. 462

A light brown beetle about $3 / 4$ inch long, at the base and about the middle of each wing cover, pairs of ivorylike, oval elevations, bores as a larva in ash, hickory and honey locust.............. 4-marked ash borer, Eburia quadrigeminat a, p. $4^{62}$

Slender, flattened, tortuous galleries in ash, $1 / 8$ to $1 / 16$ inch in width, cutting the wood largely, may be the work of this species............. Obrium rubrum, p. 463 
A large, brownish, yellow-marked and yellow-banded, clearwing moth with a wing spread of $\mathrm{r}^{\mathrm{I} / 2}$ inches, bores as a larva in ash......... M e m $\mathrm{t} \mathrm{th} \mathrm{r}$ us a silipen $\mathrm{n}$ is, $\mathrm{p} .4^{6} 4$

A sawfy larva bores in the partly decayed wood of standing birch and makes a gallery about $1 / 8$ inch in diameter............... Xyphidria provancheri, p. $4^{6} 5$

A horntail borer making moderately large, cylindric burrows in decaying birch

Slender birch horntail, Konowia a t te nu at a, p. +66

A flattened, brilliantly colored, purplish or bluish beetle about If inch long, occurs in May on birch and other deciduous trees..... Chry so both ris a $z$ u rea, p. 467

A slender, brownish beetle ranging from about ${ }^{3}+$ to nearly $r^{1}+4$ inches in length, bores in the larval stage under the bark of yellow birch and maple

Bellamira scalaris, 11. 46 ;

A brownish, white-striped caterpiller abont $\mathrm{r}$ inch long, bores commonly in herbaceous stalks and the more tender twigs of maple and ash

Stalk borer, Papaipema nitela, p. 468

A brownish. cylindric beetle works in the stumps of recently cut yellow birch, causing an excretion of sap, which gums the rust-colored borings to the outside of the affected wood......................... Birch bark borer, 1) ryocoetes sp. p. 468

A small, black beetle with gray or yellowish gray restiture, is sometimes bred from willow Sa jeerda mutica, p. 469

A blue black, clearwing moth having a wing spread of 's inch, bores in willow in the

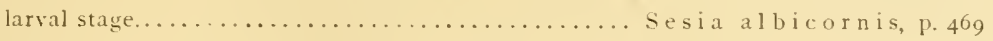

A steel blue, clearwing moth with a broad abdominal band and the fore wing tips red, bores willow canes in the larval stage $\ldots \ldots \ldots \ldots \ldots \ldots$. sesia bolteri, p. 4 ;

A black, clearwing moth with three conspicuous yellow abdominal bands, lives in the larral stage in Saperda galls on willow and poplar

Three banded clearwing, Mem yth $\mathbf{r} u \mathrm{~s}$ tricinctus, p. $4 \mathrm{ir}$

A large, brown, yellow-marked, clearwing moth having a wing spread of $\mathrm{r} 3 / 4$ inches, lives as a larva in willow and poplar trunks ............ tegeria tibialis, p. $4 i^{2}$

A large, brown and yellow-marked, clearwing moth having a wingspread of ${ }^{3} / 4$ inches, lives as a larvi in roots of willow and poplar....... Aegeria a piformis, p. $4 i^{2}$

A rather stout, blackish beetle irregularly marked with gray, occurs in June on poplar and

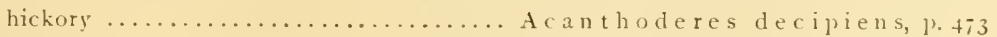

Girdling the trunks of sapling poplars or running a mine around them, causing a swelling twice the diameter of the tree, a cylindric, slaty gray beetle about $3 / 8$ inch long

$$
\text { Saperda concolor, p. } 4 \text { it }
$$

A small, brown or black, coarsely punctured beetle about $3 / 8$ inch long, may be bred from galls of balsam poplar................... saperda populnea, 1. 474 
A small, brownish black, yellowish-specked weevil about if inch long, occurs in early spring under poplar bark................ l) or y tom us parvicollis, p. 475

A small snout beetle about 1.8́ inch long, irregularly clothed with grayish pubescence, occurs under poplar bark in early May...... I Iorytomus vagenot a tus, 1) 475 Stout, white naked caterpillars about $1 \frac{\mathrm{I} / 2}{2}$ inches long, bore in poplar trunks

Poplar carpenter worm, Cossus centerensis, $1 \%+76$

A pale whitish caterpillar hores in the smaller twigs of locust and causes a thickened, irregular growth, $x$ to 3 inches long

Locust twig borer, Ec dy tolopha insitician a, p. 478

A yellow-marked, black beetle almost $1 / 2$ inch long, may be bred from woodbine, sumac and possibly poison ivy...... Woodbine borer, Saperda puncticollis, p. 478 A jet-black, highly polished curculio about $1 / 8$ inch long and with strongly grooved wing covers, occurs on ampelopsis or Virginia creeper, poison ivy and grape

Ml a darell us und ulat us, p. 479

Irregular, gall-like swellings at the base of alder stems followed by dying and breaking of the shoots..................... Alder borer, Saperda obli (j ua, p. 480

A small, legless grub boring irregularly in dead sumac and other twigs, may be the young

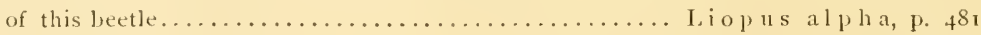

A small, thick, long-horned, brown or chestnut-colored beetle about 'f inch long, with ash gray markings, may be bred from the dead twigs and wood of a number of trees

Spotted Leptostylus, Leptostylus macula, p. 482

\section{Borers in dried, usually manufactured wood}

Pin holes less than ${ }^{1}{ }_{16}$ inch in diameter and galleries of the same size running in various directions in wood, may contain linear, black, white marked beetles about $3 / 16$ inch long

White marked powder post-beetle..... L y ctus parallelopi pedus, p. $48_{3}$ Burrows about $x_{2}$ inch in diameter may occasionally be observed in telegraph poles, doors, posts and similiur places, and a large, dusky winged bee seen going in and out

$$
\text { Large carpenter bee, X ylocopa virginica, P. } 484
$$

\section{Borers in decaying wood or species found under decaying bark}

A large, rather stout, black, white-marked beetle I/2 inches long, bearing two conspicuous eyelike spots, is frequently met with in decaying wood

Owl beetle, Alaws oculatus, p. 485

A thick, fleshy, legless grubabout 3 inches long when full grown, bores in roots and stumps of a number of trees...... liroad-necked Prionus, P'rionus laticollis, p. 486

A rather slender, lorown beetle ahout $1 \frac{1}{2}$ inches long and less than $1 / 2$ inch broad, lives in the larval stage in decaying trees

Lesser P'rionus, Orthosoma brunne $\mathrm{m} m, \mathrm{l}$. $4 \mathrm{~s} 7$ 
An olive, gray-mottled beetle with black head and thorax and about 58 inch long, occurs in early spring on partly decayed beech stumps

Anthophilax attenuatus, p. 488

A brown-headed, black-winged, rather stout beetle about If inch long, was bred from larvae taken from a hollow oak.............. Dermestes [) ul che r, p. 489 For less important species taken under decaying bark or in decaying wood, see p. $+89-79.4$

\section{Fungous beetles}

There are a number of species formed on various fungi growing on trees, and some of the more common are noticed briefly on P. 49.4

Natural enemies of one kind or another are frequently found in association with the above named species, and they are noticed briefly on p. 499-505

\section{Beautiful hickory borer \\ Gocs pulchro Hald.}

A stout beetle about an inch long and beautifully marked with dark brown, silvery and reddish yellow bores in hickory.

The parent insect is it stout beetle, about 1 inch long, beautifully clothed with dark brown, silvery and reddish yellow pubescence. There is a broad, transverse, lighter band across the wing covers, and the tips of the latter are conspicuous on account of the golden pubescence covering them [pl. 9, fig. I].

This insect deposits its eggrs on different varieties of hickory, frequently selecting smaller trees only an inch or thereabouts in diameter. The operations of the grub insicle young trees, causes the trunk to enlarge so that there is produced a grall-like swelling, which weakens the tree and may result in its breaking off in a gale. Old borings are marked by an ugly wound [pl. 9, fig. 3]. Recent operations of the larva are shown at figure 4 , its characteristic feedings at the base of leaf stems and the exit hole of the parent beetle are represented at figures 2 and 5 respectively, plate 9 .

This species is not abundant in New lork, if one may judge from the condition of the State collections. This may be due in part to the retiring habits of the adults. It was reported a number of years agro by Dr Hodge as scarce, though found every season in shaghark and pignut hickory, about 
Buffato. Dr Smith states that this species occurs throughout New Jersey during June and July on hickory, having been noted by all recorders.

\section{Liopus punctatus Lec.}

A brownish gray beetle about ${ }^{3}{ }_{16}$ inch long and with very long, slender antennae occurs on oak.

This very small dainty longicorn with enormously developed, slender antennae, is a rare species. Only two examples were taken June 26, 1901 on scrub oak at Karner. This little beetle is about 's ${ }_{16}$ inch long, of brownish gray color, inconspicuously and somewhat variably marked with black and white. It may be separated from the other species of the genus, according to Mr IVickham, by the convex front, the slightly retracted mouth, the lateral prothoracic spine being somewhat distinct from the base and by the elytra lacking distinct tufts of erect scales, and having a feebly marked post median band of whitish pubescence in place of the angulate line.

This species has been recorded by Dr Smith from several New Jersey localities and he gives Cornus floridus and plum as food plants. Messrs Leng and Hamilton record this species from 11 isconsin and Canada.

\section{Hyperplatys maculatus Hald.}

A small, grayish, black-spotted beele about it inch long, may be bred from dead twigs of oak and other trees.

This, one of the prettiest of our long-horned bectles, is noteworthy

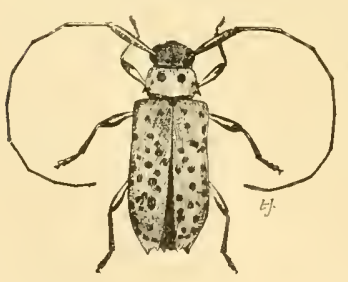
because of its extremely slender, black antennae, which are longer than the body. The thorax is broader than long, dark brown, covered with a grayish pubescence, with a pair of large black spots on the anterior third, and ornamented with conspicuous lateral spines near the posterior third. The wing covers are thickly clothed with a grayFig. 94 Hyperplatys maculatus ish pubescence, bear numerous rather large, circular, black spots and are terminated by a pair of blunt spines. The femora are distinctly clubbed. 
This species is a general feeder, it having been taken on dead twigs of orange, apple, hickory, poplar, oak, maple, yellow locust, beech and also sumac. It appears to have a general distribution in the northeastern United States, since it has been recorded from West Virginia, New Jersey, New York and the visinity of Cincinnati $\mathrm{O}$.

\section{Mordella octopunctata Fabr.}

A narrow, triangular, blackish beetle $1 / 4$ inch in length, marked with lines and spots of yellowish or orange, may be met with on various flowers in June.

This, one of the prettiest species belonging to the genus, may be quickly recognized by the linear buff markings on the thorax, and the yellowish or orange markings on the wing covers. There are, in the specimens before us, six well defined dots on the wing covers, with a somewhat irregular yellowish $\mathrm{M}$ on the base of the elytra.

The larva has been found by Riley, in oak stumps, and he states that it has a yellowish white head with three distinct yellowish lines above. The legs are short and the posterior extremity pointed, horned and blackish brown.

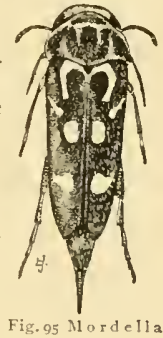

This species has been listed from the Middle and Southern octopunctata States by Dr LeConte, has been reported as rare in southwestern Pennsylvania by Dr Hamilton, while Ulke states that it, with other species, occurs on bushes and flowers. Dr J. B. Smith records it from a number of New Jersey localities, it being rated in some places as rare, and in others as common.

\section{Variable oak borer Phymatodes iariabilis Fabr.}

A rather slender, slightly flattened beetle with red prothorax and bluish wing covers, mines as a larva the inner bark of dead and dying oaks, and is also injurious to tan bark.

This beetle is rather common in midsummer. The slender, reddish antennae are a little longer than the body and rise between the deeply emarginate, rather finely granulate eyes. The face of the insect is reddish brown with a slight blackish area between the bases of the antennae. The 
sides and dorsum of the head are jet-black, coarsely and irregularly punctured. The thorax is clark brown, slightly swollen, and with an indistinct, darker area on each side. The dark bluish wing covers are rather finely and irregularly punctured and with a distinct ridge extending from the humeral angle and reaching about the middle of the wing cover at the posterior fourth. Femora, apically much dilated, black; basal portion reddish, the tibiae and tarsi the same color. This species is generally. recognized as an oak borer. It also infests hickory and Dr Smith states that it occurs in great numbers in oak cord wood.

\section{Dusty oak borer \\ Romalcum atomarium Drury}

A stout, brownish, gray-spotted, long-horned betle about $x$ inch in length, may be bred from oak, walnut, hackberry and the dry leaf stems of palmetto.

This species is a typical, long-horned beetle a little over an inch long. The slender antennae are longer than the body and rise between the eyes, which latter are deeply excavated and rather coarsely granulate. The prothorax is rounded laterally and ornamented dorsally with three distinct tubercles arranged in a triangle, the posterior one being median and clothed with a thick, yellowish pubescence. The brownish wing covers are also thickly clothed in spots with a yellowish pubescence, giving the insect a dusty appearance. Dr Hopkins states that the larvae occur in stumps and logs of recently dead oak, and it has also been recorded from walnut and hackberry and the dry leaf stems of palmetto.

\section{Urographis fasciatus DeGeer}

A stout, brown, grayish-mottled, long-horned beetle occurs in midsummer on oaks and various trees; the larva is an oak and pine borer.

A specimen of this insect was obtained from hard pine bark brought from Karner, June 18, 1902. This beetle was early brought to the notice of Dr Fitch, who bestowed on it the common name of Quercitron bark borer.

Description. Beetle, rather stout, about $1 / 2$ inch in length, the female 
with a stout ovipositor extending about $3 / 16$ inch beyond the tip of the wing covers. The antennae are slender, ringed with grayish white, and about one half longer than the body. The head, thorax and body are obscurely and somewhat irregularly marked with grayish brown and silvery white. The thorax is broader than long and armed laterally with a stout spine a little behind the middle; wing covers rounded at the base. Mr Wickham separates this species from its ally, U. triangulifer Hald., by its more elongate form, grayish pubescence on the upper surface, except for the dark markings consisting of small closely placed spots and blotches; these latter form a distinct line on each side of the middle of the prothorax, usually also an antemedian and postmedian, irregular elytral band.

The larva is a little over $1 / 2$ inch in length, and has been described by Dr Fitch as having a more or less retracted head, its base white and anterior portion deep, tawny yellow, black along each side. The body of the grub tapers slightly backwards to the middle, from whence it has nearly the same diameter to the bluntly rounded tip. There is a large, transverse, tawny yellow spot on the upper side of the prothoracic segment, occupying its basal half, and an elevated, rough, transverse, oral spot of the same tawny yellow color on the middle of all the other body segments, except the last two.

Life history and habits. Dr Fitch states that the bark of recently felled black oaks, Quercus tinctoria, are mined by borers belonging to this species, they forming large worm-eaten tracks. Transformation to the pupa occurs in the cavity, and the long-horned beetles appear in June. In Dr Fitch's time the species was so abundant that unless the bark of the black oak was peeled immediately after the tree fell, it became much worm eaten and worthless for dye purposes.

Food plants. This beetle appears to have a somewhat varied food habit. Besides occurring in pine and oak, as stated above, it has been reared by Mr Chittenden from chestnut, oak and maple, and Mr Beutenmüller also records it in addition from hickory, limbs of chestnut, and on the authority of Mr Jcutel, from apple and pear. MIr Dury records taking it on beech in the vicinity of Cincinnati. 
Distribution. This species has a wide distribution in the eastern United States and Canada, since it has been recorded from Canada south to Louisiana, and as far west as Lake Superior and $\mathrm{W}$ isconsin. It also appears in a number of local lists.

\section{Typocerus velutinus Oliv.}

A black beetle about $1 / 2$ inch long with brick-red wing covers marked with reddish yellow spots occurs on scrub oak.

This, one of our more common longicorns, occurs on scrub oak in small numbers at Karner. The beetle measures about $1 / 2$ inch in length. The head and thorax are black, the latter being bordered anteriorly and posteriorly, in well marked individuals, by a fringe of golden yellow hairs. The wing covers are brick-red, variously marked with reddish yellow spots, there being two large ones at the basal angle, two on each wing cover at about the basal third, one near the median line and another near the anterior border, and a larger spot at the distal third with a more faintly indicated one near the tip. It is abroad in July.

This species has been recorded by Dr Smith as common throughout New Jersey and it has been listed by Dr Hamilton from Sparrow lake, Ontario.

\section{Leptura emarginata Fabr.}

This large, beautiful longicorn has been found ovipositing in the limbs of white oak by Mr Joutel.

\section{Gray sided oak weevil Pandeletcjus hilaris Herbst.}

A small, grayish weevil from $1.8103 /{ }^{6}$ inch long, occurs on oak foliage from May to September, the larva tunneling the wood.

This species was taken in large numbers on scrub oak at Karner, Sep. 18,1901 , and was present in greater or less abundance during the summer. It may be separated, according to Dr Horn, from the allied P. c in ereus Horn, by the tip of the rostrum being entire and without a smooth space. 
The thorax is also different in that it is dilated, pyriform, with the anterior narrower part much shorter than the posterior.

Description. The beetle has been described by Harris as follows :

A little pale brown beetle, variegated with gray on the sides. Its snout is short, broad, and slightly furrowed in the middle; there are three blackish stripes on the thorax, between which are two of a light gray color; the wing covers have a broad stripe of light gray on the outer side, edged within by a slender blackish line, and sending two short oblique branches almost across each wing cover; and the fore legs are larger than the others. Length from I/s to $1 / 5$ of an inch.

The larva of this form has been characterized by Packard, as like that of the plum weevil. It makes a smaller gallery than Eupsalis minuta Drury, and according to Harris, lives on the trunks of white oaks. It has been recorded on white oak by Dr Hamilton in southwestern Pennsylvania, and by Dr Smith in New Jersey, who states that it occurs through-

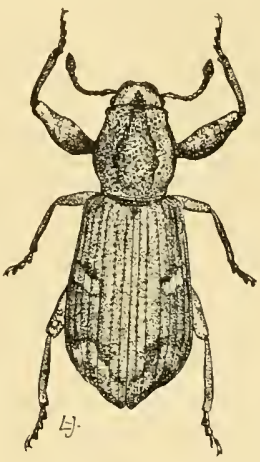

Fig. 96 Pandelecejus $\mathrm{hilar}$ is (original) out the state in the trunks of white oak and also on beech.

Distribution. This species ranges from New York to Texas and has been recorded from a number of eastern localities.

\section{Sesia rubristigma Kellicott}

A black clear wing moth with red-spotted wings and yellow-banded legs and abdomen may be reared from oak galls.

This species occurs in New York, Ohio and Iowa, and was bred from the galls of Andricus cornigerus on Quercus palustris by the late Dr Kellicott, moths being obtained in June and July.

Male. Head blue black, orbits pure white, palpi with basal joints black, second joint black except the tip, which is yellow, as is the whole of the third joint. Antennae black. Collar yellow. Thorax black with a yellow mark posteriorly and a yellow patch on each side below. Abdomen black with a narrow yellow band on the second and last segments, and a broad one on the fourth segment encircling the body; first segment with a spot on each side. Anal tuft black with a narrow yellow line on each side. 
Legs blue black, varied as follows : anterior coxae, fore tibiae, all the tarsi, the spurs, and a band at the middle and apex of the hind tibiae, yellow; the tarsi, however, have some dark scales, appearing faintly banded. Fore wings transparent, purple black, borders very narrow. Discal mark square, bright red. Underside with borders yellow to the discal mark, which is the same as above. Hind wings transparent, borders very narrow, purplish, costa orange red; underside similar to the upper.

Fimalc. Similar to the male. The outer margin of fore wings much broader, with red scales between the veins. Anal tuft with a distinct yellow lateral line.

Expanse. Nale and female, $16-18 \mathrm{~mm}$. Beutenmuller

\section{Memythrus simulans Grote}

A golden yellow and black, wasplike clearwing having a wing spread of $1 / 2 / 2$ inches is very injurious to red oak.

This insect has seriously injured the red oaks in St Anthony park, Minnesota, according to Dr Lugger, every tree showing numerous holes from which the moths had issued and in many cases the empty pupal cases were projecting from them. Adults appear in Minnescta from the end of May and throighout the month of June, some trees harboring hundreds of the borers in the trunk and larger limbs. The recorded distribution of this species has been given as Rhode Island, New York, Pennsylvania, New Jersey, Illinois, Iowa and Minnesota.

Description. Head black, orbits of eyes bright lemon yellow; palpi black at base, otherwise lemon yellow. Antennae black with a steel blue reflection. Collar lemon yellow. Thorax black, patagia at tips, a transverse posterior mark and spot at base of fore wing, yellow. Anterior coxae yellow ; femora black, marked with a little yellow; tibiae yellow and orange ; tarsi orange. Abdomen black with a broad bright yellow band on the posterior edge of each segment, those of the posterior segments much widened; sometimes the first to fourth segments have the bands very narrow and the last three segments are wholly yellow. Underside similar to the above. Forewings thinly clothed with dull orange brown scales, bordered with deep brown black along the costa and inner margin, discal mark slightly indicated. At the base of the wing is a short transparent streak, and at the hind angle is a transparent area. Underside paler than above, washed with orange. Hind wings transparent, with opalescent luster, margin very narrow brown.

Expanse. $\quad 27-35 \mathrm{~mm}$. Beutenmuller 


\section{Lesser oak carpenter worm}

\section{Prionoxystus macmurtrci Guer-Men.}

A brown-headed, greenish larva, with rose-colored elevated points, about $\mathrm{I} / 2$ inches long, bores in black oak.

This species is closely allied to the carpenter worm, P. robin iae Peck, noticed on page 79 and has very similar habits. It appears to be much rarer than its larger relative, though we have met with pupal cases in the Adirondacks which seemed referable to this species.

Description. Dr Fitch describes the moth as slightly smaller than P. robiniae, with thin, slight, transparent wings crossed by numerous black lines, the outer margin only of the fore pair being opaque and of a gray color. The hind wings of the male are colorless with the inner margin broadly blackish and the hind edge coal-black.

The larra has been characterized by Dr Lintner as an inch and a half long, pale green with a darker green dorsal stripe bordered faintly with yellow. Head flat, subtriangular, dark brown clouded with black. First segment with two brown spots extending across it, narrowed laterally, and of nearly the length of the segment medially where they unite to enclose on the dorsal line an elongate elliptical green spot. The anterior segments are flattened, and broader than the following, which gradually diminish in breadth toward the posterior end. The segments are marked dorsally with four rose-colored elevated points forming a square on the Ioth and it th segments. A similar spot occurs above each spiracle, a smaller one below and another in front, each tipped with a short brown hair. The spiracles are oval, orange colored with brown centers.

\section{Lepturges querci Fitch}

A small, black, yellowish gray marked, long-horned beetle may be reared from dead limbs of hickory, oak and other trees.

Two specimens of this interesting little species were reared from dead branches of hickory limbs taken at Ilion N. Y., May I 7, 1902, the insects issuing June Io and I 1 . This tree was badly infested by a knotty, gnarly growth, and presumably was in far from a thriving condition.

Description. This little longicorn is about $3 / 16$ inch in length, black, with irregular markings of yellowish gray on the wing covers. Seen from 
above, there is a broad, transverse band of yellowish gray pubescence across the anterior portion of the wing covers, broken by two long reniform spots near the median line and a large quadrate one laterally. There is also a patch of yellowish gray, with a central black spot at the extremity of each wing cover. The slender antennae are nearly twice the length of the body, with the tips of the segments slightly darker.

Life history and habits. This species was met with by Dr Fitch on red and white oaks. It has been recorded as common on hickory by Dr Hamilton, and Dr Smith states that it has been bred from oak, hickory and redbud in New Jersey, while Mr Chittenden has reared it in addition from limbs of butternut.

Distribution. This beetle has been recorded by Messrs Leng and Hamilton from Canada, Michigan, New York, New Jersey, Pennsylvania, Ohio, and it lias been listed by Mr Ulke from the District of Columbia. It also appears in local lists of insects taken in the vicinity of Buffalo N. Y., Cincinnati $O$., and is reported as occurring abundantly in southwestern Pennsylvania, while $\mathrm{Dr}$ Smith states that it is found throughout New Jersey.

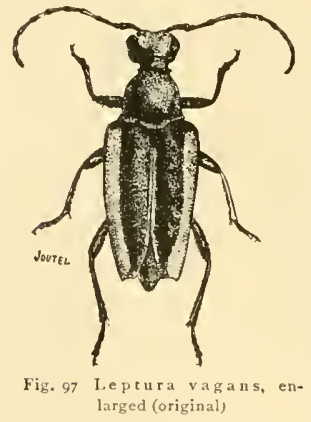

\section{Leptura vagans Oliv.}

A black beetle about $3 / 8$ inch long, variably marked with dark orange red occurs on scrub oak.

A single specimen of this small longicorn was taken on scrub oak at Karner in $190 \mathrm{r}$. The adult beetle is about $3 / 8$ inch long, with the head, thorax and a variable portion of the wing covers coal-black, the remainder dark orange red. In one specimen the black portion is represented by a somewhat lenticular, median spot on the side of the elytra, while on another there is only a rather narrow orange colored line on the humeral ridge of each wing cover. The head, thorax and wing covers are coarsely punctured.

This species has been recorded from a number of New Jersey localities 
by Dr Smith, who states that it has been bred from butternut, hickory and birch.

\section{Tomoxia bidentata Say}

A narrow, triangular, grayish beetle from $3 / 2$ to $1 / 2$ inch long, occurs on hickory in June.

This species was obtained in some numbers June 8 , from decaying hickory at Albany. It has a very close resemblance to T. l in e ella Lec., though the grayish, linear markings are not so distinct. It may be recognized, according to Dr Smith, by the long, triangular last joint of the maxillary palpi, and by the base of the thorax being rounded at the middle. The elytra are marked with broad bands not extending behind the middle, and with the posterior fascia composed of spots, a cinereous apical margin and a rhomboidal dark spot each side, near the base. This species was collected June 29 on dying
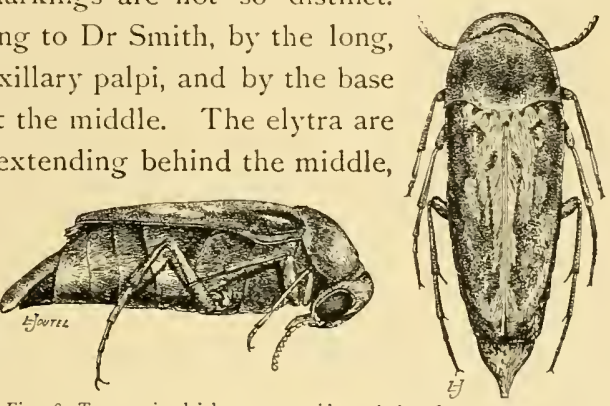
hickory by Dr Hopkins, and (originaly

Dr Smith records it from various New Jersey localities on dead trees, but nowhere common. Dr John Hamilton states that it is not common in

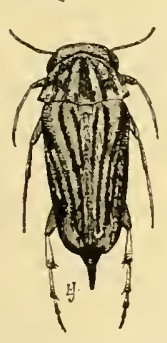
southwestern Pennsylvania about old trees. It was described by Say from Missouri, and Dr Smith lists it from the Middle and Western States.

Tomoxia lineella Lec.

A narrow, triangular, brownish, gray-marked beetle about $3 / 26$ to $5 / 16$ inch long, occurs on decaying hickory in early June.

This rare species was obtained in some numbers from a decaying hickory at Poughkeepsie, June 4, 1903. It has Fig. 99 Tomoxia somewhat variable linear grayish markings on the head and
lineella, en- sol larged (original) thorax, and has been recorded by Ulke as occurring on old twigs in the District of Columbia, and Dr Smith reports it from dead trees. 
He also states that it is much rarer than T. biden t a t a Say, from which it may be distinguished by the form of the maxillary palpi and the markings. He has seen specimens from Ohio, but has not learned of its occurring beyond the Mississippi. Dr John Hamilton records it as not common in southwestern Pennsylvania.

\section{Red-shouldered twig borer \\ Sinoxylon basilare Say}

A small, cylindric, stout, black, red-shouldered beetle about $s / 5$ inch long, makes short, curved galleries in the branches of a number of deciduous trees.

This small borer is rather uncommon in New York State, though it has been recorcled as breeding in the twigs of a considerable variety of trees such as hickory, persimmon, mulberry, apple, peach and grapevine. Dr Hopkins states that it infests most other deciduous trees and that the larvae bore in solid wood.

Description. This small beetle is black or very dark brown with a variable area on the shoulders reddish. The antennae are light rufous with the terminal portion composed of three enlarged segments and a smaller one. Head coarsely and irregularly punctured; thorax strongly rounded, tuberculate anteriorly. WVing covers rather coarsely punctured and with several inconspicuous striae. Declivity straight and bordered above with three conspicuous teeth. Length about $1 / 5$ inch.

This species is probably generally distributed in the northeastern United States, since it has been recorded from New York, New Jersey, the vicinity of Cincinnati $\mathrm{O}$., and Minnesota.

\section{Lurid Dicerca}

\section{Dicerca obscura var. luvida Fabr.}

A flat-headed, yellowish white grub bores in the trunks and limbs of pignut hickory, transforming to a flattened, hard-shelled, lurid, dull brassy colored beetle.

This rather pretty borer was bred in considerable numbers from a badly galled hickory branch taken at Ilion, May I 7, I902.

Description. The beetle is a flattened, hard-shelled insect ranging 
from about $5 / 8$ to almost $3 / 4$ inch in length. It is a lurid brassy color above and a bright coppery underneath. The tips of the wing covers diverge slightly and each bears a pair of small spines.

The larva is a yellowish white color, long, narrow, depressed in form and with abruptly widened thoracic segments. The head is brownish, small, and largely concealed by the prothorax. The mandibles are tridentate, black, the antennae very short. The prothorax is short and transverse, the mesothorax is oval, broader than long, and much depressed or flattened; the following segments are much narrower, gradually becoming longer.

Life history and habits. We bred this insect from hickory limbs June Io and July I, and Dr Harris states that this species occurs during the greater part of the summer on the trunks and limbs of hickories. The larvae make shallow burrows in sickly and dying limbs. This species is recorded from West Virginia by Dr Hopkins, who met with specimens May 2.

Distribution. This borer is common in the Middle, Southern and Western States, according to Dr LeConte, and appears in a number of local lists for the northeastern United States.

\section{Bibliography}

1890 Packard, A. S. U. S. Ent. Com. 5th Rep't, p. 290-91

\section{Calloides nobilis Say}

A stout, black beetle with golden yellow spots and transverse bars on its wing covers occurs on chestnut, oak and hickory in midsummer.

This rare insect is a magnificent beetle closely related to the very destructive sugar maple borer, Plagionotus speciosus Say, which it resembles in general structure. It probably has somewhat similar habits. This very dark brown or black beetle may be instantly recognized by the three bright yellow spots at the base of each wing cover, the smallest being at the extreme margin, in connection with the two somewhat transverse lines of the same color across the apical half. This attractive insect is rare in our collections and is probably not very abundant, though its pre- 
sumably retired habits enables it to escape observation to a large extent. A specimen was taken at Albany June I 3 , and it occurs in the vicinity of New York city. It has been recorded from Massachusetts, the District of Columbia and southwestern Pennsylvania. It probably inhabits the northeastern United States, possibly ranging north into Canada.

\section{Thunderbolt beetle}

Arhopalus fulminans Fabr.

A rather slender, blackish, gray marked beetle about $5 / 8$ inch long, mines as a larva the inner bark and sapwood of chestnut and oak.

This beautiful insect may be recognized by the peculiar oval, black spot on the prothorax, surrounded by yellowish white pubescence, and also by the much smaller, oval, more lateral spots of the same color. The black antennae are nearly as long as the body and rise between the somewhat conspicuous, deeply emarginate, finely granulate eyes. The black wing covers taper posteriorly and are irregularly marked with a whitish pubescence, frequently forming a series of $I V$-like marks, the extreme tip of each wing cover bearing a rather conspicuous, oval, grayish area. This species has been recorded by I) Hopkins as infesting the sapwood of hemlock. Beetles were taken by him in West Virginia in April, May, June,

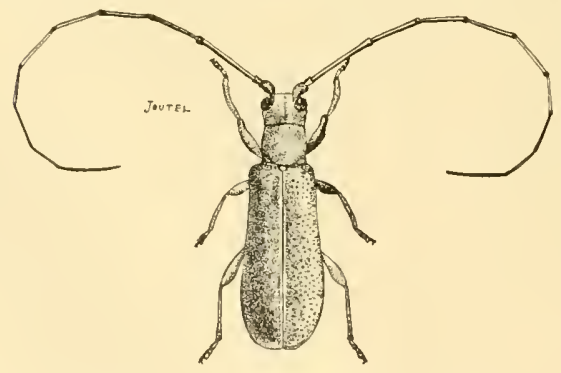

Fig. 100 Dorcaschema nigrum, enlarged (original)

July and August, indicating an extended adult existence. Pupae were met with about the middle of April, and eggs in August.

\section{Dorcaschema nigrum Say}

A black, slender, cylindric, longhorned beetle about $3 / 8$ inch long, is easily reared from hickory twigs.

This species occurs in several localities in the State, and was taken at Poughkeepsie on hickory June 2, 1903 . It may be easily recognized by the long antennae, entirely black color and cylindric form, the 
prothorax being tubularly narrowed behind the middle and with a rugose disk. The elytral punctures are deep, not very large or crowded, and the under surface is clothed with a pale pubescence, giving a leaden effect. This insect appears to be confined to the hickory, from which it has been bred by a number of entomologists. It has been recorded by Messrs Leng and Hamilton from New York, Massachusetts, Canada West, northern Illinois, Louisiana, has been bred from hickory in southwestern Pennsylvania by Dr Hamilton, found fying in a spruce forest in West Virginia by Dr Hopkins, and listed by others from the vicinity of Buffalo N. Y., Cincinnati O., and the District of Columbia. Dr Smith records it from a number of localities in New Jersey.

\section{Red-edged saperda}

Saperda lateralis Fabr.

A brownish black, red-bordered beetle about $1 / 2$ inch long, bores as a larva in hickory.

This species is rather rare and exhibits a marked preference for injured portions of hickories near the root and the base of sprouts on recently cleared land. The larvae frequently work along the juncture of dead and living bark and inhabit the base of dead shoots. This species has been recorded from alder, though this appears to be an exceptional food plant.

\section{Euderces picipes Fabr.}

A small, jet-black beetle $1 / t$ inch long, and with an oblique white line on each side, works in hickory and chestnut branches.

This small beetle presents a somewhat general resemblance to an ant because of the snowy white, oblique stripes on either side near the middle of the wing covers. The prothorax is strongly con-

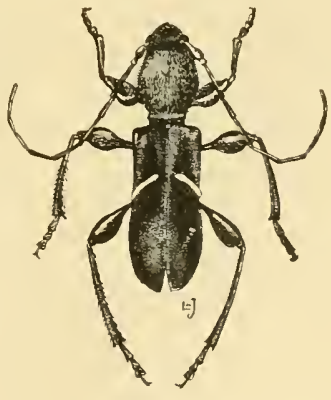
Fig. xor Euderces picipes, enlarged (original) stricted behind and inclosing most of the head, assists in this deception. The antennae are about as long as the body and the femora strongly swollen. This little species is not abundant enough to cause material 
injury. It has been recorded from a number of Northern States, and has been taken on linden, beech, hickory and chestnut.

\section{Hickory timber beetle \\ Jyleborus celsus Eich.}

A cylindric, brownish beetle about $3 / 16$ inch long, makes holes of nearly uniform diameter in hickory and oak.

This species was bred in considerable numbers out of hickory logs from trees killed by the hickory bark borer, Scolytus quadrispinos u s Say, at Geneseo N. Y.

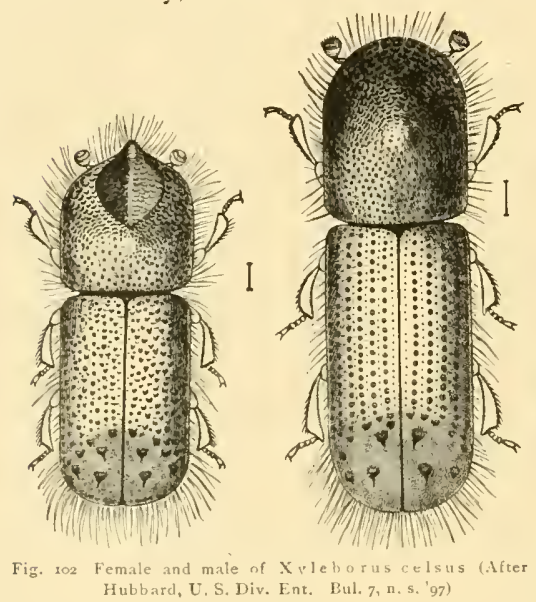

Description. The beetle is about $3 / 16$ inch long, rather slender, almost cylindric in shape, with the tips of the protruding mouth parts slightly darker. The prothorax and elytra are rather sparsely clothed with slender, yellowish hairs, and there are two prominent and a number of less distinct tubercles on the somewhat steep declivity. This species, according to Dr LeConte, differs from X. dispar Linn. by its much more elongate form, the thorax

being about one half longer than wide, with the sides parallel behind the middle and the elytra much more than one half longer than the thorax. The antenna is illustrated on plate 67 , figure 14 and a portion of the proventriculus on plate 69 , figure $\delta$.

Life history. This is our largest American

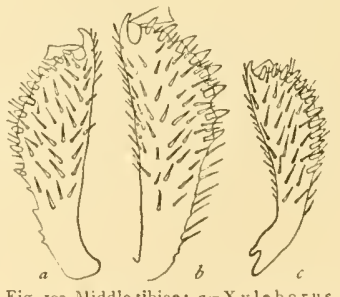
Fig. $x \circ 3$ Middle tibiae : $a=\mathrm{X}$ y leborus celsus: $b=\mathrm{X}$. dispar: $\varsigma=\mathrm{Chra-}$ mesus hicoriae, much enlarged (origitual) species of the genus, and according to Mr Hubbard, has been found only in hickory, though Drs Packard and LeConte record it as an 
oak-boring species. Their position, however, is not sustained, so far as we have been able to ascertain, by other observers, who almost invariably give its food plant as hickory. Mr Hubbard states that the beetles make a short entrance passage, from the end of which numerous branches radiate in a nearly horizontal plane. These penetrate deeply into the heartwood and

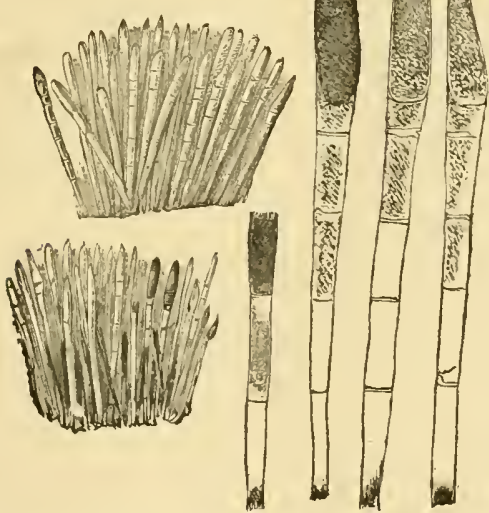

Fig. ros Ambrosia of $\mathrm{X} y$ leborus celsus (After Hubbard, U. S. Div, Ent. Bul, 7, n. s. '97) been described by LeConte as X. b i o gra phu s. greatly hasten decay. The galleries are blackened as in the case of other wood borers, but the stain does not extend far into the wood, indicating that comparatively lifeless trees are attacked by this species. He states that the ambrosia consists of clubshaped stems growing upright in dense clusters. The joints are long and the terminal conidia when they spread are several times longer than wide. The young and adults of the beetles live socially in the galleries, and the pupae lie free in the passages. Hubbard states that the male of this form has 
Distribution. This species has been recorded from the Middle and Southern States by Dr LeConte, and it is undoubtedly generally distributed, since it has been listed from the vicinity of Buffalo N. Y., Cincinnati O., southwestern Pennsylvania, New Jersey and the District of Columbia.

\section{Bibliography}

I 897 Hubbard, H. G. U. S. Dep't Agric. Div. Ent. Bul. 7, n. s. p. 24

\section{Hickory twig borer \\ Chramesus hicoriae Lec.}

A short, stout, black beetle about $1 / x 6$ inch long, may be bred from hickory twigs.

This common species was reared from hickory limbs infested with a gnarly or knotty growth, the adults appearing June I I and July I, I902.

Description. A black or dark brown beetle, rather stout, about $1 / 16$ inch long. Club of antennae large and longer than funicle. Eyes slightly emarginate, coarsely granulate; thorax sparsely clothed with short, yellowish pubescence. Wing covers plainly striated and with a pubescence similar to that of the thorax. The antenna is figured on plate 67 , figure 9 , a portion of the proventriculus on plate 69 , figure 6 and the tibia in figure 103 .

The larva has been described by Dr Smith as curculionid in form, pure white, about s, is inch in length, and with a brown, chitinous head, usually retracted so as to show only the mandibles, which latter are very stout, curved, with a broad, gougelike, cutting edge.

Life history and habits. This insect is quite common in hickory twigs from $3 / 5$ to 1 inch in diameter, the burrows being mostly in the wood and just scoring the bark. A single upright channel about $\mathrm{I}$ inch long is cut by the parent beetle, and eggs are deposited at nearly regular intervals on each side, the larvae working at right angles for a short distance and then turning and boring nearly parallel with the wood fibers. Dr John Hamilton states that he reared a few specimens of this beetle from hickory limbs the first summer after cutting, and great numbers during the second season. 
Distribution. This species probably has a wide distribution in the eastern United States, since it has been recorded from New York, New Jersey, Ohio, southwestern Pennsylvania, District of Columbia, Louisiana and Minnesota.

Natural enemies. Dr Hopkins has reared Elasmocerus terminat us Say, from wood infested by this species in company with others, and has also obtained $\mathrm{Hypophloeus}$ parallelus Melsh. from the galleries of this insect. Dr LeConte has reared Chariessa pilosa Forst, and Phyllobaenus dislocatus Say from hickory limbs infested by this species.

\section{Bibliography}

I 890 Packard, A. S. U. S. Ent. Com. 5th Rep't, P. 296

\section{Chestnut timber worm \\ Lymexylon scriceum Harr.}

A slender, white grub with a conspicuous hump behind the head and a dark brown, obliquely truncate, serrate posterior extremity, makes extensive galleries in the wood of living and dead chestnut and oak.

This destructive borer tunnels the sapwood and heart of chestnut in all directions, though its galleries are frequently oblique and along the lines of growth. Entrance is effected at some wound or where a limb has broken off. Its work in chestnut is so abundant in many sections as to cause material depreciation in the price of otherwise valuable timber. The parent is a slender, chestnut-brown, yellow-haired beetle about $1 / 2$ inch long. The larva is white, slender, cylindric, about $3 / 4$ inch long. It has a peculiar hump behind the light yellow head, and a hard, dark brown, excavated, obliquely: truncate posterior extremity margined with stout quadrate teeth.

All fallen or dead timber should be removed from the forest as soon as practical, as this species breeds readily in dead trunks. Unnecessary blazing or wounding should be avoided, since such places are very favorable to infestation by this borer. 


\section{Callidium aereum Newm.}

A brownish, flattened beetle about I/2 inch long, occurs on chestnut, the larvae mining the inner bark.

This species appears to be generally distributed in the eastern United States. It has been recorded from New York, New Jersey and the District of Columbia. The larvae mine the inner bark of chestnut, and in the opinion of Dr Hopkins may hasten and perhaps cause the death of aged or injured trees. The adult may be separated from others of its species, according to Wickham, by its color, it being entirely testaceous or brownish, while the related forms, Callidium antennatum Newm. and $\mathrm{C}$. $\mathrm{j}$ a n th in u m Lec., are metallic blue or green or buff. This species breeds in chestnut, while the others occur, more commonly at least, in pine and perhaps other coniferous trees. Mr Ulke records this, among other species, as being common on pine. This record evidently refers to places
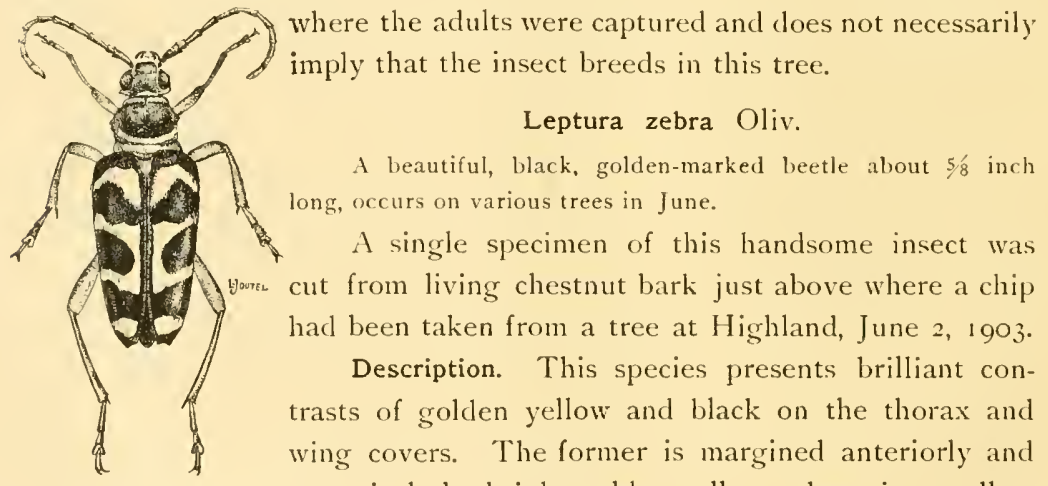

A beautiful, black, golden-marked beetle about $5 / 8$ inch long, occurs on various trees in June.

A single specimen of this handsome insect was cut from living chestnut bark just above where a chip had been taken from a tree at Highland, June 2, 1903.

Description. This species presents brilliant contrasts of golden yellow and black on the thorax and wing covers. The former is margined anteriorly and Fig.tof Lepturazebra, en posteriorly by bright golden yellow; there is a yellow band near the base of the elytra, each half being arcuate; a broad band across the middle of the wing covers is more or less divided into two large, oval, black spots. Underneath, the insect is clothed with yellowish pubescence, thickest on the posterior margins of the abdominal segments. There is a much narrower band near the tip of the elytra. The mouth parts and the legs are yellowish red. 
Food plants: This insect hits been recorded on several food plants. Dr. Smith states that it occurs throughout New Jersey on chestnut, oak and beech, and Mr Beutenmuller grives pine in addition to the above.

Distribution. This species has a wide distribution, occurring in New York, and having been recorded from the vicinity of Buffalo, Cincinnati, southwestern Pennsylrania and the District of Columbia. Dr Hamilton states that it is common in southwestern Penusylvania, where it breeds in white oak stumps.

\section{Sesia scitula Harris}

I hue black clearwing about ; inch long, with yellow-banded legs and abdomen, bores in the larval stage under the bark of chestnut and dogwood.

This species is known to occur in Canada, New England, Middle States to Virginia and westward to Ohio and Illinois. It is said to be closely allied to Sesia pyri Harris. It lives in the larval stage under the bark of chestnut and dogwood and also inhabits the gall of A n d ricus cornigerous. The dogwood, Cornus florida appears to be its favorite food plant. This species was bred July 4 from rough, black, polythalamus galls on limbs of black and red oak by Walsh, and the late Dr Kellicott obtained the same insect from globular swellings on oak twigs in May.

Malc. Head and antennae black; palpi yellow; tip black; orbits white. Thorax deep blue black with a yellow line on each side and a yellow patch on each side beneath. Abdomen deep blue black with a narrow yellow ring on the second and fourth segments, the latter covering the whole segment beneath. Anal tuft black. At the base of the abdomen is a yellow line reaching to the end of the second segment. Femora blue black, tibiae yellow with a purple band on the middle and hind femora. Anterior coxae yellow. Forewings transparent, borders and discal mark blue black, narrow ; outer margin broad, with yellow rays. Underside brighter than the upper. Hind wings transparent, margins very narrow, blue black.

Fimale. Similar to the male, but heavier. The palpi are wholly yellow and the fourth segment is yellow above and below; the fifth and sixth are yellow beneath; on the forewings the yellow between the veins of the outer border is more distinct and the anal tuft is yellow at the sides.

Expanse, male and female, is-22 mm. Beutenmuller 


\section{Peach bark beetle \\ Phlocotribus liminaris Harr.}

A minute, brownish, rather stout beetle about $1 / 2$ inch long, runs transverse galleries in the inner bark of peach, phum and cherry.

This little species is better known as a pest of fruit trees than a depredator on ornamental or forest trees, though it occasionally attacks wild cherry, probably plum and related trees. Its methox of work is very characteristic. The galleries of the adult beetles run transversely or nearly so to the grain of the wool, two diverging from a common entrance cham-

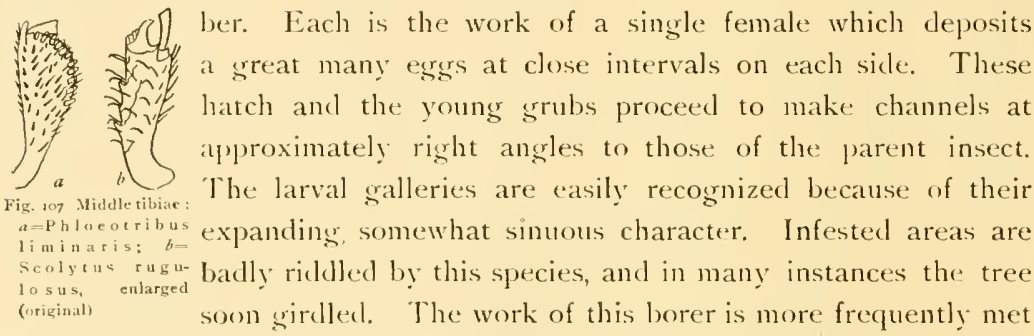
with in early spring, though occasionally beetles are taken in the fall. The easiest way to identify the adults is by their work. Occasionally this is impossible and then recourse must be had to structural characters, the peculiar antennae [pl. 66, fig. 1] being the most striking. This little beetle is rather sparsely clothed with a short, yellowish pubescence, and the elytra are coarsely striate with series of almost confluent punctures.

Remedial measures. There is no practical method of checking this pest, beyond cutting and burning infested trees before the insects have had an opportunity to escape and enter others. Ordinarily its attacks are confined to unhealthy trees. 


\section{Fruit tree bark beetle \\ Scolytus rugulosus Ratz.}

A dark brown or black, stout beetle about $1 / 8$ inch long, runs longitudinal galleries under the bark of plum, peach, cherry and apple.

This species is well known as a fruit tree pest and it is mentioned in this connection because it occasionally attacks wild cherry. Infested branches are badly tunneled by the numerous borings of both adults and larvae, resulting in their speedy death. Woodpeckers are very efficient natural enemies and do much toward keeping this species and its allies in check.

Sesia pictipes Gr. \& Rob.

A blue black clearwing having a wing spread of about $\mathrm{I}$ inch and with narrow yellow bands on the abdomen and leg lives as a larva under the bark of plum and several related trees.

The larva of this species lives under the bark of plum, wild and cultivated cherries, beach plum, peach, juneberry (A melanchier can adensis) and chestnut. It ranges from Canada to Florida and Texas and westward to the l'acific. Its life history has been worked out quite fully by the late Dr James S. Bailey of Albany N. Y., and the following records are taken from his account.

The moths emerge during June and July, the most favorable time for their appearance being between $\&$ and 10 o'clock in the morning. One cluster of eggrs, consisting of 92, was found by Dr Bailey on the under surface of loosened bark within six inches of the root. During rainy days he observed the caterpillars crawling out of the openings and drinking the moisture from the wet surface. Larvae of all sizes from that of a fine pin to those full grown were found beneath the bark of the infested tree. The injured area was perforated with holes made for the exit of the pupa and in other places the bark was cracked and its edges turned outward disclosing the split sapwood beneath. The pupal cells were constructed of fine sawdust, cemented with gum and slightly excavated in the surface of the sapwood. The pupae lay concealed with the head pointing to and in contact with the perforations in the bark. 
Dr Bailey observed that the infested tree was visited several times by the hairy woodpecker, Picus villosus, and on each occasion it worked industriously for a considerable time exploring the bark in search of larvae and undoubtedly securing a number.

Malc. Head blue black, sometimes with a few yellow hairs between the antennae, palpi pale yellow, black above. Collar at the sides pale yellow. Thorax bluse black with a narrow pale yellow line on each side. Abdomen blue black with a very narrow pale yellow ring on the second and fourth segments; the ring on the fourth segment encircles the body, or is only present beneath and sometimes in form of a patch. Anal tuft hastate, blue black, narrowly edged with white at the sides. Legs blue black, with pale yellow tufts on the tibiae, and yellow rings on the tarsi; anterior coxae marked with yellow. Forewings transparent, with the margins very narrow, blue black; discal mark, narrow, straight. Sometimes the inner margin is scaled with pale yellow. Underside with inner and costal marsins, and discal mark scaled with pale yellow. Hind wings transparent, no. discal mark, and with very narrow outer margin ; fringes becoming whitish towards the base. Underside like the upper.

Ficmalc. Same as the male, but more robust, with straight anal tuft and simple antennae.

Expanse, male $15-20 \mathrm{~mm}$; female 20-26 $\mathrm{mm}$. Bentenmuller

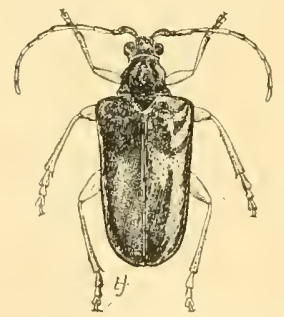

Gaurotes cyanipennis Say

A red-horned, red-legged, black, brillianı, greenish beetle ahout 1/2 inch long, occurs on butternut, oak and hirch.

Specimens of this brilliant beetle were taken on birch at Bigr Moose N. Y., July 2, 1903. This beetle is easily recognized by its striking colors, the head and thorax being black and the wings a brilliant green. The reddish antennae are a little over half the length 1.ig. 108 Gaurotes ey in iof the body. The thorax is subcylindric, tapering pennis, entarged (orieinuly of the body

Life history. Mr Wickham states that he has found this insect largely confined to sumac blossoms in IVisconsin. It has been found pairing and ovipositing on butternut, by $\mathrm{Mr} \mathrm{F}$. B. Caulfield, while Dr Hamilton reports it common in southwestern Pennsylvania, where it breeds in Juglans a 1 ba. 
Distribution. This species probably has a wide distribution in the northeastern United States, since it has been recorded from Arkansas, Kentucky, Cincinnati O., southwestern Pennsylvania, Buffalo N. Y., New Jersey and the District of Columbia.

\section{Goes pulverulentus Hald.}

This species appears to present an interesting diversity of food habits in various localities as illustrated by the following records. It occurs in elm about Lowell Mass., as recorded by Blanchard, affects ironwood in the vicinity of New York as stated by Mr Joutel, and local entomologists about New York record it from beech.

\section{Cossonus platalea Say}

A flattened, jet-black, snout beetle about $I_{4}$ inch in length, sometimes occurs in considerable numbers in butternut, poplar and other woods.

This borer was bred in abundance from a section of butternut wood cut the previous year and sent to us by Mr George S. Graves of Newport N. Y. The insects emerged in early April, and with them were also obtained some specimens of Stenoscelis brevis Woll.

This jet-black beetle, about '+ inch long, may be recognized by' its somewhat depressed form; short, rather stout beak, and reddish antennae. The head is prolonged f into a somewhat expanded beak, which latter is rather coarsely punctured; prothorax smooth, with irregular, large punctures; wing covers deeply striate with series of rather large, separate punctures. It occurs in large numbers under dead butternut bark in September and October and has been bred from butternut wood. This beetle runs
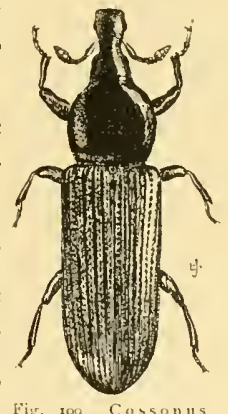
Fig. 109 Cossonus Hlatalea, enlarged numerous irregular galleries which, in the case under observation, were filled with fungus. It has been obtained by Drs Hamilton and Hopkins from under dead white walnut bark, while I)r Smith records it from under partly decayed poplar bark. This species probably inhabits the north- 
eastern United States, since it has been listed from Ohio, southwestern Pennsylvania, New Jersey, and it occurs in the edge of the Adirondacks in New York.

\section{Centrodera decolorata Harr.}

I slender, light brown beetle about an inch long, bores in butternut and beech.

A single specimen of this uniformly light brown beetle was sent to us by George S. Graves of Newport N. Y., Jan. 5, 1903. It was cut out from

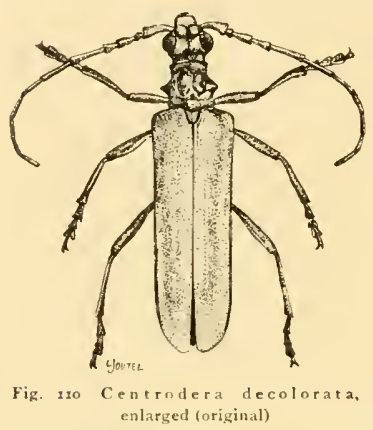
a butternut tree, and Mr Wickham states that it has been found by Mr Harrington on beech. This beetle is a rather slender insect almost an inch in length. The antennae are rather stout, not quite equal to the body in length, and both they and the legrs are a little darker than the wing covers. Head dark reddish with coarsely granulated black eyes; thorax subcylindric, longer than wide, and armed with stout, lateral spines. IVing covers long, slender, closely punctured, and with two indistinct ridges. This species has been listed from New Jersey, District of Columbia and southwestern Pennsylvania, being somewhat rare in the latter two localities.

Sesia corni Hy. Edw.

A purplish black, yellow-marked, red-tailed clearwing moth, with a wing expanse of about $3 / 4$ inch, bores in the larval stage in maple.

This interesting form infests the branches and twigs of maple which are often enlarged at several points by rough bark or gnarled excrescences. These are often nearly globular, more frequently, however, oblong and not unusually there are openings into the center of the stem. An examination of the wood shows that it may be mined in various directions and in a decaying condition. The attack often causes branches to die or so weakens them that they are broken by winds. One or more larvae may be found in a single enlargement. Adults are abroad from about the middle of May to the middle of Junc. 
The above observations on the life history are from Dr Kellicott's published account.

This species is known to occur in Massachusetts, New York, Pennsylvania and Ohio.

Male. Head black; palpi orange, orbits white; collar dull orange. Antennae black. Thorax deep purplish black with a very narrow stripe on each side; pale orange beneath. Abdomen slender, deep purplish or blue black with a very narrow ring on the second and last three segments; underside pale yellow. Anal tuft black above, bright red beneath. Legs bluish or purplish black, tibiae and tarsi banded with pale yellow; anterior coxae yellow. Forewings transparent with borders purplish or bluish black ; inner margin very narrow; outer margin rather broad. Discal mark large, black. Unclerside same as above or washed with pale yellow. Hind wings transparent, with very narrow margins. Discal mark small. Underside same as upper.

Fomalc. Like the male, except the anal tuft, which is wholly red, and the antennae have a large white patch on one side before the tip.

Expanse; male and female, i $8-21 \mathrm{~mm}$. Beutenmuller

\section{Divaricated buprestis}

\section{Diccrat divaricata Say}

A flat, brassy beetle with divergent wing covers hores as a larva in peach, cherry, beech, maple and other deciduous trees.

This is one of our common flat-headed borers which, as a rule, does not cause much injury though it operates in a large variety of trees.

Description. The beetles have been described by Dr Harris as "copper-colored sometimes brassy above and thickly covered with little punctures; the thorax is slightly furrowed in the middle; the wing covers are marked with numerous fine, irregular, impressed lines and small, oblong, square, elevated, black spots; they taper very much behind, and the long, narrow tips are blunt pointed; the middle of the breast is furrowed; and the males have a little tooth on the underside of the shanks of the intermediate legs. They measure from seven to nine tenths of an inch." The slender tips of the wing covers diverge more or less, affording a character for the ready separation of the species and one from which its specific name is derived. 
The larva is one of the familiar flat-headed borers and has been described by Dr Packard as follows:

Prothoracic segment moderately broad, not so long as wide, but not so wide in proportion to the two succeeding segments as in Chrysobothris; the second thoracic segment trapezoidal, narrower than the first by two thirds of its length; third thoracic segment a little narrower and a little longer than the second. All the abdominal segments about two thirds as wide as the third thoracic, and round and thick. The terminal segment a little over one half as wide as the one before it. Prothoracic segment with a large broad rough chitinous surface, with an inverted narrow $V$ with long slender arms to the $V$. On the underside of the segment, the rough surface is divided into two by two nearly parallel longitudinal smooth lines. Length. of body, $35 \mathrm{~mm}$; length of prothoracic segment, $5 \mathrm{~mm}$; breadth, $7 \mathrm{~mm}$; width of metathoracic segment, $5 \mathrm{~mm}$; width of an average abdominal segment, $4 \mathrm{~mm}$.

Life history. The beetles occur abroad during the months of Junt, July and August, at which time they may be found sunning themselves on the limbs of affected trees. Dr Fitch states that the beech is undoubtedly the original food plant of this insect, and that wherever a dead tree of this species occurs some of the beetles will almost always be found on it on sunny midsummer days.

Food plants. This species breeds in a considerable variety of deciduous trees, having been listed from apple, pear, plum, cherry, peach, beech and maple.

Distribution. This beetle is recorded as abundant from the Middle States by Dr LeConte, and it has been listed from New York, New Jersey; District of Columbia and Ohio by various writers. It is undoubtedly generally distributed and rather abundant in the northeastern United States.

\section{Banded buprestid \\ Buprestis fasciater Fabr.}

A brilliant green, golden yellow, flat beetle about $5 / 8$ inch long, bores as a larva in maple.

This brilliant green, flattened beetle, ranging from about $1 / 2$ to $5 / 8$ inch in length, may be easily recognized by the bright golden yellow markings 
on the wing covers. These latter are as follows: A somewhat irregular triangular spot at the basal third of each wing cover, an irregular, angulated, transverse band at the apical third, and a short, oblique, subrectangular spot near the apex. The mark at the basal third is absent in some specimens. This beautiful buprestid bores in maple, according to $\mathrm{Mr}$ Hunt. Dr Fletcher has found it abundant on poplars, and it is recorded as rare in New Jersey.

\section{White-horned maple borer \\ Yyphidria albicornis Harr.}

A slender, blackish, wasplike insect about half an inch long and with most of the antennae white, bores as a larva in diseased hard Fig. 1 . Buprestis malle in July.

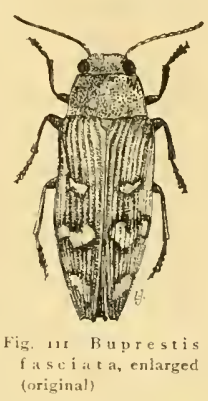

Examples of this interesting species were taken July 4 , 1905, at Nassau, on the underside of a dying sugar maple limb, evidently destroyed by a fungous or bacterial affection. The foliage had wilted just a few days before and discolored areas extended through the wood almost the entire length of the limb, the abnormality being more evident at its base. The bark separated readily from the wood and an examination about the places where the insects were found, showed masses of eggs evidently belonging to this species, deposited in peculiar elongate cavities in the inner bark. A favorite spot seemed to be at the very base of the limb, usually near an elevated or rough portion of the bark.

The eggs occurred in irregular masses of a few to about 15 , were pure white in color, about $1 \mathrm{~mm}$ long, fusiform and with a slender, transparent, flagellate appendage about $.75 \mathrm{~mm}$ long. The eggs were almost invariably in slight cavities, possibly induced by sap collecting and fermenting in these places. The smaller cavities were very slightly discolored while larger ones apparently varied from dark brown to nearly black. Oviposition was so abundant that 15 to 20 or more of these egy masses were easily found in 10 or 15 minutes work. This species undoubtedly bores in decaying hard maple limbs in much the same way as X y p idria provancheri Cress. 
works in decaying birch and it is probable that the larvae are somewhat similar [sce p. 466, fig. I 16 for an illustration of this latter insect].

\section{Grynocharis quadri-lineatus Melsh.}

This black, rather flattened beetle occurs on beech stumps in May. The eyes are medium, rather finely granulated; head somewhat coarsely; and prothorax rather finely punctured, while the wing covers are marked by a number of conspicuous ridges with the interspaces coarsely punctured, almost reticulate.

\section{Xylocleptes species}

Dark brown or black beetles, about $\mathrm{x} / \mathrm{z}^{2}$ inch long, make longitudinal burrows in partly decayed sugar maple limbs.

This species was met with by the writer in very small numbers August, 1901 at Axton N. Y., in a dead sugrar maple limb. The adult beetles run a

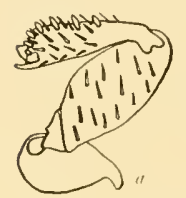

Fig. 112 " portion of leg

of Xylocleptes sp.;

$b=$ middle tibia of Pity -

ogenes sp. a (p. 374),

enlarged (wriginal) somewhat tortuous longitudinal gallery just under the bark and escape, as in the case of most bark borers, through round holes about 'ot inch in diameter. A central chamber was detected in one instance and in this case there were two longitudinal galleries proceedingr therefrom and slight notches inclicated the beginning of two others. Egrgs are evidently deposited on either side of the burrow and the young makes somewhat tortuous galleries at approximately right angles to those of the adults. The insects were probably breeding at the time they were collected, as a

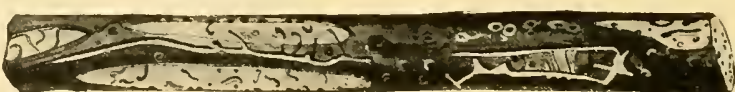

Fig. $1 r_{3} \mathrm{Xy}$ locleptes work in decaying maple twig (original) few larvae were seen but not preserved.

Description. The beetle is less than $3 / 32$ inch in length, cylindric, rather slender and of a dark brown color except the legs, which are a light brown. The head is well retracted and the black eyes are coarsely granulate. The anterior portion of the prothorax is tuberculate, the dorsal part and the wing covers or elytra are rather sparsely and coarsely punctured. 


\section{Prickly leptostylus \\ Liptostylus aculiferus Say}

Small worms similar to young apple borers, sometimes occur in multitudes under the bark, forming long, narrow, winding, gradually expanding tracks on the outer surface of the wood of apple and maple trees.

This species was noticed by Dr Fitch in 1856 , who is responsible for the above diagnosis. He states that the beetles appear the last of August.

Description. The adult has been described by Dr Lugger as a brownish gray beetle with "numerous small, thornlike points upon the wing covers and a $\mathrm{V}$-shaped band margined with black a little behind the middle of the elytra. Some well marked and fresh specimens are little beauties, being almost silvery white with clark clots on the band already mentioned. The insect measures a little more than ', inch in length." Professor Wickham separates this form from its allies by the tubercles on the elytra, each bearing apically; black scalelike hairs, in connection with the feeble and distant puncturing on the elytra, the latter often inconspicuous or concealed. The less are not hairy and the antennae are scarcely longer than the body, even in the male, the third joint being considerably longer than the fourth. New York specimens are stout, yray-brownish with the prothorax roughly tuberculate, pubescent, with the punctures sparse and irregularly placed. The elytra have raised tubercles or ridges and are ornamented with a grayish and whitish pubescence, which tencls to form a postmedian, transverse band broadest at the suture, the pubescence becoming darker anteriorly; tij) dark.

Food plants. Dr Hopkins reports it from IVest Virginia as infesting dead and dying apple and maple trees, and Mr Beutenmuller records it from sweet gum, oak and osage orange. In addition to some of the preceding, Professor Wickham records it from sycamore. Dr Hopkins states that the larvae mine the inner bark of dying and dead tulip trees.

Distribution. This species has been recorded from New York, New Jersey, District of Columbia, IVest Virginia and Ohio, and probably occurs over an extended portion of the northeastern United States. 


\section{Physocnemum brevilineum Say}

A rather stout, black beetle about $5 \%$ inch long and with brownish or bluish purple wing covers ornamented with three whitish lines, occurs on elm in midsummer.

This species is an elm borer in the larval stage and the beetles have been met with on this tree in May, June and July, ovipositing in the latter

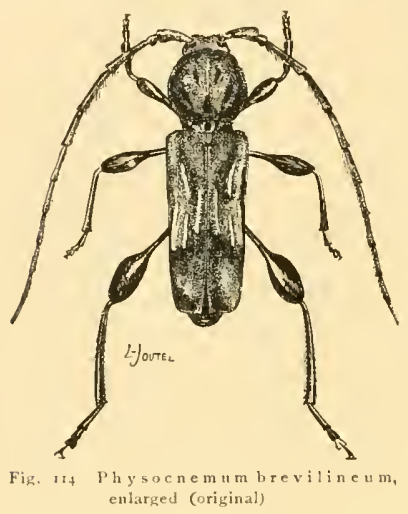
month. The adult is easily recognized by its rounded thorax and brownish or bluish purple wing covers, each ornamented with three short, slightly oblique, whitish or yellowish lines, one being on the basal third and the other two behind, slightly parallel and near the middle. It is also remarkable because of its dilated femora, those of the hind legs being much the larger.

\section{Four-marked ash borer Eburia quadrigeminatu Say}

The larva of this stout, light brown beetle about $3 / 4$ inch long and bearing at the base and about the middle of each wing cover, pairs of ivorylike, oval elevations, bores in ash, hickory and honey locust.

This handsome borer is easily recognized on account of its light brown color and the conspicuous pairs of ivorylike elevations at the base and middle of each wing cover. The slender, brown antennae are longer than the body and rise between the deeply emarginate eyes. The prothorax is cylindric, with conspicuous lateral tuberosities and a pair of sublateral tubercles just before the middle, and posteriorly a slight median elevation. The wing covers are closely and irregularly punctured, marked by several more or less distinct ridges and each terminated by a pair of conspicuous spines. The larva of this insect bores the trunks of honey locust, hickory and probably ash, and Dr Hopkins reports taking adults in July on dead beech and elm, adding that it probably infests these trees. Dr Smith states that this species is rare throughout New Jersey in July on oak and hickory: 
It has also been recorded from West Virginia and the vicinity of Washington, Cincinnati $O$., and is probably generally distributed in the northeastern United States. Dr Packard, in his account of this insect, cites a case where beetles were bred from an ash sill used in the construction of a house erected some 19 or 20 years before. It hardly seems possible that this insect could have existed during all these years, still there is no occasion for doubting the authenticity of the report.

\section{Obrium rubrum Newm.}

Slender, flattened, tortnous galleries in ash, $1 / 10$ to about $1 / 8$ inch in width, cutting the wood largely, are very likely the work of the larva of this species.

This insect is a flattened, reddish or rufous beetle about $1 / 4$ inch in length and remarkable for its long, slender antennae. The thorax is nearly cylindric, with lateral tuberosities and much narrower than the elytra, which are rather coarsely punctured and thickly clothed with yellowish hairs. The thighs are strongly clubbed. This beetle emerges from an exit hole a little over $\mathrm{I} / \mathrm{I} 6$ inch in diameter.

The full grown larva is about $\mathrm{I} / 2$ inch in length, slender, tapering gradually from the swollen prothoracic segment, and with the body' strongly' annulate. The mouth parts are inconspicuous and tipped with dark brown. This larva is remarkable on account of the ventral and dorsal callosities or leglike processes on the anterior portion of body segments $6,7,8$ and 9 . The resemblance to prolegs is very striking though superficial, and on the dorsum of the fifth body segment the same structure exists in a much more rudimentary form, though there are no indications of thoracic legs. The work of this borer in ash is represented on plate 38 , figure 2.

Distribution. This species is probably widely distributed in the Eastern States at least, though we have records only of its occurring in Ohio, southwestern Pennsylvania and the District of Columbia, aside from its being taken in New York State.

Natural enemies. A parasite, kindly determined by Dr Ashmead as Brachistes phymatodis Ashm., was reared from a log infested by this borer. 


\section{Memythrus asilipennis Boisd.}

A large, brownish, yellow-marked and yellow-banded clearwing moth, with a wing spread of $\mathrm{I} / 2$ inches, hores as a larva in ash and alcler.

The ash tree suffers very much in Massachusetts from attacks of this lorer, according to Dr Harris. It has been recorded from New Hampshire to Florida, westward to Minnesota and southward to Texas. The species occurs in Buffalo in small numbers. It also attacks alder.

The following account of the habits of this borer is hased on observations by Mr M. 1. Devereaux of Clyde N. Y. The species is very abundant in that section, being more plentiful in some swamps than in others. It runs its cylindric burrow from the tap root directly up the trunk, sometimes to a height of three or more feet, before turning and cutting its way out. This burrow is never in the center of the tree, but is generally nearer the bark than the heart, and the upright or vertical portion of it is as perfectly made as though cut by a carpenter with bit and brace. Mr I devereaux considers the alder the farorite host plant of this species lecause ash trees in swamps not containing alder are almost exempt from attack while no clump of alder is without evidences of its work.

Description. Malc. Head blackish, palpi pale yellowish white beneath, rufous above. Antennae rufous. Collar edged with dull orange brown. Thorax brown, patagia rufous, hind portion with a yellow transverse line. Abdomen dull brown black with a very narrow yellow ring at the posterior edge of each segment above and below: Legs orange, femora black. Fore wings transparent with narrow brown borders and discal mark which is marked with rufous; underside marked with orange brown on the opaque portions of the wings. Hind wings transparent, with a very narrow brown border; underside similar to the upper.

Fimalc. Like the male, but the forewings are opaque, deep brown, violaceous, with an oblique reddish discal mark, and a triangular transparent arcal above the hind angle. Abdomen like that of the male, but more robust, with the second segment marked with red above. Antennae simple

Expanse, male $30-38 \mathrm{~mm}$; female, $32-4+\mathrm{mm}$. Beutemuller 


\section{Xyphidria provancheri Cress.}

The larvae of a sawfly may be found boring in the partly decayed wood of standing white birch trees, making a gallery about $1 / 8$ inch in diameter, the adults emerge from the tree through circular holes of about the same size.

This species was met with Aug. 20, I900, at Saranac Inn, where the larvae were working in a partly rotten standing birch, and living adults bred therefrom Sep. 6, 1901. A few of the insects had emerged earlier and then died.

Description. The adult sawfly is a jet-black insect, about $5 / 8$ inch long, with a yellowish white mark on the dorsum and one on the posterior lateral corner of the head, one at the base of the wings, one each on the sides of the third to the sixth and the eighth abdominal segments. Those on the head and at the base of the wings are somewhat elongate, broken and angulated in the latter, while those on segments 3 to 6 of the abdomen are subtriangular, and that on the eighth segment is subquadrangular. The mandibles are a deep rufous, tipped with black, and the mouth is bordered anteriorly and laterally with yellowish white. The dorsum of the head and the thorax is rough, tuberculate. The wing spread is about one inch. The male is more slender and a little smaller than the female.

The larva when taken in August was about $5 / 8$ inch long, of a yellowish white Fig. rrs Xyphidria provancheri, work in color. The head is a creamy white, with the mouth parts bordered with black. The segmentation is well indicated and the thoracic segments bear somewhat rudimentary legs. The posterior extremity of the body is tipped with a short dark brown spine which rises from a yellowish brown 
tubercle. The dorsum of the anal plate is deeply furrowed along the median line.

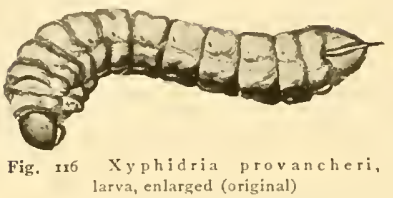

The burrows of this larva are confined very largely to the heartwood of decaying birch, and are invariably filled with the borings, except a short, curved portion through which the adult makes its way to the surface

This species has been recorded from Canada, White mountains, New Hampshire, and Massachusetts, and Professor Cresson considers it closely allied to $\mathrm{X}$. al bicorn is Harris.

The writer has succeeded in rearing a number of small parasites from this borer, which were kindly described by Dr Ashmead as P a m megischia $x$ iphydriae.

\section{Slender birch horntail}

\section{Konorvia attenuata Nort.}

A horntail borer making moderately large cylindric burrows in decaying birch. very likely belongs to this species.

This insect has been reared from dead black birch by Mr Patton, who also obtained therefrom a parasite, R hyssa humida Say, which in all probability preys on this borer in the same way as the lunate long sting, Thalessa lunator Fabr., attacks the pigeon tremex, Tremex columba Linn. This species can hardly be considered of much economic importance, as it appears to infest only decaying birch.

Description. The adult has been described by Mr Norton as follows:

Malc. Pale honey yellow; antennae 16 jointed, blackish, two or three basal articles yellowish; a spot inclosing ocelli, tip of mandibles, sides of neck, of meso-and metathorax blackish, tergum irregularly clark, pectus brown piceous; body beneath and legs whitish; wings hyaline, nervures and stigma pale; under wings with two middle cells.

This species has been recorded from Connecticut, New Jersey and Pennsylvania. 


\section{Chrysobothris azurea Lec.}

A flattened, brilliantly colored, purplish or bluish beetle about $1 / 4$ inch long, may be met with in May on birch and other deciduous trees.

This beautiful little insect was bred by us from white birch taken at Karner, Ap. 6, I903. The specimens emerged May 12. This insect is one of our most brilliantly colored native species, and may be recognized by the three sparkling blue depressions on each purplish wing cover. Underneath, the insect is brilliant green or bluish, with coppery on the sides, particularly of the abdomen. The coloring of this species is somewhat rariable, and Dr LeConte states that it may be distinguished from C. harris i Hentz, by the structure of the antennae. He records this insect from New York, Illinois, District of Columbia, Georgia and Texas, and it has been listed from Ohio by Dury. It is probably widely distributed in the eastern United States, at least.

\section{Bellamira scalaris Say}

A slender, brownish beetle, ranging from about $3 / 4$ to nearly $1 / 4$ inches in length, bores as a larva under the bark of yellow birch and has been taken ovipositing on maple.

Description. The beetle has been described by Mr IVickham as follows :

The form is slender, the elytra tapering greatly to and rounded at tip, deeply sinuate at sides, the tip of the abdomen uncovered. The prothorax is bell-shaped, with prominent, rather flattened hind angles. Color brownish; most of the head, a greater portion of the fore and middle legs, the bases of the hind femora and the bases and tips of the ventral segments inclining to reddish or even yellowish. Antennae rufous. Elytra brownish, with a large lighter (golden-sericeous) wedge-shaped mark (wavy on the edges and sometimes interrupted at about one third its length by a transverse brownish band) which extends about two thirds to tip. The body is finely and densely in most places rugosely punctured, clothed with fine golden pubescence, which is much denser on certain parts, notably the abdomen.

This insect has been taken in the Adirondacks in August, and $\mathrm{Mr}$ Harrington has observed it ovipositing in a maple stump in July. It has also been recorded from New Jersey. Dury records taking a jet black variety of this species in the vicinity of Cincinnati. 


\section{Stalk borer \\ Papaipema nitcla Guen.}

A brownish, white-striped caterpillar about an inch long, bores commonly in herbaceous stalks and occasionally in the tender twigs of certain trees.

This stalk borer, well known because of its infesting thick herbaceous stems, occasionally works in the younger twigs of maple and ash.

\section{Birch bark borer}

\section{Dryococtes spccies}

A brownish, cylindric beetle, works in the stumps of recently cut yellow birch, causing an excretion of sap which gums the rust-colored borings to the outside of the affected wood.

This species was met with by the writer Aug. 23, 1900, at Axton N. Y., where it was working under the bark of the stump of a recently cut

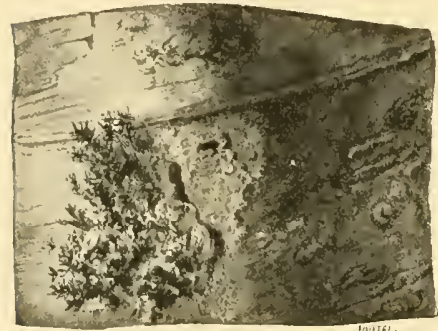

Jourte

Fig. 117 Work of Dryocoetes sp, in birch, showing entrance and galleries (original)

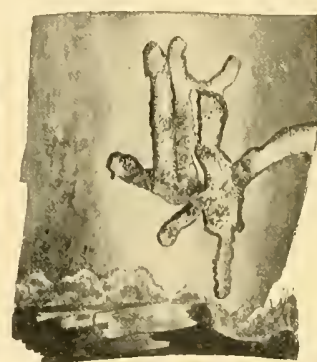
of finding it. It

was taken by Mr Young, July 1903, in recently burned trees at Big Moose and Saranac Inn, at which time it appeared to be common, probably because of the large number of trees offering favorable conditions for its development. The only exterior indication is oozing sap which causes the rust-colored borings to adhere to the entrance of the gallery. The insect works in a very irregular manner under the rough bark. There is usually a central chamber from which several galleries of greater or less lengths may diverge, in almost any direction, and sometimes there is a large excavated area with apparently no plan. 
The parent insect is a brownish, rather stout beetle, about $5 / 32$ inch in length. The black, coarsely granulated eyes are emarginate, the head and thorax are finely punctured and the wing covers ornamented with longitudinal rows of coarsely set punctures. The structure of the tibiae, antennae and proventriculus of this species and the allied Dryocoetes a utographus Ratz. is illustrated in figure irs and on plate 67 , figure 17 , plate 69 , figures 9 , II.

\section{Saperda mutica Say}

A small, black beetle with gray or yellowish vestiture is some. times bred from willow

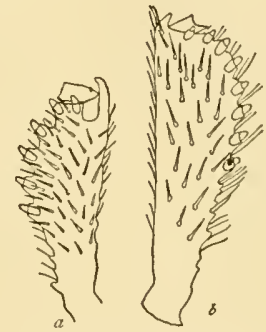

Fig. 118 Middle tibiae: $a$, Dry.
ocoetes sp.; $b$, D. a u tograph us, enlarged (original)

Very little is known respecting this insect. Beetles were captured by Mr IV. H. Harrington on May 15 and June 29, and he states that this species lives in decaying willow. It has been recorded from Canada south to Missouri and westward to Nebraska. It appears to be an uncommon species.

\section{Bibliography}

1904 Felt, E. P. \& Joutel, L. H. N. Y. State Mus. Bul. 74, P. 2 I

Sesia albicornis $\mathrm{Hy}$. Edw.

A blue black clearwing moth havirig a wing spread of 78 inch, bores as a larva in willow.

This species lives in the trunks and branches of young willows growing in swampy places. It also breeds in the burrows of the mottled willow borer, Cryptorhynchus lapathi Linn. and in the galls of Saperda concolor Lec. It has been recorded from New York, New Jersey, Pennsytrania, New Hampshire, Illinois, Colorado, California, Nevada and Oregon.

The type of this insect, according to its describer, came from Nevada, though the late Dr Riley, in commenting on this species, states that it was received from Karner [Centre] N. Y. It is recorded as a common species in certain localities. The pupal case is represented on plate 16 , figure 15 . 
Male. Head bronzy black; palpi white, rarely pale yellow. Antennae blue black, rarely with a white patch before the tip. Thorax bronzy black with a very slight, pale yellow stripe on each side, sometimes absent. Underside of thorax with a very pale yellow spot on each side. Abdomen wholly bronzy black. Anal tuft marked with white beneath. Legs blue black; tibiae with white tufts; anterior coxae pure white. Forewings transparent, with violet brown borders; costal and inner margins narrow ; outer margin broad, golden yellow between the veins. Discal mark distinct, blue black. Underside scaled with pale yellow. Hind wings transparent with outer margin narrow, violet or blue black. Underside similar to the above.

Fomale. Wholly bronzy black with violaceous reflections, except the transparent parts of the wings. The legs with bluish reflection and white tufts on the tibiae. Forewings beneath on the costal margin and discal marked with yellow scales. Antennae always with a prominent white patch before the tip.

Expanse, male I 5-1 $8 \mathrm{~mm}$; female i $8-22 \mathrm{~mm}$. Beutcumullor

Sesia bolteri Hy. Edw.

A steel blue clearwing moth with a broad abdominal band and the fore wing tips red, bores willow canes in the larval stage.

The larvae of this species bore in willow canes. It has been recorded from New York, New Jersey, Illinois and Manitoba.

Malc. Head and thorax deep steel blue black, orbits pure white; palpi above black, bright orange beneath. Antennae deep steel blue black, with the tip, for one third the length, yellowish on one side. Abdomen deep steel blue black, with the fourth and fifth segments bright scarlet red above and below. Anal tuft blue black tipped with white. Legs blue black, tibiae tufted with white; tarsi pale yellow. Fore wings transparent, costal and inner border narrow, deep black with a steel blue lustre; discal mark straight; outer margin broad and heavily scaled with scarlet or coppery red between the black veins; fringes violet brown. Underside brighter than above, costal and inner margin pale yellow. Hind wings transparent, outer margin very narrow, black, fringes violet brown. Underside same as above.

Finalc. Larger and more robust than the male. The red on the forewings is usually brighter; the sixth segment is red beneath, and the hind tarsi are bright orange, otherwise same as the male.

Expanse, male and female, I 2-20 mm. Beutcnmullcr 


\section{Three banded clearwing}

\section{Hemythrus tricinctus Harris}

A black clearwing moth with three conspicuous yellow abdominal bands lives in the larval stage in Saperda galls on willow and poplar.

This borer attacks the small trunks of willows and poplars, and the moth has been bred from the galls of Saperda concolor Lec. It occurs in Canada, New England and the Middle States westward to Ohio and Michigan. Dr D. S. Kellicott, in writing of this insect, states that he took larvae from the branches, suckers and small trunks of the balm of Gilead, P opulus c and i a n s, growing on lowlands along the Niagara river below Buffalo. The smaller grubs were sometimes found in the sapwood or just beneath the bark, but the larger ones were generally in the center or pith of the stems. They cause considerable swellings on the small branches, which are frequently as prominent as those made on willow branches by a tortrix larva, which he found very abundant in the same locality. Dr Kellicott was of the opinion that the adult deposited her eggs in the deserted burrows of $\mathrm{Saper} d \mathrm{a}$ moesta Lec, thus permitting the young caterpillars to easily gain access to the wood, its home for at least a year. The Saperda galls become more enlarged by the attacks of this insect.

Description. Male. Head black, collar yellow in front and at each side behind; palpi black, yellow inside towards the tip. Antennae blue black above, ferruginous beneath. Thorax black, with a yellow spot at the base of the fore wings and one on each side posteriorly. Abdomen black, with a slight bluish reflection. Second, fourth and last two segments with a yellow band above and below. Anal tuft black. Legs black, middle and hind tibiae partly orange, the latter yellow inside; tarsi orange. Fore wings opaque, violet black with a short transparent streak at the base; inner margin streaked with red at the base, sometimes also along the costa for a short distance; underside yellow at the base. Hind wings transparent, with a narrow outer margin and discal mark violet black, as are also the veins. Underside with discal mark and costal margin orange red or same as above.

Female. Like the male, but with only three yellow bands on the abdomen instead of four, one on each of the second, fourth and sixth segments. Expanse, male and female, 25-28 mm. Beutenmuller 


\section{Aegeria tibialis Harris}

A large brown, yellow-marked clearwing moth having a wing spread of $13 / 4$ inches lives as a larva in willow and poplar trunks.

This species occurs in Canada, the New England States, New York, British Columbia, Vancouver, Colorado and California, and attacks the trunks of willow and poplar.

Male. Head black, orbits and top lemon yellow, as are also the palpi. Antennae jet-black. Thorax deep brown black, with a very narrow yellow line on each side forming a yellow spot behind and meeting a rather broad curved line on each side in front. Sometimes the two lines on top are very indistinct or almost absent. The lateral line connects with the yellow spot on the base of the fore wings; sometimes the line is broken below the middle. Posterior edge of thorax with black hairs, broadly edged with yellow: Abdomen with first segment black, more or less narrowly edged with yellow behind, second segment wholly black, third segment yellow, narrowly edged with yellow behind, fourth segment wholly brown black, remaining segments brown black, with very narrow yellow bands behind, or yellow with very narrow brown black bands behind. Anal tuft brown black mixed with yellow. Underside of abdomen brown black with yellow bands. Legs yellow, washed with brown. Fore wings transparent with the margins, veins and discal mark orange brown or deep brown black. Hind wings with the borders very narrow, orange brown or brown black.

Fomale. Nore robust than the male, with the markings of head, thorax, and wings similar, but as a rule a little more pronounced. Abdomen with the first, second, third and fourth segments as in the male; last three sometimes almost entirely golden yellow, with the tip washed with brown; the fifth and sixth segments are half yellow and brown. Underside yellow, with narrow brown, black bands, except the last or last two segments, which are wholly yellow.

Expanse, male 30-32 mm; female 35-40 mm. Bcutcumuller

\section{Aegeria apiformis Clerck}

A large brown, yellow-marked clearwing moth having a wing spread of $13 / 4$ inches lives as a larva in roots of willow and poplar.

This European species is relatively rare in this country although it has been recorded as far west as Nevada. It attacks the roots and trunk of willows and poplars, requiring two years to attain maturity. The adult is very sluggish in habit and readily captured. 
Male. Head and palpi lemon yellow. Antennae black above, ferruginous below. Thorax brown, with a large lemon yellow spot on each side in front, and a similar one on each side of the posterior part. Sometimes the spots are united by a yellow dash along the patagia. Abdomen with a very broad yellow band on the anterior part of each segment, except the last two, which are entirely yellow; posterior parts of segments narrowly brown. Legs yellow, slightly washed with brown. Fore wings transparent, with narrow light brown borders and discal mark. Hind wings transparent, with outer margin very narrow, brown. Discal mark absent.

Fimale. Much more robust than the male, with the second and fourth abdominal segments usually wholly brown. Otherwise similar to the male. Expanse, male $30-35 \mathrm{~mm}$; female $40-45 \mathrm{~mm}$. Beutcumaller

\section{Acanthoderes decipiens Hald.}

A rather stout, blackish beetle irregularly marked with gray, may be taken in June on poplar and hickory.

This insect was met with on poplar at Karner, June 18, 1902, and appears to be a somewhat rare species in this section. Dr J. B. Smith records taking this species in New Jersey on dead hickory in May.

Description. It is a rather stout beetle, about $1 / 2$ inch long, black, irregularly marked with gray, with annulate antennae about the length of the body. The thorax is wider than long and with a prominent tuberosity on each side. The elytra are nearly truncate anteriorly and bluntly spined posteriorly. This species may be separated from its allies, according to Leng and Hamilton, by the maculate white pubescence on the body; the sutural region is not grooved, the elytra are with- Fig.rng Acanthoderes deout a whitish space, each bears a distinct M-shaped, black mark behind the middle, and the base is irregular, with an oblong, obtuse umbone at its middle.

Distribution. This species has been recorded by Messrs Leng and Hamilton from Massachusetts, New York, New Jersey, Pennsylvania, Virginia, Georgia, Louisiana, Nebraska, Ohio, Canada and Maine, and it has been listed from the District of Columbia, by Ulke. It has also been taken by Zesch and Reinecke in the vicinity of Buffalo, and is recorded in Dury's list of Coleoptera, from near Cincinnati O. 


\section{Saperda concolor Lec.}

Girdling the trunks of sapling poplars or running a mine around them, causing a swelling twice the diameter of the tree, the larva of a cylindric slaty gray beetle $3 / 8$ inch long.

Life history. The insects appear from the last week in May till after the midlle of Jume and select for oviposition the smaller canes of dwarf willow. The beetle gnaws a longitudinal incision through the bark about $3 / 4$ inch in length and deposits an egg in each end. Several are usually made in the same cane some distance apart and these often cause its death the following year. A warty, gnarly swelling occurs around each incision. The young larrae bore nearly to the center of the smaller canes, while the larger ones are from one third to one half girdled, the gallery being marked by a rough, anmular swelling.

Distribution. This species ranges from Canada south to Texas and from Massachusetts westward probably to the base of the Rocky mountains, since it has been recorded from New Mexico.

\section{Bibliography}

190.4 Felt, E. P. \& Joutel, L. H. N. Y. State M[us. Bul. 74, p. 73-76

\section{Saperda populnea Linn.}

A small brown or black coarsely punctured beetle about $3 / 6$ inch long may be bred from galls of balsam poplar.

This European species occurs on the Pacific coast and is of interest because it has two varieties, moesta Lec, and tulari Felt \& Joutel. The latter variety is western, the former occurs in New York and ranges from Canada to IVyoming south to Pennsylvania. Our form is a small blackish beetle ranging in length from about $3 / 8$ to a little over $1 / 2$ inch, the larger being females. This variety occurs in balsam poplar, and though it has been reported from the vicinity of New York city, this record is probably founded on an erroneous identification, and the species taken about New York city is really S. concolor Lec. 
Life history. The beetles occur abroad in June and larvae have also been met with the same month. Its borings cause galls in balm of Gilead branches, the larvae occasionally being very abundant and in some instances not more than an inch or two apart and located chiefly at the base of the buds, where their presence is indicated by a swelling in the branch surmounted by a brown patch of partly decayed bark. The larva makes an excavation more than an inch long, much of which is filled with debris.

\section{Bibliography}

1904 Felt, E. P. \& Joutel, L. H. N. Y. State Mus. Bul. 74, P. 68-73

\section{Dorytomus parvicollis Casey}

A small, brownish black, yellowish specked weevil about if inch long, occurs in early spring under poplar bark.

This snout beetle was very abundant under the loose bark of poplars at Karner, up to the middle of May igo2. The insects evidently sought this retreat for shelter, because there were no evidences of borings in their immediate vicinity. The beak is moderately long in the male, longer in the female; the thorax is rounded, rather coarsely punctured; the elytral striae are coarsely punctured, and the wing covers are clothed with a somewhat sparse golden pubescence, frequently present in bunches here and there, giving a spotted appearance. This species has been recorded from Indiana.

\section{Dorytomus vagenotatus Casey}

A small snout beetle about $1 / 8$ inch long, irregularly clothed with grayish pubescence occurs under poplar bark in early May.

This species is much smaller than the preceding, and apparently correspondingly scarce, since only four specimens were taken as compared with over one hundred of the former species. This differs from the first not only in size but in the finer sculpturing of the prothorax and the smaller dots of the wing covers, which latter are partially clothed with a grayish instead of golden pubescence. This species was described from Indiana. 


\section{Poplar carpenter worm}

\section{Cossus ccutcrensis Lint.}

Stout, white, naked caterpillars about $\mathrm{x} / 2$ inches long, bore in poplar trunks.

This comparatively rare species was first described by Dr Lintner from specimens taken on poplars at Karner, then Centre. It appears to be rather rare, though occasionally it may become quite abundant, as evidenced by our finding many larvae of this species in a badly affected cottonwood tree in Albany. This insect has been taken in the vicinity of New York city, and Dr Smith is of the opinion that it occurs in New Jersey. It has been recorded from the Atlantic States by Dr Dyar, and Dr Fletcher has found it about Ottawa Can.

Description. Larra. Head dark brown; mouth parts nearly black; thoracic shield pale yellowish, with a sublateral, oblique darker line on each side; body creamy white. Length about 1 1/4 inches.

Labium yellowish white, broad at base, sutures brown; spinneret conspicuous, brown, slender; labial palpi very small, i segmented and bearing two minute apical setae; maxillary palpi 3 segmented. Mandibles dark brown, apex black, with two inconspicuous teeth; epistoma yellowish brown, tuberculate and bearing a number of stout, short setae; labrum yellowish, smooth. Clypeus dark brown, sutures black. Antennae very short, basal segment yellowish white, apical brownish and bearing a conspicuous seta. Simple eyes few, yellowish brown, with a few setaceous tubercles interspersed. Thoracic shield weakly chitinized, yellowish, with a distinct sublateral, oblique line on either side. Anal shield yellowish, weakly chitinized; body tubercles rudimentary and represented only by sparse hairs, spiracles dark brown. Thoracic legs well developed, claws black, the tip of last segment dark brown. Well developed prolegs on the third to the sixth and last abdominal segments.

The pupa has been described by Dr Bailey as "about $30 \mathrm{~mm}$ in length, narrow, brownish black, shining, rugose. The clypeus presents a strong, broad, spinous process, supported at base by lateral projections. On the underside it descends into a wide sulcation terminating in a broad projection. The capital appendages are visible, and here and there arise isolated hairs as in the previous stage. The abdominal segments are provided with teeth over the dorsum, decreasing in size to the stigmatal line. The anal segment is provided with two unequal-sized terminal teeth on each side of the vent."

This adult has been described by Dr Lintner as follows: 
The female, in its appearance, approaches nearer C. querciperda Fitch than any other of our species. The collar and thorax are black, edged with gray scales. The abdomen is black above, interspersed with gray scales towards its tip, and more thickly beneath. The primaries are black over rather more than their inner half, with some gray scales a little within the center of the wing; the center portion of the wing beyond the reniform mark is grayish. The wing is traversed by broken, black, transverse lines, of which tiventy or more can be counted on the costal margin; three or four of those on the outer portion are more continuous and conspicuous than the others. The fringe is marked with black scales opposite the veins. The secondaries are nearly transparent, darker along their inner margin, showing some faint reticulations, which are more conspicuous beneath. [The type is illustrated on plate 44 , figure $\mathrm{I}$.]

The male strongly resembles the female, instead of presenting the marked contrasting differences found in Prionoxystus robiniae Peck and P. macmurtrei Guer.-Men. Its wings are only a little more projected apically thai in the other sex.

Expanse of wings of the pair in my collection, male 2 inches; female 2.5 inches. Length of body, female .95 inch; male 1.2 inch.

Life history. This species has been carefully studied by Dr Bailey, and the following account of its life history is based largely on his published observations. The recently emerged moths are rather sluggish and can be easily captured. They resemble the color of the bark so closely that it requires a very good eye and close observation to find them. After the moths have been abroad a few days, they are wild and more or less mutilated. The females deposit their eggs in clefts near the base of the trunk, one producing over fifty. This species appears every season, and observations seem to indicate that three years are necessary to complete the life cycle. The pupae, as in the case with related species, wriggle partly out of the burrows before disclosing the moths, and these conspicuous empty pupal cases are therefore a very convenient means of detecting the number of moths which should be found about infested trees.

Remedial measures. It is probable that this species could be controlled in the same way as the carpenter worm noticed on pages 79-84. Ordinarily the poplar is of so little value and this insect so rare, that it will be unnecessary to check it.

\section{Bibliography}

$189^{\circ}$ Packard, A. S. U. S. Ent. Com. 5th Rep't, p. 439-42 


\section{Locust twig borer \\ Ecdytolopha insiticiana Zell.}

A pale whitish caterpillar bores the smaller twigs of locust, causing a thickened, irregular growth $\mathrm{I}$ to 3 inches long.

The work of this species has been observed by us in several localities, though the borer is rarely abundant enough to cause material injury Mr J. G. Jack of the Arnold arboretum, states that the young locusts are very subject to serious injury by this borer.

Description. The full grown larva, according to Professor Comstock, is about half an inch long, yellowish and somewhat darker along the dorsal line. The head is dark brown and the thoracic shield a light honey yellow.

The moth has dark ashy brown fore wings with a large patch of dull pinkish white on the outer part and several small black spots near the middle of this patch. The hind wings are a little lighter than the basal portion of the fore wings; wing spread about $3 / 4 \mathrm{inch}$.

Life history. The larvae, according to Professor Constock, become full grown about the first of October and desert the stems through holes c'ut to the surface, descend to the ground and transform to pupae among the dried curled leaves in which they spin thin, tough silken cocoons. One moth emerged October 17 and others from the 20 th to the 27 th.

Distribution. This species apparently has a wide distribution, as it has been recorded from as far west as Colorado.

Remedial measures. The most effective method of checking this species is to cut off and burn the infested twigs any time before October.

\section{Woodbine borer \\ Saperda puncticollis Say}

$\Lambda$ bright yellow-marked, jet-black beetle, almost I/a inch long, may lee bred from woodbine, sumac and possibly poison ivy.

This is one of the smallest and prettiest species belonging to this important genus. It is a rare form in most collections in spite of the fact that the insect lives in the dead branches of the common Virginia creeper.

Life history. The beetle is shy, rarely seen, and though it may occa- 
sionally be taken on the foliage of its food plant, specimens are more easily obtained by rearing from infested twigs. The adults occur abroad in June and July; The larvae or grubs feed on the inner bark of the branches and stems of the Virginia creeper. Its method of work is represented on plate 6, figures I 7-19.

Food plants. It occurs on woodbine and has been recorded from poison ivy and sumac.

Description. This little black beetle may be easily recognized by its golden thorax with four dots and a wide golden margin, including a sutural and marginal stripe on the wing covers [pl. 6, fig. 24].

Distribution. This species ranges from Canada south to Louisiana and west to Kansas and Nebraska. It is probably generally distributed in the eastern and middle United States.

\section{Bibliography}

1904 Felt, E. P. \& Joutel, L. H. N. Y. State Mus. Bul. 74, p. 66-68

\section{Madarellus undulatus Say}

A jet-black, highly polished curculio about $1 / 8$ inch long and with deeply striated wing covers, occurs on Virginia creeper, poison ivy and grape.

This little species is widely distributed, having been recorded by LeConte from Massachusetts to Alabama, Texas and Kansas. The northern beetles are entirely black, while those from the south and west have the prothorax red. Dr Hamilton records two varieties as occurring in southwestern Pennsylvania. This species bores woudbine in association with Saperda puncticollis Say and transforms to the adult in an oval pupal cell composed of
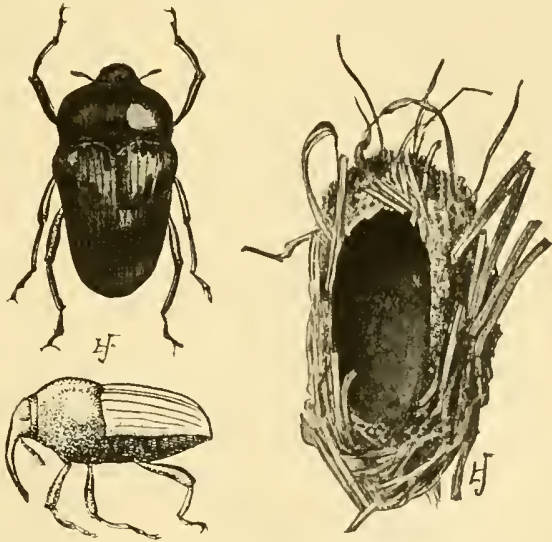
Fig, rzo Madarellus undulatus, dors.l and lateral vieus of beetle, pupal cell, enlarged (original) finely comminuted, partly decayed pieces of bark and wood glued together. 


\section{Alder borer \\ Saperda obliqua Say}

Irregular, gall-like swellings at the base of alder stems, followed by dying and breaking of the shoots, are very characteristic of this insect.

The white-footed, legless grub closely resembles that of the appletree borer and is most easily recognized by the food plant it inhabits.

The adult is a light reddish brown with darker oblique bands on the wing covers. The thorax has a pair of broad, dark brown bands which extend backward onto the base of the wing covers. The spaces occupied by the darker bands on the elytra are depressed, an instance of where coloration is emphasized by sculpture.

Life history and habits. This species is a common one in the State of New York, if one may judge from the numerous dead shoots in alder swamps killed by this species. The beetle oviposits close to the ground in black alder and the larvae frequently girdle the stems, there sometimes being two or three borers near together, one of which is very apt to work downward three or four inches and often below the surface of the ground; the others usually tunnel in an opposite direction. The general method of work is very similar to that of the common round-headed appletree borer, and the beetle emerges from a circular hole very closely resembling that made by the above mentioned species. The adult may be found near the top of alder shoots, and according to Mr Fred. Knab of Chicopee Mass., easily escapes notice on account of its close resemblance to a withered leaflet, and its remaining perfectly motionless, clinging tightly to a branch, with the antennae extended forward. This species has also been taken on birch.

Distribution. This species has been recorded from Canada south to Mississippi and westward to IVisconsin. It is probably generally distributed in the northeastern United States,

Natural enemies. Native woodpeckers appear to be very efficient in checking this borer, as we have found a number of infested stems showing the characteristic marks of these beneficial birds. The larvae are also 
destroyed by an unknown Tachinid parasite and another small dipterous larva is sometimes found feeding in considerable numbers on the larva or pupa.

\section{Bibliography}

1904 Felt, E. P. \& Joutel, L. H. N. Y. State Nus. Bul. 74, 1. 18-20

\section{Liopus alpha Say}

A small, legless grub boring irregularly in dead sumac and other twigs, may be the young of this beetle.

This species occurs rather abundantly in dead sumac twigs at Clinton Heights. The infested twigs were gathered and many of the beetles bred therefrom the latter part of May.

The beetle is about ${ }^{1}+$ inch long, rather stout, and remarkable for the long, delicate antennae, which have the enlarged distal portion of each joint dark brown or nearly black. It is rather prettily marked with silvery gray; light and dark brown, the irregular oblique stripe just behind the middle of each wing cover being the most conspicuous, the two forming a $\mathrm{I}^{\top}$ with its point toward the head. Accordding to Messrs Lengr and Hamilton, this species is quite variable and difficult to separate from allied forms. They describe five variations in markings and state that it may be separated from its ally, L. cine reus Lec., by the finely punctured surface, behind the band almost impunctured.

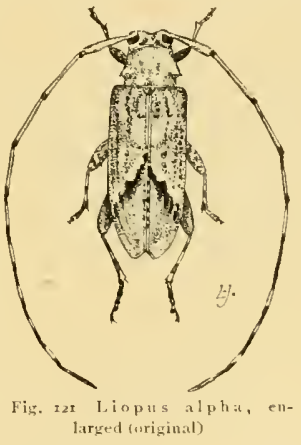

The full grown larvae are about 1/2 inch long, and present no unusual characters. Unfortunately specimens were not preserved and a detailed description is impossible.

The working of this larva is limited very largely to the central portion of the twig, and the gallery of one borer may have a length of 2 or 3 inches. The exit hole is oval and a little over $1 / 6$ inch in diameter.

Distribution. Say states that this species is not rare in Pennsylvania and that he has obtained it from the Northwest Territory, and LeConte 
records it from the Middle and Southern States, while Schwarz found it abundant at Biscayne bay, Florida. Dr Smith states that it occurs commonly throughout New Jersey, and we have met it in the vicinity of Albany. It has also been reported from Newport and Buffalo.

Food plants. IVe have reared this insect in numbers from sumac, while I) $r$ Smith states that it occurs on sumac berries of the previous year. Mr Beutenmuller records apple as a food plant in addition to that given above, while Dr Hopkins states that it infests yellow locust twigs on dead trees in West Virginia.

Natural enemies. A single parasite was reared from infested twigs, presumably from this species. It has been kindly determined by Dr Ashmead as Temelucha fusiformis Prov.

\section{Pityogenes consimilis Lec.}

I minute, dark brown or black, cylindric beetle about $1 / 3 z$ inch long, makes the familiar oblique galleries under the bark of decaying sumac twigs, grooving the wood in it very characteristic fashion.

The work of this species is exceedingly common, easily recognized and of little importance except when the carved branches are sometimes employed in rustic structures.

\section{Spotted leptostylus Leptostylus macula. Say}

A small, thick, long-horned, brown or chestnut-colored beetle, about $1 / 4$ inch long. with ash gray markings, may be bred from the dead twigs and wood of a number of trees.

This is one of our common borers having very similar habits to its ally, L iopus alpha Say. It breeds in a wide variety of twigs, having been taken from sumac, witch-hazel, chestnut, oak, walnut and apple. 1)r Fitch states that old butternut trees are sometimes filled with the grubs of this little beetle. 


\section{HORERA IN DRIED USUALLY MANUFACTURED W(DOD \\ White marked powder-post beetle \\ Lyctus parallclopipadus Melsh.}

Pin holes less than $2 / 16$ inch in diameter and galleries of the same size running in various directions in wood, may contain linear, black, white marked beelles about $3 / \mathrm{r}^{6}$ inch long.

This powder-post beetle has very similar habits to those of the more common species, Lyctus un ipunctatus Herbst., though it appears to be much rarer. Its destructive work was brought to our attention in July 1903, on the reception of a piece of ash from a large furniture manufacturer of New York city, accompanied by the statement that the insects were causing considerable damage to rough stock on hand and had also bred out in numbers from manufactured products, to their great detriment. The piece of ash was badly tunneled by the galleries of this insect and practically worthless for furniture purposes.

Description. The beetle is a jet black or dark brown, linear insect about $3 / 16$ inch long and easily distinguished from the common powder-post beetle, Lyctus unipunctatus Herbst., by the broad, creamy white band near the middle of the wing covers and extending almost to the suture. The head and prothorax are rather coarsely and irregularly punctured, while the wing covers are ornamented with rows of closely set. coarse punctures. The young or larvae are small, six legged, yellowish white grubs with the tip of the body curved.

The work of this species, like that of the common powder-post beetle, is characterized by fine sawdust dropping from the infested lumber.

Life history. This species evidently breeds freely in ash. It has been recorded in fig and probably infests other dry hard woods. The beneficial clerid, Elasmocerus terminatus Say, was bred from the ash board infested with this species and is undoubtedly of considerable service in preying upon this wood borer.

Remedies. Measures of value against the powder-post beetle should be of equal service in checking this species. 


\section{Large carpenter bee \\ Xylocopa airginia Drury}

Burrows about t/2 an inch long may occasionally be observed in telegraph poles, donrposts and similar places, and large-bodied, dusky winged bees seen going in and out.

This common insect is sometimes very persistent in its efforts to tunnel posts or timbers about houses. It is about the size, and has the general appearance of a bumblebee. The abdomen, however, is jet-black and frequently somewhat bare. The tunnels are excavated in solid wood, sometimes to a distance of a foot and are used as nesting places. A unique example of this insect's work together with the bee is represented at plate 39, figure 3. This shows the outside appearance of a $5 / 8$ inch board, from a weatherworn building, and near the top a small entrance hole $3 \%$ inch in diameter. The board has been split and the inner aspect with the three long nearly parallel ${ }_{2}$ inch burrows, split when the board was sawed in two, is represented in the foreground. The slight enlargements seen along the course of the galleries indicate the location of individual cells. These are separated from each other when filled by chips of wood securely cemented together. The nature of the partition is easily seen from below. The cells are provisioned with a paste of pollen or nectar, and when the young insects mature, those in the lower chambers are obliged to await the exit of the bees in the upper cells.

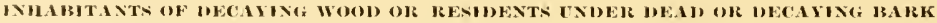

A considerable number of species occur in such places. They are of comparatively slight economic importance, yet should be characterized because of the liability of their being mistaken for more destructive species, and to aid in this identification the following brief accounts of some of the more common species are given. 


\section{Owl beetle \\ Aluzs oculatus Linn.}

A large, rather stout, black, white-marked beetle, $\mathrm{I}^{1 / 2}$ inches long, bearing two conspicuous eyelike spots, is frequenty met with in decaying wood.

There are a number of insects brought to the attention of the entomologists from year to year on account of some peculiarity and such is the case with this species. Its conspicuous eyelike spots on the prothorax excite the attention of even the most casual observer, and as the beetle is not very common, most specimens observed are captured, and are very likely to find their way into the hands of some entomologist.

This species cannot be considered injurious, since it occurs only in decaying wood, and the observations of 1)r Lugger would seem to indicate that it can be classed among our beneficial species. He has found in his own experience that it was impossible to rear the larvae or grubs, unless they were provided with living insects which they soon found and clevoured.

Description. This large smapping beetle may be easily recognized by reference to plate 39. figure 2 , which shows it about natural size and represents the appearance of a well marked individual. The conspicuous eyelike spots are found only in one other native beetle, a very rare species. This insect is representative of a very large family, members of which possess the power of projecting themselves upward sudclenly by the means of a peculiar springing apparatus on the ventral surface. A stout spine on the thorax projects back in a socket in the abdomen and by bending its body backwards, the beetle can raise its spine and rest it on the edge of the socket, and then with a sudden muscular exertion, spring it back into the cavity. The result is that the beetle is thrown into the air to a hight several times its length. This device is apparently for no other purpose than to enable the insect to regain its feet, evidently very useful, since this beetle and its allies are nearly helpless whenever they fall on their back. This peculiar snapping has led to these insects being called snapping or click beetles, and the entire family, which is composed of a large number of forms, are known to scientists as Elateridae. 
The large grubs of this giant snapping beetle have been described by Dr Harris as about $21 / 2$ inches long, nearly 1/2 inch in breadth, Hattened, reddish yellow in color. It is frequently found in decaying appletree wood.

\section{Broad-necked prionus}

\section{Prionus laticollis Drury}

A thick, fleshy, legless grub about 3 inches long when full grown bores in the roots and stumps of a number of trees.

This is a very common insect in New York State, though it rarely causes much damage so far as known, for all that the grubs are capable of doing considerable mischief. As a rule we believe their depredations are confined very largely to comparatively valueless forest trees, and therefore this insect is not often brought to the attention of economic entomologists. The operations of this grub being very largely under ground, also enable it to escape notice. The adult beetle is one of the largest native forms, measuring about $1 \frac{1}{2}$ inches in length and $5.8 \mathrm{inch}$ or more in breadth. It varies from brown to very dark brown or black. The powerful mandibles are very conspicuous with sharp, cutting edges. The antennae are about half as long as the body. The head is minutely and irregularly punctured, the dorsum of the thorax smooth, the lateral portions being punctured and the edges prolonged into two or three prominent teeth. The wing covers are coarsely rugose with several more or less distinct ridges and are usually decidedly broader at the base. The larva of this insect has been recorded as infesting pine stumps, roots of living black oak, oak logs, roots of linden, poplar, oak, chestnut, apple, pine and grapevine. Dr Riley records a case where this species was very destructive to young appletrees in Kentucky. 'These borers as a rule work within the roots, though Dr Riley states of an allied species, P. imbricornis I.inn., that where the root is too small to accommodate the borer, it eats away about one third of the bark and hollows out the remainder of the root, thus causing great injury in nurseries The adults are abroad during midsummer.

Remedial measures. Since the larva of this species works in the roots, it is very difficult to check its operations and there is nothing better than 
destroying the infested trees and avoiding so far as possible conditions favorable to the breeding of this borer; namely; a great many stumps and dead trees in which it can thrive.

\section{Lesser prionus}

\section{Orthosome brunnemm Forst.}

A rather slender, brown beetle about ${ }_{1}{ }_{2}$ inches long and less than $I_{2}$ inch broad, lives in the larral stage in decaying trees.

This beetle is another rather common species frequently met with in midsummer and attracts notice largely on acconnt of its size. Its larva lives almost entirely in decaying wood, and as a consequence this form is of comparatively slight economic importance. The adult beetle is about $1 \mathrm{I} / 2$ inches long with powerful mandibles, and tapering antennae a little over one half the body length. The large eyes are comparatively inconspicuous, finely granulate, and the thorax is prolonged laterally into a series of two or more irregular teeth. The wing covers are very long, rather slender, with parallel sides, irregrularly and finely punctured and ornamented with several rather prominent ridges. The larra of this species has been recorded as boring in decaying pine, hemlock, hickory, walnut, oak, chestnut, and I)r Hopkins states that it inhabits the decaying logs and stumps of nearly all forest trees.

Description. The larra and pupa have been described by I)r Packard as follow: :

Larva. Described while alive. Body cylindrical, not flattened, the segments very distinct, as the sutures are deeper than ustual ; head moderately broad; prothorax large and broad and rather long, being $9 \mathrm{~mm}$ broad and $41 / 2 \mathrm{~mm}$ long; surface rough on the posterior two thirds. On each of the first to seventh abdominal segments is a transverse oral cylindrical fleshy area, each with three transverse folds, the area on the seventh ring being nearly twice as long (antern-posteriorly) as that on the first, the areas becoming longer and narrower, i. e. more rounded, going backward towards the seventh segment; the end of the abdomen smooth and shining; each thoracic segment with a pair of slender three-jointed feet. Length, $35 \mathrm{~mm}$ (138 inches).

Pupac. Antennae bent near their end at right angles and laid across the end of the elytra, the latter reachings to the middle of the hind tarsi. 
End of the abdomen terminates in a singular rufflelike expansion, armed on the edges with stout spines. Hind tarsi reaching to the middle of the fifth abdominal segment. The body considerably curved. Maxillary palpi extended well beyond the end of the mandibles. Prothorax with a broadbased spine on the side. The projecting parts of the abdominal segments with fine spines, and segments 3 to 5 with a pair of transverse, thin, dark brown chitinous patches. Length $30 \mathrm{~mm}$.

\section{Anthophilax attenuatus Hald.}

An olive gray, mottled beetle with black head and thorax, and about $5 / 8$ inch long, occurs in early spring on partly decayed beech stumps.

This Lepturid has the characteristic form of this subfamily, and has been taken in early May on dead or decayed beech at Newport N. Y. by Mr D. B. Young. The beetles were observed by him, ovipositing in the galleries made by Ptilinus ruficornis, and the process has been described by him as follows :

The beetle crawled along with an odd jerky motion and carefully examined every hole and crevice which it crossed. The crevices were aban-

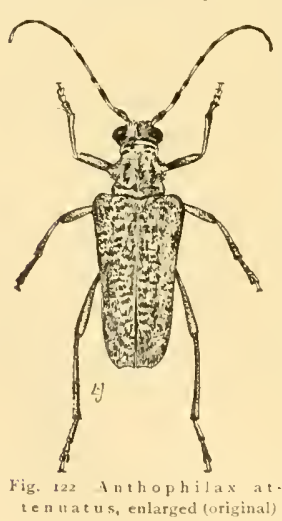
doned almost immediately ; the galleries were examined with more care and evidently those selected were a year old; the beetles invariably oviposited with the head turned nearly or wholly down. One of the galleries removed after the beetle had oviposited and flown contained 16 esrgs. Nothing had been placed in the gallery to prevent parasites from entering. The eggs were placed $1 / 2$ inch from the outside in four lots of four each, with their ends slightly tapering, just filling the diameter of the gallery. The eggs were cylindrical, rounded at both ends, polished, and waxy white; they were gummed together with a yellowish secretion, and were $\mathrm{I} / 2$ to nearly $2 \mathrm{~mm}$ in length.

Beetle. Length 5/8 inch; antennac, legs and wing covers olive, mottled with grayish white; head and thorax black and clothed with a short, sparse golden pubescence. This form may be recognized, according to Mr Wickham, by its elytra being testaceous and irregularly marked with piceous spots. The surface is coarsely and sparsely punctate and with small spaces which are distinctly pubescent. Median line of thorax distinctly impressed. 
This species was found on the shores of Lake Superior by 1)t LeConte, is reported from Ottawa Can., by Mr Harrington, and Dr Hamilton states that it is rare in southwestern Pennsylvania. It las also been listed from Mt Washington, by Mrs Slosson.

\section{Dermestes pulcher Lec.}

A brown-headed, black-winged, rather slout beelle about ${ }^{1}+$ inch long, was bred from larvae taken from a hollow oak.

This species, according to Jayne, may be easily recognized by its general red color and almost entirely black wing covers, the flattened thorax with two basal foveae, and the absence of abdominal spots and white rings on the femora. He records this species from the Southern, Middle and Western States. It must be rare in southwestern Pennsylvania, since Dr Hamilton met with only two specimens. It has been listed also from the vicinity of Buffalo N. Y. and Cincinnati $O$.

Ditoma quadriguttata Say. This minute, black and reddish bectle occurs in early spring under dead bark of beech stumps. It is about ${ }_{3}^{32}$ inch long. Head and thorax almost entirely black, coarsely punctured with conspicuous lateral ridges on the latter. The wing covers have an oblique, reddish stripe at the base of the wings, a similar spot near the middle and a smaller one at the posterior third. These organs are conspicuously. striated and with coarse, distinct punctures between the ridges.

Mycetochares binotata Say. This species occurs under poplar bark.

Cerylon castaneum Say. This minute, reddish, rather flattened beetle occurs under dead bark of maple stumps in early spring. It is about ${ }^{3} \mathrm{r}$ inch long, the head somewhat rounded, the thorax rather irregularly punctured and the wing covers finely striate with series of confluent punctures.

Silvanus imbellis Lec. This minute, slender, grayish brown beetle occurs sparingly under the dead bark of beech and maple in early spring. It is about $1 / 8$ inch long, slender, the head and thorax grayish, rather thickly and irregularly punctured; the wing covers distinctly striate with a series of nearly confluent punctures.

Catogenus rufus Fabr. This dark, reddish, somewhat flattened beetle has been taken under dead elm bark in May. It is nearly $1 / 2$ inch long with conspicuous moniliform antennae. The head and thorax are finely and irregularly punctured and the wing covers marked by a series of deep groores and with the humeral angles continued as a conspicuous ridge their entire length; costal margin strongly sinuate.

Cucujus clavipes Fabr. This tlattened, bright or dark reddish beetle 
occurs in eariy spring under dead elm bark. It is about $1 / 2$ inch long with conspicuous blackish moniliform antennae, the head and thorax are strongly flattened, irregularly and coarsely punctured, the latter with a series of minute denticulations along its lateral margins; wing covers finely punctured and apparently hollowed. The humeral angles are continued as conspicuous ridges along their entire length.

Laemophloeus biguttatus Say: This small, flattened beetle may be: found under dead maple bark in April and May. It is about $1 / 8$ inch long, the head and thorax are finely though irregularly punctured, mostly dark brown. while the wing covers are finely striate with series of confluent punctures and are mostly dark brown with a middle, somewhat broken band of pale yellowish

Laemophloeus testaceus Fabr. This minute, slender, flattened beetle is not uncommon under the lead bark of maple and beech stumps in early spring, It is about $3{ }_{32}$ inch lons, the slender antennate are nearly as long as the body. The brown head and thorax are rather finely and sparsely punctured, the latter with distinct sublateral ridges and with the lateral margrins prolonged, toothed posteriorly; wing covers finely striate with series of minute punctures; lateral marsins produced.

Dendrophagus cygnaei Mamn. This flattened, brownish species occurs mnder elm bark in March and April. The dark brown head and thorax are ornamented with irregular, coarse punctures and the brown wing covers are striated with series of rather larese, almost confluent punctures; humeral angle pronounced and continued as a distinct ridge along the entire length of the wing covers. The legs are light brown with strongly swollen femora.

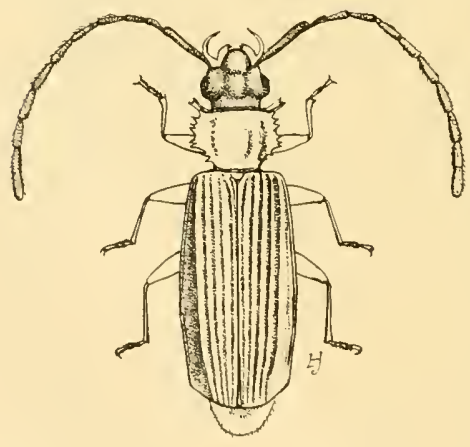

Uliota dubius Fabr. This flattened, brownish or black beetle occurs under lead elm, beech, maple and buttermut bark in early spring. It is abont $1 / 4$ inch long, dark brown or blackish. The reddish brown antennae are as long as the body, and just anteriorly there is on each side a conspicuous curved, hornlike process apparently peculiar to the male. The dark brown head is coarsely punctured with two deeply impressed lines; the prothorax is also coarsely punctured, with lateral margins serrate, the anterior angles being prolonged into conspicuous processes. The wing covers are coarsely Fig. ${ }^{23}$ Uliot, dubiun, mate, enlarged (wriginal, striate with a conspicuous humeral ridge their entire length and the interspaces ornamented with numerous confluent coarse punctures. 
Ephistemus apicalis Lec. 'This is a very minute, shining black species which occurs under beech bark in February. It is so very small that a hand lens is necessary to distinguish it from mites found in similar places.

Hister lecontei Mars. A small, stout, flattened, jet-black beetle occurs under the dead bark of such trees as beech, maple, elm, pine etc. frequently. in association with various bark borers. The head is minute, partially retracted under the expanded portions of the prothorax. The short, highly polished wing covers are marked with steveral distinct striat.

\section{Hister parallelus Say}

Jet-black, somewhat elongated, subcylindric beetles, about 18 inch long, may be met with in considerable numbers under the hark of white elm and other trees.

This species was abundant under decaying elm bark at Albany, Nor: 3, 1903, and we have also met with it under spruce bark at Davis 11 . Ia., associated with a species of Pityophthorus. Dr Hamilton records the same species as common under pine bark in sonthwestern Pennsylvania, and Dr Smith finds it not rare uncler bark in New Jersey, and states that in one instance specimens were feeding on sap. This species is not a borer, and like its close relatives, is frequently found in the galleries of various wool borers, where it probably feeds on partially decaying or decayed vegetable matter. This species has been recorded from eastern Florida by its describer and, in addition to above named localities, has been listed by Ulke from the District of Columbia and Dr Horn records it from South Carolina and Georgia.

Plegaderus transversus Say. This stout, roundish, dark brown beetle less than ${ }^{\mathrm{i}}{ }_{16}$ inch in length, occurs in early spring in damp situations under basswood bark and probably frequents other trees presenting similar conditions.

Colastus truncatus Rand. This small, oval beetle is plentiful in early spring under the bark of freshly cut maple and butternut stumps, where it feecls on the sap. It is about $3 / 32$ inch in length, oval, reddish brown, with the wing covers protecting only the anterior two thirds of the body.

Cryptarcha concinna Nlelsh. This species is aburidant in early spring under the bark of freshly cut maple and butternut stumps, apparently feeding on the sap. It is a minute, oblong, banded beetle about $3 / 32$ inch long, with the thorax and wing covers obscurely marked with dark brown and pale yellow: 
Tenebrioides corticalis Melsh. This black, somewhat flattened bectle from $x_{+}$to 38 inch in length, is common under the bark of elm, willow and other trees. The head and thorax are rather coarsely punctured and the wing covers are finely striate with series of small distinct punctures.

Tenebrioides castanea Melsh. This flattened, dark brown beetle occurs in considerable numbers under the dead bark of beech, pine and probably other trees. It is about 3,8 inch long, dark brown, the head and prothorax somewhat coarsely though sparsely punctured and the wing covers weakly striate with rows of shallow, nearly confluent punctures.

Nyctobates pennsylvanica 1)eG. This large, rather stout, jet-black beetle tapers slightly anteriorly and is about 78 inch in length. It is found under dead bark of various trees such as beech, hemlock and birch. The head and prothorax are rather finely punctured and the wing covers are ornamented with a series of minute striae composed of small distinct punctures with the intermediate spaces marked by almost microscopic punctulations.

Iphthimus opacus Lec. This dull black, coarsely punctured beetle about $3 / 4$ inch long, occurs under the decaying bark of various trees.

Tharops ruficornis Say. This insect has been taken from dead beech.

Elater nigricollis Herbst. This species has been found under decaying basswood, beech and maple bark.

Elater humeralis Lec. This beetle may be taken in decaying beech or maple stumps in March, April and May.

Melanotus communis Gyll. This species occurs under tlie decaying bark of various trees, being perhaps more numerous under that of pine than any other.

Corymbites sulcicollis Say. This species occurs under dead birch bark in March and April.

Dorcas parallelus Say. Larvae of this brownish beetle live in decaying logs or stumps of various trees. We have taken it on elm.

Ceruchus piceus $1 V^{\top} \mathrm{eb}$. The larvae of this species have been recorded from old beech stumps, decaying chestnut, willow and birch. W'e have taken it abundantly in rotting black cherry.

Horned passalus. Passalus cornutus Fabr. This very striking, large mahogany brown beetle with its coarsely striate wing covers and cleep, broad constriction at the base of the wing covers, lives in the larval stage in the decaying stumps of basswood, hickory and other deciduous trees.

Rough flower beetle. Osmoderma scabra Beaws. This stout, brownish, purplish black beetle about 1 inch long and over $1 / 2$ inch in breadth, with its wing covers roughened by irregular coarsely punctured striae, occurs about decaying portions of various trees. Its larva is very similar to that of the well known white grub, only larger. 
Hermit flower beetle. Osmoderma eremicola Knoch. This flower beetle is slightly larger than the preceding, of a dark mahogany color, with smooth, highly polished wing covers. It presumably has the same habits as the preceling form.

Stenosphenus notatus Oliv. This insect was taken at Poughkeepsie on dead hickory and oak. It has been recorded as breeding in dead limbs of the former.

Lepturges symmetricus Hald. This species was taken in early July on beech injured by fire.

Oberea schaumii Lec. This species bores in the twigs and branches of poplar, beetles appearing in early May:

Oberea ocellata Hald. This small longicorn has been reared from sumac.

Scotobates calcaratus Fabr. This large, black beetle about $5 / 8$ inch in length, occurs under the dead bark of various hard woods. The head and thorax are rather finely; irregularly punctured and the wing covers marked with conspicuous striae composed of fine and in many cases confluent punctures.

Tenebrio tenebrioides Beaur. This large, brownish black species occurs under decaying willow, butternut and basswood bark in early spring. It is about $1 / 2$ inch fong, rather stout, the head and thorax are finely and irregularly punctured, while the wing covers are ornamented by series of striae composed of thickly set though distinct punctures.

Penthe obliquata Fabr. This species is very similar to the preceding and like it, occurs under dead beech bark, particularly on trees that are down, and may be distingruished from the following by the yellowish scutellum and from the preceding by the deeply impressed thorax and the coarsely punctured elytra. It is also a somewhat stouter form.

Penthe pimelia Fabr. This stout, black species occurs under dead beech bark, most frequently on trees that are down. The head and thorax are coarsely punctured, the latter with a deeply impressed spot posteriorly: The wing covers are coarsely marked with irregular series of deep punctures.

Melandrya striata Say. This large, black beetle occurs under the dead bark of beech, maple and probably of other trees in July. The beetles range in length from i 16 to about 5 inch and may be recognized by the very finely punctured head and thorax, the latter tapering strongly anteriorly, and specially by the prominently ridged, slightly pubescent, finely punctured wing covers.

Phloeotrya liturata Lec. This black or dark brown, yellow-marked melandryid is about 5,16 inch long and occurs under dead maple bark the latter part of June and July. It may be recognized by the rather peculiar irregular black mark on each side of the anterior third of the elytra 
and a smaller one about the posterior third, which latter extends aimost to the suture.

Phloeotrya simulator Newm. This species occurs in rotting beech and maple stumps.

Asclera puncticollis Say. This dull black beetle, 5 16 inch long, with a dull red and black-spotted pronotum was taken in midwinter at Newport N. Y., from the dead tissues of a birch, by Mr D. B. Young.

Dendroides canadensis Latr. This species has been taken under the decaying bark of oak, birch, maple, beech and other deciduous trees.

Dendroides concolor Newm. This species has been taken under the decaying bark of oak, maple, beech, birch and other decicluous trees.

Cryptorhynchus parochus Herbst. The larvae of this species have been taken under butternut bark, adults being found the latter part of May:

Gonotropis gibbosus Lec. This species was taken in early July on living birch and maple trees, which had been injured by fire.

\section{Stenoscelis brevis Bohm.}

A dark brown or black, cylindric beetle scarcely 1's inch long and with prothorax and wing covers coarsely punctured, is a common borer in dead and partly rotten wool of various trees.

IVe have taken this species boring in deack limbs of butternut, ash, willow, poplar, and it has been recorded by others as occurring in elm and maple. It runs irregtular sinuous galleries about $1 / 2$ inch in diameter.

\section{RUNGOUS HEETLEN}

There are a number of species of very diverse appearance, which feed on fungi and are frequently met with on various trees. They, of themselves, are of comparatively slight importance, and on that account they should not be confused with the more dangerous borers which may occur under similar conditions.

\section{Tritoma thoracica Say}

A rather broad, oval, black and bright red beetle about $3 / s^{6} \mathrm{inch}$ in length, occurs in June and July on soft mushroom growths on decaying poplar.

The head and prothorax are bright reddish, the eyes small, finely gramulate, and the wing covers are faintly striate with small, well separated punctures. 


\section{Mycetophagus punctatus Say}

This somewhat elongate beetle, brightly marked with reddish brown and black, nearly $1 / 4$ inch long, infests soft fungi of basswood in June and July.

The mouth parts and extremities of the antennae are rufous, the middle portion of the latter being black. The eyes are slightly emaryinate, rounded, coarsely granulate; labrum, dorsum of head and prothorax black, coarsely punctured. The wing covers have a large, black scutellar spot and are margined laterally with the same color, from which there extends near the middle a conspicuous lobe; near the posterior extremity there is a broad, somewhat irregular black band across the wing covers. These organs are rather finely striate with coarse punctures and clothed with a short, rather coarse pubescence.

\section{Mycetophagus flexuosus Say}

This rather narrow, elongated, oval beetle conspicnously marked with black and reddish, infests soft fungi on basswood in June.

The mouth parts and the extremities of the antennae are reddish, the middle segments of the latter being black. Eyes prominent, coarsty granulate; head and prothorax coarsely punctured. Wing covers with conspicuous striae composed of almost confluent punctures; reddish brown, with a conspicuous black scutellar spot extending some distance each side of the scutellum. There is a broken, irregular black band about midway of the length of the wing covers, and a nearly complete one at the posterior third; wing covers clothed with a coarse pubescence.

\section{Triphyllus humeralis Kirby}

This minute, oval, dark reddish brown beetle may be found on fungi growing on basswood.

It is about $1 / 8$ inch in length. The head and thorax are slightly darker than the dark reddish brown wing covers, and the dorsal surface of the entire insect is faintly punctured and sparsely clothed with a short, appressed, golden pubescence. 


\section{Phenolia grossa Fabr.}

This rather flattened, rounded beetle about $5 / 26$ of an inch in length, may be taken abundantly on soft fungi on the side of fallen beech.

It is obscurely marked with black and very dark red. The head is partially covered by the enormous prothorax, which is arcuate in front, rounded laterally and coarsely and irregularly punctured. The wing covers bear several rather conspicuous though slight ridges.

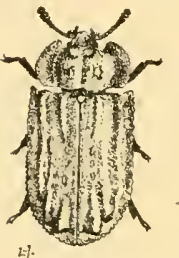

Calitys scabra Thunb.

This flattened, reddish beetle, about $3 / 8$ inch in length, may be found in June on certain fungi growing on the ends of decaying hemlock logs.

This insect has a peculiar form, with enormously produced thoracic margins, which are rounded and serrate exteriorly, and the wing covers have the humeral angle produced 25.

Fi, 12s Cality. behind in a conspicuous ridge and with the margin extended (uriginal)

\section{Phellopsis obcordata Kirby}

This peculiar appearing rusty red, dark brown beetle about $1 / 2$ inch in length, may be found in lune on certain fungi growing on the ends of decalying hemlocks.

This species is rather flattened and is remarkable on account of the enormous prothorax with its conspicuous lateral anterior protuberances. IVing covers very coarsely punctured and with the humeral angle prolonged into a conspicuous ridge, which is distinctly notched at the anterior fourth and at the posterior fourth enlarged to produce a conspicuous tubercle. There is also a thickened lateral ridge extending back to a smaller tubercle below the one mentioned above. The tips of the wing covers are also somewhat enlarged.

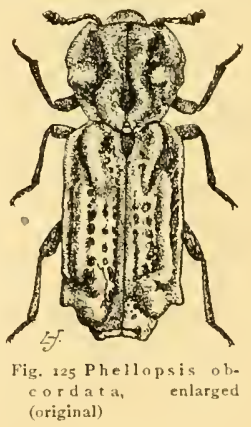




\section{Upis ceramboides Linn.}

This conspicuous jet black beetle, easily recognized because of the coarsely reticulate, ridged wing covers may be found in July on fungi growing on white birch.

This handsome beetle is about $3 / 4$ inch in length, jet black. Eyes inconspicuous, finely granulate; head and thorax finely punctured, and wing covers coarsely reticulate as stated above.

\section{Platydema ruficorne Sturm.}

This small, oval, dull black beetle about $3 / 26$ inch in length feeds in fungi.

The antennae, palpi and anterior margin of the labrum are more or less rufous. The eyes are deeply emarginate, coarsely granulate, and the top of the head coarsely, and the prothorax finely punctured. The wing covers are faintly striated with a series of slight, well spaced punctures. This species occurs in early spring.

\section{Platydema americanum Lap.}

This brownish black, glistening, oval beetle about $1 / 4$ inch in length infests fungi.

The mouth parts are rufous, the eyes deeply emarginate, coarsely granulate; the labrum and dorsum of the head coarsely, and the prothorax finely punctured. The striae of the wing covers are deeper than in $P$. ruficorne Sturm. and the punctures a little closer. It is easily separated from the preceding by its glistening color and different form.

\section{Platydema subcostatum Lap.}

This oval, rounded, brownish black beetle about $1 / 4$ inch in length, occurs on fungi.

The mouth parts and antennae are rufous, the eyes are deeply emarginate, coarsely granulate; the labrum and dorsum of the head coarsely, and the pronotum finely punctured; wing covers somewhat deeply striated with rather coarse, slightly elongate punctures.

\section{Diaperis hydni Fabr.}

A rather stout, rounded, reddish and black beetle nearly $1 / 4$ inch long, occurs during June and July on fungus growths affecting white birch and basswood.

This species has the head and thorax jet black and the faintly striate wing covers are bright red with black markings. The latter have a black 
sutural line, slightly broader posteriorly, with two circular black spots at the anterior third, one subdorsal, the other lateral, and at the posterior third a much larger irregular black spot, which is prolonged along the ventral margin.

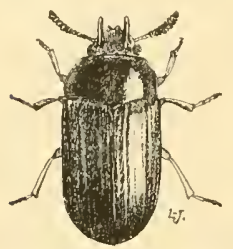

\section{Hoplocephala bicornis Oliv.}

This small, rather stout, greenish beetle occurs on maple and beech fungi in April and May in association with Cratoparis lunatus Fabr.

This beetle is about ' $/ 8$ inch in length and the smaller males nay be at once recognized by the two conspicuous hornlike processes on the front. The anterior margin of the

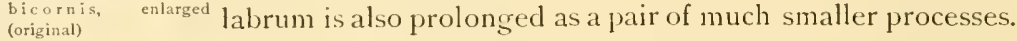

\section{Forked fungous beetle}

\section{Bolctotherus bifurcus Fabr.}

This very striking beetle occurs on fungus growing on beech and maple in June. In spite of its dull colors, its grotesque form renders it somewhat conspicuous.

Both sexes are dark brown or brownish black and are remarkable because of the peculiar irregular elevations on both head, thorax and wing
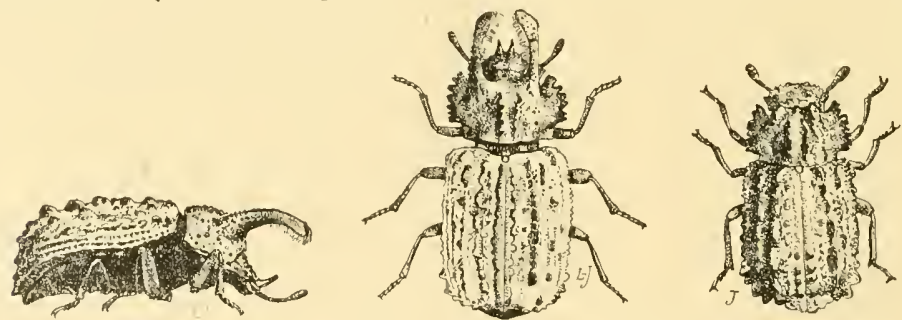

Fig. 127 Forked fungous beetle, Boletotherus bifurcus, side and dorsal view of male, dursal view of female, enlarged (original)

covers which, in the male, are accentuated. The female has a pair of rather conspicuous tubercles on the prothorax. Her consort may be at once recognized by these prominences being prolonged into enormous horns bearing at their extremities on the underside, delicate brushes of reddish yellow hairs. 


\section{Cratoparis lunatus Fabr.}

A rather stout, narrow, grayish brown mottled beetle about if inch in length, may be found on fungi growing on maple and beech stumps, often associated with $\mathrm{Hoploce}$ phala bicornis Oliv., in April and May. It also occurs in September.

The head of this peculiar beetle is distinctly prolonged and the front thickly clothed with yellowish, grayish scales. Mandibles very lárge, eyes rather large and finely granulate; prothorax tapering anteriorly, slightly swollen near the middle and thickly clothed with yellowish gray pubescence, sparse posteriorly and exposing the dark brown chitin. The wing covers are strongly striate with coarse, distinct punctures and thickly clothed with yellow, brownish and almost black pubescence, giving the insect a peculiar mottled appearance.

There are a number of natural enemies of bark borers, some of which occur on the bark or in the galleries, and one not conversant with their habits might easily mistake them for destructive species. A few of the more important of these beneficial forms are noticed briefly on the following pages.

\section{Ibalia maculipennis Hald.}

This striking and peculiar cynipid was taken at Poughkeepsie N. Y. ovipositing on hickory infested with Dicerca obscura var. 1 urida Fabr., and a species of tremex. The European 1. cult e 11 a tor Latr., has been recorded as a rare parasite on tremex and it is possible that this species has similar habits.

It is a small, wasplike insect about 5,8 inch long, with the membranous wings clouded near the

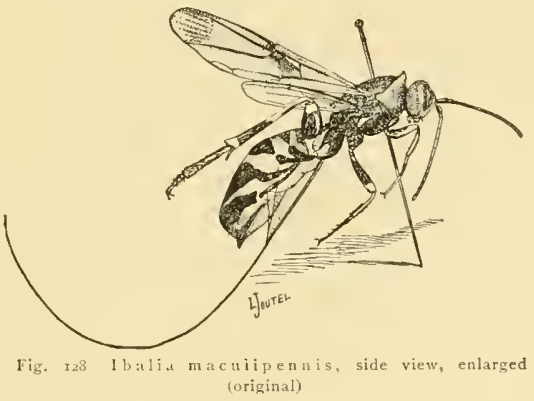
middle and at the tip. It is black, marked with yellowish and at once recognizable because of the very strongly compressed abdomen with its alternate irregular bands of black and yellowish white. 


\section{Xylonomus albopictus Cress.}

Specimens of this parasite were cut from hickory infested by D i c e r c a obscura var. I u rida Fabr, on which it was probably parasitic. It has been recorded by Dr Hopkins as a parasite of buprestid larvae.

\section{Foenus tarsatorius Say}

This insect was observed oviposting on butternut. It is undoubtedly a parasite of some wood borers infesting this tree.

\section{American bark beetle destroyer \\ Thanasimus dubius Fabr.}

This is one of the commoner, larger clerids. It measures nearly $3 / 8$ inch in length, and may be recognized by the head, thorax and basal portions of

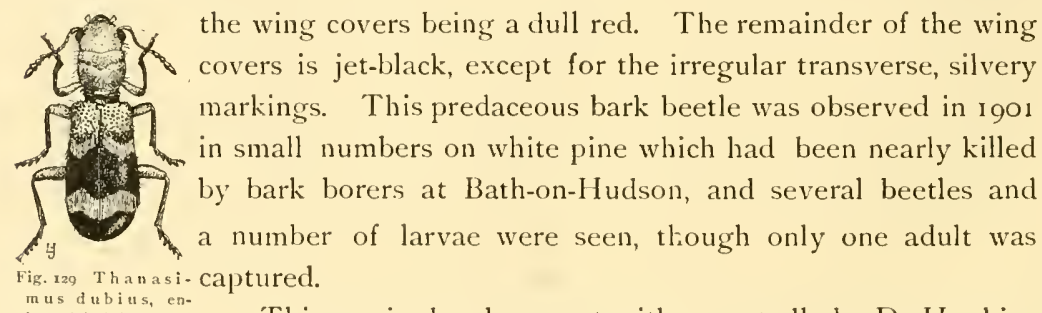
larged (original) $\quad$ This species has been met with repeatedly by Dr Hopkins in his investigations of insects affecting forest trees in IVest Virginia, and he states that this form is the one most closely related to the European species, Clerus formicarius Linn., which was introduced by him in 1892 , in the hope that it would prove a very efficient agent in preventing serious outbreaks of bark borers.

The American bark beetle destroyer passes the winter in all stages from larva to adult, as stated by Dr Hopkins, in the bark under which it breeds and sometimes in the loose bark and moss at the base of the tree. The beetles appear in the spring, and soon after bark beetles begin to emerge from their winter quarters, tly to infested trees, logs or tops, where they station themselves beneath loose flakes of bark, awaiting an opportunity to pounce on their prey. They also move rapidly over the bark in 
search of beetles or for entrances to galleries of the bark borers, in which the females deposit eggs. These soon hatch, and the minute active grubs find their way into the egg and brood galleries of the bark borers where they may frequently be found by the collector. These beneficial grubs feed on the eggs and young of the bark borers till they have attained full growth, when they leave the inner bark and excavate cavities in the outer bark where the transformation to the adult occurs.

This clerid attacks and feeds, on all kinds of bark beetles which infest the spruce and pine, and it has also been found attacking bark beetles in deciduous trees. It is a common insect wherever pine and spruce grow in West Virginia according to Dr Hopkins. This beneficial species is unfortunately preyed on by at least two parasites. One braconid apparently attacks the full grown larva when it enters the outer bark to pupate and lives within its host. This parasite is in turn attacked by another which Dr Hopkins bred in large numbers from clerid larvae. A small, two winged fly, resembling a house $\mathrm{fly}$, deposits its eggs on the living beetle, and the maggot hatching therefrom, enters the abdomen and subsists by absorbing nourishment from the body fluids of its host. The infested beetles remain alive and active, till the parasitic larva leaves it to undergo its final transformations, which probably take place in the ground. This clerid has been recorded by Dr Smith as generally, though locally, distributed through New Jersey. Dr J. A. Lintner ${ }^{x}$ observed numbers of these insects on cut pine and timber at Schoharie, May 13, where they had probably been feeding on wood-boring grubs.

\section{Bibliography}

r 899 Hopkins, A. D. W. Va. Agric. Exp. Sta. Bul. 56, p. 262-64

\section{Elasmocerus terminatus Say}

A small, cylindric, nearly black beetle about $1 / 4$ inch long, may be found with Lyctus and some other borers in infested wood.

This very interesting clerid was obtained from a piece of ash badly infested with Lyctus parallelopipedus Melsh., on which it evidently preys.

I I 888 Lintner, J. A. Ins. N. Y. fth Rep't, p. I 42. 
Description. The adult beetle is about $1 / 4$ inch long, with the head, antennae, legs and wing covers jet-black. The reddish yellow thorax is

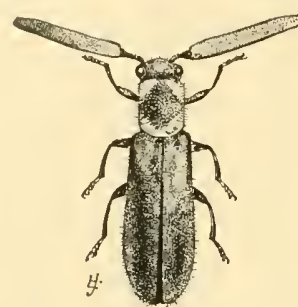

Fig. $x_{30}$ Elasmocerustermi-

nat us, enlarged (original) marked by a median, large black spot. This beetle is remarkable on account of the very large terminal antennal segment, which equals in length the remainder of that organ. The head and wing covers are coarsely punctured, eyes coarsely granulate. The abdomen is reddish, with the terminal segment black. This species has been bred abundantly by Dr Hamilton from grapevines infested by $\mathrm{Phy}$ mat odes a mo enus Say, on which it preys, and Dr Hopkins records finding it with Sinoxylon basilare Say, Agrilus otiosus Say, and Chramesus hicoriae Lec. in dead hickory branches, while Dr Smith states that he has found it on trees infested with Scolytus and Bostrichus, adding that it is not uncommon.

Distribution. This species probably has a wide distribution in the United States, since it occurs in New York, and has been recorded from Ohio, New Jersey, District of Columbia and IVest Virginia.

\section{Orange-banded clerid \\ Clerus ichncumoncus Fabr.}

This very striking black and red marked insect preys on developing broods of the hickory bark beetle, Scolytus quadrispinosus Say, and wherever abundant is undoubtedly of considerable service in checking that destructive bark beetle.

This beneficial species is about $5 / 16$ inch in length, bright red, with a small interrupted black band just behind the shoulders, and a broader continuous one at the posterior third of the wing covers, which latter are gray apically. This species has been recorded by Messrs Ulke and Dury from $\mathrm{W}^{\top}$ ashington $\mathrm{D}$. C. and the vicinity of Cincinnati O. respectively, and we have received specimens from Kansas through the kindness of Dr Snow. 


\section{Scarlet winged clerid \\ Thaneroclerus sanguincus Say}

This brilliant little beetle occurs under the dead bark of maple and beech in dry situations. It is only about $3 / 16$ inch in length and has a dark brown, rather coarsely punctured pubescent head and thorax and may be easily recognized by the brilliant scarlet wing covers which are coarsely though irregularly punctured.

\section{Phyllobaenus dislocatus Say}

A small, blackish, yellow-marked beetle about ${ }^{3}{ }_{16}$ inch in length, may be met with in the galleries of certain bark borers.

This species was reared from hickory limbs obtained at Ilion N. Y., the adults appearing June 20. The tree was also infested with $\mathrm{Chrys}$ obothris femorata Fabr., and Magdalis olyra Herbst, which were preyed on by several parasites, and this clerid may possibly have been subsisting on the latter borer.

Description. The adult beetle is about $3 / 16$ inch in length, the head and thorax black, and the wing covers jet-black, marked with pale yellowish, having an irregular oblique mark near the humeri and one near the posterior third, with a small spot near the tip. The head and thorax are rather coarsely punctured, and the wing covers are ornamented with very coarse, almost confluent punctures. This species, according to Dr Hopkins, attacks Polygraphus rufipennis Kirby in black spruce, and Pityophthorus consimilis Lec. in sumac, and he found it associated with Scolytus rugulosus Ratz. in apple. Adults were obtained by him from the middle to the Fig. ${ }_{33}$ Phyllo. latter part of June and in early December.

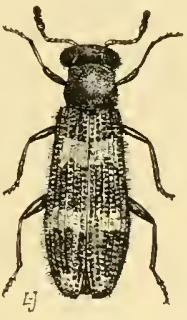

baenus disloc a tus, enlarged

Distribution. This species probably has a wide distribution in the eastern United States, since it occurs in New York, and has been listed from the vicinity of Cincinnati O., southwestern Pennsylvania, various localities in New Jersey, and from West Virginia. 


\section{Chariessa pilosa Forst.}

This rather stout, black beetle with yellow-margined prothorax, may be easily recognized by reference to the accompanying figure.

This clerid, about $1 / 2$ inch long, is predaceous and undoubtedly renders considerable service in keeping various pests in check. Specimens were taken at Pough-

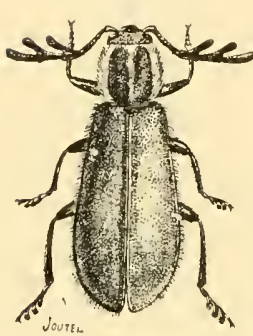

Fig. 132 Chariessa pilosa, enlarged (origiral) keepsie on a hickory tree in which Dicerca lurida Fabr. was ovipositing, and Dr Smith records its occurrence in New Jersey on oaks and also pear infested by the sinuate borer, Agrilus sinuatus Oliv., the larva probably preying on the pupa of this latter insect. Dr Hopkins states that the larvae are very efficient checks on several of our destructive flat-headed buprestid borers.

This very dark brown beetle about $1 / 8$ inch long, occurs in the galleries of Scolytus quadrispinosus Say, and has been recorded in those of $\mathrm{Xyleborus}$ celsus Eich., preying undoubtedly on this ambrosia beetle. It has been recorded from the vicinity of IVashington, West Virginia and New Jersey, and is probably widely distributed in the northeastern United States. The antennae are reddish, stout, moniliform, the terminal segments being larger than the basal ones. The eyes are prominent, black, coarsely granulate; the head and prothorax brown, irregularly and finely punctured, the latter being remarkable because of the prominent median sulcation. The wing covers are very dark brown or black, sparsely clothed with rather coarse hairs and irregularly and finely punctured. 


\section{Bothrideres geminatus Say}

This rather slender, slightly flattened, light brown beetle about $1 / 8$ inch long, was taken in the galleries of Scolytus quadrispinosus Say, and it has also been found by Dr Smith under dry oak bark.

This species has brownish, moniliform antennae, the two apical segments being distinctly enlarged. The prominent eyes are coarsely granulate and the head and prothorax coarsely and confluently punctured, the latter with expanded margins, particularly anteriorly. The wing covers are strongly ridged and the entire body sparsely clothed with rather long, golden yellow setae. 


\section{LEAF EATERS AFFECTING DECIDUOUS FOREST TREES}

This comprises a very large assembly of species, many of which are of very little importance. It is impossible to adequately notice all the species found on forest trees, consequently this portion of the work is by no means complete.

\section{Leaf eaters}

Small, triangular, flattened, metallic beetles occur in midsurnmer on oak and elm leaves, Brachys aerosa, p. 5 I $2^{2}$ B. ovata, p. $5 \mathrm{I} 3$

A small, stout, brown and black beetle a trifle less than 1/4 inch long, occurs on scrub oak in June....................................... Yellowish brown, black-margined flea beetles about $3 / 16$ inch long, feed in summer on oak, hickory and birch.... Black-margined flea beetle, Systen a marginalis, p. 5r5 A small, shining, dark brown, black-headed leaf beetle $1 / 4$ inch long on scrub oak in July

Tymnes tricolor, p. 515

A slaty gray, brown-striped weevil $/ / 4$ inch long on oak in July

A phrastus taeniatus, p. 5 is

Terminal lobes of oak leaves rolled into neat cylindric cases containing an egg, may be the work of this species... Two spotted curculio, At telabus bipustulatus, p. 516 A large, greenish weevil $1 / 2$ inch long, occurs on the buds of a variety of trees from May to July............. New York weevil, I th y cerus noveboracensis, p. 5 7 A stout, light apple-green caterpillar with a conspicuous caudal horn and seven lateral oblique white stripes, feeds on hickory, black walnut and ironwood

Walnut sphinx, Cressonia juglandis, p. 518

A red-headed, striped caterpillar with a conspicuous red hump on the eighth abdominal segment, feeds on oak in midsummer

Red-humped oak caterpillar, Sy m merist a albif rons, p. 519

A red-headed, grayish caterpillar about $1 / 2$ inches long, with conspicuous pointed elevations on the first and eighth abdominal segments, occurs on oak in midsummer

Rosy Hyparpax, Hy parpax a urora, p. 520

A pale greenish caterpillar about $1 / 2$ inch long, with a more or less distinct yellowish lateral line, occurs on oaks and various other trees in midsummer

Green oak caterpillar, $\mathrm{Nad}$ at a gibbosa, p. $52 \mathrm{I}$

A large, greenish, stout caterpillar with fascicles of irritating, sharp spines over the body, feeds in late summer on the foliage of oak and other trees

Io caterpillar, A utomeris io, p. 521 
A yellow-headed, light yellowish, tufted caterpillar closely resembling that of the white marked tussock moth, feeds on oak and a number of other trees

Definite-marked tussock moth, Hem erocampa definita, p. 522

A black-headed caterpillar about $\mathrm{I}^{\mathrm{T} / 4}$ inches long, thickly clothed with yellowish hairs and black tufts of the same, feeds in September on a variety of trees

Oak tussock caterpillar, Halisidota maculata, p. 523

A yellowish, brown-headed caterpillar about $1 \frac{1}{4}$ inches long, clothed with delicate buff yellow hairs and with four light brown dorsal pencils of the same, feeds in the fall on a large variety of trees... Pale tussock caterpillar, Hal is id ot a tes sell a ris, p. 523

A black-headed, yellow or white-tufted caterpillar with a black hair pencil on each side, feeds on most deciduous forest trees

Rusty tussock moth, Notolophus antiqua, p. $52+$

A black-headed caterpillar clothed with grayish hairs and with two black hair pencils on the second segment, and square tufts on segments 5 to 12 , feeds on various deciduous forest trees........... Dark tussock moth, (1) e ne a chat in a, p. 524

Large caterpillars thickly covered with greenish yellow and bearing a pair of long, black hair pencils on the first and third abdominal segments and a single one on the eighth, occurs in September on a variety of trees

American dagger moth, A patela ame rican a, p. 525

A grayish, scarlet-marked caterpillar about $2 \frac{1}{2}$ inches long, remarkable because of the large bordering fringes on each side, occurs in September on oak, ash and apple

American lappet moth, Epicnaptera americana, p. 525

A very large, pea-green, brown-headed, fleshy caterpillar with small reddish brown tubercles with silvered bases, occurs in midsummer on the foliage of a great variety of plants............... American silk worm, Telea poly phemus, p. 526

A stout, apple-green caterpillar about 3 inches long and with six rows of small, pink, hairbearing tubercles, occurs in midsummer on a variety of trees

Luna moth, Tropaea 1 una, P. 526

A bright, tawny or orange-colored caterpillar with a dusky stripe along its back and prominent spines on its thoracic segments, feeds on oak in September

Spiny oak worm, In is ot a stigma, p. 527

Peculiar, brightly colored, variously shaped and usually motionless, sluglike caterpillars occur in midsummer on the foliage of various deciduous trees

Slug caterpillars, p. 527

A peculiar larva about $r$ inch long, thickly covered with long, mouse gray and fawn-colored hairs, occurs on the foliage of various trees in September and October

Crinkled flannel moth, L, a go a crispat a, p. 529 
A slaty brown measuring worm with two pairs of peculiar dorsal filaments, occurs in June on oak, maple and currant............ Filament bearer, A n i l i m b at a, p. $53^{\circ}$

Black-headed, yellowish green caterpillars forming thick web nests on scrub oaks in early

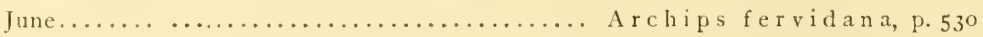

Delicate green, brown-headed caterpillars about $3 / 4$ inch long feed on oak and other trees in early June, August and September

V-marked leaf roller, Archips argyrospila, p. 53r

A small, light green, brown-headed caterpillar feeds in early June on the foliage of a considerable number of trees.... Red-banded leaf roller, Eulia trif erana, p. $53^{2}$ A grass-green larva about $3 / 4$ inch long occurs during July in folded oak leaves

Oak leaf roller, Tortrix que rcifoliana, p. 532

Whitish, blotchlike mines on the upper surface of oak leaves, contain minute footless, brownish and yellow larvae

White-blotch oak leaf miner, Lithocolletes hamadryella, p. $53^{2}$ Similar mines on the under surface and possibly on the upper

Fitch's oak leaf miner, Lithocolletes fitchella, p. 533

Green or brown, sticklike insects sometimes measurng 3 inches in length, occur in forests of deciduous trees in early autumn

Walking stick, Diapheromera femorata, p. 533

Clusters of black, yellow-striped caterpillars about 2 inches long, occur on hickory, walnut and birch.............. Striped hickory caterpillar, Dat an a ang usi i, p. 535

Clusters of black, yellow-necked, yellow-striped caterpillars nearly 2 inches Iong, occur in midsummer on the twigs of a variety of trees

Yellow-necked apple worm, Dat a $n$ a $m$ in ist $r a$, p. 535

Large, flocculent masses on the underside of butternut leaves in midsummer, may conceal a bluish, yellowish white sawfly larva about $3 / 4$ inch long

Butternut woolly worm, Monophadnus c a ry a e, p. 536

Small, roundish, brown and black marked or black beetles about $1 / x^{6}$ inch long, occur on butternut and mountain ash in May.......... T y pophorus canellus, p. 537

A large, pale yellowish green larva striped with darker green, occurs in midsummer on maple trees......... Green-striped maple worm, An isot a rubicanda, p. 537

A drab-colored caterpillar with a large, orange, dorsal spot exposed at the juncture of the first and second abdominal segments when the body bends, feeds on maple, oak, willow and rose......... Semilooper maple worm, $\mathrm{Homoptera} l$ u nata, p. 538

A very large, pale green caterpillar about 4 inches long, ornamented with conspicuous green, blue, yellow and red tubercles, feeds on the foliage of a large number of trees and shrubs............................. Cecropia moth, Samia cecropia, p. 539 
A large, slender bodied spanworm about $13 / 4$ inches long and marked with dark purple brown and reddish markings, occur! on maples in July

Large maple spanworm, S abulodes transversata, p. 539

Small caterpillars boring maple or buckeyc leaf petioles cause the foliage tc drop in early summer.............. Maple leaf stalk borer, E pin ot i a clay poleana, p. $54^{\circ}$

Maple leaves with irregular, oval holes $\mathrm{t} / \mathrm{so}$ to $4 / \mathrm{xo}$ inch in diameter may have been injured by this species....... Maple leaf cutter, Incurvaria acerifoliella, p. $5+$ r

Yellowish, black-spotted, caterpillarlike larvae nearly $3 / 4$ inch long, feed on the foliage of American elms in August................ Hy lotoma scapularis, p. $54^{2}$

A brilliant, bottle-green, oval beetle $1 / 8$ inch long, with silvery white, green-marked wingcovers, feeds on the leaves of elm, linden, willow and alder

Alder leaf beetle, Chrysomela scalaris, p. 542

A small, long-snouted weevil about $3 / x 6$ inch long, with strongly ridged elytra and prettily marked with dark brown, yellowish white and reddish brown, occurs on elm

Conotrachelus anaglypticus, P. 544

A red-headed, black-spined caterpillar about $\mathrm{I}$ inch long, feeds on elm foliage

Violet tip, Polygonia interrogationis, p. 544

A yellowish, spiny, black-marked caterpillar about $\mathrm{I}$ inch long, feeds on elm

Hop merchant, Polygonia comma, p. $5+5$

A brown-headed, yellowish brown, spiny caterpillar about 1 inch long, feeds on elm

Gray comma, Polygonia progne, p. $54^{6}$

A stout, pale green or reddish brown larva about 3 inches long, with a conspicuous caudal horn and four large, tubercular elevations on the thoracic segments, occurs in early September on elm, beech, linden and probably ash

Four-lined sphinx, Cerat om i a am y n tor, p. $5+6$

Dark striped measuring worms about $\mathrm{I}$ inch long, defoliate apple and elm trees in early spring.................. Spring cankerworm, Pa le a crita vernata, p. 547

A stout, apple-green caterpillar 3 inches long, with seren oblique stripes on each side and a light blue caudal horn, feeds on the leaves of ash, lilac and mountain laurel

Ash sphinx, Sphinx kalmiae, p. 548

A variable, light green caterpillar about $\mathrm{I} 3 / 4$ inches long, with reddish legs and caudal horn and a series of seven oblique white stripes on each side of the body, feeds on the foliage of white and black ash, lilac and privet

Wary ash sphinx, Cerat omia undulosa, p. $54^{8}$

A pretty, yellowish or whitish, long-haired caterpillar about $\mathrm{I}^{1 / 2}$ inches long, with three dark hair pencils arising on the median line, occurs in midsummer on various foodplants ................................... 
Black-headed, yellowish green, black-spotted, false caterpillars nearly $3 / 4$ inch long, feed in August on chokecherry foliage.............. H y lotoma macle a y i, p. 549

A small, red leaf beetle about ${ }^{\prime}{ }_{5}$ inch long, eats in midsummer irregular, round holes in the leaves of wild cherrytrees

Cherry leaf beetle, Galerucella cavicollis, P. $55^{\circ}$

Web tents in the forks of wild cherry and apple trees in early spring

Ipple tent caterpillar, II a lacosoma ame ricana, p. $55^{\circ}$

Brown, webbed-together leaves occur on wild cherry shoots in July and August

Cherry scallop shell moth, Hydria undulat a, p. 55 I

Yellow, llack-headed caterpillars about iz inch long, web together chokecherry leaves in midsummer......... Ugly nest cherry worm, Archips cerasivorana, p. $55^{2}$

A greenish solitary sawfly larva resting on its venter on the underside of shadbush leaves

Pteronus thoracicus, p. 553

A large, brownish caterpillar with conspicuous angular, cream-colored markings on its middle and at its posterior extremity, is sometimes abundant on prickly ash

Orange dog, Papilio thoas, p. 554

A small leaf miner works in sourgum leaves the latter part of August and early September, cutting oval cases therefrom the latter part of that month

Sour gum case cutter, Antispila nyssaefoliella, p. 555

A red-headed, blue flea beetle about $1 / 8$ inch long, is sometimes abundant on locust and apple foliage.......... Red-footed flea beetle, Crepidodera rufipes, p. $55^{6}$

Large, pale green caterpillars about 2 inches long, with a red neck and large, red head and yellow spot on each side of the mouth, draw the leaves of locust together and feed ly night............... Locust leaf folder, E pargyreus tity rus, p. $55^{6}$

A large, delicate, bluish white caterpillar with four large, yellow or red tubercles on the posterior thoracic segment and a large one on the dorsum of the eighth abdominal segment, feeds on the foliage of lilac and a number of trees and plants

Promethea moth, Callosamia promethea, p. 557

A whitish, green-tinted sawfly larva on willow, white and yellow birch, belongs to this species.......................... Pristiphora sycophanta, p. 557

A pale brown, black-spotted beetle about $1 / 4$ inch long, is occasionally destructive to willow and poplar........... Poplar leaf beetle, Phy todecta pallida, p. $55^{8}$

A somewhat tuberculate, angular, reddish brown, yellowish marked caterpillar about I inch long, feeds singly on willow and poplar

Viceroy, Basilarchia archippus, p. 559

A peculiar, light green, brown-marked caterpillar with a pair of long, slender, annulated caudal appendages, occurs on willows and poplars.... Har p y i a cinerea, p. 559 
A black-headed, velvety black caterpillaz, usually with a conspicuous somewhat broken subdorsal yellow stripe and another along the stigmatal line, occurs in the fall on poplar, willow and other trees and shrubs

Smeared dagger moth, Ipatela oblinita, p. 560

A black, yellow-striped larva about $1 / \frac{1}{4}$ inches long, feeds in the folded, welbed-together leaves of poplars and willows... Poplar tent maker, M elalopha inclusa, p. $5^{60}$ A yellowish sawfly larva occurs on willow........... Pteronus mendicus, p. $5^{6}$ I A black-headed, light green sawfy larva on willow..... Pteronus odoratus, p. $5^{62}$ A striped, rather stout, blitch and yellow beetle about $1 / 4$ inch long, occurs in June on willow

Willow flea beetle, D is on y cha caroliniana, p. $5^{6} 3$ A reddish, black-spotted beetle about It inch long, feeds during the summer on willow leaves............ Spotted willow leaf beetle, Me lasoma lapponica, p. $5^{6} 4$

A yellowish, black-marked, hemispheric beetle $I / 4$ inch long, feeds the latter part of the summer on willows and hard pine.......... Chry somela bigs b y an a, p. $5^{66}$ A dull red leaf beetle about $1 / 4$ inch long, feeds on willow

Dull red willow leaf beetle, Gale rucella decora, p. 566 A small, brownish, long-snouted beetle thickly clothed with golden and brownish pubescence, occurs in considerable numbers on willow in early spring

Elleschus ephippiatus, p. $5^{67}$

Orange-yellow, black-spotted larvae about $7 /$ ro inch long, feed side by side on the foliage of poplars in early June... Poplar sawfly, Triehiocam pus viminalis, p. 568

Black-headed, bluish or leaf-green sawflies feed on the edge of poplar leaves

Pteronus hudsonii, p. 569

A greenish, solitary edge-feeding sawfly on peplar.. Pteron us vertebratus, p. $57^{\circ}$ Yellowish, black-spotted saw fly larvae feed during August and September on birches

IH ylotoma pectoralis, p. 570

A brown-headed, greenish solitary sawfy larva feeds on the underside of birch leaves

$$
\text { Nematus unicolor, p. } 57 \text { r }
$$

Brown-headed, purplish solitary or partly gregarious saw fly larvae occur on white birch

l'teronus latifasciatus, p. $57^{2}$

A black-headed, greenish sawfly larva feeding gregariously on the edges of alder leaves

Ama uronematus 1 uteotergum, p. $57^{2}$

Deep prussian blue, rounded flea beetles about ' 5 inch long, or dark brown, black-headed, black-tubercled larvae oceur in large numbers on alder

Alder flea beetle, $\mathrm{H}$ altic a bima rginat a, p. 573

Peculiar, thimblelike rolls of leaves on alder, hazel and sumac may be the work of this

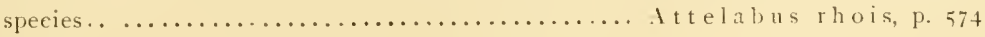


Reddish, black-ringed caterpillars about $\mathrm{x} 1 / 2$ inches long, feed from June to August on Virginia creeper and grape.. Eight-spotted forester, Alypia octom a culat a, p. 575 Sprawly, yellowish green beetles about $3 / 8$ inch long, swarm on rosebushes and the foliage of trees and shrubs ..... Rose beetle, Macrodactylus subspinosus, p. 575 Greenish, black-headed caterpillars about I/z inch long, bore in the buds or web together leaves of roses........... Rose bud worm, Olethreutes nimbat ana, p. 576 Yellow-headed, dark green larvae tying rose leaves together

Rose leaf tier, Olet hreutes cyanana, P. 577

Yellowish green, brown-headed caterpillars $1 / 2$ inch long occur on oak and rose

Cenopis pettitana, p. 579 Cenopis reticulatana, p. 580

Brown headed, greenish caterpiliars about $3 / 4$ inch long, live in the webbed leaves of roses and those of a large number of trees

Oblique banded leaf roller, A rchips $\mathrm{r}$ os a ce a n a, p. 580 Rose leaf folder, Archips rosana, p. $58 \mathrm{r}$

\section{Insects affecting fruit of deciduous forest trees}

A curculio much resembling the plum pest, though larger, $1 / 4$ inch long, frequently infests walnuts and butternuts... Walnut curculio, Conotrachelus juglandis, p. $5^{81}$

Conotrachelus seniculus, p. $5^{82}$

A slender, white caterpillar about $3 / 8$ inch long, mines hickory shucks, causing them to abort and fall prematurely...... Hickory shuck worm, Enarmonia caryana, p. 583

A weevil with a remarkably long, slender, curved beak, occurs on acorns or may be bred from white, legless grubs within them or other nuts

Acorn weevil, Balaninus nasicus, p. $5^{8} 3$

A similar weevil and legless grubs occur in chestnuts

Chestnut weevils Balaninus proboscideus and B. rectus, p. 585

Frequenters, usually injurious, of deciduous forest trees ........... p. 588

Frequenters, usually beneficial, of deciduous forest trees............. p. 603

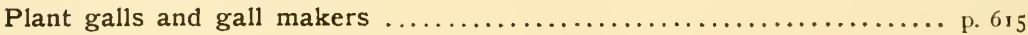

\section{Brachys aerosa Melsh.}

A triangular, flattened, metallic colored beetle about $3 / 16$ inch in lẹgth, occurs on oak and elm leaves in midsummer.

A number of examples of this species were taken on elm May 20, I903, at Poughkeepsie N. Y., where they were eating irregular, oval holes near the edges of the leaves. 
Description. This beetle is about $3 / 16$ inch in length, subtriangular in outline, metallic in color, the head and thorax being golden, the basal portion of the wing covers greenish and purple and their tips reddish and yellow.

The larva has been described by Professor Gillette as "whitish, $9 \mathrm{~mm}$ long, flattened, segments deeply notched; head widest and body gradually tapering to the tail. The mandibles are brown and the prothoracic segment has brown, rectangular plates above and below. The anal extremity is provided with a small spine extending behind, which is used by the larva in progression."

Life history and habits. The adults, as stated above, feed on elm leaves, and according to Professor Gillette, probably on oak also. He states that in October I 886, while collecting leaf miners, he obtained larvae of two of these beetles from poplar, from which adults were bred later. Dr Packard states that he has found this small buprestid on the leaves of oak early in summer in Maine, and late in May near Providence, and adds that the larva probably mines the foliage.

Distribution. This species is probably generally distributed in the northeastern United States at least, since it has been recorded from the vicinity of Buffalo N. Y., from southwestern Pennsylvania and the District of Columbia, and is not rare on oak throughout New Jersey.

\section{Brachys ovata $1 \mathrm{~V}$ eber}

A small, triangular, metallic colored beetle about $3 / i^{6}$ inch in length, may be found abundantly on scrub oak foliage in May and June.

This species was very numerous on scrub oaks at Karner during the latter part of May and June 1901. The beetles rested quietiy on the leaves or ate irregular holes through the tissues and when startled, flew readily.

Description. This small, flattened buprestid is subtriangular in outline, metallic green or olive in color and ornamented with sparse gray and fulvous pubescence. The elytra have a stout, sublateral ridge, and there may be one or two more or less rudimentary ones between it and the suture. 
Life history and habits. The beetles are abroad, as previously stated, during May and June, and according to Professors Gillette and Hubbard,

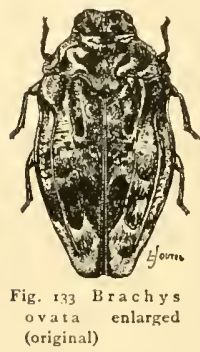
the grub is a miner of oak leaves. Mr Hubbard states that the beetle occasionally eats small holes in orange leaves, and leaves us to infer that the larvae are found only in oak foliage.

Distribution. This species has been recorded by $\mathrm{Dr}$ LeConte from the Middle, Southern and WVestern States, and local lists show that it is presumably generally present in various sections, since Dr Smith states that it is common throughout the State on oak, and adds that the variety, tessellata Fabr. occurs on pine. It has been recorded from the vicinity of Buffalo N. Y. and Cincinnati O., and listed by Ulke from the District of Columbia, and Dr Hamilton states that it is common on oak in southwestern Pennsylvania.

\section{Serica trociformis Burm.}

This is a small, stout brown and black beetle a trifle less than $1 / 4$ inch long. It may be recognized by its black head, very dark thorax, and brick-red, rather deeply striated wing covers, and by its stout, somewhat rotund shape, so characteristic of the allied June beetles.

This species was somewhat common on the scrub oaks at Karner in June Igor, and much more so the following May and June, when it was exceedingly abundant and large numbers could be captured with very little effort. A few were also taken on poplar, evidently an accidental occurrence. The insects eat small, irregular holes in the foliage, and fly readily from one leaf to another. One of the beetles was observed in the grasp of a large robber fly, though the specific identity of the latter could not be determined.

This species occurs in a number of localities in New Jersey, according to Dr Smith. Prof. W. E. Britton found it abundant on young hornbeam trees, C a r p in us carolinian a, at Westville Ct., May 30,1898 . They were so numerous that the foliage was completely riddled in some cases. 


\section{Black-margined flea beetle \\ Systena marginalis Ill.}

A yellowish brown, black-margined flea beetle about $3 / 16$ inch long, feeds in summer and autumn on oak, hickory and birch.

This little species appears to be a somewhat general feeder and occasionally it occurs in great numbers. It may be recognized by its yellowish brown color in connection with the narrow, black margin on the prothorax and wing covers. The eyes are rather prominent, finely granulate; the head smooth, and the prothorax closely and shallowly punctured. The wing covers are ornamented with irregular, small, rather deep punctures. This species occurs about Albany and has been taken in Ontario by Mr Harrington, who found it abundant on oak, eln and other trees in midsummer and also ôn sweet hickory. It has been recorded by Dr Smith from New Jersey, who states that it is sometimes numerous on oaks. It has also been listed from the vicinity of Washington.

\section{Tymnes tricolor Fabr.}

This small, shining leaf beetle about $1 / 4$ inch in length, has a dark brown or nearly black head and prothorax and reddish brown wing covers, which are slightly and irregularly punctured.

A single example of this species was taken July 8 , 1901 on scrub oak at Karner. It has been recorded by Dr Smith as local throughout New Jersey, where it occurs on chestnut, hickory and other plants.

\section{Aphrastus taeniatus Gyll.}

This slaty gray-brown, striped weevil, about $1 / 4$ inch in length, was taken in small numbers on scrub oak at Karner, one specimen being captured July 27 , 1901. Its distribution has been given by Dr Horn as the Middle and Southern States and Dr J. B. Smith

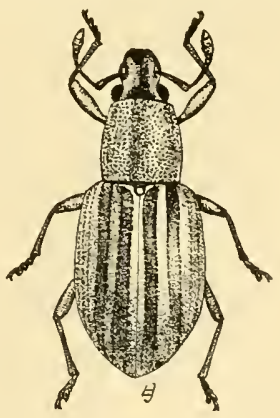
Fig. r74 A phrastus taenia t 1 s, enlarged (original) records it as occurring throughout New Jersey on pawpaw, hazel and other bushes in July. 
Two spotted curculio

Attelabus bipustulatus Fabr.

Portions of the terminal lobes of oak leaves rolled into neat, cylindric cases containing an egg, may be the work of this species.

The peculiar rolled, usually cylindric cases of this species are occasionally met with in early spring on oaks of various species, it having been recorded on the red, post and laurel oak. The work of this beetle has been observed, though it is not abundant in the vicinity of Albany. The insect has been listed from New Jersey, District of Columbia and also from the vicinity of Cincinnati $O$. Dr Packard has recorded this species from near Providence R. I.

Description. Lara. Average dorsal length, .22 inch; diameter on abdominal segments, .o6 inch, tapering anteriorly from fourth segment. Yellowish white; thoracic segments slightly depressed on the back and smaller beneath; abdominal segments convex above and flat beneath, each one divided into three irregular shallow transverse folds, lateral surfaces with a double row of smooth polished oval tubercles, most symmetric in form and position from segments 4 to 11 inclusive; above the tubercles on each segment is a deep depression. Head horizontal, rounded, small, about half the diameter of segment next behind, into which it retreats; white, the mandibles and other mouth parts reddish brown, surrounded by long hairs.

The pupa is cream white, . I 2 inch long; abdominal segments sharply ridged; posterior extremity terminates in a pair of bristly points, white, tipped with brown. Murtfeldt

The egg has been described by Riley as almost globular, slightly ovoid, tender, pale yellowish and translucent. It is deposited near the tip on the underside of the leaf, which is then cut transversely near its middle, punctured a short distance each side of the midrib, which causes it to fold with its lower side out, then curled round and the outer edges tucked in.

The beetle is about $3 / 16$ inch long, rather stout, highly polished, black, with two large orange-red spots at the base of the wings.

Life history and habits. This beetle has the curious habit of rolling up a leaf, trimming and tucking in the lower ends with her beak. The egg is first deposited near the tip of the leaf, and a little to one side; the blade of the leaf is then cut through on both sides of the midrib, about $1 \frac{1}{2}$ inches 
below ; a row of punctures is made on each side of the midrib of the severed portion, which facilitates folding the leaf together, upper surface inside, after which the folded leaf is tightly rolled up from the apex to the transverse cut, bringing the egg in the center; the concluding operation is the tucking in and trimming off the irregularities of the ends. A few days after completion, the cases, first observed the latter part of April, dropped to the ground; by May i 5 several larvae hatched and fed on the dry substance of their nest, and by the end of May they pupated within the nest; this state lasted from five to seven days, the first beetles issuing by June 2, while a second brood of larvae may be found early in July. The above is based largely on Dr Packard's account.

\section{New York weevil Ithycerus noveboracensis Forst.}

A large, grayish weevil about $3 / 2$ inch tong, occurs on the buds of a variety of trees from Niay to July.

This giant weevil is of interest on account of its large size, it not being exceeded in dimensions by any of our native species.

Description. The head is prolonged into a short, rather stout, slightly tricarinate beak tipped with a pair of large jaws, eyes reddish. The head and prothorax are coarsely punctured and rather thickly clothed with a yellowish and white pubescence. The wing corers are deeply striate and are also rather thickly clothed with a yellowish and whitish pubescence and each bears a series of about 10 rather inconspicuous circular brown spots.

Life history and habits. This large weevil has been recorded on the twigs of oak, hickory and a variety of fruit and forest trees. Mr Harrington considers beech as a favorite food plant for both larvae and beetles. He has met with weevils in early June and two or three days later failed to find any specimens on the same tree, concluding therefrom that the beetles were abroad during a very limited time. We have taken specimens in New York July I9, and as they also occur in May and June, this would seem to indicate that adults might be abroad during an extended 
period. The beetles eat the buds and gnaw into the twigs chiefly at the base, thus causing them to break and fall. They also feed on the younger bark of twigs, eating numerous holes into it, the tender shoots being entirely devoured, and later they may feed on the base of leaves. It is a nocturnal species and consequently escapes observation to a large extent. The larvae are found in the twigs and tender branches of oak and hickory, and according to Saunders, the female makes a longitudinal excavation with her jaws for the reception of the eggs. The larva is a soft, footless, pale yellow grub with a tawny head.

Agrilus otiosus Say has been taken from ash, oak and butternut foliage.

Anthaxia quercata Fabr, was taken on leaves of scrub oak at Karner July 23, 1902 .

Cistela sericea Say occurs on basswood the latter part of June on oak and also on pine.

Glyptoscelis barbata Say was taken on hickory and oak at Poughkeepsie in May and June I903.

Rhynchites bicolor Fabr. is common on scrub oak at Karner.

\section{Walnut sphinx}

\section{Cressonia juglandis Abb. \& Sm.}

A stout, light apple-green caterpillar with a prominent horn at its posterior extremity, and ornamented with seven oblique white stripes on each side, feeds on the leaves of hickory, black walnut, ironwood and has been reported as occurring on wild cherry.

The parent insect is a modestly colored, yellowish brown hawk moth having a wing spread of about $2 \mathrm{r} / 2$ inches. The fore wings bear a nearly straight, oblique, light brown line at the basal third, and near the outer edge there are three slightly undulating, light brown lines. These latter markings are slightly more developed on the posterior wings. The young larva is yellowish green. The head is truncate in front, conic, the apex of the cone bearing two rough, brownish projections. There is a yellowish strip on each side of the head and the lateral streaks on the body are very indistinct. The caudal horn is rough, pinkish at the base and has black points on the surface. The full grown larva tapers from the seventh 
segment toward the extremities, is light apple-green, granulated with white and with seven oblique stripes on each side, formed by the whitish granulations which are more numerous there than elsewhere. The caudal horn is $1 / 5$ inch long, brownish, and covered with black spinules. The head is quite pointed and bifid at the top.

\section{Red-humped oak caterpillar}

Symmerista albifrons Abb. \& $\mathrm{Sm}$.

A red-headed, striped caterpillar with a conspicuous red hump on the eighth abdominal segment, feeds on oak in midsummer.

This is a rather common species on oak, and in its early stages at least, is easily recognized by its very large, swollen red head in conjunction with the conspicuous reddish enlargement on the eighth abdominal segment. Ordinarily these caterpillars are not very abundant, though there are records of considerable areas being defoliated by voracious hosts belonging to this species. Dr James Fletcher records serious injury to both oaks and maples at Ottawa Can. in I884.

Description. The larva has a large, orange-red, swollen head distinctly raised toward the apex. It is wider than the thoracic segments and the body increases gradually in width back to the red enlargement of the eighth abdominal segment. The body is smooth, shining, with no hairs and ornamented with a pair of subdorsal yellow lines inclosing five median black lines on a pale lilac ground. There are three black lines below the yellow line and a second yellow line below the spiracles. Anal legs pale orange-red, true legs pale orange. Length when full grown about $\mathrm{I} / 2$ inches.

The moth has a wing expanse of about $23 / 4$ inches and is easily recognized by its whitish ash color, the square apex of the fore wings and the broad white costal margin on the outer two thirds of the same.

Life history. The pale green, subglobose eggs are laid in small masses on the underside of the leaves, and the young caterpillars, at first gregarious, scatter over the tree after the first or second molt. The larvae are common on white oaks in August and through September, attaining full 
growth early in October and pupating within a thin cocoon between the leaves, the moths appearing the following June.

Food plants. This species displays a marked preference for oak. It is also injurious to maple, as stated by Dr Fletcher, and Dr Packard has observed it at Brunswick Me. on beech. It is widely distributed, ranging from Georgia and Texas north into Canada and westward to at least Minnesota.

\section{Rosy hyparpax}

\section{Hyparpax aurora Abb. \& Sm.}

A greenish caterpillar about $\mathrm{I} / \frac{1}{2}$ inches long, with a red head and conspicuons pointed elevations on the first and eighth abdominal segments and variable brown and yellowish or pinkish dorsal markings, occurs on different species of oak during midsummer.

This, one of our most striking caterpillars, is rarely abundant. It may be recognized by its very peculiar angulate appearance, due to the unusual elevations on the first and eighth abdominal segments and to the slender anal prolegs, which are produced posteriorly. The strange effect is further hightened by the caterpillar's habit of carrying its posterior extremity in an elevated position. The young larvae are variably marked with yellow, yellowish orange and lilac or purple, and in the earlier stages the angular projections are comparatively much greater than in the full grown larva.

Description. The parent insect is a pretty yellowish, rosy marked moth having a wing expanse of about one inch. The yellowish forewings are marked with pink as follows: an angulate line near the base of the wings, a short, oblique one near the middle, a wavy, subterminal one and the outer edge of the wings. The hind wings are either unspotted or with a pink line along the edge.

The color scheme of the nearly full grown larva has been given by Dr Packard as follows :

The body is now a deep delicate pea-green, with a large reddish brown triangular patch extending from the prothoracic segment next to the head and ending at the anterior base of the tubercles on the first abdominal segment. Behind the said tubercles a broad reddish brown patch extends to the large tubercles on the eighth segment, the band being edged with whitish yellow; from the rear of the tubercle a similarly colored band extends 
to the end of the suranal plate. The underside of the body in front and the middle abdominal legs are brownish.

\section{Green oak caterpillar \\ Nadata gibbosa Abb. \& Sm.}

A pale greenish caterpillar about $1 / 2$ inch long, with a more or less distinct yellowish lateral line, occurs on oaks and various other trees in midsummer.

This leaf feeder is rather common though rarely abundant. The larva is a pale green form not easily separable from several species having similar habits.

Description. The full grown larva has been described by Dr Packard as follows :

Body green, large; head very large, full, rounded, high toward the vertex, as wide as the body, deep pea-green; the labrum whitish green; mandibles bright yellow, tipped with black, making them very conspicuous. Body glaucous pea-green, thick, full, soft, tapering toward the end, and the surface with minute, raised, flattened more or less confluent granulations. A lateral yellow line formed of yellow, raised, flattened areas. Spiracles deep red. Supra-anal plate conical, flattened, apex much rounded, the edge colored bright yellow. The thoracic and abdominal feet pale pea-green; all concolorous. Length $33 \mathrm{~mm}$, thickness $6 \mathrm{~mm}$.

The moth is a light buff color and has a wing spread of a little over 2 inches. Near the basal third there is a dark brown, slightly curved line and an ob!ique one of the same color at the apical third, which latter is margined outwardly by pale yellow. Outer edge of wing with minute whitish scallops.

This species has been recorded on oak, maple, white birch and sugar plum. It has a wide range, extending from Maine and Canada to Oregon and California, southward to the Atlantic and Gulf coasts.

\section{Io caterpillar}

\section{Automeris io Fabr.}

A large, greenish, stout caterpillar with fascicles of irritating, sharp spines over the body, feeds in late summer on the foliage of a number of trees.

This caterpillar with its light green body and delicate markings of yellowish red, is a beautiful creature. When full grown it is about 2 inches 
long, light pea-green in color, with a magenta stigmatal band bordered below with creamy white. The body is clothed with spreading, blacktipped, delicate green spines. The moth has a wing spread of $2 \mathrm{I} / 2-3 \mathrm{t} / 2$ inches and is easily recognized by the conspicuous purple-centered eye spots on the hind wings [pl. 43, fig. I, 2]. The gregarious habit of this species makes its depredations more noticeable, though it is a very general feeder. It has been recorded by various writers on oak, elm, locust, maple, cherry, ash, beech, poplar, birch, black alder, sassafras and other trees and some herbaceous plants.

\section{Definite marked tussock moth Hemerocampa definita Pack.}

A yellow-headed, light yellowish, tufted caterpillar closely resembling that of the white marked tussock moth, feeds on oak and a number of other trees.

This species is much rarer in New York State than the more common white marked tussock moth, H emerocampa leucostigma Abb. \& Sm., and the larva can be best separated therefrom by its yellowish head. It possesses about the same habits as its ally, and while Dr Thaxter gives oak as its food plant, Dr Dyar states that in practice he has found this caterpillar as omnivorous as its more common, closely related ally. The full grown caterpillar has been described by Dr Dyar as follows:

Male (6th stage). Head pale yellow, shiny, the labrum and antennae white; width $2.8 \mathrm{~mm}$. Body pale yellow, a pale, almost colorless, dorsal band, replaced on joint two by the pale yellow cervical shield containing two darker yellow warts, narrow and greenish on joints three and four, widening and enclosing the yellow dorsal brushlike tufts on joints five to eight, narrowed on joints nine to $\mathrm{I} 2$ enclosing the concolorous retractile tubercles, and absent on joint I3. A narrow, subdorsal and fainter stigmatal, similarly colored line. These bands are in some specimens more or less blackish, or black, blue gray, or dark brown, and there is a velvety black spot between the dorsal tufts on joints six, seven and eight. The warts are all pale yellow; the pencils on joint two are long, plumed, black; that on joint I 2 of light brown hair with a few long black plumed ones on its posterior side. The other hair is long, thin and white.

Fcmale ( $;$ th stage). Head pale yellow minutely mottled with grayish spots; labrum, antennae and a spot before the eyes, white; ocelli and jaws 
black; width $3.5 \mathrm{~mm}$. The body is as in the previous stage, but the warts on the cervical shield are not distinctly darker. The dorsal blackish or pale gray shade is in triplicate on joints three and four. Spiracles white in a fine black border. The body is often bright yellow, as are the dorsal tufts, and even the hair is yellowish.

\section{Oak tussock caterpillar}

Halisidota maculata Harr.

A black-headed caterpillar about I I// inches long, thickly clothed with yellowish hairs and black $t$ ufts of the same, feeds in September on a variety of trees.

The larva of this species has a decided preference for oak, though it has also been recorded as feeding on poplar, willow and alder. It may be recognized by its black head in conjunction with the thick covering of tufts of bright yellow and black hairs. The two posterior thoracic segments and the first abdominal segment are covered with mixed yellow and black hairs, those of the former overhanging the head. The first to eighth abdominal seginents inclusive, bear a dorsal black tuft, the largest being on the seventh and eighth. There is also a black tuft on each side near the base of the first and eighth abdominal segments. The hairs of the second to seventh segments are bright yellow, while those on the ninth and tenth are mixed with black. The parent insect has pale yellowish wings mottled with dark brown, the hind wings being pale straw yellow.

\section{Pale tussock caterpillar}

\section{Halisidota tessellaris Hübn.}

A yellowish, brown-headed caterpillar about $1 / 4$ inches long, clothed with delicate buff yellow hairs and with four light brown dorsal pencils of the same, feeds in the fall on a large variety of trees.

The larva of this species is a very general feeder, it having been recorded on about 30 trees and shrubs, representing ro natural orders. It can hardly be considered a dangerous species, though exceptional conditions might enable it to multiply to an unprecedented extent. The larva has been described by Riley as follows :

The hairs delicate buff yellow; four dorsal pencils in front, of light 
sienna brown, with two pairs of shorter lateral white tufts; a pair of whitish tufts near the end of the body; head yellowish brown; a row of lateral black spots above the base of the abdominal legs; length $30 \mathrm{~mm}$.

The adult is a very pale yellowish brown moth [pl. 44, fig. 4].

\section{Rusty tussock moth \\ Notolophus antiqua Linn.}

A black-headed, yellow or white-tufted caterpillar with a lateral black hair pencil on each side, feeds on most deciduous forest trees.

This hair-tufted caterpillar resembles the much better known and very destructive larva of the white marked tussock moth, Hemerocampa leucostigma Abb. \& Sm., and may be separated therefrom at once by its black head and from other allied forms by the presence of the lateral black hair pencil about midway of the body. This species has been received on several occasions from northern parts of the State, where it seems to be slightly more abundant than farther south. We have yet to learn of its causing serious injury. Dr Lintner records taking this species on low willows at Keene Valley N. Y.

\section{Dark tussock moth Olene achatina Abb. \& $\mathrm{Sm}$.}

A black-headed caterpillar clothed with grayish hairs and with two black hair pencils on the second segment, and square tufts on segments five to i 2 , feeds on various deciduous forest trees.

This species is allied to the rusty tussock moth, Notolophus a n tiqua linn. and has somewhat similar habits. It has been recorded as feeding on oak, hickory and wild cherry, while Dr Smith states that in New Jersey its larva occurs on the usual orchard trees and also oak, hickory and chestnut. 


\section{American dagger moth}

\section{Apatela americana Harr.}

Large caterpillars thickly covered with yellowish hairs and bearing a pair of long black hair pencils on the first and third abdominal segments and a single one on the eighth, occur in September on a variety of trees.

This is one of our rather common caterpillars. It is a quite general feeder, having been recorded as living on maple, elm, chestnut, linden, oak, hickory, ash, sycamore, poplar, birch and alder.

The full grown larva is about $2 \mathrm{I} / 2$ inches long, thickly covered with short pale yellow hairs and bears a pair of long black hair pencils on the first and third abdominal segments and a single one on the eighth. The head is black, the body greenish white above with a subdorsal and stigmatal black line, venter black.

American lappet moth

\section{Epicnaptera americana Harr.}

A Igrayish, scarlet-marked caterpillar about $21 / 2$ inches long, remarkable because of the large bordering fringes on each side, occurs in September on oak, ash and apple.

This caterpillar is peculiar on account of the prominent depressed lappetlike fringes on each side which, when the larva is at rest, touch the bark and harmonize therewith so closely that the insect usually escapes detection. This species is never abundant enough to cause injury. The larva has been described by Harris as follows :

Body large, broad, and flat, with hairs on the side spreading out so as nearly to conceal the feet, the hairs arising from large lappets hanging from the side of each segment, the first pair the largest; upper side of the body gray, variegated with irregular white spots and sprinkled with fine, black dots; in front are two transverse velvetlike bands of a rich scarlet color, with three black dots on each band; underside of the body orange-colored with a row of diamond-shaped black spots; length $2 \mathrm{I} / 2$ inches. 


\section{American silk worm}

Telea polyphemus Hübn.

A very large, pea-green, brown-headed, fleshy caterpillar with small, reddish brown tubercles with silvered bases, occurs in midsummer on the foliage of a great variety of plants.

This, one of the largest of our native caterpillars, is frequently known as the American silk worm on account of its dense silken cocoon, and various attempts have been made to use the silk in a commercial way. It, like other large forms, is not abundant as a rule, and only under exceptional conditions does it become destructive. The nearly full grown caterpillar is a beautiful object with its reddish brown tubercles silvered at the base and ornamented at the tip with white hairs. These present a striking contrast to the delicate pea-green color of the body. The head is a dull brick-red and the anal plate is margined with maroon. The spiracles or breathing pores are a delicate salmon color and the thoracic shield may be bordered anteriorly with yellowish green.

The adult is a dull ocher yellow moth with its wings, shaded with innumerable black particles, extending $5 \frac{\mathrm{I} / 2}{2}$ inches from tip to tip. The larva may be found on a considerable number of food plants, it having been recorded by various writers on oaks, hickories, black walnut, chestnut, elms, maples, poplars, willows, birches, witch-hazel, linden, and a number of other plants. It is never abundant enough so that repressive measures are necessary to prevent serious injury. The moth is illustrated on plate 42 , figure I.

\section{Luna moth}

\section{Tropea luna Linn.}

A stout, apple-green caterpillar about 3 inches long, with six rows of small, pink, hair-bearing tubercles, occurs in midsummer on a variety of trees.

This giant caterpillar is never present in numbers sufficient to cause material injury, yet the large size and exquisite beauty of the adult makes it an object of general interest. The larva is a general feeder, having been recorded on walnut, hickory, oak, butternut, chestnut, sweet gum, 
birch, willow, beech, plum and ironwood. The full grown caterpillar is pale green shading into darker yellow, with yellow spiracles. There are six rows of small, pink tubercles, each with one or more black hairs and a few white hairs, some clavate, are scattered over the body. The anal shield is brown, triangular, yellow-bordered and the anal plates are brown bordered anteriorly with yellow.

The adult, a magnificent light green, long-tailed moth with a wing spread of about 4 inches, may be instantly recognized by reference to plate 41 , figure 2.

\section{Spiny oak worm \\ Anisota stigma Hübn.}

A bright, tawny or orange-colored caterpillar with a dusky stripe along its back and prominent spines on its thoracic segments, feeds on oak in September.

This species is a rare one in the Northern States, though in the South it is frequently as destructive as our more common orange-striped oak worm, A. sen atoria Hübn., to which it is closely related in structure and food habits.

\section{Slug caterpillars}

Peculiar, brightly colored, variously shaped and usually motionless sluglike caterpillars occur in midsummer on the foliage of various deciduous trees.

This group comprises a number of very interesting caterpillars remarkable because of the apparent absence of legs and on account of their brilliant color in connection with a more or less well developed defensive armor. These species vary widely in appearance, occur on a large number of trees and shrubs and are very rarely abundant enough to be regarded as anything more than natural curiosities. Some of these remarkable forms sting severely and occasionally call attention to themselves in a very unpleasant manner. It has been questioned some whether the sting is more than a mechanical one due to the insertion in the flesh of multibarbed spines, and in some instances, particularly with slug caterpillars, it would appear as if such might be the case. Glands at the base of the spine have been detected by European investigators who state that the hollow spines may be filled with formic acid or a formate in solution. Still, careful investiga- 
tions of the urticating spines on the brown tail moth larva, Euproct is chrysorrhoea Linn. failed to detect a poison. A number of these peculiar larvae are oval in shape, with the flattened surface closely appressed to the leaf, griving them the appearance of brightly colored, very large scale insects or slugs. The general appearance is not at all suggestive of their natural affinities. A few representative forms are noticed briefly.

The hag moth caterpillar, Phobetron pithecium Abb. \& Sm., is a brownish, sluglike caterpillar about $3 / 4$ inch long and with from a few to 10 long, plumelike processes extending from either side of the back. It occurs from July till September on the foliage of a number of trees and occasionally is somewhat abundant. Specimens were sent the writer in August I902 with a statement that it was so numerous at IVestwood N. Y. as to destroy the leaves of several large maple branches. This larva is supposed to sting severely, yet Miss Emily L. Morton has handled dozens of them and states that she has met with no injury therefrom. This slug caterpillar occurs on various low shrubs and the lower branches of trees, having been recorded on various oaks, chestnut, ash, apple, cherry, plum, sugar maple, sassafras, witch-hazel and dogwood.

The saddleback caterpillar, Sibine stimulea Clem., is another common slug caterpillar and a very striking species. It is a brownish caterpillar about I inch long, apparently with a green saddlecloth on its back and a brownish saddle, the latter margined with white and edged with a black line. Both the anterior and posterior extremities are adorned with long, brown, spined tubercles. This striking larva is capable of inflicting a very severe sting. It occurs commonly on oak and cherry:

Another striking species, Euclea indetermin a Boisd., is about $5 / 8$ to $3 / 4$ inch long when full grown, oval in shape, with a series of six fiery red lines along the back on either side. It is banded with red, lined with black and with pale yellow and white markings. This larva feeds on various low bushes and limbs of trees, having been recorded from wild cherry, oak, hickory and bayberry.

Another type of slug caterpillar, Euclea delphin i i Boisd., when 
rull grown is about $1 / 2$ inch long. It is oval in shape, closely appressed to the leaf, greenish and variably marked with red and pale orange, the latter forming a pair of subdorsal stripes, in the course of which there may be bright red blotches. Tubercles short and bearing numerous short spines. This interesting caterpillar occurs on oak, chestnut, Layberry, Andromeda, beech, sour irum, wild cherry and probably other deciduous trees.

The life history of this group has been the subject of careful and painstaking study by Dr Dyar, and those interested will find his biologic and bibliographic accounts given below of extreme value.

\section{Bibliography}

I 895 Dyar, H. G. N. Y. Ent. Soc. Jour. 3: $151-57$ [A poda y-inversa Pack.]

I $896-$ N. Y. Ent. Soc, Jour. 4: I-9 [Sibine stimule a Clem.]; p. r67-90 [Tortricidia pallida Her.-Sch., Eulimacodes scapha Harr, Phobetron pithecium Sm. \& Abb., Sisyrosea textula Her.Sch.]

$1897-N$. Y. Ent. Soc, Jour. 5: 1-I 4 [Tortricidia fasciola Her.-Sch., Adoneta spinuloides Her.-Sch., Euclea indetermina Boisd., Parasa chloris Her.-Sch.]; p. 57-66 [Euclea delphinii Boisd.]; 1. 167-70[A poda bigut t a t a Pack.]

$1898-$ N. Y. Ent. Soc. Jour. 6:, 1-9 [Packardia geminat a Pack., P. elegans Pack.l; P. 94-98 [Heterogenea flexuosa Grote]; P. $241-46$ [Heterogenea shurtleffii Pack.]; P. I5I-58 [Tortricidia testacea Pack.]

I899 N. Y. Ent. Soc. Jour. 7:6 I-67 [Nat a da nasoni Grote]; P. 234-53 [Table of larvae, generic revision]

\section{Crinkled flannel moth}

\section{Lagoa crispata Pack.}

A peculiar larva about $\mathrm{r}$ inch long, thickly covered with long muse-gray and fawncolored hairs, occurs on the foliage of various trees in September and october.

This species is an interesting form because the larva possesses it 4 abdominal legs and is very similar in habit to the allied slug caterpillars, and like some of them, may inflict a severe sting. The larva rests flat on the surface and appears for all the world like a bunch of hairs. It has 
been recorded as feeding on oak, elm, apple, raspberry and common brake, Pteris a quilina. Dr Smith states that it lives on most of the orchard trees and small fruits as well as many other trees and shrubs. Occasionally it is common though not destructive. The full grown larva ranges in length from about $3 / 4$ to $1+$ inches. The body is short, broad and flat and the head a deep honey-yellow. The caterpillar is so densely covered with long hairs that it appears about one half as long as broad and rounded at each end. The hairs on the thoracic segments are mouse-gray, those on the remainder of the body are pale fawn brown, sometimes dark reddish orange.

\section{Filament bearer \\ Anic limbata Haw.}

A slaty brown measuring worm about $3 / 4$ inch long, remarkable because of the two pair of dorsal filaments near the midrle of the body, occurs in June on oak, maple, currant and strawberry.

This larva is a rather rare one and is noted in this connection because of the peculiar dorsal filaments which at once excite the curjosity of the observer and afford an easy means of identifying this species.

\section{Archips fervidana Clem.}

Black-headed, yellowish green caterpillars occur in thick web nests on scrub oak in early June.

This species, kindly determined by Prof. C. H. Fernald, was common . in June and July 1901 on scrub oaks at Karner. It was rarer in I902, indicating a considerable fluctuation in numbers.

Description. The larvae are nearly I inch long with the head and thoracic shield jet-black and the body varying in color from yellowish to olive-green. The dark brown tubercles are inconspicuous. The larvae spin scanty cocoons in their nests, the meshes entangling a mass of excreta.

The pupa is about $3 / 8$ inch long, dark green, ringed with lighter brown, and each segment bears a conspicuous row of stout spines with another row of smaller ones behind.

The adult has reddish brown fore wings, which are rather clouded with 
fuscous beyond the middle. The posterior wings are dark fuscous above, pale yellowish beneath. Wing spread about 1/2 inch.

Life history. The nests of this species began to appear June I3, I901, and were common on the 26 th and later. Inhabited webs were also taken July 27 and others Aug. 9. The period of flight is probably extended and the insect appears to breed more or less during the summer months. The web is rather small, irregular, measuring 3 to 4 inches long and $2 \mathrm{I} / 2$ to 3 inches in cliameter. It is filled with a mass of excrement, as in allied species. A number of small, dark colored caterpillars about $2 / 5$ inch long were observed in the nests after most of the moths had appeared. They closely resemble full grown larvae and may have been retarded individuals. Unfortunately none of the latter were brought to maturity.

Natural enemies. This species is preyed on by several parasites. M i crocentrus delicatus Cress. and M. solidagin is Cress. MS., have been reared from this insect. Several parasites were bred from this species anci a plant bug, probably $\mathrm{Pod}$ is $\mathrm{us} \mathrm{placidus}$ Uhl., presumably preys on the larvae.

\section{$\mathrm{V}$-marked leaf roller Archips argyrospila Walk.}

Delicate green, brown-headed caterpillars about $3 / 4$ inch long, feed on oak and other trees in early June and also in August or early September.

This species is very closely allied to the oblique banded leaf roller, Archips rosaceana Harr., and like it is a general feeder, having been recorded on oak, hichory, apple, wild cherry, rose, soft maple and elm. It lives between the webbed-together leaves and produces two generations annually, the moths of the first appearing the latter part of June or early in July. The larva has been described by Dr Packard as follows :

Color delicate grass-green, with a darker dorsal vesicular line, not polished, piliferous spots polished; head brown, cervical shield polished, glasslike, and scarcely darker than body; anterior edge lighter. Thoracic legs pale. 


\section{Red-banded leaf roller \\ Eulia triforana Walk.}

A small, light green, brown-headed caterpillar feeds in early June on the foliage of a considerable number of trees.

The larva of this red-banded leaf roller is a general feeder and has been recorded as depredating on oak, elm, apple, rosebushes, soft maple, cranberry and a number of herbaccous plants including some field and garden cropls. Professor Slingerland records rearing a parasite, U ro gas t e r can arsiae Ashm., from this species.

\section{Tortrix albicomana Clem.}

The larva of this species has been recorded on oak, rose and A qu ilegia can adensis. The parent insect is a delicate moth having a wing spread of about $5 / 8$ inch. The fore wings are pale brown diffusely marked with sulfur yellow. The hind wings are silvery gray.

\section{Oak leaf roller}

\section{Tortrix quarcifoliana Fitch}

A grass-green larva about $3 / 4$ inch long occurs during July in folded oak leaves.

This species, according to Dr Fitch, may be found within oak leaves which are curved upward and drawn slightly together by silken threads. It is a rather slender grass-green leaf roller, which pupates in the end of the leaf, the moth appearing in New York about the first of July.

\section{White-blotch oak leaf miner}

\section{Lithocollctes hamadryclla Clem.}

Whitish, blotchlike mines on the upper surface of oak leaves, contain minute, "footless, brownish and yellow larvae.

This species is one of our common leaf miners ranging from New York to Washington. Occasionally it is exceedingly abundant, particularly toward the end of the season, and the writer has taken oak leaves in Buffalo park, which were very seriously mined by this insect. Professor Comstock 
states that there are five or six generations annually in the vicinity of II ashington. He recommends the collecting and burning of infested leaves before the insects escape.

\section{Fitch's oak leaf miner Lithocollites fitchclla Clem.}

This species works in much the same way as the preceding, except that its tentlike mines occur on the under surface of the leaves and are visible on both sides. Professor Comstock states that it is a very common species on all kinds of oak at $\mathbf{I V}^{\top}$ ashington and records the insect from Kirkwood Mo.

\section{Walking stick \\ Diapheromera femorata Say}

Green or brown, sticklike insects sometimes measuring, exclusive of the antennae, 3 inches in lengtl, are more or less abundant in forests of deciduous trees in early autumn.

This peculiar insect is a rather common form, though it frequently. escapes observation because of its general resemblance to a stick. The young are green and closely mimic the color of the surrounding foliage, while the adults as they age and the foliage turns, change from the green to brown and toward the end of the season mimic brown sticks. On this account, in particular, specimens arouse considerable interest in the mind of the finder, and requests for identification and a brief account of its life history and habits are not infrequently made.

Early history. This deliberate, slender insect appears perfectly harmless and as a rule it causes very little damage. Occasionally it becomes excessively abundant and has been known to strip large areas. Prof. C. $I$. Riley, in his report for the year 18,8 , gives several abstracts from published reports of ąbout that date, which are of considerable interest, particularly as they relate to depredations occurring in New York State and vicinity. Mr G. C. Snow of Yates county N. Y., published in the Ncw Fork II cekly, Tribunc, Nov. I I, i 875, the following:

I noticed about August i 5 th, in a reservation of young timber; mostly white oak and hickory, a few trees having the appearance of being burned 
just enough to kill the leaves. On closer investigation I found many of these insects devouring the leaves. Later, l judge at least 25 acres were completely stripped of foliage; as much so as if fire had run through the wood and killed every tree. They seemed to have no choice as to what variety of timber they attacked. There were many in my peach orchard and lawn. On single trees, far removed from my timber lot, they were as thick as could well be, in many places in heaps. Fences adjoining the timber were fairly covered with them. They have been known for years in this vicinity, but were heretofore always considered harmless. From present appearances they are greatly to be feared as a scourge, consequently anything relating to them will be read with great interest. I hear from them in Florida but not in such numbers as here.

The same year these peculiar insects were exceedingly abundant and destructive in the vicinity of Ferrisburg $V^{\prime}$., as stated in the Rural $V^{\top}$ cw Iorker for Nor. 7, 1874. There were also serious injuries to forest areas in Pennsylvania. The above accounts relate to one of the unusual outbreaks frequentiy seen among insects, and as a rule this species may be considered comparatively harmless.

Description. The brownish, bean-shaped eggs, a little less than $1 / 16$ inch in length, are dropped at random in the forest and remain unhatched over winter. The recently emerged young are nearly $1 / 2$ inch long, exclusive of the antennae, and are then a pale yellowish green. The full grown adults have a body length of about 3 inches and the slender, tapering antennae extend forward from the head about 2 inches. The slender, long legs are attached to the anterior portion of the body and measure from about $1 / 2$ to 2 inches in length. They are rather easily detached and as a consequence perfect specimens are somewhat rare. The female is easily recognized by her stouter form. This peculiar insect in nature has the habit of extencing its anterior legs and antennae, clinging largely by the posterior and middle legs and in this way simulating the appearance of a twig very closely.

Life history and habits. The eggs are dropped at random among the trees and remain unhatched till the following spring. The young appear sometime during the month of May, and are general feeders, grow rapidly and attain maturity in early fall. 
Food habits. This species seems to have a preference for oaks, though it is recorded as feeding on most deciduous trees.

Remedies. Being a leaf feeder it should be readily controlled by thorough spraying with an arsenical poison whenever such is advisable.

\section{Bibliography}

1890 Packard, A. S. U. S. Ent. Com. $5^{\text {th }}$ Rep't, $1^{2}-3^{17-21}$

\section{Striped hickory caterpillar}

Datuma angusii Gr. \& Rb.

Clusters of black, yellow-striped caterpillars ahout 2 inches long, occur on hickory, walnut and birch.

This species may be distinguished from the more familiar yellownecked apple worm, D. min istra Walk., by the prothoracic shield being entirely black. It has very similar habits, though its list of food plants is more restricted. The parent insect is marked almost exactly like D. $\mathrm{m}$ i n is tra Walk, differing in the dark smoky brown color throughout.

\section{Yellow-necked app'e worm Datana ministra IValk.}

Clusters of black, yellow-necked, yellow-striped caterpillars nearly 2 inches long, occur in midsummer on the wigs of a variety of trees.

This species is well known in economic entomology as the yellownecked apple worm because of its depredations on this valuable fruit tree. It is however a general feeder, having been recorded on apple, pear, cherry, quince, linden, walnut, hickory, oak of various species, chestnut, beech, hazel, hornbeam, birch, locust and sumac.

Description. The full grown caterpillars are black, about 2 inches in length with a yellow thoracic shield and a series of four black lines on each side of the body: This species and its associates feed in clusters and have the peculiar habit of elevating both extremities when disturbed.

The adult insect is a reddish brown moth with a wing spread of about $13 / 4$ inches. The fore wings are crossed by a series of four or five oblique 
or curved brown lines, the outer margin being dark brown. The hind wings are pale yellowish brown.

Life history. The ergse are laid in June and the larvae are met with from August onwarl, the moths appearing the following May.

\section{Butternut woolly worm}

Monophadnus ciryenc Nort.

Large, flocrulent masses on the underside of butternut leaves in midsummer, mav conceal bluish, yellowish white sawfly larvae abont $3 / 4$ inch long.

This species is rather rare and was brought to our attention on account of the woolly white covering of the caterpillars which, when they occur in masses, gives them a resemblance to anything else but insects. This species was taken in August 1902, on butternut at Nassau N. Y. The larvae rested so closely together that the woolly covering gave them the appearance of being a solid mass. These false caterpillars feed in company, devouring the terminal portion of the leaf, rejecting the midrib and usually a small portion of the basal part. Cast skins or exuviae were found on the older leaves and these were yellowish white, with the tip of the mouth parts and eyes a dark brown or nearly black.

Description. The nearly full grown larvae are about $1 / 2$ inch long, with the head, thoracic and terminal abdominal segments pale yellowish white. The other body segments are bluish gray with a very narrow, interrupted black dorsal line. The woolly matter is excreted from the conspicuous transverse folds and appears in narrow bands about ${ }_{1 / 32}$ inch wide. These develop rapidly and on larvae naked the previous night, had attained a lengtl of ' ${ }^{6}{ }_{4}$ inch the next morning. These waxy filaments are pushed out and eventually are about ${ }_{+}^{\prime}$ inch long, giving a very peculiar appearance to the bearer.

The adult is a black, red-marked sawfly having a wing spread of nearly $1 / 2$ inch.

Natural enemies. Numerous pupae of a species of Cratotechus were found on a leaf near the larvae of this sawfly, undoubtedly parasites of this species. 


\section{Typoptiorus canellus Fabr.}

A small, roundish, brown and black marked or black beetle alout ' wo inch long occurs on butternut, mountain ash and various plants in May and during tarly fall.

This species is a variable one, as is illustrated by 1)r Horn's key for the separation of It varieties. It has been taken by Mr Young on butternut, mountain ash and such low plants as strawberries in May, and on the heathlike aster, Aster ericoides, the last of August and the first of September. It eats irregular, oval or elongate holes in almost any part of mountain ash leaves and occasionally causes considerable injury: Mr Young is of the opinion that a similar form occurring on low plants, may be different

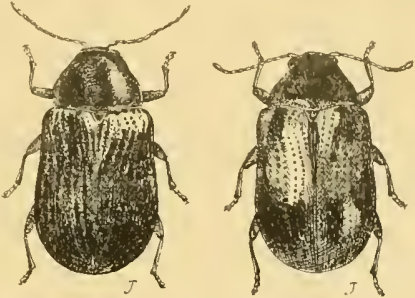

Fig. 335 Typophorus canellus, showing dark and light forms, nuch enlarged (original) from that met with on trees, though at present he is not able to detect constant differences. This species, according to Dr Horn, is widely distributed over the continent east of the Rocky mountains, occurring from Kansas to Texas, west through Arizona to Fort Yuma.

\section{Green-striped maple worm \\ Anisota rubicunda Fabr.}

A large, pale yellowish green larva striped with darker green, occurs in midsummer on maple trees.

This species is generally distributed throughout the State, though rarely abundant enough to cause serious mischief. The late Dr Lintner, however, records an instance of this larva occurring in large numbers in Monticello, Sullivan co., where it defoliated a number of soft mapletrees. This species is much better known as a pest in the IVestern States, where it frequently strips the leaves from large numbers of maples. It feeds on the sugar maple as well as the soft maple.

Description. The larva has been clescribed by Dr Riley practically as follows : 
The recently hatched larva is yellow with a large, black head, the spines forming little black tubercles of nearly uniform size. The head is browner after the first molt and the spines and stripes of the full fed larva more apparent. The third stage is very like the fourth or last, except that the caterpillar is smaller. The full grown larva is an inch and a half long, pale yellowish green, longitudinally striped above alternately with eight very light yellowish green lines and seven of a darker green, inclining to black, with two slender black spines on the second segment behind the head, and two lateral rows of sharper, shorter spines. Head copal yellow; abdominal segments seven and eight a little dilated and rose-colored at the sides.

The moth is rose-colored, with the fore wings crossed by a broad, pale yellow band. The hind wings are pale yellow. The body is yellow and the underside and legs rose-colored. Wing spread about 2 inches.

\section{Semilooper maple worm Homoptera Innata Drury}

A drab colored caterpillar about $\mathrm{x} / 2 / 2$ inches long, and with a large, orange, dorsal spot exposed at the juncture of the first and second abdominal segments when the body bends, feeds on maple, oak, willow and rose.

The caterpillar of this widely distributed species is seldom abundant enough to cause much injury. The larva is about $1 \frac{1}{2}$ inches long, drab colored, with indistinct markings except for the large, orange, dorsal spot exposed when the body is bent at the juncture of the first and second abdominal segments. On the eighth abdominal segment there is a pair of small, brown-tipped tubercles. The head is quite flat, sloping and irregularly marked with brown. The caterpillar when walking loops much as does a measuring worm and displays a marked tendency to remain quiet and rely on its protective color to escape injury. The parent insect is an obscurely brown colored moth having a wing spread of about 2 inches. Both the fore and hind wings are rather prettily ornamented with wavy dark and light brown bands or lines interspersed here and there with indistinct grayish markings.

The eggs of this insect are deposited the latter part of April and full grown larvae are met with in early June, moths appearing the latter part of the month and in early July. Larvae also occur in August and September, 
the moths appearing in the fore part of November, some wintering in the pupa. There are probably two or three broods during a season.

\section{Cecropia moth}

Samia ccoropia Linn.

A large, pale green caterpillar about 4 inches long, ornamented with conspicuous green, blue, yellow and red tubercles, feeds on the foliage of a large number of trees and shrubs.

The larva of this insect is very striking in appearance and were it at all abundant its voracious appetite would result in a great deal of injury. Ordinarily it is so rare that no repressive measures are necessary. The giant moth shown at plate 42 , figure 2 , is rather common, and of interest largely because of its immense size. This insect has been recorded on about 50 plants representing some 20 grenera, the more important of which are the following: linden, maples, apple and pear, cherry, elm, birch, alder, willow and poplar.

\section{Large maple spanworm}

\section{Sabulodes transiersata Dru.}

A large, slender-bodied spanworm about $13 / 4$ inches long and marked with dark purple brown and reddish markings, occurs on maples in July.

This species is rather common and typical of a large class of span or measuring worms, which may be instantly recognized by their peculiar looping walk and their tendency to remain motionless on twigs when discovered. There are a great many species and almost all are so shaped and colored as to closely resemble the twigs on which they occur.

The larva of this species has the body thickened behind and ridged on the sides. It is a dark purple brown mixed with reddish and has a dull reddish gray crescent-shaped spot on the middle of the fourth abdominal segment, behind which is a pair of low kidney-shaped tubercles, and a pair of dorsal pointed black ones on the eighth abdominal segment. The parent insect is a yellowish tawny color with a dark brown oblique stripe extending from the apex of the fore wings to the middle of the anal margin of the hind wings. Wing spread about 2 inches. 
Maple leaf stalk borer

Epinotio claypolanu Riley

Small, yellowish caterpillars nearly ${ }^{2} 2$ inch long, in midsummer bore the leaf petioles of maple and buckeye.

The work of this insect in maple leaf stems was brought to the notice of the late I). Lintner in 1895 , through specimens received from Concordsville Pa. The first indication of trouble was the apparently causeless dropping of leaves, and on examination a small caterpillar was found boring within the portion of the leaf stalk remaining on the twigs.

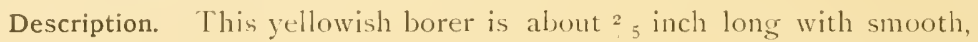
minute granulations on the skin, not pointed as in the case of another borer, Proteoteras aesculana Riley, which works in a similar manner. The adult is a small moth with a peculiar hopping flight. The fore wings are mottled with black and white and the hind ones are a nearly uniformly dusky color, slightly spotted with black near the tip.

Life history. According to Professor Claypole, the larvae occur in the early part of May, and about the roth desert the leaf stems by the holes through which they have entered and migrate to the fading leaves on which growth is completed. Transformation to the pupa occurs within a rolled silk-lined leaf the latter part of May, the moth appearing about 15 days later. This species also works in the leaf stalks of the buckeye. The portion traversed by it shrivels, blackens and is soon broken off by the weight of the leaf.

The larva of another moth, Proteoteras aesculana Riley, also works in the leaf stalks of both buckeye and maple and extends its tunnels for a distance of about $1 / 2$ inch to 2 inches into the slender terminal twigs of both these trees, often causing a pseudogall. The maple leaf stalk borer seldom or never bores along the leaf stem more than $1 / 2$ inch, very rarely enters the terminal twigs and lives in the rolled-up leaf after the first two or three days.

Remedial measures. This insect, where abundant, can probably be 
checked by collecting and burning the fallen leaves. Possibly it would be amenable to arsenical sprays were they applied early in the season.

\section{Bibliography}

IS97 Lintner, J. A. Ins. N. Y. I2th Rep't, p. 2I I $^{-17}$

\section{Maple leaf cutter \\ Incurvaria accrifoliclla Fitch}

Maple leaves with irregular, oval holes $1 /$ ro to $t / 20$ inches in diameter may have been injured by this species.

This peculiar leaf feeder is occasionally rather abundant on maples in the eastern part of New York State. It is particularly common in the forests, and in May $1 S_{50}$, according to Dr Fitch, its work was so prevalent as to attract popular notice. Dr Fletcher of Canada records an instance of severe injury in 1885 , stating that the foliage on four acres was almost entirely consumed, the flat, disklike cases of the larvae carpeting the ground and occurring in great numbers on the tree trunks. Some beeches were also attacked after the maple foliage had been devoured.

Description. The moth has a wing spread of about $1 / 3$ inch, with the fore pair a brilliant steel blue, sometimes bluish green with purplish reflections. The hind wings are a pale smoky brown, translucent, with pale blue and purple reflections and a pale brown fringe: The top of the head bears a tuft of erect, bright orange hairs, the thorax is a brilliant steel blue and the abdomen a dark satiny brown.

The full grown larva is about $1 / 4$ inch long, slender, flattened, cylindric, with slight constrictions marking the segments. It is a dull white with the head and three thoracic segments a pale rusty brown and an interrupted broad dorsal stripe.

Remedies. This species can probably be controlled by timely spraying with an arsenical poison. 


\section{Hylotoma scapularis Klug.}

Yellowish, black-spotted, caterpillarlike larvae nearly $3 / 4$ inch long, feed on the foliage of American elms in August.

This species has heen studied by Mr J. G. Jack of Jamaica Plain, and his description of the larvae and account of their habits follows:

The full grown larvae have a pretty general resemblance to those of H. pectoralis Leach and are about is $\mathrm{mm}$ long. Head light orange yellow, body somewhat flattish and light yellowish green in color. There are six distinct rows of small closely adjoining black spots on the upper portion of the body extending from the head to the anal segment. On each of the fleshy projections on the sides of the segments, except the last, there is an oblong dark spot; but these spots above the two posterior pair of true lecrs appear as two large somewhat triangular black blotches. Above the anal segment there is a large oval shaped black spot. The legs are black on the outer side, and the prolegs are marked by a dark brown blotch on the outer side. The black legrs and black blotch on the anal segment are the chief marks which distinguish this larva from that of H. pectoralis in which the legs and anal segment are yellowish. The cocoons are of a dirty white or light brown color and average about $12 \mathrm{~mm}$ in length. They are composed of two walls, the inner being closely, and the outer loosely spun.

The eggs are deposited along the margins of the leaves of the common American elm ( $\mathrm{U} l \mathrm{~m}$ us a mericana) on which the larvaefeed. Young larvae were found early in August and those observed attained full growth about the end of the month. Two males and many females were raised from these about the first of July following.

\section{Alder leaf beetle}

\section{Chrysomelar scalaris Lec.}

A brilliant, bottle-green, oval beetle about $1 / 8$ inch long, wirh silvery white wing covers, the latter omamented with several conspicuous green spots and with a median jagged stripe of the same color down the back, feeds on the leaves of elm, linden, willow and alder throughout the season.

This, one of the prettiest of our native beetles, sometimes becomes excessively abundant, and Dr Hagen records an instance in $188_{4}$, when this insect was very abundant on elms in Cambridge, and in $188 \mathrm{I}$ it was so 
numerous at Brunswick Me., as to seriously injure lindens on the campus of Bowdoin College, according to Dr Packard. Dr Fitch states that this species feeds on elms throughout the season and is also common on willows.

Description. This insect has been described in its various stages, by Dr Packard as follows:

Egg. Rather large, oval cylindrical, yellow, several together attached by one end; about $1.5 \mathrm{~mm}$ in length.

Laria. Body very thick, curved up like that of the grub of the Colorado potato beetle, being much swollen behind the thoracic segments, while the tip of the abdomen is curved down. Head honey-yellow, darker over the jaws: antennae bluish, except at base; eyes black. Prothoracic shield blackish in the young before the last molt; in full grown individuals not all black, but pale, with four irregularly square black spots. Body behind dirty white with a row of clorsal and lateral dusky spots. Legs pale, spotted with black at the joints. A pair of mesothoracic spiracles, and eight pairs of smaller abdominal ones. Low down, on the sides of the second and third thoracic segments a curvilinear black spot. Length, 8 to $9 \mathrm{~mm}$.

Pupa. Body pure white; prothoracic shield with long scattered hairs around the edge and in two groups on the back; antennae curving around between the eyes and jaws, and with the ends resting on the tips of the elytra. The insect undoubtedly descends into the earth to pupate.

Bectle. Head, prothorax, and underside of body dark coppery green, with scattered pits. Antennae, palpi, and legs pale pitchy yellow; elytra coppery green and whitish, the green forming a broad median stripe, sending prolongations outwards toward the middle of the elytra, the first pair of branches nearly parallel to the band, the second becoming more and more at right angles to the band, the last short and broad near the tip of the body. Eleven rounded dark green spots in the whitish field; the pair near the shoulders gourd-shaped; two of the spots behind the middle of the elytra touching each other. The pits or punctures near the sutures of the elytra arranged in three lines parallel to the median line of union of the body; elsewhere they are arranged irregularly.

Life history. Dr Packard states that the beetles may be found abroad from May to June and that a second brood occurs in September and October. The grubs hatch from eggs deposited on the leaves in the spring, attaining full growth toward the end of June in Massachusetts. The transformation of the adult is believed by Dr Harris to occur in the ground. Among natural enemies, Dr Hagen records Podisus spinosus Dall. 
as preying on the larvae of this leaf feeder. This species has an extended distribution, ranging, according to Linell, from the East to Nebraska and Texas.

Remedial measures. There is no reason why this species, when abundant, can not be controlled as in the case of other leaf feeders, by thoroughly spraying the infested foliage with an arsenical poison, preferably arsenate of lead.

\section{Conotrachelus anaglypticus Say}

A small, long-snouted weevil about $3 / 16$ inch long, with strongly ridged elytra and prettily marked with dark brown, yellowish white and reddish brown (the latter forms a large spot near the anterior hateral margin of the elytra and nearly covers the posterior iourth) occurs on elm.

This species was taken by Mr Young, at Poughkeepsie, June 5 and 6 , on slippery elm. The occurrence of the weevil on two successive days on

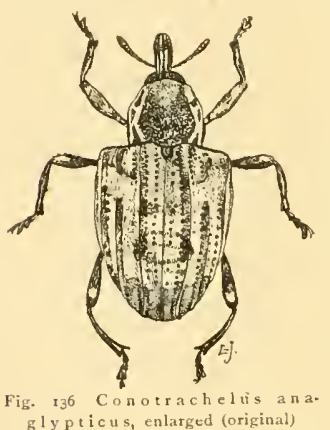
this tree, would indicate a certain attraction for this food plant. The tree had been stripped of bark and the surface was dry though the leaves were green. Mr Young has also taken this species in the Adirondacks. Say records taking many specimens on a hickory, and states that they oriposit in the fruit. This species has been recorded by Dr LeConte, as abundant from Massachusetts to Kansas, Georgia and Texas. It has been listed as occurring on walnut throughout New Jersey, and Ulke states that it commonly occurs in the District of Columbia, under moist bark and on various bushes. Dr Horn records it as common in southwestern Pennsylvania, and Dury has listed it from the vicinity of Cincinnati.

\section{Violet tip \\ Polygonia interrogationis Fabr.}

A red-headed, black-spined caterpillar about $\mathbf{I}$ inch long, feeds on elm foliage.

This species is one of our common butterflies and occasionally its larvac become somewhat abundant and destructive to elm. It is easily 
controlled by thorough spraying with an arsenical poison. The larva is more or less variable in coloration. It has been described as follows by Professor Fernald. The full grown larvae "are about an itch and a half long, pale yellow, variegated with brown, with a yellowish line on each side of the body: The head is rust-red, with two blackish, branched spines at the top. The spines of the body are arranged in seven rows, one along the middle of the back, from the fourth to the i 1 th segment inclusive and three rows on each side."

This insect, as do some of its allies, hibernates in the adult and under favorable conditions produces two generations. The butterflies of the first brood appear early in May and disappear by the middle of June. The larvae attain their growth rapidly and appear as butterflies in July, continuing on the wing till nearly the middle of August, depositing eggs late in July and during August, which produce butterflies again toward the end of August. Mr Scudder states that there are at least three broods in the South, and Mr Edwards thinks that there may be four or five in Florida.

\section{Hop merchant}

\section{Polygonia comma Harr.}

A yellowish, spiny, black-marked caterpiplar about an inch long, feeds on elm.

This species closely resembles the preceding and according to Dr Packard, the larva differs in being brownish red anteriorly and white or pale yellow behind. It has been described by Prcfessor Fernald as follows :

The mature larva is one inch long, armed with seven rows of long, tapering spines; one along the middle of the back, from the third to the twelfth segment, inclusive, and three along each side; the upper row on each side running from the third to the twelfth segment; the next row from the third to the thirteenth, but the spine on the fourth is below the row and in line with the spiracle; the lower row extends from the fifth to the twelfth segment. A little below the summit of each spine, from three to five branches start out, each branch and spine ending in a bristle. The color varies greatly; some are black with yellow bases to the spines and a yellow lateral line; others are nearly white, with red spots along the sides.

Its life history and habits are very similar to the two preceding, and 
when abundant it can be controlled in the same manner. This species is one of the forms so well known as hop merchants, the hop being its favorite food plant.

\section{Gray comma \\ Polygonia progne Cram.}

A brown-headed, yellowish brown, spiny caterpillar about one inch in length, feeds on elm,

This species, according to Dr Fitch, is the more common spiny caterpillar found on elm. He states that it is white mottled with gray. It has been described by Professor Fernald as follows :

The mature larva is about one inch long, buff-colored, and armed with branching spines as in l'. co m m a Harr. Head subcordate, with a large, compound, spinous process on each vertex, the main stem black, the branches black and yellow, the face and sides of the head thickly covered with simple, conical, yellowish spines of various sizes. The surface of the body varies greatly in color and markings.

The life history is very similar to the preceding and it can be controlled in the same manner.

\section{Four-lined sphinx}

\section{Ccratomia anymtor Hübn.}

A stout, pale green or reddish brown larva about 3 inches long, with a conspicuous caudal horn and four large tubercular elevations on the thoracic seginents, occurs in early September on elm, beech, linden and probably ash.

This striking and to some disgusting larva is not uncommon in early September, and on account of its peculiar appearance attracts more or less notice, though it is rarely abundant enough to cause material injury to trees on which it feeds. The recently hatched pale green larva emerges from a spheric, greenish egg and is then about $1 / 5$ inch long. It has a straight, brown-tipped caudal horn about half the length of the body and there are four minute, tubercular processes on the posterior thoracic segments. These latter structures continie throughout the different stages and afford a ready means of identifying the larva which, when full grown, ranges from $23 / 4$ to $3 \frac{1}{4}$ inches in length. It is then pale green or reddish brown with the head and body strongly granulated. There is a dorsal row of fleshy teeth, 
one on each wrinkle, tipped with whitish or pink and extending along the abdo anal segments. The two posterior thoracic segments are each ornamented with a pair of straight tuberculated horns, a line of granulations connecting them. Seven oblique stripes of whitish granulations occur on each side, each reaching from one segment across the following and onto the third, the last stripe extending to the caudal horn. The parent insect is a magnificent sphinx moth with a wing expanse of about 5 inches. The fore wings are broad with a large, distinct, round discal spot, light brown and variously marked with dark brown. The abdomen is marked with a narrow, black, dorsal line, a crenulate black, subdorsal line and a somewhat broken, black, lateral line.

\section{Spring canker worm Paleacrita a'crnata Peck}

Dark striped measuring worms about an inch long, defoliate apple and elm trees in early spring.

This species is a well known apple pest in New England and inflicts considerable loss in certain portions of New York State. Its original food plant is the elm, and occasionally it is somewhat injurious to this, though most of the injury in later years has been in apple orchards. The fall canker worm, Anisopteryx pometaria Harr., is a closely allied form possessing similar habits except that the adult is more likely to emerge and deposit its eggs in the fall, whereas the spring canker worm does not usually appear till very early spring. The eggs of both hatch about the tinie the leaves begin to appear, and where the pest is at all abundant defoliation quickly follows. The caterpillars complete their growth, forsake the tree and transform to pupae in the soil. This makes it possible to take advantage of the wingless condition of the female and injury can be prevented by employing a sticky band in early spring or fall as the case may be, or by thorough spraying with an arsenical poison. 


\section{Ash sphinx}

Sphinx kalmiae Abb. \& Sm.

A stout, apple-green caterpillar about 3 inches long, with seven oblique stripes on each side and with a light blue caudal horn, feeds on the leaves of॰ash, lilac and mountain laurel.

The parent insect is a very handsome hawk moth having a wing spread of about $3 \frac{1}{2}$ inches. It may be recognized by its narrow, yellowish brown fore wings margined on the outer part and posteriorly with brown. The head and thorax are chestnut brown on the top and whitish or yellowish along the sides. A pair of light brown stripes extend down the back and there is a series of five or six lateral transverse stripes on the abdominal segments.

The full grown larva is three inches long with a rather small, flat head of a clear apple-green color, yellowish on the sides and with a lateral black stripe. The body is apple-green in color, lighter above and darker on the sides. There are seven oblique stripes on each side, confined to one segment each, which are whitish through the middle, yellowish on the lower side and dark blue, almost black on the upper side. The caudal horn is light blue thickly studded with shining black tubercles, and is quite curved. The caudal shield and anal plate are yellowish green and dotted with small, black, elevated points. Spiracles, pale orange, their upper portion extending into the yellow of the bands. Legs, black and pearly at the base. Prolegs with two black spots on the outside separated by yellow, or connected posteriorly by a black line. Fernald

\section{Wavy ash sphinx \\ Ceratomia undulosa IValk.}

A variable, light green caterpillar about $13 / 4$ inches long, with reddish legs and caudal horn and a series of seven oblique whitish stripes on each side of the body, feeds on the foliage of white and black ash, litac and privet.

This leaf feeder is not abundant as a rule, and the parent moth is a magnificent insect having a wing spread of nearly four inches. It is rather prettily marked with various shades of gray and dark brown or black, the latter in more or less wavy lines at the base and near the apex of the fore wings. The young pale greenish yellow larvae emerge from pale green 
egrgs and are then about $\mathrm{x} / 5$ inch long with a large, straight caudal horn pointing obliquely up and backward. After the first molt the seven oblique whitish stripes are visible, and in the next stage there is an additional series of reddish spots along the longitudinal whitish stripe.

\section{Apatelodes torrefacta Abb. \& Sm.}

A pretty yellowish or whitish, long-haired caterpillar about two inches long, with three dark hair pencits along the median line, one each on the second and third thoracic and eighth abdominal segments, occurs in midsummer on various food plants.

This caterpillar is a rather general feeder, having been recorded on ash, wild cherry, willow, sassafras, alder, blackberry, bayberry, azalea, viburnum, hazel, ironwood and gall berry. It is clothed with long, yellowish hairs which bend backward and the body beneath is marked with yellowish white. The long, yellow hairs part along the median line, where there are also a few short black hairs, giving a distinct black marking. The eggs are laid the latter part of June, hatching early in July, the larva requiring about 30 days to complete its growth. A parasite, Eremotylus macrurus Linn., has been reared from this insect.

\section{Bibliography}

I895 Packard, A. S. First Memoir on the Bombycine Moths, p. 100-3

\section{Hylotoma macleayi Leach}

Black-headed, yellowish green, black-spotted, false caterpillarlike larvae nearly $3 / 4$ inch long, feed in August on chokecherry foliage.

This larva has been carefully described ${ }^{*}$ by Mr J. G. Jack of Jamaica Plain, and his account follows:

Full grown larva from 15 to is mm long. Head black. Body flattish; pale yellowish green, with four distinct lines of black spots along the back extending from the head to the anal segment; and with some minute, less regularly arranged spots or dets along the sides above the fleshy projections which characterize larvae of this genus. Each fleshy projection bears a long narrow black spot. The anal segment is surmounted by a large irregular oval black blotch and is brown above the

$$
{ }^{x} \text { I } 89 \text { I Psyche, 6: I I. }
$$


anus. The legs are dark brown or black on the outer base and have a heavy black blotch at the base. The prolegs are marked on their outer side by a somewhat triangular, black or very dark brown spot. The cocoon is double walled, the outer wall being loosely woven and it is dull white or pale brown in color, and is from $12-14 \mathrm{~mm}$ in length.

The larvae were found in considerable numbers in the month of August feeding on the foliage of common chokecherry (Prunus virgin ia na) at Jamaica Plain Mass. From these larvae a number of female imagos were bred in the latter part of the following May.

\section{Cherry leaf beetle}

Galcrucclla caricollis Lec.

A small red leaf beetle, about $1 / 5$ inch long, eats in midsummer irregular round holes in the leaves of wild cherrytrees.

This little species is somewhat abundant in the Adirondacks on wild cherry, and was repeatedly observed by the writer in August 1900. It was so numerous that the foliage on many of the trees was badly riddled, and large numbers of the beetles could be collected with little trouble. This species has also been observed by Dr Lintner injuring cultivated cherry trees on several occasions.

\section{Bibliography}

1896 Lintner, J. A. Ins. N. Y. I ith Rep't 1895 , p. 197-98

\section{Apple tent caterpillar}

\section{Malacosoma americana Fabr.}

Web tents in the forks of wild cherry and apple trees in early spring, are most characteristic of this very common species.

This caterpillar is well known because of the conspicuous and characteristic tents or webs it spins in the forks of wild cherry and apple trees. The full grown caterpillar is about two inches long and may be easily distinguished from the closely allied forest tent caterpillar, M a la cosoma disstria Hülon., by its possessing a continuous white line down the middle of the back, whereas the forest species has a row of silvery white, diamond-shaped spots. This caterpillar has marked preferences for the 
plants named above, though it has also been recorded as feeding on sugar maple, shadbush, mountain ash, thorn, rose, witch hazel, elm, oak, birch, willows and poplars. It is kept in check to a considerable extent by natural enemies, prominent among which may be mentioned the small plant bug, Podisus placidus Uhl. The writer has taken five from a single nest and observed six or seven on the outside of another.

\section{Bibliography}

I 898 Felt, E. P. State Ent. I th Rep't. N. Y. State Mus. Bul. 23, p. I77-90

\section{Cherry scallop shell moth Hydria undulata Linn.}

Brown, webbed-together leaves occur on wild cherry shoots in July and August.

This species is rather common and attracts notice because of the curious way in which the cherry leaves are fastened together, edge to edge, with the upper surface inside. The yellow, black-striped caterpillars occur within this cavity. It is seldom abundant enough to cause material injury even to its comparatively worthless food plant. This species has been recorded on willow by Dr Packard, though the larvae presented some differences from the typical form on cherry.

Description. The full grown caterpillars are about $3 / 8$ inch long and have a dark amber head and thoracic shield. The body is a variable yellow, marked as follows : dorsally there are four approximately equal, somewhat broken yellowish white lines inclosing brownish yellow lines, and laterally there is a broad, jet-black stripe neariy continuous across the anal plate, venter yellowish white. True legs dark brown, prolegs yellowish, tipped with fuscous.

Life history. The larvae attain full growth early in August or September, enter the soil and transform to pupae within slight silk-lined cocoons where the winter is passed. The moths appear the following spring and deposit their eggs in an irregular cluster on the lower side near the tip of the branch, as recorded by Messrs Comstock and Slingerland. 


\section{Ugly nest cherry worm \\ Archips corasizarana Fitch}

Yellow, black-headed caterpillars about t'á inch long. web together chokecheiry leaves in midsummer.

This common species is not of much economic importance because its attacks rarely cause material injury, since they are so largely confined to the comparatively vahueless chokecherry. It occasionally feeds on the cultivated cherry. Dr Lugger states that this species is sometimes so abundant in Minnesota, that the larvae enclose entire trees with their webs. It is sometimes extremely numerous in the province of Quebec, though rarely causing material injury.

Description. The full grown larvae are lemon yellow, clothed with scanty, fine, yellowish hairs, and have the head, the prothoracic shield, the anal shield and true legs black, the mouth parts being brown.

The moths vary greatly in size, having a wing spread ranging from t's to $\mathrm{I}^{\mathrm{x}} \mathrm{s}$ inches. The wings are broad, the outer edge being rounded toward the base and straight from the middle to the tip. They are crossed by irregular, wavy bands, alternately of bright ocher yellow and pale leaden blue. The yellow bands are varied with darker spots, the most conspicuous of which is placed on the outer margin of the tip, and from this spot a broader ocher yellow band extends toward the hind angle and curves thence to the inner angle. The hind wings and the entire under surface are pale ocner yellow.

Life history. The dense web nests of this species are rather common the latter part of June, the larvae transforming to pupae early in July The interior of the nest at this time contains large black masses composed of larval excrement, among which the larvae spin their cocoons and transform to pupae. The moths emerge during July, and prior to the disclosure of the adults, the pupae wriggle partly out of the nest, so that after the escape of the insects, empty pupal cases may be seen projecting therefrom. The eggs have not been observed. Professors Comstock and Slingerland are of the opinion that the eggs are deposited in clusters on a 
twig near the end of the branch and remain unhatched till the following spring.

Natural enemies. This species is very subject to the attack of parasites, and we have bred from one nest a number of specimens of $\mathrm{I} \mathrm{a} \mathrm{c} \mathrm{r} \mathrm{O-}$ centrus solidaginis Cress. This and other species are undoubtedly of considerable value in keeping the pest in control.

Serica sericea Ill. was taken on alder at Karner June 8, 1902. It is common in Herkimer county on the blossoms of wild cherry, visiting these trees when in bloom.

\section{Pteronus thoracicus Harrington}

A greenish, solitary sawfly larra resting on its venter on the under surface of shadbush leaves ( $\mathrm{Amelanchier}$ canadensis) may belong to this species.

This larva was met with by Dr Dyar at Plattsburg N. I. and its various stages have been characterized by him as follows:

First stage. Head round, higher than wide, but not narrowing to vertex, shining, eye black, mouth brown; width .25 mm.

Second stage. Similar; eye surrounded by a black spot; head rather higher; width $.33 \mathrm{~mm}$

Third stage. Head almost whitish, pale; width $.5 \mathrm{~mm}$; joint 2 small, making the head appear prominent. Body much as in the following stages, but paler.

Fourth stage. As in the next stage in all points, but a little paler, though darker than in the previous stage; width of head $.7 \mathrm{~mm}$.

Fifth stage. Head round, smooth, shining, greenish testaceous, prominent; eye black, mouth brown; width $\mathrm{I}$ mm. Thorax a little enlarged, the feet spreading widely, not concealed. Abdomen slightly tapering posteriorly, gradually becoming smaller from the thorax; feet present on joints 6-11 and 13 ; segments 4 -annulate, smooth, without tubercles, not shining ; color pale clear green, the alimentary canal showing dark green or the surface covered with a slight white bloom. Thoracic feet watery greenish; abdominal ones short, concolorous with the pale subventral region; anal plate rounded.

Sirth stage. As before, width of head $1.4 \mathrm{~mm}$.

Seventh stage. Head held forward; light testaceous, faintly brownish, smooth, shining, minutely reticulated; eye black, mouth brown; width $2 \mathrm{~mm}$; joint 2 depressed anteriorly. All as in the previous two stages; skin smooth, but not shining; at the end of this stage the larvae fade to a whitish color with a bright green dorsal band and enter the earth without molting. 
Cocoon double, the outer layer thin, brown, the inner dark brown, compact, but not very hard; size $4 \times 8 \mathrm{~mm}$.

The adult female is about $1 / 4$ inch in length, reddish yellow with darker markings. The male is slightly smaller, black, marked with reddish yellow.

\section{Bibliography}

I 895 Dyar, H. G. Ent. Soc. Trans. 22: 307-8

I 896 Marlatt, C. L. U. S. Dep't Agric. Div. Ent. Tech. Ser. 3, p. 64

Orange dog

Papilio thoas Linn.

A large, brownish caterpillar with conspicuous angular, cream-colored markings on its middle and at its posterior extremity, is sometimes rather abundant on prickly ash.

This species is southern and only occasionally is it abundant as far north as Albany, though it is quite common near Poughkeepsie and undoubtedly more abundant farther south. Dr Smith states that only single examples occur throughout New Jersey.

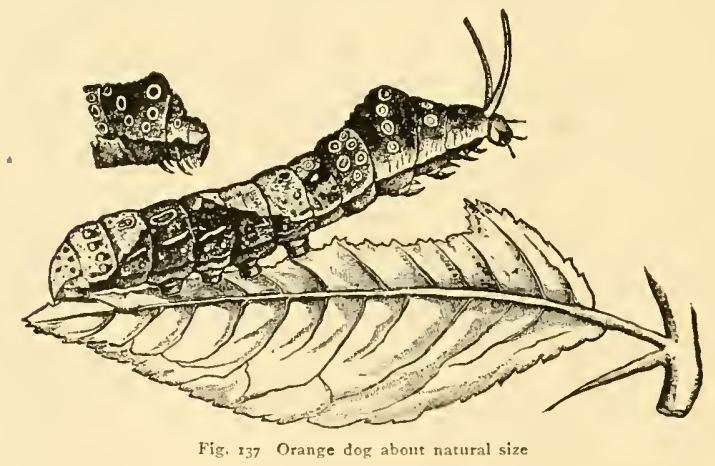

Description. The full grown caterpillar is about $2 \mathrm{I} / 2$ inches long, dark brown in color with a conspicuous angular, cream-colored blotch about the middle and another similar colored area at the posterior extremity. The thoracic segments are slightly swollen and marked with several yellowish ocellate spots, so that when the head is drawn under the anterior thoracic segments there is a strong resemblance to a mask face. This caterpillar when irritated, as in the case of its allies, is capable of projecting two long, fleshy, orange-colored tentacles from a fold just behind the head. These emit a very disagreeable odor and are 
probably of value in protecting the insect from its enemies. The parent insect is a magnificent brownish, yellow and red-marked butterfly with a wing spread of over 4 inches.

Life history. This insect, according to Dr Scudder, ranges from the northern part of South America to about the latitude of Albany, and in the warmer portions of its habitat develops about four generations and in the northern only two, the butterflies of the first appearing in early June or even the last week of May, and those of the latter occurring at the end of July. The caterpillar feeds on orange, prickly ash, hoptree and a number of other plants. The life cycle may be completed from within 20 to 60 days, dependent largely on conditions. A number of eggs are usually: deposited on a single bush or tree and consequently the work of the larvae is easily detected.

Natural enemies. This species is subject to the attack of several natural enemies, among which may be mentioned a tachina fly; a small chalcid, Chalcis robusta Cress. and Pteromalus vanessae Howard.

Remedial measures. Like most leaf-feeding species, this caterpillar when unduly abundant, can easily: be checked by the timely application of arsenical poisons.

\section{Sour gum case cutter Antispila nyssacfoliclla Clem.}

A small leaf miner works in sour gum leaves the latter part of August and in early September, cutting oval cases therefrom the latter part of that month.

This species is occasionally very abundant on Long Island, and in September 1893 , it was brought to the attention of the late Dr Lintner by Dr Dyar, who had observed the work of this species.

Description. The larva has a dark brown head and thoracic shield, the body is a very pale green with dark atoms along the dorsum. Ventral surface with a line of two black spots. The adult has dark brown fore wings with greenish reflections and a bright coppery hue at the base. The hind wings are a purple brown, the fringe yellowish gray.

Life history. The larvae may be found early in July, making first a linear mine and later excavating a blotch. The cocoon is spun within the 
mine, well lined with silk and the upper and lower walls composed of the leaf epidermis, is cut away so that the case with its occupant, drops to the ground. It is then secured to surrounding objects by small strands of silk.

1895 Lintner, J. A. Ins. N. Y. ruth Rep'l, p. 157-59

\section{Red-footed flea beetle \\ Crepidodera rufipes Linn.}

A red-headed, blue flea beetle alout $5 / 8$ inch long, is sometimes very abundant on locust and apple foliage.

Specimens of this little flea beetle were taken from badly damaged honey locust foliage at Poughkeepsie, May 21, 1903.

Description. 1/8 inch long, with head, antennae, legs and prothorax a brick-red color, while the wing covers are bluish and plainly marked with rows of punctures. The ventral surface of the meta- and mesothorax and abdomen black.

Life history and habits. This little insect is liable to appear in large numbers in early spring, at which time its depredations on locust, apple and other fruit trees may be somewhat serious. Dr Smith states that in New Jersey it also attacks grape.

Distribution. This is an European form, according to Dr Horn, now widely scattered over the Atlantic recrion and as far west as lowa. It is probably generally distributed over this area, since it has been recorded in a number of local lists.

\section{Locust leaf folder}

$$
\text { Epargyrous tityrus Fabr. }
$$

Large, pale green caterpillars about 2 inches long, with a red neck and large red head and a yellow spot on each side above the month, draw the leaves of locnst together and feed by night.

The caterpillar of this rather handsome butterfly is a somewhat general feeder, eating freely the leaves of many of the Leguminosae and occasionally being so abundant in New England as to strip the foliage from the common locust and specially the viscid locust, Robin i a $\mathrm{v}$ is cosa, 
which latter is used as an ornamental tree. Ordinarily it does not cause a great deal of injury. The parent butterfly is a beautiful orange-red, dark brown-marked butterfly with a wing spread of about two inches. The fore wings have a number of irregular black spots, the outer margin being a dull brown, while the greater portion of the short-tailed hind wings are dark brown, the prolongations and posterior margin being blue. Dr Scudder states that this insect produces two generations in the South and but one in the North, hibernating in the chrysalis. The eggs are laid during June or early July, the caterpillars hatching in the latter month, and when quite small conceal themselves in the leaf fold, which is bent over their bodies and secured by silken threads. As they increase in size two or more leaves are fastened together so as to form a leaf case, which shelters them from the weather and screens them from the prying eyes of birds.

\section{Promethea moth Callosamia promethea Drury}

A large, delicate bluish white caterpillar with four large yellow or red tubercles on the posterior thoracic segments and a large one on the dorsum of the eighth abdominal segment, feeds on the foliage of lilac and a number of trees and plants.

This is another common species remarkable in its larval stage for the delicate color, which so closely resembles that of the underside of a lilac leaf, that the caterpillars are difficult to detect. The full grown larva is a stout, bluish white caterpillar about $2 \mathrm{I} / 2$ inches long and ornamented as described above. The parent insect is one of our larger moths and can be easily recognized by reference to plate 43 , fig. 4 . This species feeds on a number of trees and shrubs, being commonly found on lilac, and occurring on sassafras, wild cherry, oak, maple, birch, beech, apple, peach, plum, tulip, poplar and occasionally on pine.

\section{Pristiphora sycophanta Walsh}

A whitish, green tinted sawfly larva on willow, white and yellow birch belongs to this species.

This sawfly was found by Dr Dyar on the leaves of white birch at Keene Valley N. Y. and also on willow and yellow birch at Jefferson N. H. 
The later stages of this sawfly have been characterized by Dr Dyar as follows :

Lara. Head whitish, scarcely shining, eye black, mouth brown; a green tint by transparency; width $1.5 \mathrm{~mm}$. Body smooth, not shining, faintly 4-annulated, translucent, leaf-green, the pulsating edges of the dorsal vessel forming a geminate white dorsal line, filled in with the darker green blood, the anal end usually touched with crimson; segmental incisures a little folded, forming transverse whitish bands when the segments are retracted; tracheal line evident; thoracic feet clear, moderately spreading, abdominal ones small, present on joints 6-1 1 and 13 .

Last stage. As before, but the head is shining, with brown dots; body also more shiny; wicth of head the same as before; the larvae form brown cocoons in the earth.

The female is ' ${ }^{1}$ inch in length, black marked with yellowish.

\section{Bibliography}

1895 Dyar, H. G. Am. Ent. Soc. Trans. $22: 301$

${ }_{1896}$ Marlatt, C. L. U. S. Dep't Agric. Div. Ent. Tech. Ser. 3, p. I15-16

\section{Poplar leaf beetle \\ Phytodecta pallida Linn.}

A pale brown, black-spotted beetle about $1 / 4$ inch long, is occasionally destructive to willow and poplar.

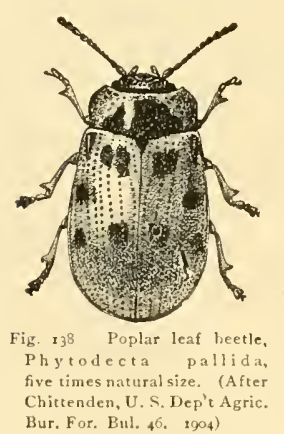

This species, according to Mr Chittenden, ranges across the continent from the White mountains of New Hampshire through the Lake Superior region, Wyoming and Utah to California and British Columbia. It has been observed in injurious numbers in Michigan, occurring in early June in such abundance as to skeletonize the leaves and inflict serious injuries to the trees. Its coloration is more or less variable, and like other leaf feeding insects, it may be controlled with arsenical poisons. 


\section{Viceroy \\ Basilarchia archippus Cram.}

A somewhat tuberculate, angular, reddish brown, yellowish marked caterpillar $1-1 \frac{1}{4}$ inch long, feeds singly on willow and poplar.

The parent insect is a very striking and common butterfly in the Adi. rondacks, having a wing spread of about three inches. It may be instantly recognized by the broad, oblique, white band extending across the middle of both the fore and hind wings. The caterpillar is rather curious in appearance and has a red or purplish brown head ornamented with many reddish brown tubercles. The thoracic segments are somewhat enlarged, dull dirty brownish yellow or clay brown and with darker markings. The middle segment bears a pair of long, spiny tubercles. The rest of the body is a dark brown, olive or dark reddish, tinged in places with brownish yellow, occasionally running into black, and on the middle of the back is a large saddle-shaped spot of a dirty dull cream color, usually slightly tinged with green. While this species is abundant in the Adirondacks, the caterpillars are rarely numerous enough to cause material injury. It feeds by preference on poplars and willows and it has also been taken on other trees such as apple, plum, cherry and it is said to occur on oak.

\section{Harpyia cinerea II'alk.}

A peculiar, light green, brown-marked caterpillar with a pair of long, slender, annulated caudal appendages, occurs on willows and poplars.

- This insect is interesting largely because of the very peculiar caterpillar which, when at rest, appears somewhat like a linear brown scar on a leaf. This peculiar form and coloration is undoubtedly a protective device. This species is so rare that it can not be considered dangerous. A male is represented on plate 44 , figure 7 . A larva, probably of this species, is illustrated on plate 16 , figure 10. 


\section{Smeared dagger moth Apatela oblinita Abb. \& Sm.}

A black-headed, velvety black caterpillar usually with a conspicuous, somewhat broken, subdorsal, yellow stripe and another one along the stigmatal line, occurs in September and October on poplar, willow, alder, buttonbush and a variety of deciduous trees.

This caterpillar is very common, though rarely abundant enough to cause material injury, partly because of its very general food habits.

The full grown larva has a black head, the body is velvety black mottled with yellow dots which, along the subdorsal line coalesce more or less to form a somewhat broken, subdorsal stripe. There is a broad, yellow, stigmatal band deeply incised at the white spiracles. The tubercles are black and bear short bristly hairs. There is more or less variation in color; the tubercles may be deep red, or situated in a series of broad, transverse, red bands reaching across to the spiracles on each segment. The yellow markings may be much more apparent, forming a broad and nearly continuous substigmatal band.

\section{Poplar tent maker}

\section{Melalopha inclusa Hübn.}

A black, yellow-striped larva, about $1 \frac{1}{4}$ inches long, with a pair of large, black tubercles close together on the top of the first and eighth abdominal segments, feeds in the folded, webbed-together leaves of poplar and willows

The larva of this species is easily recognized on account of its remaining in an enclosure formed of several leaves fastened together at the ends of the twigs. It is gregarious in habit and ordinarily is not sufficiently abundant to cause material injury.

Description. The full grown larva is about $11 / 4$ inches long with a nearly cylindric body, bearing on the first and eighth abdominal segments a pair of large contiguous black tubercles. The general color of the body is black, irregrularly mottled with grayish white. There are four subdorsal, lemon yellow equidistant stripes, a substigmatal line of the same color and beneath, a broad, lemon yellow or orange band mottled irregularly with black and dark brown [pl. r6, fig. I]. The second and third thoracic segments and abdominal segments one to eight inclusive, bear anteriorly a rather inconspicuous subdorsal, black setaceous tubercle between the sub- 
dorsal stripes and larger supralateral ones on the middle of each segment. There is a more or less indistinct lateral, dark brown or black line bordered above and below by grayish or yeilowish. The stripes above and below this indistinct line are lighter and irregularly mottled with grayish or yellowish. The true legs are jet black, prolegs dusky orange or yellowish.

The moth has a wing spread of a little over an inch, the fore and hind wings being pale gray, the latter sparsely marked with dark brown scales [pl. 16, fig. 2].

Life history. The eggs of this species, according to Riley, occur in April, May, July and August, the larvae from May to July and August to September, adults March, April, May and July and August. There are evidently two generations annually.

\section{Pteronus mendicus IValsh}

A yellowish, leaf-feeding species. This sawfly larva was taken on willow in Central park and also at Plattsburg by Dr Dyar, who describes its method of oviposition and early stages as follows:

$E g g$. Laid anywhere on the leaf in semicircular saw cuts just under the upper epidermis ; cuts $1.5 \mathrm{~mm}$ in diameter.

First stage. Head blackish testaceous, shining, eye and mouth black; higher than the body; width $.3 \mathrm{~mm}$. Body indistinctly 4 -annulate, not very shining, greenish. Thoracic feet and anal prongs blackish; abdominal feet on joints 6-I I and I 3 .

Second stage. Head dull testaceous, a blackish longitudinal line at the vertex, one upward from each ocellus; eye black, mouth brown; width $.55 \mathrm{~mm}$. Body dull greenish, thoracic feet concolorous; a faint blackish tinge above spiracles and a little on subventral ridge on joints $2-4$, pale along dorsal line; posterior portion of the body curved under so as to touch the venter; anal prongs blackish.

Thir al stage. Head rounded, flattened before, pale green, faintly brownish tinged; a black longitudinal line over the vertex, reaching top of clypeus; a lateral transverse line over ocellus, not quite reaching vertex; mouth brown: width $.9 \mathrm{~mm}$. Body soft, leaf-green, a faint blackish dorsal and substigmatal shade line; venter a shade paler. Feet small, green; anal prongs blackish. Body scarcely annulate, not shining; tracheae showing as a white line.

Fourth stage. Head clear green, marked as before, the marks clouded, not so black as ocelli; an additional patch at apex of clypeus; width I.15 mm. Body uniform leaf-green, not shining, except in the creases of the 
annulets; feet clear, no marks; color paler, clearer greenish yellow than before, tracheae very distinct, white; annulets very obscure; anal prongs with a very faint blackish shade, a few setae on anal plate.

Cocoon. At first pale yellow, later brown, opaque. The adult female is about $1 / t$ of an inch long, light yellow, marked with darker and with brownish antennae. The male is a little smaller, black, and marked with yellowish red.

\section{Bibliography}

1895 Dyar, H. G. Am. Ent. Soc. Trans. $22: 302-3$

I 896 Marlatt, C. L. U. S. Dep't Agric. Div. Ent. 'Tech. Ser. no. 3, p. 69-70

\section{Pteronus odoratus Dyar}

This species lives on willow and has been taken at Ithaca N. Y. The eggs and larval stages are characterized by Dr Dyar as follows:

Eggs. Laid in masses on the underside of a leaf, on the surface without any saw cuts. The dried, empty skins measure $.8 \times .4 \mathrm{~mm}$.

First larval stage. Head $.3 \mathrm{~mm}$ wide, rounded, shining black as in the next stage.

Sccond stage. Larvae eating holes in the leaf, near the eggs. Head rounded, full at vertex, black; width $.5 \mathrm{~mm}$. Body held S-shaped; thoracic feet blackish. Segments annulate shining greenish yellow, pale; the two rows of subventral tubercles visible, smoky; none seen dorsally. Anal plate small, black.

Third stage. Head as before; width .7 mm; anal plate and spines black. Lateral and subventral tubercles blackish; subdorsal black spots faintly indicated. Body light green ; joints 2, I 2 and 13 posteriorly yellowish. On approaching a group of these larvae on a tree, their peculiar odor is very obvious.

Fourth stage. As in the next stage, except that the black markings are smaller. Width of head $\mathrm{I} \mathrm{mm}$.

Fifth stage. Head well rounded; clypeus large, quadrate, smooth, shining black, the sutures and antennae honey-yellow; width $1.4 \mathrm{~mm}$. Body normal for Nematus, terminal segments somewhat swollen. Thoracic fect large, abdominal ones present on joints 6-1 I and 13 (20 feet), the last pair small. Five medioventral eversible pale yellow scent glands behind the feet on joints 6-IO. These function in the normal position of defense of the larvae when the abdomen is held up in an S-shape. A black anal plate with a pair of terminal spines. Segments $4-5$ annulate, smooth, slightly shining, the tubercles obsolete dorsally, but represented laterally and subventrally by large, smooth, rounded, shining black prominences, largest subventrally. A dorsal and subdorsal row of round black spots with 
irregular edges, four on each segment in a straight, even line, not shining like the subventral tubercles. Body light green; joints 2,12 and 13 posteriorly orange. Venter orange tinted. Thoracic feet black, except at the joints; abdominal ones green.

Larvae entered the earth without molting and formed thin, elliptic black cocoons of uniform close texture. Size 6 to $7 \times 2.5$ to $4 \mathrm{~mm}$.

The adult female of this species is nearly $1 / 4$ inch long; black, marked with dusky and ferruginous. The male is slightly smaller, black and marked with light yellowish, which is also the color of the venter.

\section{Bibliography}

1894 Dyar, H. G. Can. Ent. 26:187

I 896 Marlatt, C. L. U. S. Dep't Agric. Div. Ent. Tech. Ser. 3, p. 65

\section{Willow flea beetle \\ Disonycha caroliniana Fabr.} on willow.

A striped, rather stout, black and yellow beetle about $1 / 4$ inch long, occurs in June

This insect was taken by us in small numbers on willow and as a general thing it can hardly be considered injurious. Dr Walsh records rearing it from a cecidomyid gall, $\mathrm{R} \mathrm{h}$ abdophaga brassicoides, of the same season's growth, and states that he captured another at large on that gall about the same date. He also records, on the authority of Dr LeConte, that Say found this species in considerable numbers on the common elder (Sambucus) and some other plants, but he states that he failed to obtain any specimens on elder at Rock Island, though it is a common plant in that section. Dr J. B. Smith records this species from a number of New Jersey localities. Mr F. H. Chittenden obtained eggs of this species and succeeded in bringing the insect to maturity on purslane, though the larvae rejected chenopodium and amarantus. The eggs were obtained July 30 , and the largest larvae had attained full growth by Aug. 9, and entered the earth the following day. The remainder buried themselves in the sand Aug. II, and all but one had transformed to pupae on the $\mathrm{I} /$ th. He found the pupal stage to be of about nine days duration. He has described the larva and pupa as follows: 
The larva when full grown is subcylindrical in form, abdominal segments 2 to 7 subequal in width, the others gradually narrowing toward the extremities. Ground color either olive or green, variegated with red, forming with a dark green mediodorsal and two submedial stripes, seven longitudinal stripes of alternate green and red. Sometimes red and sometimes green is the prevailing tint. Surface finely granulate, feebly shining. Aside from color the general characters are much the same as in D. xan thomelaena Dalm. . . Each segment is produced into a transverse row of 10 papillae, each surmounted by a small black piliferous wart, and terminating in a fine bristle. The first thoracic segment has an additional row of papillae, and each spiracle is surrounded by a ring of black. Head small, nearly circular, color shining black or very dark brown, triangular space in middle and clypeus brown. The posterior end of the body terminates in a proleg which is concolorous with the surrounding portions of the terminal segment. This is surrounded with two rows of black bristles, one above and the other below. Legs considerably darker than the neighboring portions; sutures and some other portions marked with black, last joint nearly black. Length $10 \mathrm{~mm}$, width $3 \mathrm{~mm}$.

From the variability in color of the larva we would expect a similar variation in the pupa. As with the larva there are two prevalent ground tints; in one, rose is the prevailing color; in the other, somewhat greenish orange. Probably these colors represent the similar colors in the larva, rose corresponding to red and orange to olive and green. Asicle from color the pupa of this species closely resembles that of D. xant hom ela ena. The pink or rose-colored form of the pupa has pearly antennae, elytra, and legs, while the orange type has orange-yellow as the color of the same parts. Length, 6-6.5 mm, width, 3-3.2 $\mathrm{mm}$.

\section{Bibliography}

1898 Chittenden, F. H. U. S. Dep't Agric. Div. Ent. Bul. I 8 n. s. p. $83-84$

\section{Spotted willow leaf beetle}

Melasoma lapponica Linn.

A reddish, black-spotted beetle about $1 / 4$ inch long, feeds during the summer on willow leaves.

'This species is closely allied to the striped cottonwood beetle, M elasoma scripta Fabr., noticed on page 317 , and it is stated that the 
larvae of these two species cannot be separated, though the young of this form appear to excrete the milky fluid more freely than its ally. The parent insect may be recognized by its red color above and conspicuous black markings, and were it not for its rather elongated, pear-shaped form, it

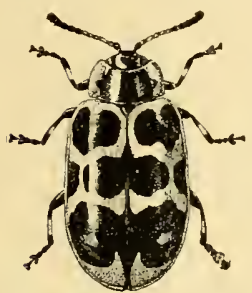

Fig. t40 Spotted willow leaf beetle, Melasoma lapponica, southern form, five times natural size. (After Chittenden, U. S. Dep't Agric. Bur. For. Bul. $4^{6}$. IgO4) might be mistaken for a ladybeetle. This insect feeds on willows and poplars and apparently has very similar habits to those of M. scripta Fabr. $\mathrm{Mr}$ Chittenden states that in some seasons it is just as abundant as the more injurious cottonwood leaf beetle. $\operatorname{Mr} \mathrm{F} . \mathrm{IV}$.

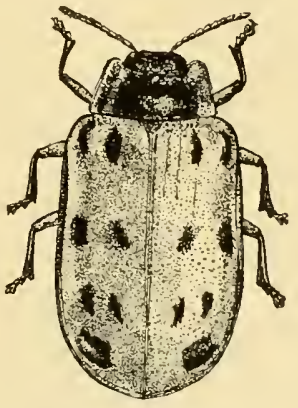

Fig. I $_{39} \mathrm{Mlel}$ asoma lapponica, common New Vork form, en: larged (original)

Hubbard recorded it as being destructive to willows at Lyons N. Y. in 1902. It has been reported as generally distributed in New Jersey by Dr Smith, who also gives alder as a food plant.

Remedial measures. This species, like its ally, is a leaf feeder and can be controlled by a thorough application of a poisoned spray.

Melasoma tremulae Fabr.

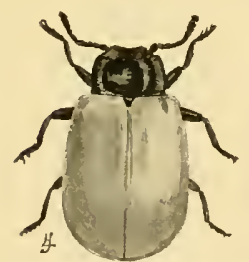

Fig. 14 I Melasomatremula enlarged (original)
This species is very closely allied to M. script a Fabr.

It may be recognized by its brownish, finely punctured elytra, and greenish head and thorax. This form is exceedinglyab undant and injurious in the northwestern states writes Dr Lugger, who adds that it sometimes strips the leares from willows of Minnesota windbreaks. He ranks it as next to M. script a Fabr. in economic importance. This species was taken by Mr D. B. Young at Newport N. Y. in I 898 , where it was stripping the leaves from small poplars and willows. 


\section{Chrysomela bigsbyana Kirby}

A yellowish, black-marked, hemispheric beetle about $1 / 4$ inch long feeds the latter part of the summer on willows and hard pine.

This leaf feeding beetle was taken on hard pine at Karner, September I901, nine specimens being collected on the 6th, and two on the 17 th.

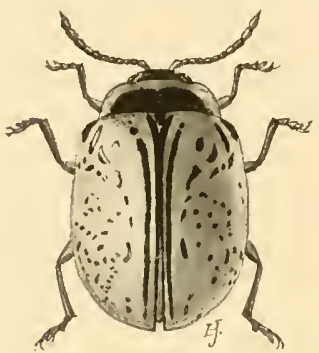

Fig. 142 Chrysomela bigsbyana, enlarged (original)

This species is recorded by Walsh as feeding in the larval stage on willow. He states that the young resemble the grub of potato beetle. It has been described by Mr Coquillett as follows:

Body white, tinged with yellow; spiracles black with a white dot in the center of each; on each side of the segments 2 and 3 is a curved black dash, the curve downwards; cervical shield concolorous, marked with a blackish spot in the micklle of each outer edge; head yellowish brown, ocelli black, in two clusters; length $10 \mathrm{~mm}$.

Dr J. B. Smith states that this species occurs with C. multipunctata Say, on maple, willow, and alder, but that it is more rare. This form is regarded by some as a variety of C. multipunctata and is often confounded with it, so that many references to Say's species, in reality apply to this form.

\section{Dull red willow leaf beetle Galcruccllar decora Say}

This is one of our most abundant leaf beetles and has been considered by Riley to , be the most numerous and dangerous among our willow insects. It closely resembles the related, exceedingly destructive elm leaf beetle, Galerucella luteola Mull. Its eggs, according to $\mathrm{Mr}$ Chittenden, are a little larger, more brightly colored and less acuminate, and the young larvae are darker in color though very similar. He has observed this species on swamp willows

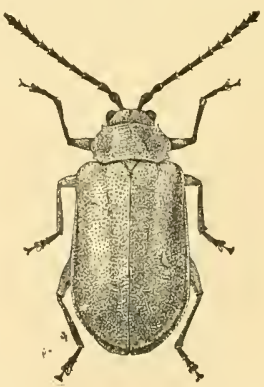

Fig. I43 Dull red willow leaf beetle, Galerucella decora, five times natural size. (After Chittenden, U. S. Dep't Agric. Bur. For. Bul. 46. 1904 ) in central New York in great numbers, both larvae and adults. 
Anaspis flavipennis Hald. occurs abundantly on willow catkins and also on shadbush when in bloom.

Orchestes ephippiatus Say and O. niger Horn, occur on swamp willows in Herkimer county in May and June.

Rhynchites cyanellus Lec. was taken on willow at North Chatham, June 6, igo2.

\section{Elleschus ephippiatus Say}

A small, brownish, long-snouted beetle thickly clothed with golden and brownish pubescence, occurs in considerable numbers on willow in early spring.

This species was met with by us May 16, 1903, at Nassau, where it was abundant pairing and feeding at the base of the ovaries of willow blossoms. This insect appears to be limited to this food plant, since it has been taken on or bred from this plant by a number of entomologists. Dr Walsh reared this insect from a cecidomyid gall, R. brassicoides, on Salix longifolia, and Dr Hamilton records it as common on willow sprouts in southwestern Pennsylvania.

Description. The beetle may be recognized from the following description by Dr LeConte.

A small yellowish brown insect, densely clothed with yellow pubescence, with a large dark spot near the base and another transverse one behind the middle, connected by a sutural stripe; sometimes there is an appearance of a third spot near the tip of the elytra.

Dr LeConte states that this species might easily be confused with some of the varieties of Phyllotrox nubifer Lec., and adds that the elytra are less broadly rounded at the tip and the claws are not simple but broadly appendiculate. He states that it varies greatly in size, ranging from .07 to .11 inch in length.

Distribution. This species has an extended distribution. It has been recorded by Dr Dietz from the Atlantic States, Michigan, Georgia, Kansas, New Mexico and California. 


\section{Poplar sawfly \\ Trichiocampus viminalis Fallen}

Orange-yellow, black-spotted larvae, about $7 / x^{\circ}$ inch long, feed side by side on the foliage of poplars in the early part of June.

This species was brought to notice by Dr J. A. Lintner, under the name of $\mathrm{Aulacomerus}$ lutescens as he was unable to refer it to any described species.

Life history. He states that he found a number of the larvae in the early part of June feeding in parallel rows side by side, on two leaves which had been eaten from the tips, downward. The scars made by oviposition were observed on the leaf stalks and on the leaves, 30 in the case of one, and 28 in the case of the other. He adds that both lots were probably deposited by one female. The larvae feed heartily, and when all but the basal parts had been eaten on one leaf it was abandoned for another. In some cases some of the larger veins were left uneaten. The larvae fed in company till mature, though as they approach this period, they separate into smaller groups and would at once do so if disturbed by the removal of some from the leaf. They commenced to spin irregular cocoons between the leaves on which they had been feeding June 25, and by the 27 th all had spun up. The perfect insects appeared July I3 to 18. A second brood of this species was observed in August. A large number of leaf petioles bore the marks of oviposition, the eggs being placed in two parallel rows on opposite sides, usually on the upper side of the leaf stalk, the rows apparently being made one after another, as they were selclom of equal length, and each for the most part, having the punctures in a perfectly straight line. The foliage of the infested trees was so badly eaten that it was necessary to pick off such infested leaves as could be conveniently reached, in order to destroy the larvae and prevent further depredations. The work of this insect was also observed by Dr Lintner on other trees that same year. The young of this second generation were not carried to maturity, and consequently nothing further could be learned regarding its life history in America. This species is stated by an European authority 
to feed in August and September on the undersicle of willow and poplar leaves, the adults appearing in June.

Description. The larvae of this insect have been described by $\mathrm{Dr}$ Lintner as follows:

When near maturity, they were $7 /$ io of an inch long, of an orange-yellow color, with two rows upon the back (subdorsal) of i 2 large irregularly rounded black spots, measuring in diameter about $1 / 2$ the length of the segment. There is also a row on the side (stigmatal) of 12 smaller black spots, of which the 2 anterior ones are the largest, and semicircular in form. Numerous short white hairs are given out from two transverse rows of tubercles on each segment, the longest of which about equals one half the diameter of the body. The head is black superiorly and laterally, with a central black spot in front surrounded with brown. The tarsal hooks are brown.

Adult. Head, shining black, short, broad, not so wide as the thorax; antennae brown, the seven long joints are slender, tapering regularly to the last. Thorax black above, yellow laterally and beneath, except posteriorly where it is black. Abdomen yellow, distinctly incised, short, flat, subovoid; legs yellow. Wings yellowish towards the base and particularly on the costa ; the stigma large, conspicuous, with a black spot on its base.

\section{Bibliography}

1888 Lintner, J. A. Ins. N. Y. th Rep't, p. $44^{-46}$

I 889 Ins. N. Y. 7 th Rep't, p. $223^{-24}$

Pteronus hudsonii Dyar

Black-headed, bluish or leaf-green sawfly larvae with series of orange-yellow, large blotches on segments $3^{-12}$ and numerous black spots, sit on the edge of poplar leaves.

The larva has been described by Dr Dyar as follows:

Larva. Sitting on the edge of a leaf and thrashing the abdomen about when disturbed. Head normal, round, black, sutures paler; width $2.2 \mathrm{~mm}$. Thoracic feet moderate, pale, abdominal ones on joints $6-1 \mathrm{r}, \mathrm{I} 3$, well developed; short black anal spines. Body smooth, shining, faintly 3-annulate, dorsal vessel yellowish; color bluish or leaf-green, with a series of orange-yellow, large lateral blotches on joints $3-12$ and numerous black spots as follows: two transverse rows per segment above the spiracles, the anterior of three on each side, the posterior of four, its lower (lateral) one largest; two black patches on the halves of the subventral ridge, the lower posterior one somewhat broken; on joint $\mathrm{r}_{3}$ a large lateral błack patch and dorsal suranal blackish cloud. 
The adult insect is a little over $1 / 3$ inch in length, black with a rusty yellow abdomen.

\section{Bibliography}

1895 Dyar, H. G. Am. Ent. Soc. Trans. 22:306

1896 Marlatt, C. L. U. S. Dep't Agric. Div. Ent. Tech. Ser. 3. p. 59

\section{Pteronus vertebratus Say}

A greenish, solitary edge-feeding sawfly on poplar belongs to this species.

This sawfly larva was taken by Dr Dyar on poplar at Plattsburg N. Y. and its egg and early stages have been described by him as follows:

$\mathrm{mm}$ long.

$E g g$. Laid in semicircular incisions under the upper epiclermis, I.5 eye; width $.65 \mathrm{~mm}$. Body pale yellowish, the food showing green by transparency, slightly shining, subannulate.

Third stage. Head as in the next stage, but pale testaceous; jaws black, width I mm. Body the same, slightly shining, subannulate.

Fourth stage. Head greenish, with a slight honey tinge, large, higher than the dorsum; a faint blackish shade runs up not far from the black ocellus which is surrounded by a black spot; mouth brown, a dark mark for antennae; width r.t mm. Body subtranslucent, poplar leaf-green, not shining, the segments folded; no annulets or the merest trace. Feet on joints 6-1 I, 13; anal prongs short, brownish; blackish marks at the base of the clear thoracic feet; tracheal line evident, no tubercles.

Fifth stage. The same with the same wilth of head.

The achult female is about ${ }_{t}^{\prime}$ inch in length, light yellow marked with black or darker brown. The male is a little smaller, black, marked with yellow, and with the entire venter of the same color.

\section{Bibliography}

1895 Dyar, H. G. Am. Ent. Soc. Trans. $22: 303$

1896 Marlatt, C. L. U S. Dep’t Agric. Div. Ent. Tech. Ser. 3, p. 68-69

\section{Hylotoma pectoralis Leach}

Yellowish, blark-spotted, sawfly larwae about $3 / 4$ inch in length, with reddish yellow heads, feed during August and early September on birches.

This insect is rarely brought to the attention of economic entomologists, though several reports of its occurring in immense numbers on 
birches in Quebec have been placed on record. The larva may be recogrnized by its jet-black eyes and yellowish red head, and specially by the six rows of conspicuous black, nearly confluent spots down the back, in connection with a lateral row of elongated ones and the two rows of black spots on the underside of the body at the base of the legs. The dorsal rows of spots are nearly confluent, about three to each segment, except on the last, which is naked and sparsely clothed with rather coarse hairs. This species feeds on white birch in the neighborhood of Quebec during August and September. Dr Fletcher has recorded this insect as very abundant in several Quebec localities in 1887 , they being present in myriads in the eastern portion of the province. These false caterpillars spin cocoons on attaining full growth, the adults appearing the following July or early in August and deposit eggs for a subsequent generation. The perfect insect has black antennae and head, with spots on the breast and ovipositor blue black, the remainder of the body, excepting the legs which are steel blue, being yellowish red. This species has a general distribution in the northeastern United States and Canada, and is probably rather abundant some seasons in the Adirondacks. There is no practical method of preventing its depredations, particularly as birch has very little commercial value.

Nematus unicolor Marlatt

A brown-headed, greenish sawfly larva resting alone on its venter on the underside of birch leaves belongs to this species.

This sawlly was met with by Dr Dyar on white birch at Keene Valley N. Y. Its larra has been characterized by him as follows:

Laria. Head slightly granular, shagreened, a little pilose, pale brownish, pale around mouth, not shining; eye on a black spot; two blackish shades on the back of head behind the rertex; width $1.8 \mathrm{~mm}$. Thorax a little enlarged, its feet spreading; venter flattented feet on joints 6-1 I and $I_{3}$; subventral region slightly fluted with a few pale setae; segments not very completely 5- to 6-annulate, segmental incisures folded; not shining, translucent greenish, food giving a dusky tint; subdorsally below the skin a series of emerald-green or pale green granules and streaks, forming a nearly continuous band, or even an evident white subdorsal band; tracheal line evident; spiracles pale. When mature the larvae became pale 
yellowish with a bright emerald green tint on the thorax and entered the ground.

The adult female is nearly $1 / 3$ inch in length, uniformly reddish yellow marked with brown.

\section{Bibliography}

1895 Dyar, H. G. Am. Ent. Soc. Trans. 22:308

1896 Marlatt, C. L. U. S. Dep’t Agric. Div. Ent. Tech. Ser. 3, p. 88

\section{Pteronus latifasciatus Cress.}

Brown-headed, purplish, solitary or partly gregarious sawfly larvae occur on white birch.

The larva of this insect was met with by Dr Dyar at Keene Valley and his description is as follows:

Head vinous brown, dotted with brown over the vertex, eye black; width $1.6 \mathrm{~mm}$. Body purplish vinous tinted, a metallic red-green shade over the dorsum, partly produced by the food showing by transparency; segments indistinctly 6-annulate, shining, a lateral black shade band, scarcely noticeable against the metallic shade, supplemented by black patches on the folds around the spiracles, subventrally and on the bases of the legs, the latter distinct against the pale purplish subventral color. Feet all pale, yellowish tinged; abdominal on joints 6-11, 13, small; anal plate and short prongs black; setae minute, seen with a lens.

The adult insect is a dusky black, white-marked, sawfly about $1 / 3$ inch in length.

\section{Bibliography}

I 895 Dyar, H. G. Am. Ent. Soc. Trans. 22:304

IS96 Marlatt, C. L. U. S. Dep't Agric. Div. Ent. Tech. Ser. 3, p. 50

\section{Amauronematus luteotergum Nort.}

A black-headed, greenish sawfly larva feeding gregariously on the edges of alder leaves belongs to this species.

This larva was met with by Dr Dyar on alder at Keene Valley N. Y. and he has described two stages as follows:

Larra. Head shining black, sutures of mouth pale; width $.85 \mathrm{~mm}$. Feet on joints $6-11$ and 13 ; anal prongs black. Body shining green, yellowish subventrally and on the legs; segments obscurely annulate, all minutely pilose, but no distinct tubercles; a blackish subdorsal shade-band 
and also blackish on the two parts of the subventral ridge. Thoracic feet and anal plate shaded with dusky black; a medioventral series of black patches.

Last stagc. Head shining dark vinous, eye black; minutely pilose; width $\mathrm{I} .1 \mathrm{~mm}$. Body shining, sordid greenish, rather dark, shaded more or less with vinous, especially subventrally; segments obscurely annulate, minutely pilose; dorsal vessel a dark band; the subventral ridges show as blackish elevations. Thoracic feet partly; anal plate and prongs largely black.

The female is about $1 / 3$ inch in length, very robust, black, marked with yellowish rust-red.

\section{Bibliography}

1895 Dyar, H. G. Am. Ent. Soc. Trans. $22: 304$

I896 Marlatt, C. L. U. S. Dep’t Agric. Div. Ent. Tech. Ser, 3, 8z

\section{Alder flea beetle \\ Haltica bimarginata Say}

Deep prussian blue, rounded flea beet'es about $1 / 5$ inch long or dark brown, blackheaded, black-tubercled larvae occur in large numbers on alder.

This species is sometimes exceedingly abundant in the Adirondacks, and were it not for the fact that alder is comparatively valueless, its depredations would result in considerable loss, as it is more or less abundant from year to year. The ravages by this beetle have been recorded by Dr Harris and Dr Packard in Maine and New Hampshire, and Dr Lugger states that this species is sometimes exceedingly numerous and destructive to willows growing on the shores of Minnesota lakes.

Description. The pupa and larva have been described by Dr Packard as follows :

Larva. The body is somewhat flattened; head scarcely two thirds as wide as the body in the middle, black, becoming brown in front near the jaws. Body livid brown above; the tubercles black; paler beneath, with three pairs of black jointed thoracic legs; no abdominal legs, but an anal prop leg. The abdominal segments each with a transverse, oval-rounded, ventral, rough space forming a series of creeping tubercles; and in front of each segment is a transverse, oval, crescentic, chitinous area bearing two piliferous tubercles; the back of each segment divided into two ridges, each bearing a row of six sharp tubercles, bearing short hairs; a single 
ventral row on each side of the ventral plate. Length 7-10 $\mathrm{mm}(.28$ to .4 inch).

Pupu. Body rather thick white. Antennae passing around the bent knees (femero-tibial joints) of the first and second pairs of legs, the ends scarcely groing beyond the middle of the body. Elytra with five or six rather deep, longitudinal creases. The salient points of the body armed with piliferous warts. Abdominal tip square at the end, with a stout, black spine projecting from each side. Length $6 \mathrm{~mm}$ (.24 inch).

The parent insect has a uniform, deep prussian blue color with greenish reflections on the head and an elevated line near the outer border of each wing cover. It is a rather stout, rounded flea beetle about $1 / 5$ of an inch long.

Life history. The larvae are abundant skeletonizing alder foliage in July and even as late as August and into September, though beetles begin to predominate in the latter months. Dr Lintner states that the pupae are normally found under moss coating adjacent rocks; hundreds were brought to light lying loosely in the mold and without the slightest indication of cocoon or cell. They were about an inch below the surface and distinctly yellow in color, though Dr Packard has characterized them as white.

Distribution. This species has an extended distribution according to Dr Horn, who states that it occurs in the entire northern portion of the continent, as far south as Pennsylvania, thence westwardly, extending over the western plains to Texas and Arizona, and on the Pacific slope from Alaska to Mexico.

\section{Attelabus thois Bohe.}

Peculiar, thimblelike rolls of leaves on alder, hazel, and sumac, may be the work of this species.

This dull reddish beetle has the body clothed with a short yellowish down, and is about ${ }^{1 / 5}$ inch long. The egg is nearly spheric and about $1 / 25$ inch in diameter.

Life history and habits. The singular, thimblelike rolls of this weevil may be found in June and July on alder and also on hazel and sumac. When about to lay her eggs, the female begins to eat a slit near the base of the leaf, on each side of the midrib and at right angles to it, so that the leaf may be folded together. Before rolling, she gnaws the stem nearly off, so that the rolled portion of the leaf will dry in perhaps a day and drop 
with the wind. The ends are neatly tucked into the somewhat tight roll till a compact, cylindric, nearly solid mass of vegetation is formed. Before the entire leaf is rolled, she deposits a single egg, rarely two, in the middle next to the midrib, where it lies loosely in a little cavity. The egg hatches in about a week.

\section{Eight-spotted forester Alypia octomaculata Fabr.}

Reddish, black-ringed caterpillars about $\mathrm{I}^{1 / 2}$ inches long, feed from June into August on Virginia creeper and grapevine.

This rather common insect is occasionally quite injurious to Ampelopsis or Virginia creeper, and it is also a grapevine pest. The caterpillar is easily recognized by the above characters and can be readily controlled by spraying with an arsenical poison wherever this measure is practical. The parent insect is a beautiful black moth with eight lemon yellow spots on its wings, which latter have a spread of $1 \frac{1 / 2}{2}$ inches.

\section{Rose beetle \\ Macrodacty'lus subspinosus Fabr.}

This familiar species is a well known pest of roses and needs no description. It is particularly abundant on sandy soils, where it sometimes occurs in immense numbers. Grapevines and rosebushes in particular suffer from its depredations, though it is almost equally injurious to apple, pear, cherry, peach, plum and most other fruit trees as well as some forest trees. A few specimens were taken on hard pine at Karner in June 190I, and it was abundant the following year on scrub oak.

There is probably no better way of protecting valuable plants from the ravages of this voracious insect than by covering them with mosquito netting.

Calligraphus lunata Fabr. was found eating wild rose blossoms at North Chatham June 6, 1902. 


\section{Rosebud worm \\ Olethreutes nimbatana Clem.}

Greenish, black-headed caterpillars about $1 / 2$ inch long, boring in the buds or webbing together leaves of roses, may belong to this species.

This insect was brought to the attention of the late Dr Lintner in March i $88_{3}$, on account of its injuries to rose plants in greenhouses at Scars-

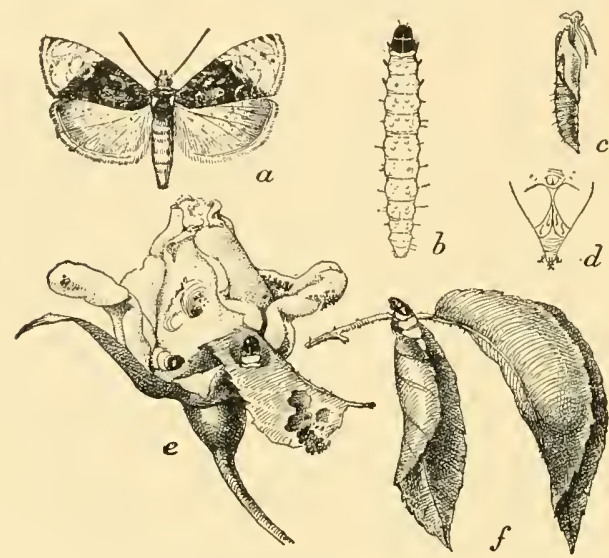

Fig. 244 Olethreutes $\mathrm{nimb}$ at ana: $a=$ moth; $b=$ larva ; $c=$ empty pupal case : $d=$ terminal segment of pupa; $e \Rightarrow$ rosebud showing larva at work i $f$ leaves folded by larva: all twice natural size excepe $d$, which is greatly enlarged. (After Chittenden, U.S. Dep't Agric. Div. Ent. 1gor, Bul. 27, n. s.) dale, IVestchester co. It is well distributed over the State and probably more or less common, since it is known as an annual rose feeder in Albany.

Description. The full grown caterpillar is about $5 / 8$ inch long, a clear apple-green color, with the head and thoracic shield dark blackish brown and the true legs a dull black.

The parent insect is a brownish gray moth with the outer portion of the fore wings and the under surface of the hind wings lighter. The inner part of the fore wings is dark brown mottled with white, black and light purple spots; wing spread about $5 / 8$ inch.

Life history The life history of this species has been given by Dr Lintner substantially as follows. The parent insects appear about the middle of April and deposit their eggs at night, presumably on the terminal leaves of rosebushes. The caterpillars soon hatch and at once commence to draw together margins and surfaces of the folded leaf, and as they increase in size the single leaf is deserted and several fastened together or, as observed by Mr Chittenden, they may enter the unopened buds. The 
caterpillars feed within these shelters, grow rapidly and mature by the last weck in May, transforming to pupae among the folded or fastened leaves of the bush. The moths of the second brood were observed by Dr Lintner as early as June 2. Eggrs are quickly laid and caterpillars of the second brood are soon at work. The pupal stage is limited to about five days. There are two and possibly three broods in the vicinity of Albany, and Mr Chittenclen states that in the District of Columbia there may be three or even four generations annually:

Natural enemies. A single parasite, Eulophus cyriades Walk was bred from this bud worm by Mr Chittenden.

Remedial measures. About the most practical way of controlling this species is to destroy the caterpillars in their web retreats or on open buds, by pinching off and burning or crushing the affected parts.

\section{Bibliography}

I $\$ 99$ Lintner, J. A. Ins. N. Y. $5^{\text {th }}$ Rep't, p. $213^{-15}$

\section{Rose leaf tier Olethroutes cyanana Nurtf.}

This rose leaf insect occurs as far north as Michigan, south to Missouri and District of Columbia. It has been recorded from Pennsylvania and probably occurs in New York State. This species has been carefully studied by its describer, Miss Murtfeldt.

Description. Larato. Length .5 inch, diameter . I, cylindrical. tapering slightly in both directions from middle, but most posteriorly; color dark green, surface glossy with two shallow wrinkles to each segment, spots minute, blisterlike, each griving rise to a fine short hair. A dark vesicular line extends along the dorsum, and on each sicle below the small dark stigmata is a pale translucent ridge or fold, bearing an irregular row of light hairs more conspicuous here than elsewhere. Head polished, honey-yellow inclining to olive, with a few scattered hairs, palpi white, tipped with crimson. Cervical shield polished, nearly same color as the head, covering top of segment I. Terminal point of thoracic legs black. Prolegs concolorous with .reneral surface.

Pupa. Enclosed in a pouchlike case formed from a portion of a leaf folded over and lined with silk, elongate oval in form, very pointed poste- 
riorly and of a bright brown color. Each of the abdominal segments is provided with two transverse rows of teeth, the posterior ridge composed of minute, close-set, rasplike points, while those composing the anterior ridge are longer and more scattered.

In disclosing the moth the chrysalis protrudes itself from its case for nearly its entire length, holding itself in position by the anal hooks.

Imago. Alar expanse from .5 to .55. Length.22. Head and palpi densely tufted, brown with a slight purplish reflection, eyes grayish blue, antennae short. Thorax with a brown dorsal tuft and dark blue patagia. Abdomen fuscous shading to brown above with a silky lustre; front and middle legs fuscous inclining to cinerous, hind legs silvery cinerous, tarsi annulated with pale buff. Front wings dark chocolate-brown and metallic blue; the latter color predominates in the basal third, but is interrupted about midway by an irregular fascia and some scattered flecks of brown; middle portion of the wing mainly brown, but penetrated from both apical and basal sides with streaks and points of blue; on the outer third the blue and brown colors are thoroughly intermixed in a somewhat intricate pattern, the apex being brown variegated with four or five irregular, blue spots, while the inner angle is occupied by a large oblong blue spot divided by an oblique, narrow, brown stripe. The costa presents in a strong light a succession of broad and narrow blue streaks on a purplish brown ground and on the outer edge is a narrow border of the latter color, while the fringe is of a more or less intense blue. Hind wings fuscous, shading to cinerous at base, with a silky lustre, fringe cinerous. Under surface of both front and hind wings fuscous, the former a shade darker than the latter and displaying a faint irridescence. No sexual differences except the smaller size, the relatively narrower abdomen, and conspicuous anal tuft of the male. Murtfoldt

Life history. A considerable proportion of rose leaves will be found in early spring, with their tips blackened and tightly webbed together with glistening white silk. An examination may reveal a minute larva eating into the heart of the growing point, not only blackening and distorting the young leaves, but in many instances destroying the incipient flower bud. This species is occasionally so abundant in Missouri that fully $20 \%$ of the buds, particularly white or light colored varieties, are destroyed. There are at least three successive broods in a season, the later ones attacking plants in full leaf. The full grown larva deserts the mass of webbed leaves and constructs for its protection a neat case by slitting the blade of a leaf on 
both sides a little below the tip and folding and fastening the partially severed portions by the edges to the upper surface. This is lined inside with white silk and in this retreat the insect transforms to a pupa, the moth issuing about ro days later.

\section{Bibliography}

I8so Murtfeldt, M. E. Am. Ent. $3: 14^{-1} 5$

\section{Cenopis pettitana Rob.}

A yellowish green, brown headed, sparsely haired caterpillar a little over $1 / 2$ inch long occurs on oak and rose.

This is another rose leaf roller, which may occasionally be injurious and is likely at any time to invade greenhouses and possibly destroy buds. The adult flies, according to Dr Lintner, in early July. The moth has been described by Dr Robinson as follows :

Palpi pale yellow above, ochreous or brownish ochreous beneath. Head and thorax above pale lemon-yellow, sometimes of a deeper shade.

Anterior wings very pale yellow or lemon-yellow, shining. Costa in the male with two aggregations of brownish ochreous scales at basal and apical third.

Posterior wings and fringes pure shining white. white.

Under surface of both pairs, and abdomen, above and beneath, pure

He states that the wing spread of the male is about $7 / 8$ inch, and that of the female ranges from the same to about $11 / 8$ inches. He gives its habitat as western Canada, Ohio, Illinois, and as stated above, it has been recorded from New York. Dr Dyar lists it from the Atlantic States. Dr Robinson states that this is a quite variable species, and an examination of specimens from Illinois resulted in the following description made on the spot: "Head, thorax and palpi above, clear lemon-yellow, the latter brownish ochreous laterally and beneath. Upper surface of primaries in both sexes lemonyellow; the costa covered with brownish ochreous scales to one third from base. Hind wings above and under surface of both pairs brilliant white." The female is slightly larger than the form described above. 


\section{Cenopis reticulatana $\mathrm{Clem}$.}

This rose leaf roller is abroad in New York State in July and may be considered a form capable of doing more or less clamage from year to year, and should it invade greenhouses is likely to be rather injurious. It has been recorded by Dr. Smith from New Jersey localities, where it is stated to feed on rose, geranium, oak, persimmon, pear and maple. Dr Dyar lists it from the Atlantic States. The little moth has been described by Dr Rolinson as follow's :

Palpi red, very long, proboscidiform. Head and thorax yellow above. Anterior wings yellow finely reticulated with orange. Costa at base tinged with purple. Central fascia purple, commencing in a spot on costa before the middle and ending in the apex of a large triangular spot of the same hue on internal margin. The large purple costal spot throws out a line which is forked just below it, one branch running obliquely inwardly to the triangular spot on internal margin, the other outwardly to before internal angle.

Posterior wings and fringes very pale yellow. Under surface of both pairs pale straw color, the anterior pair slightly reflecting the hue and markings of the upper surface.

The wing expanse has been griven by Dr Robinson as from 5 s to ${ }^{3}+$ inch in the male, and in the female from about $3+$ to $78 \mathrm{inch}$. This species he states varies greatly, the reticulations sometimes being obsolete and the ordinary markings partially so.

\section{Oblique banded leaf roller \\ drchips rosaceana Harr.}

Brown-headed, greenish caterpillars about $3 / 4$ inch long, occur in May and early June in the webbed leaves of a large number of trees.

This species is a very common leaf roller and occasionally destructive to rose and some other more valuable shrubs and trees. It is an exceedingly general feeder, having been bred by Mr Coquillett from some 24 different species of plants, including among others, apple, cherry, lilac, horse-chestnut, burr oak, poplar, hazel and sumac.

The larvae draw together the young leaves at the ends of the limbs, 
secreting themselves therein and feed on the foliage. They are slender, pale green or yellowish green caterpillars sometimes reddish or hrownish, about $3 / 4$ inch long, with the head and thoracic shield brown and often a green stripe along the back. They attain their growth in early June, transform to pupae, delicate brown moths with a wing spread of about $7 / 8$ inch appearing the latter part of June or early in July.

\section{Rose leaf folder Archips rosana Linn.}

A dark olive-green, brown-headed caterpillar feeds within the webbed-together leaves of rose and a number of olher plants.

This leaf roller is an introduced species and like its allies, not very particular as to its food plants. It has been recorded from wild rose, apple, hawthorn, raspberry, hazel, currant and gooseberry: Both larva and moth are darker than those of most of our native species. The brownish gray moth, having a wing spread of about $3 / 4$ inch appears in early June.

Platynota flavedana Clem. This is another small rose leaf roller liable to cause more or less injury outdoors and likely to invade greenhouses, in which latter it may acquire the bud-eating habit.

\section{Walnut curculio}

Conotrachelus juglandis Lec.

A curculio very much resembling the plum pest though larger, $1 / 4$ inch long, frequently infests walnuts and butternuts.

This species very closely resembles the plum curculio. It is about $1 / 4$ inch in length, reddish brown and prettily ornamented with golden and silvery hairs. The most conspicuous feature is the broad transverse whitish band on the posterior third of the wing covers. The curious projections on the wing covers seen in the plum curculio

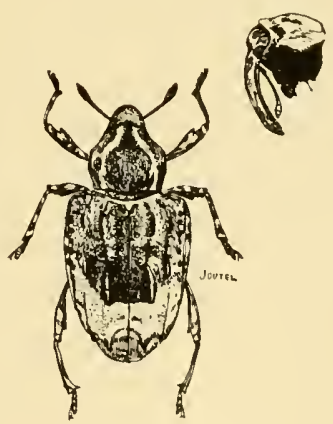
Fig. 145 Conutrachelus jug. landis, enlarged (original) also occur, and an examination with the lens shows them to be strongly ridged and ornamented with several minor processes. 
This curculio is the parent of the worm frequently occurring in walnuts and butternuts, and the presence of the pest is indicated by a discolored spot on the green husk. Dr Lugger states that these insects frequently take the lion's share of our native nuts. Mr Young has met with the insect in early June at Poughkeepsie, and has taken it at Newport N. Y. Mr UThe records this species on hickory from the District of Columbia, and Dr Packard states that it has been taken from walnuts at Mt Carmel 111.

This species was described from the Middle States. It occurs in various sections of New Jersey, breeding in green butternuts and walnuts, and has been listed from southwestern Pennsylvania by Dr Hamilton, who states that it is common on walnut and hickory.

\section{Conotrachelus seniculus Lec.}

A small, long-snouted obscure brown-colored weevil about $3 / 26$ inch in length, marked with a yellowish white rransverse band on the posterior third of the wing covers, occurs on butternut and hickory.

This small species was taken on hickory May 26 and June 5 at Poughkeepsie by Mr Young. It is a small, inconspicuously colored species which may be recognized by the elytral markings given above. The wing covers are rather strongly riclged. Dr LeConte states that it is of the same form and size as C. n en uph a r Herbst., and is distinguished from C. a $\mathrm{f} f$ in is Boh., chiefly by the broader and more strongly carinate prothorax; by the two lines of pubescence being straight and meeting at the front margin, and by the first ventral segment being less punctured than the others.

Dr LeConte records this species from the Middle and VVestern States and Texas, and Dr Hamilton states that it is not common in southwestern Pennsylvania. It has also been listed from the District of Columbia, from the vicinity of Cincinnati and New Jersey. 


\section{Hickory shuck worm}

\section{Enarmonia caryana. Fitch}

A slender, white caterpillar about $3 / 8$ inch long, mines hickory shucks causing them to abort and fall prematurely.

This little miner of the hickory shucks or husks is very common in New York State and so far as our observations go, its operations have been confined to the husk or shuck enveloping the nut. Dr Shimer states that in Illinois the larvae live in the nut of the bitternut hickory, Carya a ma $r$ a, destroying its interior and causing it to fall. Dr Fitch has placed on record the statement of Louis Potter of Easton N. Y., to the effect that this insect was so numerous in his section in 1856 , that several of the hickory trees scarcely produced a single nut. According to Dr Shimer, the moths appear the latter part of November, hibernate in this stage and live till some time in June, when they deposit eggs on the young nuts. Dr Fitch states that specimens of this insect were received by him from Easton $\mathrm{X}$. Y., in April, with a letter saying that the insect pupated about the first of February, the moth emerging the latter part of that month. Dr Packard records taking unrubbed specimens of this moth May 20, in a growth of young hickories at Providence. These two records seem to indicate that some of the insects hibernate in the larval or pupa stage.

Description. The moth has been described as follows, by Dr Fitch :

Sooty black, the fore wings with reflections of tawny yellow, blue and purple; their outer edge black, with oblique triangular whitish streaks placed at equal distances apart. A very oblique faint silvery blue streak extends inward from the points of two of these white streaks, namely, the fourth and sixth ones from the tip of the wing ; while the usual white spot on the inner margin of the wings is wanting. Expanse of wings, .6 inch.

\section{Acorn weevil \\ Balaninus nasicus Say}

A weevil, with a remarkably long slender curved leak, occurs on acorns or may be bred from white legless grubs within them or other nuts.

This species was met with in small numbers when collecting in June at Karner in 1901, and was bred the following season from acorns on the 
hear or chestnut scrub oaks. This species was noticed by Dr Harris who states that it is one of the most common nut weevils known to him, and he adds that it is very common in hazelnuts, chestnuts and acorns. Dr Fitch states that hickory nuts are seldom affected by worms, referring to this species or perhaps also to allied forms, and adds that they are much more frequently met with in hazelnuts, chestnuts and acorns. He failed to rear any of these insects as was also the case with 1)r Harris. Dr Packard states that Professor Riley bred this species from a lot of acorms of Q uercus srisea, received from Fort Grant Ariz., July 26, r882, and Messrs Howard and Riley record breeding this species from a lot of acorns from which 13. un iformis Lec. was obtained. I) Packard also published a note of Professor Riley's to the effect that this species breeds antirely on hickory nuts, while Mr Harrington states that in the neighborhood of Ottawa Can., it is never found on hickory but frequents the hazel almost entirely, being very numerous on these bushes in some years.

Description. This species has been lescribed by Dr Harris as follows:

Its form is oval, its ground color dark brown; it is clothed with very short rust-yellow Hattened hairs which more or less conceal its original color, and are disposed in spots on its wing covers. The snout is brown and polished, longer than the whole bocly, as slender as a bristle, of equal thickness from one end to another, and slightly curved; it bears the long elbowed antennat, which are as fine as a hair, just behind the middle. This beetle measures nearly $3 / 10$ of an inch in length, exclusive of the snout. [Sec pl. 17 , fig. 19,20$]$

The larva or grub of this species has been desribed by 1)r Riley as yellow, with reddish brown head and dark brown mandibles.

Life history. Dr Harris records finding this species paired on hazelnut bushes in July, at which time the egos are probably laid. He adds that others appear in September and October, and must pass the winter concealed in some secure place. Mr Glover states that there are said to be two broods, the last one probably hibernating in the earth, and reports $\mathrm{Mr}$ Akhurst of Brooklyn as observing that these insects sometimes remain in the larval condition over one season. $\mathrm{Mr}$ IV H. Patton states that the following species of Balaninus have been reared from acorns: $B$. 
caryae Horn, B. uniformis Lec., B. nasicus Say, B. rectus Say, and B. quercus Horu.

Natural enemies. This species is apparently exempt from the attacks of natural enemies. Messrs Riley and Howard record the rearing of Trichacis rufipes Ashm. MS., from cocouns infested with this insect. and Holcocera glandulella Riley from St Lonis Mo., and states that this is probably from a Cecidomyiid inquiline. It thus appears that no undoubted parasitic enemy has yet been obtained.

\section{Bibliography}

1856 Fitch, Asa. Ins. N. Y. 3it Rep't, 1) $142-43$

${ }_{1890}$ Packard, A. S. U. S. Ent. Com. $5^{\text {th Rep }}{ }^{\circ}$ t, $1,216,327,641$

\section{Chestnut weevils}

Balaninus proboscideus Fabr.; Balaninus rectus Say.

Wormy chestnuts are familiar to all lovers of this favorile nut, though the parent insects are not so well known as their unwelcome grubs.

Chestnuts are so seriously infested by this insect in some seasons that a large proportion of the crop is rendered worthless. It not infrequently happens that a lot of chestnuts stored in some box or vessel soon after gathering are found a few weeks later badly infested and sometimes nearly entirely destroyed by the white grubs or young of this weevil. The chestnut is a valuable native nut, and one which is apparently capable of considerable development. There are now many acres in this and other States almost unproductive which might produce large crops of this nut. It is stated that great quantities of Spanish nuts are imported yearly though equally good, if not better ones, can be grown here. Several individuals are now engaged in growing this nut for the market, and as an illustration of what has been done, the 20 acres of bearing paragon trees of Mr H. M. Engle, Marietta Pa., may be mentioned. Natise trees were cut on a steep hillside and the sprouts grafted to this improved variety, and in about three years they began to bear. The trees were kept trimmed and the ground clear from underbrush, and it was stated in 1896 that the land 
yielded more in value than an equal area of potatoes, and at much less expense. The grafting of an improved variety on native stock renders it easy in a few years to transform worthless trees to valuable fruit producers. The most serious drawbacks are stated to be underbrush, injury by insects and thieves.

Injury by chestnut weevil. The amount of damage this insect causes varies with the season and the locality. The following facts published by Dr lintner give an jolea of the damage caused by the insects:

Mr R. C. Hewson, Penı Yan N. Y. estimates the annual loss of native nuts in that vicinity at from 5 to ro\% of the crop. This appears to be rather a conservative estimate, since in Massachusetts as high as $40 \%$ of the chestnuts in certain seasons are injured by these weevils. Sometimes in New Jersey $50 \%$ of the Jipanese and Spanish varieties are ruined, and Dr Smith cites an instance in which the crop was almost entirely destroyed at the Parry Brothers nursery. The loss in Maryland ranges from io to $25 \%$, in Delaware from 30 to $40 \%$, and in North Carolina from ro to 50, possibly averaging about $20 \%$. From 5 to $25 \%$ of the few native nuts in Michigan are injured by the weevils.

Species attacking chestnuts. There are at least two species which injure chestnuts in this country.

The large chestnut weevil, Bal a n in us proboscideus liabr. may be distinguished from other American species of this genus, as stated by 1)r Horn, by the first joint of the antennae being shorter than the second. It is a beautiful variegated insect with fuscous lines and spots interspersed among the dense ocherous scales on the thorax and wing covers. Some examples of this species are entirely ocherous. The beak of the female is very long, and ranges from i t to twice the length of the body. The distribution of this species has been given by Dr Lintner as follows: Massachusetts, New Jersey, Pennsylvania, District of Columbia, North Carolina, IVest Iirginia, Ohio, Illinois, Tennessee, Middle States westward. Other localities are recorded by McCarthy for chestnut weevils, but the species are not indicated.

The smaller chestnut weevil, Bala nin us rectus Say, has a wider recorded distribution, as follows: Canada, Massachusetts, New York, New 
Jersey, Pennsylvania, District of Columbia, Virginia, West Virginia, Ohio, Southern States and Arizona. Besides the above, chestnut weevils have been reported from Delaware, Maryland, Georgia, Michigan, and Missouri, but without haring been referred to either species. Possibly each of the species may have a distribution over the United States coextensive with its chosen food.

The smaller chestnut weevil, Balaninus rectus Say ranges from about $1 / 6$ to $1 / 3$ inch in length, the general color of the scales or hair is light brown above, pale yellow below, and on the thorax there is a dark brown discal stripe, which is limited at the sides, and divided longitudinally by a pale yellow line. The wing covers are variously marked with the same color. The beak of the female is very long, being equal to or even longer in proportion than in the larger species. The long beak and the long conical thorax is said to distinguish $\mathrm{B}$. rectus from the other members of the genus. The male is not so readily recognized. "It has a shorter thorax, but it is still narrowed anteriorly; this, with small femoral tooth oval elytra rapidly narrowed from base, and a yellowish or brownish spot of condensed scales on each side of the central line of the metasterum (occasionally obsolete), will, with practice, distinguish it." Hamilton

Life history. The life history of these two species agrees very closely so far as known. The weevils appear about the time the chestnuts bloom and oviposit in the young burrs. The long snout of the female is well adapted for piercing the kernel, and one or more eggs are then deposited therein. The slight injury to the husk and nut soon heals, and there is no exterior indication of the insect's presence. The holes observed in wormy chestnuts are made by the larvae when forsaking the nut. The females are said to live but a short time, a week or two at the most. All the larvae of this species enter the ground in the autumn, none winter in the nut, though this has been thought probable by some writers. Dr Hamilton states that the appearance of the smaller chestnut weevil in breeding cages was much more irregular than that of the larger, varying from June 28 to Oct. 1. On this latter date he found in the cage pupae in various stages, and many 
larvae or grubs that would doubtless live through the winter. 'A delay till the second season appears to be quite common in this species, and is one of nature's safeguards against extermination should there be an entire failure of the crop in any one year, as happens occasionally. This smaller species is known to breed in chinquapin nuts and acorns, as well as chestnuts while the larger form has been obtained only from the latter. There is apparently no record of the larger species remaining in the pupa stage till the second year, although it is probable that such occurs. Only one parasite, Urosigalphus armatus Ashm. has been bred from this chestnut weevil.

Remedial measures. There is no practical method of preventing oviposition, unless it be by jarring which would probably prove too expensive in most cases. The infested nuts should be destroyed each year before the insects forsake them and enter the ground. Wormy chestnuts may be easily recognized by pouring the nuts into a vessel of water, and the lighter ones will rise to the surface after a little stirring. The sound ones should be dried, and it would be safer to thoroughly treat them with carbon bisulfid, using at least one pound for each rooo cubic feet of space and exposing the muts to the fumes for about 24 hours.

\section{Bibliography}

1897 Lintner, J. A. Inч. N. Y. I 2 th Rep't, 1. $267-72$

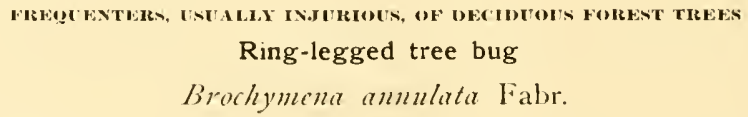

This dark grayish black, rather thick tree bug abous 58 inch long, may be taken from midsummer to the end of the season and probably in early spring, on various trees.

There are only three examples in our collection and these were captured from miscellaneous trees; one, in particular, probably occurring near or on pines.

Description. This species has been frequently mentioned in literature, though in some instances it has probably been confused with B. f-pus- 
$\mathrm{t} u$ lat a Fabr. Mr E. P'. YanDuzee of Buffalo, who kindly determined our specimens, states that this species may be recognized by the short, broad head, truncate at the apex, with the apical sinus nearly transierse. The surface is finely and coarsely punctured and ornamented in places by groups of large, black punctures; the sides of the pronotum before the sinus are stronsly arcuated and armed with close regular teeth; the second joint of the antennae is much shorter than the third, and the rostrum is longer, usually reaching the third ventral segment. He states that this is a comparatively rare species, which he has seen only from the castern United States, his material showing a range from southern New York to Filorida. Messrs Walsh and Riley record the insect from Hannibal Mo, in 1869, at which time it was considered beneficial. Its distribution has been griven by Uhler as Colorado, Texas and a large part of the United States east of the Mississippi river. Mr C. H. T. Townsend lists it from Kansas, and Professor Osborn states that it is common in Iowa. Dr Smith also lists

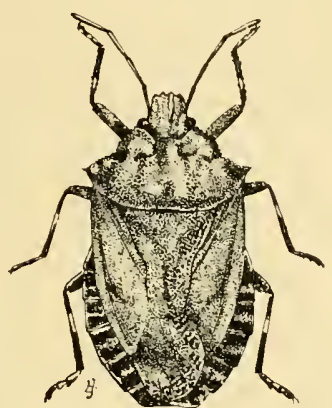

Fig. so Brochymena annulata, enlarged (wriginal) this insect from a numbar of New Jersey locations and from Staten Island.

Habits. There are several records of this species ociurring on appletrees in considerable numbers, and Messrs Riley and Howard cite a case in Virginia, where this insect attacked a new growth of appletrees in the month of May. It is there known as the "large chinch bug," and many twigs and limbs were said to have been killed by the insect. These gentlemen add that the adults occur under bark in midwinter, and that the eggs and young larvae have been found on pea rines and willow.

Professor Webster also records a case where this insect killed the shoots on some young appletrees in May i 894 , at Owensville O. This was on the farm of Mr Lowell Rauderbush, who wrote Professor Webster that he had carefully watched the insect in the summer and found that it also 
attacked young plumtrees. Professor IVebster observed this species in large numbers on larches near Cincinnati, and on various fruit trees in Ohio northward to Lake Erie, and he records in addition, taking the insect in Illinois and Indiana. Professor Pettit notes its occurrence in Michigan, though no record of injury is given.

\section{Bibliography}

I894 Riley, C. V. \& Howard, L. O. Insec1 Life, $7: 47-48$

1896 Webster, F. M. O. Agric. Exp. Sta. Bul. 68, p. 26-27

\section{Brochymena quadri-pustulata Fabr.}

This is a rather stout, dark gray plant bug about $5 / 8$ inch long. It was taken by us on hard pine at Karner and on willow at Nassau, and occurs rather commonly from July to the end of the season and in March, April and May on various trees and shrubs in different sections of the state. We have specimens kindly determined by Mr E. P. VanDuzee of Buffalo from the following New York localities: Warwick, Nassau, East Greenbush, Karner, Ilion, Newport, Ithaca, North Hector, Pike, Batavia and Hambury. Mr VanDuzee has seen this form in several collections under the name of B. a n nulat a Fabr. The distinguishing characteristics as given by him are the "long head, narrow and cleft at the apex, the rounded anterior margin of the humeri, and the pale, irregular teeth on the sides of the pronotum anteriorly." It is probable that some of the records given under B. a n nulata Fabr., refer to this insect. This is probably the species we have met with in abundance on appletrees, four or five being observed within a short distance of each other, and we have also taken it on plumtrees, though no instance has come to our knowledge of serious injury. This species is noticed but rarely in literature, though Uhler has recorded it from Texas, New Mexico and Louisiana, and Dr Smith lists it from several New Jersey localities, adding that it occurs late in the fall, early in the spring and occasionally in winter and that it is not injurious. 


\section{Brochymena arborea Say}

This is a stout, grayish, rosy or red-marked tree bug about $5 / 8$ inch in length. It is remarkable for the serrate and angular projections of the pronotum and the large toothlike processes of the head. We have taken this species at both Nassau and Lansingburg N. Y., in the former locality on or near willows, and in the latter probably about growths of miscellaneous bushes. Mr Townsend gives its distribution as the Atlantic States, while Professor Osborn records it as common in Iowa. Dr Smith lists it from Staten Island and a number of New Jersey localities, stating that it is common about Caldwell.

\section{Buffalo tree hopper}

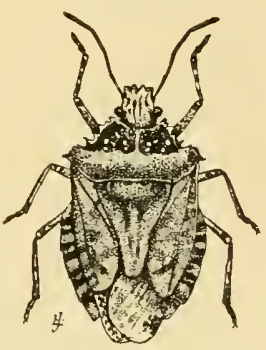

Fig. $x_{47}$ Brochymena arbox $a$, enlarged (originai)

\section{Cercsu bubalus Fabr.}

A grass-green, triangular two-horned leaf hopper, about 38 inch long, may be met with in the latter part of the summer on a number of trees and shrubs.

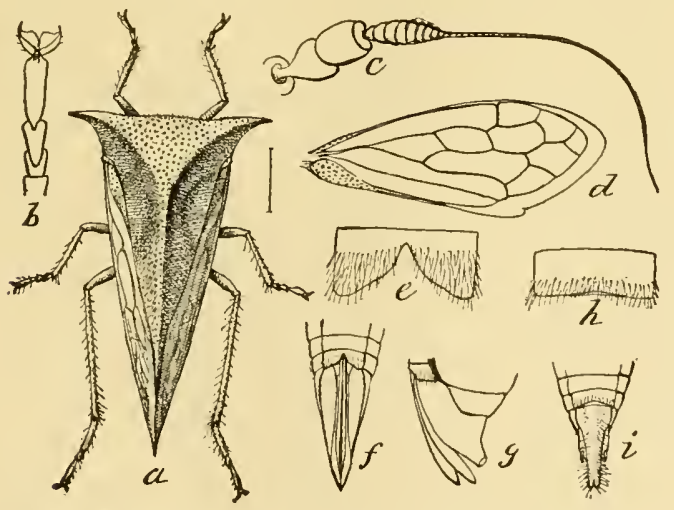

Fig. $y^{8} a$-female; $b=$ enlargement of foot: $c=$ intenna; $d$-wing: $c_{,} f, g$-terminal segment and ovipositor of female; $h, i=t e r m i n a l$ segment of male abdomen. (After Marlatt, U. S. Dep't Agric. Div. Ent. 1897, Cir. 23, 2d s.)

This grotesque little insect is a very common species sometimes present in considerable numbers. It rarely inflicts much injury on forest trees and is important from an economic aspect largely. on account of the damage done to young fruit trees.

Description. The egg is about $1 / 16$ inch long, slightly curved, tapering

toward the outer end and more rounded at the other. It is a dirty whitish 
color, without markings, and cylindric, except as its shape is modified by pressure of the wood and adjacent egoss. The young resemble the adults but are wingless and armed along the dorsal line with numerous forked or barbed projections. The adult is a green insect, about $3.8 \mathrm{inch}$ in length, and may be easily recognized by the greatly enlared thorax which bears on its anterior angles lateral projecting horns, as represented in figure 148 .

Life history. The life history of this insect has been given by $\mathrm{Mr}$ Marlatt substantially as follows :

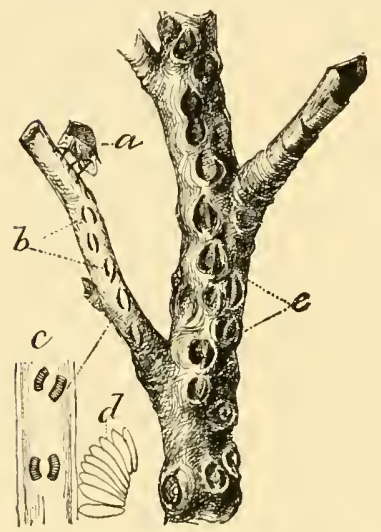

The adult insect deposits her egrgs in twigs of various trees, preferably those of two or three year's growth, particularly the apple, willow, cottonwood, maple etc. and confines its operations in greneral to the upper surface of the twigs. It works more abundantly on the south sicle of the trees than on the north, though in this respect the prevailing winds and other conditions appear to have an influence. The esgs are deposited quite as readily in the new growth of olel trees as in young growth though the damage is much more noticeable in the latter. They are placed in small compound groups of from H1 449 Twig of anple showitn: $a$-female

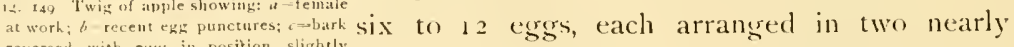
reversed with eggs in position, slightly enlarsed; $d$ single raw of exgs still more parallel or slightly curved slits extending in the years's standing on older limbs. After direction of the twigs about ${ }^{3}{ }_{16}$ inch, and sepaMarlaut, $\mathfrak{C}^{\circ}$. \&. Wep't Auric. Hiv. Ent. 1897 (ir. 23, at s, Pated by 18 inch or less of bark. The bark is cut by the ovipositor in such a way when depositing the esses that the narrow portion intervening between the two incisions is loose. This has a very important bearing on the subsequent condition of the wounds made by the insect in oviposition. The object is doubtless to cause a deadening of the wood between the two rows of eggs, and thus prevent their being crushed or choked by the subsequent rapid growth of the twin, and it is due to this peculiarity that the injury later assumes such a serious nature. A single 
incision made by the insect would heal over and cause little after-damage, but the combination of the two incisions and the killing of the intervening bark causes it to adhere to the wood and a large scar is produced, which with subsequent years' growth assumes an oval form, the dead bark of the center breaking out. Limbs which have been thickly worked by the insect become very scabby and rough, are easily broken off by the wind, and are very liable to attack by wood-boring insects. The adults appear about the micklle of July and become most numerous during August and September. They besin oviposition about the middle of the former month, or even earlier, and continue till they are killed by the frost of early winter, sometimes working as late as the end of October. The number of eggs deposited by a singrle female exceeds 100, and possibly 200. The egrss remain unchanged or dormant in the twigs till the following spring, hatching in May or carly in June.

Food plants. The young as well as the adults feed on all sorts of succulent vegetation, such as weeds and garden regetables, and are apparently not particularly fond of the apple, much preferring the more succulent annual plants. Mr J. G. Jack states that he has found the adults feeding on the young tender shoots of the apple near the ground, though Dr Marlatt states that after careful and repeated observations in an orchard, so badly infested as to be nearly ruined, he failed to find any indication of the insects feeding on the apple, and he concludes that the infestation that Mr Jack observed must relate to the suckers springing from the base of the: tree.

Distribution. This insect has evidently a very general distribution in the United States, since it has been recorcied from Canada, southward to Missouri, at least, and westward to the Rocky mountains.

\section{Bibliography}

I897 Marlatt, C. L. U. S. Dep't Agric. I)iv. Ent. ('ir. 23, 2 d s. 


\section{Two-marked tree hopper \\ Enchenopa binotata Say}

A peculiar, brownish, black tree hopper with an enormous hornlike projection over its head, occurs in the fall on a number of plants.

This little insect is very peculiar on account of the enormously developed prothorax, which makes it appear as though it were the bearer of a large horn. It is very probable that this structure is of advantage, since the resting insect bears a very close resemblance to a thorn and on this account is no doubt overlooked by natural enemies. This tree hopper is specially fond of bittersweet, which it occasionally injures seriously. It occurs on this plant during July and August in company with its young, a group somewhat resembling a flock of old and young partridges in miniature. The egg covering of this insect is as unique as the parent. It is a snow-white, frothy mass about $3 / 16$ inch long by $1 / 8$ inch broad, and an examination with a lens shows that it is composed of a clouble row of numerous small, stringy, transverse masses laid side by side, those of each row meeting end to end along a somewhat irregular median ridge. See plate 17 , figure 15 , for an illustration of the adult and plate 49 , figure 4 , for a representation of the peculiar egg coverings.

Description. The full grown insect has been described by Dr Harris as nearly $3 / 10$ inch long, including the horn of the thorax; of a dusky brown color, and with two yellow spots on the ridge of the back. When seen sideways it presents a profile much like that of a bird, the head and neck of which are represented by the curved projecting horn of the thorax. The young of this little tree hopper, of various sizes, clustered together on a stem of the waxwork, may be likened to a flock of old and young partridges. They appear to pass through all their transformations on the plant, are fond of society, and sit close together with their heads all in the same direction. The eggs, as stated by Dr Lintner, are arranged in much the same way as those of the cicada, inserted through a single hole, in two parallel series separated by a small interval. There are in each row from six to 12 eggs, which partly overlap one another. They are elongrated. 
almost cylindric, of a delicate green color, pointed at the more deeply buried end, and rounded and of a yellowish tint at the opposite extremity:

Life history. The life history of this insect is incompletely known. The young were found by Dr Riley on the soth of May at which time after passing their first and third molts, on May is and June 5, they transformed to perfect insects June 12. The young are described as being without the hornlike projection of the thorax, and they appear to lack the ability to hop which the adults possess, and from which they derive the common name of treehoppers. The time of oviposition is not known, but it is probably not prior to the middle of August in New York State, for on the 8 th of that month Dr Lintner observed the mature insects abundantly on locust, when none of the egg coverings were observed. A correspondent of Dr Lintner's records finding the egg covering in the early part of September. We have found them in October and the insect undoubtedly winters in the egg.

Food plants. This species occurs on a number of plants during the latter part of the summer. It may be found on grape, red hoptree and trefoil, the latter its favorite home. It has been recorded as occurring on the leaves of the butternut and locust, and has been observed on wisteria.

Distribution. This insect has an extensive range, having been recorded by various writers from Canada, Massachusetts, New York, New Jersey, Pennsylvania, Maryland, Illinois, Michigan, Iowa, Missouri and Texas.

\section{Bibliography}

1882 Lintner, J. A. Ins. N. Y. Ist Rep't, p. $28 \mathrm{I}-88$

\section{Thelia acuminata Fabr.}

This, one of the most grotesquely shaped of our tree hoppers, is characterized by the enormous development of the prothoracic horn, which extends nearly vertically with a uniform diameter to a rounded tip $1 / 8$ inch above the large prothorax. The insect is about $1 / 4$ inch in Fig. 150 Thelia acumilength, yellowish, densely mottled with brown or dark brown, specially 
on the prothoracic horn [pl. 17, fig. 17]. A single specimen was taken on scrub rak at Karner July 24, 19or, and Mr E. P. Van Duzee, who kindly iclentified the species, states that it is a rather rare form, being met with only occasionally in his own collecting, and seldom represented in lots sent for identification. It has been recorded by various writers from Pennsylvania, Irkansas, New Jersey, Massachusetts, Michigan and New York.

Thelia godingi Van I)แ\%.

This is one of our more grotesquely shaped leaf hoppers. It may be

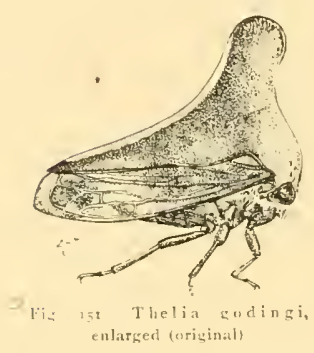
recosnized by the enormously developed prothorax which forms a stout, nearly rertical, rounded horn. The median line on the posterior portion of the horn and on the top of the immensely developed prothorax is marked by a lenticular whitish line. The remainder of the prothorax is yellowish brown marked with darker brown, specially near the extremity of the horn, where it is nearly black. The head is yellowish and the ey's are black. This pretty leaf hopper was taken in small numbers on scrub oak at Karner, July 27, 1901.

\section{Telamona monticola fiabr.}

This grotesque little leaf hopper measures about 38 inch in length and may be distinguished hy its yellowish brown color and the broadly rounded elevation of the immensely developed prothorax. It is a very common species on the Virsinia creeper or ampelopsis, and was taken by the writer in small numbers on scrub oak at Karner in July 1901. I)r Fitch in his catalogue of the Homoptera of the State of New York, published in 1851 , described this form as T. quer $\mathrm{i}$ and states that it occurs on scrub oak.

This insect has been recorded from Massachusetts, New York, New Jersey, Maryland, North Carolina and Illinois by various entomologists and presumably has a general distribution in the Eastern States at least. 


\section{¿ Archasia galeata Fabr.}

An apple-green, somewhat triangular tree hopper with an enormously developed prothorix, occurs on scrub-oaks and other trees from midsummer to early fall.

This species hats the prothorax remarkably developed into an arched shield covering most of the body [pl. 17, fig. 16]. It is triangrular in outline, whether viewad from the front or above, and the membraneous wings extending from under the pronotum, are areenish, brownish or yellowish brown in color. This species is about 38 inch in length, and was met with in small numbers on scrub-oaks at Karner in rgor, specimens being taken the latter part of June, during July and toward the latter part of September. 'This species is occasionally rery' abundant and infests hickories as well as oak.

\section{Cyrtolobus fenestratus Fitch}

This is a prettily marked tree hopper measuring only about $3 / 16$ inch in length. It is triangular in form when viewed from almost any aspect, and has somewhat the shape of a very small beechnut. The prothoracic shield is irregulariy bancled with light, brownish yellow, light brown, dark brown and white, and the banded effect is greatly increased by the brown wing tips. The eyes vary in color from a yellowish Fix. ${ }_{152}$ cyrotobus white to dark brown. Three specimens of this insect imenivit

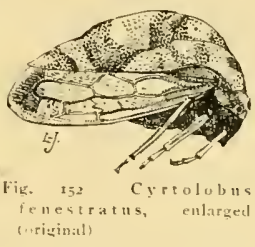
were taken on scrub oak at Karner June 26, 1901 . It has been recorled from as far west as Colorado, as ranging north into Canada and as occurring in several southeastern states. It is doubtless a widely distributed form.

C Jassus olitorius Say was taken on scrub oak at Karner Aug. 20, $\mathrm{I} 9 \mathrm{O} 2$.

Pediopsis basilis $\mathrm{V}$. D) was abundant at Karner June 2, 1903, on poplars.

$\checkmark$ Idiocerus suturalis Fitch was taken at Karner the latter part of June 1903 in considerable numbers on poplar. 
Agallia quadripunctata Prov. was abundant at Poughkeepsie May 21, I903, on honey locust.

Clastoptera proteus Fitch. Larvae and adults of this species were abundant on Cornus at Kenwood N. Y. July 11.

\section{Lightning leaf hopper}

Ormenis pruinosa Say

This active little leaf hopper is a trifle over $1 /+$ inch in length and may

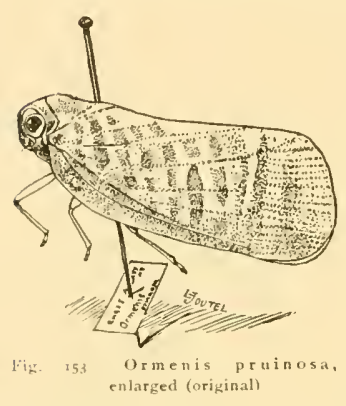
be recognized by its whitish covering over the lark purplish or brownish wings. The young insects are a delicate green and bear long flocculent masses of woolly matter. Both young and adults are very active and occasionally occur in immense numbers. A single example was taken on scrub oak at Karner July 19, 1901. It has been met with by the writer in large numbers about ornamental bushes in a dooryard, and Mr Young found it present in enornous numbers on a catalpa tree, which did not seem to be injured in the slightest.

\section{Hawthorn tingis \\ Corythuca arcuata Say}

I small net-veined insect, about $1 / 8$ inch in length, may be found on the underside of Crataegus or thorn and oak leaves during the summer.

This species or one of its varieties is quite common in New York State on oak leaves and an assemblage of its peculiar egg masses is an interesting sight. It is occasionally abundant enough so that toward the end of the summer foliage of oaks and other plants infested become somewhat dry and withered.

Description. The insect in its various stages has been described by Professor Comstock as follows :

The eggs of this insect, which, I think, have not been described, are smooth, whitish, glistening, semitransparent and ovoid in shape. Their 
average length is .or inch. They are deposited on their broad end, and seem to be somewhat inserted into the substance of the leaf; they are cov-
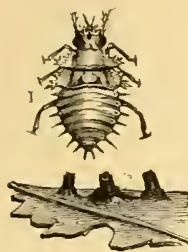

Fig. $x 54$ Corythuc a r cuata, eggs and young (After Comstock) ered completely by a brown, sticky substance, which hardens soon after oviposition. It adheres so firmly to the egg, specially to the upper portion, that it is impossible to remove it without crushing the egr. At its upper end this covering of the egr is squarely truncate, giving the whole mass the appearance of a frustum of a cone with a porous lid. From the funnel-shaped summit the young insect makes its exit, and the round hole at this point renders the empty eggs readily distinguishable from those still unhatched. The eggs are usually laid, in groups of from 10 to 30 , along both sides of some prominent leaf vein. They bear a much greater resemblance to certain forms of fungi, notably the genus Phoma, and to certain young homopterous galls, than they do to egrss of any sort.

The immature insect is of the same dirty brown color as the substance covering the egg, and but little darker than the withering leaf. It is of a broad, flat, oval shape, and spines seem to project from almost every portion of its body. It looks under the microscope more like a lobe of a prickly cactus than anything else we can think of. The cast-off shins stick to the leaf, and give it the appearance of being much more seriously infested than it really is.

The general appearance of a mature individual is well shown in figure 155 . It is about $1 / 8$ inch long.

Professor Comstock states that the species ordinarily

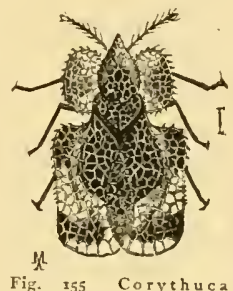
Fig. 155 Corythuca arcuata, adult (After Comstuck) hibernates in the adult condition, and may be found during the winter under the loose bark of a tree or under sticks or stones on the ground.

\section{Bibliography}

I880 Comstock, J. H. UT. S. Dep't Agric. Rep't I879, p. $221-22$

\section{Ciliated tıngis Corythuca ciliata Say.}

Very delicate reticulate winged insects, about $1 / 2$ inch in length, may be found on the foliage of buttonwood.

This species was brought to the attention of Dr Lintner about 1888 , and was noticed briefly in his report. It was received by him from Prof. 
D. S. Martin who took this species in its young and adult condition on the leaves of buttonwood or sycamore. The adult has been described by say as follows :

Whitish, reticulate with nervures on which are short spines; widely margined; color whitish; thorax with an inflated carina before, extending over the head; sides dilated, bullate, a little elevated, lateral and anterior margins cilate with short spines; scutel with the lateral margin elevated and an acute, highly elevated carina on the middle; hemelytra dilated, with an intlated carina before the middle of each, on which is a brown spot: edge ciliate with short spines, excepting the posterior third and tip, which are unarmed, rectilinear; beneath piceous-black; feet pale yellowish.

Length to tip of hemelytra, ${ }^{3}$ zo $_{0}$ of an inch.

The larva is spinous, fuscous, with a large yellowish spot each side of the middle, and before the middle a broad yellowish vitta. The species is very common.

\section{Bibliography}

1888 Lintner, J. A. Ins. N. Y. th Rep't, P. 107-9

\section{Woolly maple leaf aphid \\ Pemphigus acerifolii Riley.}

Blackish or purplish, winged, woolly plant lice or wur in large numbers on the underside of curled, soft maple leaves.

This species is rarely abundant enough to excite attention, though occasionally it is quite injurious, specially in the Southern States. I'rofessor Johnson has recorded instances of serious injuries to soft maples for several years in succession, and in June I905, this species was excessively abundant on soft maples at several points in the Hudson valley. It may be easily recognized by the large amount of woolly matter, it being sometimes nearly as long as the insect. This form may be separated from the closely allied Pemphigus a ceris Monell, which lives on the underside of hard maple limbs, by the antennae reaching only to the wing insertion, whereas in this last named the fourth joint extends to the base of the wings. This species is sometimes excessively abundant on the underside of soft maple foliage in June and the leaves may be badly curled as a result. The insects usually desert the trees early in July and as a rule remedial measures are unnecessary: 


\section{Birch aphid \\ Callipterus betulaccolens Mon.}

A delicate yellowish plant louse is sometimes excedingly abundant in midsummer on the underside of birch foliage.

This little species is sometimes very injurious to birches in the vicinity of Albany, particularly the ornamental cut-leaved variety, and it is occasionally quite destructive in other portions of the State, complaints of its depredations having been received from Herkimer county and also in the vicinity of Buffalo. There is no method of keeping it in check aside from spraying with contact insecticides such as a whale oil soap solution or kerosene emulsion and ordinarily that is impractical. The pest, when abundant, is fed on to a considerable extent by adults and larvae of the two-spotted lady beetle, A dali a bi punctat a Linn.

\section{Woolly beech leaf aphis$$
\text { Jhyllaphis fagi Linn. }
$$

Cottony masses occurring on the underside of purple beech leaves usually shelter groups of this plant louse.

This species is a common one on purple beech in parks, and sometimes becomes so abundant as to cover a large proportion of the uncter surface of the leaves and at such times it may cause considerable injury to the tree.

Description and habits. This aphid is shown clustered on the underside of leaves and alongr the mid ribs and smaller veins on plate 11 , figures IO, I $t$. The adult females may be recognized by the conspicuous cottony tufts largely concealing the body. The young are pale greenish yellow and may frequently be seen nestling among the hairs so abundant along the leaf veins. The cast skins or exuviae are snow-white, sometimes abundant and may then give a whitish appearance to the undersicle of the foliage. The partly grown plant louse has the habit of resting with its head close to a ven, from which it is apparently drawing nourishment. The extremity of the young is usually ornamented by a few scattering bluish, white fibers. 
The latter become more abundant as the insect develops and eventually' nearly conceal it.

Remedial measures. The flocculent woolly secretion serves to protect this species in a large measure, from applications of such contact insecticicles as kerosene emulsion or whale oil soap solution, and in order to obtain satisfactory results the spraying must be done very thoroughly and preferably with considerable force.

\section{White flower cricket \\ Ocanthus nivcus DeGeer}

This delicale, pale greenish or white insect is one of our common species from the middle of August till the laster part of September, when it occurs on various plants, shrubs and trees.

This flower cricket is about $3+$ inch in length and may be recognized by its pale color and the usually two nearly circular, black spots on the basal two segments of the antennat.

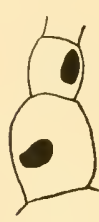

Fig. 156 i)

c anthus

niveus, underside

of basal an-

tenual seg-

ments (Af-

per Beuten-

miviter, Am.

Mus. Nat,
Hist. Hul,

94)

ne.it morning.

This species, as well as its allies, is more or less nocturnal in habit, and though found on various plants during the daytime, it is usually comparatively motionless, becoming more active on the approach of night. It is at this time, according to Miss Murtfeldt, that its predaceous habits may be observed. She states that as the twilight cleepens, the young crickets awaken to greater activity, and that with the aid" of a light they may be seen " hurrying, with a furtive, darting movement over the leaves and stems, the head bent down, the antennac stretched forward, and every sense apparently on the alert." A plant louse is seized and rapidly deroured. She observed that unless a very liberal number of aphuds were supplied, none would be found in the jar the

It is interesting in this connection to refer to the observation of an Indiana nurseryman, who is reported by Professor Webster, substantially as follows: This gentleman experienced much trouble from plant lice till after he planted raspherries in his young orchard, after which his troubles 
from these pests ceased to a considerable extent, though the raspberry plants were frequently seriously injured from oviposition by tree crickets.

Professor Piper states that these crickets, after attaining full growth, feed to some extent on the tender shoots of various shrubs and sometimes do a little damage in this manner. The principal injury, however, is caused by the deposition of the eggs in the smaller limbs of various bushes and trees, where they remain over winter and hatch in June. This injury is particularly marked in the case of raspberry and similar soft-stemmed plants. These insects also deposit their eggs as stated by various writers, in peach, apple, grape, cherry, oak, elm, hazel, sumac and willow, and the observations of Dr Hopkins, now of the United States Bureau of Entomology, convince him that considerable injury may follow this act. The wounds made by the tree crickets afford ready entrance for fungous diseases or an opportunity for such plant lice as the woolly aphis to attack the tree and serious deformities may result. Tree crickets, as well as some other insects, suffer to some extent from egrer parasites. Two species, C a cus o ecanthi Riley MS. and Baryconus oecanthi Riley MS., have been reared from eggrs of this species, and the former also from those of (). latipennis. Generally speaking, these tree crickets are beneficial, and as a rule they should not be destroyed, though occasionally some injury niay be caused.

\section{Bibliography}

1899 Murtfeldt, Mary E. Insect Life, $2: 130-32$

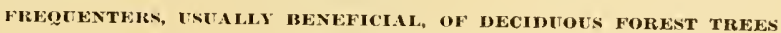

Cicada killer

Sphecius speciosus Drury

This handsome black, yellow-marked wasp, with rust-brown wings, about an inch in length, is a southern form and ordinarily occurs from Poughkeepsie southward, being more abundant in New Jersey and places having a similar climate, than farther north. This fierce, striking wasp was rather common at Karner, only a few miles west of Albany, in the summer of $190 \mathrm{I}$, at which time it was observed about scrub oaks, evidently 
attracted to the exudation from the starting buds, though in no instance

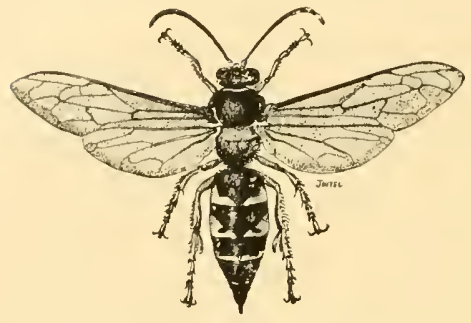

Fig. 157 Cicada killer (author's illustration) was it detected trying to capture insects.

This species received its common name because of its habit of preying on the cicada, which is stung into insensibility, then dragged to the foot of the burrow, an egrg deposited and the excavation filled. In due time the grub appears, feeds on its prey and develops into a wasp. This insect has been so abundant at Poughkeepsie as to occasion complaints because its numerous large burrows rendered lawns unsightly.

\section{Fifteen-spotted lady beetle}

\section{- Inatis occllata Linn.}

This large rather common species was met with on hard pine at Karner in 1901, where it probably preyed on plant lice and other small forms infesting the trees. This species was observed on several occasions about other trees infested by plant lice, particularly piries where $\mathrm{Chermes}$
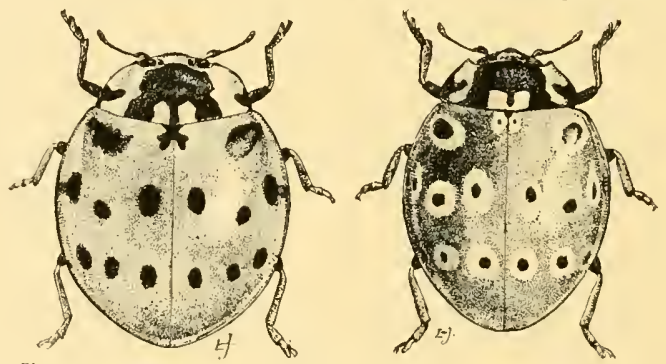
pinicorticis Fitch was abundant and also in the vicinity of Torwa maples infested by $\mathrm{Cha}$ itophorus aceris Linn. 


\section{Neomysia pullata Say}

This, one of our medium sized to large ladly beetles, was taken in small numbers on hard pine at Karner in 1901. One specimen was captured June $t$ and another July S. The species may be recognized by its head being nearly black, or with very few light markings on it and more specially by the nearly uniform yellowish red or yellowish brown wing covers.

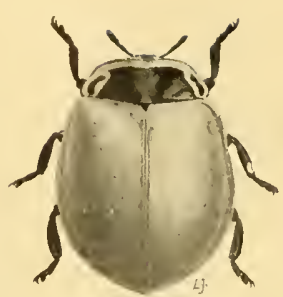

\section{Hyperaspis binotata Say}

A minute, black, red-spotted lady beetle less than I/8 inch in length, was met with on scrub oak at Karner, May I 4, I902. It was bred in some numbers October 3, I902 from a branch of scrul oak badly infested with a species of Lecanium found at North Chatham N. Y. July 6. It probably preys on such soft-bodied insects as it can overcome as well as on scale insects. The species appears to be rare in this State. It has been recorded by Casey from New Hampshire, Pennsylvania, Maryland, Indiana, Wisconsin, and I) S Smith lists it from New Jersey, where it occurs on pine trees in spring and on willows in summer. It probably appears in I)r Hamilton's list of southwestern Pennsylvania, Dury's list of Cincinnati specie, and in Ulkes list of forms occurring in the District of Columbia, under the name of H. signat a Oliv:

Limonius quercinus Say. This beetle was beaten in June from scrub oak at karner.

\section{Hydnocera verticalis Say}

A slender, yellow-lyeaded, blackish and yellowish beetle occurs in early spring on low shrubs and trees.

This species was reared from a larva found in an oak gall at Normanskill near Albany, May IO, I902. 
Description. Length about $1 / 8$ inch; head yellowish; eyes black; thorax longer than wide, cylindric, black; wing covers shorter than the abdomen, not meeting at the suture and narrowed to the rounded tip; densely punctured and with a large yellowish spot extending from the base nearly to the middle; legs yellowish.

Habits. This predaceous insect is undoubtedly beneficial and has a wide distribution in the northeastern United States, having been recorded from the vicinity of Buffalo N. Y., southwestern Pennsylvania, various localities in New Jersey and from the District of Columbia.

Hydnocera subaenea Spin. This species was beaten in June from both pine and scrub oak at Karner.

\section{Paratenetus punctatus Sol.}

A small, brownish black beetle about $1 / 8$ inch long, occurs among dead leaves and also in nests of tent caterpillars.

This small beetle is rather stout, with a clark brown coarsely punctured head and thorax, coarsely granulated eyes, the thorax with its lateral mar-

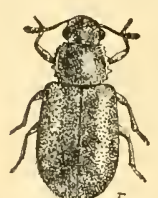

Fig. 160 Paratenetus punc$t$ a $t$ is, enlarged
(original) gins irregularly serrate. The wing covers have rather large, almost confluent punctures and are ornamented with a somewhat coarse pubescence. This species was met with in early June I902 at Kenwood N. Y., where it was present in considerable numbers in nests of the appletree tent caterpillar, M a Iacosom a a mericana Fabr. It presumably was feeding on the frass and cast skins in the nests, particularly as it has been recorded by Dr Hamilton, as abundant on dead leaves on bushes. 1)r Horn records it from the Middle and Eastern States. It has been listed by Ulke, from the District of Columbia, who also states that it is very common on dried leaves. Dury records it from Ohio, Smith from several New Jersey localities and Staten Island, and it has been listed by Zesch and Reinecke, from the vicinity of Buffalo. 


\section{Soldier bugs: Podisus and Euschistus Podisus placidus Uhl.}

This species ranges in length from $3 / 8$ to nearly $1 / 2$ inch and was present in small numbers on hard pine at Karner in Igor, three specimens being taken June ${ }_{3} 3$ and two July 9. It has the angles of the prothorax slightly developed, is yellowish in color, thickly mottled with reddish or reddish brown and with the anterior and posterior angles of the abdominal segments marked with small black spots.

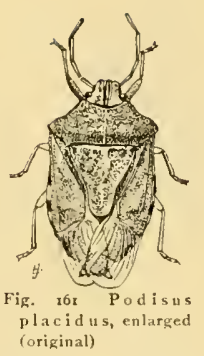

Mr Kirkland states that in the nearly full grown young the head, thorax and wing pads are an intense pitch black, the abdomen dark red, margined with a series of black spots, one on each segment, and with four black spots in a longitudinal row on the dorsum.

This insect is an exceedingly valuable check on several injurious species. The writer in May I 902 found five of these bugs within one tent of the common appletree tent caterpillar ( $\mathrm{I}$ a lacosoma a mericana Fabr.), and six or seven were observed on the outsicle of another. Several bugs were seen with their beaks inserted in caterpillars, and in two or three instances a caterpillar hung from the beak of its voracious enemy. Another was observed in association with sawfly larvae (Lophyrus) on hard pine and was probably preying on them, since it did not hesitate to do so in confinement. Young of this plant bug were also taken at Karner in July' 1902 feeding on the eggs of the senatorial oak caterpillar, $A \mathrm{n}$ is ot a se na toria Abb. \& Sm. In addition to the above, Mr Kirkland states that this species has been recorded as destroying currant worms, Pteronus ribesii Scop., spiny elm caterpillars, Euvanessa a n t iopa Linn., fall webworms, Hyphantria textor Harr., caterpillars of the white marked tussock moth, Hemerocampa leucost igm a Abb. \& Sm., H. def in it a Pack,, and gipsy moth caterpillars, Porthetria dispar Linn.

He also states that over-wintering adults appear in early spring, and after feeding about a fortnight on caterpillars occurring at this time, 
deposit their egrss on the underside of leaves or on twigs, 50 to 60 being laid ly a single female. They hatch in about io days and the red and black young feed on the leaves for about a week and then begin to prey on insects, becoming full grown during July. He states that there are undoubtedly two annual broods in Massachusetts, the young of the second maturing in September, and that possibly three generations may appear in favorable seasons.

This species has been recorded from Colorado by Messrs Gillette and Baker, from southern Michigan by Professor Townsend, from lowa by Professor Osborn, from Canada by Mr Saunders, and Dr Smith states that it is common in New Jersey. The latter is true of both Massachusetts and New Jork.

\section{Spined soldier bug \\ Podisus maculinentris Say}

This insect is yellowish, with its upper surface so thickly spotted with rectdish or lark brown as to grive it a general dull brown color. It is about

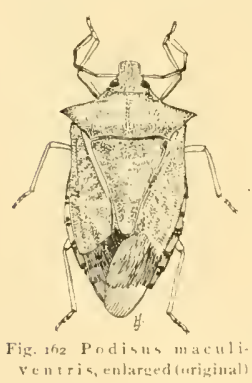
$1 / 2$ inch in length and is remarkable for the prolonged acute projections of the pronotum.

This species is well known in economic literature under the above common name, while its scientific name has almost universally been given as P. spinostis I)allas. It is the form frequently met with on various plants and is an enemy of the elm leaf bectle. Immature specimens and eggs of this insect were taken at Karner, Sep. 30, 1902 by Mr Young who olsserved the former preying on zelora caterpillars, $M$ a mest ra picta IIarris, and he succeeded in bringing the insects to maturity on these caterpillars. This buy is a very general feeder, having been recorded by various authors as preying on such diverse forms as walking sticks, D i apheromera femorat a Say, asparagus beetles, Crioceris asparagi linn. Colorado potato beetles, Doryphora decemlineata Say, 
cabbage butterfly, Pieris rapae Linn., fall webworm, Hyphantria textor Harr., white marked tussock moth, Hemerocampa le ucost igma Abb. \& Sm., a climbing cutworm, Carneades scan dens Riley, cotton worm, Alabama argillacea Hbn., a webworm, Archips fervidan a Clem., codling moth, Carpocapsa pomonella Linn., Gymonychus appendiculatus Hartig, the morning glory leaf cutter, Loxostege obliteralis Walk, and a sawfly, Selandria b a rda Say. It is subject to attack by egg parasites, two species, T elenom us podisi Ashm. and Trissolcus podisi Ashm., having been reared from its eggs, which have been described by Dr Riley as " bronzecolored caldron-shaped objects, with a convex lid, around which radiate I 5 or 16 white spines." They are placed side by side in small clusters on leaves or other objects. The young bugs, according to Riley, are ovoid, shiny black, with some bright crimson about the abclomen, and when fuil grown four yellow spots appear on the thorax and the abdomen is more yellowish. This author also states that the diet of the young is principally vegetarian, though a young bug has been observed to destroy a grub of the Colorado potato beetle four or five times its own size. This species has been taken by Mr Bueno, in June, July, September and October, in various localities about New York city, and has been recorded by Dr Smith, from Staten Island. Its distribution has been given by Kirkland, in addition to the above localities, as follows: Canada, Massachusetts, Pennsylvania, Maryland, Virginia, Wisconsin, Mllinois, Nebraska, Kansas, Iowa, Missouri Colorado, Indian Territory, Texas and California. He states that it is said to occur generally throughout the south and west, and that it is rare in Massachusetts. Professor Osborn records this species from IVilliams Ariz.

\section{Bibliography}

I898 Kirkland, A. H. Mass. State Bd Agric. Rep't, p. I3 I-35 


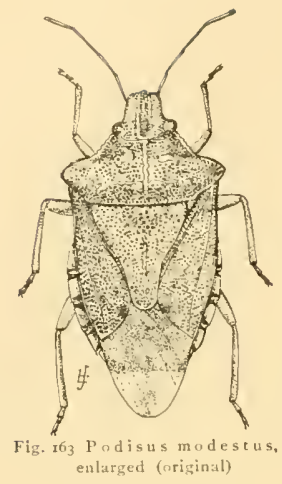

This rather large, yellowish green, brown-mottled species measures about 5 's inch long, and was taken by us in May and June, on hard pine and scrub oak at Karner. It must be somewhat common at times, since four were taken in one day, and it probably preys, like its relatives, somewhat indiscriminately on caterpillars and other soft-bodied insects occurring on these trees. This species is probably common in New York State, as it has been listed from Staten Island by Smith, and been taken by Mr Bueno, from various localities in the vicinity of New York, during May, June, July and August. It has also been recorded by Uhler, from Colorado, Nebraskic, lllinois and parts of the Atlantic States. Professor Osborn states that it is common in Iowa, and lists it from Tacoma, Wash. Messrs Gillette and Baker record it from several Colorado localities, where it evidently occurs throughout the season, having been taken at Fort Collins from April 23 to ()ct. 24, and Dr Smith lists it from several places in New Jersey. Prof. F. M. Webster observed this species extracting the milk from immature kernels of wheat in Indiana, and adds that it must inflict considerable damage to both fall and spring grain. 


\section{Euschistus variolarius Beauv.}

This is a rather stout, reddish or yellowish gray plant bug about $1 / 2$ inch long, with the humeral angles somewhat prominent. It was found by us quite common on white pines at Round Lake N. Y., Sep. 22, 1902, at which time it appeared to be deeply interested in the web nests of an undetermined tortricid on the larvae of which it probably feeds to a considerable extent. We have taken this insect at Karner during the months of May, early June, September and October, and $\mathrm{Mr}$ Bueno records its occurrence about New lork city during June, July, August and September. It has been listed from Staten Island by Dr Smith. It is very probable that this species, like some of its congeners, feeds in its early stages on plants to some extent and becomes predaceous and therefore beneficial after attaining some size. It is interesting in this connection to note that Mr F. F. Crevecouter of Onaga Kan., states that the fluid exucled by this species caused a very painful sensation on a sore spot on his finger, being almost like that of a burn. The active character of this fluid has been observed by others, and Mr Young states that Fig.r64 Euschistus varioin the case of the common Cosmopepla carnifex Fabr., its exudation burns the tender portion of the lip much as described above.

This species, according to L'hler, occurs in Cohrado, Texas and generally throughout the eastern United States. It has been recorded by Osborn from Albuquerque N. M., and Colorado, by Townsend from southern Michigan, by Gillette and Baker as present in a number of localities in Colorado and from the vicinity of Woods Holf Mass. by T. H. Nontgomery jr.

This species evidently occurs on various plants, which are injured to some extent. It has been recorded about raspberry bushes (the fruit of which it injures seriously) in gardens by Townsend, and on melon stalks from July to September. Professor Webster reports it as puncturing the 
skin of ripening tomatoes, numbers being clustered on the fruit and juice oozing from the wounds, and states that the bugs also attack peaches in a similar manner. Professor Garman has observed serious injury following the presence of this insect on young tobacco plants, causing the sudden wilting of the leaves, and Mr Crevecoeur, mentioned above states, that it often feeds on strawberries.

\section{Bibliography}

I 897 Garman, Harrison. Ky. Agric. Exp. Sta. Bul. 66, p. $83-84$

\section{Euschistus tristigmus Say}

This dark brownish plant bug is about $3 / 8$ inch in length and was met with by the writer in small numbers on hard pine at Karner, one specimen

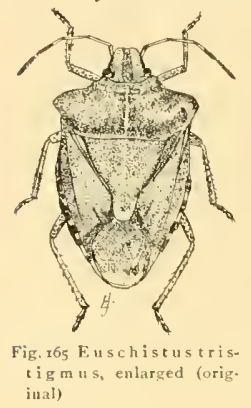
being taken Sep. I8, Igor. This species has been described by Uhler as from Texas, Indian Territory, Kansas, Missouri, and as ranging from Floricla to New York. He states that the form with blunt, lateral angles has been taken at Wrashington, Kansas, Canada, Pennsylvania, Maryland, Jowa and New York, and adds that it sometimes occurs in large numbers during late summer on bushes in damp situations. The species has been listed by Mr Townsend from southern Michigan and Dr Smith records it from a number of New Jersey localities, where it is stated to be locally common.

\section{Euschistus politus Uhler}

This is one of the smaller members of this genus, being only about $3 / 8$ inch in length. It is yellowish and so thickly spotted with dark brown as to give it a yellowish brown appearance. The posterior portion of the wing covers are nearly black. Its head is short and the pronotal angles less developed than in other species. A single specimen was taken by us at Karner, Sep. 30, 1902. It probably occurs on hard pines to some extent. Mr Kirkland states that this rare insect has occasionally been taken under . circumstances which gave the impression that it is predatory in habit. The 
eggs have been described by him as pearly white, $1 \mathrm{~mm}$ long and $8 \mathrm{~mm}$ wide, nearly cylindric in form, with both extremities flattened. The cap is surrounded by a row of black, elongated, club-shaped spines, and the surface of the egg is covered with small blunt spines between which are numerous smaller ones. He has found the insect preying on gipsy moth caterpillars, though he is inclined to believe that it more frequently feeds on plants than insects.

\section{Bibliography}

I897 Kirkland, A. H. Mass. State Bd Agric. Rep't, p. 58-59

\section{Alydus eurinus Say}

This black species, with red-banded abdomen is about $1 / 2$ inch in length, and on account of its slender form and peculiar movements, resembles an ant to some extent. It was observed in small numbers on scrub oak at Karner, one specimen being taken June 21, I901 and another in early July I902. This insect has a wide distribution, having been recorded from as far west as Colorado, south to Texas, as occurring in the Eastern States and ranging north into Canada.

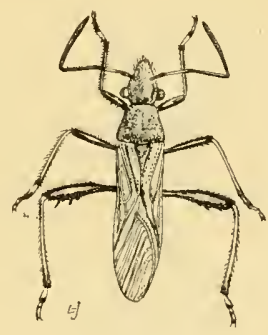

Fig. I66 Alydus eurinus enlarged (original)

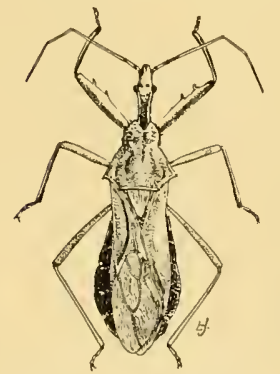

Fig. 167 Acholla multis p in os:a, eniarged (original)

\section{Acholla multispinosa DeG.}

This predaceous, spiny hemipteron is one of our rather common though rarely abundant forms. It is about $1 / 2$ inch long, slender in shape, and varies in color from light to dark brown, and it may be recognized by the prominent spines on the top of the head. The young are similar in appearance to the adults, though usually with the abdominal segments colored more or less deeply with red.

Adults of this species were taken in 1901 on hard pine at Karner Aug. 9 and 21, and Sep. 6. Immature specimens of what probably belong to this species were also taken earlier 
in the season, three less than half grown being captured July 8 , nine about half grown July 19 and two nearly full grown July 27 . This species is predaceous and is therefore beneficial. It has a wide distribution, having been recorded from as far west as Nebraska and from a number of the Eastern and Middle States.

\section{Camptobrochis grandis Uhl.}

This species was somewhat common on hard pine at Karner during June and July igor, though on account of its timidity and rapid movements
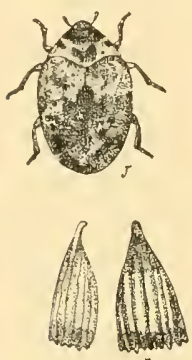

$a$

lig. 168 anthrenus castaneque, entarged; $a, b$, scales much enlarged (origina!) comparatively few specimens were taken. The adult insect is about $1 / 4$ inch long, oval in outline and inconspicuously marked with brown and yellowish brown. This species has been recorded by Dr Howard as sucking the eggs of the imported elm leaf beetle, Ga ler u c e 11 a 1 u t e o la Müll., and it is very probably a predaceous form living on some of the weaker insects infesting the plants on which it occurs.

Mr E. P. VanDuzee lists this species from the Muskoka lake district and states that it is apparently nocturnal in habit, since several were captured while flying around a candle at camp. Some of these inclividuals, he states, are extremely dark, even approaching an almost uniform piceous black. It has been listed from Iowa by Professor Osborn, from Colorado by Messrs Gillette and Baker, and probably has an extended distribution in America.

\section{Anthrenus castaneae Melsh.}

An oval, black, golden specked beetle about $3{ }_{32}$ inch in length, occurs on blossoms of alcler and cornus.

This species was taken at Poughkeepsie on cornus blossoms June 3, 1903, and has also been met with on alder blossoms at Newport by Mr roung. The insect is remarkable because of the triangular shaped, crinkled scales covering its body, by which it may easily be distinguished from A. museorum Linn., with which it has probably been confused. 


\section{PLIVT GILLS AND GALL MAKNIES}

The abnormal growths frequently found on plants and known as insect galls, excite considerable interest and have led to much speculation as to their origin and manner of development. The species producing these peculiar structures do not compose a natural group, but are found in six orders and two classes of the animal kingdom. Certain of the insects present most remarkable features in their life histories and all have attained the position sought by many of a higher race, in that they secure both food and shelter with little or no labor.

Development of galls. Galls produced by insects or by the somewhat closely allied mites, may be found on practically every portion of the plant. The roots are affected by a number of species of plant lice and mites; trunks or stems are attacked by certain +-winged gall flies, beetles or Coleoptera, 2-winged gall tlies and plant lice, while branches, foliage and 1ruit or seeds are infested by varjous species producing most remarkable and diverse growths. These abnormal structures may vary from the comparatively simple galls of certain plant lice, which consist of little more than a folded leaf to the nearly solid, hard cynipid galls on stems. The many celled bud galls may be contrasted with the beautiful fuzzy swellings adorning the stems or leaves of oaks and various plants. These structures, as previously stated, are caused by several insects belonging to widely separated groups, and it is probable that no general law can account for their production. Certain galls like those of the Tenthredinidae or sawflies, are probably produced by the irritation incident to oviposition or the presence of the egg, since, according to several observers, the gall develops before the young hatches from the egg. The larvae of the 4 -winged gall flies or Cynipidae, are probably responsible in most cases for the development of the abnormal growths caused by this family, as their activity results in abnormal stimulation followed by excessive cell formation and the development of a mass of unhealthy tissue. The plant lice illustrate another and in certain ways a more remarkable method of development, in that the tissues of the affected plant grow around and inclose the insect. The plant 
louse establishes herself on a stem or leaf, drawing nourishment therefrom, and the affected tissues shrink away to some extent, while those adjacent bend over her and eventually form an almost complete inclosure.

Alternation of generations. Certain gall insects are remarkable on this account. The Cynipids hat long been a puzzle to entomologists, and the classic studies of Dr Hermann Adler explained many enigmas. Dr Adler's investigations were largely with the oak gall flies, and proved that a remarkable alternation of generations occurs in this group. He found that insects, previously assigned to separate genera, were only members of different generations, and in general his conclusions may be stated as follows: that the parthenogenetic bud-inhabiting gall tlies are parents of a sexual generation which oviposits on foliage, producing leaf galls, these in turn producing the preceding form. Previous to Dr Adler's investigations, these parthenogenetic forms had been supposed to be asexual, and according to him certain European species are thus restricted.

The Cynipidae have always attracted more interest, probably because of their higher organization and more perfect galls, yet in complex alternation of generations they are far surpassed by certain plant lice which produce six or seven generations with marked variations in structure and radical changes of food plant, as detailed in the accounts of $\mathrm{H}$ orm a p h is ha $\mathrm{ma}$ melidis Fitch and $\mathrm{H}$ a mamelistes spinosus Shim., to which the reader is referred for details. It would not be at all surprising if there were other species of gall-inhabiting plant lice presenting almost as great diversities in their life histories.

Gall makers. These, as previously stated, belong to very diverse groups and the gall-making habit has undoubtedly arisen independently in each instance.

The Hymenoptera include some of the best known gall makers, notably the Cynipidae and certain Tenthredinidae. The former are small, clark colored insects with few veins in their four nearly transparent wings. Their galls are always completely closed and though very diverse in character are easily recognized by exclusion, as a rule. They contain, when 
inhabited, footless, comparatively helpless maggots. The Tenthredinid gall tlies are small creatures with many veins in their four wings. Their galls are likewise closed, and when inhabited are easily recognized by the many footed, somewhat cylindric larvae within.

Coleopterous larvae produce swellings in trunk and limb, which have been classed as galls, and these are in most cases due solely to the mechanical irritation caused by the larvae.

The Diptera or 2-winged flies, include several distinct groups of gall flies. Certain Trypetidae produce solid, closed galls, the one on goldenrod or Solidago being an excellent example. The Cecidomyidae or gall gnats, are the most important gall makers of the family, and deformities may be produced by them in stem, branch, leaf or fruit. Their galls are usually closed and when inhabited can easily be recognized by the character of the larva, which has the somewhat unique power of propelling itself some distance by bringing the two extremities together and then suddenly extending them. Some gall flies also belong to the Mycetophilidae, but the habit is abnormal for this group.

The Hemiptera include a number of important gall insects, some of which are quite destructive. The Psyllidae or jumping plant lice, include a few gall insects belonging to the genus Pachypsylla, while the majority of galls referable to this group are the work of plant lice or aphids whose characteristics are well known. The deformities caused by these insects, may be easily recognized by the mouth of the gall being open, and when fresh by the peculiar inhabitants.

The Acarina or gall mites, produce many deformities in vegetation, particularly on leaves. These creatures are usually pyriform in shape and remarkable among mites because of their possessing but four legs. Their galls are always open and are frequently ornamented with hair growths. They are sometimes very abundant on foliage and occasionally somewhat injurious.

Gall insects display a marked preference for certain trees, various oaks, the willows and rose-bushes suffering specially from their attacks. Fortunately this group is comparatively harmless to vegetation. 


\title{
Key for the separation of insect galls
}

Gulls on trigs

\author{
Affecting ouk
}

Delicate white, pinkish, woolly growths on twigs

Wool sower, Andricus seminat or, p. 622

Woolly oak gall, Andricus operator, p. 622

Rough, gnarled, scaly swellings on red oak limbs

Gouty oak gall, Andricus p in ctatus, p. 623

Irregularly rounded gall with numerous hornlike protuberances

Horned oak gall, Andricus cornigerus, ]). 624

A green or brown, club-shaped gall on tips of white oak twigs

Oak tipgall, Andricus clavula, p. 624

A rough, globular gall with conelike apex

Rough bullet gall. Holcaspis d u ricoria, p. 624

Bulletlike galls in clusters on white oak twigs

Oak bullet gall, Holc a s p is globulus, p. $62+$

Large uneven galls somewhat resembling a potato in shape, on white oak twigs

Oak potato gall, Neuroterus bat a tus, p. 62.4

An irregularly rounded gall on swamp white oak

Noxious oak gall, Neuroterus noxiosus, p. 624

A i oval gall composed of wedge-shaped lobes on swamp white oak

Lobed oak gall, Cynips strobila 13 a. 1). 625

Irregular reddish or greenish galls in clusters on white oak stems

Gills on liare's

Oak fig gall, Biorhiza forticorn is, p. 626

A nearly globular, greenish or brown gall

Large oak apple, $\lambda \mathrm{mphibolips}$ confluentus, p. 625

Similar to the above but with interior nearly hollow

Larger empty oak apple, Amphibolips in an is, p. 625

Elongate, fusiform galls on leaves and petioles of dwarf and scrub oak

Black scrub oak gall, Amp h i bolips ilic if (1) iae. p. 625

Globular, smooth, green galls $1 / 4$ inch in diameter on red oak

Oak leaf apple, Andricus s ing $\| 1$ il $\mathrm{r} i \mathrm{~s}, \mathrm{p}, 625$

White or buff-colored woolly masses on veins of white oak leaves

Oak wool gall, Andricus la na, p. 625

Irregular, woody enlargements at base of the leaf

Oak leaf-stalk gall, Andricus petiolicola, p. 625 
Small globular galls on scrub and post oak

Oak leaf bullet gall, Dryophanta polita, p. 626 Irregular reddish or greenish galls in clusters on leaves and stems of white and scrub

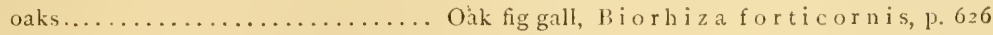
Somewhat rounded, hard, woody, red, reticulate galls

Warty oak leaf gall, Cecidom yi a pilula e, p. 627

Rounded, oblong or oval galls with numerous long spines

Oak hedgehog gall, Acraspis e rin acei, p. 627

A globular, spiny gall on dwarf chestnut oak

Spiny oak gall, C'ynips prinoides, p. 627

Clusters of seedlike lodies on red oak.... Oak leaf seed gall, Cy n ips decid u a, p. 627 Small, brown, buttonlike galls.. Oak button gall, Ne uroterus umbilicatus, P. 627 Marginal fold at base of leaf serration

Galls on catrins or fruit

Marginal fold gall, Cecidomy ia erubescens, p. 627

Shotlike, white catkin gall.......... Oak flower gall, Andricus pulchra, p. 627 A globular gall growing from the side of acorn cups

Oak plum gall, Amphibolips prunus, p. 628

Galls on twigs

\section{Affecting hickory}

Green or black irregular galls on leaf stem or twigs

Galls on leazes

Hickory gall ap!hid, Phylloxera carya ecaulis, p. $33^{\mathrm{r}}$

Smooth, green, onion-shaped galls with pointed tip

Hickory seed gall, Cecidomyia caryaecola, p. 628

Subglobular, pubescent, onion-shaped gall

Diplosiscaryae, p. 628

Hickory onion gall, Cecidomyia holotricha, p. 628

Rounded, brownish, downy gall

Hickory peach gall, Cecidomy ia persicoides, p. 628

Narrow, cylindric, tubelike galls.. Hickory tube gall, Cecidomy i a t u bicola, p. 628

Flattened, circular, yellow or whitish galls

Hickory button gall, Phylloxera foveola, p. 629

Affecting maple

Red, yellow-ringed galls in red maple leaves

Ocellate maple leaf gall, Cecidom yia ocellaris, p. 629

Slender, fusiform galls on upper surface of sugar maple leaves

Fusiform maple gall, Eriophyes a cericola, p. $63^{\circ}$ 
Small, bladderlike galls on upper surfitce of soft maple leaves

Bladder maple gall, Eriophyes quadripes, p. 630

\section{Affectimg linden}

Sul-globular greenish or whitish galls on both sides of leaf

Linden wart gall, Cecidomyia verrucicola, p. $63^{1}$

Top-shaped galls on upper surface of linden leaves

Linden mite gall, Eriophyes abnormis, p. $63 \mathrm{r}$

\section{Afficting ash}

Elongated, greenish or reddish brown galls on the leaf midril,

Ash midrib gall, Cecidomyia pellex, p. 632

Lobulate green or brown deformed catkins

Ash flower gall. Eriophyes fraxiniflora, p. 633

Affecting elm

Cockscomblike structures on the upper surface of elm leaves

Cockscomb elm gall, Colop ha u I micola, p. 186

Solitary, spindle-shaped galls on the upper surface of red elm leaves

Red elm leaf gall, Pempligus u $1 \mathrm{~m}$ if us us, p. 633

Affecting poplur

Irregular, subglobular enlargements of the young twigs

Poplar twig gall, A gromyza a eneiventris, p. 634

Folded, convolute masses of foliage

Vagabond gall, Pempligus vagabundus, p. 635 •

Oval, sumewhat elongated galls on the leaf petioles of cottonwood

Poplar leaf stem gall, Pemphigus populi-transversus, p. 635

Imperfect, globular galls at base of cottonwood leaves

Basal leaf gall, Pempluigus populicaulis, p. 636

Galls on shoots

Affecting willow's

Fusiform apical galls........... Willow club gall, R habdoph a ga rigidae, p. $63^{6}$ Irregular fusiform enlargements on the young shoots

Galls on leaves

European willow gall midge, R ha b dophaga salicis, p. 299

Sinooth, globular or slightly oval galls like a miniature apple, occur on the leaf midrib

Willow apple gall, Pont an i a pom um, p. 636

Subspheric, pealike, yellowish galls on the underside of willow leaves

Pontania pisum, p. 637 
Smooth, flattish, sessile, yellowish green galls on both sides of the leaf

$$
\text { Pontania desmodioides, p. } 638
$$

Fleshy, reddish galls in parallel rows on either side of the midrib

A conelike deformity on the tips of willow shoots

$$
\text { Pontania hyalina, p. } 638
$$

Willow cone gall, Rhabdophaga strobiloides, p. 639

$$
\text { Afficting witch-hazil }
$$

Conical, green or reddish galls on upper surface of the leaves

Witch-hazel cone gall, H ormaph is ham amelidis, 1). 639 Many spined, green or reddish bud galls

$$
\begin{aligned}
& \text { Spiny witch-hazel gall, H a mamelis tes sp in osus, p. } 643 \\
& \text { Affecting liveh }
\end{aligned}
$$

Deformed catkins with enlarged, globular seeds

Birch seed gall midge, ()lig otrophus betulae, p. 647

$$
\text { Affecting sumac }
$$

Pear-shaped, round or reddish galls on the leaves

Sumac tomato gall, Pemphiğ us rho is, p. 647 Affecting hatkbery

Broadly rounded elevations on the under surface of the leaf

Hackberry nipple gall, Pachyps y 11 a celtidis-m a m ma, p. 647 Affecting rose

A large, smooth, reddish brown root gall.. Rose root gall, $R$ h o d it es radic u m, p. 647 Fibrous, mosslike masses on rose and blackberry bushes

Rose bedegar, R hodites rosae, p. 647

Irregular, spheric, mealy galls.......... Mealy rose gall, Rhodites ignot a, p. 647 Round galls covered with prickly spines.. Spiny bullet gall, R hodites bicolor, p. 647 Smooth rounded galls on twigs..... Globular rose gall, Rho dites globulus, p. 6.47 Elongated, hard, woody galls on twigs

Long rose gall, Rhodites dichlocerus, p. 648 An oblong or rounded gall on wild rose twigs

Knotty rose gall, R hodites verna, p. 648

Stunted pitch pine needles with basal enlargement

$$
\text { Affecting eqergreens }
$$

Pine needle gall fly, Cecidom yia pin i-rigidae, p. 423

Baisam needles with basal enlargement

Balsan gall midge, Cecidom yia bals a micola, p. 685 


\section{Wool sower}

Andricus seminator Harris

A delicate white, pinkish marked woolly growth, from $I$ to $I_{12}$ inches in drameter encircles in June the small I wigs of white oak.

This abnormal growth is one of the most beautiful things in nature when in its prime. The delicate creamy white color is admirably set off by blotches of bright pinkish red, and the unexpected weight of the woolly mass only adcls to our appreciation. This beautiful gall is a common species in New York State, and specimens are frequently sent to the entomologist with inquiry as to its source and character. As the gall agres, the white becomes a light brown and the pink a somewhat dark brown, and examination of its structure shows that it is composed of numerous small seedlike cells with the spaces between filled by a soft hairlike growth. Each of the seedlike bodies contains an insect and from a specimen received in $1 \$ 9 \&, 235$ adults were reared. The flies appear in June or early July: The operation of egg laying has been described by Dr Harris substantialiy as follows. He states that the female lays a great number of eggs in ringlike clusters around small twigs of white oaks, and that her punctures are followed by the growth of a rough or shaggy reddish gall, sometimes as large as a walnut. Dr Fitch states that the growth from the eggs laid by the midsummer flies forms a harder and more woolly gall, of a coarser texture and duller color, and that it resembles a ball of wool. These remain through the winter, though their attachment to the twig is so slight that birds often tear them off. The yall is illustrated on plate 49 . figure 1 .

The actult fly has been described by Dr Harris ats ' in inch long, almost black or of the color of pitch, highly polished, except on the alrelomen, with the mouth parts and legs a cinnamon color. 1). Fitch states that the female may be distinguished by its longer abdomen and its being black.

Woolly oak gall. Andricus operator Osten Sacken. This gall closely resembles the beautiful structure produced by the wool sower, An d r ic us 
sem inator Harr. It, when fresh and growing, consists of whitish filaments forming a white round body with beautiful pink spots. Within there are a series of seedlike kernels containing larvae. This gall occurs on the young flowering branches of oaks in June.

\section{Gouty oak gall \\ Andricus punctatus Bass.}

Rough, hard, woody, gnarled scaly swellings on red oak limbs and twigs not over $1 \frac{1}{4}$ inches in diameter, occasionally occur in immense numbers.

This interesting gall insect is ordinarily rare in the vicinity of Albany, if we may base an opinion on the absence of earlier records. The writer's attention was called by Dr H. M. Pollock, in April 1902, to a red oak at Loudenville near Albany, which was very badly infested with the galls of this species. It will be seen by reference to plate 48 , figure 4 , that these unnatural growths are irregular swellings along the smaller limbs, ranging in diameter from less than $1 / 2$ to $\mathrm{I} / 2$ inches, depending on the size of the twig. They are of variable length and frequently several coalesce to form an elongated mass of diseased tissue. The galls illustrated were inclosed in a box and produced over 500 insects, some of which were guest flies and a iew were probably parasites. These galls were macle the basis of an estimate and it was calculated that the entire tree bore 20,000 and produced over 500,000 insects. The general character of the infestation is well shown on plate 47 .

This species was reared $\lambda_{p}$. I I by Mr Bassett, from a young, thrifty red oak growing in the vicinity of $\mathbb{N a t e r b u r y ~} \mathrm{Ct}$. Its local habit is confirmed by his finding galls only on the one tree. Professor WValsh also described what is probably this same species, under the specific name of podagrae, and he likewise refers to its local habits. Both gentlemen, as well as ourselves, reared large numbers of the insects without obtaining males. The perfect insect has been described by Bassett as follows:

Femulc. Head and thorax black, face pubescent, palpi light brown, tips darker: antennae reddish brown at the base, gradually deepening to a dull dark brown, $1+$ jointed. Thorax finely and beautifully punctate : three 
longitudinal grooves, converging towards the scutellum and a short groove on each side of the middle one, reaching halfway from the collar to the scutellum, also a short, shallow groove or depression over the base of the wings. Scutellum with coarse, irregular pits or punctures. Legs reckdish brown, coxae and tips of tarsi dark brown or black. Dorsal portion of the abdomen black, ventral, reddish brown, second secrment has a few scattered hairs beneath the wings, others (except the first) minutely punctate. IVings hyaline; veins brown, rather slender; areolet small, distinct; radial area not closed. Length . 15 .

Horned oak gall. Andricus cornigerus Osten Sacken. This irregularly rounded gall is woody with numerous hornlike protuberances through which the gall flies escape. It is very hard, of the same color as the branch, is from $1 / 2$ to $1 \frac{1}{2}$ inches in diameter and contains within many larval cells. It occurs on the branches of pin oak, scrub oak and black-jack oak and is recorded by Beutenmuller as being exceedingly common in the vicinity of New York city.

Oak tip gall. Andricus claiula Bass. A green or brown, club-shaped, hard, woody gall with a few leaves growing from its summit, occurs at the tips of white oak twigs. It is recorded by Beutenmuller as very common about New York.

Rough bullet gall. Holcaspis duricoria Bass. A globular, rough gall with conelike apex, occurs somewhat commonly on scrub and swamp oak.

This gall resembles the bullet gall but may be distinguished by its much rougher exterior, less globular form, flattened base, and the apex extended into a conelike process. It occurs rather commonly on scrub oak at Karner and it is stated by Beutenmuller to be rare on swamp oak in the vicinity of New York city.

Oak bullet gall. Holcrspis globulus Fitch. Bulletlike galls in clusters of two, three or more are common on the terminal twigs of white oak and occur also on the post and chestnut oaks. This gall is yellow or reddish in summer, turning brown with the approach of cold weather, is corky in texture and contains a larva in the small central cell.

Oak potato gall. Neurotcrus batatus Fitch. I,arge, hard, uneven galls $3 / 4$ inch thick and two or three times as long, somewhat resembling a potato in shape, occur on white oak twigs.

This peculiar deformity to oak twigs is abundant on the branches of young trees in the vicinity of New York city: It is a hard, woody growth with the surface coated with pale bluish bloom and internally it has a dense corky texture with numerous larval cells. It is sometimes quite injurious on account of its deforming young trees.

Noxious oak gall. Neuroterus noxiosus Bass. An irregularly rounded, hard, woody gall resembling that of $N$. bat atus Fitch, occurs on the terminal twigs of swamp white oak. 
Lobed oak gall. Cynips strobilana Osten Sacken. A large, oval body consisting of a number of wedge-shaped parts closely packed together with their pointed extremities attached to the twig, occurs on swamp white oak [pl. 48, fig. 3]. Each of these wedgelike structures is hard, corky, and contains a larva in the central cell. It is not common.

Large oak apple. Amphibolips confuentus Harr. This is one of our common oak galls. It is nearly globular in shape, greenish or brown in color dependent on its age, and its interior is filled with a spongy mass in the center of which is a single larval cell. This species is occasionally quite abundant on trees, as may be seen by reference to plate 50 , figure $\mathrm{I}$, though it cannot be considered injurious. Mr. Beutenmuller states that a certain number of these galls produce both males and females in June and others females in October or the following spring. These latter are merely a dimorphic form.

Larger empty oak apple. Amphibolips inanis Osten Sacken. A globular gall closely resembling the oak or Nlay apple, A. con f l u e n t us Harr., occurs on the leaves of scarlet and red oak. It is much like the preceding in general appearance, though considerably smaller and may be at once recognized by the nearly empty interior, the small larral cell being held in position by numerous radiating filaments.

Black scrub oak gall. Amphibolips ilicifolize Bass. Elongate, fusiform galls tapering at both ends, with the apex more slender and frequently slightly curved, occurs on the leaves and petioles of dwarf and scrub oak. It is about $1 / 2$ inches long, half that in diameter, and contains an elongated kernel held in position by radiating fibers. It is green and soft in summer, turning brown and becoming brittle on the approach of winter [pl. 50, fig. 2].

Oak leaf apple. Andricus singularis Bass. A globular, smooth, green gall from $I_{+}$to $I_{2}$ inch in diameter, occurs rather commonly on the leaves of red oak. This gall is first green and succulent, turning brown and becoming brittle later in the season. It contains a central oblong cell held in place by radiating fibers.

Oak wool gall. Andricus lana Fitch. The white or buff-colored woolly masses composing this gall, occur on the underside of the principal veins of white oak leaves. Within it is composed of numerous small larval cells closely crowded together and attached by their lower ends to the vein of the leaf. It is recorded by Beutenmuller as common in the vicinity of New York.

Oak leafstalk gall. Audricus petiolicola Bass. These irregularly rounded or fusiform, hard, woody enlargements at the base of the leaf contain many cells. The full grown galls are about $3 / 4$ inch in diameter, green in summer, brown in winter and common on several oaks. 


\section{Oak leaf bullet gall \\ Dryophanta polita Bass.}

A small, globular gall occurs in numbers in August and September on both surfaces of the leaves of scrub and post oak.

This gall ranges from about $/ 4$ to $3 / 4$ inch in diameter, is at first pale green but sunlight changes it to red or reddish brown. It is found on the foliage of young and thrifty shoots, from one to 20 occurring on a leaf. When dry the shell is very thin and brittle and contains a round larval cell held in a central position by radiating branching fibers which extend to the outer shell. The perfect insect becomes matured in October and remains in the gall over winter.

\section{Oak fig gall \\ Biorhiza forticornis $1 \mathrm{Valsh}$}

Irregular reddish tinted, greenish galls occur in dense clusters along the midrib of the leaves or on the stems of white and scrub oaks in midsummer.

This species is rather common, and was met with at Karner on the dwarf chestnut oak, Quercus prinoides, being quite abundant in limited localities. The galls on the young twigs and leaves are very pretty about the middle of August, being irregular in shape, greenish yellow and tinted with red. Plate 48 , figure 1 , represents a mass of forming galls and shows the badly infested shoots as well as the foliage. The galls are found along the midrib on both the upper and under surface. The old galls, as they appear on the dead twig are represented at plate 48 , figure 2. It will be seen that they constitute a very irregular mass and look not unlike figs closely packed around a central stem. The gall flies emerge from small circular holes. This species was met with by Dr Fitch on thrifty growing white oaks, on which tree he stated it is quite abundant. His description of the formation of the galls is as follows:

The fema!e pierces the bark with her ovipositor, and inserts a number of egrgs at a.short distance from each other, apparently sinking them into the wood beneath the bark causing a little discoloration and a spongy spot runs inward from the gall to the pith of the limb. These wounds of the bark heal over so that no indication of their presence can be detected with a magnifying glass. A little smooth round swelling or elevation on the bark soon commences above the egg, increases in size, till at length the bark 
bursts, and small round granules, the size of a pinhead, protrude from the openings. These grow more and more, resembling miniature ciusters of grapes, at which time they begin to press on each other. They are from $1 / 4$ to $1 / 2$ inch in diameter, and the outer surface is covered with fine short hairs which become rubbed off from the more exposed portions. The larva lies in a small oval cavity at the base of each gall or lobe, and on account of the tough, whitish leathery walls, there is considerable resemblance to a seed.

Dr Fitch states that most of the galls are perforated before winter, indicating that the flies appear before cold weather. He adds that some clusters may be found in winter containing insects, and these latter appear the following June.

Warty oak leaf gall. Cccidomyiz pilulac Osten Sacken. Somewhat rounded, hard, woody galls occur commonly on the leaves of pin, red, black-jack and scrub oaks. They appear in May and become fully developed in August or September, at which time they are bright red or reddish brown. These galls vary greatly in size and may be recognized by the characteristic reticulate markings [pl. I, fig. 16].

Oak hedgehog gall. Acraspis erinaciillialsh. A rounded, oblong or oval gall covered with numerous rather long spines, is attached to the upper side of the principal veins of white oak leaves. This yellowish or greenish gall with bright red spines is rather common.

Spiny oak gall. Cynips prinoides Beut. This globular gall about I/2 $_{2}$ inch in diameter, covered with numerous conelike projections, occurs on the upper side of the leaves of dwarf chestnut oak. It is green tinged with red and contains only one cell.

Oak leaf seed gall. Cynips dccidua Bass. Clusters of secdlike bodies often 30 or 40 together, grow from the underside of the mid rein of leaves of the red oak. The larger cells are smooth, greenish white with the apex enlarged and are about the size of grains of wheat.

Oak button gall. Neuroterus umbilicatus Bass. This small, round, brown, buttonlike gall occurs in considerable numbers on the underside of swamp white oak leaves. The galls are about ${ }^{\mathrm{I}}{ }_{\mathrm{ro}}$ inch in diameter and are rather common.

Marginal fold gall. Cecidomyia crubescons O. S. This peculiar pocket-shaped, marginal gall [pl. I, fig. IS] occurring in the angles of oak leaves, is somewhat abundant in early summer on certain species of oak, though rarely injurious.

Oak flower gall. Andricus pulchra Bass. The rounded, shotlike, greenish white, soft, spongy polythalamous galls of this species were taken on catkins of red oak at Poughkeepsie May 20, I903, adults appearing: 
May 29. This species, identified by Beutenmuller, is described in American Entomological Society Transactions, I $890,17: 73$.

Oak plum gall. Amphibolips prumus IValsh. This globular gall about I inch in diameter, grows from the side of acorn cups of the black and red oak, maturing in August and September. It is a solid, fleshy growth with a central larval cell. The parent flies appear in April, according to 1)r WValsh.

Hickory seed gall. Cicidomyia caryaccola Osten Sacken. The pale green, smooth, elongate, onion-shaped galls of this species have the tip prolonged into a point and are frequently found in clusters on the underside of leaves of various kinds of hickories. Osten Sacken states that the galls are somewhat larger than those made by Diplosis cary a e Osten Sacken, and that it occurs through the summer either in separate clusters or mixed with other galls, and Beutenmuller records it as common in the vicinity of New York city [pl. 1, fig. 21].

Diplosis caryae O. S. Clusters of the pale greenish pointed galls [pl. 1 , fig. 8], of this species are somewhat abundant in midsummer along the midrib and on the under side of hickory leaves.

Hickory onion gall. Cocidomyia holotricha Osten Sacken. A subglobular, pubescent, onion-shaped gall occurs on the undersides of leaves of shellbark and other hickories. They sometimes cover the entire under surface of the leaf, producing a deformity and gradual shriveling. The gall is covered with a pubescence, pale when the gall is young and growing. and becomes rose color as it approaches maturity. It is hollow and contains a single larva. This species has been figured by Glover and Beutenmuller states that it is abundant everywhere in the vicinity of New York city [pl. I, fig. 4].

Hickory peach gall. Cecidomyia persicoides (). S. This rounded, brownish, downy gall [pl. 1, fig. 9], is rather common in midsummer on the under surface of hickory leares.

Hickory tube gall. Cccidomyia tubicola Osten Sacken. Narrow, cylindric, tubelike galls occur on the underside of the leaves of different kinds of hickories. They are inserted in a small protuberance, break off very casily, are green when immature, becoming brown and blackish when ripe. They are hollow, and in October contain a whitish larva with the breastbone teminating anteriorly in a single elongated point. These galls generally occur in clusters. This species has been figured by Glover and Bentenmuller records it as very common in the vicinity of New York city [pl. 1, fig. Io]. 


\section{Hickory button gall \\ Phyllowera focicola Perg.}

Flattened, circular, greenish yellow or whitish galls about 18 inch in diameter, occur on the under surface of hickory leares.

These peculiar growths [pl. I, fig. 19] are very interesting and are probably the work of this species, though we were unable to obtain adults. This species has recently been described by Mr Pergande, who states that it may possibly be P. f ovea t a Shimer, a form which produces galls very similar to this. These structures were rather abundant on hickory leaves at Nassau in August. They have been described by Mr Pergande as follows :

In the largest and perfectly developed galls the upper side is either of a delicate pale red with the dimple darker and its basal circumference yellowish green; or entirely yellowish green with only the dimple of a beautiful pink color. Beneath they are uniformly yellowish green, often with a faint reddish tinge, especially toward the nipple. On the other trees, most densely covered by them, they were less beautiful, with less red and shallower dimples. The walls are very thin and paperlike and readily collapse when old. All galls are perfectly smooth on bcth sides.

\section{Ocellate maple leaf gall Cecidomyia ocellaris Osten Sacken}

Red maple leaves are frequently thickly spolted with circular ocellate spots about $3 / 8$ inch in diameter, the disk being yellow with the margin and central dot cherry-red.

This peculiar affection of maple foliage is the work of a small gnat, which, judging from the abundance of its work, must be numerous in the vicinity of Albany [pl. I, fig. 12]. It has been recorded by Professor Comstock as being very common at Ithaca and as occurring at V ashington D. C.

The tissue inhabited by the gall is undoubtedly rendered of little value to the plant and therefore the foliage is injured to some extent. Generally speaking, this species is not injurious, and ordinarily its work may be regarded as ornamental in character, since it gives a decidedly variegated appearance to the foliage. There is no unquestioned record of the adult insect having been reared. The full grown larva drops to the ground 
the latter part of September and spins a rude cocoon a short distance below the surface, where it undergoes its transformations.

\section{Fusiform maple gall \\ Eriophyes acericola Garm.}

Slender, fusiform galls are sometimes very abundant on the upper surface of the leaves of sugar maple.

This gall is very slender, about $1 / 5$ inch in length and tapers at both extremities. It is occasionally rather abundant on sugar maple leaves in the vicinity of Albany. This species has been studied by Professor Garman, who states that in five examples of this mite the striae were counted and in three of them numbered 30 and in the other two 28 and 29 respectively. The prongs of the featherlike appendage seemed to be three The mite is about .0075 inch. He ha, recorded this species as being abundant in galls collected in Illinois in June.

\section{Bladder maple gall \\ Eriophyes quaaripes Shimer}

The small, bladderlike galls of this species, about $1 / \mathrm{ro}$ inch in diameter, are sometimes very abundant on the upper surface of soft maple leaves.

This trouble is sometimes exceedingly prevalent in the vicinity of Albany, the galls being so numerous on certain trees as to disfigure a very considerable proportion of the foliage. The galls, according to Professor Garman, appear with the unfolding of the leaves in spring, as slight swellings of the parenchyma, and as the foliage expands they develop into top-shaped galls on its upper surface. The form varies from discoid to more or less spherical, while occasionally two are fused and have a common opening. The gall is at first of the same color as the leaf, changing later to dull purple or green and afterward becoming the light green of the veins and veinlets, and later changes to purplish, drying up and becoming black at the end of the summer. The outer surface is smooth, though the walls are broadly and irregularly impressed. The position of the gall 
is usually indicated on the under surface by a deep impression with a tuft of white hairs in the center Lpl. 1, fig. 11 ].

This mite, according to Professor Garman, has from 37 to +2 coarse striae and is about oos inch in length. The tarsal claw is slightly curved and terminates in an evident knob. The featherlike appendage has four pairs of prongs. It varies in color from pale yellow to light orange. Matured females, young and eggs occur in June.

\section{Linden wart gall \\ Cecidomyia acrucicola O. S.}

This gall [pl. I, fig. I3] is sometimes exceedingly abundant in midsummer on linden and quite variable in color, being pale greenish or whitish when young and dark brown or almost black later in the season. It shows about equally on both sides of the foliage. The leaf tissues at the edges of the galls weaken as the season advances, allowing the latter to drop to the ground, so that toward the end of the summer badly infested leaves may be fairly riddled with irregular, circular holes from which the galls have disappeared.

\section{Linden mite gall \\ Eriophyes abnormus Garm.}

Top-shaped galls about $1 / 10$ inch in diameter, are sometimes exceedingly abundant on the upper surface of linden leaves.

This species is more or less common in the vicinity of Albany, and occasionally leaves are very badly affected. The abnormal growth is produced by a small mite which, according to Professor Garman, differs from all Eriophyidae, in that the abdomen, just before the terminal sucker, is noticeably enlarged. He describes the gall as "top-shaped, expanding above and contracting toward the upper surface of the leaves into a neck. It measures. 55 of an inch in height and $1 /$ ro inch in diameter. The walls are deeply infolded, sometimes giving rise to unequal lobes. The outer surface is smooth, green and devoid of hairs. The cavity of the gall is made unsymmetrical by the deeper impressions of the wall. The inside of the latter is slightly roughened by small folds and is clothed with long 
aciculate unicellular hairs." He has recorded the species from Wilmington I11. [Sce pl. 1, fig. 1t]

\section{Ash midrib gall}

Cecidomyia pellex Osten Sacken.

A peculiar, elongated, greenish or reddish brown gall wrapping itself about the midrib and inclosing whitish, footless larvae, is the work of this species.

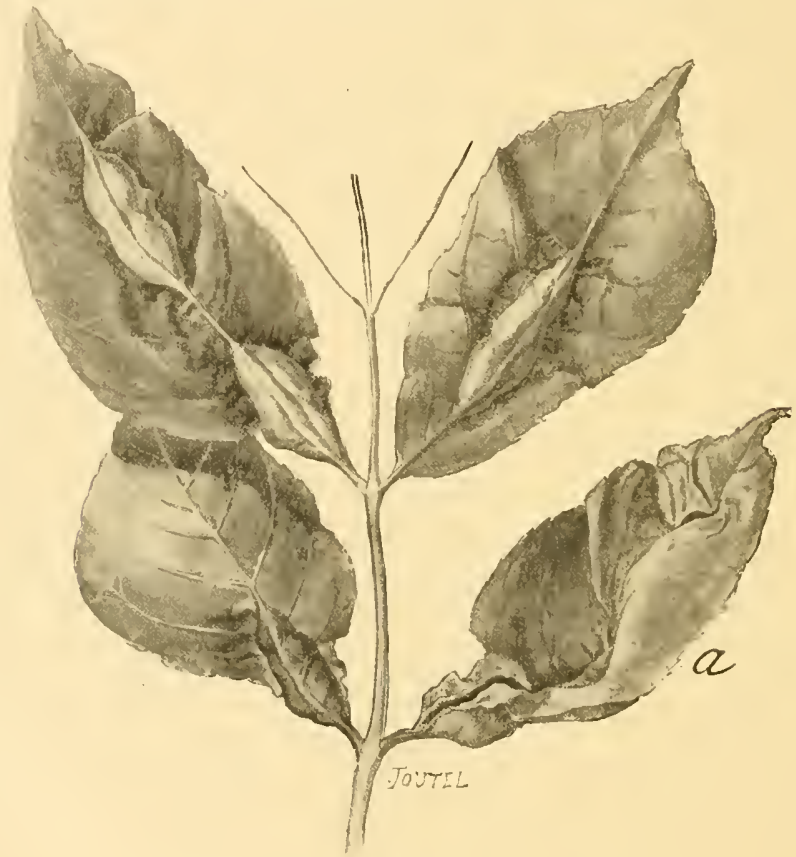

Fig. 169 Ash midrib gall, ( e ecidonyia pellex (ariginal)

This insect is somewhat common in the Hudson river valley, having been observed in the neighborhood of South Durliam by Mr O. Q. Flint and found in numbers at Poughkeepsie by Mr Young. It also occurs about Albany, the galls being nearly full grown the latter part of May or early in June. 
The development of the gall is interesting. It appears to be formed by the irritation due to one or more larvae on the upper surface of the midrib of the leatlet. The longer, more conspicuous galls are inhabited by a considerable number, while smaller ones may contain only one or two or three larvae. In each instance it will be observed that the tissues on either side of the midrib and inclucling it to.some extent, begin to swell enormously, thicken and gradually close over the irritating larva. The fly has not been bred, due to the rapid withering of the gall, in spite of several attempts to obtain the adult. When young, the gall is a pale green and as it ages it becomes tinged with brown. It is thick and the hypertrophied tissue is very succulent [fig. 169]. This species has been recorded by Professor Beutenmuller from Fort Lee N. J., where it occurs in June.

Red elm leaf gall. Pemphigus ulmifusus IValsh. The solitary spindleshaped galls produced by this plant louse on the upper surface of the leaves of the red elm, are about an inch long. This species is rare in New York State. It occurs in small numbers on slippery-elm.

\section{Ash flower gall \\ Eriophyes froxiniflore n. sp.}

The staminate flowers of white ash are sometimes very curicusly deformed by the work of a small gall mite, which appears to attack them about the time they begin to develop, and by the latter part of June peculiar irregular masses of green tissues are found on the flower stem. An examination shows that each mass consists of a series of irregular, fringed, lobulated masses joined one to the other, each group at this time ranging from $1 /+$ to about $1 / 2$ inch in diameter. Later they become nearly $3 / 4$ inch or more in diameter, eventually drying and remaining on the trees over winter, giving the infested ones a very peculiar appearance. The work of this mite appears to be moderately common in New York State, though it does not seem to have attracted much attention. Specimens of this mite's work have been received from Brooklyn N. Y. where it appears to infest several trees year after year, and we have also observed its 
operations in the vicinity of Albany. It probably causes very little or no injury.

\section{Poplar twig gall fly \\ Agromyza aeneiventris Fallen}

This little fly, kindly identified by Professor Coquillett through the courtesy of Dr Howard, produces oval, smooth swellings about $1 / 2$ inch long on one side of small poplar twigs [pl. 50, fig. 3]. It is rather abundant at Karner, the insects wintering within the galls as larvae, adults appearing in early spring.

Description. The parent insect is a small, black $\mathrm{fly}$, with red eyes, less than $1 / 8$ inch long.

The larva is a greenish yellow maggot about $1 / 8$ inch long with strongly

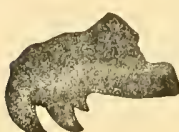

Fig. i7o Larval mandible of $\mathrm{Ag}$ rom $\mathrm{yz}$ a a eneiventris, ment with an irregular, slightly wavy, transverse series of much enlarged (original) tridentate jet-black mandibles, as shown in figure 170 , and with a pair of spiracles borne on knobbed elevations at each extremity of the body:

The puparium is oval, less than $1 / 8$ inch long, each segchitinous points near its anterior margin. Posterior extremity terminated by a pair of stout, blunt, slightly moniliform processes.

Life history. The young larva apparently begins operations in the green bark, causing an irritation which results in the rapid development of abnormal tissues, producing a spongy, oval mass on one side of the twigprobably hypertrophied bast. These galls vary considerably in size, ranging from about $3 / 8$ inch in length to compound masses about an inch long. The smaller galls contain a single larva while the larger ones may be inhabited by several. The gall tissue is very soft, almost cheesy in texture, very different from the ordinary wood fiber. This is true of the majority of the galls found in the spring, which occur on last year's growth. A few are found on growth of the preceding year, and these are remarkable for containing oval, hard masses of woody tissue a little less than $1 / 8$ inch long. The galls, in older tissues, usually contain several maggots. The larvae make rather broad, short galleries about an inch long in a portion 
of the diseased tissues. Fresh excavations are bright green, showing that the dentate mandibles are very effective tools. The gall is sometimes inhabited by an undetermined curculionid larva.

This gall insect is preyed on by a parasite, detemined through the courtesy of Dr Howard as Urogaster forbesi Ashm. This gallmaking fly has been reared by Professor Webster from larvae burrowing in the roots of clover and tunneling the pith of the common garden sunflower, and Mr Pergande has bred it from stems of ambrosia.

\section{Vagabond gall}

Pemphigus vagabundus IValsh.

A peculiar folded convolute mass of foliage some two inches in diameter, frequently occurs on the tips of poplar twigs.

This species appears to be rather common in the vicinity of Albany, and the peculiar convolute, greenish galls or the dry brown remains of the same may often be met with on poplar shoots [pl. 51, fig. I].

This gall is sometimes very abundant on the tips of certain cottonwoods and poplars, and according to Walsh is much more numerous some years than others. The old blackened galls hang on the twigs for several seasons, thus giving them a characteristic appearance, particularly in winter. The winged plant lice make their appearance in September, and the green, shining, hollow gall appears the following summer. The skin of the latter is quite thin and contains a single wingless plant louse, which is the parent of the colony subsequently inhabiting this peculiar shelter. All become winged in September and desert the gall.

\section{Poplar leafstem gall \\ Pcmphigus populi-transucrsus Riley}

Oval, somewhat elongated galls, with transverse openings, develop near the middle of the leaf petioles of cottonwood during the latter part of the summer.

The galls are nearly $1 / 2$ inch long, about $3 / 8$ inch in breadth, and of the same color as the leaf petiole. The mouthlike orifice, when the plant lice are mature, gapes, is nearly transverse and may extend two thirds the way 
around the gall though occasionally it is smaller. The interior of the inhabited gall is crowded with plant lice, they being sometimes so abundant as to literally stand on their heads in attempting to obtain nourishment from the succulent walls. The mealy white powder, cast shriveled skins and globules of honeydew are also characteristic features of this insect's retreat. This species has been very abundant in the vicinity of Albany in recent years and was the occasion of a brief note by $\mathrm{Dr}$ Lintner in 1897 . [See pl. 11, fig. 15, 16]

\section{Basal leaf gall \\ Pemphigus populicaulis Fitch}

Imperfect, globular galls $1 / 4$ to nearly $1 / 2$ inch in diameter, occur in June at the base of cottonwood leaves.

These little galls at the very base of the leaf are somewhat irregular in size and shape and otherwise closely resemble the preceding species. This insect was clescribed by Dr Fitch in 1858 , at which time it was very abundant in Albany and attracted much notice.

\section{Willow club gall \\ Rhabdophaga rigidare O. S.}

Purplish, fusiform galls $3+$ to 1 inch in length are common on or near the tips of low willow shoots. This gall is quite abundant at Karner, the large, pale orange larva wintering in a central channel within the gall, the flies appearing the following May.

\section{Willow apple gall Pontania pomum Walsh.}

A smooth, globular, or slightly oval rosy cheeked gall, like a miniature apple, measuring from 310.55 inch may be found growing on one side of the midrib of the leaf of Salix cordala.

This species is rather common in certain localities, and on opening the gall a pale greenish white larva with a pale brown head may be found within. The gall has been desribed by Walsh as follows:

The gall S. pom um is found on $\mathrm{Salix}$ cordat a and very rarely 
on S discolor. A smooth, fleshy, sessile, grlobular, or slightly oral monothalamous gall, like a miniature apple, .3 to .55 inch diameter, growing on one side of the midrib of a leaf, and extending to its edge or beyond it. The principal part of the gall projects from the underside of the leaf; very rarely it is bisected by the leaf. Color greenish yellow, sometimes with a rosy cheek, especially the upper surface and often with little dots. Fully mature July 31. An analogous gall is formed in Europe on various willows by Nematus gallicola Westw.

The transformations to the yellowish red adult occur within the gall in case of specimens reared by Walsh. There was no earth in the jar and some cocoons were spun between the galls.

\section{Pontania pisum Walsh.}

Subspherical, pealike, pale yellowish galls growing on the underside of the leaves of Salix discolor are the work of this species.

This gall-making sawty is a common species in some sections at least, and on breaking open the hollow galls a whitish, 1 S-footed caterpillar with a slightly dusky head and dusky mouth parts may be found within.

The gall has been described by Walsh as follows:

A subspherical, pealike, hollow, pale yellowish green gall, always srowing on the underside of the leaf and almost always from one of the side veins (in one case from the midrib) and attached to the leaf by only a minute portion of its surface; . 18 to .28 inch in diameter, and a few, immature, only os inch in diameter. Almost invariably there is but one sail to the leaf, but on four leaves there were two, and occasionally two are confluent. Surface in some smooth and even, without pubescence; in others a little shriveled, generally studded in the medium sized ones with four to 12 small, robustly conical nipples, which in the larger ones have burst into a scabrous brown scar. Only in 3 out of 62 was there any rosy cheek, as in S. pomu m. The point of attachment is marked on the upper side of the leaf by a brown subhemispherical depression.

The final transformations to the black yellowish marked adult occur in the ground. 


\section{Pontania desmodioides IValsh}

A smooth, flattish, sessile, yellowish green gall on both sides of the leaf of Salix $\mathrm{hum}$ ilis in all probability leelongs to this species.

The galls of this insect were taken by $\mathrm{Mr}$ Pergande at Richfield Springs on Sep. 28, 1886, and it is probably a somewhat common species. The gall has been described by Mr Walsh as follows:

The gall. is found on S. humilis. It is smooth, flattish, fleshy, sessile, yellowish green, monothalamus, semicircular in general shape like the seed of a Desmodium or the quarter of an orange. It is about equally divided between the two surfaces of the leaf; no rosy cheek. Generally there is but one gall on a leaf; one leaf was secn with three upon it. Length .23 to .5 inches. 131 specimens. Gall mature July 30.

The larvae resemble those of other gall-inhabitating species belonging to this group, and when full grown transform to the adult within their shelters, at least when there is no earth that can be conveniently entered. The parent insect is about $1 / 5$ inch long, dark brown marked with reddish brown, and with the lowe: part of the abdomen and the legs rust yellow.

\section{Pontania hyalina Norton}

Fleshy, reddish galls on Salix $\mathrm{fragilis}$, occurring in two parallel rows one on either side of the midrib, sometimes fouching but not originating from the latter, and rarely extending to the edge of the leaf, may be those of this insect.

This species occurs in New York State, the galls having been collected at Richfield Springs by Mr Pergande in February is86, adults being bred from the same Mar. 3 and Ap. 27. The gall and its arrangement has been described by Marlatt as follows:

Fleshy galls, occurring in two parallel rows, one on either side of the midrib sometimes touching but not originating from the latter, and rarely extending to the edge of the leaf; sometimes as many as 20 on a single leaf; in other cases confined to a row on one side of the leaf, or occasionally occurring singly; shape irresular, elongate ovate, projecting equally on both surfaces of the leaf; length 7 to $10 \mathrm{~mm}$, the abortive ones smaller. Color on upper side more or less brownish red; beneath white with slight purplish tinge. The galls result from the punctures of the females in the very tenderest leaves, the wound closing and becoming invisible. 


\section{Willow cone gall \\ Rhabdophagra strobiloides WValsh}

A peculiar conelike deformity on the tips of willow shoots is due to the work of this insect.

These interesting galls are rather common objects about Albany, and the insect presumably has a wide distribution in the United States, though specific records of its occurrence are not abundant.

Description The gall, a tapering, conelike, terminal growth, is obviously a mass of aborted leaves, one overlapping the other much as the scales of a pine cone. This deformity was figured by Glover in 1874 , in addition to the description and illustrations given by Walsh, who also figured the adult fly without describing it.

Life history. The parent insects, according to Walsh, appear in April or early May, and the gall commences its growth shortly after and attains full size by the middle of June. In its early stages it is spherical and enveloped in a dense mass of foliage, which gradually falls off toward autumn, and by November the twig on which it occurs, if small, is killed at the tip. At this time the larva is in the heart of the gall inclosed in a delicate membranous cocoon, where it remains till the following spring, when it transforms to the pupa and shortly after the fly escapes.

\section{Witch-hazel cone gall}

Hormaphis hamamelidis Fitch

Conical, green or reddish galls occur in considerable numbers on the upper surface of witch-hazel leaves.

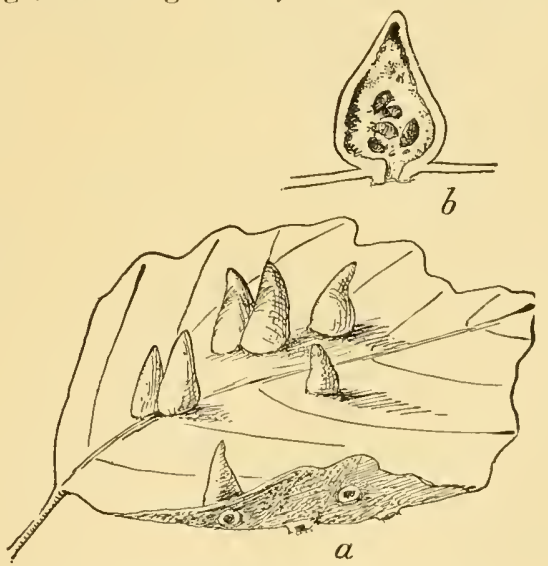

Though this remarkable plant Fig, ${ }_{77}$ Hormaphis hamamelidis: $a=$ galls, natural size louse was briefly described by Dr Dep't Agric. Div. Ent. Tech. Ser. 9, 20,a) Asa Fitch in 1851 , very little was known concerning the species till it was 
sturlied by Mr Theodore Pergande, who had been interested in the insect for over 20 years, and in 1899 succeeded in completing its life history. The following is an abstract of his detailed notice.

The rapidity of growth depends on the season. The galls usually begin to appear in the latitude of 11 ashington D. C., about the middle of April, attaining full growth toward the end of May. Young stem mothers hatch a week or more before the leaves appear and frequently assemble in
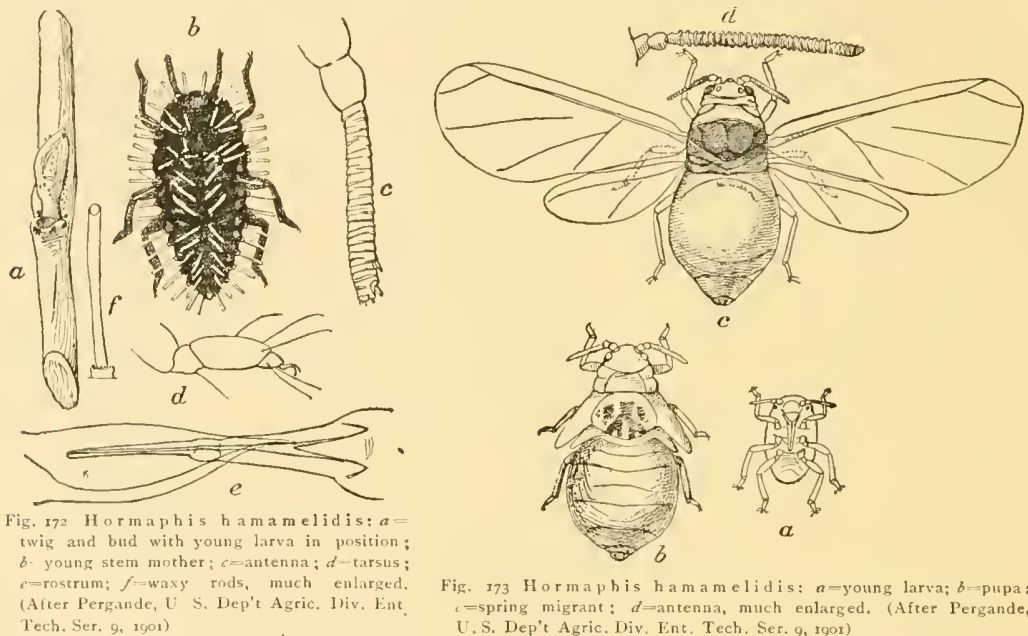

Fig. I73 Hormaphis hamamelidis: $n$-young larva; $b$--pupa: $c=$ spring migrant: $d$ =antenna, much enlarged. (After Pergande, U. S. Dep't Agric. Div. Ent. Tech. Ser. 9, 1901)

considerable numbers awaiting the unfolding of the buds. The plant lice settle along the midrib and the lateral veins of the unfolking leaves, and soon cause a pale yellowish green discoloration on the upper surface. The few days old gall appears as a small blisterlike swelling on the upper side. It develops rapidly and in May is quite convex or slightly conical, with the opening on the under surface nearly closed. The young galls are greenish yellow with the tip more or less purplish. The fully developed gall is shown on plate 1 , figure 7 .

The dormant season is passed as a winter egg deposited on the 
branches of twigs, generally near the base of buds or leaf scars. The eggs resemble those of the common apple plant louse, Aphis mali Fabr. though they are considerably smaller. The young stem mother is but slightly larger than the egr and appears in the latitude of IVashington about the midclle of April. She is a dull black color corered with a
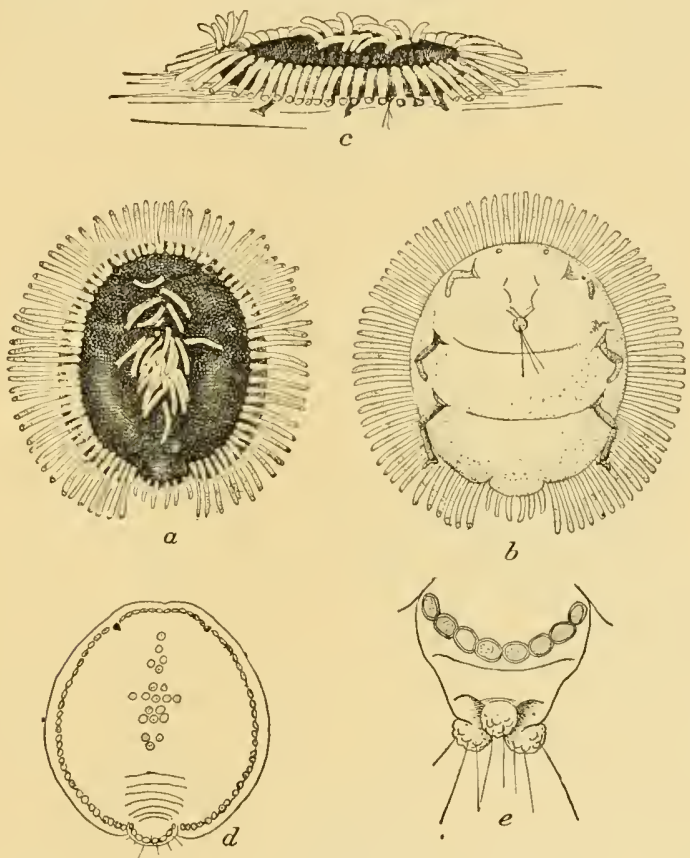

Fig. 174 Hormaph is ham amelidis, 3 d generation, fourth or final stage:
$a=$ dorsal view; $b$-ventral view; $c=$ lateral view, $d=$ dorsal view, showing the
arrangement of pores; $c=$ end of body. (After Pergande, U. S. Dep'i Agric. Div.
Ent. Tech. Ser, 9, sgor)

delicate, slightly bluish secretion and ormamented with a waxy secretion as shown in figure 172. She molts three times, attainms maturity the middle of May and from then producing +-6 young till about the midclle of June.

The second or winged generation, the young of the stem mother, com. 
plete their growth within 16 to 20 days. They emerge from the galls and migrate to birches toward the end of May or early in June. The various forms of this generation are shown at figure 173. These plant lice live on the unclerside of birch leaves, sometimes covering them. Their young are met with in the ricinity of $\mathrm{W}$ ashington early in June, attaining maturity in about it days. This generation has a characteristic appearance in its fourth stage, as shown in figure 174 . It is remarkable because of its almost perfect mimicry of certain $A$ leurodids. The insects are first pale brownish, changing gradually to a dusky or black color. The fourth and fifth grenerations are essentially identical with the third, the last named attaining

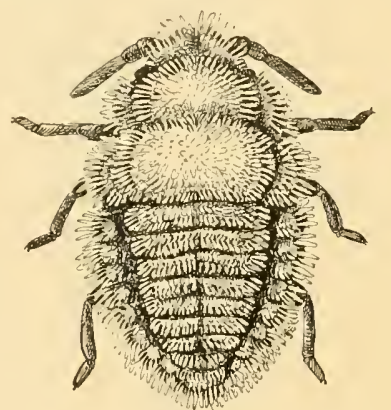

$a$

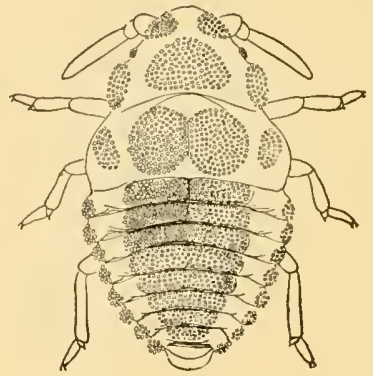

6

Fig. 275 Horm aphis hamamelidis, 6th generation, second stage: $a=$ dorsal view ; $b=$ dorsal view denuded, showing arrangement of pores, much enlarged. (After Pergande, U.S. Dep't Agric. Div. Ent, 'Jech. Ser. 9, 19os)

maturity about the middle of August. It gives birth to a sixth generation which presents an entirely different form, as shown at figure 175 .

The young are yellowish brown at first, naked, but soon become covered with a pruinose or bluish white secretion, giving them a moldy appearance. Later the bristly white iridescent waxy threads develop. This generation acquires wings, feeds for a time and then forsakes the birch, migrating back to the witch-hazel, where the sexual generation is developed. This latter sometimes becomes exceedingly abundant. The general characters of this generation are well illustrated at figure $1 ; 6$. Each female produces from 
five to ro eggs deposited as previously stated, and thus the life cycle of this extremely interesting form is completed.

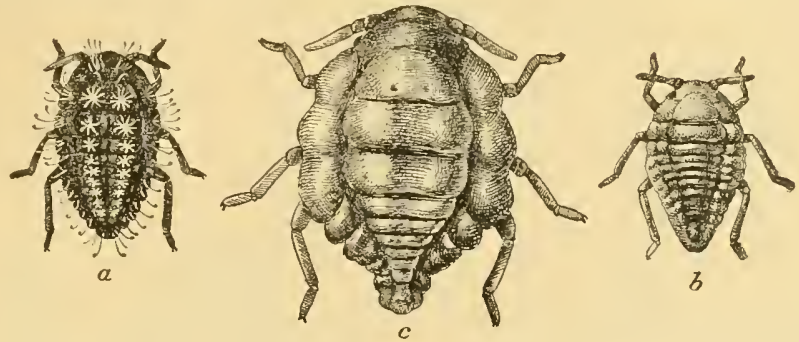

Fig. I76 Hormaphis hamamelidis, sexual generation: a=young larva: $b$-male:

$c \rightarrow$ female, much enlarged. (After Per $\$$ ande, L.S. Dep't Agric. Div. Ent. Tech. Ser. 9, 19or)

Spiny witch-hazel gall

Hamamelistes spinosus Shimer

Many spined, green or reddish galls occur on witch. hazel from June to the latter part of Octoluer.

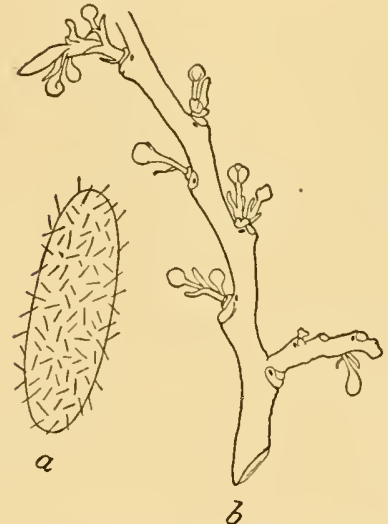

Fig. $177 \mathrm{Hamametistes} \mathrm{spinosus:}$ $a$-winter egg much magnified; $b=$ twig of witch-hazel with young flower buds and eggs in position, natural size (After Pergande, U. S. Dep't Agric. Div. Ent. Tech. Ser. 9, Igor)

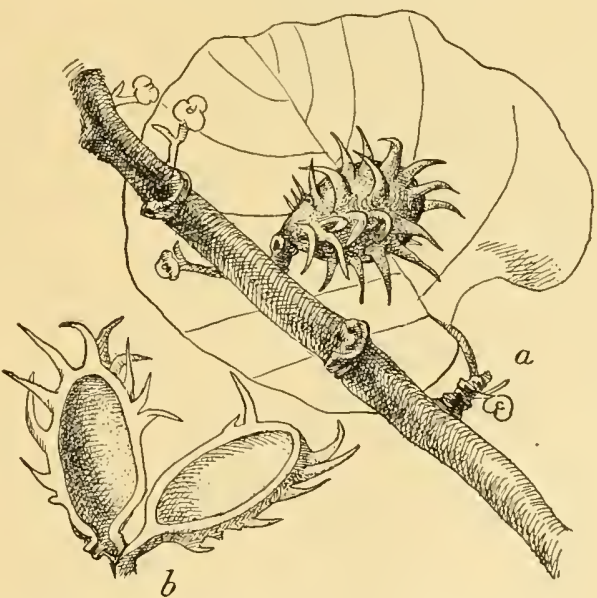

Fig. $178 \mathrm{H}$ amamelistes spinosus: $a=$ mature gall: $b=$ section of same, natural size (After Pergande, U. S. Dep't Agric. Div. Ent. Tech. Ser, 9, 1901)

Our knowledge of this insect is due almost entirely to long continued patient investigations by Theodore Pergande of the Bureau of Entomology. 
United States Department of Agriculture. The following is a brief abstract of his detailed account: Winter eggs are deposited in rough places on the stems of witch-hazel, from the middle of Jume to early in July and remain unhatched till the following May or June, thus being dormant almost 12 months. The egrg is quite flat, about $1 / 125$ inch long and is covered with a glistening, hairlike secretion harmonizing well with the twigs [fig. I77]. The recently hatched young are yellowish green and densely pubes-

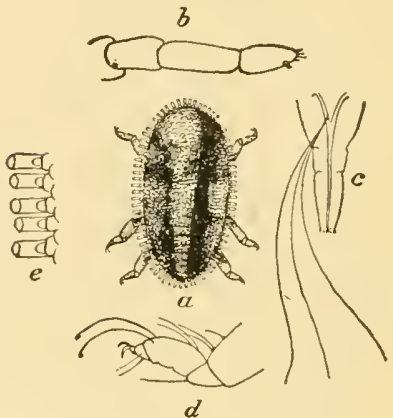

Fig. I79 Hamamelistes spinosus, 3d generation: $a=$ hihernating larva ; $b=$ antenua ; $c=$ rostrum or beak; $d$-tarsus; $e=$ lateral tubercles and waxy rods, much enlarged (After Pergande, U. S. Dep't Agric. Div. Fint. Tech, Ser, 9, rgor)
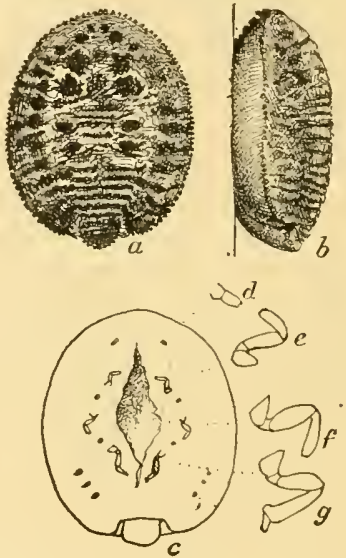

Fin, 180 Hamamelistes spinosus, 3d generation: $a$-dorsal view of adule female; $b=$ lateral view; $c-$ ventral view: $d$ =antenna: $c, f$, and g=legs, much enlarged (After Pergande, U. S. Dep't Agric. Div. Ent. Tech. Ser. 9. 1 gor)

cent or hairy and almost invariably locate on the side of buds next the twig. The irritation caused by the insect checks the growth of the petiole and hastens that of the bud, specially on the side opposite the insect, which lengthens, broadens, curves orer the gall maker and soon assumes a beautiful rosy color. The plant louse is completely inclosed in a few days, only a transverse scar and small opening where the insect settled, remaining. The gall is now globular and hardly larger than the original bud. It develops rapidly and by the middle of June is about half grown, chang- 
ing from rosy to a pale dingy color. The general form and structure is shown at figure 178 The young of the stem mother or the second generation attain maturity early in July and commence leavins the galls, continuing to issue till late in the fall. They migrate to birches where they settle on the leaves and each female produces from 30 to fo or more young. This, the third generation, is peculiar in its resemblance to the

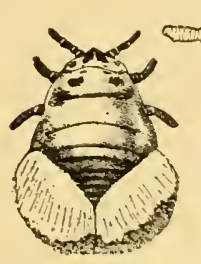

(?)

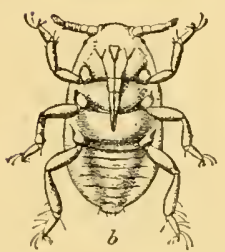

Fi.s. 181 H a mitmelistes spinosus th generation : a- young larva, dorsal view ; b-ventral view; =antenna: $t=$ eye : $c=a d u l t$ female, dorsal view ; $f=$ ventral view : $g$ antenna, much enlarged (After Pergande, ['. S. Dep't Agric. Div. Ent. Fech. Ser. 9. I(g)r)

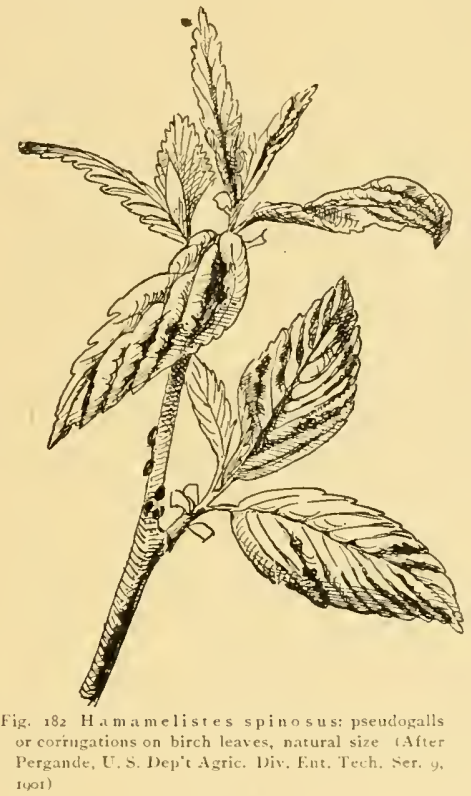

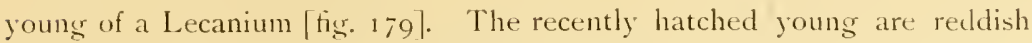
brown, with pale yellow legs and antennat and purplish eyes. They soon change to a brilliant dark metallic blut green. The adult female is broadly oval, deep black, convex [fig. I So]. This insect hibernates on the birch twigs, becoming covered with a waxy secretion. Activity is resumed the middle of April, when the females become full grown and produce young, the fourth generation. These latter are remarkable insects with their 
conspicuous waxy tufts [fig. ISI]. They settle in folds on the underside of the developing leaves and produce pseudogalls caused by the area between the veins bulging and forming ridges or corrugations [fig. I 82].
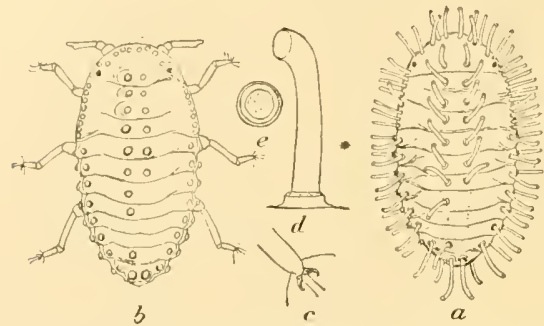

These galls are reddish brown, soon changing to recldisli or crimson. The young attain their. srowth by the end of April or early in May and then produce a fifth generation, which is sometimes abundant enough to seriously injure the trees. This latter, on attaining its development, Fig. $8_{3}$ Hamamelistes spinosus, 6 th or sexual genera-
tion: $a$-dorsal view of young larva: $b=$ the same denuded; migrates early in June back to showing arrangement of pores; $r$-tarsus; $d=$ lateral tubercle the witch-hazel, where the sexual
and waxy rod; e-apex of lateral tubercle, much enlarged the and waxy rodi e-apex ut lateral tubercle, much enlarged the - Wfer Pergande, U. S. Dep't Agric. Div. Ent. Tech. Ser. 9 . rgor) and the life cycle of the species completed. This last develops rapidly, attaining maturity in two or three weeks and deposits eggs as stated

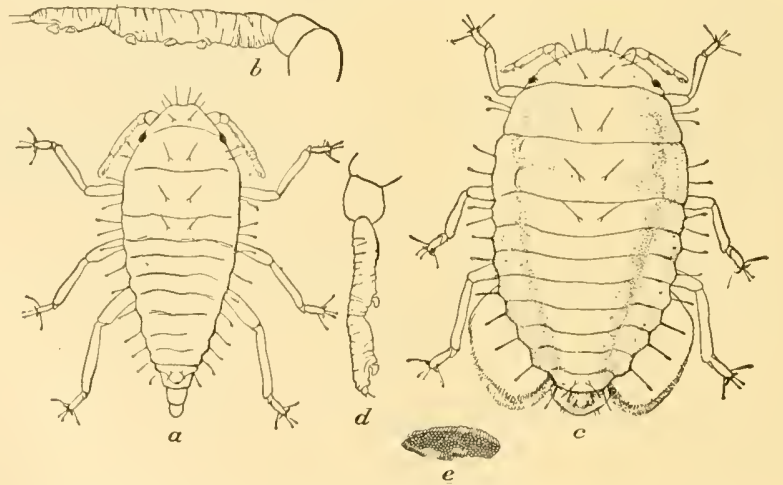

Fig. ${ }_{18} \mathrm{Ham}$ amelistes spinos u $\mathrm{H}: a=$ dorsal view of male; $b=$ antenna $;=$ dorsal view

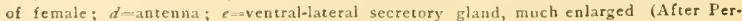
gande, U.S. Dept. Agric. Div, Ent. Tech, Ser, 9, rgor)

above. The general appearance of the full grown males and females is shown at figure $18+$. 
Birch seed gall midge. Oligotrophus bitulac Winnertz. Deformed catkins of white birch produce enlarged seeds, each containing a reddish, legless maggot.

This European species is rather common about Albany and is of interest because of the peculiar deformity it produces in birch seeds. The larvae become full grown early in October, at which time a windowlike spot is easily discerned on the surface of the seed. The normal alate or winged seed is transformed by this insect into a nearly globular form with the alae rudimentary.

Sumac tomato gall. Pemphigus rhois Fitch. Somewhat pear-shaped or round, rechlish galls of different sizes occur on sumac leaves in September.

These galls are rare in the vicinity of Albany. They are quite rariable, round, spheroid in form, with the surface uneven and usually slightly knobby. The face exposed to the sun is nomally bright crimson and the interior is sometimes thickly crowcled with plant lice. These galls occur on Rhus glabra and R. typhina. [Sec pl. 49, fig. 3.]

Hackberry nipple gall. Pachypsylla coltidis-mamma Riley. This gall is represented by a cup-shaped depression on the upper side of the leaf; beneath it is broadly rounded and about $1 / 4$ inch in diameter. It is common on hackberry.

Rose root gall. Rhodites radicum Osten Sacken. This large, smooth, reddish brown gall occurs on the roots of various wild roses. It is deeply incised at the point of attachment to the roots. The interior is pithy and contains numerous cells.

Rose bedegar. Rhodites rosate Linn. Curious, curved, fibrous, mosslike masses occur on rose and blackberry bushes. This peculiar gall is composed of a mass of hard cells formed around a branch and is entirely covered with long, dense, green filaments forming a mosslike mass $1 \mathrm{1} / 2$ inches or more in diameter.

Mealy rose gall. Rhodites ignota Osten Sacken. Irregular, spheric galls about the size of a pea, covered with a white mealy substance, are rather common on wild rose in the vicinity of Albany. Occasionally several of these galls coalesce, forming an elongated, irregular mass. The gall is a woody one and contains sereral cells.

Spiny bullet gall. Rhodites bicolor Harr. Round galls a third to nearly half an inch in diameter, covered with prickly spines about as long as the diameter of the galls, are common on twigs of different kinds of wild roses. This gall is yellowish green sometimes tinged with red and occurs in clusters of two or more.

Globular rose gall. Rhodites globulus Beut. A smooth, rounded gall arising abruptly at each end from the branch, occurs on wild rose on Staten Island. It has a rather soft corky texture and contains numerous cells. It 
is more or less oblong or almost round and measures from $3 / 4$ to $1 \frac{\pi}{2}$ inches in length, being about 3 , inch in diameter.

Long rose gall. Rhodites dichloccrus Harr. This elongate, hard, wooxly gall, gradually tapering at both ends, occurs on the branches of wild roses. It has been taken on Staten Island and I)r Smith records it from New Jersey:

Knotty rose gall. Rhodites arma Osten Sacken. This gall, which is somewhat allied to the long rose gall, R. di ch l ocerus Harr., occurs on wild rose. It is oblong or rounded and about $1 / 3$ inch long, and occasionally, three or four galls are more or less fused. This species has been taken by Mr Bevtenmuller on Staten Island.

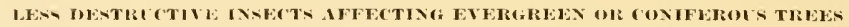

This group, comprising insects of minor importance found on our evergreen trees, is rather small because of the peculiarly close association existing between bark borers and species found with them, making it advisable in certain instances at least, to notice comparatively unimportant forms frequently met with in the burrows of destructive species.

\section{Borers in trunk and limbs}

Pinc, species affecting

Large, white, fleshy, flat-headed borers ${ }^{1}{ }_{2}$ inches long occur under pine bark in long, narrow, very shallow grooves in the surface of the wood, transforming to a dark metallic gray, flattened beetle 1 to 1 inches long

Larger tlat-headed pine borer, Chalcophora virginiensis, p. 653 A similar boter working in aloout the sime way and transforming to a brilliant, coppery colored, flattened beetle about $3 / 4$ inch long

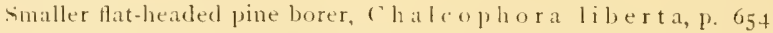

$A$ brilliant, sparkling, (opper-red beetle a little over t to to nearly $13 / 4$ inches long occurs on pine and spruce............. (iolden Buprestis, buprestis striata, ]) 655

An obscure, coppery or black, thattened beetle about I, inch long on pitch pine

$$
\text { 1) icercil punetulata, p. } 656
$$

A brassy, metallic, flattened beetle about 58 inch long ocrurs in midsummer on pine and

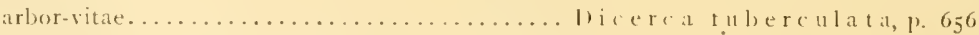

An ashy loronze or obscurely bronze, flattened, metallic beelle from a litule over $1:$ to nearly ${ }^{2}+$ inch long xours on white pine from mirlsummer wo () tolser

$$
\text { l)icer:a tenebrosa, p. } 657
$$

An oblong, oval, flattened, bronze or purplish beetle, copper-colored beneath and in in long oruts on hard pine.............. ('hrysoliothris dentipes, p. 657 
A modestly colored, flattened beetle about 3/8 inch long occurs in midsummer on hard pine branches..................... Chry sobothris floricola, p. 658

A small, flattened beetle $1 / 4$ inch long is abundant on hard pine from June till September

Chrysobothris pusilla, p. $65^{8}$

A large, stout, brownish beetle $1 \frac{1}{4}$ inches long breeds in pine stumps

Harris's Prionus, 'Tragosoma harrisi i, p. 659

A large, brownish black, narrow beetle about $\mathrm{I}$ inch long occurs on pines in June and July

Criocephalus agrestis, p. 659

A bluish, flattened beetle about $1 / 2$ inch long occurs in early spring on pines

Blue pine borer, Callidium antennatum, p. 660

A blackish brown beetle $\mathrm{I}_{2}$ to $5 / 8$ inch long occurs late in May on pine

Lesser pine borer, A se m u m moestum, p. 66 t

A grayish brown, mottled beetle $5^{\prime}{ }_{16}$ to $1 / 2$ inch long occurs on white pine

Acanthocinus obsoletus, p. 662

A slender, grayish brown beetle about $3 / 4$ inch long occurs on pine in July

Sylotrechus sagit tatus, p. 663

A small beetle $1 / 4$ inch long with a dark head and thorax and lighter wing covers and antennae, occurs on pine...................... Bat y le suturalis, p. $66_{3}$

A small, dark brown longicorn ${ }^{1}+$ inch long occurs on pine and willow in midsummer

Pogonocherus mixtus, p. $66_{3}$

A black beetle about $3 / 4$ inch long sparsely clothed with white hairs and downy white spots on the wing covers, forming two irregular bands, occurs on pine

$$
\text { Hylotrupes bajulus, p. } 66_{+}
$$

A dark chestnut-colored weevil $3{ }^{8}$ inch long occurs in May and June on pines or in mill yards..................... Pales weevil, Hylobius pales, p. $66_{t}$

A stout, brownish bark beetle about 3,16 inch long occurs under pine bark

Pine Hylurgops, $\mathrm{Hy}$ lurgops glabratus, p. $66_{5}$

A jet-black beetle only $1 / 4$ inch long and with silvery white markings on the wing covers, occurs in midsummer on pines............ Clerus quadriguttatus, p. 666

Spruce, species affecting

A conspicuous bluish black horntail about $1 \frac{1}{4}$ inches long occurs on spruce

White-horned Urocerus, U rocerus albicornis, p. 667

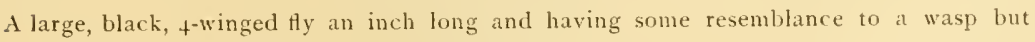
with a stout, cylindric body, attacks spruce

Banded horntail, Urocerus abdominalis, p. 668

A small horntail with a blue abdomen and rufous legs attarks spruce and fir

Blue horntail, P a u r urus c y a ne us, p. 669 
A somewhat cylindric, black or brownish beetle about $1 / 2$ inch long occurs in midsummer on spruce.................... Tetropium cinnamopterum, p. 669

A black, red-shouldered, flattened beetle about ${ }^{5}$ if inch long occurs on spruce

Phy matodes dimidiat us, p. 669

A large, handsome, black beetle with the basal portion of the wing covers deep red and the middle antennal joints broadly ringed with reddish

Canadian Leptura, Leptura can a densis, 1). 670

A cylindric brownish beetle about $1 / 2$ inch long and ornamented with irregular, sulfur vellow bands, occurs on hemlock and spruce.. Xylotrechus undulatus, p. 67

$A$ slender, whitish, wood-boring grub enters the wounds of living trees and bores deep into the sapwood and heartwood

Blazed tree borer, Serropalpus barbatus, p. 67 I

A small, narrow, triangular beetle about $3 / x 6$ inch long and irregularly marked with silvery white, occurs on spruce and decaying maple........ II ordella borealis, p. 672

A small, stout, nearly cylindric, brownish bark beetle about $1 / 8$ inch long occurs in spruce bark......................... Dryocoetes a utographus, p. 672

A small, yellowish brown to almost black bark beetle occurs in spruce bark, particularly at the base of the limbs.................... ryphalus striatulus, p. 673

A minute, black or brown bark beetle excavates many short, radiating, curved galleries in young dying red and black spruce

$$
\text { Spruce wood engraver, Pityophthorus cariniceps, p. } 674
$$

Balsam, species affecting

A large, metallic, flattened, oval beetle about $3 / 4$ inch long occurs on balsam in July

Buprest is maculiventris, p. 674

Hemlock, species affecting

A rather slender, somewhat triangular beetle with a subtriangular spot near the middle of the outer margin of each wing cover, occurs on hemlock

$$
\text { I. ept it a subham at a, p. } 675
$$

\section{Colur, species affecting}

A brownish beetle from $3 / 8$ to nearly $1 / 2$ inch long with two large, blue patches at the base

D the wing, bores as a larva in cedar

Cedar tree borer, Hylotrupes 1 igneus, p. 675

\section{Leaf feeders}

Pinc, specics affecting

Loose web nests thickly sprinkled with excrement, occur on the terminal twigs and contain greenish or brownish false caterpillars... False pine webworm, L y d a species, p. 676 
Loose web nests with considerable brown excrement on the needles of terminal pine twigs contain true caterpillars.... Pine web worm, Benta ma lanogrammos, p. 676 A large, thick, pale green caterpilar, 3 to 4 inches long with pale orange head and legs and 6 spined, yellow tubercles behind the head, occurs on white pine late in August and through September.......... Imperial moth, Basilona imperialis, p. 677

A grass green, yellow and white striped caterpillar feeds on pine in the middle of September.......... Harris's pine hawk moth, Lapara bo m bycoides, p. 679

A duli red caterpillar banded with brighter red with a light lateral line and reddish hairs in clusters, occurs on pine in late August and September

White pine tufted caterpillar, Pant he a furcilla, p. 679

A duil rusty brown, irregularly white-spottẹd, flattened caterpillar with series of grayish tufts on each side harmonizes very closely with the bark

A small, cylindric larva mines the leaves of various pines

Larch lappet, Tolype 1 a ricis, p. 680

Pine leaf miner, Paralechia pinifoliella, p. 681

Peculiar tubes of webbed-together pine needles occur in midsummer and September on white and probably other pines....... Pine tube builder, Eulia polit an a, p. 68I

Short, stout beetles from $1 / 3$ to nearly $1 / 2$ inch long are numerous on hard pine foliage the latter part of June and throughout July

Light-loring grapevine beetle, An omala 1 ucicola, p. 682

A light brown beetle less than $1 / 3$ inch long is rather common on hard pine from the latter part of June till the last of August..... N e tachrom a marginalis, p. 682

Spruce, species affecting

Pale green, false caterpillars feed singly on spruce the latter part of the summer

Spruce sawfly, P teronus in teger, p. $68_{3}$

A red-headed, brownish caterpillar about $5 / 8$ inch long feeds on young, fresh spruce cones.................. Spruce cone worm, Diory ctria ren ic ulella, p. $68_{4}$

Balsam. gall fly affecting

A small midge produces an oval enlargement near the base of balsam needles

Balsam gall midge, Cecid om y i a bals a micola, p. 685

\section{Sucking insects}

Pine, species affecting

A small, grayish and brown plant bug $3 / 16$ inch long occurs on hard pine and other trees and shrubs.................. False chinch bug, Ny sius angust at us, p. $68_{5}$

A small, brown plant bug I/ inch long............ Phy tocoris eximius, p. $68_{5}$

Pilophorus crassipes, p. 686 
A brownish, membranous, winged plant bug a little over $1 / 4$ incls long

$$
\text { Oliarius quinquelineatus, p. } 686
$$

Small, stout, triangular or rounded bugs producing masses of frothlike spittle on pines

Spittle insects, sereral species, p. 6.86

A greenish brown leaf hopper about $5 /{ }_{16}$ inch long.. Stictocephala inermis, $1 \% 68_{7}$

A small, active, ratlier slender plant lug about $\mathrm{T} / \mathrm{t}$ inch long with yellowish head and prothorax and yellowish red wing overs occurs on hard pine in midsummer

Dichrooscytus rufipennis, p. 68 ;

A light brown, slender plant bug about if inch long with the thorax variously marked with red, pinkish and light brown orcurs on hard pine

$\mathrm{Nab}$ is $\mathrm{rufusculus,p.688}$

A grayish, yellowish or red-marked, elliptic insect, about is inch long occurs the latter part of summer on hard pine, many shrubs and plants

Gypona octolineat a, p. 688

A small, reddish brown, jumping plant louse $1 / 8$ inch long abounds on hard pine the latter part of the season and in early spring

Bramble flea louse, Trioza tripunctat a, p. 688

A conspicuous snow-white, woolly scale is sometimes very abundant on the more tender growths of pitch and southern yellow pine

Woolly pine scale, Pseudophilippia quaintancii, p. 689

Hemlock, species affecting

An oval, dark gray often blackish scale with a lighter margin, occurs on hemlock, pine, fir and maple................... Hemlock scale, $1 \mathrm{sp}$ idiot us a bietis, p. 690

\section{Frequenters of evergreen or coniferous trees}

A brilliantly marked, brick-red and blue ground beetle about $3 / 4$ inch long

A yellowish, 9-spotted hemispheric beetle

$$
\text { L, ebia grandis, p. } 690
$$

Nine-spotted lady beetle, Coccinellat novemnotata, p. 69t

A yellowish, almost black banded hemispheric beetle

Three-banded lady beetle, Coc cinella trif a s c iat a, p. 69r

A black leetle about If inch long with a conspicuous orange band containing two circular black spots on the basal two thirds of the wing covers

I ps sanguinolentus, p. 69r

A shining black beetle about $1 / 4$ inch long with four irregular, orange markings on the wing covers........................... I s s uadriguttat us, p. 69z

A snall, snapping beetle less than $3 / 8$ inch long with a light head and light yellowish elytra marked with dark brown................. Corymbites propola, p. 692 
A small, snapping beetle about $1 / 2$ inch long with its yellowish wing covers thickly marked with curved, dark brown or black lines. Corymbites hieroglyphicus, p. 692

A small, black clerid with wing covers marked with zigzag black and gray transverse bands occurs on spruce

Cloudy bark beetle destroyer, Than as im us nubilus, p. 693 A small beetle $3 / 10$ inch long with pale yellow irregularly mottled wing covers and black head and thorax.................... II y dnocera pall i pen $n$ is, p. 693

A jet-black, slender beetle nearly 316 inch long occurs on late scrub growths

Hy dnocera humeralis var. cyanescens, p. 693

A small, variable, somewhat elongated, brown beetle about Ís inch long

Ernobius mollis, 1. $69+$

A greenish, coppery, elongate, parallel-sided beetle about $1 / 2$ inch long

I) ichelonycha albicollis, p. $69+$

A thick, cylindric, brilliant brassy, coppery hued, rather stout beetle

Pine Chrysomela, G lyptoscelis pubescens, p. 695

A stout, yellowish brow beetle a trifle over $1 / 8$ inch long

Cryptocephalus schreibersii, p. 695

A small, stout, black, red-spotted beetle $\mathrm{I} / 8$ inch long

Cryptocephalus quadrimaculatus, p. 695

A small, brown or blackish beetle, $\mathrm{r} / 8$ inch long, with lighter transverse bands on the wing covers and a conspicuous pronotal process....... Notoxus bif a sciat us, p. 696

A small, brown, black-marked beetle about If inch long with a conspicuous pronotal

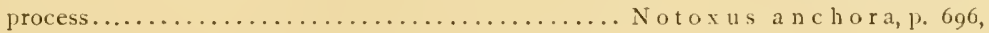

A yellowish brown, black-dotted, somewhat oval plant bug $3 / 8$ inch long

Coenus delius, p. 697

Delicate, greenish or brownish lace-winged flies with golden eyes, occur on many plants

Lace-winged flies, Heme robius stigmaterus, p. 697

Micromus montanus, p. 697

Slender, pale green or greenish white, cricketlike creatures

Flower or tree crickets, several species, p. 698

\section{Larger flat-headed pine borer \\ Chalcophora airginionsis Drury}

Large, white, fleshy, flat-headed borers $\mathrm{I}^{1 / 2}$ inches long occur under pine bark in long narrow, very shallow grooves in the surface of the wood, transforming to a dark metallic gray, fattened beetle i to $1 / 4 / 4$ inches long.

This large, white, fleshy, flat-headed borer about $1 \mathrm{I} / 2$ inches in length may be met with under pine bark, where it inhabits long, narrow and very 
shallow grooves in the surface of the wood. The irregular, wavy or serpentine galleries enlarge with the growth of the larva and differ in general appearance from the borings of other insects inhabiting similar situations. This, the largest of the flat-headed pine borers, was met with rather commonly by the writer on hard pine at Karner in igos from early in June to the latter part of September. The record of captures is as follows: June

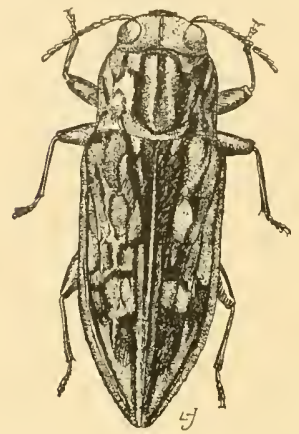
4, two; June I3, two; June 26, four; July 8 , two; August 9, two and September is, one. The beetle may be found resting on the sumny side of the trunks and branches and occasionally among the needles of the smaller twigs. It is probably attracted by light, since one was taken in a trap lantern. The adult is a dark metallic gray colored beetle measuring from i to I't inches in length.

I) Packard states that the beetles appear in the Northern States toward the end of May and occur Fig. ${ }^{3} 5$ Chatcophor.t vir through the month of June, according to Harris, while giniensis, enlarged (original) he observed them in Nlaine on pinetrees in the middle of July. Dr LeConte records this species as abundant in the Middle, Eastern and Southern States and adds that this form may be readily distinguished by its dull color, fine punctuation of the depressed spaces of the wing covers, of which the four impressed spaces are better defined than any others, and finally by the sides of the thorax being anteriorly rounded to the middle and not at all angulated.

\section{Smaller flat.headed pine borer \\ Chalcophora liberta Germ.}

This species may be distinguished from C. virginiensis Drury by its smaller size, it ranging from about $3 / 4$ inch in length, and by the brilliant coppery color which is usually much more marked than in C. virginiens is.

It was taken by the writer in relatively small numbers on hard pine at Karner in Igor as follows: June 4, one; June 3, four; September 6, one and October 3, one. Dr Fitch states that this species is much more com- 
mon in eastern New York than the larger C. virginiensis Drury, though such has not been our experience. He instances a small growth of young pines, only a few rods in extent, where upwards of 100 specimens of this beetle were taken in the middle of September, one or two being found on almost every tree in the grove, while only six of C. virginiensis Drury were met with.

This smaller form, according to our observation, is present in the adult stage rather more abundantly late in the fall and this may be the reason why Dr Fitch failed to meet with more of the larger beetles. Dr Fitch states that he found the insects mostly at the tips of the limbs, clinging to the leaves with their heads inwards, the position in conjunction with shape and size giving them a close resemblance to the young fruit cones growing irom the same points on several of the limbs. He adds that they appeared to be eating the young buds, which are probably the food on which all these beetles subsist in the perfect state.

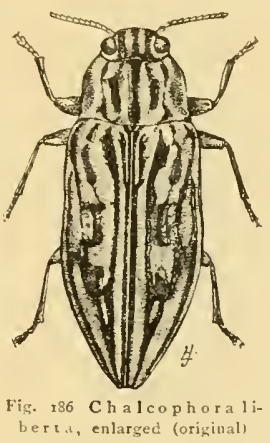

Dr LeConte has recorded this species as abundant in the Middle and Eastern States and adds that it varies slightly in color, but is usually of a fine golden copper tint. He states that the broadly rounded sides of the thorax, the deep dorsal grooves and the entire sutural striae are characteristic of this species.

\section{Bibliography}

I 890 Packard, A. S. U.S. Ent. Com. 5th Rep't, p. 678-79

\section{Golden buprestis \\ Buprestis striati. Fabr.}

A brilliant, sparkling, copper-red beetle a little over $1 / 2$ to nearly $3 / 4$ inch in length, occurs on pine and spruce trees in May and June.

This handsome, flat, metallic beetle was noticed by Dr Fitch about a half century ago. It appears to infest the dead wood of logs and stumps. The 
adults are said to feed on the tender buds of pine and spruce. This insect, according to Dr Saunders, is a very handsome beetle from $6 / 10$ to $7 / 10$ inch long, of a coppery red color, with a broad, bluish green stripe on each wing cover, which varies in brilliancy in different specimens. There are four raised, smooth lines on each wing cover and a wide, shallow groove along the middle of the thorax. Both thorax and wing covers are pitted with minute dots. Dr LeConte records this species from the Middle States, Canada and Lake Superior.

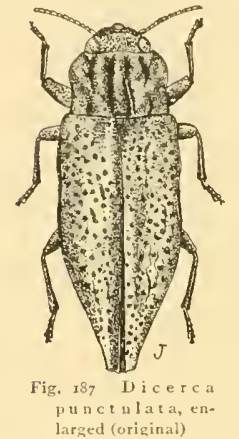

\section{Dicerca punctulata Schonherr}

An obscure, coppery or llack bronze, flattened beetle about $1 / 2$ inch long, occurs on pitch pine.

This buprestid was rare at Karner in Igor, only two specimens being taken, one in Jume and the other in August. Dr Fitch states that this species may be recognized by the smooth, transverse elevation on its front, extending from eye to eye, The wing covers taper to a rounded, nearly truncate tip.

punctulata, en-

A brassy, metallic flattened beetle about s/s inch in length, occurs in midsummer on pine, arbor-vitae and probably some other evergreens.

This species was taken on arbor-vitae July 6, I903, at Big Moose. It is a brassy colored species, having coarse, rough, irregular marks. The rows of coarse punctures on its wing covers are about equally distant from each other instead of being in pairs. The intervening spaces have many irregular, elevated, black, polished spots, and the elevated, transverse lines upon the front are interrupted and not very prominent. LeConte states that the terminal segment of the male is truncate, emarginate, with tibiae simple, while in the female the last segment is rounded apically. This species has been recorded from Maine and, as stated above, occurs in New York. Blanchard records it from Massachusetts. 


\section{Dicerca tenebrosa Kirby}

An ashy bronze or obscurely bronze, flattened, metallic beetle from a little over $1 / 2$ to nearly $3 / 4$ inch long occurs on white pine from midsummer to October.

This insect has been described by LeConte as follows:

Ashy bronze or obscurely bronze, the prothorax dilated on the sides, which are rounded in front, sinuous behind, coarsely punctured; behind broadly excavated on each side, with apical and basal shining smooth rugosities; a definite dorsal deep furrow with smooth sides, somewhat interrupted in the middle; elytra densely punctured, with alternate oblong, raised, shining interstitial spaces, prolonged entire to the apex; length .57 to .75 inch. Male with the pectus broadly sulcate, villose; the intermediate tibiae armed with an internal acute tooth; the last ventral segment truncate emarginate. Female with the pectus smoother, less sulcate; the last ventral segment tridentate; the intermediate tooth obtuse, defined by minute incisions.

LeConte also adds the following regarding this species:

The under surface is copper-colored, coarsely and densely punctured on the sides, abdomen and prosternum, less densely on the metasternum and middle of the first segment of the abdomen; the divided portions of the mesosternum are coarsely and tolerably densely punctured. The outer costae of the thorax are interrupted so as to form on each side an apical and basal callosity. A female from Newfoundland differs by the epipleurae being green, the under surface of the prolonged extremity of the elytra blue, and by the incisures between the anal teeth being more widely separated.

Beetles belonging to this species were taken in July on arbor-vitae at Big Moose, and a specimen found in June rgoo, at Saranac Inn. It is recorded as being abundant at Lake Superior, and according to Kirby, has been taken in latitude $65^{\circ}$ in the Rocky mountains. The beetle has also been taken under the bark of white pine in the Adirondacks by Mr George Hunt. Mr Blanchard records finding it in Massachusetts on spruce wood piles and logs in June and also lists it from New Hampshire.

\section{Chrysobothris dentipes Germ.}

An oblong, oval, flattened, bronzed or purplish beetle, copper-colored beneath and about $/ 2$ inch long, occurs in small numbers on hard pine.

This species was somewhat rare on hard pines at Karner in I9or. It is similar in coloration to C. flo ricola Gory, though it is considerably 
larger [pl. 20, fig. II]. Dr Harris states that this species issues from the trees between the end of Mlay and the first of July: It may be recogrnized by the aid of the above characters and the following: The thorax is not so wide as the hinder part of the body and its posterior margin is hollow on both sicles to receive the rounded base of the wing covers, on each of which there are three irregular, smooth, elevated lines divided and interrupted by large, thickly punctured, impressed spots, two of which are oblique. The larva makes a slender, winding, serpentine gallery between the bark and the wood of newly felled trees and presents the usual buprestid characters. This species is reported as rather common on pine wood and timber in Massachusetts, though not so abundant as C. floricola Gory. It occurs in Canada and the northern United States.

\section{Chrysobcthris floricola Gory.}

A modestly colored, fattened beetle about $3 / 8$ inch long occurs in midsummer on hard pine branches.

This modestly colored buprestid about $3 / 8$ inch long [pl. 20, fig. 10] occurred at Karner on hard pine branches and young needles from the 13 th of June to the latter part of August I gor. It ranges from Florida through the Middle States probably into Canada.

\section{Chrysobothris pusilla Lap. \& Gory}

A small, flattened beetle $1 / 4$ inch long is abundant on hard pine from June till September.

This small buprestid $1 / 4$ inch long [pl. 20, fig. 9], was very abundant on hard pine at Karner early in June till the first part of September Igor. The blue abdomen, uncovered when the insect is in flight, glistens brightly in the sunshine. This is a common pine insect, ranging from North Carolina probably to Canada and westward to IVisconsin. 


\section{Harris's Prionus \\ Tragosoma harrisii Lec.}

A large, stout, brownish beetle about $\mathrm{I} / \mathrm{T} / \mathrm{inches}$ in length, and closely resembling a rather slender prionid, breeds in pine stumps.

This species, according to Wickham, is consiclered by some writers as identical with the North European T. depsarium Linn. He characterizes it as a curious looking beetle of elongate form and brownish color. The antennae are slender, the prothorax small in comparison with the elytra, very hairy and armed on each side with a single sharp tooth, in front of which the lateral margins are convergent. The elytra are shining, distinctly punctured and with numerous raised lines.

This species probably ranges across the continent in the more northern latitudes, having been reported from Fort Coiville Wrash. Leng records it from Newfoundland to Vancouver and Coney Island. The state collection con- Fig. r88 Tragosoma tains a specimen taken by. Erastus Corning at Murray Bay, $\begin{aligned} & \text { harrisii, enlarged } \\ & \text { (original) }\end{aligned}$ Province of Quebec, in July or August, and it has also been captured in the pine forests of the Adirondacks.

\section{Criocephalus agrestis Kirby}

A large, brownish black, narrow beetle about $\mathrm{I}$ inch long occurs on pines in June and July, its white footless grub boring therein.

The adult insect is a large, brownish black, narrow beetle about 1 inch in length. It may be recognized by the pair of deep thoracic impressions, the fine punctures on the elytra and by the third joint of the hind tarsi being two thirds longer than wide, emarginate for about one half its length. This beetle closely resembles A sem um moest um Hald., though twice as large and with longer, more slender antennae. This species is evidently rery abundant in Quebec, since a large series was taken at Murray Bay by Erastus Corning in July or August i 878 . It occurs in New York 
State, has been recorded as infesting the roots of pine and spruce, and is evidently widely distributed in the northern United States and Canada.

\section{Blue pine borer \\ Callidium antennatum Newm.}

A bluish, flattened beetle about $1 / 2$ inch long, is common in early spring on pines.

This pretty borer was bred in large numbers from a young dead pine taken at Karner, Ap. 17, 1903, at which time larvae, pupae and adults were piesent.

Description. The beetle may be easily recognized by its blue or violet color and black antennae and legs. It is about $1 / 2$ inch long, flattened, eyes coarsely granulate, strongly emarginate, almost divided; thorax broad,

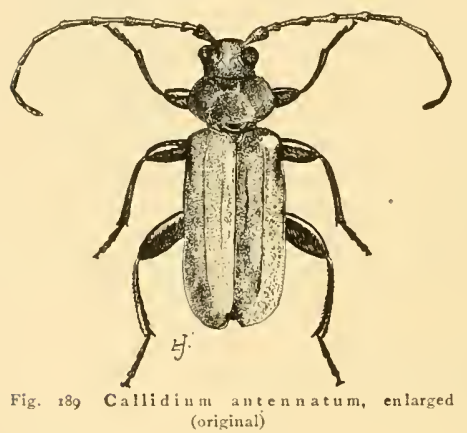
rounded laterally; wing covers rather coarsely corrugated. This species may be separated from the closely allied C. ja $n$th in un Lec, according to Wickham, by the impressions on the thorax and its finer punctures.

Life history. The beetles occur in early spring, at which time they may be cut out of their burrows or collected from pine foliage. The boring by the larva is somewhat characteristic, being a broad, wavy channel just under the bark and largely confined to wood that is quite dry. Frequently considerable proportions of the sapwood are eaten away, so that only ridges remain as illustrated on plate 61 , figure 3 . The life cycle is probably completed in one year.

Food plants. This insect is a common borer of the pine, and has also been recorded from red cedar. Dr Walsh was of the opinion that the cedar-inhabiting form was simply a phytophagic variety.

Distribution. This insect probably has an extended distribution in America, since it has been recorded in various local eastern lists, and from 
California, ranging as far south at least, as IVest Virginia. It probably occurs in most places where pine grows.

\section{Bibliography}

I89o Packard, A. S. U. S. Ent. Com. 5th Rep't, p. 700-I

\section{Lesser pine borer}

\section{Asemum moestum Hald.}

A blackish brown beetle $1 / 2$ to $5 / 8$ inch long occurs late in May on pine.

The larva of this species makes flattened, cylindric holes or mines which perforate the trunk of white pine and other trees in all directions. It is rather small, and the blackish brown beetle, about $1 / 2$ to $5 / 8$ inch in length, appears late in May. We have met with this small borer on hard and white pine in May. Dr l'ackard states that this species appears to attack healthy as well as diseased trees, and cites several instances of injurious work. He finds that the exit holes are usually most abundant on the south side of the tree or stump, and that in some cases they are very numerous, as many as ro occurring in a space of five square inches. The larval gallery is deep, extending 6 or 8 inches toward the heart of the tree, where it ends in an oval pupal cell.

Description. The larva has been described in detail by Dr Packard, who states that it is about $1 / 2$ inch long, and that the prothorax inclines downward toward the head, being long and no wider than the mesothoracic or metathoracic segments. Abdominal segments rather broad, and on the two hinder thoracic and first abdominal segments are transwerse, regular, oblong areas banded by inpressed lines. On segments two and four the callosities are narrower and pointed anteriorly, on six and seven they are a little longer than broad, contracted posteriorly. Smaller callosities occur on the ventral surface. The true legs are minute, threejointed, small and rather short.

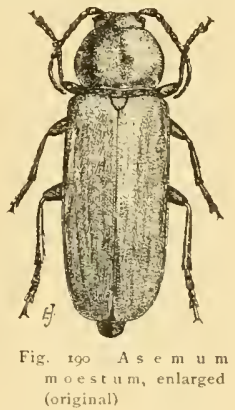

The pupa is flattened, nearly $1 / 2$ inch in length, somewhat broad and 
may be readily distinguished from other pupae of the genus, by the short antennae not extending to hinder edge of the metathorax, and the component segments being much shorter than in other species. The two raised, longitudinal lines of the wing covers corresponding to those of the beetle are very characteristic. The end of the abdomen is square and terminates in two sharp, slender, incurved hooks which are dark red at the tip.

The achult is a rather stouth, blackish or very dark brown beetle from $1 / 2$ to $5 / 8$ inch in length. The short antennae do not extend to the hind edge of the metathorax, the prothorax is short with rounded sides, and the elytra are marked by two conspicuous ridges.

Food plants. Dr Hopkins states that this species works at the base of dying pine and spruce trees, hastening their death and decay. Mr Beutenmuller records this species as occurring upon oak and grapevine as well as pine, spruce and other conifers.

Distribution. We have taken this beetle at Nassau and Troy N. Y., and it has been reported from Buffalo N. Y., Cincinnati O., southwestern Pennsylvania, District of Columbia, and Dr Smith states that the beetles occur throughout New Jersey, during Nay and June, and that the larvae may be found in pine.

\section{Bibliography}

1890 Packard, A. S. U. S. Ent. Com. 5th Rep't, p. 697-99

\section{Acanthocinus obsoletus Oliv.}

A grayish brown, mottled beetle 516 to $1 / 2$ inch Iong, occurs on white pine.

The female of this species is remarkable because her long ovipositor extends about $3 / 8$ inch beyond the tip of the abdomen. The delicate antennae are longer than the body, ringed with dull, yellowish white and the wing covers are marked with obscure, oblique, darker areas. It occurs in small numbers during July and August on white pine. This species has a wide distribution in the northern Atlantic region, according to Dr LeConte. 


\section{Xylotrechus sagittatus Germ.}

A slender, grayish brown beetle about $3 / 4$ inch long occurs on pine in July.

A single example of this interesting borer was taken at the base of a dying white pine July 26, $190 \mathrm{r}$ at Bath-on-Hudson. Dr Smith states that this species is generally distributed, though rare in New Jersey.

\section{Batyle suturalis Say}

A small beetle $1 / 4$ inch long with a dark head and thorax and lighter wing covers and antennae, occurs on pine.

This small longicorn, about $1 / 4$ inch long, may be recognized by its dark brown head and thorax, lighter wing covers and antennae. The head,
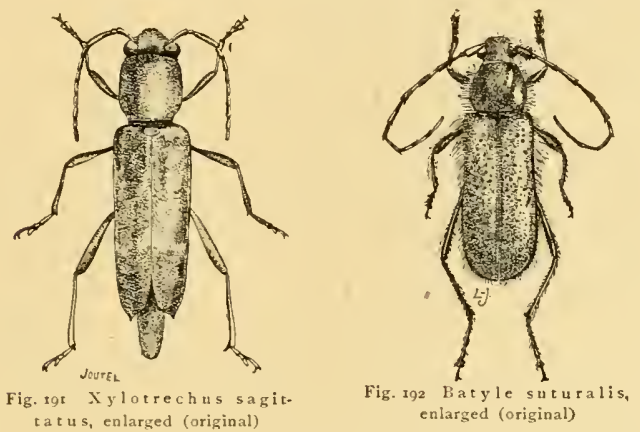

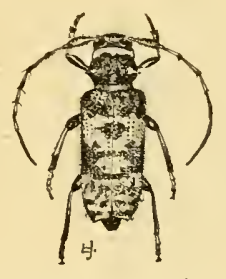

Fig, 193 Pogonocherus mixtus, enlarged (original)

thorax and wing covers are rather coarsely punctured and all, as well as the antennae, are clothed with stiff, somewhat sparse hairs. A single specimen was taken on hard pine at Karner, June 26, I90i.

\section{Pogonocherus mixtus Hald.}

A small, dark brown longicorn about $1 / 4$ inch long, occurs on hard pine and willow.

This beetle has a nearly black head and thorax, the latter with a conspicuous spine on each side and the wing covers are irregularly mottled with black or dark brown, brown or grayish. It is abroad during June and July and has been recorded as a willow borer. 


\section{Hylotrupes bajulus Linn.}

A black beetle about $3 / 4$ inch long, with a gibbous prothorax sparsely clothed with white hairs, with shallow, confluent punctures and the elytra with downy white spots forming two irregular bands, occurs on pine and spruce.

This species appears to be rare in New York State, since we had no specimens in the collection prior to receiving a few beetles in June igot from Yonkers, where it was stated that they were emerging in some numbers from flooring, presumably spruce. Harris states that this is probably an introduced species, and that it is found in this country only near the seacoast.

\section{Pales weevil}

Hylobius palcs Herbst.

A dark, chestnut-colored weevil $3 / 8$ inch long, occurs in May and June on pines or in mill yards.

This beetle [pl. 20, fig. 8] lives under the bark of various pines and is widely distributed, ranging from Florida northward to Maine and Lake Superior. It occurs somewhat commonly on hard pines at Karner from June to the latter part of September.

Life history. The life history is summarized by Dr Packard as follows : The grubs make irregular galleries uncler white pine lork and later traverse the sapwool, transforming in autumn in pupal cells excavated in the latter. The insects protect their shelters with a thick roof of sawdust or chips and sometimes as many as eight or to cells may be found within an area of four square inches. The grubs remain till early spring in these retreats, transforming to pupae in March, the beetles appearing in May or June. The eggs are laid either in the sides of the old burrow or in crevices of the bark. We have taken adults as late as October 23 and it is probable that oviposition continues throughout the summer. 


\section{Pine Hylurgops \\ Hylurgops glabratus Zett.}

A stout, brownish bark beetle about $3 / 16$ inch in length, may be found working under pine bark during early spring and again in September.

A single example of this species was taken by us at Bath-on-IJudson, Sep. 26, Igor, from under the moist bark of a hard pine infested with Rhagium lineatum Kirby. The tree had eviclently been killed by borers, and it is probable that this species had a part in the destructive work.

Description. This brownish black beetle is about $3 / 16$ inch in length. The labrum bears a few golden yellow hairs at jts lower extremity; the prothorax is rounded at the sides, narrowed anteriorly, and thickly and somewhat coarsely punctured. The wing covers are deeply striated, the striae being almost a series of confluent punctures. The posterior third of the elytra is sparsely clothed with rather coarse, yellowish hairs. The larva is a footless, curved, white grub, according to Packard.

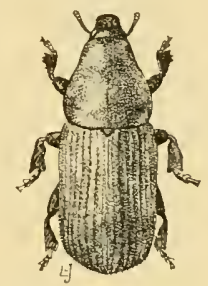

Life history and habits. This borer was first noticed Fig. $19+11,1 u r g o p s$ by Dr Fitch, who records it as occurring frequently on pine glabratus, ent lumber in mill yards early in Nay, and who characterized it as the pine destroying Hylastes. Dr Packard has recorded finding the beetles under the bark of a white pine stump at Brunswick Me., Aug. I5-20, I88 I. This species has been met with by 1)r Hopkins of IVest Virginia, who states that it mines the green bark of pines, both at the base of dying trees and also in logs and stumps. He states that the adults were met with in early May (some entering the bark on the Isth), and the latter part of June, pupae occurring Oct. +. Eggs were observed in early May, young larvae June 13 , and full grown ones July I 4 .

Distribution. This species has been recorded by Dr LeConte, from 
Lake Superior, Canada and Ohio, and it has been listed by Ulke from the District of Columbia, where it occurs on pine.

\section{Bibliography}

I 890 Packard, A. S. U. S. Ent. Com. 51h Rep't, p. $7^{22-24}$

\section{Clerus quadriguttatus Oliv.}

A jet-black beetle only $1 / 4$ inch long and with silvery white markings on the wing. covers, occurs in midsummer on pines.

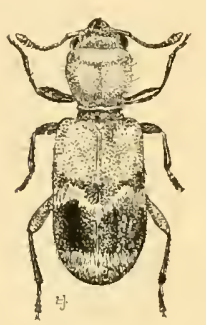

This, one of our smaller beneficial species, is only 1/t inch in length. The head, thorax and posterior portions of the wing covers are jet-black except for transverse, silvery white markings on the latter; the basal portion of the wing covers is reddish. This little beetle occurs rather commonly on hard and probably other pines infested by Tomicus or other borers, on which it undoubtedly preys. Adults were taken from the latter part of June throughout Fig. 295 Clerus July. It is a common, somewhat abundant species in the enlarged (original) northeastern United States.

\section{Rhyncolus brunneus Mann.}

This rather slender, jet-black beetle about $5_{32}$ inch in length occurs under decaying pine bark. The head and thorax taper slightly anteriorly, are finely punctured and the wing covers coarsely striated with series of almost confluent, coarse punctures.

\section{Synchroa punctata Newm.}

This obscurely colored, brownish melandryid with the wing covers thickly clothed with a yellowish pubescence, is about $3 / 8$ inch long and has been taken under the bark of white pine and maple. Larvae and pupae were found by Mr Young under maple bark at Ilion, May 3I, the beetles issuing June 5 .

Scymnus tenebrosus Muls. was beaten from pine at Karner July 27 , I9OI. 


\section{Cardiophorus gagates Er.}

This species was taken on pine in June and probably lives under the bark of decaying trees.

\section{Limonius confusus Lec.}

This beetle was beaten in June from hard pine at Karner.

$$
\begin{aligned}
& \text { Callidium aereum Newm., sec p. } 450 \text {. } \\
& \text { Leptura zebra Oliv., see p. } 450 \text {. } \\
& \text { Urographis fasciatus DeG., sec p. } 434 \text {. } \\
& \text { Platydema subcostatum Lap. }
\end{aligned}
$$

This insect was taken under decaying white pine bark at Schuylerville in October. pine.

Eustrophus repandus Horn. occurs under the decaying bark of white

Rhinomacer pilosus Lec. was taken on hard pine at Karner, Ap. I5.

\section{White-horned Urocerus \\ Uroccrus albicornis Fabr.}

A conspicuous, bluish black horntail about $\mathrm{I} / 4$ inches in length may be observed upon spruce, or its thick, fleshy larvae may be found at work in the wood.

This species is a close ally to the common pigeon tremex so frequently observed on diseased or dying maples and elnus, and has similar habits.

Description. The adult may be easily recognized on account of its resemblance to the pigeon tremex, p. $6 \mathrm{I}$, in connection with the following description by Dr Harris:

The white-horned Urocerus has white antennae, longer and more tapering than those of the pigeon tremex, and black at each end. The female is of a deep blue black color, with an oval white spot behind each eye, and another on each side of the hinder part of the abdomen. The horn on the tail is long, and shaped like the head of a lance. The wings are smoky brown, and semitransparent. The legs are black, with white joints. The body measures about an inch in length, and the wings expand nearly two inches. 
Life history and habits. Idults of this species have been observed ovipositing on recently sawed spruce lumber, and Dr Hopkins states that it attacks spruce, hemlock and fir. This is one of the more common of our species in the eastern United States, though it is far from abundant and the male appears to be quite rare. The adults are usually found during fuly and August on the trunks of coniferous trees on bright days. 'The eggs are deposited in the wood with the stont ovipositor, the insects apparently preferring recently felled trees. The larvae run large burrows through the trunks, often rendering them unfit for lumber.

Distribution. This species has been recorcled by Fabricius from both North and South America. It has in addition also been reported from the following localities: New England, New York, New Jersey, Louisiana, Washington, Ottawa Can., Lake Winnipeg, Newfoundland and Northwest Territory. 1t has also been taken in England, probably carried there in infested lumber. Some allied species are regarded as destructive to pine forests in Germany, and reports of considerable injuries to coniferous trees have been received from the Northwest Territory, though we believe that, as a rule, in this country comparatively little damage results from this insect's work.

\section{Bibliography}

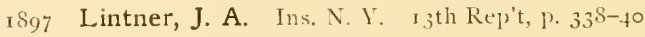

\section{Banded horntail}

\section{Urocerus abdominalis Harr.}

A large, blitck, 4-winged fly an inch long having some resemblance to a wasp, but with a stout, cylindric body, attacks spruce.

This species has smoky, transparent wings and its larvae have the general character of other horntails. The different sexes of these insects vary' considerably, and it is possible that this species is the male of Urocerus albicornis Jiabr. noticed above. 


\section{Blue horntail \\ Paururus cyancus Fabr.}

A small horntail conspicuous because of its blue abdomen and rufous legs attacks spruce and fir.

This horntail is even rarer than the preceding and may be recognized by its unicolorous antennae, the triangular apical horn of the female in connection with its blue abdomen and the rufous legs. Its habits are probably similar to those of the foregoing species, and it has likewise been recorded as working in spruce and fir.

\section{Tetropium cinnamopterum Kirby}

A somewhat cylindric black or brownish beelle about $1 / 2$ inch long occurs in July on spruce.

It may be recognized by its jet-black head and thorax, which latter is nearly cylindric, though swollen at the middle, and by the dull brown wing covers. This borer, according to Dr Hopkins, infests the green bark and wood of injured and dying spruce trees in West Virginia. He states that it is very injurious, since it hastens the death of the trees and causes rapid decay of the wood. Adults were taken by him in March and July.

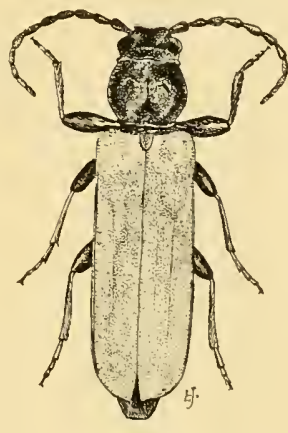

Fig. 196 Tetropinm cinnamopterum, eniarged (original)

\section{Phymatodes dimidiatus Kirby}

A black, red-shouldered, flattened beetle about $5 / 16$ inch in length, occurs on spruce. Examples of this species were taken on spruce at Big Moose N. Y., July 7 , 1903 .

Description. The head, thorax and posterior portion of wing covers black; anterior portion of latter and legs brownish. The antennae are slender, about as long as the body, thorax subpyriform, swollen anteriorly; sides nearly parallel, femora clubbed. This species may be distinguished from its allies, according to Wickham, by the absence of narrow cross- 
bands on the dark elytra, which are of a lighter shade before the middle.

Life history and habits. The beetles have been met with in IV est

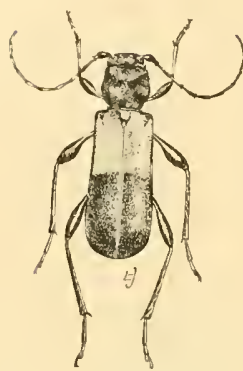
Virginia the latter part of June, by Dr Hopkins, who records this species as a borer in spruce bark. $\mathrm{Mr}$ Young has known of this insect emerging from spruce siding after it had been manufactured, and Dr Hamilton lists it as occasional in southwestern Pennsylvania, stating that the larva is probably imported in lumber.

Distribution. This insect is probably widely distributed in the northeastern United States, since it has been recorded from West Virginia, New Jersey, Staten Fig. ${ }^{197} \mathrm{P}$ h y matodes Island and Buffalo N. Y., besides being occasionally found $d \mathrm{i}$ mid i at $\mathrm{u} s$, enlarged in southwestern Pennsylvania.

\section{Canadian Leptura}

Lcptura canadensis Fabr.

A large, handsome, black beetle with the basal portion of the black wing cases deep red and the middle antennal joints broadly ringed with reddish, works as a footless grub under spruce and hemlock bark.

This species is more or less common in hemlock, and according to Dr Hopkins, the stout, fleshy, round-headed grubs mine the sapwood of dead spruce and hemlock, inducing rapid decay. We have met with what we believe to be this larva working in live hemlock tissues, though this habit may be somewhat exceptional. The adult beetle is a handsome insect about $3 / t$ inch in length, deep black, with the surface coarsely and densely punctured. It may be readily distinguished from its allies by the deep red basal portions of the wing covers and also by the antennae being broadly ringed with paler red, the joints of the middle being alternately red and black. The beetle may be met with in July and is rather common in the Adirondack region. 
Xylotrechus undulatus Say:

A beautiful, cylindric, brownish beetle about $1 / 2$ inch long, and ornamented by sulfur-yellow markings, occurs on both hemlock and spruce.

This species is closely allied to $\mathbb{X}$. colonus Fabr, but may be separated, according to Mr Wickham, by the thorax having an apical and basal pubescent band, the elytral bands being angulated or undulatory. It is a beautifully marked species with considerable sulfur-yellow on the lateral anterior portions of the thorax. Specimens were taken on spruce and hemlock at Lake Clear and Big Moose in early July I903. Dr Packard also states that he has beaten it from spruce at the end of July, and Dr Lintner states that Erastus Corning jr of Albany, met with the insect at Murray Bay Can., in the month of August, at which time they were emerging from burrows in spruces.

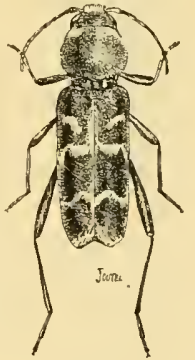

Fig. Ig 8 y lotreclius undulatus, enlarged (original)

this country, since it has been recorded from Canada and the Eastern States, and Dr Packard mentions having received it from Tacoma IV $\mathrm{T}$ h. Mr Fall records it from the northern portion of California. This species is stated by Dr Hamilton to be rare in southwestern Pennsylvania. It has been recorded from New Jersey by Dr Smith.

\section{Blazed tree borer \\ Serropalpus barbatus Schall.}

A slender, whitish, wood-boring grub enters the wounds of living trees and bores deep into the sapwood and heartwood.

The larva of this Melandryid is a slender, whitish, wood-boring grub, which enters wounds on living trees and bores deep into the sapwood and heartwood, causing rapid decay of the infested parts. Dr Hopkins states that it is common in blazed wood on balsam, fir and spruce trees along trails in northwestern Maine, while Dr Smith lists it from New Jersey and states that it has been taken from dry fungus. 


\section{Mordella borealis Lec.}

A small, narrow, triangular beetle about $3 / 16$ inch in length, irregularly marked with silvery white, occurs on spruce and decaying maple.

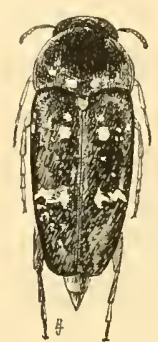

Fig. 199 Mordella boreali s, enlarged (original)

This species may be recognized, according to Dr Smith, by the short, truncate anal style, its dull black color, with the thorax, pygidium and the elytra sprinkled with small, rounded spots of silvery pubescence; wing covers with a narrow, interrupted band, composed of confluent spots behind the middle.

This species was taken on dying or recently killed spruce at Big Moose N. Y., July 2, 1903, by Mr Young, and he has also found it breeding in decaying maple stumps. This is essentially a northern species, and has been recorded by Dr LeConte, from the Northern States. It is also listed from the vicinity of Cincinnati by Dury.

\section{Dryocoetes autographus Ratz.}

A small, stout, nearly cylindric, brownish bark beetle about $1 / 6$ inch in length, may be met with in spruce bark.

This borer was taken in considerable numbers under spruce bark at Big Moose N. Y., July 2, 1903. It may be distinguished, according to Dr LeConte, from its allies, by its larger size and the smooth front of the strongly punctured prothorax. He records this species from Alaska, Canada and Virginia under pine bark, while Dr Hopkins states that it occurs under green bark of logs and stumps of spruce. It is possible that there is a mistake in the preceding record. This species evidently has a wide distribution in the northern part of this country, since it has been recorded from Alaska, Hudson Bay Territory, Canada, Lake Superior, Mount Washington N. H., New Jersey, southwestern Pennsylvania, Virginia and West Virginia. The peculiar structure of the proventriculus is illustrated on plate 69 , figure 9 , and that of the tibia in figure is 8 , page 469. 


\section{Dryocoetes sp.}

A species belonging to this genus was met with by the writer Aug. I4, 1900, at Saranac Inn, where it was breeding under spruce bark in company with the spruce bark borer. Polvgraphus rufipennis Kirby. The beetle is about $3 / 32$ inch long, and in the case of the specimen obtained, of a yellowish brown color. It is doubtless much darker in mature individuals and its galleries are larger than those of Polygraphus.

\section{Cryphalus striatulus Mann.}

A small, yellowish brown to almost black bark beetle occurs in spruce bark, working particularly at the base of limbs.

This species was taken by us, working in spruce bark in association with Tomicus balsameus Lec. The affected tree was near water and was noticeable because of $\mathrm{jts}$ red foliage. The trunk was not injured though this borer was working in some numbers at the base of the limbs and appeared to be the primary cause of the trouble. This species was taken in August, working at the base of a small hemlock limb, the foliage of which had begun to turn brown. It was also observed at work in a small balsam tree, which had been cut several months.

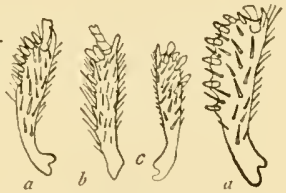

The adult is a light yellowish brown to almost black beetle about $3 / 32$ inch long. The prothorax bears a number of prominent chitinous tubercles and the wing covers are faintly striated with rows of fine punctures. The galleries of this species are very irregular and appear to have no plan, consisting, as they do, of a series of interlacing burrows, which often unite to form large excavations around the base of a twig. 


\section{Spruce wood engraver \\ Pityophthorus cariniccps Lec.}

A minute, black or brown beetle excavales many short, radiating, curved galleries in young dying red and black spruce.

This minute form excavates many short, radiating, curved galleries from a large central chamber, working in the bark and surface of the wood of twigs and branches of dying trees and stems of young, dying red and black spruce. This species ranges from western Maine to Mlorgantown IV. Va., and westward to Detroit Mich., according to Dr Hopkins. Like its allies, it is of comparatively little importance because its attacks are confined to dying or dead trees, mostly limbs.

\section{Buprestis maculiventris Say.}

A large, metallic, flattened, oval beetle about $3 / 4$ inch long, occurs on balsam in July. This species was taken on balsam at Lake Placjd, July so, 1903.

Description. It is a brassy-brown beetle about $3 / 4$ inch in length, and

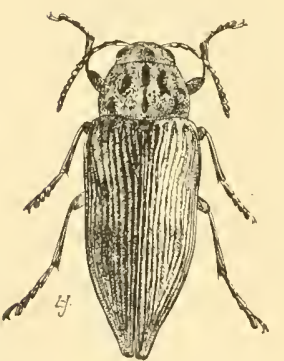
is easily distinguished, according to $\mathrm{Mr}^{-}$Harrington, by the reddish yellow ventral spots on each side of the abdominal segments, and by smaller spots of the same color on the anterior lateral margin of the thorax. The prothorax is rather coarsely, irregularly punctured and the wing covers deeply striated (according to Harrington frequently rumpled), tips almost truncate.

Life history. Mr. Marrington states that this Fig. zo: Buprestismaculi- species is common on both old and young spruce ventris, enlarged (origiral) trees in June and July, and adds that he has had the beetles emerge from pine timbers about the end of June.

Distribution. Dr LeConte states that this species occurs in Pennsylvania, Lake Superior and Newfoundland. 


\section{Leptura subhamata Rand.}

A rather slender, somewhat triangular beetle with a subtriangular spot near the middle of the outer margin of each wing cover, occurs on hemlock.

This beautiful insect may be easily recognized by its yellowish elytra with a subtriangular spot near the middle of the outer margin. It was taken on tamarack at Lake Clear Junction July \&, 1903. The trees had been killed by a fire, and this species was evidently about to oviposit on them. This bectle has been taken by Mr Harrington on oak and also from a beech $\log$.

This form was described from the IV hite mountains, and has been recorded from New Jersey, by Dr Smith, on the authority of $\mathrm{Mr}$ Leng. It is also listed by $\mathrm{Mr}$ Ulke, from the District of Columbia, and six examples were taken by Dr John Hamilton, in southwestern Pennsylvania. This, in connection with its occurrence in New York State, leads us to believe that it is some-

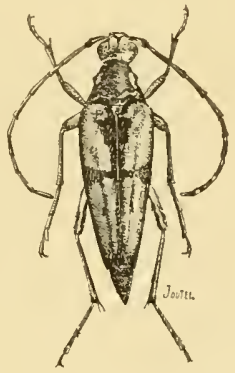

Fig. 202 Leptur.1 s 11 bham ata, enlarged (original) what generally distributed in the northeastern United States and probably ranges into Canada.

\section{Cedar tree borer Hylotrupes ligneus Fabr.}

A brownish beetle from $3 / 8$ to nearly $1 / 2$ inch long, with two large, blue patches at the base of the wing, bores in the larval stage in cedar.

This species is common in northwestern Maine, according to Dr Hopkins, who states that its slender, whitish bark and woodboring grub excarates winding burrows in the bark and surface of the wood of living arbor-vitae, causing the death of trees and serious defects in the wood. Mr Fall states that this species is common in southern California, where it depreclates on pine, and that a nearly black variety occurs only on fir wood piles situated in more or less shady forests. He states that the typical form of this species may be taken on pine and spruce wood piles in sunny 
situations. This beetle may be recognized by its brown head, antennae, prothorax and legs, while the wing covers are mostly a dark prussian blue with a broad, yellowish band near the apical third, extending anteriorly along the margin and to the base of the wing covers along the suture. This insect ranges from about $3 / 8$ to nearly $1 / 2$ inch long.

\section{False pine webworm Lyda sp.}

Loose web nests thickly sprinkled with excrement, occur on the terminal twigs and contain greenish or brownish false caterpillars.

Several species of these interesting false caterpillars feed on both hard and soft white pine. They are easily recognized by the conspicuous antennae and almost equally developed anal filaments at the opposite extremity which, with the prominent anal shield, give the creatures a somewhat two-headed appearance. While the nests of these sawfly larvae are somewhat common, the insects are rarely abundant enough to cause serious damage. Their method of feeding is somewhat different from that of Benta, in that there is more of a tendency to eat the needles off at a uniform level. A soldier bug, Euschistus variolarius Beauv., is rather common on the nests of these insects in September and is probably of considerable service in keeping these leaf feeders in check.

\section{Pine webworm}

\section{Benta malanogrammos Zell.}

Loose web nests, with considerable brown excrement, on the needles of terminal pine twigs, are very characteristic of this species.

This leaf feeder appears to be a somewhat common one on pine in the vicinity of Albany, but as it is a difficult insect to rear, it has been impossible to determine its specific identity beyond question. The peculiar nests, found in midsummer and later, are two to three inches long and consist of an irregular, loose, cobwebby structure with brown pellets of excrement thicklv sprinkled throughout the mass. This species has been 
observed by Professor Comstock in Florida, and he states that the larvae on attaining maturity, enter the ground for pupation.

The parent moth has a wing spread of about an inch with the fore wings dark brown, nearly black on the basal third and beyond there is a broad, light gray band crossing the wings, outside of which is a dark brown area followed by gray. The hind wings are a dark ashy color with a silky luster.

The full grown larva is about $3 / 4$ inch long, dark yellowish brown, paler beneath and with a moderately distinct subdorsal line extending from the thoracic shield to the posterior extremity: Head, thoracic shield and last abdominal segment yellowish brown, more or less irregularly marked with dark brown or black.

This species has not, to our knowledge, caused any serious injury and it is hardly probable that it will ever become dangerous. One of the soldier bugs, Euschistus variolarius Beauv. is common in the fall on web nests of Lyda and doubtless preys on this species also.

\section{Imperial moth \\ Basilona imperialis Drury}

A large, thick, pale green caterpillar 3 to 4 inches long, with pale orange head and legs and six spined, yellow tubercles behind the head, occurs on white pine needles late in August and through September.

This, one of the largest native caterpillars, is most common in New York State on white pine though it lives on a considerable variety of food plants and in the South it is said to have a marked preference for species of oak.

Description. The male of this magnificent moth has a wing spread of + inches and that of the female exceeds $5 \frac{1}{2}$ inches. The insects are light yellow, spotted and banded with brownish as represented on plate 4I, figure $\mathrm{I}$.

The summarized descriptions of the early larval stages are drawn from Dr Lintner's more extended account. The recently hatched larva is 
dull red, ${ }^{+}$inch long, each segment except the last two with six rows of bristle-tipped spines, annulate with three fuscous bands. True legs black. After the first molt the head is a shining red and the segments reddish in the middle shading into an obscure color at the incisures. The spines are glossy black with branches bearing apical white bristles. The two long spines of the second and third segments and the mesal one of the ith about one fifth the length of the body, directed slightly forward and unequally forked. After the second molt the larva is ${ }^{8}$, in inch long, the head dull red with fuscous mesally and laterally. The body is an umber brown, lighter at the incisures, gray dorsally and with a dark vascular line. Spines of second, third and eleventh segments curved, glossy black with yellowish base. The caterpillar after the third molt may be recognized by the long white hairs arising from the central portions of the segments, the dorsal ones being nearly twice the length of the thoracic spines, the lateral ones shorter. These spines are honey-yellow studded with conical projections and each bearing a short, acute, fuscous spinule. After the fourth molt the larva is $13 \frac{f}{t}$ inches long and the heretofore cylindric spines are conic and armed with stout spinules, anal plates with conspicuous whitish granulations.

The nearly full grown larva is 3 to 4 inches long, green with a reddish tinge on the back. The yellowish black marked head and anal shield, the conspicuous spined yellowish tubercles and the prominent light spiracles with their darker margins are all conspicuous features. This larva can easily be recognized by reference to plate 19 , figure 1.

The pupa is dark mahogany brown, 1 to $1 / 2$ inches long and subcylindric in form.

Life history. The moths fly in June and deposit eggs, producing caterpillars which attain maturity in September, at which time they forsake the trees and construct cells in the ground and change to pupae, in which condition the winter is passed.

This caterpillar has a wide range of food plants. It has been recorded from 52 species representing i 5 natural orders. The white pine appears to 
be the farorite in the North and a number of species of oak in the South. It has been stated that in the vicinity of Germantown Pa., the larvae of this species have displayed a marked preference for red maple foliage in recent years.

\section{Bibliography}

I 890 Packard, A. S. U. S. Ent. Com. 5th Rep't p. $77^{\text {I-2 }}$

I 898 Lintner, J. A. Ins. N. I. I 3 th Rep't, p. 342-5 I

\section{Harris's pine hawk moth Lapara bombycoides IValk.}

A grass-green, yellow and white striped caterpillar feeds on pine in the middle of September, the moths appearing the following June.

This caterpillar is interesting largely because of its peculiar appearance, its striking color rendering it inconspicuous on pine needles. The young larva is remarkable because of its large, high head terminating in a conspicuous cone. Just before the last molt the head is triangular, conical, the body thick and stout. It is then green with yellowish and red stripes.

The full grown larva is green like that of the pine leaves, and has the broad, brick-red dorsal stripe wanting on the prothoracic segments and represented by patches on the two following. This band is bordered with a whitish yellow line. There is a lateral straw yellow line and a broad white line becoming yellow anteriorly, below the spiracles. This larva may be easily recognized by its conspicuous striping.

\section{White pine tufted caterpillar \\ Panthea furcilla Pack.}

A dull red caterpillar banded with brighter red, with a light lateral line and reddish hairs in clusters, occurs on pine during late August and in September.

This species is not common. The larva, when full grown, measures about $15 / 8$ inches in length. It has been described by Dr Packard as follows :

The body is black, with sparse, dull, light yellow hairs radiating from dark or pale mamillae. A pair of long prothoracic straight tufts projecting 
over the head, and a pair of long similar erect ones on the eighth segment. All the legs are reddish. Some of the full grown larvae turn black. The moth appears the following June.

\section{Larch lappet \\ Tolype laricis Fitch}

A dull, rusty brown, irregularly white-spotted flattened caterpillar with series of grayish tufts on each side, harmonizes very closely with pine bark.

This caterpillar feeds on pine, hemlock, and larch and occurs on plum and cherry: It is rarely abundant encugh to cause any injury and its claim to notice in this connection is based on its being a most excellent example of protective mimicry. This latter is due to several causes. In the first place it is a dull, rusty brown color, broken by irregular, white markings, which give it a striking resemblance to the bark of a tree. This protective feature is further lightened by the flattened form of the caterpillar and especially by the grayish tufts of hair springing from the large lateral tubercles and extending on either side a distance nearly equal to the width of the caterpillar itself. This curious larva when at rest harmonizes so closely with its surroundings as to render its detection exceedingly difficult. This latter was nicely exemplified by an experience of the late Dr Lintner. who showed an entomologic friend (well known because of his keen sight further sharpened by long experience in collecting, so that few caterpillar: could escape his eyes) a small twig on which were four of these caterpillars, and though they were within reach of his extended finger, le was unable to discover them until their presence was revealed by movements as one after the other was touched. The cocoons of this interesting species are equally difficult to detect. They are placed longitudinally in a slight angle or depression and so spun as to harmonize very closely with their surroundings, even to the extent of light markings of the bark being continued on the eocoon.

\section{Bibliography}

1882 Lintner, J. A. Ins. N. Y. 1st Rep't, p. 87-99 


\section{Pine leaf miner \\ Paralchia pinifolucllar Chamb.}

A small cylindric larva mines the leares of various species of pine.

This small leaf miner is common on hard pine at Karner and the same is undoubtedly true in other sections of the State where this tree occurs. The tip of the leaf and in many instances the larger portion above its base is mined, dies and turns brown [pl. 20, fig. 5].

Description. The moth is very small, brownish, irregularly gray banded with a wing spread of $3 / 8 \mathrm{inch}$, and may be recognized by reference to plate 20, figure 23. The egg has been described as reddish brown, globular, about $.14 \mathrm{~mm}$ in diameter. The larva is $\mathrm{r} / 6$ inch long, yellowish brown with the head, thoracic shield and anal plate dark brown.

Life history. A single needle apparently affords ample sustenance for the development of the larva, which enters near the middle of the leaf and burrows toward the end, and then, reversing its course, proceeds toward the base. The borings are pushed out at the point of entrance. Professor Comstock states that there are certainly two and possibly three generations annually:

Natural enemies. This leaf miner is subject to attack by a number of parasites, notably several minute Chalcids and a small Tachina fly.

\section{Bibliography}

I880 Comstock, J. H. U. S. Dep't Agric. Rep't I879, p. 238-4I

I 890 Packard, A. S. U. S. Ent. Com. 5th Rep't, p. 793-97

1903 Felt, E. P. For. Fisis \& Game Com. 7th Rep't, p. 509-ro

\section{Pine tube builder \\ Eulia politana Haw.}

Peculiar tubes of webbed-together pine needles occur in midsummer and in September on white and probably other pines.

This insect is rarely abundant and is worthy of notice largely because of the peculiar tubes it constructs among the pine needles. These consist of about 15 needles, which are bound together by silken threads, and the 
terminal third eaten off. 1)r Packard states that there appears to be two broods, full grown larvae having been observed by him the latter part of September, in tubes from which the terminal portions of the needles were not eaten. He was of the opinion that this was prevented by the approach of cold weather. The typical short tubes are found in midsummer.

Description. The maker of these tubes is a pale green larva about $t_{3}$ inch long. The head is a light brown color with darker, somewhat recklish patches on each side. It is very active, escaping from the tube and dropping by a thread when disturbed. The pupa is found inclosed in a slight web within the tube.

The head, thorax and fore wings of the parent insect are a dull rustred color, the latter with two oblique paler bands; one a little before the middle and the other beyond parallel to it, crossing the wings. The hind wings and the upper side of the abdomen are silky gray. WVing spread half an inch.

This is a widely distributed form, as Dr Dyar has listed it from Europe and the north Atlantic States.

\section{Light-loving grapevine beetle \\ Anomala lucicola Fabr.}

A short, stout beetle from $1 / 3$ to nearly $1 / 2$ inch long, is abundant on hard pine foliage the latter part of June and throughout July.

This beetle [pl. 20, fig. $\left.\mathrm{I}_{2}, \mathrm{I}_{3}, \mathrm{I} 4\right]$ is more commonly known as a grape feeder, though its presence in large numbers on hard pines would also indicate that it is able to subsist on the pine. Its presence may be merely inciclental, as soil conditions at Karner N. Y. are unusually favorable for the larvae.

\section{Metachroma marginalis Crotch}

A light brown beetle less than $I / 3$ inch long is rather common on hard pine in midsummer.

This light brown beetle occurs rather commonly on hard pine from the latter part of June till the last of August. It does not appear to be 
injurious to the tree, though usually taken at the base of the needles. This species probably has an extensive range, as it has been recorded from North Carolina and Kansas. The larra are probably root feeders.

\section{Spruce sawfly Pteronus integer. Say}

Pale green, false cateryillars feed singly on spruce the latter part of the summer.

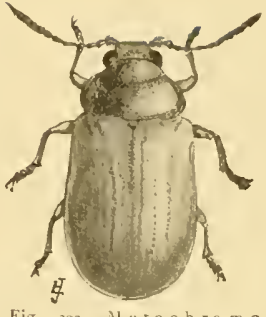

This species is stated by Dr Packarcl to be com-

Fig, 203 Il tetachroma matginalis, enlarged (original) mon over the Northern States and may at times prove obnoxious. It occurs on spruce in Maine during the latter part of the summer and feeds singly; not being gregarious as in the case of many species. He states that possibly the fly appears in the fall, though probably it winters in the cocoon and may be found abroad in the early part of June. The larra and its cocoon have been described by Dr Packard as follows ${ }^{x}$ :

Larva. The body is long, broader than the head; pale pea green; of the color of the leaves of the spruce among which it feeds. The head is smooth, of the same color as the body, with a dark patch extending upward behind each eye. Body not spotted, but with a dorsal dark green stripe, bordered on each side with whitish glaucous green. Along the body is a lateral conspicuous broad white stripe, the stripe much scalloped below. Body beneath and abdominal legs uniformly green; thoracic legs pale honey yellow, except at base. Length $17 \mathrm{~mm}$.

Cocoon. Of the usual oval cylindrical form; of a pale horn color, of the usual density, the walls being opaque. Length $13 \mathrm{~mm}$; diameter $4 \mathrm{~mm}$.

The adult sawfly is about $1 / 4$ inch long, yellow with black or dark brown markings, except on the sides and renter of the abdomen, which are a greenish tinge.

\section{Bibliography}

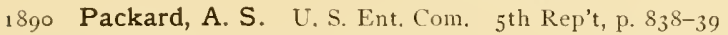

I 896 Marlatt, C. L. U. S. Dep't Agric. Div. Ent. Tech. Ser. 3. p. 69

r Possibly the larwa of another species. Dyar records Pteron us integer Say as an oak feeder. N. Y. Ent. Soc. Jour. I898. 6:I 22. 


\section{Spruce cone worm \\ Dioryctria reniculella Grote}

A red-headed, brownish caterpillir about 5/8 inch long, feeds on young fresh spruce cones, surrounding them with a mass of webbed excreta.

This species was brought to our attention by the receipt of a large number of infested cones collected in the Adirondacks. The attack, according to 1)r Packard, is usually confined to the young cones, into which the larvae bore and mine in different directions, excavating galleries in the interior and separating the scales from the axis of the cone. The caterpillar may mine one cone and then pass into an adjoining one, spinning a rude silken passage between the two. Occasionally a bunch of three or four cones is tied together with silken threads, in which latter masses of castings or excrement become entangled.

Description. The larva has been clescribed by Dr Packard as follows:

Head and prothoracic shield deep amber brown; the body reddish carneous or amber brown, with a livid hue; a faint, dark dorsal, and a broader, subdorsal line; piliferous warts distinct; each segment divided into a longer anterior and shorter, narrower, posterior section, bearing two dorsal piliferous warts, besides a lateral one.

Length $5 / 16$ inch.

The parent insect has its fore wings ornamented with light and dark gray. There is a broad basal light patch and before the middle of the wing a white zigzag line ancl near the outer margin another white zigzag line with a dark border. Wing expanse about $3 / 4$ inch.

This is considered by Ragonot to be a synonym of the closely allied D. Jecuriella Hübn., a form which feeds both on firs and pines, and it is possible that the species under description has similar food habits. There is no practical method of preventing its depredations, were it desirable, other than collecting and burning the infested cones before their inhabitants have escaped.

\section{Bibliography}

$189^{\circ}$ Packard, A. S. U. S. Ent. Com, 5th Rep't, p. $854-56$ 


\section{Balsam gall midge \\ Cccidomyia balsamicola Lintn.}

A small midge produces an oval enlargement near the base of balsam needles.

This insect was first brought to the late Dr Lintner's attention in I886, because of its abundance on balsam fir in Adirondack localities. It does not appear to occur in the vicinity of Albany, though it has been taken at Shelbourne N. H., and specimens of what appears to be the same insect, were received by Dr Lintner from North Carolina, where they infested the southern balsam, A bies fraseri. Occasionally this insect is so abundant as to give a peculiar nodose appearance to affected trees, at which times as many as three quarters of all the leaves may be infested. The larvae are inactive, hardly move and show no disposition to feed. Badly infested trees lose a considerable portion of their foliage in December, all the galls dropping. The adult has not been reared so far as known.

\section{False chinch bug \\ Nysius angustatus Uhler}

A small, grayish and brown plant bug ${ }^{3}{ }_{\text {is }}$ inch long occurs on a variety of plants.

This species is best known on account of its being confused with that notorious enemy of the farmer, the chinch bug, Blis sus 1 e ucopterus Say. It is a general feeder, occurring on such diverse plants as appletrees, hard pines, grapevines, potato vines, turnips and radishes.

\section{Phytocoris eximius Reut.}

This is an inconspicuous, brownish marked Capsid (fig. 204), a little less than $1 / 4$ of an inch

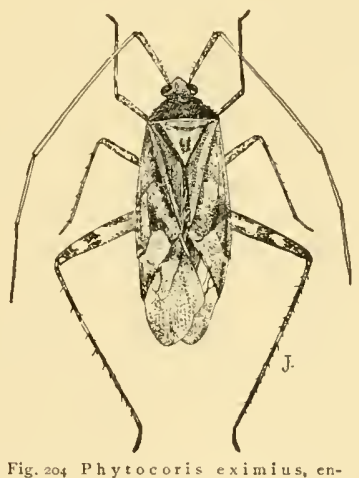

Fig. 204 Phytocoris eximius, enlasged (original) long. It occurred somewhat sparingly on hard pine at Karner in September, 1901 . 


\section{Pilophorus crassipes ['h].}

This small, brown plant bug [pl. 20, fig. 15], only about 1/t inch long, occurs rather commonly on hard pine in midsummer.

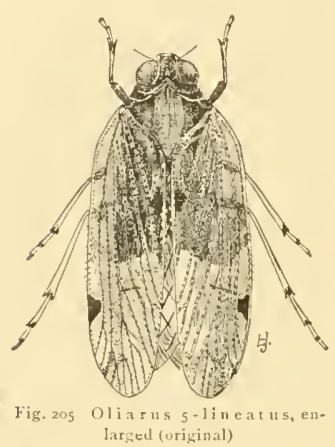

Oliarus quinquelineatus Say

This brownish, membraneous winged plant bug a little over $1 /$ inch in length occurred in midsummer on hard pine. It was taken in $190 \mathrm{r}$ at Karner as follows: July S, two; July 19, two; July 27 , one and Aug. 8, one.

\section{Spittle insects}

Masses of frothlike spittle on pines indicate the presence beneath of small stout, triangular or rounded bugs.

Several of these interesting forms are briefly noticed below:

Saratoga spittle insect, Aphrophora saratogensis Fitch. This spittle insect may be recognized by its uniform brownish color variegated with very light brown or yellow. It is about 38 inch long and more siencler than A. paralle la Say. Adults occur from the latter part of June to the last of September.

c Parallel spittle insect, I phrophora parallela Say. This spittle insect is somewhat common on hard pine at Karner, adults occurring during July: It is about $1 / 2$ inch long and may be easily recognized by the whitish spot in the center of each wing cover and by the smooth, whitish line along the dorsum of the head and prothorax [1, 20, fig. 22].

6 Quadrangular spittle insect, Aphrophora quadrangularis Say. This small, rather prettily oblique-banded spittle insect $\mathrm{I}_{\mathrm{t}}$ inch long, occurs in small numbers on hard pine in August and September.

Pine clastoptera, Clastoptera pini Fitch. This species, described by Dr Fitch, is a stout, oval, blackish tree hopper $1 / 6$ inch long. Head pale yellow, margined anteriorly with black; thorax sculptured transversely and ornamented with a pale yellow anterior band. Wing covers with 
a broad, clear, white margin outwardly, broken by black behind the middle and with a shining black dot near the tip. Legs and ventral surface yellow.

The young of this little species occur on pines about June 1 , in this State. They are enveloped in frothy masses among the terminals, and about this time they are ${ }_{1}+$ inch in length, and have a small shiny black head and thorax, with the body broad, flattened, and flesh color, or sometimes brick-red, as described by Miss Wolsey, of Matteawan.

O Obtuse clastoptera, Clastoptera obtusa Say. This little spittle insect occurred in small numbers on hard pine at Karner, the young being located at the base of leaf petioles. Adults were taken from June 13 to 10. They Fig. 200 clastoptera are from $1 / 8$ to 3 inches long and irregularly marked with obriginal) brown, yellowish brown and yellowish white. It is remarkable for its obtuse form.

\section{Stictocephala inermis Fabr.}

A greenish brown leaf hopper about $5 / 16$ inch long, occurs on hard pine in midsummer.

This species has somewhat the shape of a beechnut and is not marked by any excessively developed processes. It was present in small numbers on hard pine during July Igor. This tree hopper probably has a wide distribution as it has been recorded from a number of eastern and several western States.

\section{Dichrooscytus rufipennis Fall.}

A small, active, rather siender plant bug about $1 / 4$ inch long with yellowish head and prothorax and yellowish red wing covers occurs on hard pine in midsummer.

This is a small, active, rather slender plant bug, measuring about $1 / 4$ inch in length. The head and prothorax are yellowish and the yellowish red wing covers are bordered by the same. This species was met with by the writer in small numbers on hard pine at Karner in 1901. It is quite aurile and but few specimens were captured, the numbers and dates being as follows: one on June 13 , two on the 26 th and two July 8 . The species has been listed from New Jersey by Dr Smith and Douglas \& Scott ${ }^{x}$

${ }^{2}{ }_{1} 865$ British Hemiptera, p. 478 . 
record the beating of specimens from Pinus sylvestris in several English localities.

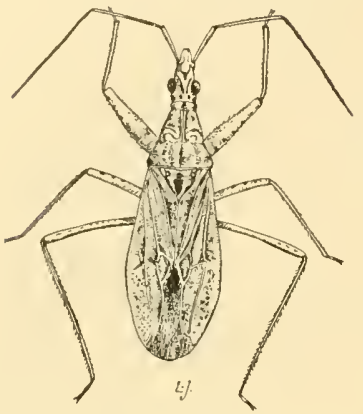

Fig. $207 \mathrm{Nab}$ is rufusculus, enlarged (original)
Nabis ruíusculus Reut.

A light brown, slender plant bug about $1 / 4$ inch long with the thorax variously marked with red, pinkish and light brown occurs on hard pine.

This slender plant bug $/ / 4$ inch long occurred in small numbers on hard pine at Karner in 19or. It is slender, widening gradually to the posterior third of the wing covers. The black eyes and the brilliant carmine ocelli are conspicuous. The thorax is variously marked with red, pinkish and light brown and the wing covers have a pinkish shade mottled with light frequenting pines and other trees.

\section{Gypona octolineata Say}

A grayish, yellowish or red-marked elliptic insect about $1 / 2$ inch long, occurs the latter part of summer on hard pine, many shrubs and plants.

Specimens of this insect were taken on hard pine at Karner, Sep. 18 , I 90 . This variable form presents marked differences; some individuals have eight reddish or rosy lines, while others have yellowish lines on the thorax, and with the wing veins and margins similarly ornamented. It has a wide distribution, having been recorded from Colorado, Missouri and several localities in New Jersey.

Eutettix strobi Fitch is common on pines in May.

\section{Bramble flea louse \\ Trioza tripunctata Fitch}

A small, reddish brown, jumping plant louse $1 / 8$ inch long, abounds on hard pine the latter part of the season and in early spring.

This species is very abundant on hard pines at Karner and its presence on these trees has also been recorded from Canada and Florida. It occurs 
on blackberry, which may prove to be its normal food plant. The following paragraph is a summary of Mr Sirrine's biological account of this insect :

Life history. Last stage nymphs were taken Sep. 12 on blackberry and the first adults were seen Sep. 29 and by Oct. 15 all had transformed. The light yellow eggs are cleposited in June and July on blackberry, maturity being attained in September or October, the adults hibernating in sheltered places.

Description. The perfect insect is about $1 / 8$ inch long with the wings deeply tinged with brown Fig. zos Trioza tripunctata, eno along the veins and the entire body a yellowish brown color except the darker eyes. The young are nearly pure white, ranging to a greenish white and when seen by the unaided eye, resemble leaf mites or the young of spiders more than plant lice.

\section{Bibliography}

I 896 Sirrine, F. A. N. Y. Agric. Exp. Sta. I $4^{\text {th }}$ Rep't, p. 19-23

\section{Woolly pine scale Pseudophilippia quaintancii Ckll.}

A conspicuous snow-white, woolly scale is sometimes very abundant on the more tender growths of pitch and southern yellow pine [pl. 5 I, fig. 3].

Examples of what are presumably this species were received from Orange county, New York, and Pike Pa., where the insect was extremely abundant on thousands of young pitch pine. It may be at once recognized by the thick woolly masses at the base of the pine needles, the woolly covering being conspicuous and easily detected at some distance. This scale is known to the natives as "bleeding pitch" and "pitch pine wool." The twigs turn brown and become brittle soon after the scales drop off. The attack was confined largely to trees less than $1_{4}$ feet in hight. The pest was not observed on white pine, hemlock, spruce or larch in the infested region. This species was found in 1897 by Prof. A. L. Quaintance at Lake 
City Fla., where it was very abundant and generally distributed on branches and young trees of Pinus australis. He states that the insects secrete an abundance of honeydew in which a black fungus develops.

\section{Hemlock scale Ispidiotus abictis Schr.}

An oval, dark gray, often blackish scale with a lighter margin and sometimes with a bluish, brownish or purple tinge, occurs on hemlock, pine, fir and maple foliage.

This species is reported by P'rofessor Comstock as being rather common on the lower surface of hemlock leaves at Ithaca, and has been found by us in small numbers on hard pine leaves at Karner. It is an European species, which has been reported in this country from Maine, Massachusetts, New York, New Jersey and Georgia. The female scale has been described by Professor Comstock as follows:

The scale of the female is rather elongated, with its sides parallel and ends rounded. The exuviae are nearly central, and are covered with secretion. The color of the scale is dark gray, often approaching black, with the margin lighter, and sometimes with a bluish, brownish, or purplish tinge. In many specimens of the fully formed scale, the part covering the

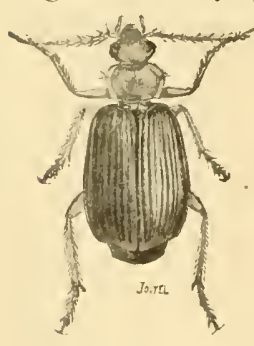

Fig, 209 Lebia grandis, much enlarged (original) exuviae is more or less distinct, appearing like a small scale with a light margin superimposed upon a larger scale. Length .08 to .1 2 inches.

\section{Lebia grandis Flentz}

This brilliantly marked grounel beetle ahout $3 / 8$ inch in length may be recognized by its brick-red head and thorax and bluish, deeply striated wing covers.

It is well known as an enemy of the potato beetle, and was taken in small numbers on hard pine at Karner in 1901 , one specimen being captured Sepr. I8. It probably preys on some of the more defenseless forms infesting these trees. 


\section{Nine-spotted lady beetle \\ Coccinclla noicmnotata Herbst.}

1 hemispheric, yellowish, nine-spotted beetle.

This little lady beetle is one of our more common species and is somewhat abundant on hard pines at Karner from July to September. The insect is a well known species and may be easily recognized by the accompanying illustration. It appears to be one of the more effective species in controlling plant lice, since it is quite commonly met with on trees infested by these little insects, and is probably an efficient check on those living on pine. This species has been recorded by Mr Crotch from comnotata, enlarged the Atlantic region, Mexico and Guatemala.

\section{Three-banded lady beetle}

\section{Coccincllar trifasciata Linn.}

A yellowish, almost black-banded, hemispheric beetle.

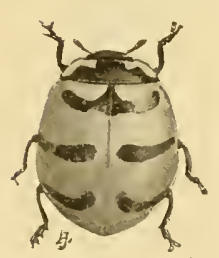

Fig. 21I Coccinella trif as ciata, enlarged

(uriginal)

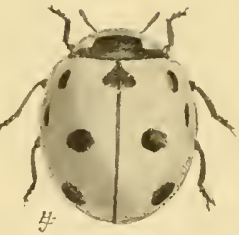

Fig. 210 Coccinella no-

Crotch from Lake Superior, Oregon, Siberia and Lapland.

\section{Ips sanguinolentus Oliv.}

I black beetle about $1 / 4$ inch long with a conspicuous orange band containing two circular black spots on the basal two thirds of the wing covers.

This species has a general resemblance to I p s quadriguttatus Fabr, and possesses similar habits. It measures about If inch in length, 


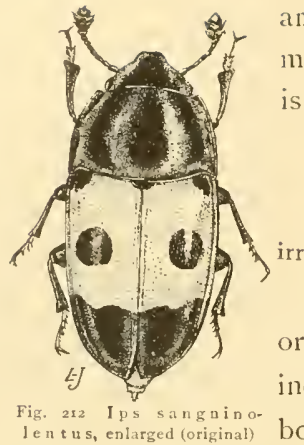

and may be recognized by the large reddish orange markings on each wing cover in the center of which is a jet-black, nearly circular spot.

\section{Ips quadriguttatus Fabr.}

A shining black beetle about If inch long with four irregular, orange markings on the wing covers.

This shining black beetle with four irregular orange markings on the wing covers, is from $3 / 16$ to $5 / 16$ inch long and occurs in the galleries of various wood lentus, enlarged (original) borers, particularly those moist with exuding sap. It feeds on decaying fruit, corn on the ear, seed after it has been planted and has been taken in the fall on oak and hard pine at Karner.

\section{Corymbites propola Lec.}

A small, snapping beetle less than $3 / 8$ inch long with a light head and light yellowish elytra marked with dark brown.

This little snapping beetle is less than $3 / 8$ inch in length and may be recognized by its light head and the light yellowish elytra marked with dark brown. This species was met with in small numbers on hard

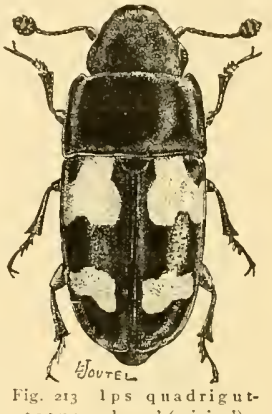

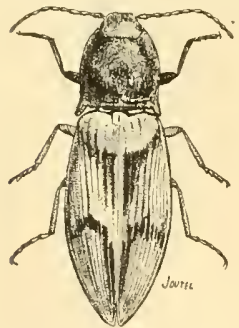

Fig. 2I4 Corymbites

hieroglyphicus, en-

larged (original) pine at Karner, one specimen being taken June 4 and two June 13, igor. It has been recorded from Lake Superior, Eagle Harbor, and is also found in western New York as stated by Dr LeConte.

\section{Corymbites hieroglyphicus Say}

A small, snapping beetle about $1 / 2$ inch long with its yellowish wing covers marked with curved, dark brown or black lines.

This peculiar snapping beetle, about $1 / 2$ inch long with dark brown head and thorax and yellowish wing covers marked with curved, dark brcwn or black lines, occurs on hard 
pines in June and July. This somewhat rare species has been recorded from Massachusetts, New Mampshire, New Jersey and Pennsylvania and Dr LeConte gives its distribution as Lake Superior, Ohio and Maine and states that it is not rare.

\section{Cloudy bark beetle destroyer}

Thanasimus nubilus Kl.

A small, black clerid with wing covers marked with zigzag black and gray transverse bands occurs on spruce.

The adults of this beneficial clerid feed on the spruce destroying bark beetle, Dendroctonus piceaperda Hopk., and associated species. The larvae of this predaceous form prey on the young and pupae of bark beetles in their galleries. This very beneficial species resembles an ant in appearance. It may be recognized by its black head, by the middle portion of the body being red and the wing covers marked with zigzag black and gray transverse bands.

\section{Hydnocera pallipennis Say}

A small beetle $3 / 10$ inch long with pale yellow, irregularly mottled wing covers and black head and thorax.

This is a small beetle about $3 / 16$ inch in length. It has a black head and thorax, and the wing covers are a pale yellow and irregularly mottled with brown. A single specimen was taken July I9, I90I, on hard pine at Karner. It has been recorded by Dr Smith as generally distributed and not rare in New Jersey.

\section{Hydnocera humeralis Say, var. cyanescens Lec.}

A jet-black, slender beetle nearly $3 / 16$ inch in length, may be taken on low shrub growths in midsummer.

Examples of this species were taken on hard pine at Karner July 2, 1902.

Description. This beetle is about $3 / 16$ inch in length, black in color, except that the head and thorax have dark grayish reflections in certain lights. Eyes large, prominent; thorax broader than long, subcylindric, with 
lateral, rounded tuberosities. Wing covers rather coarsely, irregularly punctured, rounded at the apex and diverging.

Habits and distribution. This predaceous species appears to be common in midsummer on late shrubs, and is probably generally distributed in the northeastern I'nited States, having been recorded from the vicinity of Buffalo N. Y., southwestern Pennsylvania, various localities in New Jersey and the District of Columbia.

\section{Ernobius mollis Linn.}

A small, variable, somewhat elongated, brown beetle about $1 / 8$ inch long occurs on hard pines in June and July.

This common European species introduced about 1865 , is a common form on hard pines in midsummer. It is recorded as generally distributed in New Jersey though not common. Its allies, E. granulatus Lec. and E. $\mathrm{l}$ ut eipe $\mathrm{n} \mathrm{n}$ is Lec. have been taken on pines in New Jersey.

\section{Dichelonycha albicollis Burm.}

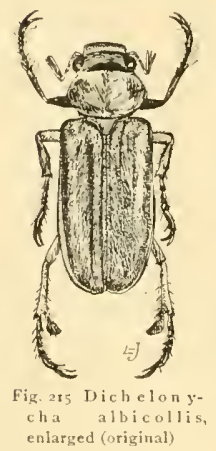

A greenish, coppery, elongate, parallel-sided beetle about 1/2 inch in length, occurs rather sparsely on hard pine in midsummer.

This species was taken in midsummer in rather small numbers at Karner, where it occurred at the base of hard pine needles. Specimens were captured at intervals throughout June and early July 1901, and also the following season. Dr Fitch ${ }^{x}$ states that it becomes quite common on pines about the middle of May, eating the foliage and continuing for about a month. Its distribution has been given by Dr Horn as the Middle States and Canada, and it has been recorded from several localities in New Jersey by Dr Smith.

${ }^{x} 1858$ Fitch, Asa. Ins. N. Y. 4th Rep't, p. 6 I. 


\section{Pine chrysomela \\ Glyptoscelis pubescens Fabr.}

Thick, cylindric, brilliant, brassy, coppery hued, rather stout beetles occur on hard pine foliage in Mlay and June.

This species ranges from $3 / 8$ to 5,16 inch in length [pl. 20, fig. 7]. It was common on hard pines at Karner in June I901, and occurred throughout May, June and early July the following year. This insect ranges from the Middle States to North Carolina and has been recorded from Oregon. It appears to be a rather characteristic spruce and pine beetle, judging from accessible records.

\section{Cryptocephalus schreibersii Suffr.}

A stout, yellowish brown beetle a trifle over $\mathrm{r} / 8$ inch long occurs on hard pine.

This stout yellowish brown beetle, only a trille over I/8 inch in length, was taken in small numbers on hard pines at Karner in September. This species has been recorded by Dr LeConte, from Massachusetts and Georgia, and Dr Smith reports it from several localities in New Fig. 215 Cryptocepho Jersey, and states that it occurs on hard pine leaves.
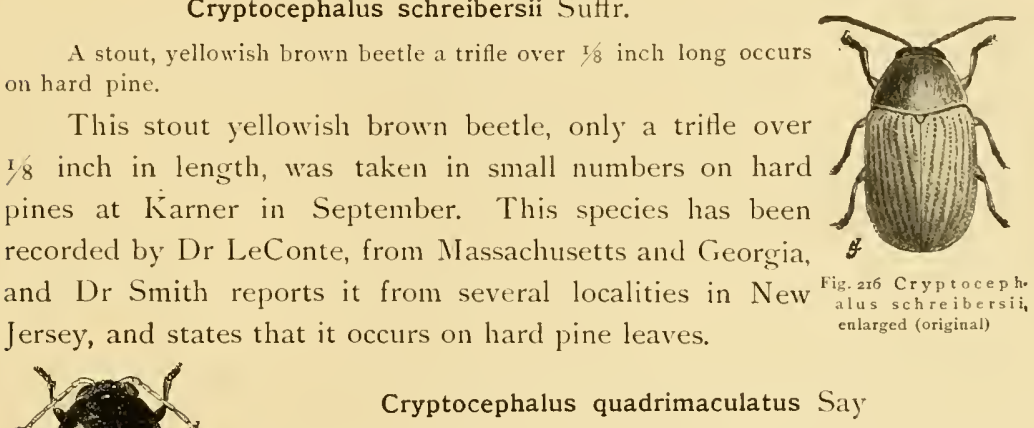

A small, stout, black, red-spotted beetle $1 / 8$ inch long occurs on hard pines in midsummer.

This species was taken through June and in early July I 901 , and the latter part of June 1902, on both scrub oak Fig. $217 \mathrm{Cryptoceph}$ and hard pine at Karner. It has also been listed from

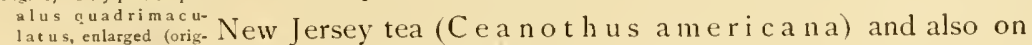
inal)

Rubus. Little is known of its life history. 
Notoxus bifasciatus Lec.

A small, brown or blackish beetle with lighter transverse bands on the wing covers and a conspicuous pronotal process.

This small beetle only about $\mathbf{x}$ inch long, was exceedingly common on hard pine at Karner during the latter part of June and early July rgoz. It

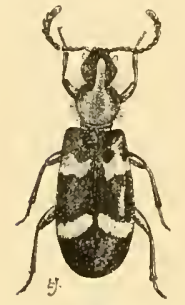
could have been taken by thousands, if clesired. This species, like its ally, N. a n chor a Hentz, has the peculiar hornlike process on the prothorax, only in this case it is distinctly spatulate at the tip. The elytra are dark brown or black with two transverse bands, the anterior one always being interrupted at the suture.

This species, according to Dr Horn, occurs everywhere Yig. 228 Notoxusfrom Canada to Arizona, westward to the Rocky mountains. bifasciatus, en-
larged (original) it stated by Dr Smith to be locally common, and Dr Hamilton records it as abundant in southwestern Pennsylvania, along the river shore on herbage, willow etc.

\section{Notoxus anchora Hentz}

A small brown, black-marked beetle about $1 / 8$ inch in length, may be met with on hard pine and various shrubs and herbs during the summer.

Members of this genus are remarkable for the enormous hornlike projection on the prothorax. This species is somewhat variable, though I) Horn states that the markings are rather constant. There is usually a more or less crescentic black band on each wing cover at the apical third. These join at the suture and extend forward, becoming broader at base. Near the side margin, just behind the humeri, there is a short stripe of varying size, sometimes wanting. This species is widely distributed, though it has not been observed in Arizona or the Pacific States.

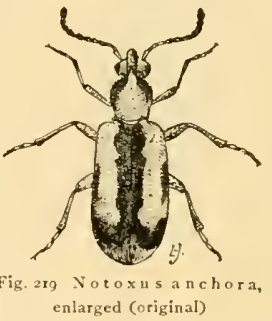
It appears in most of the local lists, except in that for the District of Columbia, and is usually recorded as rather scarce. Large numbers of this 
species have been sent to us by a correspondent, who took them from about the roots of wheat plants.

\section{Coenus delius Say}

A yellowish brown, black-dotted, somewhat oval plant bug $3 / 8$ inch long.

This yellowish brown, black-dotted, somewhat oval plant bug, measuring about $3 \dot{\delta}$ inch in length, was taken at Karner on hard pine in 1901. The species has a wide range, it having been listed from Colorado, New Jersey, Iowa, and Professor Uhler records it from as far south as Texas and as occurring in Massachusetts, New York and other states.

\section{Lace-winged fly \\ Honcrobius stignaterus Fitch}

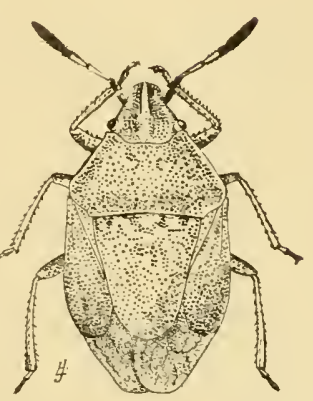

Fig. 2zo Coenus delius, enlarged (original)

Delicate greenish or brownish lace-winged flies with golden eyes, occur on many plants, their flattened long-jawed ferocious larvae devouring plant lice.

These flies are rather well known both as adults and larvae. The above named species was found in small numbers on hard pine at Karner. It appears to be a common species according to Dr Fitch, in the Northern and Western States. The general appearance of a lace-winged $\mathrm{fly}$ is shown at plate 20 , figure 18 . The peculiar spheric cocoon is illustrated at $18 \mathrm{a}$ of the same plate and the singular stalked eggs at I $8 b$. The young aphis lions are very bloodthirsty, even attacking smaller larsae of their own species as well as destroying many aphids.

\section{Micromus montanus Hag.}

This grayish brown, lace-winged fly $1 / 4$ inch long with a wing spread of $3 / 4$ inch occurs in September on hard pine. The veins are prettily marked with irregular alternating light and brown spaces. This beneficial species has been recorded from Massachusetts and the White mountains. 


\section{Pine tree cricket}

Occanthus pini Beutm.

This flower cricket was taken by the writer on hard pine at Karner in I gor as follows; July 27, four; Aug. 2I, four, and Sep. 6, one. Immature specimens of what probably beiong to the same species were taken, one on July 8 , and two on the sgth.

This insect has been described by Mr Beutenmuller as follows:

Head and antennae testaceous, the latter becoming darker towards the tip ; first two joints with four black marks; the inner mark on the first joint long and straight, the outer oblique; those on the second joint parallel; eyes black; thorax testaceous with a longitudinal line on each side above; anterior pairs of legs testaceous; posterior femora green, tibiae testaceous; body beneath black with the sides yellowish green; body above blackish with a green stripe along the back; elytra transparent, with grass-green veins; hind wings slightly protruding beyond the elytra; veins also green.

The female is somewhat paler than the male, and the wings Fig. 22 r Oc-extend a little more beyond the elytra ; ovipositor dark testaceous, pini, ander tip black. Average length from head to tip of wing covers, 14 pini, of basal $\mathrm{mm}$; body, $12 \mathrm{~mm}$; width, $4.5 \mathrm{~mm}$.

antennal seg-
ments (After $\quad$ He states that it may be easily distinguished from $\mathrm{O}$, $\mathrm{nig} \mathrm{r}$ Beutenmuller, cornis ITalk, by the grass-green color of the wings and the Hist. Bul. "9.4) testaceous head and thorax and the marks on the basal joints of the antennae. He adds that it lives only on pinetrees and usually on the high branches. It has been recorded from Riverton N. J., by Dr Smith and probably occurs in other pine sections of the state.

\section{Bibliography}

$189+$ Beutenmuller, William. Am. Mus. Nat. Hist. Bul. 6:27 I 


\section{Black-horned tree cricket \\ Occanthus nigricornis Walker}

This tree cricket may be recognized by its dark or nearly black antennae, the black markings on the basal joints as illustrated in figure 222, and by the rufous and dark markings upon the head and abdomen. It is somewhat variable in coloring, though possessing a characteristic appearance.

This species occurred in small numbers on hard pine at Karner in 1901, and was as abundant as any other species of this genus in that section. Adults were taken in August and September, and the species is undoubtedly of some benefit to trees because of its predaceous habits, though shrubs, particularly those with soft wood, may be injured to a considerable extent by the deposition of eggs. This insect was noticed by Dr Fitch in 1856 , who states that it is almost as common as the snowy tree cricket (O e ca nthus niveus DeG.), and who treated of it under the name of O. fasciatus DeGeer. This species occurs from the lat- Fig. $22 z$ Oecanter part of July till frost, along roadsides and in open fields, according to Mr Beutenmuller, who considers it one of the most common in the vicinity of New York city. Professor Bruner states that it is almost as abundant in Nebraska as the snowy Bus. Nat. Hist. tree cricket, and that it is a frequenter of meadows and may be found among weeds and grasses, depositing eggs as a rule, in weed stems. Professor Lugger considers it a very common form in Minnesota. It is interesting to note that it occurs in Mississippi, where $\mathrm{Mr} \mathrm{W}$. H. Ashmead detected a small parasite, Antigaster mirabilis Walsh ovipositing in the cricket's eggs.

\section{Bibliography}

I 894 Beutenmuller, Wm. Am. Mus. Nat. Hist. Bul. 6:270

Four-spotted tree cricket

Occanthus quadripunctatus Beutm.

This species occurs in small numbers during early fall on hard pine at Karner. It has been recorded from Ithaca, Staten Island and a number of 
New Jersey localities. It may be recognized by aid of the figure and the following description by Mr Beutenmuller.

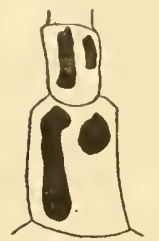

Head and antennae testaceous, the latter becoming darker towards the tip; first two joints with four black marks; the inner mark on the first joint long and straight, the outer oblique; those on the second joint parallel; eyes black; thorax testaceous with a longitudinal line on each side: above; anterior pairs of legs testaceous ; posterior femora green, tibia testaceous ; body beneath black with the sides yellowish green ; body above blackish with a green stripe along the back; elytra transparent, Fig. 223 Oecan-with grass-green veins; hind wing slightly protruding beyond punctatus, un- the elytra; veins also green.

derside of basal The female is somewhat paler than the male; and the

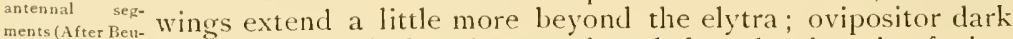
tenmuller, Am. testaceous, tip black. Arerage length from head to tip of wing

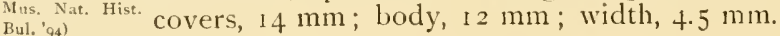




\section{SUPPLEMENTAL BIBLIOGRAPHIC AND DESCRIPTIVE CATALOGUE}

The following list comprises a large number of species which have been observed upon various shade and forest trees. These insects are very rarely abundant enough to cause any material injury, yet their identification is necessary if one would be certain that he has not some more destructive form. References are given to records of food habits and also to descriptions of immature stages. These latter will prove of great value to all working entomologists, since it will enable them to ascertain readily whether a certain caterpillar has been described or not. The more striking larval characters have been included because they will assist in eliminating many species, and thus save much labor in referring to the literature. Many references are given to Packard's well known Inscts Injurious to Forest and Shade Trees, fifth report of the United States Entomological Commission. These are so numerous that in the interest of brevity, the name of the author is given in abbreviated form, followed by the page whenever the volume contains more than a record of food habits. We have endeavored to select the best available larval description, and, as a rule, food plant records compiled from other authors follow the reference.

Synchita obscura Horn, red oak. Ins. N. J. p. 225

Cucujus clavipes Fabr., hickory, maple, locust, buckeye, gum. Ilamilton. Can. Ent. 18:27. Linden

Sandalus petrophya Knoch, white oak. Psyche, 4: 203

Melasis pectinicornis Mels. Ins. N. J. p. 2.45

Athous cucullatus Say. Pack.

Coelostethus notatus Say. Am. Ent. Soc. Trans. 31: I 87

Elater sayi Lec. Ins. N. J. p. 2.48

Elater nigricollis Herbst. Pack.

Buprestis rufipes Oliv., beech. Ins. N. J. p. 254

Dicerca asperata Lap. \& Gory. Pack. Hickory

Chrysobothris scitula Gory, in white oak bark. Pack. p. 69

Agrilus obsoletoguttatus Grory. Am. Ent. Soc. Trans. 18:317. Beech

Agrilus interruptus Lec. Ent. Am. 5:32

Agrilus acutipennis Mann. Am. Ent. Soc. Trans. I 8:307

Cinyra gracilipes Mels., white oak. Ent. Am. 5:30

Xenorhipis brendeli Lec. Ent. Am. 5:3I

Mastogenius subcyaneus Lec. Ins. N. J. p. 256. Hop hornbeam

Bostrichus bicornis Web., under bark. Pack. p. 92

Dinoderus punctatus Say. Pack.

Lucanus dama Thunb. Can. Ent. 13: 118. Willow

Ceruchus piceus Web. Decaying oak, black cherry

Parandra brunnea Fabr. Ent. Soc. Wash. Proc. 3:96. Beech, linden, wild cherry

Hymenorus obscurus Say. Wickham. N. Y. Ent. Soc. Jour. 4:12I

Hymenorus communis Lec. Pack.

Androchirus fuscipes Mels. Pack.

Dendroides canadensis Latr. Pack.

Smodicum cucujiforme Say, beech, hackberry. N. Y. Ent. Soc. Jour. 4:74 
Phymatodes varius Fabr., black oak, Pack. p. 76. Hickory

Dryobius sexfasciatus Say. 1...k. p. 227. Beech, elm, maple

Romaleum rufulum Hald. Ins. ‥ J. p. 287

Elaphidion inerme Newm., orange. N. Y. Ent. Soc. Jour. 4:75

Elaphidion suppubescens 1.ec., white oak. L. S. Div. Ent. Bul. 18, n. s. p. 41

Elaphidion mucronatum Fabr., hackberry. N. Y. Ent. Soc. Jour. 4:75

Elaphidion unicolor Rand., redbud. lns. N. J. p. 288

Curius dentatus Newm. Ins. N. J. p. 288

Tragidion coquus Linn. var. fulvipenne Say. Pack. p. 91

Purpuricenus humeralis Fabr. N. Y. Ent. Soc. Jour. $+: 76$. Maple

Microclytus gazellula 1Fald. N. Y. Ent. Soc. Jour. 4:77

Cacoplia pullata Hald. N. Y. Ent. Soc. Jour. $4: 78$

Cyrtinus pygmaeus IIald, hickory, box elder, locust. Ins. N. J. p. 293

Goes debilis Lec., white oak, chestnut. Pack, p. 82. Hickory

Goes tessellata Hald. N. Y. Ent. Soc. Jour. $4: 78$

Acanthoderes quadrigibbus Say, oak twigs. Pack. p. 91. Hickory, beech, hackberry

Leptostylus parvus Lec. Am. Ent. Soc. Trans. 22:369. Box elder

Typocerus zebratus labr., white oak. Wickham. Can. Ent. 29:188

Leptura nitens Forst. Wickham. Can. Ent. 29:192

Ataxia crypta Say, hackberry, box elder. N. Y. Ent. Soc. Jour. $4: 80$

Cryptorhynchus minutissimus l.ec. lins. N. J. p. 353

Cryptorhynchus ferratus Say. N. Y. Ent. Soc. Jour. $1: 8_{3}$

Cryptorhynchus bisignatus Say. N. Y. Ent. Soc. Jour. 1:83. Cinestnut, beech

Cryptorhynchus tristis Lec. N. Y. Ent. Soc. Jour. $1: \Omega_{3}$

Copturodes quercus Say. Ins. N. J. p. $35+$

Copturodes longulus Lec. Ins. N. J. p. $35+$

Zygomicros minutus Lec. Ins. N. J. p. 354

Pityopthorus querciperda Schwz., oak bark. l'ack. p. 93

Pityopthorus fagi Hop. lns. N. J. p. 362

Pityopthorus frontalis llop. Ins. X. J. p. 362

Hypothenemus aveccae llorning. In. N. J. P. 362

Hypothenemus erectus Lec. l'ack. J Hickory

Stephanoderus dissimilis Zimm. Ins. N. J. p. $3^{62}$

Xyleborus pubescens Zimm., butternut, chestnut, magnolia, cherry. Ins. N. J. p. $3^{6} 3$

Micracis opacicollis Lec. Ins. N. J. p. 363

Thysanoes quercus Hop., chestnut. 1ns. N. J. p. 363

Corthylus columbianus 1Hop. Ent. Soc. Wash. Proc. 3:104

\section{WIK LEIN FEEUER:}

\section{Sawfly larvae}

Periclista albicollis Nort., greenish; conical tubercles; white oak. Dyar. N. Y. Ent. Soc. Jour. 6:130

Periclista media Nort., green; white oak. Dyar. N. Y. Ent. Soc. Jour. 6:132

Periclista purpuridorsum Dyar, srecnish white, thorax greenish; white oak. N. I.

Ent. Soc. Jour. $6: 130$

Periclista subtruncata Dyar, smooth waxy greenish; black oak. N. Y. Ent. Soc. Jour. $\quad 6: 132$ 
Periclista emarginatá MacGill., pale spined, green. Dyar. N. Y. Ent. Soc. Jour. $6: 131$

Isodyctium infrequens Dyar, white spined, green; white oak. N. I. Ent. Soc. Jour. $6: 135$

Isodyctium subgregarium Dyar, black spined, green; white oak. N. Y. Ent. Soc. Jour. $6: 134$

Isodyctium murtfeldtiae Dyar, green, spined; black oak. N. Y. Ent. Soc. Jour. $6: 135$

Nematus chloreus Nort., whitish green. Dyar. N. I. Ent. Soc. Jour. 6:123

Pteronus integer Say, green, dark behind eye. Dyar. N. Y. Ent. Soc. Jour. 6: 122

Pteronus quercus Marlatt, yellowish or dark green. Dyar. N. Y. Ent. Soc. Jour. $6: 122$

Hemichroa albidovariata Nort, brown, black spots laterally. Dyar. N. Y. Ent. Soc. Jour. 6:125

Hemichroa fraternalis Nort, greenish, with dark lateral band. Dyar. N. Y. Ent. Soc. Jour. 6:124

Hemichroa phytophagica Dyar, green. N. I. Ent. Soc. Jour. 6:125

Monophadnus dilutus Cress., pale green, 5/8 in. Pack. p. 206

Monostegia quercusalbae Nort., pale green. Pack. p. 205

Monostegia quercuscoccineae Dyar, white, black oak. Can. Ent. 26:42

\section{Beetles}

Brachys aeruginosa Gory. Ent. Am. 5:32. Beech.

Dichelonycha fuscula Lec. Am. Ent. Soc. Trans. $27: 283$

Lachnosterna quercus Knoch. Pack.

Systena taeniata Say. Pack.

Chlamys plicata Fabr., yellow case-bearer, íf in. Pack. p. 205. Sycamore, hazel, birch, alder, sweet fern, blackberry

Bassareus detritus Oliv. Ent. Soc. Wash. Proc. 2:263

Cryptocephalus mutabilis Mels., hazel. Ins. N. J. p. 302

Cryptocephalus guttulatus Oliv. Am. Ent. Soc. Trans. 22:370

Metachroma laevicollis Cress. Ins. N. J. p. 305

Metachroma pallida Say. Ins. N. J. p. 305. Poplar

Metachroma quercata Fabr., scrub oak. Ins. N. J. p. 305

Xanthonia decemnotata Say. Am. Ent. Soc. Trans. 22:370

Xanthonia villosula Melsh. Am. Ent. Soc. Trans. 22:370. Hickory, hazel. poplar Odontota nervosa Panz., miner, elm. Ent. Soc. Ont. 13th Rep't, p. 61. Linden Xylopinus saperdoides Oliv. Pack.

Strongylium terminatum Say. Pack.

Eugnamptus angustatus Herbst., hickory, sycamore, butternut, chestnut. Ins. N. J. p. 339

Rhynchites aeratus Say, scrub oak. Ins. N. J. p. 339

Attelabus nigripes Lec., scrub oak. Ins. N. J. p. 340

Pterocolus ovatus Fabr. N. Y. Ent. Soc. Jour. 1:37

Piazorhinus pictus Lec. Am. Ent. Soc. Trans. 22:376

Piazorhinus scutellaris Say, hickory. N. Y. Ent. Soc. Jour. I : 8 I

Laemosaccus plagiatus Fabr. N. Y. Ent. Soc. Jour. 1:82. Hickory

Balaninus uniformis l.ec. Pack.

Balaninus quercus Horn. Pack. 


\section{Caterpillars}

Papilio glaucus Linn. var. turnus Linn., green, yellow and black marked, $13 / 5$ in.; ash, linden, tulip, sassafras, apple, quince, plum, thorn, poplar, birch, alder. Am. Mus. Nat. Hist. Bul. $5: 244$

Basilarchia archippus Cram., whitish or olive-green, mottled, horned; plum, willow, poplar. French. Butt. East. U.S. p. 212

Basilarchia astyanax Fabr., greenish yellow, tuberculate. Pack, p. 128. Hornbeam, huckleberry, gooseberry, apple, plum, cherry, thorn

Thecla edwardsii Saund, dark green. Pack. p. 130

Thecla calanus Hübn., yellowish or green, white liaired, $x / 2$ in. : hickory, walnut, butternut, chestnut, thorn. Beut. Am. Mus. Nat. Hist. Bul. 5:278

Thecla liparops Boiscl. \& Lec., green, brown humped, 1/2 in.; chestnut, apple, plum, cherry, thorn, willow, holly. Beut. Am. Mus. Nat. Hist. Bul. 5:279

Thanaos brizo Boisd. \& Lec., scrub oak. Pack. p. 131

Thanaos juvenalis Fabr., green, yellow lincd and dotted, I in. Beut. Am. Mus. Nat. Hist. Bul. 5:301

Anisota virginiensis Dru., yellow, rosy striped, prickly, 2/5in. Pack. Nat. Acad. Sci. Mem. 9:102

Haploa clymene Brown. Pack.

Charadra deridens Guen., white, with tufts of silky white hair; elm, birch. Sm. \& Dyar. U. S. Nat. Mus. Proc. 21:25

Apatela afflicta Gr., brown, with black dorsal stripe. Sm. \& Dyar. U. S. Nat. Mus. Proc. 21:127

Apatela brumosa Guen., olive-green, yellowish, banded. Sm. \& Dyar. U. S. Nat. Mus. Proc. 21:117. Hickory, witch-hazel, plum, willow, birch

Apatela hamamelis Guen., brown, blackish dorsal stripe; horse-chestnut, chestnut, birch. Sm. \& Dyar. U. S. Nat. Mus. Proc. 21: I4I

Apatela lobeliae Guen., gray, yellow marked, 1/2 in. Pack. p. I68. Cherry

Apatela modica Walk., brown shaded, blackish. Sm. \& Dyar. U. S. Nat. Mus. Proc. 21:139

Apatela ovata Grote, brown, yellow marked; chestnut, beech, birch. Sm. \& Dyar. U. S. Nat. Mus. Proc. $21: 135$

Pyrophila pyramidoides Guen., green, white dotted, $1^{2}{ }_{5}$ in.; hickory, walnut, chestnut, maple, box elder, linden, apple, cherry, lilac, willow, poplar. Beut. Am. Mus. Nat. Hist. Bul. 16:452. Hazel

Rhynchagrotis alternata Gr., dark brown, white lined. Dyar. Ent. Soc. Wash. Proc. $4: 316$. Hickory

Psaphidia thaxterianus Grote, brown, green tinted, with creamy patches; white oak. Dyar. N. Y. Ent. Soc. Jour. 9:84

Peridroma margaritosa Haw. var. saucia Hübn., mottled, gray, I 1/2 in. Pack. p. 173

Mamestra atlantica Grote, greenish or brown, 11/6 in. Fletcher \& Gibson. Can. Ent. 34:279

Graphiphora alia Guen., whitish, red marked. Pack. p. 172. Hickory, sassafras, birch

Crocigrapha normani Grote. Can. Ent. 23:36

Jodia rufago Hübn., yellow, black marked. I'ack. p. 172

Calymnia orina Guen., whitish green, ? to in. Beut. Am. Mus. Nat. Hist. Bul. 16:457 
Scopelosoma devia Grote, dark green, gray or blackish, with dark dorsal band, $1^{1 / 4}$ in. Thaxter. Can. Ent. 16:33

Scopelosoma morrisoni Grote, black, greenish, bluish white marks, 1 r/2 in. Thaxter. Can. Ent. 16:30

Scopelosoma sidus Guen., dark olive-green, purplish markings, I/f in. Thaxter. Can. Ent. 16:33. Hickory, apple, wild cherry, peach

Scopelosoma tristigmata Grote, dark olive-green, orange yellow lined, $1 \frac{\mathrm{I}}{2} \mathrm{in}$. Thaxter. Can. Ent. 16:33

Scopelosoma walkeri Grote, velvety black, purplish white lined, $1_{1}^{1}$ in. Thaxter. Can. Ent. I6:3 I

Scolecocampa liburna Geyer, black headed, whitish, brown spotted, $\mathrm{I}^{2}, 5$ in.; chestnut. Edw. \& Elliot. Papilio, 3:134

Catocala amasia Abb. \& Sm. Pack. p. 175

Catocala amica Hübn., slender, greenish yellow, black marked, I/4 in. Pack. p. 174

Catocala coccinata Grote, dark gray, black marked, 21/2 in. Coq. Papilio, $1: 56$

Catocala epione Drury, reddish gray, bluish marbled. Pack. p. 178. Hickory

Catocala fratercula Gr. \& Rob., gray, black spotted, white marked, $13 / 4$ in. Coq. Papilio, $1: 7$

Catocala ilia Cram., greenish gray, blue, gray marked. Pack. p. 177

Catocala lacrymosa Guen., walnut. Pack. p. 178. Black walnut

Catocala polygama Guen., ash-gray, dark marked, 21/2 in. Pack. p. 179. Thorn

Catocala similis Edw., greenish gray. Pack. p. 175

Catocala ultronia Hübn., dull grayish brown, 16/10 in. Pack. p. I76

Catocala vidua Abb. \& Sm., greenish gray, black marked. Pack. p. izS. Hickory, black walnut, locust, willow

Panapoda rufimargo Hübn,, dark green, yellow marked, I5/8 in. Pack. p. 172. Wild cherry

Zanclognatha protumnusalis Walk. Pack.

Palthis asopialis Guen. Pack.

Hyperaeschra georgica H.-S., green, white lined, red dotted. 1/2 in. Pack. Monogr. Bombycine Moths, p. 153

Lophodonta angulosa Abb. \& Sm., green, white lined, white dotted. Pack. Monogr. Bombycine Moths, p. I47

Heterocampa manteo Dbldy., green, purple and white marked, $I^{1 /}$ in. ; walnut, linden, apple, hawthorn, birch, persimmon. Pack. Monogr. Bombycine Moths, p. 224

Heterocampa obliqua Pack, gray headed, white or green, many brownish dots. Pack. Nonogr. Bombycine Moths, p. 242

Heterocampa umbrata Walk., green, white marked, I1/t in. Pack. Monogr. Bombycine Moths, p. 249. Hickory, black walnut, hormbeam, birch

Ianassa lignicolor Walk., green, brown marked: hump on first abdominal segment, 13/8 in.; beech, birch. Pack. Monogr. Bombycine Moths, p. 190. Chestnut

Schizura ipomoeae Dbldy., brown, green marked; humps on first, fifth, eighth abdominal segments, $11 / 4$ in.: elm, maple, honey-locust, birch. I'ack. Monogr. Bombycine Moths, p. I94. Witch-hazel, linden

Schizura unicornis $\mathrm{Abb}$. \& Sm., lilac, light marked larva; hump on first and eighth abdominal segments; sides of thorax green, 1 I/ in. ; hickory, blackberry, winterberry, elm, apple, plum, thorn, dogwood, rose, willow, birch, alder and probably hazel, locust, cherry, poplar, holly. Pack. Monogr. Bombycine Moths, p. 203 
Fentonia marthesia Cram., green, yellow and red marked, long tailed, ${ }_{4}^{3}$ in.; beech. Pack. Nonogr. Bombycine Moths, p. 257

Pseudothyatira cymatophoroides Guen., yellowish brown, white marked, 11/2 in. Pack. P. 167

Alsophila pometaria Harr., green, white lined spanworm. Dyar. Psyche, 9:262 Hickory, hop-hornbeam

Tephroclystis miserulata Grote, green, brown marked, 34t in. Parck. p. 190. Tamarack, cedar, juniper

Epirrita dilutata Denis \& Schiff,, dirty green, red spotted spanworm. Pack. p. 233

Eustroma diversilineata lIübn., dark brown, reddish tinted spanworm. Pack. p. 189 . Elm, woodbine

Mesoleuca gratulata Walk. Dyar. Psyche, 10:191

Nemoria subcroceata WValk, brownish, white specked, tuberculate spanworm. Dyar. Psyche, $8: 386$

Aplodes mimosaria Guen., dingy brown spanworm with curved lateral appendages. Pack. p. 189

Orthofidonia vestaliata Gucn., hombeam, apple. Ins. N. J. p. 445

Paraphia subatomaria IVood var. unipuncta llaw., gray, black marked spanworm, $1^{t / 1}$ ro in. Pack. p. 185 . Elm

Cingilia catenaria Drury, yellow, black, brown marked spanworm. Dyar. Psychc, 9:250. General feeder. Hazel, pine, juniper

Plagodis fervidaria IH.-S., pale yellowish, black marked spanworm, $1 \frac{1}{2}$ in. Pack. p. 186. Beech, ash, cherry, birch, spruce

Therina athasiaria Walk, greenish, black marked, orange shaded spanworm. Dyar. Psyche, 9:10. Pine

Therina endropiaria Gr. \& Rob., whitish, black marked spanworm, 136 in. Pack. p. 186. Chestnut, hornbcam

Euchlaena johnsonaria Fitch, cherry. Ins. N. J. p. 450

Euchlaena pectinaria Denis \& Schiff, large, gray spanworm. Pack. p. 18.4. Poplar

Metanema quercivoraria Guen., pale green, red marked spanworm. Pack. p. 182. Elm, willow, poplar

Metanema textrinaria Gr. \& Rob., red headed, green and red marked humped spanworm. Pack. Nonogr. Geometrid Moths. p. 508

Nola ovilla Grote, hairy, white, black marked. Dyar. Psyche, 7:137

Roeselia minuscula Zell, var. phylla Dyar. N. Y. Ent. Soc. Jour. 6:43

Lacosoma chiridota Grote, greenish, yellow lined, brown marked. 1)yar. N. Y. Ent. Soc. Jour. 8:180

Cicinnus melsheimeri Harr, brown or pale brown case-bcarer. Pack. p. 142

\section{Shug catcrpillars}

Euclea chloris 11.-S., greenish, salmon lined. $3^{3}$ in.; hickory, bayberry, chestnut, elm, linden, wild plum, wild cherry, Dyar. N. Y. Ent. Soc. Jour. 5:61

Euclea delphinii Boisd., green, yellow marked, red horned; chestnut, beech, bayberry, honey-locust, wild cherry, sour gum. Dyar. N. Y. Ent. Soc. Jour. 5:57

Adoneta spinuloides H.-S., green, purple dorsally; a red and a shorter yellow horn, $2 / .5$ in.; chestnut, beech, witch-hazel, bayberry, locust, linden, plum, wild cherry, sour gum, willow, birch. Dyar. N. Y. Ent. Soc. Jour. 5:9 
Prolimacodes scapha Harr., green mottled, brown or yellow, $2 / 3$ in.; hickory, chestnut, hop-hornbeam, witch-hazel, bayberry, maple, linden, wild cherry; sweet gum, birch. Dyar. N. Y. Ent. Soc. Jour. 4:172

Natada nasoni Grote, green, subdorsal reddish spots, 3' in. ; hickory, chestnut, beech, ironwood. Dyar. N. Y. Ent. Soc. Jour. 7:61

Packardia geminata Pack,, whitish green, white lined, $3 / 5$ in. Dyar. Can. Ent. 23:277

Packardia elegans Pack., green, yellowish and dark spotted, //2 in. Dyar. Can. Ent. 23:277

Heterogenea shurtleffii Pack, greenish, red spotted; chestnut, beech, ironwood, locust. Dyar. N. I. Ent. Soc. Jour. 6:24I

Kronaea minuta Reak., green, red lined. Pack. p. r5o. Chestnut

Cochlidion biguttata Pack., whitish green, yellow lined, I/2 in. Dyar. N. Y. Ent. Soc. Jour. $5: 168$

Tortricidia testacea Pack., green; crimson, yellow marked, 1/3 in.; wild cherry, birch. Ins. N. J. p. 487 . Linden

Tortricidia pallida H.-S., green, red or purple marked, ' 's in. ; sycamore, chestnut, witch-hazel, bayberry, maple, cherry, willow birch. Dyar. N. Y. Ent. Suc. Jour. $4: 167$

\section{Leaf rollers}

Exartema inornatanum Clem., white oak. Am. Ent. Soc. Trans. 10:30

Tmetocera ocellana Schiff, brown headed, light brown, 1/2 in.; laurel oak. Fitch. 3d Rep't, p. 27

Cenopis reticulatana Clem.. osage orange, maple, pear, persimmon. Pack. p. 194

Cenopis diluticostana IVIsm., cultivated cherry. Pack. p. 194

Archips grisea Robs. Am. Ent. Soc. Trans. 10:13

Archips semiferana Walk. Pack. p. 192. Hickory, box elder

Pandemis limitata Robs. Am. Ent. Soc. Trans. 10:14

Tortrix albicomana Clem. Am. Ent. Soc. Trans. 10:18. Rose

Eulia velutinana Walk., maple, balsım. Pack. p. 196

Aristotelia rubidella Clem., green, purple striped and dotted. Murt. Can. Ent. $6: 222$

Telphusa quercinigracella Chamb., black marked, yellowish; black oak. Can. Ent. $4: 171$

Telphusa querciella Chamb., brown headed, whitish, purple spotted. Clem. Can. Ent. 4:128

Recurvaria quercivorella Chamb., white, red spotted; in silken tube. Clem. Can. Ent. 4: 173

Trypanisma prudens Clem., ovoid larva beneath web on under surface of leaf. Tineina N. A. p. 126

Epithectis gallaegenitella Clem., in spongy gall tissues. Tineina N. A. p. 243

Ypsolophus ligulellus Hübn., striped, white and black, 6/10 in. Pack. p. 202

Ypsolophus quercicellus Chamb., grayish or greenish, reddish tinged, $1 \mathrm{in.}$ Can. Ent. 4:223

Aristotelia rubidella Clem. Pack.

Gelechia bicostomaculella Chamb., yellowish; head and thorax dark brown. Clem. Can. Ent. 4:207

Paralechia cristifasciella Chamb., dark green, red banded. Pack. U. S. Div. Ent. Bul. $32: 56$ 
Gelechia vernella Murt., gray: purple or red lined larva, laurel oak. Can. Ent. $13: 24.4$

Stenoma schlaegeri Zell., flattened, pale green, 7/8 in. Pack. p. 197

Cryptolechia quercicella Clem., brown headed, greenish, black marked, $1 / 2$ in.; in leafy nest. U. S. Div. Ent. Bul. 13:27

Machimia tentoriferella Clem.. large headed, green tapering larva under web near midrib, hickory and wild cherry. Tineina N. A. p. 148

Euclemensia bassettella Clem. Pack.

\section{Leaf mincrs}

Coleophora querciella Clem., dark brown, pistol-shaped case. Tineina N. A. p. I68 Nepticula anguinella Clem., linear, serpentine mine full of black frass. Tineina N. A. p. 175

Nepticula saginella Clenı., transparent, medium, serpentine; central frass line. Tineina N. A. p. 175

Nepticula quercipulchella Chamb. Pack.

Nepticula quercicastanella Chamb. Pack.

Nepticula platea Clem., mine moderate, winding, scattered frass line. Tineina N. A. p. 175

Lithocolletes albanotella Chamb., tentiform mine on under surface. Cin. Quar. Jour. Sci. 2:102

Lithocolletes aeriferella Clem. Ent. Soc. Wash. Proc. 5:187

Lithocolletes argentifimbriella Clem., tentiform, marginal mine under foided leaf edge. Chamb. Cin. Quar. Jour. Sci. 2:103

Lithocolletes blancardella Fabr, mine on underside near midrib. Clem. Tineina N. A. p. 141. Wild cherry, thorn

Lithocolletes bethuniella Chamb. Pack.

Lithocolletes bifasciella Chamb. Pack.

Lithocolletes basistrigella Clem., blister mine, under surface. Tineina N. A. p. zo

Lithocolletes cincinnatiella Chamb. Psyche. $2: 83$

Lithocolletes fasciella Walsm., oval, flat, upper surface, later corrugated in middle. Chamb. Cin. Quar. Jour. Sci. 2:103

Lithocolletes hageni Frey \& Boll. Pack.

Lithocolletes obstrictella Clem., cylindric, yellow larva in mine, under surface, black oak. Tineina N. A. p. 74

Lithocolletes quercialbella Fitch., marginal mine, under surface. Chamb. Cin. Quar. Jour. Sci. 2:102

Lithocolletes tubiferella Clem., serpentine frass-lined tract, upper surface. Tineina N. A. p. 140

Coriscium albinatella Chamb. Pack.

Tischeria fuscomarginella Chamb., marginal mine below under curled edge. Cin. Quar. Jour. Sci. 2:110

Tischeria pruinosella Chamb. Pack.

Tischeria badiiella Chamb., whitish blotch mine, upper surface. Cin. Quar. Jour. Sci. 2: 109

Tischeria citrinipennella Clem., white, blotch mine, upper surface. Tineina N. A. p. 82. Ash

Coptotriche zelleriella Clem., white or brown blotch mine, upper surface. Tineina N. A. p. 81

Argyresthia austerella Zell., chestnut, Ins. N. J. p. 481 


\section{Sucking insects}

Thelia univittata Harr., brown, white-lined tree hopper, $4 / 10$ in., on twigs. Pack. p. 98

$$
\text { Aphids or plant lice }
$$

Lachnus quercifoliae Fitch. Pack.

Schizoneura querci Fitch, black aphids, 1/8 in. Pack. p. 212

Chaitophorus spinosus Oestl., orange or yellow aphid, It in. Pack. p. 213

Callipterus bellus Walsh. Ins. N. J. p. 104

Callipterus discolor Mon., dark rose colored aphid. Pack. p. 210

Callipterus hyalinus Mon. Ins. N. J. p. 104

Callipterus punctatus Mon. Pack. p. 210

Callipterus quercifolii Thom., brownish aphid with annulate antennae. Pack. p. 21 I Aphis quercifoliae Walsh., pale greenish aphid. Pack. p. 209.

\section{Scale insects}

Eulecanium antennatum Sign. Fern. Coccidae, p. 181

Eulecanium lymani King, Fern. Coccidae, p. 190

Eulecanium quercitronis Fitch, ${ }^{2}$ io in.; black oak. Pack. p. 98 . Ironwood

Eulecanium quercife: Fitch, $3 / 10$ in. Pack. p. 98

Kermes andrei King, brown, hemispheric; white oak. Psyche, 9:22

Kermes perryi King, scrub oak. Psyche, 9:81

Kermes pettiti Ehrh., brown, hemispheric. King. Psyche, 9:81

Kermes kingii Ckil., red oak. Fern. Coccidae, p. 63

Kermes nivalis King \& Clk11., brown, hemispheric; white oak. King. Psyche, 9: So

Kermes pubescens Bogue, Ferm. Coccidae, p. 64

Kermes quercus Linn. Fern. Coccidae, p. 64

Eriococcus quercus Comst. Fern. Coccidae, p. 78

Sphaerococcus sylvestris Ck11., white oak. Can. Ent. $30: 326$

Chrysomphalus obscurus Comst., hickory. Fern. Coccidae, p. 291

\section{Acorn feeders}

Holcocera glandulella Riley, yellow or grayish white larva. Chittenden. U.S. Div. Ent. Bul. $44: 38$

Melissopus latiferreanus IVIsm. Am. Ent. Soc. Trans. 10:54

OAK (I.ILLS

Acorn galls

Andricus operator O.S. form operatola Riley \& Bass, five or six galls in aborted acorns. Am. Ent. Soc. Trans. 26:315

Andricus perditor Bass., galled acoms exude a liquid. Am. Ent. Soc. Trans. 26:313

\section{Twig galls and others}

Andricus seminosus Bass., subconic, apical, I/2 to 1 in. Am. Ent. Soc. Trans. 17:76

Andricus gibbosus Prov. Nat. Can. 12:2,32

Andricus obtusilobae Bass. Am. Ent. Soc. Trans. 26:316 
Amphibolips caroliniensis Bass., coarsely reticulated oak apple. Am. Ent. Soc. Trans. 17: 85

Neuroterus exiguus Bass., aments enlarged, nodular. Am. Ent. Soc. Trans. 26:333

Neuroterus crassitelus Prov. Nat. Canl. 12:232

Neuroterus dubia Bass. Am. Ent. Soc. Trans. 26:335

Cecidomyia majulis O.S., green or reddish blister gall. Am. Ent. Soc. Trans. $3: 53$

Cecidomyia niveipila O. S., pubescent folded rib gall. Diptera N. A. 1:199

Cecidomyia symmetrica O. S., small, globular, hard, red. Diptera N. A. 1:200

Phylloxera rileyi Licht., circular, yellow spot on underside. Pack. p. 208

\section{WHIT: $0.1 \mathrm{~K}$}

Root gall

Biorhiza nigra Fitch. Nox. Ins. N. Y. 5:2

\section{Twig galls}

Andricus ? indistinctus Bass., globular, broad base, 1/8 in. diameter. Am. Ent. Soc. Trans. $17: 81$

Andricus tuber Fitch, irregular swellings thrice the size of the twig. Nox. Ins. N. Y. $5: 26$

Amphibolips badius Bass. Am. Ent. Soc. Trans. 26:323

Dryophanta radicola Ashm., yellow, fig-shaped, clustered. Insect Galls Ind. p. 836

Dryophanta pallipes Bass., apical enlargement with threadlike appendages. Am. Ent. Soc. Trans. 26:327

Cynips juglans O. S., round gall, $3 / 4$ to 1 in. Ent. Soc. Phila. Proc. I : 255

Biorhiza loxaulis Mayr., woody knots at base of young shoots. Can. Ent. I $3: 76$

\section{Bud galls}

Dryophanta clarkei Bass., round, smooth, diameter ${ }^{3}{ }_{16}$ in. Am. Ent. Soc. Trans. 17:69

Neuroterus minutus Bass., greatly enlarged petioles without leaf. Can. Ent. 13:96

Cynips vesicula Bass., smooth, brown, central. Can. Ent. 13:97

\section{Leaf galls}

Andricus cicatricula Bass., polythalamous, conical, midrib, 1/2 to 1/8 in. Am. Ent. Soc. Trans. 17:80

Andricus flocci Walsh, oval, $1 / 5$ to $2 / 5$ in. Ent. Soc. Phila. Proc. $2: 482$

Andricus foliaform:s Gill., warty, leafy growth on underside of midrib. P'syche, $5: 214$

Andricus fusiformis O. S., fusiform. pedicellate, $1 / 5$ in. Ent. Soc. Phila. Proc. 1:61

Andricus futilis O. S., splecric, on both sides, $1+$ in. Ent. Soc. Phila. Proc. $1: \sigma_{3}$

Andricus utriculus Bass., globular, green or purplish, 1/6 in. Can. Ent. 13:78

Neuroterus exiguissimus Bass., woolly, midrib gall, .03 in. Am. Ent. Soc. Trans. 26: 332

Neuroterus pallipes Bass., small, hairy on stem or midrib. Am. Ent. Soc. Trans. $17: 89$

Neuroterus perminimus Pass., pustulate, abundant. Am. Ent. Soc. Trans, 26:332

Neuroterus majalis Bass, green, ${ }_{+}^{\prime}$ to 1 in. Ent. Soc. Phila. Proc. $3: 683$ 
Neuroterus consimilis Bass., woody, polythalamous, $3 / 4$ in. Am. Ent. Soc. Trans. 26:335

Priloatx fulvicollis Fitch. Nox. Ins. N. Y. $5: 3$

Philonix gillettei Bass., oval, tufted, pimply, .15 in. Am. Ent. Soc. Trans. 26:323

Philonix nigricollis fitch. Nox. Ins, N. Y. $5: 3$

Biorhiza rubinus Gill., subglobular rosy'; underside, 1/8 in. P'syche, 5:215

Acraspis niger Gill., small, brown, globular, pubescent; underside of leaf. Gill. Ent. Am. 6:23

Phylloxera querceti Perg., many small, yellow spots along veins; other oaks. Davenport Acad. Sci. Proc. 9:263

Phylloxera rileyi Riley, yellowish, circular spots on post oak. Perg. Davenport Acad. Sci. Proc. 9:261

\section{SWAMP OAK}

Twig galls

Holcaspis bassetti Gill., irregular, massed. Psyche, 5:215

Neuroterus distortus Bass., leafy polythalamous gall, 1/2 in. Am. Ent. Soc. Trans. $26: 336$

Neuroterus noxiosus Bass., large terminal or subterminal swellings. Can. Ent. I $3: 108$

\section{Bud galls}

Andricus ashmeadii Bass. Am. Ent. Soc. Trans. 26:320

Andricus incertus Bass. Am. Ent. Soc. Trans. 26:317

Amphibolips melanocera Ashm., globular bud axil gall. Am. Ent. Soc. Trans. 1 $2: 299$

\section{Leaf galls}

Andricus capsulus Bass., pedicellate, marginal, 3/8 in. Can. Ent. 13: 101

Andricus ignotus Bass., oval, sessile galls on midrib and veins. Can. Ent. 13:106

Cynips floccosa Bass., many, small, hairy; under surface. Can. Ent. 13:11 I

Cynips nigricens Gill., ciustered, cone-shaped; under surface. Psyche, 5:2 I 7

\section{POST O.AK \\ Twig gall}

Dryophanta longicornis Bass., apical enlargement. Am. Ent. Soc. Trans. 26:327

\section{Leaf galls}

Andricus pattoni Bass., clustered woolly galls along mid vein. Can. Ent. 13:98

Andricus pruinosus Bass., round, thin, $1 / 9$ to $1 / 6$ in. Am. Ent. Soc. Trans. 26: 3 I 1

Andricus quinqueseptum Ashm., globular petiole galls. Am. Ent. Soc. Trans, 12:299

Andricus tubicola O. S., yellow tubular, red spined, I ${ }_{3}$ in. Ent. Soc. Phila. Proc. 1:60

Holcaspis centricola O. S., globular, silky white, 34 in. Ent. Soc. Phila. Proc. 1 : 58

Neuroterus irregularis O. S., flattened, yellow galls, I/ in. Ent. Soc. Phila. Proc. 1:65

Neuroterus verrucarum O. S., round, pubescent, ${ }^{\mathrm{I}}$ io in. Ent. Soc. Phila. Proc. I :62 
RED OAK

Twig galls

Amphibolips formosa Bass., elongate, oval, $3 / 4$ to 1 in. Ent. Soc. Phila. Proc. $3: 679$

Bud gall

Amphibolips cookii Gill., subglobular, acuminate, 1 in. Psyche, $5: 220$

\section{Leaf galls}

Andricus femoratus Ashm., globular, central, supported cell, diameter 3 in. Am. Ent. Soc. Trans. 14:141

Andricus modestus O. S., hard, irregular, green galls. Ent. Soc. Phila. Proc. 1:65 Andricus piperoides Bass., pubescent, clustered midrib gall, diameter $1 / 8$ to $3 / 8 \mathrm{in}$. Am. Ent. Soc. Trans. 26:314

Amphibolips coelebs O. S., fusiform, pale green, 1 in. Ent. Soc. Phila. Proc. 1:60 Amphibolips sculpta Bass, globular, whitish, $1 / 4$ to $3 / 4 \mathrm{in}$. Ent. Soc. Phila. Proc. $2: 324$

Dryophanta liberaecellulae Gill., globular, fuzzy, 1/2 in. Gill. Ent. Am. 6:24

Dryophanta papula Bass., many sharp points on upper surface of thickened portions; scarlet oak. Gill. Psyche, 5:187

Dryophanta pedunculata Bass., stemmed, ovate, curved; scarlet oak. Am. Ent. Soc. Trans. $17: 72$

\section{SCARLET OAK}

\section{Ament gall}

Neuroterus pallidus Bass., clustered, woody colored galls. Am. Ent. Soc. Trans. I $7: 88$

\section{Leaf galls}

Andricus pusulatoides Bass., blisterlike, apical, diameter $1 / 3$ by ${ }_{5}^{1}$ in. Am. Ent. Soc. Trans. I $7: 74$

Andcicus saccularius Bass, pouch galls on underside, diameter $3 / 16 \mathrm{in}$. Am. Ent. Soc. Trans. $17: 76$

\section{('11ESTNUT OAK}

Twig galls

Neuroterus rileyi Bass., irregular swellings on twig. Am. Ent. 3:153

\section{SWAMP CHESTNUT OAK}

\section{Leaf gall}

Andricus papillatus O. S., rounded, ${ }^{1} / 6$ in., with reddish aureole. Ent. Soc. Phila. l'roc. $1: 64$

\section{w11.Low O.sk \\ Twig gall}

Amphibolips phellos O. S., rounded swellings, 1/3 in. Ent. Soc. Phila. Proc. 1:70

-

guerces moNTaxi

\section{Leaf gall}

Biorhiza hirta Bass, round, on veins, 1/ in. Ent. Soc. Phila. Proc. 3:687 
IBL.MCK $10 . \mathrm{MK}$

Twig gall

Andricus scitula Bass., subconical, $3 / 4$ to $1 / 2 / 2$ in. Ent. Soc. Phila. Proc. $3: 683$

\section{Leaf galls}

Callirhytis tumifica O. S., midrib swellings. Ent. Soc. Phila. Proc. 4:356

Neuroterus favosus Bass., flattened polythalamous, If to I in. Am. Ent. Soc. Trans. $17: 87$

Neuroterus pigra Bass., irregular midrib swellings; beneath. Can. Ent. 13:105

HLACK JAK W.RK GALLS

Andricus operator O. S., round, woolly, seedlike grains within. Ent. Soc. Phila. P'roc. $1: 256$

Andricus nigrae O. S., elongate midrib swellings. Ent. Soc. Phila. Proc. i : 66

\section{$130120.1 \mathrm{~K}$}

Leaf galls

Neuroterus flavipes Gill., hard, woody, midrib swelling, I I/t in. Gill. Ent. Am. 6:2 I

Neuroterus vernus Gill,, enlarged petioles or swollen catkins. Gill. Ent. Am. 6:22

Neuroterus nigrum Gill, clustered, pimplelike, I/12 in. Psyche, $5: 218$

Philonix villosus Gill., globular; underside of midrib, 5/16 in. Psyche, 5:2 I 8

Philonix macrocarpae Bass., oval, faceted; lateral veins beneath. Am. Ent. Soc. Trans. $17: 84$

Eriophyes querci Garm., green, yellowish gall, I', io to I/5 in. Pack. p. 213

\section{SCRV1B OAK \\ Twig galls}

Andricus similis Bass., clarate, apical. Ent. Soc. Phila. Proc. 3:685

Andricus ventricosus Bass., truncate, cone-shaped, $1 / 2$ to $5 / 8$ in. Ent. Soc. Phila. Proc. $3: 68$ I

Cynips rugosa Bass., round, sessile galls, 1/2 to $3 \frac{3}{4}$ in. diameter. Can. Ent. 13:100

\section{Ament gall}

Dryophanta clarkei Bass., black, polythalamous, .08 in. Am. Ent. Soc. Trans. 17 : 79

\section{Bud galls}

Andricus patiens Bass. Am. Ent. Soc. Trans. 26:312

Holcaspis fasciata Bass., apical clusters, mottled or banded. Am. Ent. Soc. Trans. 26: 328

Amphibolips verna Bass. Am. Ent. Soc. Trans. 26:321

Neuroterus affinis Bass., round, thin, partly hidden by bud scales. Can. Ent. 13:103

Neuroterus corrugis Bass. Can. Ent. 13:109

Dryophanta gemula Bass., early acornlike, J/10 in. Can. Ent. 13:104

Dryophanta parvula Bass. Am. Ent. Soc. Trans. 26:326

\section{Leaf gall}

Andricus ostensackenii Bass., round, greenish yellow. Ent. Soc. Phila. Proc. 2:327 


\section{CIIIXUEAPIX OAK}

Bud galls

Cynips frondosa Bass., Conical, ${ }^{8}$ in. Ent. Soc. Phila. Proc. $3: 685$

Andricus pulchellus Bass. Am. Ent. Soc. Trans. $26: 314$

Dryophanta corrugis Bass. Am. Ent. Soc. Trans. $17: 71$

\section{TIRKLY NCRTB OAK GALL}

Andricus quercifoliae Ashm., globular, succulent; loose kernel. An. Ent. Soc. Trans. 12:299

\section{PIN OAK \\ Leaf gall}

Andricus palustris O. S., globular, hollow, I/3 in. Ent. Soc. Phila. Proc. 1:62

\section{GIEST FLIE-}

Synergus albipes IValsh. Ent. Soc. Phila. Proc. 2: 496

Synergus campanula $O$. S., in gall of $1 \mathrm{Holc}$ as pis $\mathrm{g} l$ obulus Fitch. Ent. Soc. Phila. Proc. $4: 376$

Synergus dimorphus O. S. Ent. Soc. Phila. Proc. $4: 376$

Synergus laeviventris O. S., in oak apple. Ent. Soc. Phila. P'roc. 1:57

Synergus lignicolor O.S. Ent. Soc. Phila. Proc. 1:252

Synergus mendax Valsh, bred from galls of Andricus podagrae Walsh. Ent. Soc. Phila. Proc. 2:498

Synergus oneratus Harr, bred from gall of Andricus globulus. Ent. Soc. Phila. Proc. 2: 498

Synergus rhoditiformis Walsh, in galls of Andricus podagrae. Ent. Soc. Phila. Proc. 2: 499

Ceroptres arbos Fitcl, C. tuber Fitch, guests of Andricus clavula Bass. Nox. Ins. N. Y. $5: 29$

Ceroptres petiolicola O. S., bred from gall of Andricus petiolicola. Ent. Soc. Phila. Proc. 1:67

Ceroptres ficus Fitch, guest of $\mathrm{Biorhiza}$ forticornis Walsh. Nox. Ins. N. Y. $5: 32$

Ceroptres inermis Walsh, in gall of Cecidomyia pilulae Walsh. Ent. Soc. Phila. Proc. $2: 498$

Ceroptres obtusilobae Ashm. Am. Ent, Soc. Trans. 12:300

\section{IDIRISITEN}

Acraspis pezomachoides O. S. Ent. Soc. Phila. Proc. 1:250

Anacharis subcompressa P'rov. Nat. Can. 12:237

Ibalia anceps Say. Compl. IVr. I : 2 IS

Ibalia maculipennis Hald. Acad. Nat. Sci. Proc. 3:127

Eucoila stigmata Say. Compl. Wr. 2:717

Eucoila impatiens Say. Compl. Wr. 2:717

Eucoila pedata Say. Compl. Wr. 2:717

Eucoila mellipes Say. Compl. Wr. 2:718

Figites impatiens Say. Compl. Wr. $2: 718$

Figites chinquapin Fitch. Nox. Ins. N. Y, 5:40 
Periclistis futilis O. S., in Andricus $\mathrm{f} u \mathrm{t}$ il is gall. Ent. Soc. Phila. Proc. $1: 64$ Onychia armatus Say. Compl. Wr. 2:716

Onychia quinquelineata Say. Compl. Wr. 2:716

Aegilips obtusilobae O. S., from globular galls, 1/2 in. Ent. Soc. Phila. Proc, 1:68

\section{HILUIR HORERS}

Agrilus egenus Gory. Pack. p. 291. Locust

Anthaxia aeneogaster Lap. Hlopk. W. Va. Agric. Exp. Sta. Bul. 32:182

Anthaxia viriditrons Gory, $t$ wig borer, ${ }_{5}$ in. Pack. p. 292 . Elm

Acmaeodera culta Web. Hopk. IV. Via. Agric. Exp. Sta. Bul. 32:183

Pachyscelus purpureus Say. Ent. Am. 5:32

Hadrobregmus errans Melsh. Am. Ent. Soc. Trans. 22:365

Trichodesma klagesi Fall. Am. Ent. Soc. Trans. $31: 173$

Heterachthes quadrimaculatus Newm. Pack. p. 293

Phyton pallidum Say. Ent. Soc. Wash. Proc. 3:97. Redbud

Molorchus bimaculatus Say. Pack. p. 293. Walnut, ash, maple, shad bush, dogwood

Stenosphenus notatus Oliv. Can. Ent. 20:66

Neociytus scutellaris Oliv. Am. Ent. Soc. Trans. 22:368. Elm, grape

Neoclytus luscus Lec. N. Y. Ent. Soc. Jour. $4: 77$

Clytanthus ruricola Oliv. N. Y. Ent. Soc. Jour. $4: 77$

Clytanthus albofasciatus Lap. Pack. p. 292. Grape

Tillomorpha geminata Hald. Pack. p. 294. White oak

Centrodera picta Hald. Ins. N. J. p. 291

Goes oculata Lec., oak. N. I. Ent. Soc. Jour. $4: 78$

Acanthoderes quadrigibbus Say, oak, beech, hackberry, box elder. Ent. Soc, Wash. Proc. 3:99

Leptostylus biustus Lec., orange. N. Y. Ent. Soc. Jour. 4:79

Liopus alpha Say var. cinereus Lec. Pack. p. 291. Locust

Liopus crassuius Lec. Am. Ent. Soc. Trans. 23:122

Lepturges facetus Say. Am. Ent. Soc. Trans. 22:369. Juniper

Ecyrus dasycerus Say. Pack. p. 292. Locust, tulip, redbud

Eupogonius vestitus Say. Pack. p. 292. Walnut, chestnut, dogwood

Dysphaga tenuipes Hald. Pack. p. 291. Oak, walnut, redbud

Auletes ater Lec. Am. Ent. Soc. Trans. 22:375. Sweet fern

Otidocephalus chevrolatii IIorn., elm, hazel, srape. N. Y. Ent. Soc. Jour. $1: 42$

Otidocephalus myrmex Herbst., hazel, grape. N. Y. Ent. Soc. Jour. I : 42

Anthonomus suturalis Lec. Ent. Soc. Ont. 1fth Rep't, p. 50

Conotrachelus elegans Say. N. Y. Ent. Soc. Jour. 1:S2

Conotrachelus nenuphar Herbst. Pack.

Cryptorhynchus fallax Lec. N. Y. Ent. Soc. Jour. I $: \$_{3}$

Cryptorhynchus obliquus Say. N. Y. Ent. Soc. Jour. $1: 8_{3}$

Acoptus suturalis Lec. Pack. p. 297. Beech, hornbeam

Hypothenemus crudiae Panz., oak. ins. N. J. p. 362

Hypothenemus dissimilis Zimm. Hopk. IV. Va. Agric. Exp. Sta. Bul. 31 : 133

Xylocleptes decipiens Lec. Ent. Soc. Wash. Proc. 2: 394

Micracis suturalis Lec., oak, black walnut, prickly ash, white ash, black locust, sassafras, willow, redbud. Ent. Soc. Wash. Proc. 2: 394

Micracis aculeata Lec. Can. Ent. 23:65 
Thysanoes fimbricornis Lec. Pack. p. 293

Acrobasis caryae Grote, greenish, brown spotted caterpillar, sparse white hairs, 1/2 in.. in 5 wigs. Papilio, $1: 13$

Acrobasis angusella Grote, in leaf stem. Am. Ent. Soc. Trans. 17: 121

\section{H1KOR: \\ Leaf feeders}

Odontophyes aviingrata Dyar, solitary, footless, dung-mimicking larva; butternut. Psyche, 8: 21 2

Isodyctium caryicolum Dyar, light green larva, dorsal line darker. N. Y. Ent. Soc. Jour. 6: I 35

Macrophya externa Say, sordid, pinkish, waxen larva with darker dorsal band. Dyar. Can, Ent. 30: 173

Acordulecera dorsalis Say, colorless larva, head pale or black; vak. Dyar. N. Y. Ent. Soc. Jour. 5: 199

Dichelonycha elongata Fabr., oak, beech, elm, hazel. Ent. Soc. Ont. Ifth Rep't. p. 43. IVillow, birch, alder, pine

Lachnosterna hirticula Knoch., bur oak. Ky. Agr. Exp. Sta. Bul. 120, p. 76

Bassareus mammifer Newm., hazel. lns. N. J. p. 301

Tymnes violaceus Horn. Am. E.nt. Soc. Trans. 22:370

Phyllotreta picta Say. Ins. N. J. p: 316

Eugnamptus collaris Fabr. N. Y. Ent. Soc. Jour. 1:36. Scrub oak, butternut

Rhynchites aeratus Say. Can. Ent. 23:21

\section{Caterpillars}

Apatela innotata Guen., gray, brown, yellow and black spotted. Sm. \& Dyar. U. S. Nat. Mus. Proc. $21: 74$

Apatela funeralis Gr. \& Rob., sooty black, white patches, $1_{3,5} \mathrm{in}$. ; elm, apple, birch. Sm. \& Dyar. U. S. Nat. Mlus. 1'roc. 2I:10?

Baileya dormitans Guen. Can. Ent. 23:35

Prodenia commelinae Abb. \& Sm. Pack.

Mamestra detracta Walk, pale yellowish, marbled, red brown; oik bud feeder. Dyar. Ent. Soc. Wash. Proc. 4:319

Catocala angusi Grote. Pack. p. 305

Catocala judith Streck, greenish black, lighter reticulations, $13{ }_{+}^{3}$ in. Dodge. Can. Ent. $33: 22.4$

Catocala flebilis Grote, gray, green tinted, black dotted, white marked, $21 / 2$ in. Kellicott. Papilio, I : I.4I

Catocala habilis Grote, dark or light striped, whitish ventrally, 2 in. Kellicott. Ent. Am. 2:46. IValnut

Catocala insolabilis Guen. Pack. p. 304

Catocala obscura Streck, dark gray, black marked, 2 in. Pack. p. 305

Catocala palaeogama Guen., reddish, dark striped, 23/4 in. French. Can. Ent. 20: 108. Blacie wahnut, chestnut

Catocala robinsonii Grote. Pack. p. 303

Catocala serena Edw. Pack. p. 303

Heterocampa subrotata Haw., green, black and brown marked, $21 / 2$ in.; maple, witch-hazel, dogwood, birch. Dyar. Ent. Ans. 6:209

Schizura leptinoides Grote, pale brown, darker mottled, tuberculate, $2 \frac{1}{2} \mathrm{in}$. Dyar. Ent. Am. 6:230. Black walnut 
Olene leucophaea Abb. \& Sm., black headed, whitish, hairy; black hair tufts and pencils; oak. Dyar. Psyche, 7:135. Persimmon

Cochlidion y-inversa Pack, greenish slug caterpillar. Dyar \& Morton. N. Y. Ent. Soc. Jour. 3 : I 5 I -57 . Blue beech

Tortricidia flexuosa Grote, yellowish and green slug caterpillar, dorsal mark variable, $2 / 5$ in. ; oak, chestnut, hazel, wild cherry. Dyar. N. T. Ent. Soc. Jour. $6: 94$

Exartema versicoloranum Clem. Pack. p. 313

Epagoge caryae Robs. Am. Ent. Soc. Trans. 10:21

Archips infumatana Zell. Am. Ent. Soc. Trans. 10:11

Eulia juglandana Fern. Am. Ent. Soc. Trans. 10: 15. IValnut

Ypsolophus caryaefoliellus Chamb., red headed, green, white striped, $3 / 4$ in. Can. Ent. 4:224

\section{Leaf miners}

Coptodisca lucifluella Clem., brown headed, green, black spotted. Tineina N. A. p. 143

Gelechia caryaevorella Pack. Pack. p. 3\%14

Coleophora caryaefoliella Clem., dark brown, cylindric cąe bearer; logwood. Tineina N. A. p. 166

Nepticula caryaefoliella Clem., pale green with brownish head. Pack. p. 315

Lithocolletes caryaefoliella Clem., black or brownish. Pack. p. 334. Black walnut, butternut

Lithocolletes celtifoliella Chamb., yellowish larva; tent mine on under surface. Can. Ent. 3:129

\section{Leaf sucking insects}

Nezara pennsylvanica De Gr., green, black marked bug, 3/5 in. Pack. p. 326

Cyrtolobus vau Say, butternut. Ent. Soc. Ont. 1 $3^{\text {th }}$ Rep't, p. 77

- Telamona fasciata Fitch, yellowish, black marked tree hopper, $4 / 5$ in. Pack. p. 325

Ceresa brevicornis Fitch, yellowish, brown marked, horned tree hopper, $1 / 3$ in. Pack. p. 325

Microcentrus caryae Fitch, dull brown, yellowish tree hopper, 1/3 in. Pack. p. 324

o Cixius coloepium Fitch, black tree hopper, wings brown, banded, $1 / 5$ in. l'ack. p. 326

O Cixius cinctifrons Fitch, white, brown marked tree hopper, $1 / 5$ in. Pack. p. 325

L Diedrocephala coccinea Forst., yellow leaf hopper, wings green, red striped, $1 / 3$ in. Pack. p. 324

Otiocerus amyotii Fitch, yellow, brown marked tree hopper, 1/4 in. Pack. p. 326

Phlepsius irroratus Say, white, black marked leaf hopper, $1 / 4$ in. Pack. P. 324

Monellia caryella Fitch, pale yellow. Pack. p. 323

Lachnus caryae Harr., black, bluish white, 1/4 in. Pack. p. 299. IVainut

Schizoneura caryae Fitch, cottony aphids, $1 / 8$ in. Pack. p. 298 . Black walnut

Callipterus caryae Mon. Ins. N. J. p. IO4. Black walnut

\section{Scale insects}

Chionaspis caryae Cooley. Fern. Coccidae, P. 214

Aspidiotus uvae Comst., grapevine. Fern. Coccidae, p. 280

Eulecanium pyri Schr., white pine. Fern. Coccidae, p. 194

Eulecanium caryarum Ckll. Can. Ent. 30:293 


\section{Galls}

Cecidomyia cynipsea O. S., round, hard, midrib gall, 1, in. Diptera N. A. 1: 193

Cecidomyia sanguinolenta O. S., conical, red, .15 in. high. Diptera N. A. 1:192

Cecidomyia cossae Shim. Cat. N. A. Diptera. p. 159

Cecidomyia nucicola O. S., larva in deformed husks. Am. Ent. Soc. Trans. $3: 53$

Cecidomyia caryae O. S., subglobular, seedlike, nippled, .05 to .10 in. Diptera

N. A. I : I9I

Cecidomyia glutinosa O. S., larvae beneath leaves, no gall. Diptera N. A. I : 993

Phylloxera conica Shim., depressed leaf gall. Pack. p. 323

Phylloxera caryaevenae Fitch, keellike plates in leaf veins. Pack. p. 322

Phylloxera caryae-semen Walsh, minute, subglobular galls. Pack. p. 322

Phylloxera caryae-ren Riley, reniform galls on petiole. Pack. p. 323

Phylloxera caryae-septum Shim. var. perforans Perg., single galls close to midrib.

Perg. Davenport Acad. Sci. Proc. 9:193

Phylloxera caryae-fallax Walsh, conical, crowded on upper surface. Pack, p. 323

Phylloxera caryae-globuli IValsh, hemispheric, on upper surface, I/t in. Pack. p. 322

Phylloxera caryae-gummosa Riley, stemmed, globular galls. Pack. p. 323

Phylloxera caryae-avellana Riley, yellowish or greenish, pink pubescent galls. Perg. Davenport Acad. Sci. Proc. 9:228

Phylloxera caryae-foliae Fitch. Davenport Acad. Sci. Proc. 9:194

Phylloxera deplanata Perg., reddish or greenish yellow, conical below. Davenport Acad. Sci. Proc. 9:205

Phylloxera depressa Shim.. depressed, fringed leaf gall. Pack. p. 323

Phylloxera forcata Shim., minute, seedlike gall. Pack. p. 322

Phylloxera foveola Perg., red tinted, yellowish green, thin walled gall. Davenport Acad. Sci. Proc. 9: 200

Phylloxera foveata Shim., resembles preceding. Davenport Acad. Sci. Proc. 9:209

Phylloxera globosum Shim., greenish, subglobose galls; under surface. Davenport Acad. Sci. Proc. 9:236b

Phylloxera intermedia Perg., intergrade of $\mathrm{c}-\mathrm{sep} \mathrm{t} u \mathrm{~m}$ and $\mathrm{p}$ ict a. Davenport Acad. Sci. Proc. 9:199

Phylloxera picta Perg., smaller than c-septum; flattened. Davenport Acad. Sci. Proc. 9: 197

Phylloxera pilosula Perg., pilose, light green, flattened above; convex, and with nipple below. Davenport Acad. Sci. Proc. 9:203

Phylloxera perniciosa Perg., conical galls; both surfaces. Davenport Acad. Sci. Proc. 9:25I

Phylloxera rimosalis Perg, large yellowish gall; terminal leaves. Davenport Acad. Sci, Proc. 9:217

Phylloxera spinosa Shim., irregular, spinose galls on petiole. Pack. p. 322

Phylloxera spinuloida Perg., more globular than those of P. caryaccaulis Fitch, with numerous irregular, radiating, low ridges on petiole and midrib. Davenport Acad. Sci. Proc. 9: 247

Phylloxera subelliptica Shim., elongate, nutlike petiole galls. Perg. Davenport Acad. Sci. Proc. 9:250

Phylloxera symmetrica Perg., flattened, greenish; on under surface. Davenport Acad. Sci. Proc. 9:230 
STCAMORE

\section{Leaf feeders}

Halisidota harrisii Walsh, yellow, haired larva with orange and white hair pencils Dyar. Psyche, 6:162

Misogada unicolor Pack, green, yellow lined, red marked, humped larva. Pack. Monogr. Bombycine Moths, p. 254 . Maple.

Ancylis platanana Clem. Am. Ent. Soc. Trans. 10: 50

Nepticula platanella Clem., pale green; blotched mine. l'ack. p. $6+7$

Nepticula clemensella Chamb. Pack.

Nepticula maximella Chamb. Pack.

Gelechia albisparsella Chamb. Pack.

Lachnus platanicola Riley. Pack.

Corythuca ciliata Say. Pack. Willow

\section{BETTONBENH \\ Leaf feeders}

Siobla excavata Nort., leaden black sawfly larva. Dyar. N. Y. Ent. Soc. Jour. $5: 190$

Centrinus lineicollis Lec. N. Y. Ent. Soc. Jour. $1: 85$

Ampelophaga versicolor Harr., yellowish green or green, white lined, horned larva, $2 \frac{1 / 2}{2}$ to $3 \mathrm{in}$. Hulst. Can. Ent. 10:64

\section{WILNET \\ Leaf feeders}

Bassareus mammifer Newm,, hickory. Am. Ent. Soc. Trans. 22:37o. Locust

Anthonomus profundus Lec. Am. Ent. Soc. Trans, 22:376. Thorn

Catocala neogama Sm. \& Abb., wood-brown, striped larva. Dodge. Can. Ent. $33: 299$

Catocala piatrix Grote, pale gray larva, 27/ıo in. Dodge. Can. Ent. $33: 299$. Hickory, persimmon

Mineola juglandis Le B., dark green case bearer in leaflets. Pack. p. 3I1. Hlickory

\section{Scale insects}

Eulecanium pruinosum Coq., ash, birch, laurel. Fern. Coccidae, p. 193

Aspidiotus juglans-regiae Comst., maple, locust, plum, cherry. Fern. Coccidae, p. 265

Eulecanium juglandis Bouclié, plum. Fern. Coccidae, p. 189

Aulacaspis pentagona Targ. Fern. Coccidae, p. 234

\section{BLACK WALNT}

\section{Insects}

Acrobasis demotella Grote, twig borer. Am. Ent. Soc. Trans, 17:122

Allorhina nitida Linn., greenish, stout beetle in bark. Pack. p. 329

Magdalis inconspicua Horn. Hopk. W. Va. Agric. Exp. Sta. Bul. 32:205 


\section{Leaf feeders}

Attelabus analis Ill., black, red marked, leaf-rolling weevil, If in. Pack. p. 335. Sumac

Cressonia juglandis Abb. \& Sm., bluish green, horned caterpillar. Pack. p. 330

Catocala subnata Grote. J'ack. p. 333

Allotria elonympha Hübn., gray white with rose tints. Pack. p. 331. Tupelo

Bomolocha madefactalis Guen., slender, green, white, subdorsal striped larva. Dyar. Ent. Soc. Wash. Proc. 4:329

Aplodes bistriaria Hübn., pale brown spanworm; two thoracic tubercles; four large flaps on median rings; one on end of body. Pack. Monogr. Geometrid Moths. p. 388

Coptodisca juglandiella Chamb., leaf miner. Pack. p. 335

Gracilaria juglandiella Chamb., mines under surface, then lives in curled part. Can. Ent. 4:29

Gracilariz blandella Clem., black larva in serpentine mine on upper surface. Can. Ent. $5: 14$

Nepticula juglandifoliella Clem., pale green dipteroid larva. Pack. p. 334

\section{Gall mite}

Acarus caulis Walsh, red or brown petiole or leaf vein gall. Ins. Galls of Ind. p. 859

\section{BI TTELITT}

\section{Pests}

Eriocampa juglandis Fitch, woolly, greenish or gray larva. Dyar. N. Y. Ent. Soc. Jour. 5:200

Eugnamptus angustatus Hbst. Pack.

Diacrisia virginica liabr., stout, hairy, yellowish larva. Pack. p. 340. Oak

Carynota mera Say, greenish gray, subconical tree hopper, 1/3 in. Pack. P. 3,42

Corythuca arcuata Say, small lace bug, r's in. Pack. p. $3+2$

Eulecanium juglandifex Fitch, hemispheric, brown or black scale, ${ }_{5}$ in. Pack. p. 338

\section{CHENTNTT \\ Borers}

Agrilus vittaticollis Rand, chokecherry, thorn, shadbush, mountain laurel. Ent. Am. 5:32

Leptostylus collaris Hald. Ent. Soc. Wash. Proc. 3:100

Distenia undata Oliv., hickory, hombeam. N. Y. Ent. Soc. Jour. + 77

Liopus variegatus 11ald. N. Y. Ent. Soc. Jour. 4:79. Hackberry, maple, box elder, locust

Leptura cordifera Oliv. Psyche, 4:204

Cryptorhynchus obtentus Hbst., hickory, maple. U. S. Div. Ent. Bul. 7, n. s. p. 71

Magdalis salicis Horn. N. Y. Ent. Soc. Jour. 1:43. Butternut

Dryocoetes granicollis Lec. Ins. N. J. p. $3^{6} 3$

Platypus compositus Say, black oak, stgar maple, basswood, magnolia, red elm, beech, wild cherry. IV. Va. Agric. Exp. Sta. Bul. 31:127

Platypus quadridentatus Oliv., pin holes: oak. IV. Va. Agric. Exp. Sta. Bul. 31: 127

Xylaborus pubescens Zimm., white oak, jack oak, black oak, buckeye, magnolia, basswood, honey-locust. IV. Va. Agric. Exp. Sta. Bul. $31: 137$ 
Silvanus bidentatus Fabr., light brown, flat, 1/10 in., under dead bark. Pack. p. 344 . Elm

Hydnocera unifasciata Say. Ent. Am. 6:155

Stenopsis argenteomaculatus Harr., large, naked caterpillar. Pack. p. 346. Oak, maple, willow, poplar, alder

\section{Leaf feeders}

Cercopeus chrysorhoeus Say. Ins. N. J. p. 341

Plocamus hispidulus Lec. U. S. Div. Ent. Bul. 7, n. S. p. 72. Locust

Apatela lithospila Grote, green, whitish frosted larva; oak, hickory. Sm. \& Dyar. U. S. Nat. Mus. Proc. $21: 98$

Deptalia insularia Guen. U. S. Div. Ent. Bul. 32:55

Euchlaena obtusaria IIübn., slate-colored, marbled with livid, spanworm, $15 / 8$ in. Pack. p. 347

Tetracis crocallata Guen., brown, black marked spanworm, I in. Pack. p. 347. Sumac, spicebush

Abbotana clemataria Abb. \& Sm., brown mottled, tuberculate spanworm, with lateral fingerlike processes on third segment. Dyar. Psyche, 9:142. Elm, sassafras, willow

Eurycyttarus confederata Gr. \& Rob. Pack.

Sisyrosea textula H.-S., green, yellow lined, red marked slug caterpillar, $2 / 3$ in. ; oak, hickory, beech, hop-hornbeam, bayberry, elm, maple, linden, plum, cherry. Dyar. N. Y. Ent. Soc. Jour. 4:185

\section{Leaf miners}

Nepticula castaneaefoliella Chamb., linear, crooked mine; upper surface. Cinn. Quar. Jour. Sci. 2:117

Nepticula latifasciella Chamb. Pack. p. 349

Bucculatrix trifasciella Clem. Pack. p. 349

Lithocolletes castaneaeella Chamb., blister mine on upper surface; oak. Cinn. Quar. Jour. Sci. 2: 104

Tischeria castaneaeella Chamb., larger than T. z.elle riella. Cinn. Quar. Jour. Sci. 2:111. Oak

Tischeria tinctoriella Chamb., white blotch mine; with short zigzag purple line, black oak. Cinn. Quar. Jour. Sci. 2: 108

\section{Sucking insects}

Atymna inornata Say, triangular, light green, yellowish tree hopper, $1 / 4$ in. Pack. p. 350

Atymna castanea Fitch, triangular. black, green marked tree hopper, 1/4 in. Pack. p. 350

Callipterus castanea Fitch, yellowish, black marked aphid, Io in. Pack. p. 350

\section{BEECH}

\section{Borers}

Anamorphus pusillus Zimm.. on beech fungi. Cinn. Soc. Nat. Hist. Jour. 20:251

Tenebrioides corticalis Mels. Ent. Soc. Ont. 27 th Rep't, p. 70

Rhizophagus dimidiatus Mann., under dead bark

Bostrichus bicornts Web., elm, apple. IV. Va. Agric. Exp. Sta. Bul. 32:189

Chrysobothris sexsignata Say, birch. U.S. Div. Ent. Bul. 7, n. s. p. 7 r. Pine 
Eucrada humeralis Mels. Ent. Soc. Ont. 27th Rep't, p. 71

Corymbites cruciatus Linn. Ent. Soc. Ont. 27th Rep't, p. 70

Elater discoideus Fabr. Ins. N. J. p. 248

Perothops mucida Gyll. Ins. N. J. p. 252

Chalcophora campestris Say, sycamore, maple, tulip. Ins. N. J. p. 253

Platycerus quercus WVeb. Ent. Soc. Ont. 27 th Rep't, p. 72

Platycerus depressus Lec. Ent. Soc. Ont. 27th Rep't, p. 72

Dryobius sexfasciatus Say. Pack.

Cyrtophorus verrucosus Oliv. N. Y. Ent. Soc. Jour. 4:77. Oak, linden, wild cherry

Hoplosia nubila Lec, basswood twigs. Am. Ent. Soc. Trans. 23: 1 34

Toxotus schaumii Lec. Ent. Soc. Ont. 27th Rep't, p. 73

Lepturges signatus Lec., red bud. Ent. Soc. Wash. Proc. 3:101. Sumac

Xylotrechus quadrimaculatus 11 ald. Ent. Soc. Ont. 27th Rep't, p. 73. Black alder

Pelecotoma flavipes Mels. Ent. Soc. Ont. 27th Rep't, p. 74

Phloeophagus minor Ilorn. Pack.

Scolytus fagi Walsh. l'ack. Hackberry

Xyleborus obesus Lec. Pack.

Euchaetes echidna Lec. N. Y. Ent. Soc. Jour. 1: 85

Choragus sayi Lec. N. Y. Ent. Soc. Jour. 1:88

\section{Leaf feeders}

Hyperitis amicaria 11.-S., brownish, white spotted larva, 11/8 in. U. S. Div. Ent. Bul. 13:28. Oak, beech, hornbeam, alder

Isochaetes beutenmulleri Iy. Ed., pale green larva; oak. Dyar. N. Y. Ent. Soc. Jour. $7: 208$

Exartema fagigemmaeanum Chamb. Am. Ent. Soc. Trans. 10:29

Venusia comptaria WValk. Ent. Am. 3:50. Birch, alder

\section{Sucking insect}

Pemphigus imbricator Fitch, on underside of twigs. Am. Ent. Soc. Trans. 20:301

\section{HOP-HOIENIBEAM}

\section{Leaf feeders}

Pteronus ostryae Marlt., green larva, brown on folds. Dyar. N. Y. Ent. Soc. Jour. $5: 26$

Cecidomyia pudibunda O. S., larvae in red leaf fold. Jiptera N. A. 1:202

Coptodisca ostryaefoliella Clem.. leaf miner. Pack. p. 648

Coleophora ostryae Clem., brown, flattened case; parallel edges. Tineina N. A., p. 167

Nepticula ostryaefoliella Clem., narrow, contorted, frass-lincd mine. Tineina N. A. 1). 172

Nepticula virginiella Clem., slender, long mine; scattered frass particles. Tineina N. A. p. 172

Lithocolletes ostryaefoliella Clem., marginal mine becoming corrugated. Pack. p. 6.49

Lithocolletes tritaeniella Chamb. l'ack. 
Lithocolletes obscuricostella Clem. Tineina N. A. p. 71

Chrysopeleia ostryaeella Chamb. Pack.

\section{HOLXIBEAY (OR IKONWOOH)}

\section{Leaf feeders}

Pteronus carpini Marlt., dull green, yellow blotched larva. Dyar. N. Y. Ent. Soc. Jour. 6:121

Psylla carpini Fitch. Pack.

\section{HOP THEE \\ Leaf miner}

Nepticula pteliaeella Chamb., blotch mine in very long, tortuous, linear mine. Psyche, 3: 137

\section{HAZEI.}

\section{Borers}

Agrilus arcuatus Say var. coryli Horn. Am. Ent. Soc. Trans, 22: 364

Dichelonycha subvittata Lec. Am. Ent. Soc. Trans, 27:282

\section{Leaf feeders}

Apatela falcula Grote, dark brown, green marked, spined larva, $1 \frac{1 / 4}{4}$ in. Pack. p. 637

Exartema permundanum Clem., black headed, greenish larva, $2 / 3$ in. Papilio, $3: 102$ Exartema corylanum Fern. Pack.

Eulia ministrana Linn., green larva. Am. Ent. Soc. Trans, 10:15

Lithocolletes corylisella Chamb., blotch mine; upper surface. Pack. p. 641. Hornbeam

Nepticula corylifoliella Clem., long, winding, narrow mine. Pack. p. 639

Coleophora corylifoliella Clem., case irregular, cylindric, compressed, toothed. Tineina N. A. p. 166

Anacampsis tristrigella Wlsm., pale greenish, black marked leaf roller, ${ }^{9} 16$ in. Pack. p. 639

Ypsolophus trinotellus Coq., dark brown, white marked leaf roller, 3t in. Pack. p. 640

Depressaria groteella Rob., green, dark marked leaf roller, 5/8 in. Pack. p. 639

Menesta tortriciformella Clem. Pack.

\section{Affecting nuts \\ Balaninus obtusus Blanch. Pack. \\ WITCH-HAZEL}

\section{Borers}

Hydnocera longicollis Ziegl. Ent. Am. 6:155

Mycetochares nigerrima Casey, under dead bark

\section{Leaf feeders}

Luperodes meraca Say. Ent. Soc. Wash. Proc. 2:264

Scopelosoma moffatiana Grote, white, yellow banded larva, $1 \frac{1}{2} \mathrm{in}$. Parsall. Ent. Am. 4:59 
Celama triquetrana Fitch, pale yellow larva, darker dorsally, $1 / 2$ in. Dyar. Insect Life, $3: 62$

Exartema footianum Fern. Am. Ent. Soc. Trans. 10:31

Olethreıtes niveiguttana Grote, sassafras. Am. Ent. Soc. Trans. 10:36

Gelechia hamameliella Clem., pale green leaf roller in tube. Pack. p. 668

Gracilaria alchimiella Scop., pale green leaf roller in cones. Pack. p. 668. Maple

\section{LIQUIDAMBAR}

\section{Leaf feeders}

Paectes delineata Guen., yellowish green, yellow marked, 7/8 in. Dyar. Can. Ent. $31: 27$

Paectes pygmaea Hübn., yellowish green, yellow marked, $2 / 3$ in. Edw.-Elliott. Papilio, 3:1 35

\section{FLM}

\section{Borers}

Anthaxia viridicornis Say. Pack. p. 229. Hickory, willow

Eupogonius subarmatus Lec. Am. Ent. Soc. Trans. 22:369

Leptura emarginata Fabr., stippery elm. Psyche, 4:204

Trichodesma gibbosa Say. Am. Ent. Soc. Trans. 22:365

\section{Leaf feeders}

Monocesta coryli Say., hazel, red elm. Ent. Soc. Ont. 13th Rep't, p. 59

Cotalpa lanigera Linn., oak, hickory, poplar. Pack. p. 274

Haltica chalybea Ill. Pack. p. 237

Cryptocephalus quadruplex Newm. Ins. N. J. p. 302

Plocetes ulmi Lec. N. Y. Ent. Soc. Jour. 1 : 8I

\section{Caterpillars}

Deilephila lineata Fabr., greenish, black and red, horned, 3 in. Pack. p. 27 I. Apple, plum, rose

Smerinthus jamaicensis Dru., bluish green, yellow lined, horned, $2^{1 / 5} \mathrm{in.}$; oak, hazel, horn beam, ash, apple, plum, cherry, willow, poplar, birch. Beut. N. Y. Ent. Soc. Jour. $9: 89$

Paonias excaecatus Abb. \& Sm., green, yellow marked, horned, 2.2 I in.; oak, hazel, ash, linden, apple, plum, cherry, willow, poplar, birch. Beut. Am. Mus. Nat. Hist. Bul. $7: 314$

Utetheisa belia Linn., deep buff, black marked, I 1/4 in. Pack. p. 257

Apatela grisea Walk., green, brownish, humped, $3 / 5$ in. I'ack. p. 272 . Apple, willow

Apatela interrupta Guen., purplish with long, reddish hairs, humped, I in.; oak, apple, birch. Sm. \& Dyar. U. S. Nat. Mus. Proc. 2 r: 79

Apatela morula Grote \& Rob., greenish brown, humped, 2 in. Pack. p. 272. Linden

Apatela vinnula Grote, green, brown tubercles, I in. Sm. \& Dyar. U. S. Nat. Mus. Proc. 21:93

Bomolocha abalienalis Walk, green, white striped; slippery elm. Dyar. Can. Ent. 23: 157 

Datana contracta Walk., black, yellow striped, 21/t in. Pack. p. 266. Oak,
hickory, chestnut

Nerice bidentata Walk., greenish, irregular, dorsal serrations, I in. Pack. Monogr. Bombycine Moths, p. 171

Heterocampa bilineata Pack., green, white and yellow lined, red marked, $11 / 4$ in. ; beech. Pack. Nonogr. Bombycine Noths, p. 218

Opheroptera boreata Hübn., maple. Ent. Am. 3:49

Olene plagiata Walk. Pack. Linden

Euchoeca albifera W'alk. Ins. N. J. p. 441

Mesoleuca intermediata Guen. Ins. N. J. p. $44^{\mathrm{I}}$

Percnoptilota fluviata Hübn. Ins. N. J. p. 441

Selidosema umbrosarium Guen.. horsechestnut, hemlock. Ins. N. J. p. 447

Episimus argutanus Clem., witch-hazel, black thorn, sumac. Am. Ent. Soc. Trans. 10:45

Ennomos magnarius Guen., dark green, reddish mottled, $4^{1} \frac{1}{3}$ in. : hickory, chestnut, maple, linden. Beut. N. Y. Ent. Soc. Jour. $3: 137$

Ennomos subsignarius Hübn., dull colored, $7 / 8$ in. ; hickory, chestnut, maple, linden. Pack. p. 232

Canarsia ulmiarrosorella Clem., green; on upper surface. Ky. Agric. Exp. Sta. Bul. 84, p. 72

Hulstea undulatella Clem. Am. Ent. Soc. Trans. $17:{ }_{1} 87$

Lithocolletes argentinotella Clem. Ent. Soc. Wash. Proc. 5: 190. Oak

Lithocolletes ulmella Chamb., irregular blotch mine in upper surface. Can. Ent. $3: 149$

Sucking insects, etc.

Typhlocyba tricincta Fitch, pale yellowish, dark banded leaf hopper. Pack. p. 28 I Lachnus ulmi Linn. Pack.

Aspidiotus ulmi John., catalpa. Fern. Coccidae, p. 280

Eulecanium canadense Ckll., white oak, hickory, maple, peach. Fern. Coccidae, p. 182

Eulecanium caryae Fitch, hickory, red cherry, willow. Fern. Coccidae, p. $1 s_{3}$

Eulecanium cockerelli Hunter, oak, walnut, pear, plum, peach, sweet fern. Fern. Coccidae, p. 185

Eriophyes ulmi Garm., small, slender gall, 1/10 in. Pack. p. $28 \mathrm{I}$

\section{HACKBERRY}

Borers

Agrilus fallax Say. WV. Va. Agric. Exp. Sta. Bul. $32: 184$

Urographis triangulifer Hald. Pack. p. 610

Phloeotribus frontalis Oliv. Pack. Mulberry

Scolytus muticus Say. Pack.

Micracis rudis Lec. Pack.

Proteoteras aesculanum Riley. Pack. p. 609. Maple

\section{Leaf feeders \\ Caterpillars}

Chlorippe celtis Bd. \& Lec., green, horns at both ends, I in. Pack. p. 602

Chlorippe clyton Bd. \& Lec., greenish; foliate, cephalic spines, $1 \frac{1}{2}$ in. Pack. p. 604. IVild plum 
Hypatus bachmani Kirt., green, yellow striped, 1 in. Beut. Am. Mus. Nat. Hist. Bul. 5:277

Sphinx drupiferarum Abb. \& Sm., grecn and white, horned, 3.5 in. Beut. Am. Mus. Nat. Hist. Bul. 7:300

Apatela rubricoma Guen., greenish; blackish dorsal bands; $\mathrm{I}^{3} / 5$ in. Sm. \& Dyar. U. S. Nat. Mus. Proc. 21:42

Salebria celtidella Hulst., pale green, striped, $5 / 6$ in.; in leaf fold. Beut. Can. Ent. $22: 17$

Megalopyge opercularis Abb. \& Sm. Pack. p. 609

\section{Leaf galls}

Pachypsylla celtidis-asteriscus Riley, blisterlike gall; upper surface. Pack. p. 618

Pachypsylla celtidis-cucurbita Riley, greenish yellow, pyriform; under surface; $1 / 16$ in. Pack. p. 621

Pachypsylla celtidis-gemma Riley, budlike twig gall. Pack. p. 618

Pachypsylla celtidis-globulus Riley, globular, pyriform; under surface; $1 / 16$ in. Pack. p. 621

Pachypsylla celtidis-pubescens Riley, subglobular, hairy; under surface; $1 / 12$ in. Pack. p. 620

Pachypsylla celtidis-vesiculum Riley, blisterlike; under surface. Pack. p. 6r8

Pachypsylla celtidis-umbilicus Riley, circular, buttonlike; green, woody, $1 / 5$ in. Pack. p. 6 I9

Pachypsylla venusta O. S., subglobular, on petiole. Pack. p. 617

\section{MULBEIRY}

\section{Borers}

Hetoemis cinerea Oliv. N. Y. Ent. Soc. Jour. 4:78. Walnut

Dorcaschema wildii Uhler. N. Y. Ent. Soć. Jour. 4:78. Osage orange

Dorcaschema alternatum Say. N. Y. Ent. Soc. Jour. 4:78. Orange

\section{OSAGE ORANGE}

\section{Insects}

Hormiscus saltator Lec. N. Y. Ent. Soc. Jour. I : 87

Eulecanium maclurarum Ckll. Can. Ent. 30:294

\section{AsH \\ Borers}

Tylonotus bimaculatus Hald. Pack. p. 543. Hickory, black walnut, tulip, birch Gnathotricus asperulus Lec. Pack.

\section{Leaf feeders}

Monophadnus bardus Say, whitish, gray tinged. Dyar. Am. Ent. Soc. Trans. $22: 308$

Allantus annularis Nort., green, dark dorsal line. Osborn. Ent. Soc. Ont. Ijth Rep't, p. 32

Thysanocnemus fraxini Lec. N. Y. Ent. Soc. Jour. I : 1

Psomus politus Csy., common on sprouts. Cinn. Soc. Nat. Hist. Jour. 20:256 
Sphinx chersis Hübn., greenish, yellow marked, horned, $3 \frac{1}{4}$ in. Pack. p. 546. Lilac

Sphinx gordius Syoll., green, carmine striped, $23 / 5$ in.; apple, huckleberry, myrica. Beut. N. Y. Ent. Soc. Jour. 9:87

Chlaenogramma jasminearum Boisd., green, six oblique white stripes, 3 in. Beut. Am. MIus. Nat. Hist. Bul. 7:306

Diacrisia latipennis Stretch, dark brown larva. Dyar. Ent. News, 2:115

Apatelodes angelica Grote, gray, black lined larva; lilac. Pack. Nonogr. Bombycine Moths, p. 103

Coriscium cuculipennellum Hübn., yellowish green miner in leafy cone. Ent. News, 6: 109. Privet

Neoforus petitii Uhler. Pack.

\section{Sucking insects}

Pemphigus fraxinifolii Riley, green and black aphid, $1 / 16$ in. Pack. 5.552

Trionymus americanus Ckll. Fern. Coccidae, p. 96

\section{ILAPLE}

\section{Borers}

Oryssus sayi Westw., black, white marked, wasplike. Pack. p. 383

Oryssus terminalis Newm. Pack. p. 383

Acamptus rigidus Lec., soft maple. N. Y. Ent. Soc. Jour. 4:122

Leptura proxima Say. Can. Ent. 29:192

Pyrochroa femoralis Lec. Ent. Soc. Ont. 17th Rep't, p. 32

Enchodes sericea Hald. Ent. Soc. Ont. I7th Rep't, p. 32

\section{Leaf feeders}

Platycerus quercus Web., bud eater. Pack. p. 392

\section{Caterpillars}

Cyaniris ladon Cram., green and brown. French. Butt. East. U. S. p. 29I. Wild cherry, dogwood, viburnum

Philosamia cynthia Drury, green, blue and yellow tubercled; $21 / 2$ in.: general feeder. Beut. Ent. Am. 6:216

Apatela retardata Walk., whitish, regd banded. Sm. \& Dyar. U. S. Nat. Mus. Proc. $21: 145$

Noctua c-nigrum Linn. Pack.

Morrisonia confusa Hübn., white, crimson spotted; oak, hickory, apple, willow, birch. Dyar. Insect Life, $3: 63$

Bomolocha baltimoralis Guen., pale green, 7/8 in. Pack. p. 407

Heterocampa biundata Walk., green, brown marked, 1 1/2 in. ; hickory, beech, witchhazel, cherry, dogwood, willow, birch. Pack. Monogr. Bombycine Moths, p. 235

Heterocampa guttivitta Walk., green, yellow and purple marked, 11/2 in.; oak, chestnut, beech, apple, viburnum. Pack. Monogr. Bombycine Moths, p. 230

Tolype velleda Stoll., bluish gray, white lined, $21 / 2$ in., lateral haired tufts, $21 / 2$ in.; oak, elm, cherry, lilac. Pack. p. 165

Heterophleps triguttaria H.-S., bluish green, light lined spanworm. Pack. Monogr. Geometrid Moths, p. I94 
Psysostegania pustularia Guen.. bluish green, light striped spanworm, 1/2 in. Harrington. Ent. Soc. Ont. 17th Rep't, p. 27

Lycia cognataria Guen., brown, black specked spanworm, $1_{12}^{1}$ in. Pack. p. 638. Elm, hazel, honey-locust, willow, larch

Eutrapela alciphearia IValk,, brown, gray marked, angulate spanworm. Psyche, S: 395

Eutrapela kentaria Grote, oak, beech, linden, birch. Pack. p. 405

Euchlaena serrata Dru., brown mottled, black marked, spined spanworm. Psyche, 9: 130

Phigalia titea Cram., elm, birch. Ent. Am. 3:49

Anagoga pulveraria Linn., gray, black marked, humped spanworm. Pack. p. 638. Beech, hazel, willow

Azelina ancetaria Hübn. Ent. Am. 3:47. Cherry

Sisyrosea inornata Gr. \& Rob., elliptic, flattened, green, red and yellow slug caterpillar; hickory, wild cherry. Dyar. Can. Ent. 21:77

Lithacodes fasciola 11.-S., yellowish green, white slug caterpillar, $1 / 2$ in.; oak, hickory, chestnut, beech, hop-hornbeam, linden, cherry, dogwood, birch. Dyar. N. Y. Ent. Soc. Jour. $5: 1$

Platynota flavedana Clem., sassafras, rose. Am. Ent. Soc. Trans. 10:22

Pandemis lamprosana Rob. Pack. p. 408

Lithocolletes aceriella Clem., brown headed, yellowish miner. Pack. p. 409

Lithocolletes clemensella Chamb., mine and larva closely resembles that of $\mathrm{L}$. lucidicostella Clem. Can. Ent. 11:91

Lithocolletes lucidicostella Clem., brown headed, pale green miner. Pack. p. 410 Incurvaria acerifoliella Fitch, round holes in leaves. Fitch. 2d Rep't, p. 269

\section{Leaf mutilators}

Megachile optiva Cress., leaf cutter. Pack. p. 410

Cecidomyia aceris Shim., larvae in curled, contorted leaves. Am. Ent. Soc. Trans. I: 281

\section{Sucking insects}

Lygus monachus Uhler. Pack. p. 420. Alder

Poecilocapsus goniphorus Say. Pack.

Psylla annulata Fitch. Ent. Soc. Ont. 17th Rep't, p. 33

Pemphigus aceris Mon., aphid on underside of limbs. Can. Ent. 14:16

Aleurodes aceris Forbes, white, chocolate marked, $9 / 10$ in. Pack. p. 422

Aspidiotus comstockii John. Fern. Coccidae, p. 254

Aspidiotus rapax Comst., walnut, willow, birch, cottonwood. Fern. Coccidae, p. 276

Eulecanium cerasifex Fitch, oak, ash, apple, pear, plum, cherry, peach. Fern. Coccidae. p. 184

Chrysomphalus tenebricosus Comst. Fern. Coccidae, p. 294

\section{BOX ELDEK}

Xylina grotei Riley. Pack.

Insects

Gracilaria negundella Chamb., leaf roller. Psyche, $3: 66$

Cecidomyia negundinis Gill., terminal bud gall. Psyche, 5:392 
Chaitophorus negundinis Thom. Ins. N. J. p. 104

Pulvinaria acericola IValsh \& Riley. Pack.

BURNING BUSH

Insect

Aphis rumicis Linn. Am. Ent. Soc. Trans. 20:298. Euonymus

PRICKLY ANI

Insects

Liopus fascicularis Harr. Pack. p. 659

Catapastus conspersus Lec. Cinn. Soc. Nat. Hist.Jour. 20:255

Papilio thoas Linn. Cram., dark brown, white banded caterpillar; 2 in.; orange, poplar, hop tree. Beut. Am. Mus. Nat. Hist. Bul. $5: 215$

\section{HONEY-LOCUST}

Bark beetle

Ptinidium lineatum Lec., under decaying bark. Cinn. Soc. Nat. Hist. Jour. 20:251

Leaf feeders

Caterpillars

Schizura ipomoeae Dougl., brown, green and white marked, humped, $1 / 2 / 2$ in. Pack. Mem. Bombycine Moths, p. 194

Heteropacha rileyana Harv. Pack.

Tlascala reductella Walk., greenish yellow, brown, yellow marked leaf roller, $5 / 8 \mathrm{in}$. Pack. p. 652

Catocala innubens Guen., dull white, obscurely striped, $21 / 4$ in. French. Can. Ent. $20: 170$. Black walnut

Catocala illecta Walk., black and white banded, 2 in. Beut. N. Y. Ent. Soc. Jour. 9: 189

Catocala minuta Edw., brownish, light striped; broad, white patches, $13 / 4$ in. Dodge. Can. Ent. 33:222

Adelocephala bicolor Harr., yellow, carmine, white and blue banded, I in.; coffee tree. Pack. Mem. Nat. Acad. Sci. 9:65

Mompha gleditschiaeella Chamb. Psyche, 3:66

Agnippe biscolorella Chamb. Pack.

Helice pallidochrella Chamb. Pack.

\section{Leaf gall}

Cecidomyia gleditschiae O. S., larvae in folded leaflets. Ins. Galls of Ind. p. 839

Scale insect

Aspidiotus ancylus Putn. Psyche, 9:403

LOCUST OR BLACK LOCUST

Borers

Agrilus egenus Gory. IV. Va. Agric. Exp. Sta. Bul. $32: 184$

Agrilus otiosus Say. Pack. p. 367

Agrilus politus Say. Psyche, 4:203. IVillow 
Ino reclusa Lec. Ent. Soc. Wash. Proc. 2:73

Liopus variegatus Hald., under bark (Joutel)

Liopus fascicularis Harr., prickly ash. N. Y. Ent. Soc. Jour. 4:79

\section{Leaf feeders}

Pteronus trilineatus Nort., brown headed, green sawfly larva, 2/5 in. Pack. p. 369. IVillow

Pachybrachys atomarius Melsh. IV. Va. Agric. Exp. Sta. Bul. 32:199

Myochrous denticollis Say. IV. Va. Agric. Exp. Sta. Bul. 32:199

Colaspis brunnea Fabr. Hopk. IV. Va. Agric. Exp. Sta. Bul. 32:199

Nodonota tristis Oliv. Hopk. W. Va. Agric. Exp. Sta. Bul. $32: 200$

Nodonota puncticollis Say, sumac. Ilopk. IV. Va. Agric. Exp. Sta. Bul. 32 : 200

Phyllechthrus gentilis Lec. Hopk. WV. Va. Agric. Exp. Sta. Bul. 32:201

Crepidodera aesculi Dury, buckeye. Cinn. Soc. Nat. Hist. Jour. 20:253

Coptocycla significa Hbst. IV. Va. Agric. Exp. Sta. Bul. 32:202

Apion nigrum Hbst. N. Y. Ent. Soc. Jour. 1:40

Apion rostrum Say. Pack. p. 367. Sweet ferm

Copturus binotatus Lec., oak, sumac. N. Y. Ent. Soc. Jour. $1: 83$

Anthribus cornutus Say. N. Y. Ent. Soc. Jour. $1: 88$

Cecidomyia robiniae Hald., whitish maggot in folded leaflets. Pack. p. 368

Dasyneura pseudacaciae Fitch, whitish maggots in leaflets. Pack. p. 368

Macrobasis unicolor Kirby. Pack. p. 371

Ptosima gibbicollis Say. Ins. N. J. P. 256. Redbud

Anomoea laticlavia Forst. Ent. Soc. Wash. I'roc. $2: 262$

Euparthenos nubilis Hübn., brown, dark spotted larva. Pack. p. 370

Dasylophia anguina $\mathrm{Abb}$. \& Sm., red headed, lilac, yellowish and black lined larva; black tipped tubercle on eighth abdominal segment, 2 in. Pack. Monogr. Bombycine Moths, p. 174

Sciagraphia heliothidata Guen., green, white lined spanworm. Dyar. Psyclse, $9: 203$

Salebria contatella Grote, pale green, striped, 2/3 in. Beut. Can. Ent. 22:16

Epagoge sulfureana Clem., yellowish green larva, 5/8 in. Pack. p. 362 . Willow, pine

Gelechia pseudoacaciella Chamb., green larva with reddish head, 3'5 in. Pack. p. $36_{3}$

Depressaria robiniella Pack., green, black headed. Pack. p. 364

Chrysopeleia purpuriella Chamb. Psyche, $3: 6_{4}$

Gracilaria lespedezaefoliella Clem., yellow blotch mine, upper surface. Cotton. Ohio Dep't Agric. Bul. 7, p. 37

Recurvaria robiniella Fitch, pale green, whitish or yellowish. Fitch. 5th Rep't, p. 55

Lithocolletes robiniella Clem., white blister mine, under surface. Fitch. 5th Rep't, p. 56

Lithocolletes morrisella Fitch. 5th Rep't, p. 58

Lithocolletes ostensackenella Fitch. 5th Rep't, p. $5^{8}$

Lithocolletes uhlerella Fitch. 5 th $^{2}$ Rep't, p. 58

Xylestia pruniramiella Clem. Pack.

Spermophagus robiniae Sch. Pack. 
KEDBUD

Insects

Rhopalophora longipes Say. Ent. Soc. Wash. Proc. 3:97

Bruchus mimus Say. Psyche, 4:204

\section{B.ASTWOOD OIR LINDEN \\ Bark insects}

Silvanus planatus Germ. Can. Ent. 18:66

Tenebrioides americana Kirby. Can. Ent. 18:66

Tetratoma truncorum Lec. Can. Ent. IS:67

Xyletinus lugubris Lec. Ent. Soc. Ont. 3tth Rep't, p. 6i

Orchesia castanea Melsh. Can. Ent. 18:67. Birch fungi

Eustrophus bicolor Say. Can. Ent. 18:67

Allandrus bifasciatus Lec. Ins. N. J. p. 366

\section{Leaf feeders}

Monophadnus tiliae Nort. Ent. Soc. Ont. 34th Rep't, p. 59

Chrysomela pnirsa Stal. Ent. Soc. Ont. 34th Rep't, p. 52

Odontota quadrata Fabr., oak, hornbeam, cherry, juneberry, white birch. Beut. Ent. Am. 6: 178

Rhabdopterus picipes Oliv. Ins. N. J. p. 305

Ellida caniplaga Walk., whitish green, yellow lined, $t_{5}$ in. Dyar. N. Y. Ent. Soc. Jour. 10:143

Xylina bethunei Gr. \& Rob. Ent. Soc. Ont. 34th Rep't, p. 54

Catocala cerogama Guen., ash-gray, black specked. Dyar. Can. Ent. 26:21

Erannis tiliaria Harr, yellow, black marked spanworm. Pack. P. 475. Oak, hickory, elm, apple, pear

Pantographa limata Gr. \& Rob., green, brown spotted leaf roller, I in. Pack. p. 477

Coleophora tiliaefoliella Clem., dark biown larva; pistol-shaped case. Pack. p. 478

Lithocolletes lucetiella Clem., greenish, brown headed leaf miner. Pack. p. 478

Lithocolletes tiliacella Chamb. Ent. Soc. Ont. 34th Rep't, p. 58

\section{Galls}

Cecidomyia citrina O. S., young terminal buds deformed. Pack.

Sciara tilicola O.S., pealike swelling on stem near origin of last two leaves. Pack.

Gargaphia tiliae IValsh. Pack.

\section{Sucking insects}

Drepanosiphum tiliae Koch. Pack.

Lachnus longistigma Mon. Pack.

Aspidiotus diffinis Newst., lilac. Fern. Coccidae, p. 257

Pulvinaria tiliae Kg. \& Ckll., woolly bark louse. Psyche, 8: 286 


\section{Borers}

Acanthoderes morrisii Uhler. N. Y. Ent. Soc. Jour. 4:78. Sour gum Himatium conicum Lec. N. Y. Ent. Soc. Jour. 1:87

\section{Leaf insects}

Cecidomyia liriodendri O. S., brown spots with yellow or greenish aureole. Diptera N. A. $1: 202$

Cecidomyia tulipiferae O. S., midrib swelling of leaf. Diptera N. A. I :202

Callosamia angulifera Walk., greenish, black marked, red and yellow tubercled larva, $21 / 2$ in. ; sassafras, wild cherry: Beut. Ent. Am. 5:200

Polychrosis botrana Schiff., greenish or purplish, naked larva, 38 in. Am. Ent. Soc. Trans, 10:28

Phyllocnistis liriodendronella Clem., broad, very long, linear, contorted mine; underside; brownish frass line. Tineina N. A. p. 220

Nectarophora liriodendri Mon. Pack.

\section{Tulip aphid}

\section{SASSAFRAS \\ Borers}

Oberea ruficollis Fabr., girdler. Can. Ent. 28:247. Sumac

Corthylus punctatissimus Zimm. IV. Va. Agric. Exp. Sta. Bul. $31: 127$

\section{Leaf feeders}

Prionomerus calceatus Say, larval leaf miner. Ins. N. J. p. 350

Papilio troilus Linn., green, blue spotted, yellow banded larva, 13/4 in. ; spicebush. Beut. Am. Mus. Nat. Hist. Bul. 5:243. Wild plum

Gonodontis hypochraria H.-S., rust-red, black lined larva. Dyar. Ent. News, 5:61. Persimmon

Gracilaria sassafrasella Chamb. Ins. N. J. p. $48 \mathrm{i}$

Scale insect

Eulecanium lintneri Ckll. \& Benn. Fern. Coccidae, p. 189

P'LUN, WILD

\section{Leaf feeders}

Pteronus thoracicus Harr., whitish green, banded larva. Dyar. Am. Ent. Soc. Trans. $22: 307$

Incisalia irus Godt., slug-shaped, yellowish green and reddish brown lined larva, $1 / 2$ in.; luckleberry. Beut. Am. Mus. Nat. Hist. 5:280

\section{Sucking insects}

Pediopsis trimaculata Fitcl. Ent. Am. 5:172

Aphis cerasicolens Fitch. Pack.

Aphis cerasifoliae Fitch. Pack. 
CHERRY, WILI)

\section{Borers}

Sanninoidea exitiosa Say, white, naked caterpillar at base of trunk. Pack. p. $52 \mathrm{I}$

\section{Leaf feeders}

Lyda fasciata Nort., yellowish, black tipped webworms. Pack. p. 524

Eriocampoides limacina Retz., slug-like, slimy larva. Harrington. Ent. Soc. Ont. 15 th Rep't, p. 69

Pseudanthonomus crataegi Walsh, wild thorn. Am. Ent. Soc. Trans. 22:376

Galerucella rufosanguinea Say. Pack. p. 529

Epicaerus imbricatus Say. N. Y. Ent. Soc: Jour. $1: 38$

Rhyncolus brunneus Mann. Pack.

Phloeophagus apionides Horn. N. Y. Ent. Soc. Jour. 1:87. Birch

Paonias myops Abb. \& Sm., green, yellow marked, horned larva. Psyche, 5:266. IVild plum, thorn

Strymon titus Fabr., sluglike, dull green, pink or rose patched larva, $3 / \frac{1}{\mathrm{in}}$. : plum. Beut. Am. Mus. Nat. Hist. Bul. $5: 28 \mathrm{I}$

Chamyris cerintha Treits., purplish, white lined larva. Dyar. Psyche, 8:349

Apatela furcifera Guen., black, red striped larva. Sm. \& Dyar. U. S. Nat. Mus. Proc. $21: 85$

Apatela radcliffei Harr, black, yellowish lined larva. Sm. \& Dyar. U. S. Nat. Mus. Proc. 21:107

Plagodis phlogosaria Guen. Ent. Am. $3: 48$

Cymatophora pustularia Hübn., reddish, white lined, black dotted spanworm, 1 in. Kellicott. Can. Ent. 17:32

Synelys ennucleata Guen., brown, black marked spanworm ; multiannulate segments. Dyar. Psyche, 9:165

Tortrix pallorana Robs. Am. Ent. Soc. Trans. 10:17

Alceris logiana Schiff. Pack.

Mineola indigenella Zell., brown or green larva; apple, crab apple, quince, plum, peach. Hulst. Am. Ent. Soc. Trans. 17:130

Coleophora pruniella Clem., case flattened, deeply notched distally. Pack. p. 528

Nepticula prunifoliella Clem. Pack. p. 527

Nepticula serotinaeella Chamb., mine narrow, linear, mucl convoluted, filled with frass. Can. Ent. 5:126

\section{Gall insects}

Cecidomyia serotinae O. S., enlarged terminal buds on young shoots. Am. Ent. Soc. Trans. $3: 3+6$

Acarus serotinae Beut., pouchlike galls on upper surface, $2 / 5$ in. Ins. Galls of Ind. p. 858

\section{MoUNTAIX AsH}

\section{Insects}

Euzophera semifuneralis Walk., mining under bark. Kellicott. Can. Ent. 23:250 Apatela clarescens Guen., green or greenish brown, reddish purple striped caterpillar; apple, wild cherry. Sm. \& Dyar. U. S. Nat. Mus. Proc. 21:123

Venusia cambrica Curtis, spanworm. Pack. Monogr. Geometrid Moths, p. 86 


\section{MHDHUSH OR JUNEBERRY (AMELANCHER}

Leaf feeders

Schizocerus prunivorus Marlt., green larva, blotched with yellow subventrally ; wild cherry. Dyar. N. Y. Ent. Soc. Jour. 5:23

Nyctobia limitata Walk. Ent. Am. 3:49

Ornix quadripunctella Clem., greenish, black dotted larva in mine on upper surface.

Tineina N. A. p. 177

Nepticula amelanchierella Clem., broad, contorted, irregular mine with broad, frass line. Tineina N. A. p. 174

\section{Scale insect}

Eulecanium kansasense Hunter, redbud. Ferr. Coccidae, p. 189

\section{WH,1, THOLX}

\section{Borers}

Saperda cretata Newm. N. Y. State Mus. Bul. 74, p. 50

Xylotrechus convergens Lec. N. Y. E.nt. Soc. Jour. $4: 76$

\section{Fruit insects}

Tachypterus quadrigibbus Say. Am. Ent. Soc. Trans. 22:376

Conotrachelus crataegi Walsh. Am. Ent. Soc. Trans. 22:376

Conotrachelus naso Lec. Pack.

Conotrachelus posticatus Boh. N. Y. Ent. Soc. Jour. 1:82

\section{Leaf feeders}

Anthonomus decipiens Lcc. N. I. Ent. Soc. Jour. 1:8o

Nothus varians Oliv. Am. Ent. Soc. Trans. 22:373

Tymnes metasternalis Cr. 1ns. N. J. p. 305

Stethobaris tubulatus Say. Am. Ent. Soc. Trans. 22:377

Limnobaris calva Lec. Am. Ent. Soc. Trans. 22:377

Anthonomopsis mixtus Lec. Am. Ent. Soc. Trans. 22:376

Apion herculaneum Smith. N. I. Ent. Soc. Jour. 1:30

Catocala polygama Guen. var. crataegi Saund, gray-black, red marked larva, 1 1/3 in. Pack. p. 532

Nacophora quernaria Abb. \& Sm., slate-gray spanworm with tubercle on third thoracic and seventl abdominal segments. Pack. Monogr. Geometrid Moths, p. 412

Uranotes melinus 11 übn. Pack.

Enarmonia prunivora IValsh. Pack.

Coptodisca splendoriferella Clem., linear, frass-lined mine, expanding to a small transparent blotch. Tineina N. A. p. ro5. Wild cherry.

Nepticula crataegifoliella Clem., thick, bright green larva. l'ack. p. 534

Ornix inusitatumella Chamb., nearly circular, blister mine on upper surface. Can. Ent. $5: 48$

Ornix crataegifoliella Clem., brownish, greenish white leaf miner. Pack. p. 534

Tischeria malifoliella Clem., brown, trumpet-shaped mine, upper surface. I'ack.

\section{Leaf gall}

Cecidomyia bedeguar Walsh., subglobular, midrib gall, 1/2 in. Can. Ent. 1:79 
Sucking insects

Melinna pumila Uhler, willow. Ent. Am. 3:69

Nectarophora crataegi Monell. Pack.

Schizoneura crataegi Oest. Pack.

Phenacoccus dearnessi King. Fern. Coccidae, p. 91

Chionaspis furfura Fitch var. fulva King, scurfy white scale, King. Psyche, 8: 334

\section{PERSIMUION}

\section{Insects}

Olethreutes malachitana Zell. Am. Ent. Soc. Trans. 10: $3 \dot{3}$

Artace punctistriga Walk. Can. Ent. 23:35

Brachystylus acutus Say. Ins. N. J. p. 34I

Aphis diospyri Thom. Ins. N. J. p. 103

\section{PAWPAW}

\section{Leaf feeder}

Iphidicles ajax Linn., gray or green larva; white, black and yellow bands. French. Butterflies East. U. S. p. 84

\section{TREE OF IIEA TEN \\ Leaf feeders}

Atteva aurea Fitch, dark olive-brown, white lined larva, $2 / 8$ in. Riley. Ist Mo. Rep't, p. 15 I

\section{SWEET GUM \\ Leaf miner}

Phyllecnistis liquidambarisella Chamb., indistinct, long, tortuous mine on upper surface. Cinn, Quar. Jour. Sci. Proc. 2: 106

\section{SOLR GLM OR PEPPERIDGE TREE MNECT}

Callichroma splendidum Lec. Can. Ent. 24:38

Nepticula nyssaeella Clem. Pack.

Phylloxera nyssae Perg., woolly aphid in bark crevices. Davenport. Acad. Sci. Proc. 9:269

$$
\text { CATALPA }
$$

\section{Leaf feeders}

Ceratomia catalpae Bois, black dorsal band, black and yellow lined larva, 3 in. Koebele. Bklyn Ent. Soc. Bul. 4:20

Cecidomyia catalpae Comst., abnormally brown maggoty pods. Pack. p. 666

$$
\text { ROM. }
$$

\section{Leaf feeders}

Emphytus cinctus L., banded, curled larva. Riley. Insect Life, 5:9

Cladius pectinicornis Fourcr., greenish, bristly larva. Riley. Insect Life, 5:9

Monostegia rosae Harr., greenish, sluglike larva, 1/2 in. Insect Life, 5: 10

Trichius piger Fabr. U. S. Div. Ent. Bul. 27, n. s. p. 100

Nodonota puncticollis Say. U. S. Div. Ent. Bul. 7, 11. s. p. 60 
Deilephila galii Rott., dark green, yellow spotted larva, 3 in. Beut. Am. Mus. Nat. Hist. Bul. $7: 286$

Schizura mustelina Pack., dark brown, gray mottled and green larva, $4 / 5$ in. French Can. Ent. 18:92

Chloridea virescens Fabr., Olive-green, yellow lined, 1/8 in. U. S. Div. Ent. Bul. 27 , n. s. p. 101

Nepticula rosaefoliella Clem., mine very serpentine, frequently marginal, moderately broad, filled with black frass. Tineina N. A. p. 176

Coleophora rosaefoliella Clem., brown, cylindric, hooked case. Tineina N. A. p. 251

Coleophora rosacella Clem., dark red, compressed, cylindric, serrate case. Tineina N. A. p. $25 \mathrm{I}$

Eulecanium rosae King. Fern. Coccidae, p. 196

\section{Rose galls}

Rhodites multispinosa Gill,, reddish brown, spined, knotlike excrescence on young shoots. Ent. Am. 6:25

Rhodites lenticularis Bass., lentil-shaped leaf gall on both surfaces, $\mathrm{I}_{\mathrm{i}} \mathrm{in}$. Am. Ent. Soc. Trans. I7: 59

Rhodites nebulosus Bass., globular, hollow leaf gall, ${ }_{16}^{\prime}$ in., on under surface. Am. Ent. Soc. Trans. 17:63

Periclistis sylvestris O. S., guest fly from gall of Rhodites radicum. Ent. Soc. Phila. Proc. $4: 366$

Periclistis semipiceus Harr., guest in rose root gall. Ins. Inj. Veg. p. 436

\section{Intivon}

\section{Borers}

Agrilus lecontei Saund. Psyche, 4: 203

Psenocerus supernotatus Say. N. Y. Ent. Soc. Jour. 4:78

Anthonomus corvulus Lec. N. Y. Ent. Soc. Jour. 1:81

\section{Leaf feeders}

Harpiphorus versicolor Nort., shining, blue-gray larva, marked with leaden black. Dyar. N. Y. Ent. Soc. Jour. 5:22

Harpiphorus tarsatus Say, olivaceous black larva, I in. Dyar. N. Y. Ent. Soc. Jour. $5: 21$

Euthyatira pudens Guen., semitransparent, whitish flecked caterpillar. Dyar. Can. Ent. 21:209

Ancylis cornifoliana Riley. Am. Ent. Soc. Trans. 10:51

Antispila cornifoliella Clem., fat, white larva living first in linear, then a blotch mine. Psyche, 3:149

Gall

Cecidomyia clavula Beut., capitate, apical twig gall. Ins. Galls Ind. p. 841

\section{Sucking insects}

Eulecanium tarsale Sign. Fern. Coccidae, p. 197

Chionaspis corni Cooley. Fern. Coccidae, p. 215 
Aphis cornifoliae Fitch. Am. Ent. Soc. Trans. 20:299

Schizoneura corni Fabr. Ins. N. J. p. 105

\section{SUMAC}

Borers

Pogonocherus penicellatus Lec. W. Va. Agric. Exp. Sta. Bul. 32 : 197

Cryptorhynchus obliquus Say, bores sumac roots. W. Va. Agric. Exp. Sta. Bul. 32: 206

Pityophthorus consimilis Lec. W. Va. Agric. Exp. Sta. Bul. 3I :130

\section{Leaf feeders}

Coscinoptera dominicana Fabr., oak, sassafras, apple, plum. Ent. Am. 6:175

Orthaltica copalina Fabr. Lint. 5th Rep't, p. 271

Blepharida rhois Forst. Ent. Am. 6:177

Pyrrhia umbra var. exprimens IValk., locust. Can. Ent. 23:36

Marasmalus inficita Walk. Can. Ent. $23: 36$

Marasmalus ventilator Grote. Cin. Ent. 23: 36

Datana perspicua Gr. \& Rob., black headed, yellow, red striped larva, $11 / 2 \mathrm{in}$. Pack. Monogr. Bombycine Moths, p. 117

Amorbia humerosana Clem. Am. Ent. Soc. Trans. 10:19. Pine, spicebush

Schreckensteinia erythriella Clem., dark green, deeply incised larva; middle of segments produced dorsally. Tineina N. A. p. 132

\section{Sucking insects}

Pulvinaria maclurae Kenn., osage orange. Fern. Coccidae, p. 135

Calophya nigripennis Riley. Ent. Soc. Wash. Proc. 6:244

\section{ELI)ER}

Insects

Tenthredo atroviolacea Nort., dark slaty, blue-black, shining larva. Dyar. N. Y. Ent. Soc. Jour. 5: 192

Macrophya trisyllaba Say, black mottled, white litrvi. Dyar. N้. Y. Ent. Soc. Jour. 5:192

Desmocerus palliatus Forst. N. Y. Ent. Soc. Jour. $4: 77$

LIL.A'

\section{Leaf feeders}

Phlegethontius rustica Fabr., dark green, blue banded, $f$ in. Beut. Am. Mus. Nat. Hist. Bul. 7:300. Fringe tree

Harrisimemna trisignata Walk., black headed, yellow, brown and black marked, humped, $13 / 4$ in. Goodlue. Can. Ent. is: 58 . Honeysuckle, holly

\section{PLIVET}

\section{Leaf feeder} Diaphania quadristigmalis Guen., pale yellow to bluish green larva, $t / 5$ in. Insect
Life. $1: 22$ 


\section{FRINGE TKEF}

Leaf feeder

Periclista chionanthi Murtfeldt (M. S.), yellowish larva; broken subdorsal black shade. Dyar. N. Y. Ent. Soc. Jour. 6: 132

\section{VIBURNut \\ Leaf feeders}

Macrophya bilineata MacGill., whitish translucent; body segments seven-annulated with minute black setae on second and fourth annulets. Dyar. N. Y. Ent. Snc. Jour. $5: 19$

Macrophya mixta MacGill, head reddish, body waxy greenish. Dyar. N. Y. lint. Soc. Jour. 5: 19

Hemaris thysbe Fabr., whitish green, yellow and white spotted larva, $13 \frac{1}{4}$ in.; honeysuckle, snowberry. Beut. Am. Mus. Nat. Hist. Bul. 7:277. Plum, thorn

Ampelophaga choerilus Cramer, pale green, dark lined larva, white marked, $1 / 5$ in. Beut. Am. Mus. Nat. Hist. Bul. 7:291. Sour gum

Diphthera fallax H..S., flat, velvety green larva with narrow, dorsal and subdorsal pale lines. Dyar. N. Y. Ent. Soc. Jour. 7:67

Schizura badia Pack., green, brown and yellow marked larva, $1 \frac{1 / 2}{2}$ in. l'ack. Monogr. Bombycine Moths, p. 208

Calledapteryx dryopterata Gr., trarslucent white larva, slightly greenish. Dyar. Ent. Soc. Wash. Proc. 4:414

Platynota sentana Clem. Am. Ent. Soc. Trans. 10:23

Coleophora viburniella Clem., brownish, irregular alate case. Tineina N. A. p. 167

BAYBERK:

Insects

Acrobasis comptoniella Hulst., green larva with four rows of biack spots. Am. Ent. Soc. Trans. 17: 125

Racheospila lixaria Guen. Ent. Am. 3:72

Auletes cassandrae Lec., sweet fern. N. Y. Ent. Soc. Jour. I : 36

Triachus atomus Suff. Ent. Soc. IVash. Proc. $2: 263$

\section{BLEEHERRY}

\section{Leaf feeders}

Paonias astylus Dru., pale green, yellow lined, horned larva; low huckleberry, Rosaceae Fern. Sphing. N. E., p. 76

Anarta cordigera Thunb., reddish brown and white larva. Staint. Brit. Butterflies \& Noths, 1:293

Eudemis vacciniana Pack., brown or black headed, greenish larva. Pack. Guide, p. 339

Cymatophora pustularia Hübn., reddish, white and black lined spanworm. Stant. Brit. Butterflies \& Moths, 2:62

Macaria praeatomata Haworth, green, dark green lined spanworm. Pack. Monogr. Geometrid Moths, p. 29 I

Aiceris minuta Rob., red or yellow headed, grcen larva, 1/2 in. P'ack. Bul. 12, U. S. Div. Ent. p. I 8 
Scale insect

Eulecanium kingii Chll. Fern. Coccidac, p. 189

\section{HECKLAHERTY}

\section{Leaf feeder}

Datana drexelii Edw., black, yellow lined larva, 21/4 in. Pack. Monogr. Bombycine Moths, p. 112. Witch-hazel, linden

\section{ANIROMEU. \\ Leaf feeder}

Datana major Grote \& Rob, black, stout, broken yellow or white lined larva. Psyche, $5: 415$

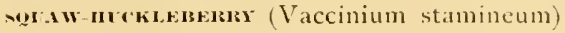

\section{Leaf feeder}

Datana palmii Beut., stout, black, yellow lined larva. Dyar. Ent. Am. 6:129

\section{IXILEA \\ Leaf feeder}

Amauronematus azaliae Marlt, shining, green solitary sawfly larva. Dyar. N. I. Ent. Soc. Jour. $5: 27$

SHEEI" LACISEL

Pseudanthonomus incipiens Dietz. N. Y. Ent. Soc. Juur. $1:$ So

\section{мкивких (Hex glabra)}

\section{Leaf feeder}

Dolba hylaeus Dru., green, pink and yellow marked, horned larva, $2{ }^{1 /}$ in. Psyche, $5: 267$

\section{WHITE ALWER}

\section{Leaf feeders}

Nola clethrae Dyar, bluish ashen larva. Can. Ent. 31:62

Pyrausta thestialis Walk, brown headed, greenish white larva. Beut. Can. Ent. $20: 15$

\section{VIRGINA CREEPER}

\section{Leaf feeders}

Adoxus obscurus Linn. Ent. Am. 6:176

Ampeloglypter ater Lec. N. Y. Ent. Soc. Jour. $1: 85$

Ampelophaga myron Cram., green, yellow dotted larva, z in. Beut. Am. Mus. Nat. Hist. Bul. $7: 292$

Pholus achemon Dru., green to brown, brown lined, horned larva, 3 in. Beut. Am. Mus. Nat. Hist. Bul. $7: 289$

Pholus pandorus Hübn., pale green larva with oval, cream-colored spots, 3 in. Beut. Am. Mus. Nat. Hist. Bul. $7: 288$

Sphecodina abbotii Swains, chocolate-brown, narrow, transverse lined larva, $2.21 \mathrm{in}$. Beut. Am. Mus. Nat. Hist. Busl. 7:283. Thorn 
Amphion nessus $\mathrm{Cr}$., chocolate-brown, checkered, black, horned larva, $23 ;$ in. Beut. Am. Mus. Nat. Hist. Bul. $7: 282$

Triptogon lugubris Linn., pale green, dark green and yellow marked larva, 2.41 in. Beut. Am. Mus. Nat. Hist. Bul. 7:281

Deidamia inscriptum Harr., greenish, yellow marked, horned larra, 21'ś in. Soule. P'syche, $7: 317$

Euthisanotia grata Fabr., red headed, bluish, orange and black banded larva, $I 1 / 2$ in. Saund. Ins. Inj. Fruits. p. 258

Acoloithus falsarius Clem., bluish black, orange and black marked larva, $3 / 4$ in. Glover. U. S. Com. of Agric. Rep't 1870, p. 8 I

Phyllocnistis ampelopsiella Chamb., narrow, much convoluted, linear mine resembling white blotcli on under surface. Cinn. Quar. Jour. Sci. 2: 107

Antispila ampelopsiella Chamb., fat, white larva living first in linear, then a blotch mine. P'syche, 3:149

\section{Tree hopper}

Telamona ampelopsidis Hitr. Ent. Soc. Ont. 13th Rep't, p. 78

\section{POISOX IV}

Insects

Corymbites hamatus Say. Psyche, 4:203

\section{Leaf feeders}

Pachybrachys tridens Mclslı. Ent. Am. 6:175

Epipaschia superatalis Clen., orange, black and blue lined larva. Dyar. N. Y Ent. Soc. Jour. 12:249

Epipaschia zelleri Grote, yellow, grat and black lined larva. Dyar. N. Y. Ent. Soc. Jour. $12: 250$

Lithocolletes guttifinitella Clem., broad, tortuous mine on upper surface. Pack. p. 665 . Horsechestnut

\section{SMIL.X.X \\ Leaf feeders}

Mitoma damon Cram., sreen, red spotted larva. French: Butterflies East. U. S. 1. 268 . Red cedar

Phiprosopus callitrichoides Grote, mahogany-red larva, 1 in. Daecke. N. Y. Ent. Soc. Jour. I1 : 105

Phyllocnistis smilacisella Clamb., linear, white frass-lined mine; upper surface. Cinn. Quar. Jour. Sci. 2: 107

\section{Sucking insects}

Proleucoptera smilaciella Busck. N. Y. Ent. Soc. Jour. 8: 244

Chrysomphalus smilacis Comst. liern. Coccidae, p. 294

Lachnus smilacis Auct., purplish gray, cottony aplid, sometimes very abundant

\section{HOXETICKL:}

\section{Borers}

Hypothenemus erectus Lec. Wr. Va. Agric. Exp. Sta. Bul. 3I : 133

Hypothenemus eruditus Westw. IV. Va. Agric. Exp. Sta. Bul. 31 : 32 
Leaf feeders

Hemaris diffinis Boisd. var, axillaris Gr. \& Rob., pale green larva. Jewett. Bklyn Ent. Soc. Bul. 4:17

Homohadena badistriga Grote. Can. Ent. 23:35.

\section{TRUMIPET VINE \\ Leaf feeder}

Sphinx plebeia Fabr., olive-pink, olive-marked, horned larva; flesh-colored dots in transverse rows, $2^{3,5}$ in. Beut. N. Y. Ent. Soc. Jour. $3: 58$

\section{MITTERSWEET}

\section{Leaf feeder}

Zelleria celastrusella Kearf, leaf-green larva with darker dorsal line, $2 / 3$ in. N. Y. Ent. Soc. Jour. 11:150

\section{TILLOW}

\section{Borers}

Agrilus politus Say. Am. Ent. Soc. Trans. 22: 364 . Locust

Smodicum cucujiforme Say. Psyche, $4: 203$. Hackberry

Mecas inornata Say, poplar. N. Y. Ent. Soc. Jour. $4: 81$

Olethreutes capreana Hübn., bright green larva in willow shoots. Staint. Brit. Butterflies \& Moths, 2: 194

Marmara salictella Clem., extremely long, narrow mine under delicate cuticle of twigs. Tineina N. A. p. 212

\section{Leaf feeders}

Cladius isomera Harr., black spotted larva. Harrington. Ent. Soc. Ont. 15th Rep't, p. 66

Priophorus irregularis Dyar, whitish larva with two irregular transverse rows of warts. N. Y. Ent. Soc. Jour. 8:28

Pristiphora sycophanta Walsh. Pack.

Pontania pallicornis Nort., transparent green sawfly larva. Dyar. N. Y. Ent. Soc. Jour. $5: 196$

Pteronus mendicus WValsh, leaf-green not shining sawfly larva. Dyar. Am. Ent. Soc. Trans. 22:302

Pteronus odoratus Dyar, light green, segments 2, 12, 13 orange posteriorly. Can. Ent. 26:187

Amauronematus similis Marlt., solitary translucent, light green sawfly larva; subdorsal line white. Dyar. N. Y. Ent. Soc. Jour. 5:27

Amauronematus oregonensis Marlt., solitary whitish green, pilose sawfly larva; addorsal and stigmatal lines white. Dyar. N. Y. Ent. Soc. Jour. 5:26

Amauronematus fur Walsh. Pack.

Pachynematus gregarious Marlt., whitish, black streaked slug-like larva. Dyar. N. Y. Ent. Soc. Jour. 5:29

Dolerus arvensis Say, steel-blue sawfly frequents buds. Pack. p. 587

Dolerus bicolor Beauv., brownish yellow sawfly frequents buds. Pack. p. 588

Litargus tetraspilotus Lec. Pack.

Orsodachna atra Ahr. Ent. Soc. Wash. Proc. $2: 262$ 
Chrysomela multiguttata Stal, hazel, elm, linden, alder. Ent. Soc. Ont. 13th Rep't, p. 58

Chrysomela philadelphica Linn. var. spireae Say. Pack. p. 590

Pachybrachys livens Lec. Ent. Am. 6:175

Pachybrachys tridens Mels. Ent. Soc. Ont. 13th Rep't, p. 56. Sumac

Galerucella tuberculata Say. Am. Ent. Soc. Trans. 22:371

Hoplia trifasciata Say. Pack.

Phyllodecta vulgatissima Linn., poplar. Ent. Aın. 6: 176

Crepidodera helxines Linn. IV. Va. Agric. Exp. Sta. Bul. 32:201. Wild cherry, thorm, poplar

Gastroidea cyanea Melsh. IV. Va. Agric. Exp. Sta. Bul. 32:200

Nodonota tristis Oliv. Pack. p. 587

Macratria murina Fabr. Ins. N. J. p. 333

Rhynchites cyanellus Lec. Can. Ent. 23:21

Apion segnipes Say. N. Y. Ent. Soc. Jour. 1:39. Probably visits fowers

Lepyrus geminatus Say. Can. lint. 23:23

Acalyptus carpini Herbst. N. Y. Ent. Soc. Jour. $1: 43$

Dorytomus squamosus I.ec. Pack. (Anthonom us tessellatus Walsh)

Orchestes niger Horn. N. Y. Ent. Soc. Jour. 1:81

Orchestes pallicornis Say. N. Y. Fnt. Soc. Jour. 1: 8 I

Orchestes salicis Linn. N. Y. Ent. Soc. Jour. I $: 81$

Orchestes rufipes Lec. N. Y. Ent. Soc. Jour. 1:8I

Elleschus bipunctatus Linn., poplar. N. Y. Ent. Soc. Jour. 1:81

Phloeophagus minor Horn. N. Y. Ent. Soc. Jour. 1:87. Beech, elm, ash, birch

Anthonomus sycophanta Walsh, gall feeder. N. Y. Ent. Soc. Jour. 1: 80

Eurymus interior Scudd., greenish fuscous, with black points. Scudd. Butterflies East. U. S. \& Can. p. 1105

Polygonia faunus Edw., brownish yellow, white spined caterpillar, $1^{\mathrm{I}}{ }_{5}$ in. Beut. Am. Mus. Nat. Hist. Bul. $5: 265$. Gooseberry, birch, alder

Aglais milberti Godt., spiny, black larva; whitish tubercles. Scudd. Butterflies East. IJ. S. \& Can. P. 420

Basilarchia arthemis 1)ru., grecn, reddish or whitish patched larva, $1^{2}{ }_{10}$ in.; elm, linden, poplar, birch. French. Butterflies East. U. S. p. 208

Thecla acadica Edw., green, oblique striped, greenish yellow larva. Saund. Canl. Ent. $1: 95$

Thanaos icelus Lintn., red headed, greenish, white lined larva, 3/5 in. Edw. Can. Ent. 17:98. Hazel, poplar

Thanaos persius Scudd., green, yellowish lined, white dotted larva, I in.; poplar. Beut. Am. Mus. Nat. Hist. Bul. 5:300

Sphinx luscitiosa Clem., green, white lined, horned larva, $2 \frac{1}{2} \mathrm{in}$. Dyar. Ent. Am. 5: 189

Marumba modesta Harr., green, granulated, horned larva with white points, 3 in.; poplar. Beut. Am. Mus. Nat. Hist. Bul. 7:312

Ecpantheria deflorata Fabr., locust. Ins. N. J. p. 398

Apütela lanceolaria Grote, green, black lined larva. Sm. \& Abb. U. S. Nat. Mus. P'roc. $21: 171$

Apatela connecta Gr., dark green, broad, yellow lined larva. Sm. \& Dyar. U. S. Nat. Mus. Proc. $21: 115$

Apatela dactylina Grote, black, yellowish and brown haired larva; birch, alder. Sm. \& Dyar U. S. Nat. Mus. Proc. 21:51 
Apatela oblinita Sm. \& Abb., velvety black, yellow dotted, hairy larva; alder. Sm. \& Dyar. U. S. Nat. Mus. Proc. 21:160. Hazel

Apatela impressa Walk., velvety black, reddish striped larva; hazel. Sm. \& Dyar. U. S. Nat. Mus. Proc. $21: 159$

Arsilonche albovenosa Goeze, black, yellow striped and dotted larva. Sm. \& Dyar. U. S. Nat. Mus. Proc. 21:175

Calocampa curvimacula Morr., light brown, white striped larva. Dyar. Psyche, $8: 336$

Scoliopteryx libatrix Linn., pale green, yellow lined larva. Pack. p. 569

Catocala parta Guen., fawn-colored, black or brown marked larva, 24'5 in. P'ack. p. 570. Poplar

Catocala relicta Walk, dark greenish, black marked, humped larvi, $23.8 \mathrm{in.}$ Clark. Can. Ent. 20:17. Poplar, birch

Catocala cara Guen., gray, brown marked, horned larva. Paek. p. 464 . Poplar

Catocala concumbens Walk, brown, black marked larva, 2-2 1/2 in. l'ack. p. 570

Catocala briseis Edw. Can. Ent. 23:36

Catocala grynea Cram., silver gray, reddish, yellowish white marked larva, $21 / 2 \mathrm{in}$. Bklyn. Ent. Soc. Bul. 4:22

Catocala babayaga Streck. Pack. p. 570

Homoptera minerea Guen. Can. Ent. $23: 36$

Homoptera lunata Dru. var. edusa Dru., dark gray larva with orange patches, $21 / 5$ in. Beut. N. Y. Ent. Soc. Jour. 9:192

Melalopha brucei Hy. Edw., black headed, purplish, white haired larva. Pack. Monogr. Bombycine Moths, p. 137

Harpyia borealis Boisd., red headed, yellow, brown marked, long tailed larv, $13_{4}$ in. Pack. Monogr. Bombycine Moths, p. 264. IVild eherry, poplar

Schizura concinna Abb. \& Sm., black and white lined, reddish, red humped larva, I 1/2 in. Pack. Monogr. Bombycine moths, p. 212, general feeder

Schizura semirufescens IValk., white headed, brown and yellow marked larva with conspicuous dorsal processes on $1 \mathrm{st}, 5$ th, and 8 th abdominal segments, $11 / 2$ in.; beech, maple, apple, poplar, birch. Pack. Monogr. Bombycine Moths, p. 210

Cerura occidentalis Lint., green, purple marked, long tailed larva, $1^{1 / 7}$ in. Pack. Monogr. Bombycine Moths, p. 268

Cerura scitiscripta WValk., greenish, purple marked, long tailed larva, I in.; wild cherry, poplar. Pack. Monogr. Bombycine Moths, p. 276

Ectropis crepuscularia Dennis \& Schiff., brown headed, green. white marked spanworm. Pack. p. 371 . Maple, poplar, alder

Hydriomena sordidata Fabr., depressed, brown, black and white marked spanworm. Pack. Monogr. Geometrid Moths, p. $9^{6}$

Deilinia erythremaria Guen., green, white striped spanworm. Dyar. Psyclse, 10: 195. Poplar

Deilinia variolaria Guen., green, pink tinted or lined spanworm, 7/8 in. Pack. p. 572

Eustroma testata Linn., gray brown, white striped spanworm; poplar, birch. Pack. Monogr. Geometrid Moths, p. 122

Cleora cribrataria Guen., poplar. Ins. N. J. P. 47

Cleora larvaria Guen., reddish, green tinted, black and white dotted spanworm. Beth. Can. Ent. 6:32. IVild cherry

Cleora pampinaria Guen., yellowish green, brown and black marked spanworm, I in. Pack. p. 571. Ash, maple, honey-locust 
Euclea delphinii Boisd. var. paenulata Clem., brown, orange marked slug caterpillar, $1 / 2$ in. Pack. p. $5 \sigma_{3}$

Phlyctaenia helvalis Walk., black headed, green larva, 5/8 in. Pack. p. 467 . Puplar

Meroptera pravella Grote, green, light and dark green striped larva, $2 / 3 \mathrm{in}$. U. S. Div. Ent. Bul. 13:23

Epinotia augustana Hübn. Am. Ent. Soc. Trans. 10:47

Alceris ferrugana Schiff. Am. Ent. Soc. Trans. 10:8. Oak, beech, birch in Furope

Alceris logiana Schiff. var. viburnana Clem. Pack. p. 576

Alceris schalleriana Linn. Anı. Ent. Soc. Trans. 10:8 (European record)

Alceris effractana Fro. Am. Ent. Soc. Trans. 10:5

Alceris permutana Dup., green, dark marked larva, 3/4 in. Pack. p. 575 . Rose in Europe

Alceris hastiana Linn., pale green larva between willow leaves. Staint. Brit. Butterflies \& Moths, 2:233. Spruce in Europe

Phalonia dorsimaculana Rob. Staint. Brit. Butterflies \& Moths, 2:191

Gracilaria salicifolielía Chamb., mines upper surface in August. Can. Ent. 4:25

Gracilaria stigmatella Fabr., greenish yellow larva, $1 / 4 \mathrm{in.}$, in linear or blotch mine or in roll at tip of leaf. Can. Ent. 13:25

Coptodisca saliciella Chamb., ycllowish larva in spatulate mine. Psyche, $3: 147$. IVild cherry

Proleucoptera albella Chamb. Pack. p. 579. Poplar

Batrachedra praeangusta llaw. Pack. p. 584

Nepticula fuscotibiella Clem., mining under surface. Chamb. Psyche, $3: 136$

Lithocolletes salicifoliella Clem., mine on under surface, usually near base and along edge of leaf. Tineina N. A. p. 169

\section{Sucking insects}

Evacanthus acuminatus Fabr. Pack.

Pediopsis viridis Fitch. Ent. Am. 5:170

Cladobius salicti Harr., black, red legged, $1 / 12$ in. Pack. p. 592

Cladobius flocculosus IVced. Am. Ent. Soc. Trans. 20:300

Cladobius salicis L. Am. Ent. Soc. Trans 20:300

Chaitophorus nigrae Oest., dark brown aphid, 1/6 in. Pack. p. 593

Chaitophorus viminalis Mon., black, yellow marked aphid, 1/I6 in. Pack. p. 592

Lachnus salicellis Fitch. Ins. N. J. p. 105

Lachnus dentatus LeB.. dark, black spotted aphid on stems, $1 / 6$ in. Pack. p. 592

Siphocoryne salicis Mon., dark or green with dark markings, 11/2 in. Pack. p. 593

Aphis salicicola Thom. Pack.

\section{Scale insects}

Chionaspis ortholobis Comst. Fern. Coccidae, p. 221. Buttemut, honey-locust, poplar, cottonwood

Chionaspis salicis nigrae Walsh., tulip tree, dogwood, poplar. Fern. Coccidae, p. 225

Eulecanium capreae Linn,, linden, plum, poplat. Fern. Coccidae, p. 183

Psocus rufus IValsh. Pack.

\section{Frequenter}




\section{WHLLOW GALLS}

\section{Twig galls}

Euura orbitalis Nort., enlarged, lateral, monothalamous bud gall. Ent. Soc. Phila. Proc. 6:250

Euura nodus Walsh, smooth twig enlargement, one fourth to twice normal diameter. Ent. Soc. Phila. Proc. 6:253

Euura ovum Walsl, oval, monothalamous twig gall, on one side. Ent. Soc. Philit. Proc. $6: 251$

Cecidomyia cornuta Walsh, larva bores stems affected by C. brassicoides. Ent. Soc. Phila. Proc. $3: 625$

Cecidomyia coryloides iValsh, large, monothalamous, apical; resembling a bunch of hazelnuts. Ent. Soc. Phila. Proc. 3:588

Cecidomyia hordeoides Walsh, resembles four rowed barley, twig not enlarged as in C. trit ic oides. Ent. Soc. Phila. Proc. 3:599

Cecidomyia nodulus Walsh, smaller, though similar to $C$. b a t at $u$ s, but monothalamous. Ent. Soc. Phila. Proc. 3: 599

Ceridomyia triticoides Walsh, polythalamous, woody, resembling a wheat head, $3 / 11 / 4$ in. Ent. Soc. Phila. Proc. $3: 598$

Rhabdophaga batatas Walsh, irregular polythalamous swelling. Eint. Loc. Phila. Proc. 3:601

Rhabdophaga rhodoides Walsh, monothalamous roselike galls at tip of twigs. Ent. Soc. Phila. Proc. $3: 586$

Rhabdophaga siliqua Walsh, monothalamous solitary oval, apical woody gall, $1 / 2-1$ in. Ins. Galls Ind. p. 840

\section{Leaf galls}

Pontania borealis Marlt., solitary, smooth, reddish, pyriform, $1 / 3$ in., $2 / 3$ below. Dyar. N. Y. Ent. Soc. Jour. 6:121

Pontania consors Marlt., gregarious, hairy, spheric, near leaf base, I/3 in. Dyar. N. Y. Ent. Soc. Jour. 6:121

Pontania gracilis Mlarlt, green, spheric gall, equally on both surfaces. Dyar. N. I. Ent. Soc. Jour. 5: 197

Pontania terminalis Narlt., green swelling on upper surface. Dyar. N. Y. Ent. Soc. Jour. 5:24

Rhabdophaga brassicoides Walsh, bunches of oval, monothalamous, sessile galls, $3 / 4-21 / 4$ in. Ent. Soc. Phila. Proc. $3: 577$

Rhabdophaga gnaphaloides Walsh, apical, solitary, subspherical, ${ }_{4}-{ }^{-1} ;$ in. Ent. Soc. Phila. Proc. $3: 583$

Rhabdophaga strobiliscus Walsh, pine cone-shaped gall. Ent. Soc. Phila. J'roc. $3: 582$

Cecidomyia verruca Walsh, small, monothalamous, irregularly spheric gall. Ent. Soc. Phila. Proc. 3:606

Phylloxera salicicola Perg., woolly aphids in bark crevicess and leaf buds. Davenport. Acad. Sci. Proc. 9:267

Eriophyes salicicola Garm., longitudinal leaf folds. Pack. p. 595

Acarus aenigma Walsh, polythalamous, irregular, spheroidal, almost sessile mass of bud or leaf tissues, $I_{3}-\mathrm{I}^{\mathrm{I}}{ }^{\mathrm{IO}} \mathrm{in}$. Ent. Soc. Phila. Proc. $3: 608$

Acarus semen Walsh, small, roughened, greenish yellow, mostly on upper surface. Ent. Soc. Phila. Proc. 3:606 


\section{Inquilines}

Cecidomyia albovittata Walsh, in various leafy, tip galls, R. strobiloides ITalsh, etc. N. Am. Diptera, p. 159

Cecidomyia annulipes Walsh, in galls of R. strobiloides Walsh. Ent. Soc. Phila. Proc. 3:629

Cecidomyia atricornis Walsh, in galls of R. strobiloides Walsh. N. Am. Diptera, p. 159

Cecidomyia atrocularis Walsh, in galls of R. strobiliscus Walsh. N. Am. Diptera, p. 159

Cecidomyia orbitalis Walsh, in various willow galls. N. Am. Diptera, p. I60

Lestodiplosis septem-maculata Walsh, in galls of R. brassicoides Walsh. Ent. Soc. Phila. Proc. 3:630

Lestodiplosis decem-maculata Walsh, in galls of R. strobiloides Walsh. Ent. Soc. Phila. Proc. 3:63I

Epinotia saliciana Clem., larva in willow galls. Am. Ent. Soc. Trans. Io: 47

Epinotia salicicolana Clem., larva in willow galls. Am. Ent. Soc. Trans. 10:47

Enarmonia gallaesaliciana Riley, larva in willow galls. Pack. p. 576

Aristotelia salicifungiella Clem., larva mines willow cabbage gall. Tineina N. A. p. 262

Batrachedra salicipomonella Clem., white, black banded larva in willow gall, 38 in. Pack. p. 5\&:. l'uplar

\section{POP'LAR}

Borers

Eros aurora Herbst. Pack.

Dicerca prolongata Lec. Ent. Am. 5:29

Agrilus granulatus Say. Pack. p. 443

Poecilonota cyanipes Say. Ent. Am. 5:30

Plectrodera scalator Fabr. Am. Ent. Soc. Trans, 23:112. IVillow

Hyperplatys aspersus Say, hickory, chestmut, cottonwood. N. Y. Ent. Soc. Jour. 4:79

Zeugophora varians $\mathrm{Cr}$. Am. Ent. Soc. Trans. 22:370

Saperda moesta Lec. Am. Ent. Soc. Trans. 23: 151

Oberea tripunctata Swed. var. mandarina Fabr. N. Y. Ent. Soc. Jour. 4:8 I

Dorytomus mucidus Say. N. Y. Ent. Soc. Jour. $1: 41$. Pine

Memythrus dollii Neum. Ins. N. J. P. 471

\section{Leaf feeders}

Pontania populi Marlt., whitish larva with two dusky brown, corneous patches. Dyar. N. Y. Ent. Soc. Jour. $5: 24$

Pontania robusta Marlt., pale emerald-green larva. Dyar. N. Y. Ent. Soc. Jour. 5: 195

Pteronus hudsonii Dyar, bluish green, orange-yellow blotched larva. An. Ent. Soc. Trans. 22:306

Pteronus lombardae Marlt., larva indistinguishable from P. ventralis. Dyal. N. Y. Ent. Soc. Jour. $5: 25$

Camponiscus americana Marlt., whitish green dorsally, not shining; at rest, spirally curled. Dyar. N. Y. Ent. Soc. Jour. 5:23

Cryptocephalus leucomelas Suffr. Ins. N. J. p. 302 
Chrysomela conjuncta Rog., gregarious, black larvae, I/3 in. Pack. p. 470.

Wollastonia quercicola Boh. N. I. Ent. Soc. Jour. I $: 87$

Raphia frater Grote, bluish green, yellow and red marked larva, $1 \frac{1}{2}$ in. Pack. p. 462. IVillow

Apatela distans Grote, black, pale yellow haired larva; willow, birch, alder. Sm. \& Dyar. U.S. Nat. Nus. Proc. $21: 16$ I

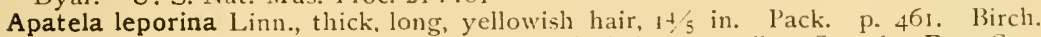

Apatela lepusculina Guen., yellow larva; 5 black hair pencils. Saund. Ent. Soc. Ont. I 4 th Rep't, p. 24

Apatela noctivaga Grote, black mottled, red banded larva. Sm. \& Dyar. L. S. Nat. Nus. Proc. 21:156

Apatela populi Riley, yellowish, hairy larva with black hair pencils. Pack. p. 433

Apatela sperata Grote, pinkish or carmine, brown mottled, blackish larva: alder. Sm. \& Dyar. U. S. Nat. Mus. Proc. 21:154

Catocala amatrix Hübı., gray or flesh-colored, black spotted larva, 3 in. Pack. p. 465

Catocala unijuga Walk., gray, white marked larva, $2^{1} 5$ in. Pack. P. $4^{6} 3$

Catocala meskei Grote, light drab, brown banded larva, 2,2 in. Pack. p. $4^{62}$

Plathypena scabra Fabr. U. S. Div. Ent. Bul. 32:55

Melalopha albosigma Fitch, yellow, gray lined larva, $\mathrm{I}_{+}+$in. Pack. N. Y. Ent. Soc. Jour. I : 27 . IVillow

Melalopha apicalis Walk., light brown or grayish larva with yellowish tubercles, $11 / 4$ in. Pack. Monogr. Bombycine Moths, p. 125. Willow.

Melalopha strigosa Grote, black headed, yellow and purple striped larva. Dyar. Psyche, $7: 424$

Gluphisia septentrionalis WValk, green, pink marked larva, $1^{1}+\mathrm{in}$. : willow, birch. Pack. Nonogr. Bombycine Moths, p. 90. Elm, sweet gum

Pheosia dimidiata H.-S., reddish, slate gray, black horned larva, I 1/2 in.; willow. Pack. Monogr. Bombycine Moths, p. 158

Hyperaeschra stragula Grote, a slate or lilac colored, brown and golden marked larva with humps on the $2 \mathrm{~d}, 3 \mathrm{~d}$ and 8 th abdominal segments, 2 in.; willow. Pack. Monogr. Bombycine Moths, p. 165

Harpyia scolopendrina Boisd., red headed, yellowish, purple marked, long tailed larva. Pack. Monogr. Bombycine Moths, p. 270

Epimecis virginaria Cram., red headed, yellowish, bluish green marked spanworm. Pack. Nonogr. Geometrid Moths, p. 443

Lycia ursaria Walk., drab or dingy purple spanworm, 2-21/2 in. Pack. p. 445. Elm, wild cherry.

Metanema inatomaria Guen. Ins. N. J. p. $15 \mathrm{I}$

Anacampsis rhoifructella Clem., green, black spotted or brown, dark marked larva, $5 / 8$ in. Pack. p. 468 . Sumac

Gracilaria stigmatella Fabr., willow. Am. Ent. Soc. Trans. 10: 192

Ancylis tineana Hübn. Am. Ent. Soc. Trans. I0:52

Coleophora cinerella Chamb. U. S. Div. Ent. Bul. $32: 56$

Phyllocnistis populiella Chamb., tortuous winding mine with central indistinct frass line. Cinn. Quar. Jour. Sci. 2: 106

Lithocolletes populiella Chamb. Pack. p. 468

Proleucoptera albella Chamb., conspicuous mine in silver-leaved and lombardy poplars, separates the two cuticles. Can. Ent. $3: 24$ 


\section{Sucking insects}

Chaitophorus candicans Koch. Pack.

Chaitophorus populifoliae Fitch, chestnut-brown, black marked aphid, 1/s in. Pack. p. 471

Chaitophorus populicola Thom. Pack. p. 434

Pemphigus popularius Fitch, brown, green, black marked aphid, ${ }^{1} 8$ in. Pack. P. 472

Pemphigus populi-globuli Fitch, basal, globular leaf galls. Pack. p. 772

Pemphigus populimonilis Riley. Pack.

Pemphigus populiramulorum Riley. Pack.

Phemphigus populi-venae Fitch, yellow mid vein galls. Pack. P. 472

Pemphigus pseudobyrsa Walsh. Pack.

Phylloxera popularia Perg., in green deserted galls of Pemphigus populic a ul is Fitch. Davenport. Acad. Sci. Proc. 9:266

Phylloxera prolifera Oestl., occurs in deserted galls of Pemphigus populic a ul is Fitch. Perg. Davenport. Acad. Sci. Proc. 9:265

\section{BIRCIt}

\section{Borers}

Campylus denticornis Kirby. Pack. p. 485

Gracilia minuta Fabr. Wickham. Can. Ent. 29:110

Rhinosimus viridiaeneus Rand., under birch bark

Liodes basalis Lec.. on woody fungus

Liodes globosa Lec., on woody fungus

Dorcatoma setulosum Lec., on woody fungus

Orchesia gracilis Melsh., fungi

\section{Leaf feeders}

Croesus latitarsus Nort., blue black larva; cherry: Harrington. Ent. Soc. Ont. 15th Rep't, p. 67

Hylotoma coerulea Nort., larva indistinguishable from If. pectoral is lecach. Dyar. Am. Ent. Soc. Trans. 22:309

Pristiphora tibialis Nort., translucent, leaf-green, shining larva; willow, yellow birch. Dyar. Am. Ent. Soc. Trans. 22:301

Strongylogaster pinguis Nort, not shining, yellowish olivacenus larva; oak, linden. Dyar. Am. Ent. Soc. Trans. 22:311

Tenthredo cressonii Kirby, whitish green to yellowish green translucent larva. Dyar. Am. Ent. Soc. Trans. 22:312

Tenthredo remota MacGill.,y whitish translucent larva, appearing yellowish green. Dyar. N. Y. Ent. Soc. Jour. $5: 19$

Taxonus multicolor Nort., translucent waxy tinged vinous and tar-brown larva. Am. Ent. Soc. Trans. 22:309

Pteronus ? lateralis Nort., dark, slightly shining green larva. Am. Ent. Soc. Trans. 22:307

Pteronus latifasciatus Cress., purplish vinous tinted larva. Dyar. Am. Ent. Soc. Trans. 22:304

Pteronus pinguidorsum Dyar, translucent green larva. Am. Ent. Soc. Trans. 22:303

Pteronus hyalinus Marlt. U. S. Div. Ent. Bul. 3, t. s. p. 67

Syneta ferruginea Germ. l'ack.

Aphrastus taeniatus Gyll. Pack. 
Strophosomus coryli Fabr. N. Y. Ent. Soc. Jour. $1: 42$

Orchestes betuleti Horn. N. I. Ent. Soc. Jour. I : 8 I

Apion walshii Smith. N. Y. Ent. Soc. Jour. I : 40

Eugonia j-album Bd.-I.ec., light green, reddish and black, bristled larva, 2 in.; paper birch. Am. Mus. Nat. Hist. Bul. 5:266; willow, poplar

Drepana arcuata IValk., green, yellow and brown marked larva. licut. Ent. Am. $5: 38$

Lophodonta ferruginea Pack., green, white lined larva; reddish dorsal line on 3 th segment. Pack. Monogr. Bombycine Moths. p. I 50

Apatela superans (zuell., soft green larva; narrow, yellow subdorsal lined; mountain ash, apple. Sm. \& Dyitr. U.S. Nat. Mus. Proc. 2 I : I I9

A patela betulae Rilcy, duil olivaceous brown, black and white haired larva, $1 / 2$ in. Sm. \& Dyar. U.S. Nat. Mus. Proc. $21: 75$

Apatela impleta 11 ill., black and white mottled larva; oak, walnut, eln, ash, maple, linden, apple, cherry, willow, poplar. Sm. \& Dyar. U. S. Nat. Mus. Proc. 21 : 152

Apatela xyliniformis Guen., blickish or gray, finely strigose, red banded larva. Sm. \& Dyar. U. S. Nat. 11 us. Proc. 2 I : i66

Euplexia lucipara Linn., green, white marked larva, 12/5 in. Pack. p. 497

Olene leucophaea Abb. \& Sm. var. basiflava Pack. Can. Ent. 23:34

Cosymbia lumenaria Hübn., green, white marked larva, ${ }_{5}{ }_{5}$ in. Pack. p. 501

Demas propinquilinea Grote, white larva with red or black pencil on joint 3; oak, walnut, beech, maple. Sm. \& Dyar. U. S. Nat. Mus. l'roc. 21:20

Falcaria bilineata Pack, rusty brown larva, $1 / 6$ in. Dyar. N. Y. Ent. Soc. Jour. $2: 108$

Mesoleuca ruficillata Guen. Ent. Am. 3: +9

Ectropis crepuscularia Denis \& Schiff. Mack.

Oreta rosea Walk. Pack. Viburnum

Oreta irrorata l'ack. Pack.

Priocycla armataria 1H.-S., black spanworm, I/2 in. ; maple, birch, currant. Saund. Can. Ent. $3: 130$

Rheumaptera hastata Linn., black or brownish black, black spotted, black and white marked spanworm; sweet gale. Pack. Monogr. Geometrid Moths, p. 164

Metrocampa praegrandaria (iuen., green headed, brown, dark spotted spanworm. Dyar. Psyche, 10: rgo. Oak, hornbeam, elm, linden, willow, poplar

Brephos infans Mosch. l'ack.

Depressaria betulella Busck. U. S. Nat. Mus. Proc. $24: 746$

Moodna pelviculella Hulst. An. Ent. Soc. Trans. 17: 194

Acrobasis betulella Hulst. An. Ent. Soc. Trans. 17:125

Eucosma transmissana Walk. l'ack.

Eucosma solicitana Walk. Pack.

Eucosma similana Hübn., hazel (in Europe). Am. Ent. Soc. Trans. 10: 42

Exartema zellerianum Fern. An. Ent. Soc. Trans. 10:29

Alceris ferrugana Schiff. Pack.

Alceris niveana Fabr. Am. Ent. Soc. Trans. 10:6

\section{Sucking insects}

Bythoscopus fenestratus Fitch. Pack.

Eutettix seminudus Say. Pack.

Corythuca juglandis Fitch. Pack. 
Calaphis betulella Walsh. Pack.

Hormaphis papyraceae Oest. Pack.

Eulecanium websteri King. Fern. Coccidae, p. 198

\section{ALIDER}

\section{Borers}

Dicerca pugionata Germ. Ent. Am. 5:30. Oak, maple

Tetrops canescens Lec. Am. Ent. Soc. Trans. 23:157

Eupristocerus cogitans Web. Ent. Am. 5:32

\section{Leaf feeders}

Kaliosysphinga dohrnii Tisch., slender, whitish leaf-mining larva, ${ }^{1} / 2^{-1 / 3}$ in. Slingerland. Cornell Univ. Agric. Exp. Sta. Bul. 233:58

Amauronematus luteotergum Nort,, shining green larva, yellowish beneath. Dyar. Am. Ent. Soc. Trans. 22:304

Poecilostoma inferentia Nort., smooth, shining, pale green larra. Dyar. Am. Ent. Soc. Trans. 22:308

Pteronus corylus Cress, slender, dark green larva. Dyar. Am. Ent. Soc. Trans. $22: 306$

Pteronus marlattii Dyar, shining green brown larva. Am. Ent. Soc. Trans. 22: 305

Calligrapha scalaris Lec., white, red headed, humped larva, 1/4 in. Pack. p. 635. Wild plum

Monachus saponatus Fabr. Ent. Soc. Ont. 13th Rep't, 1'. 56

Papilio rutulus Boisd. Pack. p. 625

Apatela hastulifera Abb. \& Sm., black, dark brown, haired larva, $1^{2}{ }_{5}$ ill. Sm. \& Dyar. U. S. Nat. Mus. Proc. 21:47. Linden

Mesoleuca truncata Hufn. Ent. Am. 3:50

Hemichroa americana Prov., yellowish larva. Dyar. Can. Ent. $25: 244$

Sabulodes arcasaria IValk., dark brown, silver-marked spanworm; 5 th abdominal segment with double hump; 1 / $/ 4$ in. Pack. p. 628

Telphusa belangerella Chamb., amber-colored leaf roller, with long caudal hairs, $1 / 4$ in. U. S. Div. Ent. Bul. $13: 25$

Acrobasis rubrifasciella Pack, brown, pinkish larva, 1/2 in. Hulst. Am. Ent. Soc. Trans. 17: 124. Hickory

Gelechia corylisella Chamb., dull whitish larva, 1/ in. Pack. p. 635

Lithocolletes auronitens firey \& Boll. Pack.

\section{Aphid}

Lachnus alnifoliae Fitch. Ins. N. J. p. 105

\section{Bud gall}

Dasyneura serrulatae $O$. S., deformed terminal, greenish or bruwn, with whitish efflorescence. Ent. Soc. IVash. Proc. 2: 388 


\section{PINE}

\section{Borers}

Urocerus flavicornis Fabr. Ent. Soc. Ont. 36th Rep't, p. 60

Chalcophora fortis Lec. Pack. p. 680

Buprestis consularis Gory. Ent. Am. 5:30

Buprestis lineata Fabr. Pack. p. $68_{3}$

Buprestis sulcicollis Lec. Ent. Am. 5:30

Buprestis ultramarina Say. Pack. p. 682

Melanophila aeneola Mels. Ent. An. 5:31

Chrysobothris blanchardi Horn. Ent. Am. 5:31

Chrysobothris harrisii Hentz. Pack. p. 680

Chrysobothris trinervia Kirby, spruce. Ent. Am. 5:31

Pityobius anguinus Lec., in pine woods, probably also on hemlocks

Laricobius erichsoni Rosen. Ent. Am. 6:155

Actenodes acornis Say. Ins. N. J. p. 255

Prionus pocularis Dalm. N. Y. Ent. Soc. Jour. 4:74

Callidium janthinum Lecc. N. Y. Ent. Soc. Jour. 4:75

Romaleum simplicicollis Hald. Ins. N. J. p. 287

Euderces pini Oliv. N. Y. Ent. Soc. Jour. 4:77

Neoclytus muricatulus Kirby. N. Y. Ent. Soc. Jour. 4:76

Atimia confusa Say. N. Y. Ent. Soc. Jour. 4:77. Cedar

Leptostylus commixtus Hald. Pack. p. 697. Locust

Leptostylus sexguttatus Say. Wickham. Can. Ent. 29:208

Acanthocinus nodosus Fabr. Im. Ent. Soc. Trans. 23: I32

Eupogonius tomentosus Hald. N. Y. Ent. Soc. Jour. 4: So. Hicknry

Eupogonius pinivora Fitch. Pack. p. 696

Pytho niger Kirby, black spruce. WV. Va. Agric. Exp. Sta. Bul. 32: 204

Podapion gallicola Riley. N. Y. Ent. Soc. Jour. 1:40

Pachylobius picivorus Germ. Pack. p. 727

Hylobius confusus Kirby. Ent. Soc. Ont. 33d Rep't, p. 117

Hypomolyx pinicola Coup. Pack. p. 726

Magdalis lecontei Horn. Can. Ent. 23:24

Magdalis hispoides Lec. Ent. Am. 6:170

Copturodes longulus Lec. IV. Va. Agric. Exp. Sta. Bul. 56:441

Cossonus concinnus Boh. Ent. Am. 6:172

Cossonus corticola Say. Ent. Am. 6:172. Spruce

Cossonus crenatus Horn. N. Y. Ent. Soc. Jour. $1: 87$

Cossonus piniphilus Boh. N. Y. Ent. Soc. Jour. 1:87

Monarthrum fasciatum Say, oak, hickory, beech, hemlock. Ins. N. J. p. $3^{61}$

Gnathotrichus retusus Lec. IV. Va. Agric. Exp. Sta. Bul. 31 : 128

Pityophthorus coniperda Schwarz. Ent. Soc. Ont. 33d Rep't, p. 117

Pityophthorus pullus Zimm. Ins. N. J. p. 362

Pityophthorus pulicarius Zimm. Ins. N. J. p. 362

Pityophthorus annectens Lec. Pack. p. 715

Pityophthorus confinis Lec. IV. Va. Agric. Exp. Sta. Bul. 31:130

Pityophthorus cribripennis Eich. IV. Va. Agric. Exp. Sta. Bul. 56:442

Pityophthorus hirticeps Lec. U. S. Nat. Mus. Proc. 25:56

Pityophthorus lautus Eich. W. Va. Agric. Exp. Sta. Bul. 31:131 
Pityophthorus plagiatus Lec. WV. Va. Agric. Exp. Sta. Bul. 31:129

Pityophthorus puberulus Lec. Ins. N. J. p. 362

Pityophthorus pulchellus Eich., spruce. IV. Va. Agric. Exp. Sta. Bul. 56:4+2

Pityogenes plagiatus Lec. IV. Va. Agric. Exp. Sta. Bul. 56:477

Pityogenes sparsus Lec. WV. Va. Agric. Exp. Sta. Bul. 56: 466

Xyleborus fuscatus Eich., oak, lickory, chestnut. Ins. N. J. p. 363

Xyloterus scabricollis Lec. IV. Va. Agric. Exp. Sta. Bul. 56:444

Tomicus avulsus Eich. IV. Va. Agric. Exp. Sta. Bul. $31: 139$

Dryocoetes affaber Mann. Canl. Eint. 23:26. Sprucc

Dendroctonus pusillus Gyll. Insect Life, 5:187. Spruce

Dendroctonus simplex Lec. Can. Ent. $23: 27$

Hylastes porculus Ehr. Pack. p. 724

Hylastes, tenuis Zimm. IV. Va. Agric. Exp. Sta. Bul. $56: 4+9$

Dryophthorus americanus Bedel. Ent. Am. 6:172

Dioryctria abietella Denis \& Schiff. Am. Ent. Soc. Trans. 17:135

\section{In dead wood or under bark}

Mycetophagus pini Zeigl. Ins. N. J. P. 229

Melanotus cribulosus Lec. Ins. N. J. p. 250

Melanotus leonardi Lec. Ins. N. J. p. 250

Corymbites vernalis Hent\%. I'syche, $4: 203$

Ernobius tenuicornis Lec. P'ack. P. 727

Ernobius luteipennis I.ec. Ins. X. J. p. 267

Ernobius granulatus Lec. Ins. N. J. P. 267

Helops aereus Germ. Ins. N. J. P. 324

Aradus cinnamomeus Panz. N. Y. Ent. Soc. Jour. 13:38

\section{Leaf feeders}

Lophyrus fabricii Leach, greenish, opacjue white larva, with quadrate black spots. J)yar. N. Y. Ent. Soc. Jour, $5: 200$

Lophyrus pini-rigidae Nort., yellowish, black spotted, false caterpillar. Pack. p. 759

Lophyrus pinetum Nort., larva with " 22 feet -6 true, It abojominal prolegs, and 2 anal. The body white, with 2 dorsal and 2 lateral rows of quadrate black spots the former rumning together. The head and true legs shining black. Length, about 3/4 inch." Kirkpatrick. Ohin Firmer. Nov. 24, 1860 (From transcript sup)plied by the editors). See Am. Ent. Soc. Trans. 2:328-20.

Chrysomela philadelphica Lin. Pack. p. Sor. IVillow

Pachybrachys femoratus Oliv. Ent. An. 6:175

Tachygonus lecontei Gyll. Ins. N. J. p. 354. Oak

Scythropus elegans Coup. N. I. E.nt. Soc. Jour. 1:39. Spruce

Cecidomyia inopis O. S., resinou coconon on scrub pine leaves. Diptera N. A. $1: 196$

Incisalia niphon Hübn., slug-shaped, green, yellow striped larva, 3/4 in. Beut. Am. Nus. Nat. Hist. Bu1. 5: 280. Jumiper

Citheronia sepulchralis Gr. \& Rob., brown, horned, red marked larva, + in. Pack. p. 772

Platagrotis condita Guen. Can. Ent. 23:35 
Pheocyma lunifera Hübn., brown, black marked, $15 / 8$ in. Pack. p. 776

Therina pellucidaria Gr. \& Rob., spanworm, whitish, black marked head: body. greenish, brown and black lined. Dyar. Psyche, 9:21

Eufidonia notataria Walk., green, white striped spanworm, i in. Pack. 1). 782. Tamarack, hemlock

Nepytia semiclusaria Walk, whitish, black marked spanworm, I-1/1/8 in. Pack. p. 781. Spruce, fir, tamarack, lsemlock

Macaria praeatomata Haw. var. bisignata Walk., red headed, green spanworm, $3 / 4$ in. Pack. p. 7 So. Birch, fir

Caripeta angustiorata Walk., grayish brown, marbled spanworm, $1_{+}+i n$. Pack. p. 779

Paraphia subatomaria Wood, brown spanworm: Junc. Pack. p. 778. Beech, linden, birch, alcker, spruce, fir

Melanolophia canadaria Guen., pine, spruce, tamarack, hemlock, sweet gale. Ins. N. J. p. 448

Alceris ferrugana Schiff., red or brown headed, green, red tinted leaf roller. P'ack. p. 790

Lapara coniferarum Abb. \& Sm., yellowish green, white lined larva, 3 in. Fern. Sphing. N. E. p. 84

Epinotia pinicolana Zell. Am. Ent. Soc. Trans. 10:47

\section{Root feeder}

Lachnosterna fusca Frohl. Pack. p. 675. Hickory

\section{Sucking insects}

Phlepsius fulvidorsum Fitch, hemlock. Am. Ent. Soc. Trans. 19: it

Melinna modesta Uhler. Ent. Am. 3:69

Tetyra bipunctata H.-S. N. Y. Ent. Soc. Jour. 13:30

- Cixius pini Fitch, brownish black, smoky winged bug, I/4 in. Pack. p. $\mathrm{SO}_{3}$

Livia vernalis Fitch, orange yellow, 1/6 in. Pack. p. 803

Schizoneura pinicola Thom., woolly aphids on tender shoots. Pack. p. 804 Chaitophorus pinicolens Fitch, yellow, white powdered aphid, in. Pack. p. 806 Lachnus strobi Fitch, dark, mealy aphids, $1 / 8$ in. Pack. p. iti

\section{MPICL}

Cupes concolor West. Pack. p. 8?

\section{Borers}

Melanophila longipes Say. Pack. P. 827. Pine

Melanophila drummondi Kirby. Ent. Am. 5:30

Chrysobothris scabripennis Lap. \& Gory. Ent. Am. 5:31. Pine

Xestobium squalidum Lec., black spruce. W. Va. Agric. Exp. Sta. Bul. 32 : 189

Graphisurus pusillus Kirby. IV. Va. Agric. Exp. Sta. Bul. $56:+39$

Pityophthorus tuberculatus Eich. IV. Va. Agric. Exp. Sta. Bul. $31: 132$

Cryphalus piceae Rat\%. IV. Va. Agric. Exp. Sta. Bul. 56:4+4

Dryocoetes granicollis Lec, black spruce. IV. Va. Agric. Exp. Sta. Bul. 3 I : 138

Dendroctonus rufipennis Kirby. U.S. Div. Ent. Bul. 17, n. s. p. 67

Crypturgus alutaceus Sz., black and Norway spruce. WV. Va. Agric. Exp. Sta. Bul. $56: 44^{8}$

Hepialus mustelina Pack. N. Y. Ent. Soc. Jour. $3: 70$ 


\section{Leaf feeders}

Oligia versicolor Grote, humped, red spotted larva, 1/2 in. Pack. p. 840 . Black walnut, pine, fir

Epizeuxis aemula Hübn., brown, dark lined larva. Pack. p. 843

Hydriomena contracta Pack., green, white and yellow lined larva, $2 / 3$ in.: pine, larch, juniper. U. S. Div. Ent. Bul. 12:21

Cleora cribrataria Guen. Pack. p. 841 . Poplar

Therina fervidaria Hübn,, yellowisl, black lined larva. Pack. p. 841

Oxyptilus tenuidactylus Fitch. Pack. p. 851

Alceris variana Fern., red headed, greenish larva, 1/2 in. L S. Div, Ent. Bul. 12:17

Tortrix packardiana Fern., fir. Pack. p. 849

Recurvaria piceaella Kearf., red larva with dorsal green patches; black spruce. N. Y. Ent. Soc. Jour. 11:155

Recurvaria obliquistrigella Chamb., reddish brown bud larva, 1/ in. U. S. Div. Ent. Bul. 12:21. Larch

Epinotia ratzeburgiana Sax, dark olive-brown bud larva; June. Pack. p. 845

\section{Sucking insects}

Bythoscopus variabilis Fitch, black, yellow and white marked, ${ }^{1}{ }_{5}$ in. Pack. p. 854 . Birch

Lachnus abietis Fitch, black aphid, $1 / 6$ in. Pack. p. 853

Chermes abieticolens Thom., apical, conelike deformities on twigs. Pack. p. 853 .

\section{IEMLOCK}

\section{Borers}

Boletophagus corticola Say, under dead bark

Boletophagus depressus Rand., under dead bark

\section{Leaf feeders}

Feralia jocosa Guen., pea-green, checkered yellow and red Jarva, $1^{2 / 5}$ in.; spruce, balsam. Seifert. N. Y. Ent. Soc. Jour. 6:182

Sabulodes lorata Grote, brownish, white marked, tuberculate spanworm, $1 \frac{1}{2}$ in. Pack. p. 873

Caripeta divisata Walk, brownish, white, yellow marked larva. Pack. p. 874

Mesoleuca vasaliata Guen. Ins. N. J. p. $4+1$

Scoparia basalis Walk. Ins. N. J. p. 461

Recurvaria apicitripunctella Clem., slender, green larva, 1/4 in. Pack. p. 876

\section{I3, A LS A M}

\section{Leaf feeders}

Panthea acronyctoides Walk.? Can. Ent. $23: 35$

Tephroclystis luteata Pack., reddish, white specked spanworm, 3/4 in. Pack. p. 865. Hemlock

Archips afflictana Walk. Am. Ent. Soc. Trans. 10: 1 3

Holcocera chalcofrontella Clem., leaf sheath worm. U. S. Div. Ent Bul. $32: 54$ 


\section{LAJCH OR TAMARACK}

\section{Leaf feeders}

Hemichroa laricis Marlt., green striped larva. Dyar. N. Y. Ent. Soc. Jour. $5: 28$ Samia columbia Smith, light green tuberculate larva, 3 in. Pack. p. 89 I

\section{Sucking insects and mite}

Chermaphis laricifoliae Fitch., solitary, black and green aphid, 1/ro in. Pack. p. 903 Lachnus laricifex Fitch, solitary, brown, white marked aphid, 18 in. P'ack. p. 902 Tetranychus telarius Linn,, brown foliage bearing minute, globular mites. Pack. p. 903

\section{CYPRESS}

\section{Gall}

Cecidomyia ananassi Riley, brown, pineapplelike gail, $1 / 2$ in. Am. Ent. $2: 2+4$

\section{ARHOL VITAE OR WHITE CEU.I:}

\section{Leaf feeders}

Recurvaria thujaella Kearf., slender, duil red, purplish larva, $1 / 3$ in. N. Yr. Ent..Soc. Jour. 11:154

Bucculatrix thuiella Pack., brown headed, yellowish larva or white ribbed cocoon. Pack. p. 917

\section{Scale insects and mite}

Eulecanium pallidior Ckll. \& Kg., brownish, hemispheric scale. Psyche, \&:349 Eulecanium fletcheri Ck11. Can. Ent. 25:221

Eriophyes thujae Garm. Pack. p. 920

\section{JUNIPER OK RED CEDAR}

\section{Borers}

Oeme rigida Say. Ins. N. J. p. 287

Leptura abdominalis Hald. N. Y. Ent. Soc. Jour. $+: 78$

Listronotus latiusculus Boh. IV. Va. Agric. Exp. Sta. Bul. "32: 205

\section{Leaf feeders}

Syssaura infensata Guen. var. biclaria Walk., brown, rough spanworm, $\mathrm{I}^{1 / 2} \mathrm{in}$. Pack. p. 907

Phalonia rutilana Hübn, webs containing yellowish larvae, $1 / 4$ in. Pack. p. 910

Recurvaria juniperella Kearf., slender, dull green, pink tinged larva, $1 / 3 \mathrm{in}$. N. Y. Ent. Soc. Jour. 11:157

\section{Sucking insect}

Psallus juniperi Heid. N. I. Ent. Soc. Jour. 13:49 



\section{EXPLANATION OF PLATES}

PLATE 49

757 


\footnotetext{
Wool sower, Andricus seminator llarr.

I Two galls

Banded bullet gall, Holcaspis fasciat a Bass.

2 Probably two young galls of this species

Tomato sumac gall, l'e mphigus rhois lïtch

3 Cluster of galls

Two marked tree hopper, Encluenopa binotata Say

+ Egrg masses on viburnum, entarged 
PARK ANI) WOOLLIVD INSECTS

Memoir 8 N. Y. State Museum

Plate 49
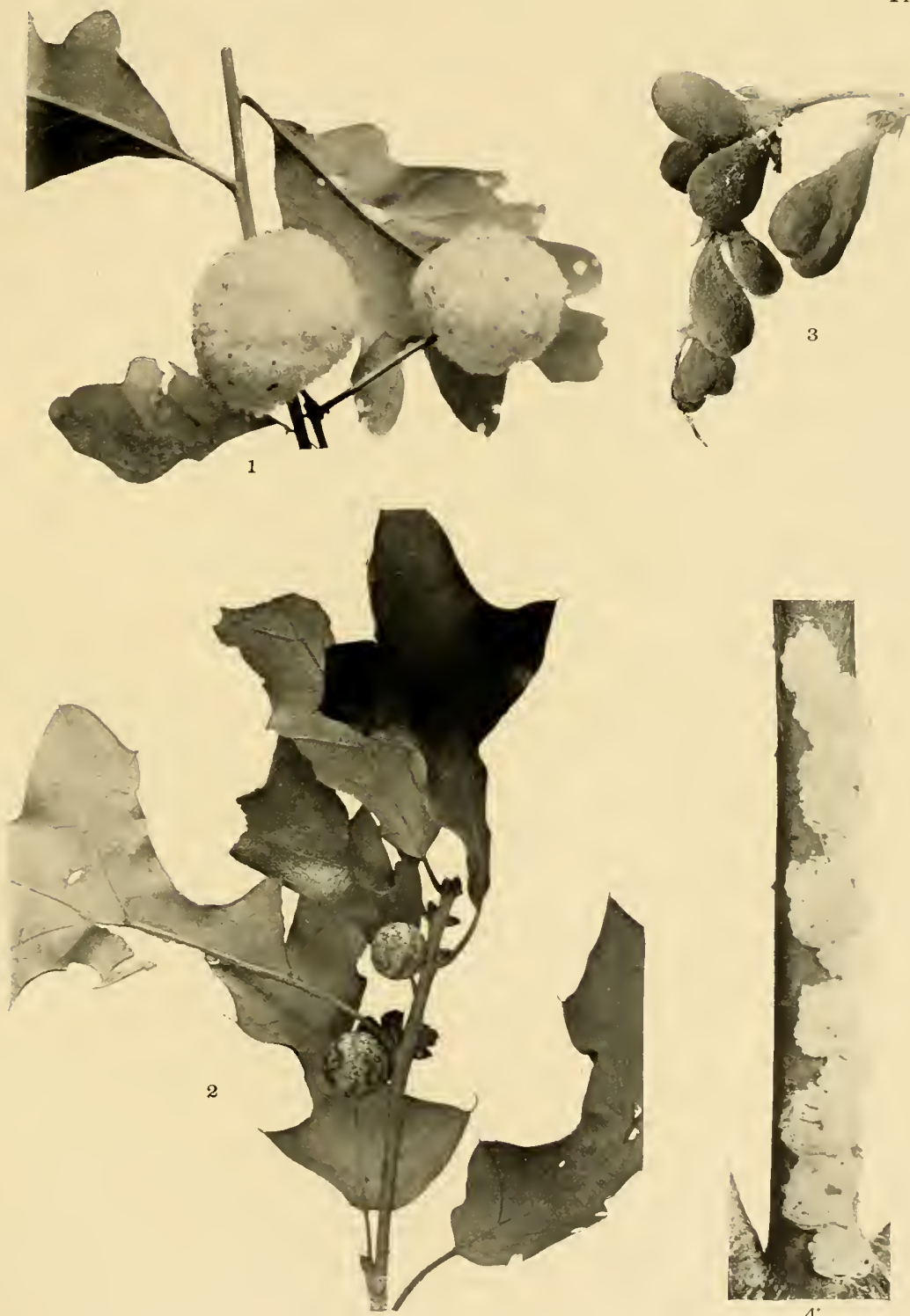

Insect galls and tree hopper eggs

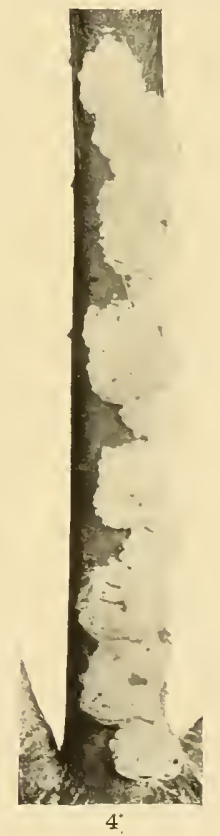



$\underset{759}{\text { PLATE }} 50$ 
Larger oak apple gall, Amphibolips confluentus Harr.

I Two galls on a small twig

Scrub oak gall, Amplibulips ilic ifoliat Bass.

2 Two twigs bearing the peculiar fusiform galls

Poplar stem gall, Agromyza a neiventris Fall

3 Several galls on twigs

Willow gall midge, $k$ habdophaga salicis Shrank

4 Gall with pupal skins protruding therefrom 
Memoir 8 N. Y. State Museum

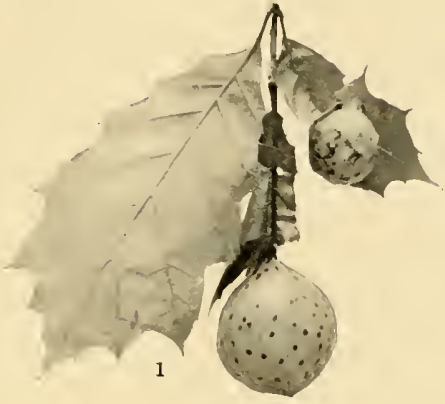

Plate 50

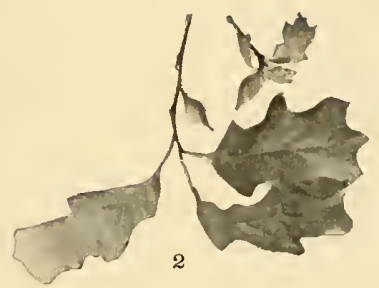

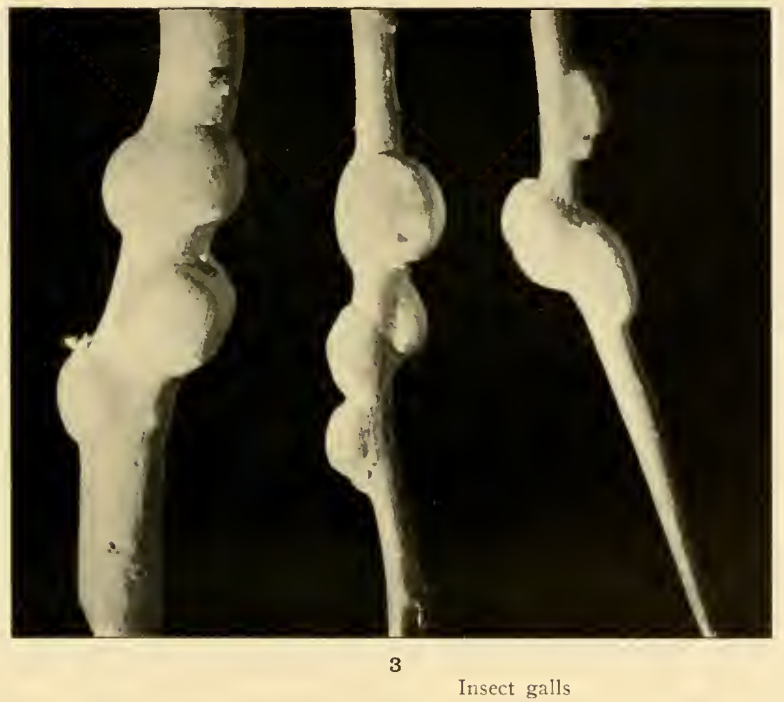

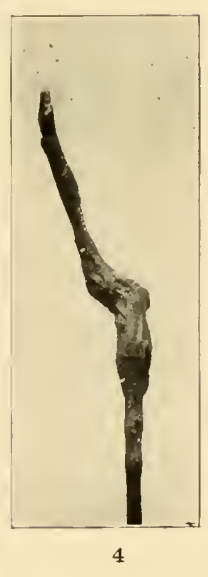



PLATE 51

761 
Vagabond gall, Pemphigus vainabundus Walsh I Two galls on poplar twig

\section{Andricus singularis Bass.}

2 Lpper gall on edge of leaf is this species

Woolly pine scale, I'scudophilippia quaintancii Chll.

3 Infested twig 
P.KK AXI WOODIAXI) IXSECTS

Memoir 8 N. Y. State Museum

Plate 51
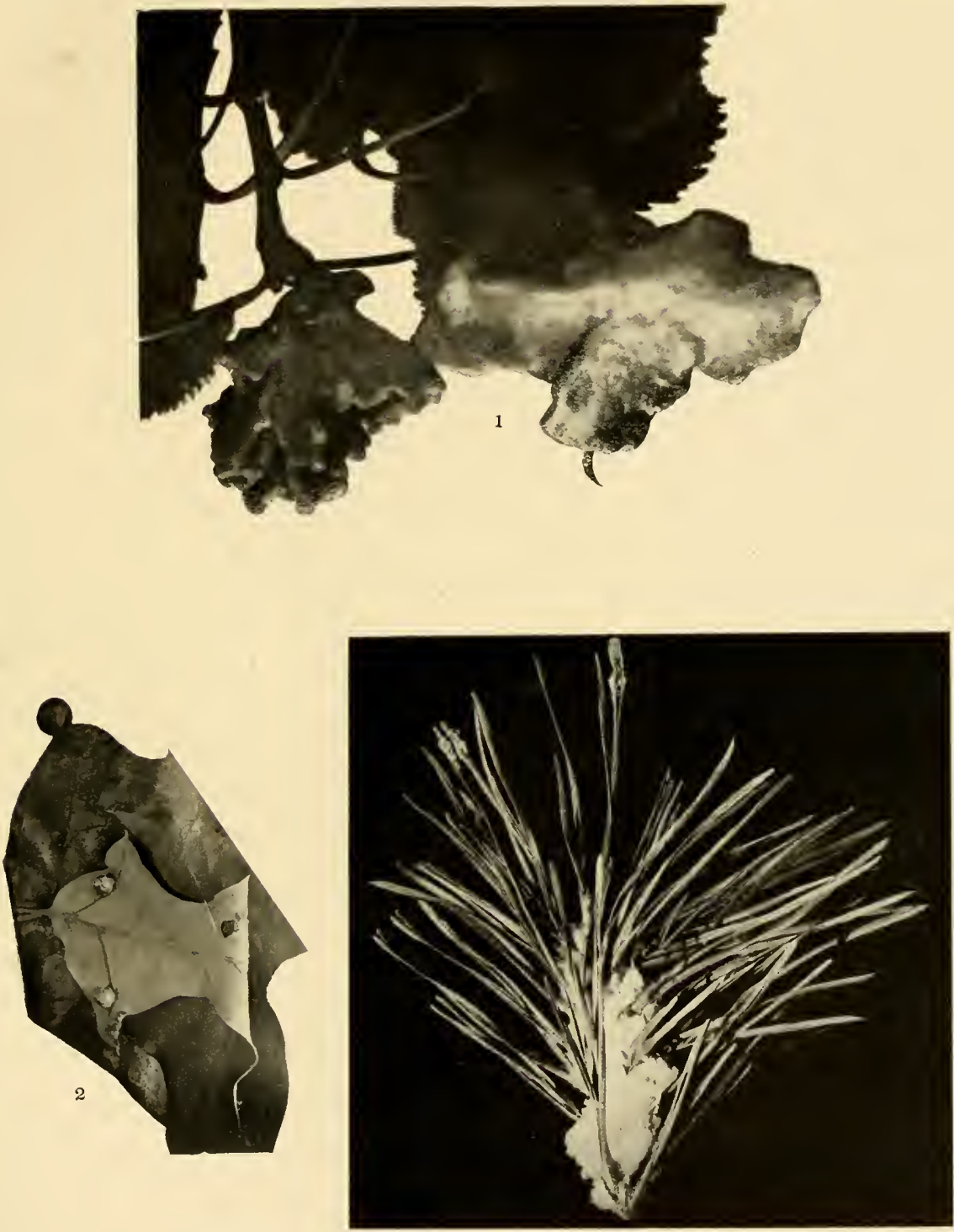

3

Insect galls and woolly pine scale 


Bark borer work at Bath-on-the-Hudson

The coarse writing bark beetle, Tomicus calligraphus Germ, was by far the most abundant and injurious in these white pines.

764 


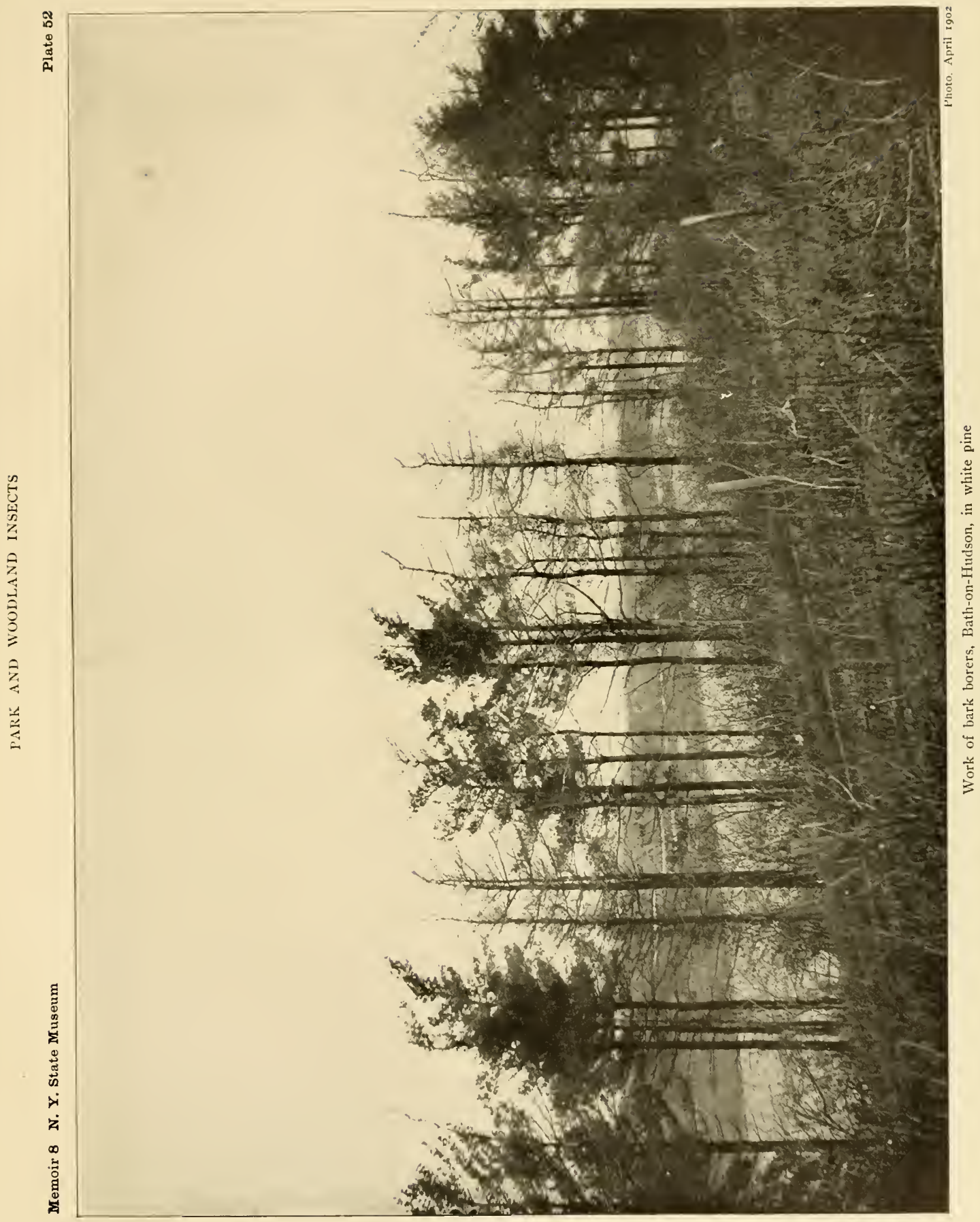



PLATE 53 765 
Bark borer work at Bath-on-the-Hudson

1 Two white pines taken September 22, 190 I

2 Same, photographed April 1902. These two illustrate the rapidity with which trees may be killed by bark borers. Tomicus calligraphus Germ. and T. pini Say were responsible for most of the injury. 
章 Now
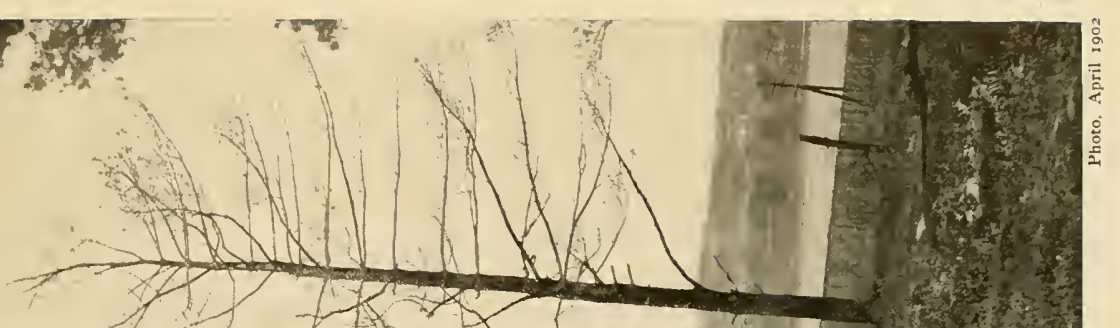

14.
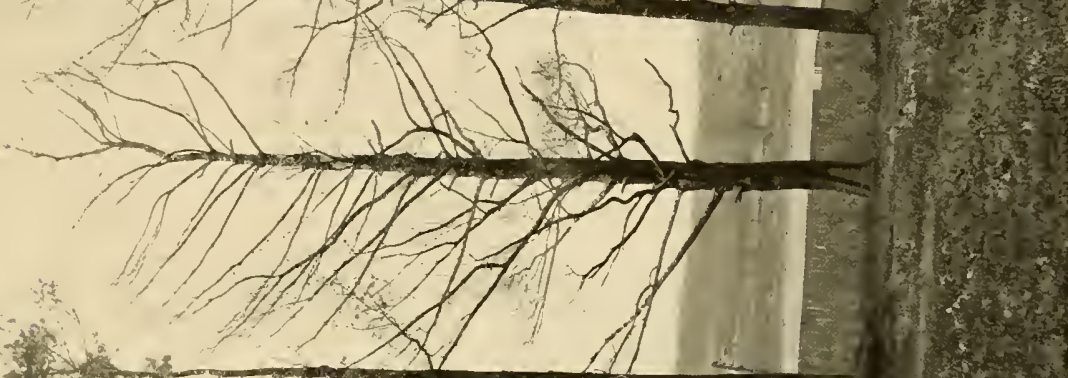

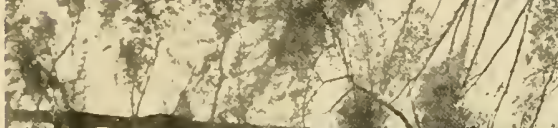
3.7. 3f 72
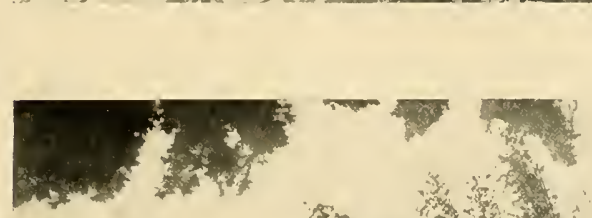

so
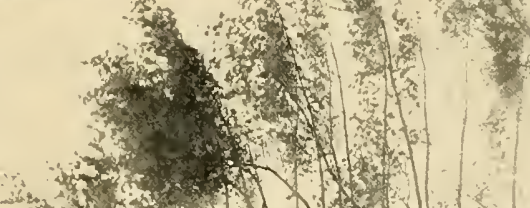

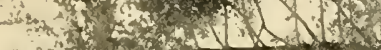
$5-\infty$
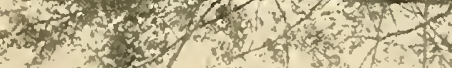

PLATE 54

767 
Coarse writing bark beetle, Tomicus calligraphus Germ.

I Bare wood surface of white pine tree badly scored by galleries

2 Pitch tubes on the trunk of a badly infested tree

3 Borings showing the entrance or central chamber under a pitch tube, the adult and larval galleries

+ A pitch tube in profile 
क्ष

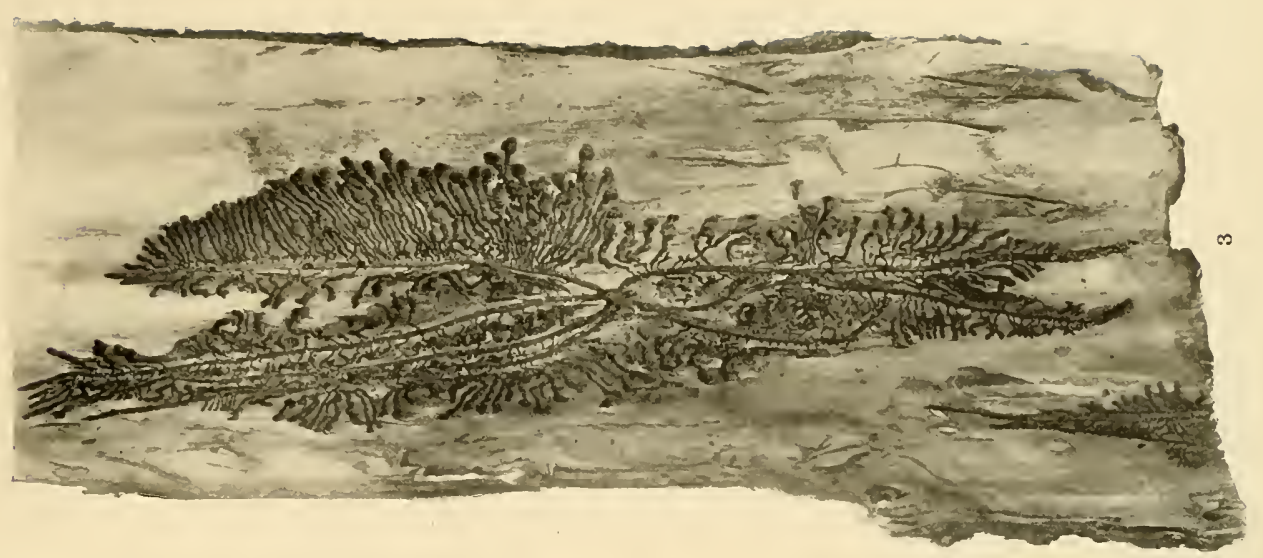

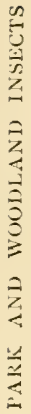
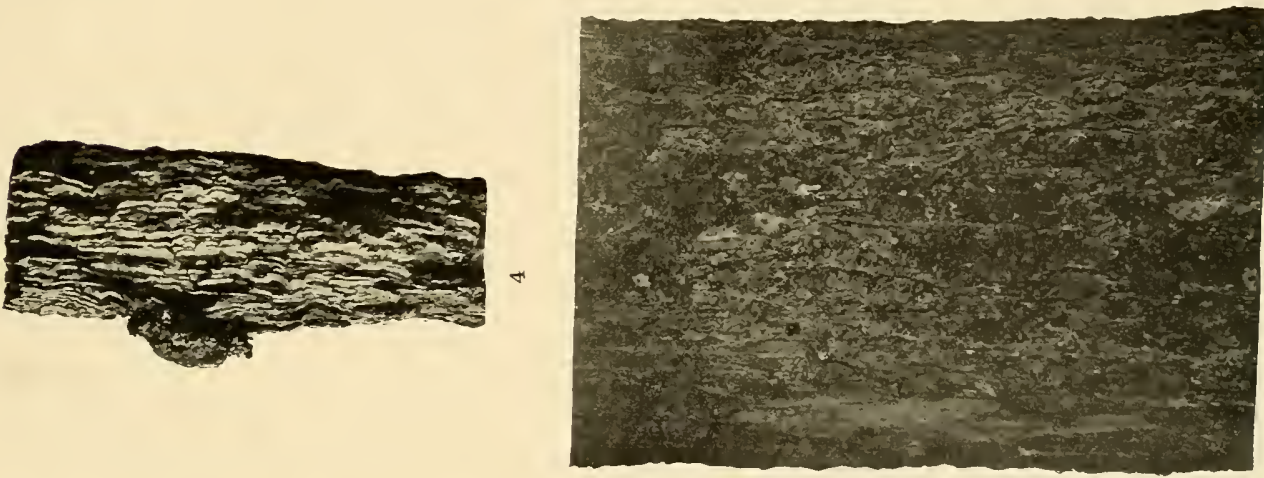

$\alpha$

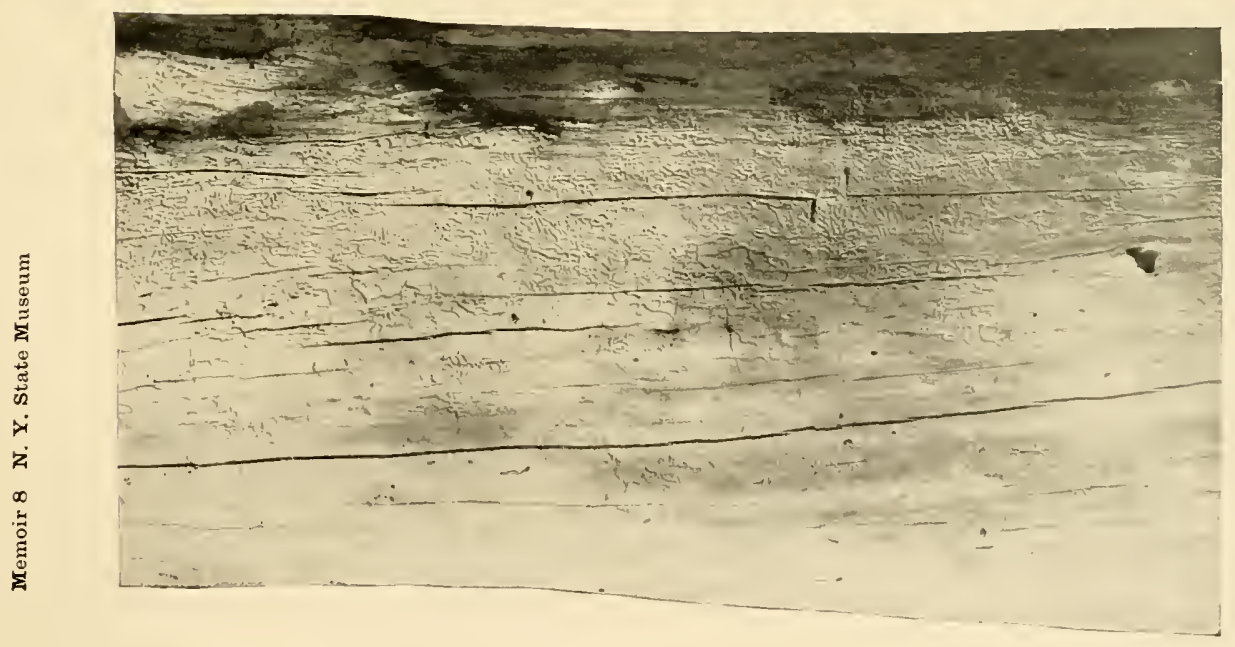


<smiles>C1CC1</smiles> 
PLATE 55

769 
Coarse writing bark beetle, Tomicus callig raphus Germ.

I Inner aspect of badly eaten white pine bark

2 Several galleries preserved by infiltrated pitch

3 Internal aspect of badily scored bark

4 Portion of bark removed from a tree which had been clead some years. most of the galleries being preserved by infiltrated pitch 


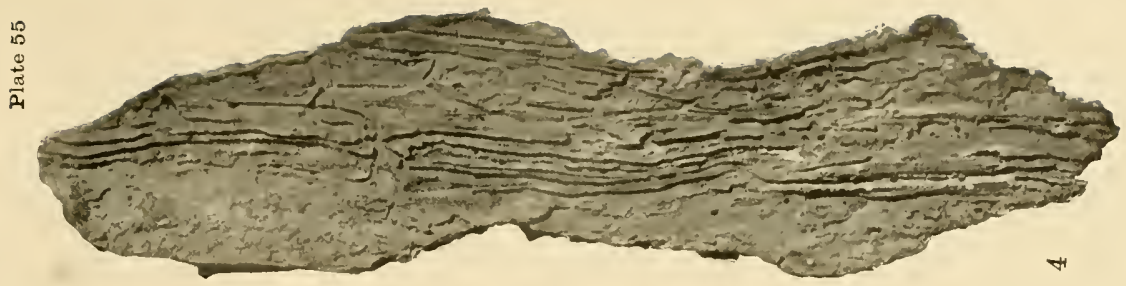

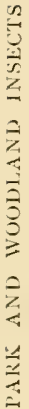
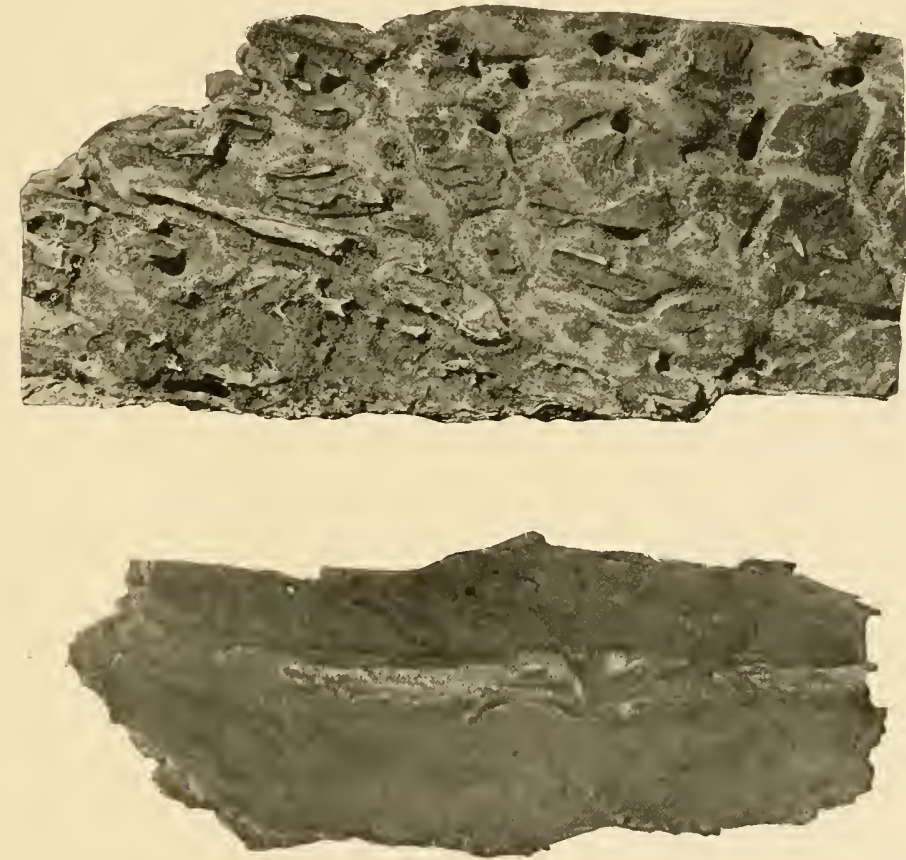

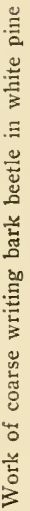

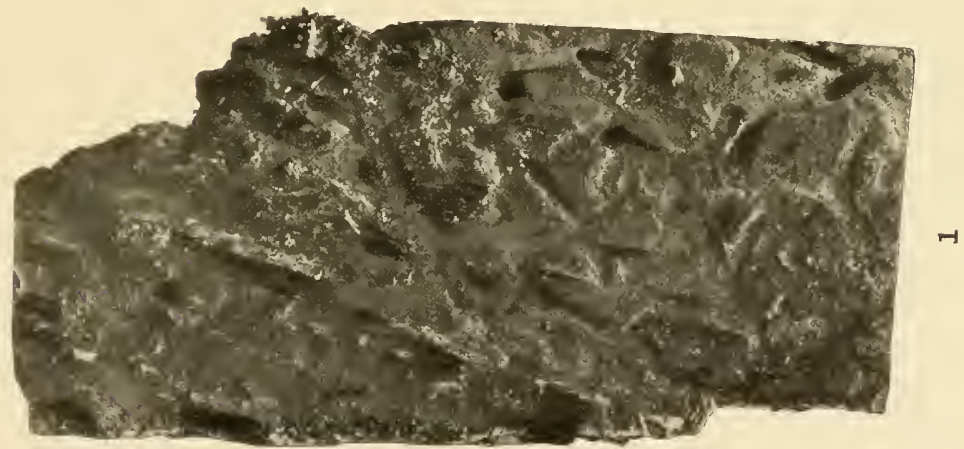



PLATE 56 
Coarse writing bark beetle, Tomicus calligraphus Germ.

I Piece of white bark showing exit holes

2 Base of a badly infested tree from which bark illustrated at figures I and 3 , was taken

3 Same as 2, except that a portion of the bark has been removed to show the condition beneath 


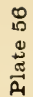
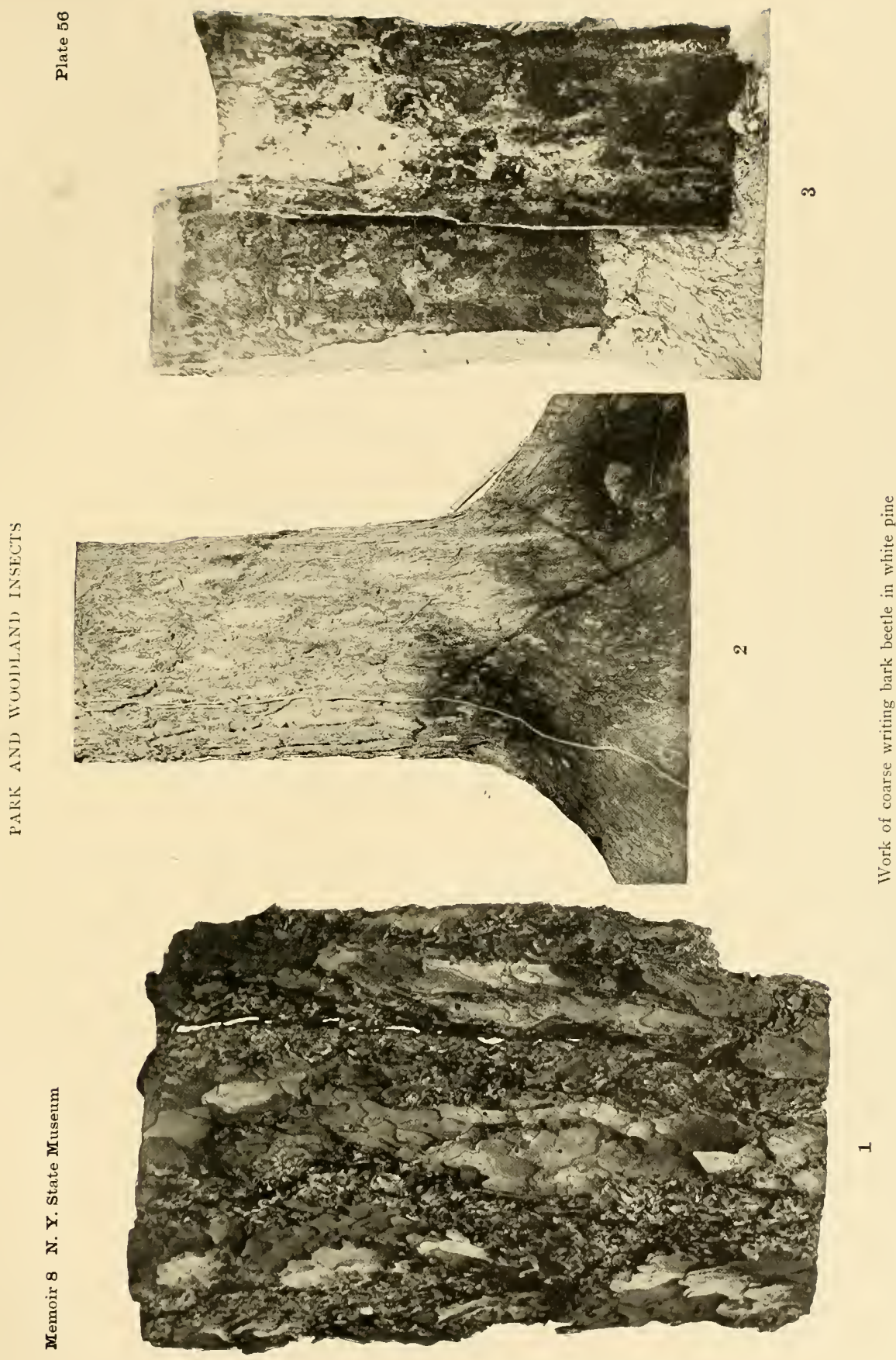

PLATE 57 773 
Pine bark borer, Tomicus pini Say

I, 2 Advanced stage of work in white pine

3 Portion of a typical mine showing in places the work of young Monohammus larvae 


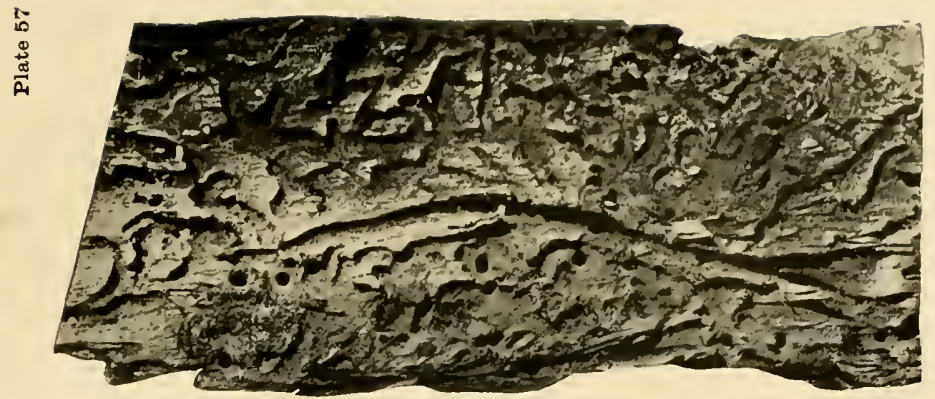

จ

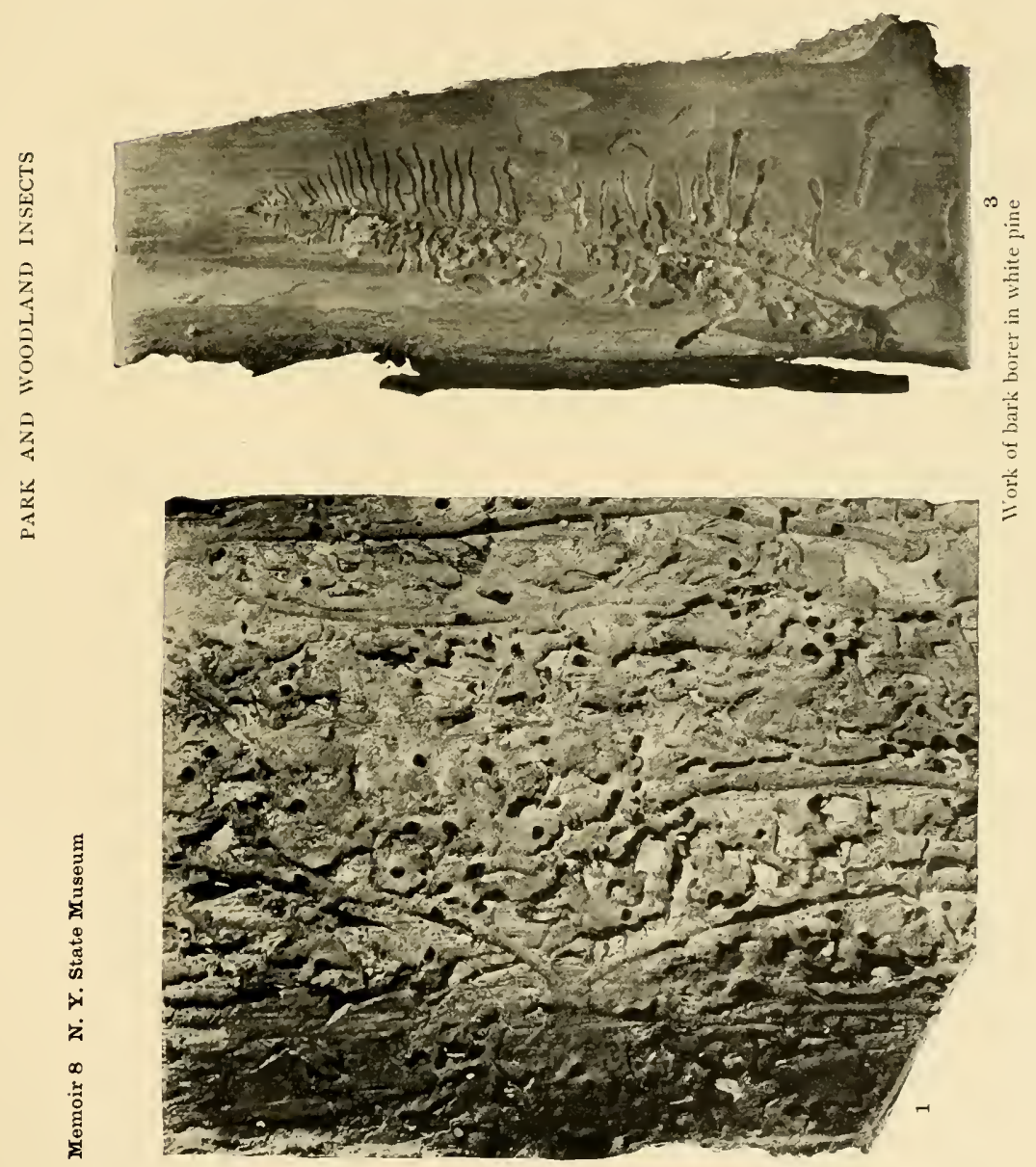





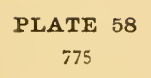


Pine bark borer, Tomicus pin i Say

I Early work in white pine bark

2 Work in a more advanced stage

Balsam bark borer, Tom ic us bals a meus Lec.

3 Early work as shown on the surface of the wood

Turpentine bark beetle, Dendroctonus terebrans Oliv.

4 Work at the base of a tree, showing main gallery with its pitch-lined walls 

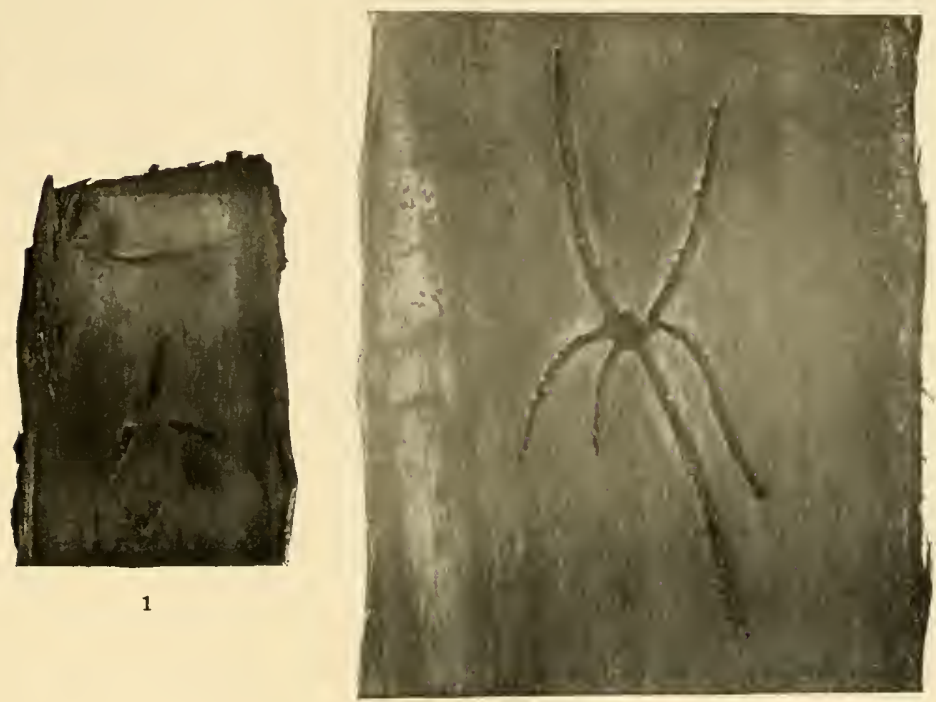

2
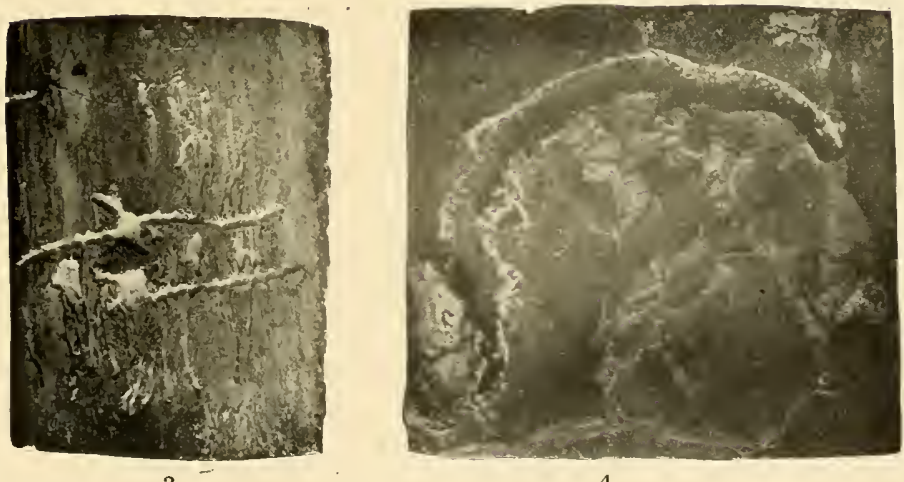

3

4

Work of pine bark borers 

PLATE 59

777 
Pine bark borer, Tomicus pini Say

I Surface of white pine bark showing numerous exit holes and small pitch tubes

2 Internal aspect of the same piece of bark showing galleries of Tomicus and young Monohammus and also exit holes

The light background used in both photographs, makes the exit holes appear as white spots

778 


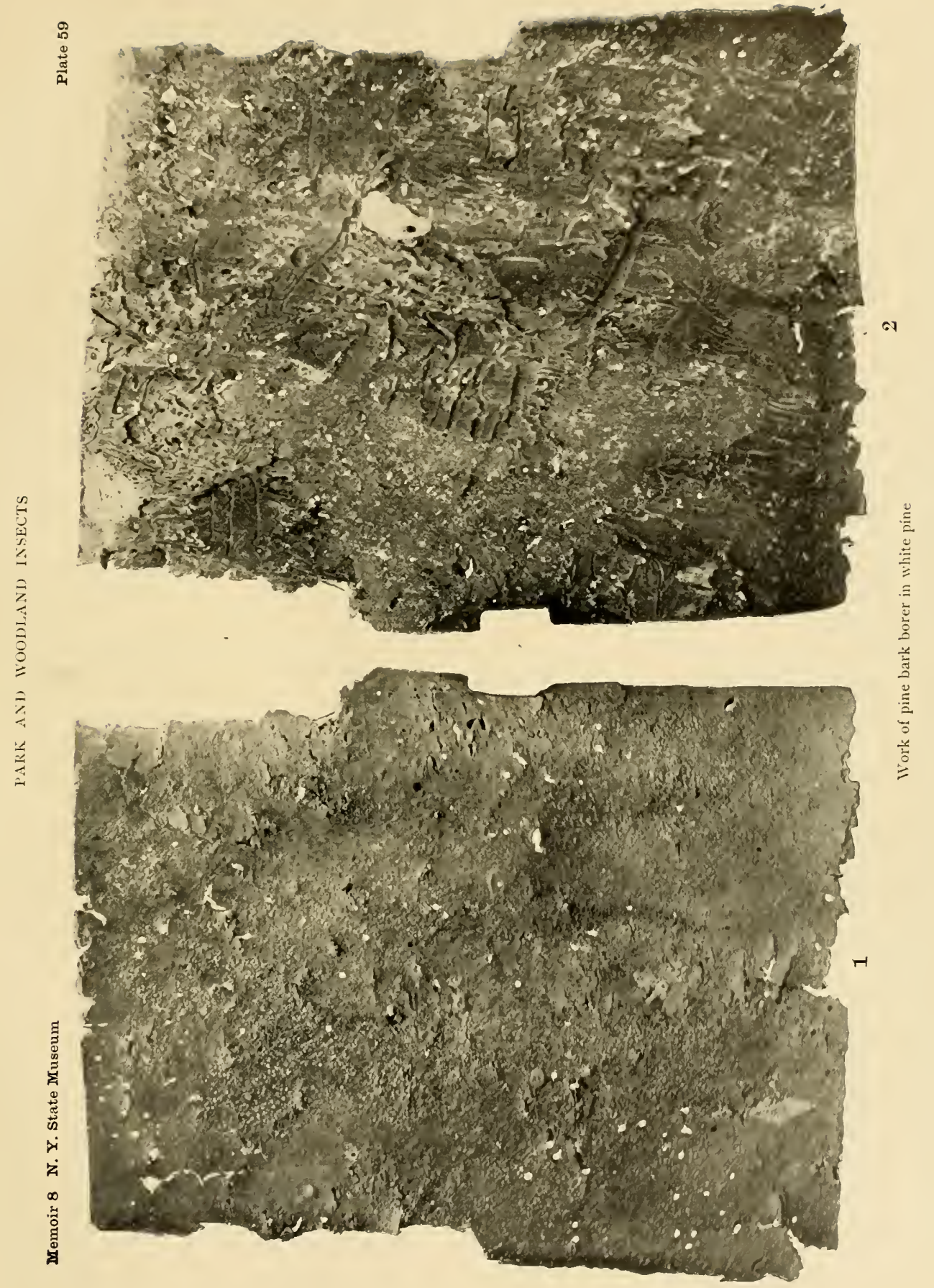





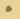

PLATE 60 779 
Southern Tomicus, Tomicus cacographus Lec.

I Early operations in hard pine

2 Same, in a more alvanced stage

3 Thick bark badly eaten l,y this species

Coarse writing bark beetie, Tomicus calligraphus Germ. and

Ribbed pine borer, R hagi um lineat um Oliv.

4 Work under white pine bark, the characteristic pupal cells showing very well 


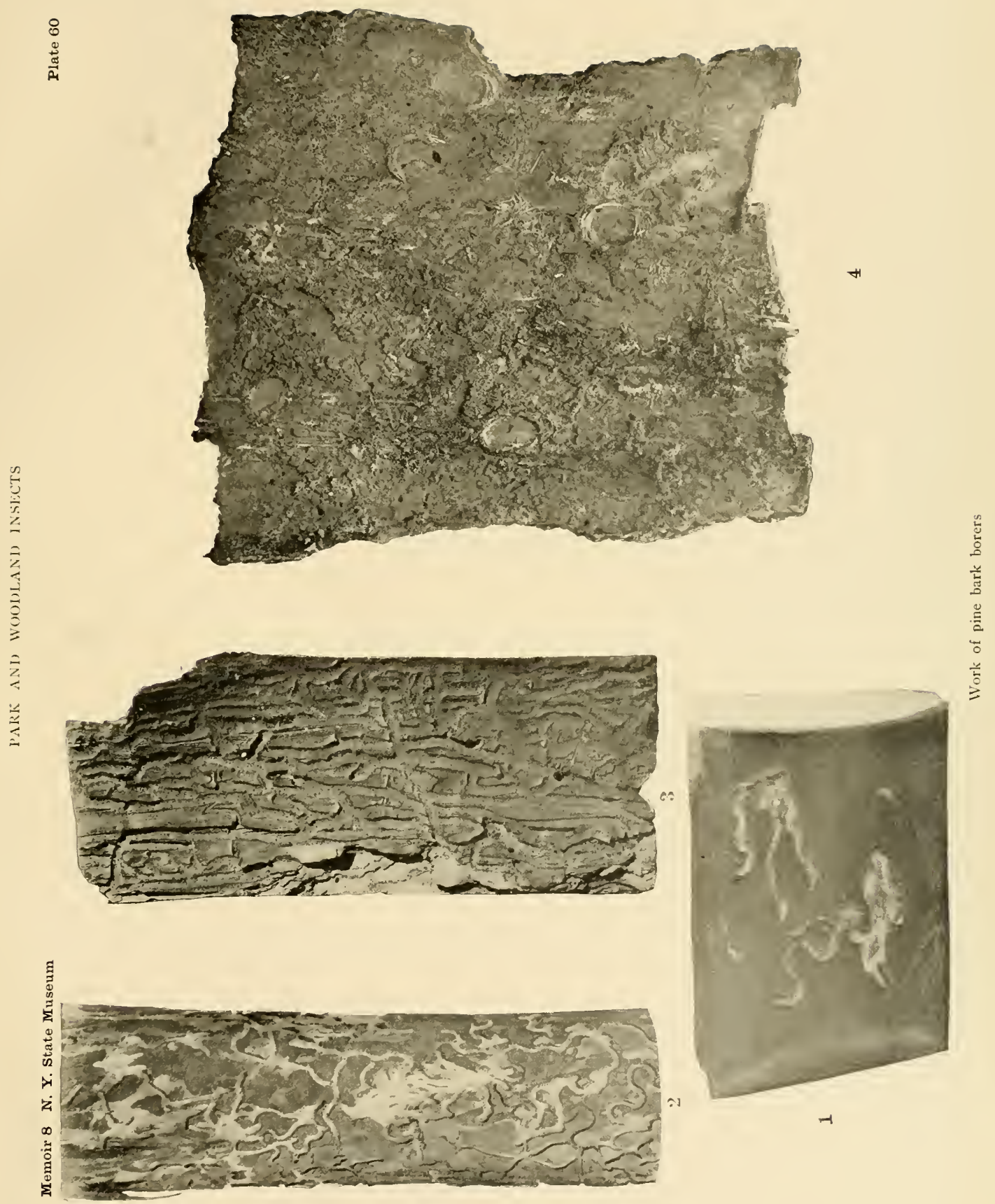




Spruce destroying beetle, Dendroctonus piceaperda Hopk.

I Internal aspect of badly mined spruce bark. This view shows the longritudinal adult gallery and the numerous irregular dilating ones made by the larvae.

2 Interior view of bark showing several longitudinal adult galleries preserved by infiltrated pitch, and also two ventilating burrows, the latter showing light, owing to the white background

Blue pine borer, Callidium antennatum Newm.

3 Hard pine branch showing characteristic mines 

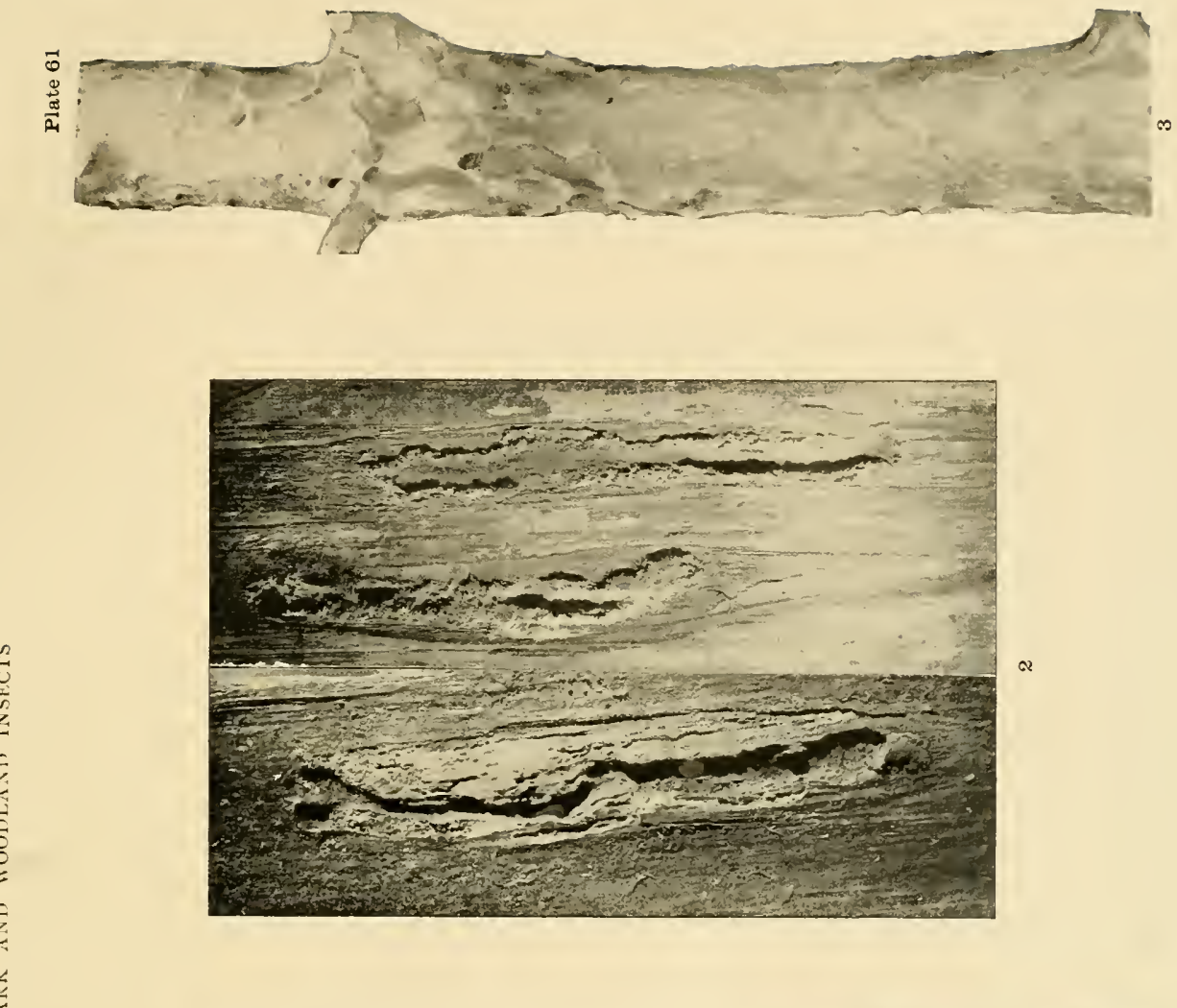

a

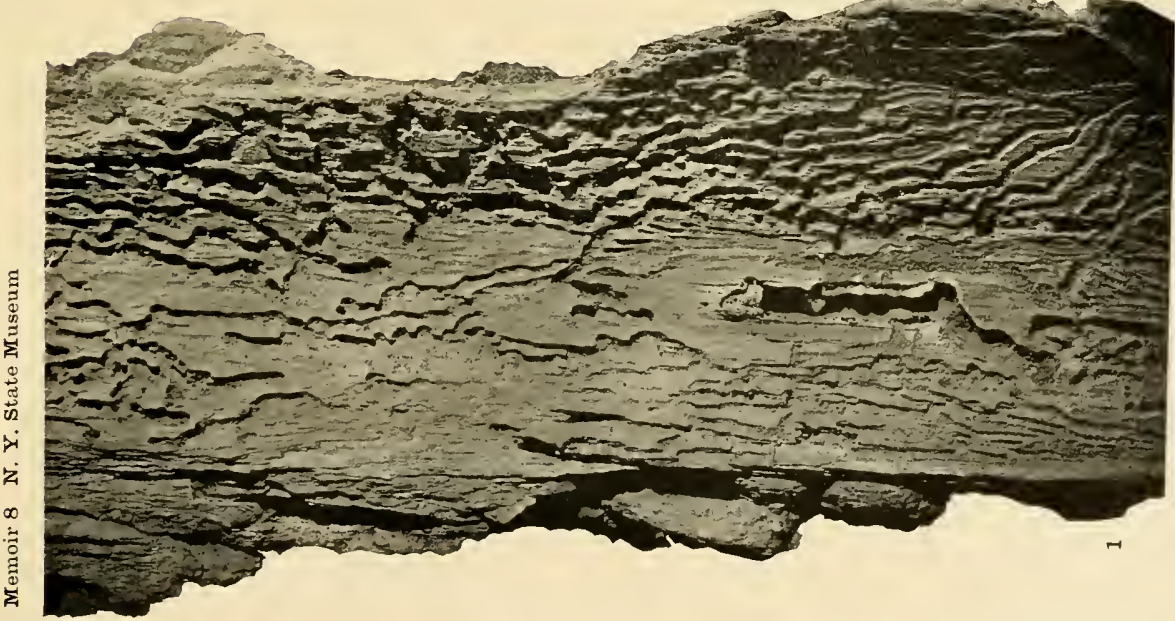



PLATE 62 
Balsam bark borer, Tomicus balsameus Lec.

1 Advanced stage of work in bark

2 A small gallery in bark

3 Portion of galleries in wood, showing the same borings as represented in 1

4 Portion of wool from which the outer bark has been removed, showing very badly riddled, probably decaying tissues

5 Wrood rather badly carved by adult galleries 

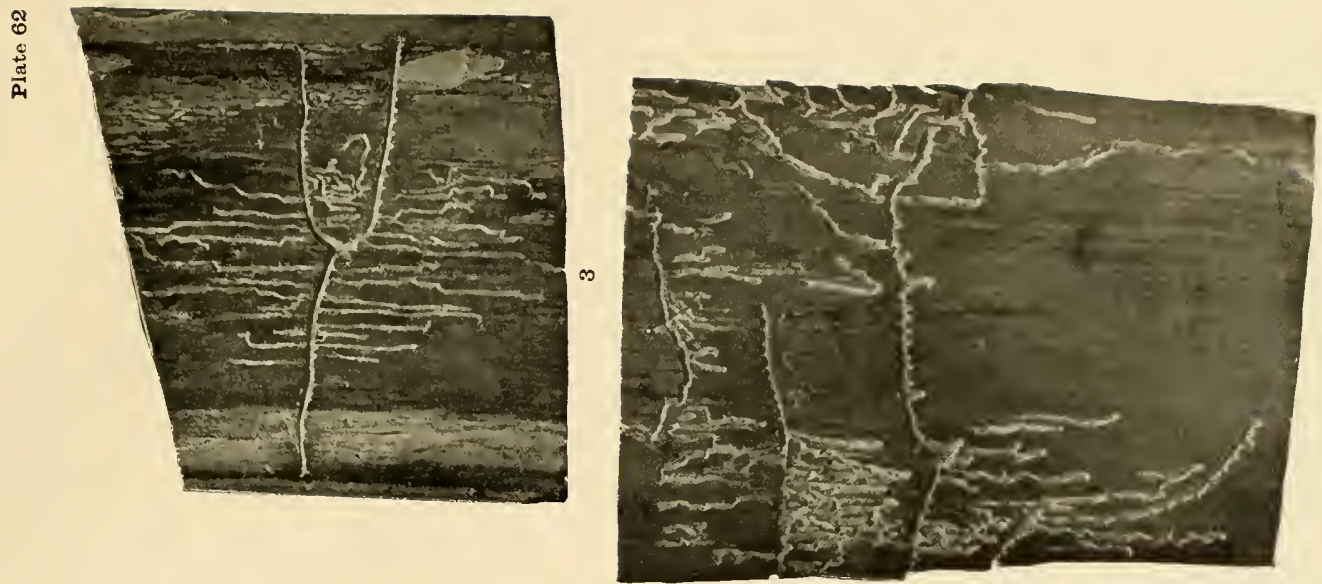

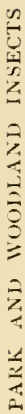

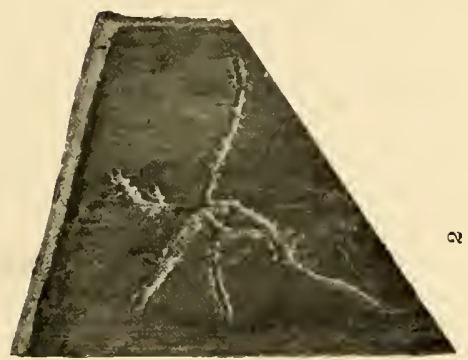

w

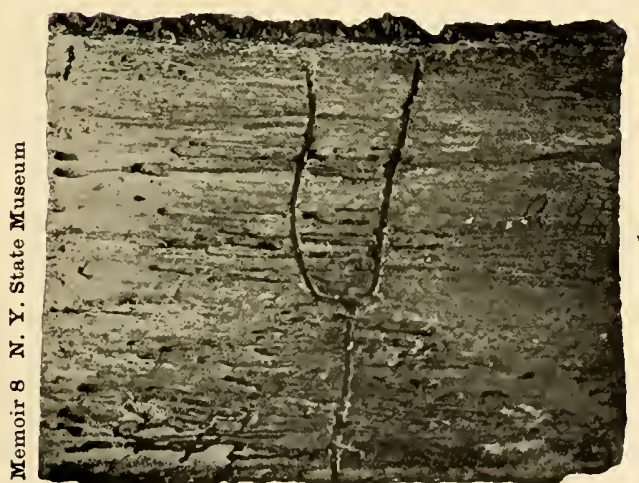

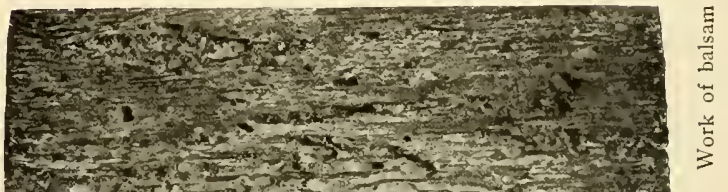

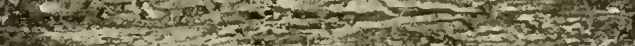

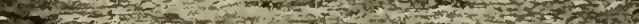

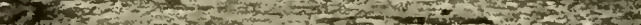

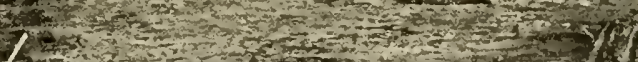

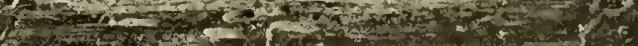

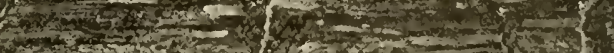

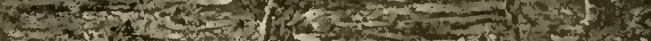

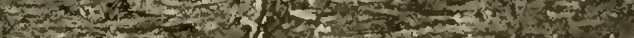

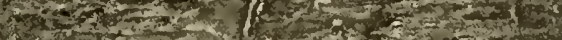

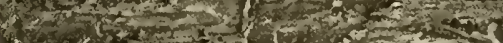

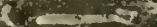

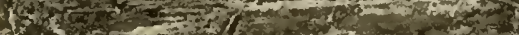

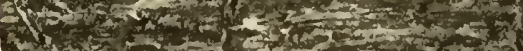

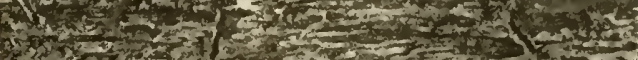

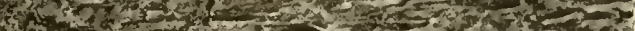

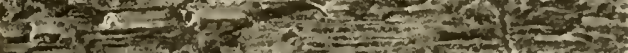

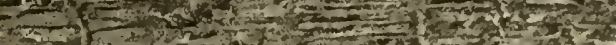

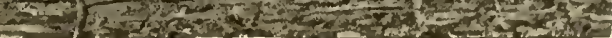





\section{PLATE 63}

785 


\section{Sawyer, Monohammus confusor Kirby}

I Adult, much reduced

2 Adult

Urographis fasciatus DeG.

White-spotted sawyer, Monohammus scutellatus Say

3 Adult

Red cedar bark beetle, Phloeosinus dentatus Say

4 Typical gallery in Arbor vitae

5 IVork in white pine

Pityogenes sp.

Pityophthorus sp.

6 Work under hard pine bark, and probably that of $\mathrm{C}$ a 11 id i u m a n t ennat u m Newm. 
Memoir 8 N. Y. State Museum

Plate 63
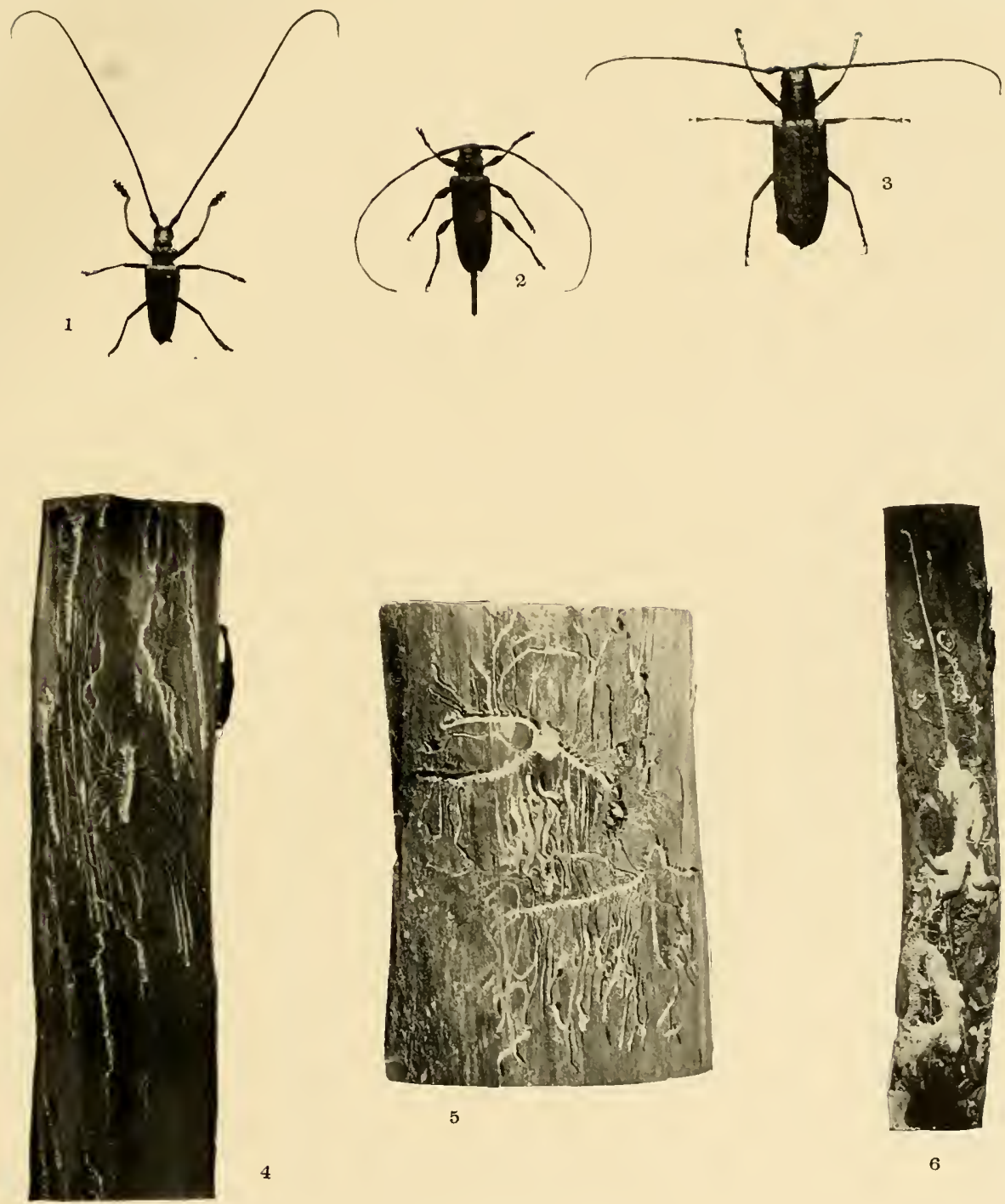

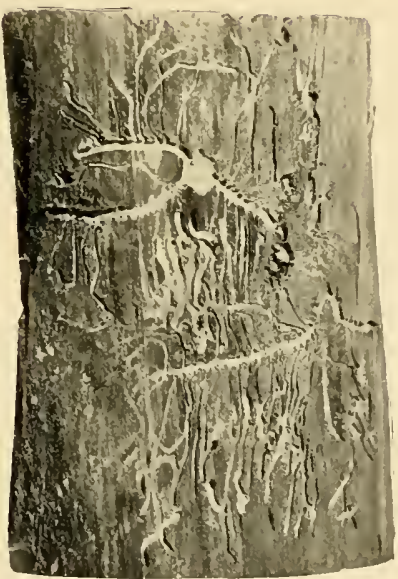

5

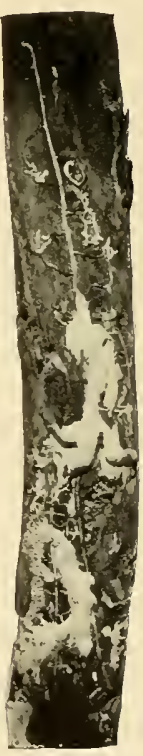

6 

PLATE 64 
Ribbed pine borer, $\mathrm{R}$ hag $\mathrm{i}$ u $\mathrm{m}$ i n eat $\mathrm{u}$ m Oliv.

I Beetle slightly enlarged

+ Pupa slightly enlarged

7. \&, ro Pupal cells

11 Larva or grub

12 Pupa in cell

\section{Pytho americanus Kirby}

2 Beetle slightly enlarged

3 Pupa slightly enlarged

5 Pupa in cell

6, 9 Pupal cells 
PAKK ANH WO(IDL.IXI) IXSECTS

Memoir 8 N. Y. State Museum

Plate 64
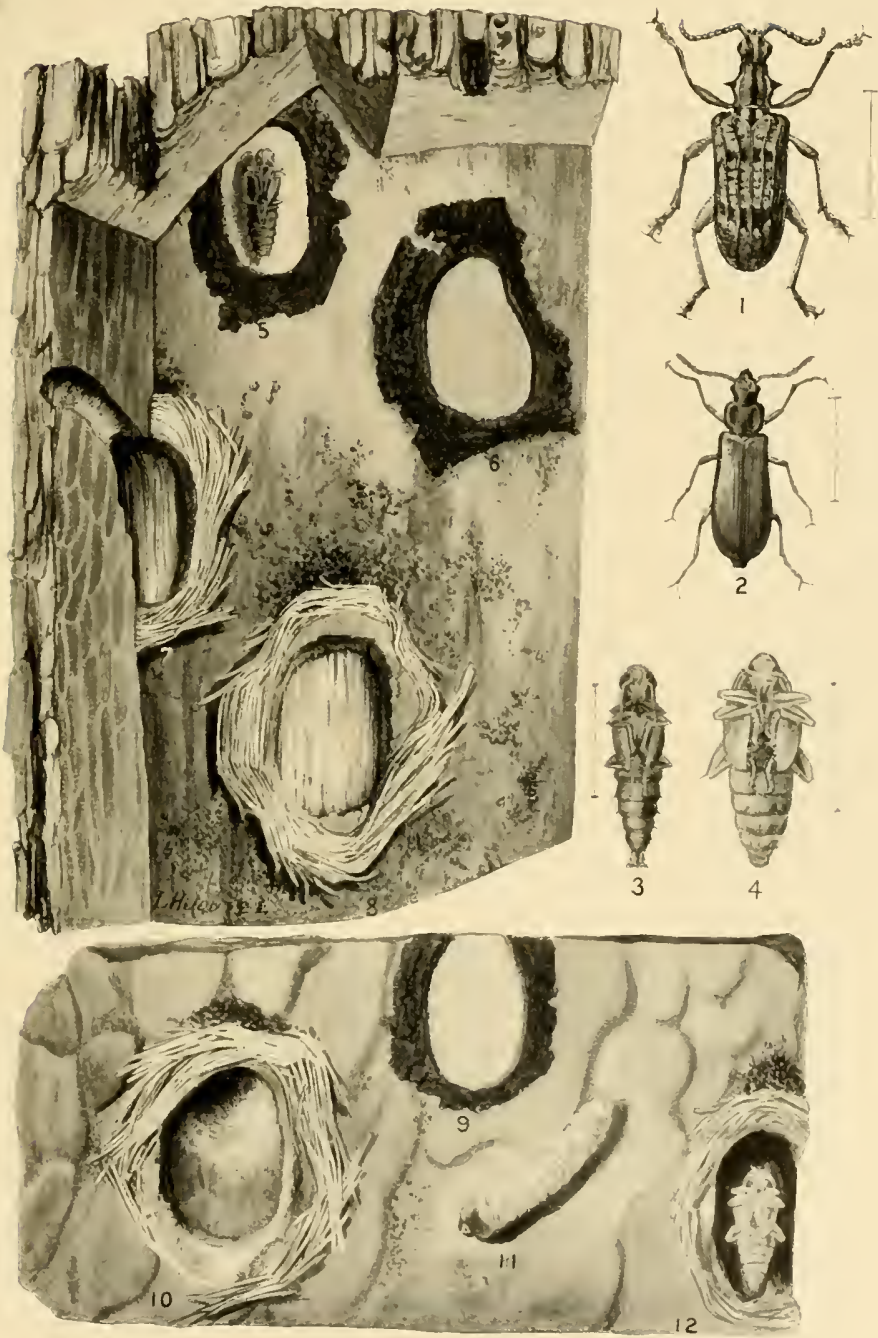

Rhagium and Probo 

PLATE 65

789 


\section{Tomicus sp.}

I White pine killed by bark borers in 1900, at Lansingburg N. Y., photo October 1902, showing the rapidity with which irjured trees decay

White pine weevil, Pissodes strobi leck.

2 Deformed hard pine at Salem N. Y., photo October Igo2 


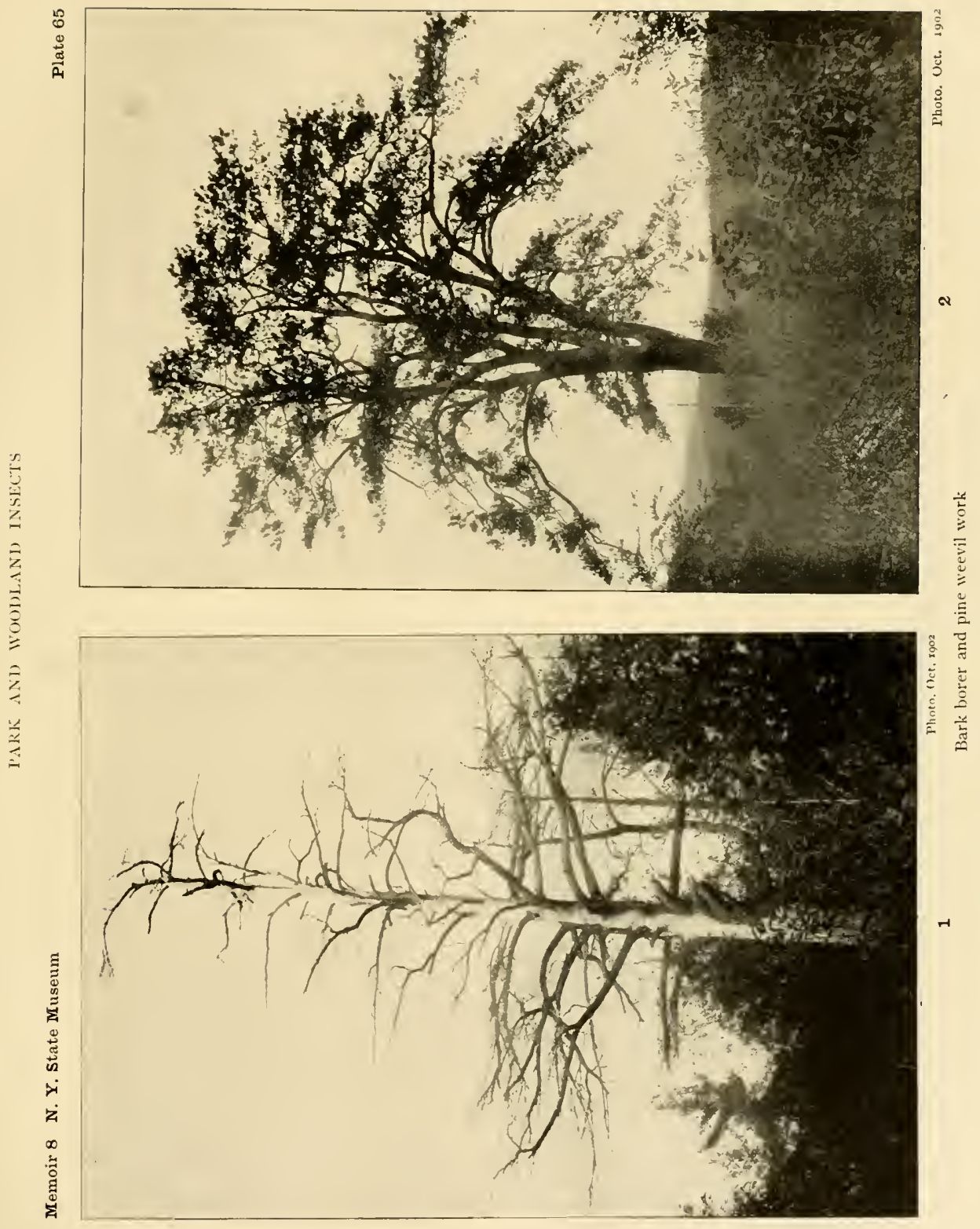



PLATE 66

791 


\section{Scolytid antennae}

I Phloeotribus liminaris Harr. $x$ I

2 Pityogenes sp. $x$ ilo

3 Phloeotribus frontalis Oliv. $x$ ino

4 Tomicus balsameus Lec. $x$ ito

5 T. caelatus Lec. $x$ ro

6 T. cacographus Lec. x i to

7 T. pin i Say. x 1 เо

8 T. calligraphus Germ. x 110

9 T. integer Lec. $x$ ito

10 Dendroctonus terebrans Oliv. $x 80$ 
Memoir 8 N. Y. State Museum
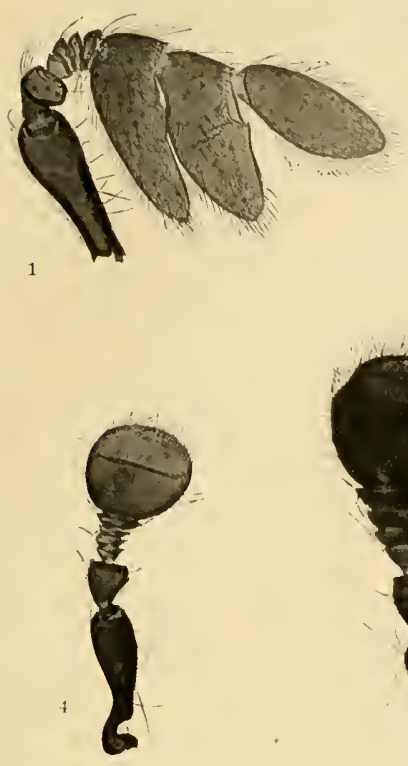

8

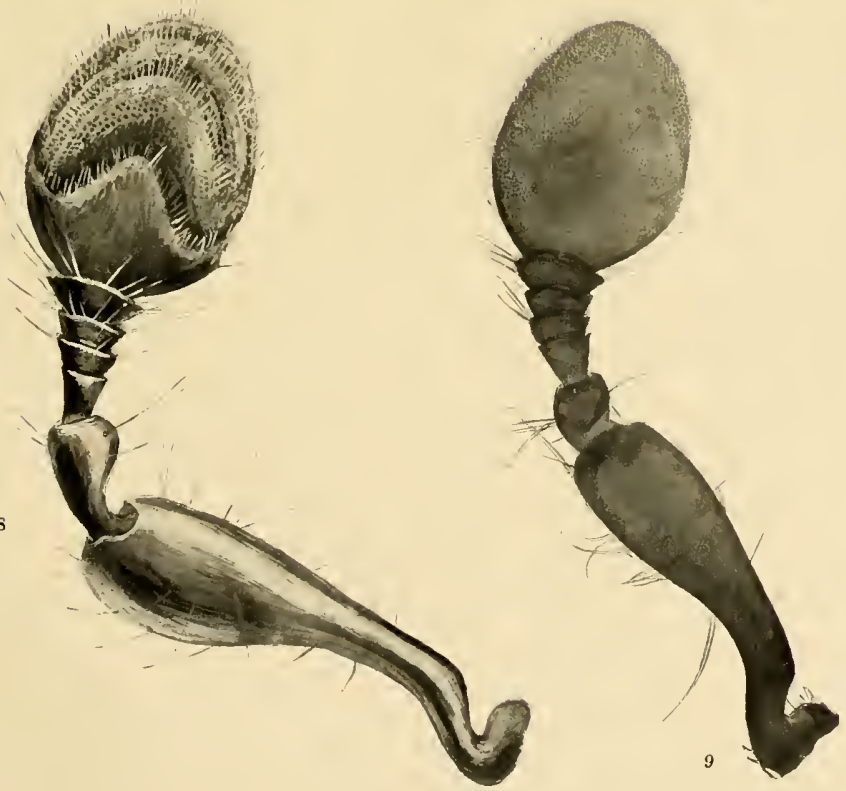

Scolytid antennae
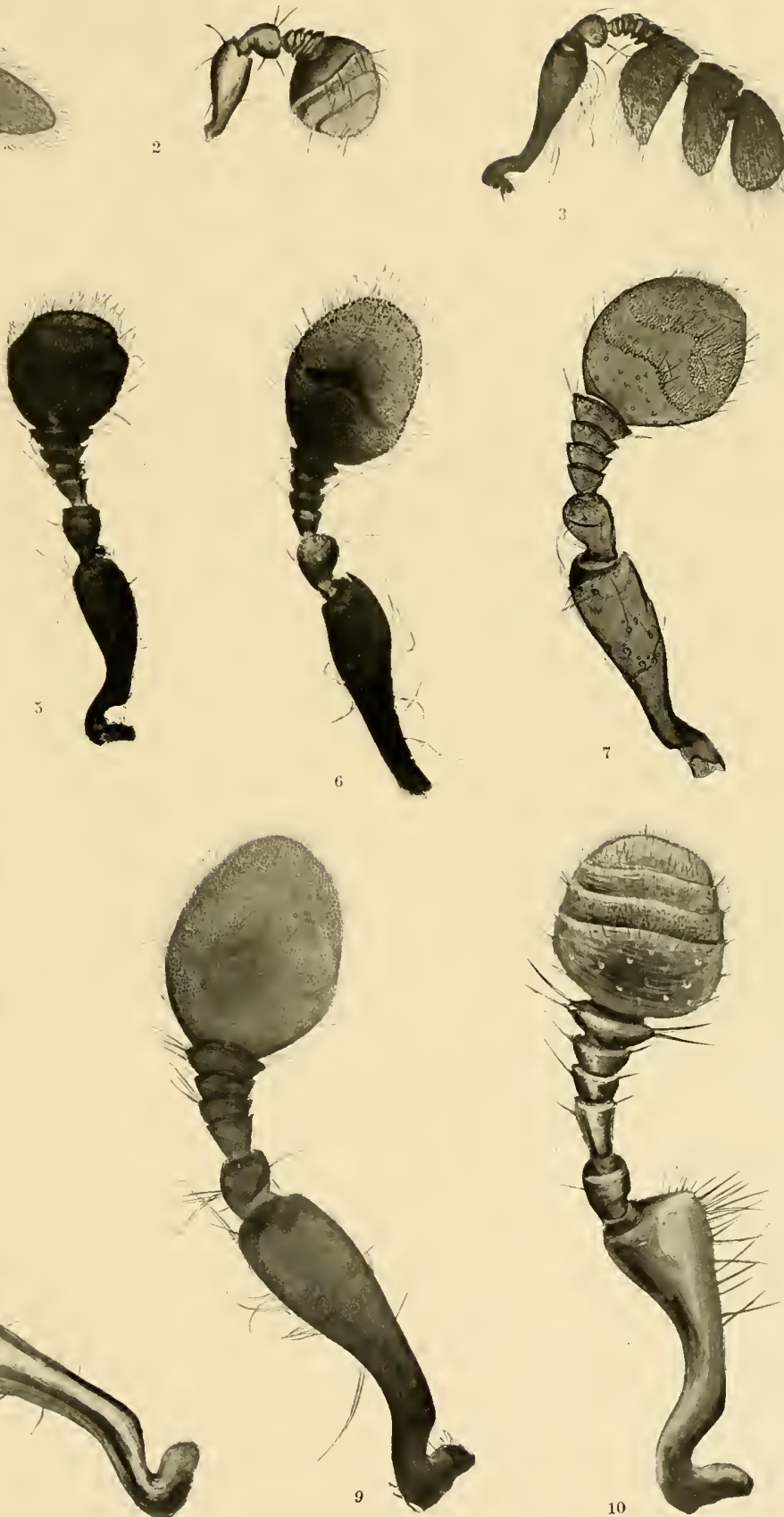

PLATE 67 793 


\section{Scolytid antennae}

INonarthrum mali Fitch. $x 1$ io

2 Pityogenes sp. $\times 110$

3 Cryphalus striatulus Mann. x 110

+ Ginathotrichus materiarius Fitch. x 110

5 Pityounces ponderosae Hopk. x I IO

6 Hylesinus anaculus Lec. x 110

7 Phloeosinus dentatus Say x $x$ to

s polygraphus rufipennis kirby. x I Io

9. Chramesus hicoriae Lec. $x 110$

Io Scolytus rugulosus Ratz. x 1 10

I Pityophthorus minutissinus Zim. $x$ I IO

12 Pityogenes sp. $\times 110$

13 Xyleborus dispar liabr. x 110

$1+$ X. cetsus Eich, X I10

15 Scolytus quadr ispinosus Say. $x$ IIo

16 Pityogenes sp. x 110

if Dryocoetes sp. x 110 
Memoir 8 N. Y. State Museum

Plate 67
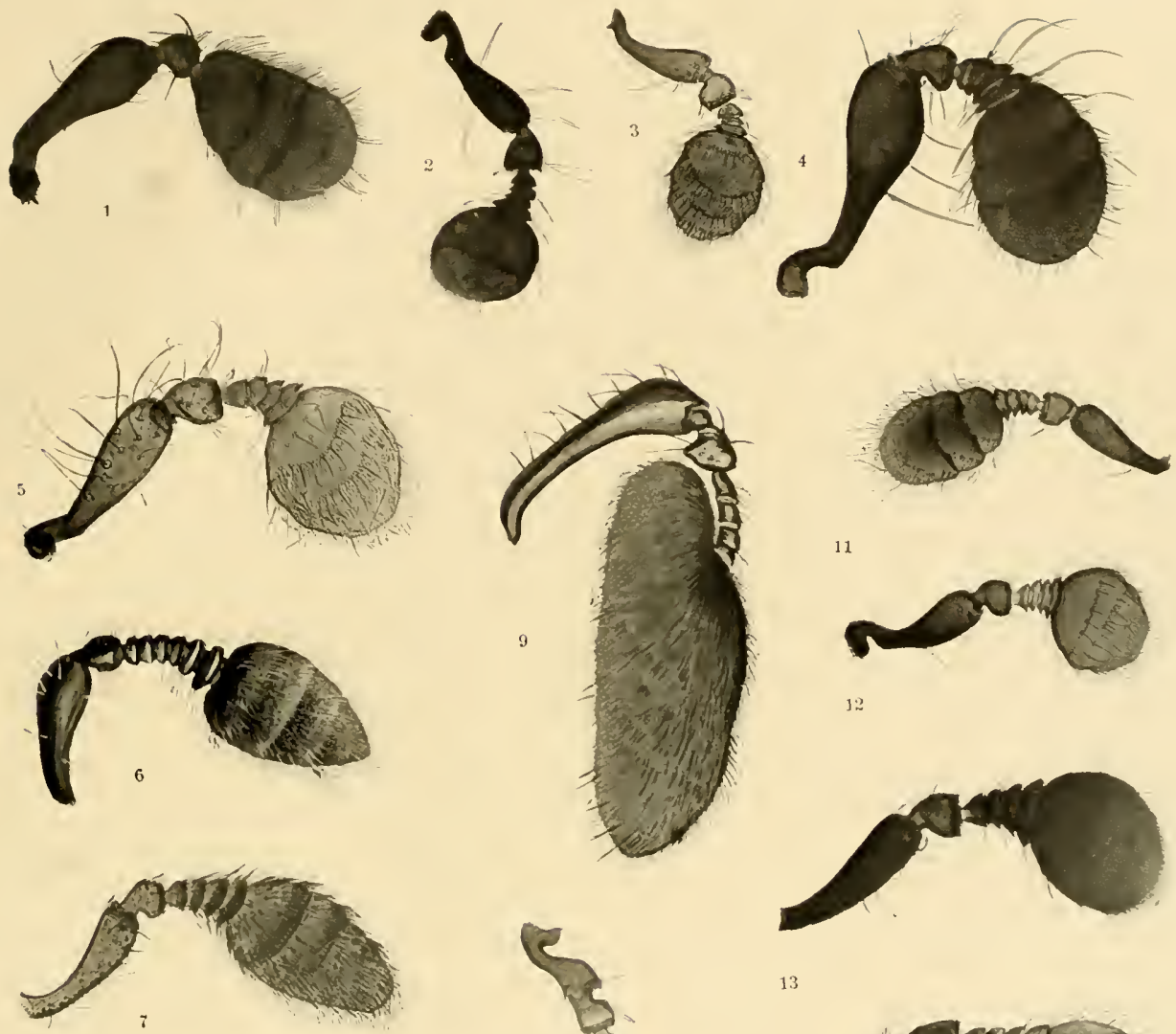

11
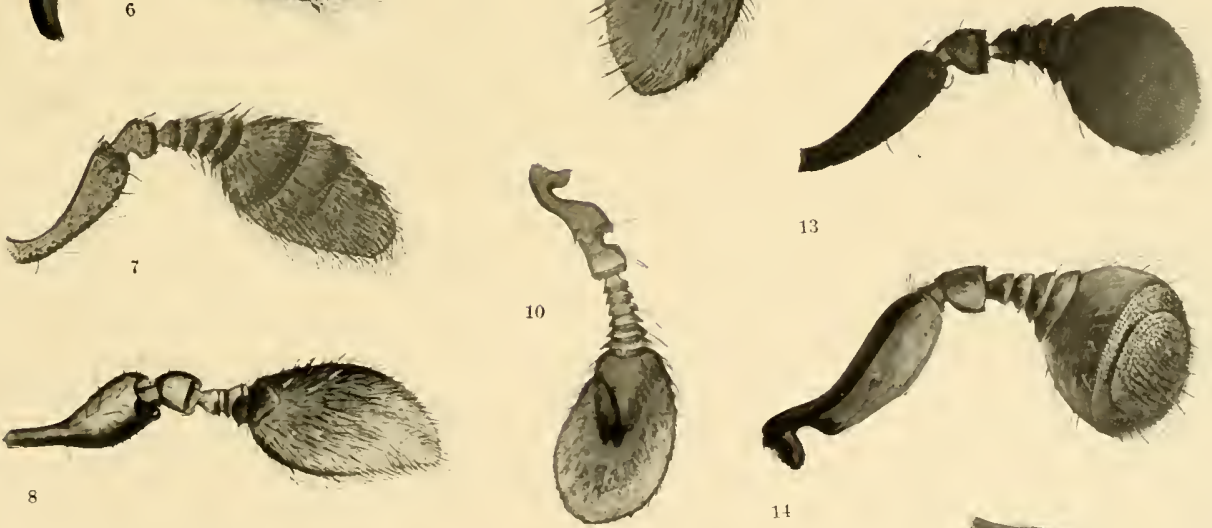

8
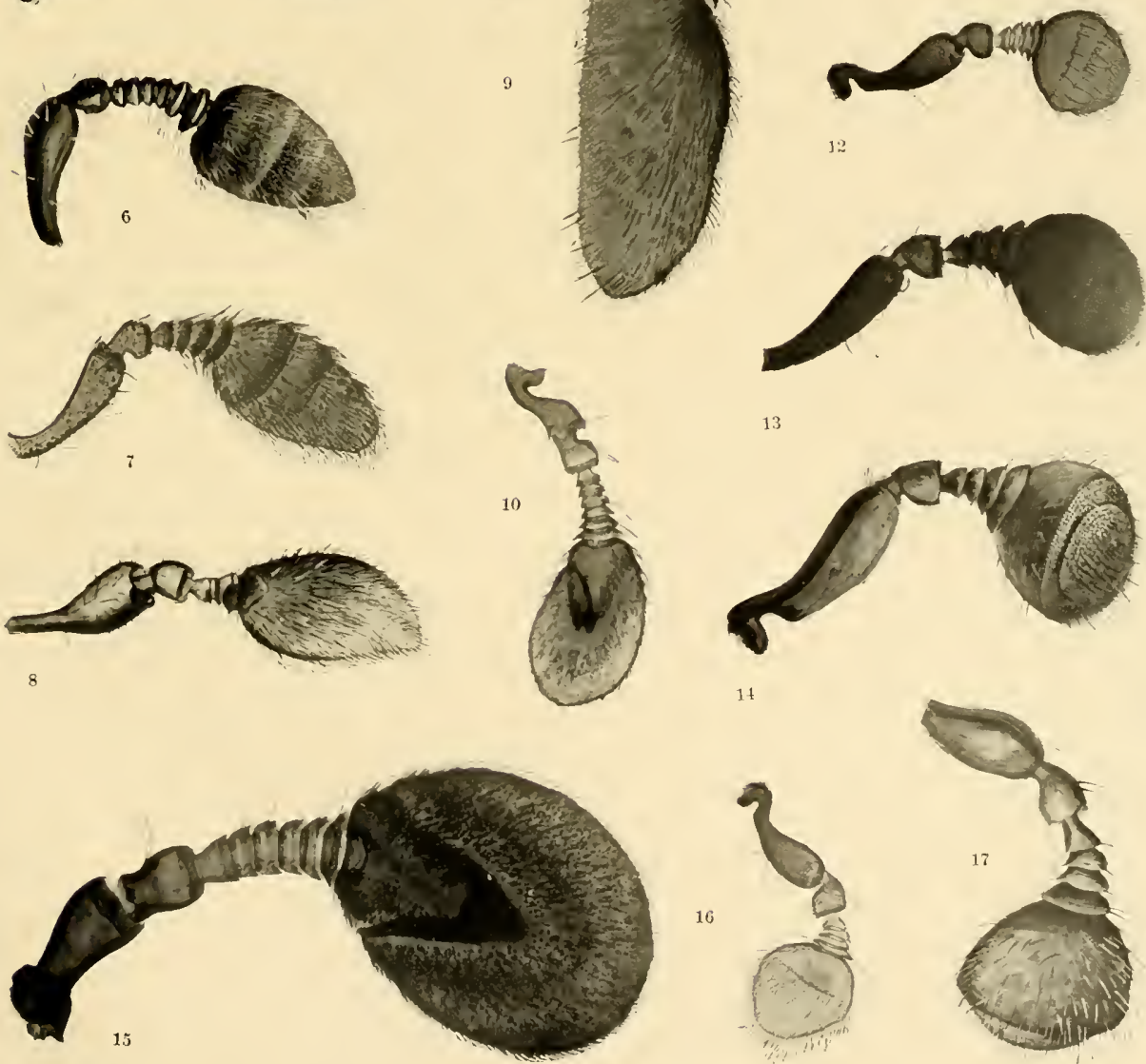

12

13

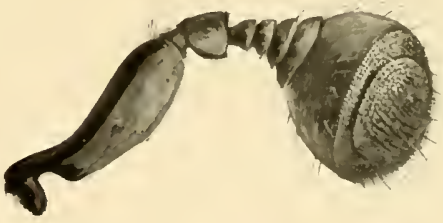

Scolytid antemae 

PLATE 68

795 


\section{Scolytid proventriculi}

I Dendroctonus piceaperda Hopk., end view. $x$ r Io

2 Tomicus caelatus Eich., internal aspect of Hattened segments. $x, 10$

3 Tomicus cacographus Lec., internal aspect of flattened segments. $x 110$

4 Pityogenes species, internal aspect of flattened segments. $x 110$

5 Xylocleptes species, internal aspect of flattened segments. $x 110$

6 Tomicus calligraphus Germ., internal aspect of Hattened segments. $\times 110$

7 Dendroctonus terebrans Oliv., internal aspect of flattened segments. $x 110$

8 Tomicus pini Say, internal aspect of flattened segments. $x$ i 10 $79^{6}$ 

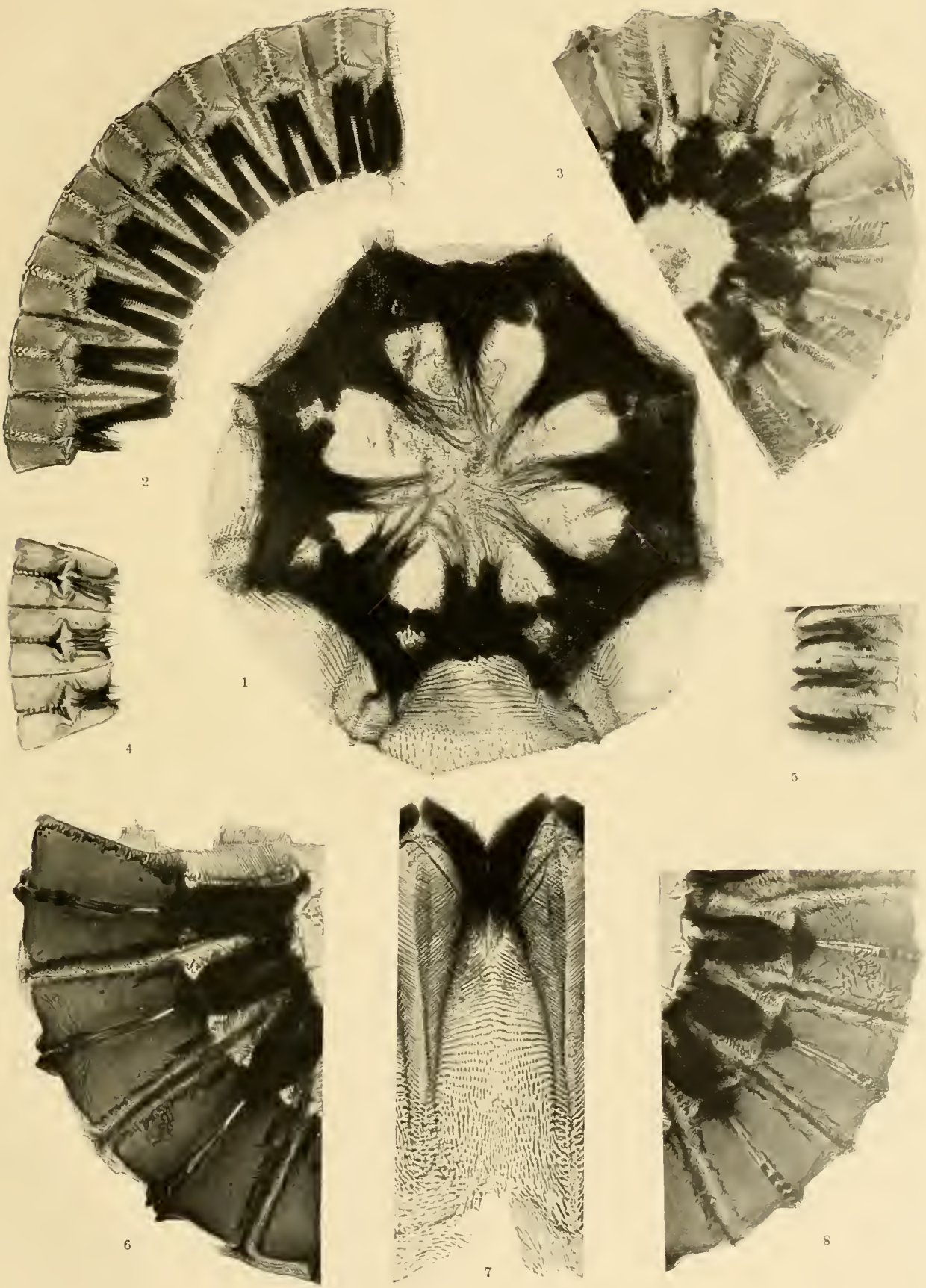




\section{Scolytid proventriculi}

I Pityogenes species, internal aspect of flattened segments. x ro

2 Tomicus balsameus Lec, end view. x 1 10

3 Ginathotrichus materiarius Fitch, internal aspect of flattened segments. $x 110$

4 Phloeosinus dentatus Say, internal aspect of Hattened segments. X 1 io

5 Polygraphus rufipen nis Kirby; cnd view. x r Io

6 Chramesus hicoriae Lec., internal aspect of flattened segments. $x$ iso

7 Ayleborus celsus Eich., internal aspect of flattened segments. $x \quad 110$

8 Xyloterus lineatus Kirby, intermal aspect of flattened segments. $x+10$

9 1) ryocoetes a utographus Ratz., internal aspect of flattened segments: $x$ i

ro Tomicus integer Eich, internal aspect of flattened segments. $x \quad 110$

I I 1)ryocoetes sp., internal aspect of flattened segments. x 110 
Memoir 8 N. Y. State Museum

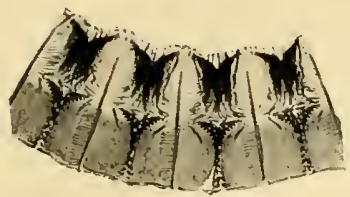

1
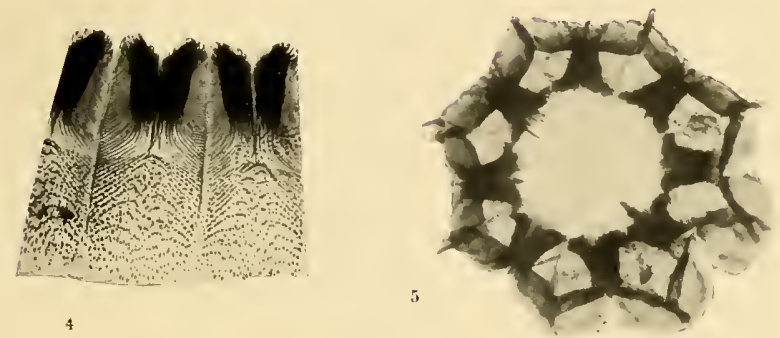

Plate 69
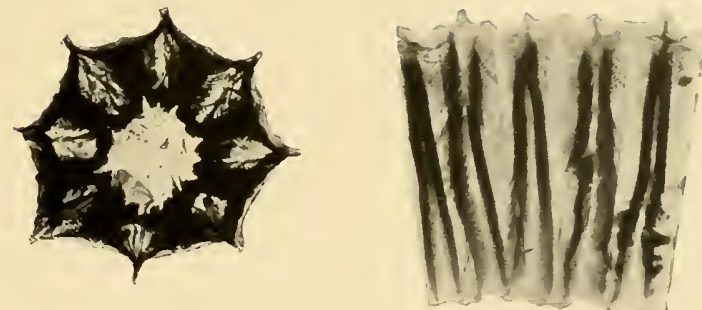

3

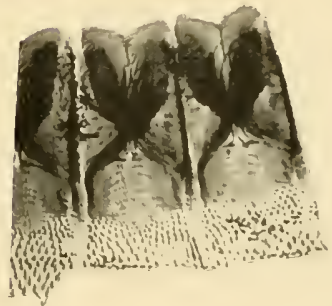

6

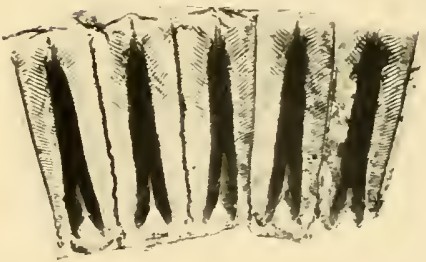

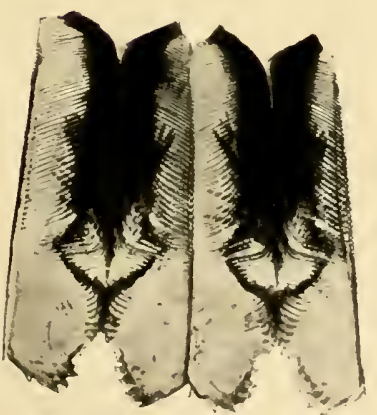

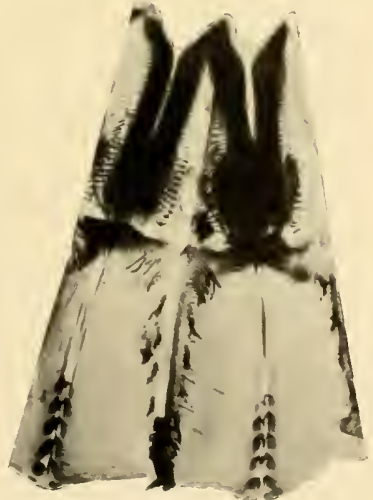

10

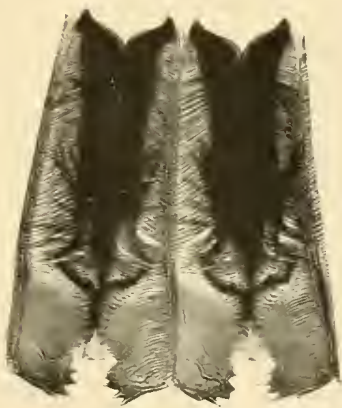



PLATE 70
799 


\section{Scolytid structures}

I Xyloterus sp. antenna. X 110

2 Xyloterus lineatus Kirby, right antenna. $x$ r

3 Nyloterus sp., inner aspect of flattened segments of proventriculus. $\times 110$

+ Xyloterus politus Say, antenna. $x$ r

5 Xyloterus politus Say, inner aspect of flattened segments of proventriculus. $\mathrm{x}$ I I 
Memoir 8 N. Y. State Museum

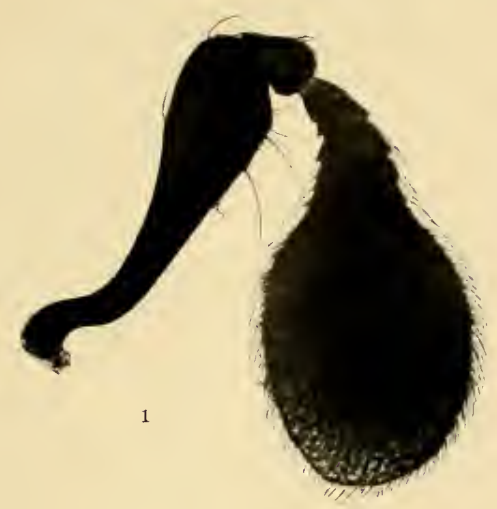

Plate 70

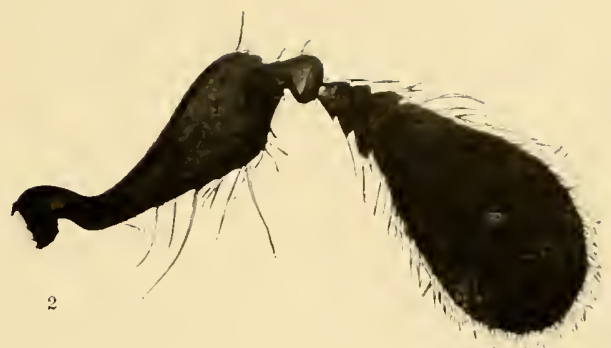

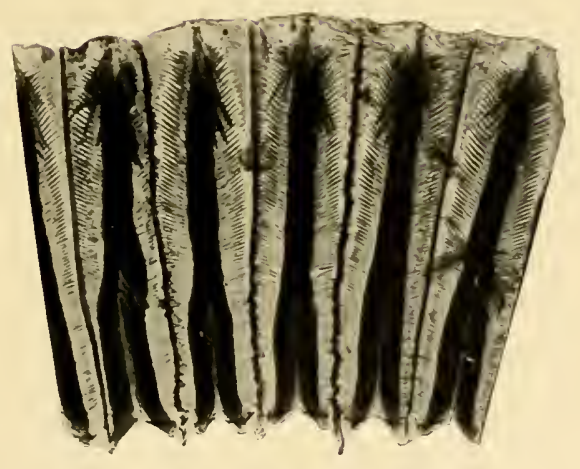

3
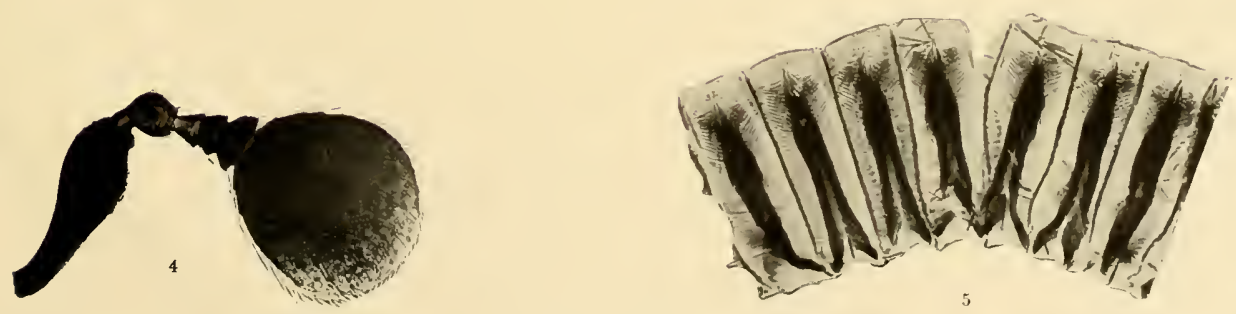

Scolytid structures 



\section{GENERAL INDEX}

The superior figures tell the exact place on the page in ninths; e. g. $685^{3}$ means page 685 , beginning in the thiral ninth of the page, $i, e$ about one third of the way down. Volume and page numbers are separated by a colon; e.g. $2: 724^{9}$ means volume 2 , page 724 .

abalienalis, Romolocha, 2: $724^{9}$. Ablotana clemataria, 2: $72 \mathrm{I}^{4}$. ab) butii, Lophyrus, 2: $340^{7},+14^{4}-15^{5}$. Splecodina, 2: $739^{9}$.

Abbott's pine sawfly, 2: $340^{7}, 4^{1} 4^{4}-$ $15^{5}$.

ahdominalis, Lentura, 2: $755^{7}$.

Urocerus, 2: $649^{\circ}, 668^{8}$.

Abies fraseri, $2: 685^{\circ}$.

ahietella, Lioryctria, $2: 752^{4}$.

abieticolens, (hermes, $2: 754^{5}$.

aliets, Aspuliotus, $2 \cdot 652^{6}, 690^{2}$.

Chermes, $1: 172^{4}, 159^{1}-91^{6}$.

Lachun us, 2: $754^{5}$.

Lophyrus, $2: 340^{4},+15^{3}-16^{4}$.

Ablerus clisiocampac, $1: 216^{3}$. abnormis, Apleclinus, $1: 212^{9}$.

Eriophyes, 2: 6202, 6316 $-32^{1}$. acadica, Thecla, 2: $742^{7}$.

Acalyptus carpini, $2: 7+2^{4}$.

Acamptus rigidus, $2: 727^{5}$.

Acanthocinus nodosus, 2: $75 \mathrm{I}^{5}$. ohsoletus, $2: 649^{4}, 662^{\text {7 }}$.

Acanthoderes decipiens, $2: 429^{8}$, $+73^{4}$

morrisii, 2: 732 '.

quadrigibbus, 2: $702^{4}, 715^{5}$.

Acarina, 2:617?

Acarus aenigma, $2: 7+5^{9}$.

caulis, $2: 720^{4}$

semen, $2: 7+5^{\circ}$.

serotinae, $2: 733^{5}$.

acericola, Eriophyes, 2:619 $630^{2}$.

Phenacoccus, $1: 49,172^{6}, 152^{7}-86^{6}$.

Pulvinaria, $\quad \mathbf{1}: \mathbf{1} 7 \mathbf{2}^{6}, \quad \mathbf{1} 79^{1}-8 \mathbf{2}^{6}$; 2: $729^{1}$.

aceriella, Castastega, I: $169^{4}$.

Lithocolletes, 2: $728^{4}$.

acerifoliella, Incurvaria, 2.5092, $5+1^{3} \cdot 728^{5}$

Tischeria, see Incurvaria. acerifolii, Drepanosiphum, I: $172^{4}$, $175^{6}-76^{5}$. acerifolii, P'emphigus, $2: 600^{5}$. aceris, Aleurodes, 2: $728^{7}$.

Cecidomyia, 2: $728^{6}$.

Chaitophorus, $1: 49,172^{3}, 174^{2}$ $75^{5}: 2: 604^{9}$.

Pemphigus, 2:600 $8728^{7}$.

acerni, sesia, $1: 49,50^{6}, 56^{7}-58^{9}$.

achatina, Olene, $2: 507^{4}, 524^{7}$.

achemon, lholus, 2: $739^{6}$.

Acholla multispinosa, 2: $613^{6}-14^{\text {? }}$.

achyrantes, Myzus, 1: $249^{8}$.

Acmaeodera culta, 2: $715^{2}$

Acoptus suturalis, $2: 715^{\circ}$.

Acordulecera dorsa]is, 2: 7 I $^{3}$.

Acorn feeders, 2: $709^{7}$.

Acorn galls, 2: $709^{8}$.

Acorn weevil, 2: $512^{6}, 583^{6}-85^{4}$.

acornis, Actenodes, 2: $751^{4}$

Acraspis erinacei, $2: 619^{2}, 627^{5}$. niger, 2: $711^{\circ}$.

pezomachoides, 2: 7 I $4^{3}$.

dcrobasis angusella, 2: $716^{1}$. betulella, $2: 749^{7}$.

caryae, 2: $716^{1}$.

comptoniella, 2: $738^{6}$.

demotella, 2: $719^{9}$.

rubrifasciella, 2: $750^{7}$.

Acronycta americana, see Apatela. oblinita, see Apatela.

acronyctoides, Panthea, 2: $754^{9}$.

Actenodes acornis, $2: 75 \mathbf{I}^{4}$.

aculeata, Micrasis, $2: 715^{\circ}$.

aculeatus, Hylesinus, $\mathbf{1}: \mathbf{2 5} 7^{\mathbf{5}}, \mathbf{2} 88^{6}$ $59^{3}$

aculiferus, Leptostylus, $2: 428^{4}$, $4^{61^{2}}$.

acuminata, Thelia, 2: $595^{8}-96^{2}$. acuminatus, Evacanthus, $2: 7+4^{6}$.

a^utipennis, Agrilus, 2: $701^{7}$.

acutus, Brachystylus, $2: 735^{3}$.

Adalia bipunctata, 1:174, $195^{\circ}$. $20^{6} 3^{9} ; 2: 60 \mathrm{I}^{5}$.

Adelocephala bicolor, 2: $729^{7}$.
Nistola americana, I: $140^{3}$.

Adoneta spinuloides, $2: 529^{5}, 7069$.

Adoxus obscurus, 2: $739^{8}$.

legeria apiformis, $2: 429^{8}, 472^{8}-$ $73^{3}$.

tibialis, $2: 429^{7}, 472^{1}$.

Aegilips obtusilobae, 2: $715^{3}$.

aemula, Epizeuxis, 2: $754^{1}$.

aenciventris, Igromyza, $2: 620^{6}$, $634^{2}-35^{3}$.

aeneogaster, Anthaxia, 2: $715^{2}$.

aeneola, Melanophila, 2: $75 \mathrm{I}^{3}$.

aenigma, Acarus, 2: $745^{9}$.

aeratus, Rhynchites, $2: 703^{8}$, $716^{5}$.

aereum, Callidium, $2: 425^{1}, 450^{1}$, $667^{3}$.

aereus, Hielops, 2: $752^{6}$.

aeriferella, I,ithocolletes, $2: 708^{4}$. aerosa, Brachys, 2: $506^{3}, 512^{9}-13^{6}$.

aeruginosa, Brachys, 2: $703^{5}$.

aesculana, Proteoteras, 2: $540^{4}$, $540^{7}$.

aesculanum, Proteoteras, 2: $725^{8}$.

aesculi, Crepidodera, $2: 730^{3}$.

affaber, Dryocoetes, $2: 752^{3}$.

affinis, Conotrachelus, $2: 582^{7}$.

Neuroterus, 2: $713^{4}$

l'issodes, $2: 340^{1}, 401^{7}, 402^{1}$.

afficta, Apatela, 2: $704^{5}$.

aftlictana, Archips, 2: $754^{9}$

Agallia quadri-punctata, 2: 5981.

agarici, Phora, I: $140^{6}$

Agathis : $. .2: 4{ }^{\prime} O^{\prime}$.

agilis, Mesochorus, I: ${ }_{3} 1^{5}$

Aglais milherti, $2: 7+2^{6}$.

Agnippe biscolorel]a, 2: $729^{7}$.

agrestis, Criocephalus, $2: 649^{3}$, $659^{7}-60^{2}$.

agrilli, Bracon, $1: 73^{2}$.

Igrilus acutipennis, 2: $70 \mathbf{I}^{7}$.

anxius, I: $257^{4}, 284^{8}-87^{9}$.

arcuatus $z(x)$. coryli, $2: 723^{4}$. 
Agrilus bilineatus, $1: 257^{3}, 280^{6}-$ $83^{3}$.

egenus, 2: $715^{\circ}, 729^{9}$.

fallax, 2: $725^{3}$.

granulatus, 2: $746^{5}$.

interruptus, $2: 701^{7}$.

lecontei, 2: $736^{6}$.

obsoletoguttatus, 2: 7or?

otiosus, $2: 502^{4}, 518^{3}, 729^{9}$.

politus, $2: 729^{9}, 74 \mathrm{I}^{4}$.

sinuatus, $2 \cdot 504^{4}$.

torpirlus, see A, anxius.

vittaticollis, $2: 720$ ?

Agromyza aeneiventris, $2: 620^{6}$, $634^{2}-35^{3}$.

ajax, Iphidicles, 2: $735^{4}$.

Alabama argillacea, $1: 6^{3} ; 2: 609^{9}$. Alaus oculatus, $2: 430^{9}, 485^{1}-86^{1}$.

albanotella, Lithocolletes, $2: 708^{4}$.

albella, Proleucoptera, 2: $7+4^{6}$, $747^{9}$.

albicollis, Dichelonycha, see D. albicollis.

Periclista, 2: $702^{8}$.

albicomana, Tortrix, 2: $532^{4}, 707^{6}$.

albicornis, Chiloneurus, 1 : $182^{1}$.

Sesia, $2: 429^{6}, 469^{6}-70^{4}$.

Urocerus, 2: $649^{8}, 667^{6}-68^{7}, 668^{9}$.

Xyphidria, $2: 428^{7}, 459^{8}-60^{1}, 466^{4}$. albidovariata, Hemichroa, 2: $703^{3}$. albifera, Euchoeca, 2: $725^{2}$.

albifrons, Symmerista, 2: 506", $519^{3}-20^{2}$.

albinatella, Coriscium, 2: $708^{8}$.

albipes, Synergus, 2: $7 \mathrm{I}^{4}$.

albisparsella, Gelechia, 2: $719^{3}$.

albitarsis, Asecodes, $\mathrm{I}: \mathrm{I} 4 \mathrm{O}^{2}, \mathrm{I} 4 \mathrm{O}^{4}$. albofasciatus, Clytanthus, 2: $715^{5}$. albopictus, Xylonomus, 2: 500 1 . albosigma, Melalopha, 2: $747^{4}$. albovenosa, Arsilonche, 2: $7+3^{2}$. alhovittata, Cecidomyia, $2: 7+6^{1}$.

Alceris effractana, $2: 744^{3}$.

ferrugana, $2: 744^{2}, 749^{9}, 753^{3}$.

hastians, $2: 744^{3}$.

logiana, $2: 733^{6}$.

var. viburnana, $2: 7+4^{2}$.

minuta, 2: $733^{9}$.

niveana, $2: 7+9^{\circ}$.

permutana, $2: 744^{3}$.

schalleriana, 2: $744^{9}$
Alceris variana, $2: 754^{3}$.

alchimiella, Gracilaria, 2: $724^{2}$.

alciphearia, Eutrapela, 2: $728^{2}$.

Alcoloithus falsarius, $2: 740^{\circ}$.

Alder, injurious insects :

Anthrenus castaneae, $2: 614^{\circ}$. aphids :

Alder blight aphid, I: $173^{\prime}$, I $95^{9}$.

Lachnus alnifoliae, 2: $750^{8}$.

borers : $2: 750^{2}$.

alder borer, $2: 430^{4}, 480^{2}$.

Jemythrus asilipennis, 2: $464^{\circ}$.

saperda, red-edged, $2: 445^{6}$.

Stenopsis argenteomaculatus, 2: $72 \mathrm{I}^{2}$.

willow borer, mottled, I: $103^{3}$.

xylotrechus quadrimaculatus, 2: $722^{3}$.

gall insects :

Dasyneura serrulatae, $2: 750^{9}$. leaf feeders : $2: 750^{3}$.

alder flea beetle, $2: 5 \mathrm{II}^{9}, 573^{5}$.

alder leaf beetle, $2: 509^{3}, 542^{8}$.

Amauronematus luteotergun, 2: $5 \mathrm{rI}^{8}, 572^{\text {\% }}$

American dagget moth, 2: $525^{3}$.

Apatela dactylina, $2: 7.2^{9}$.

distans, $2: 747^{2}$.

oblinita, $2: 7+3^{1}$.

sperata, 2: $7+7^{3}$

Apatelodes torrefacta, $2: 549^{4}$.

Attelabus rhois, 2:511 $1^{9}, 57 t^{7}$.

Cecropia moth, $2: 539^{4}$.

Chlamys plicata, 2: $703^{6}$.

Chrysomela bigsbyana, $2: 566^{5}$. multiguttata, $2: 742^{2}$.

dagger moth, smeared, 2: $560^{2}$.

Dichelonycha elongata, 2:716

Ectropis crepuscularia, $2: 7+3^{\text {? }}$.

elm saw fly, $\mathbf{r}: 157^{9}$.

Hyperitis amicaria, $2: 722^{5}$.

oak tussock caterpillar, 2: $523^{3}$.

Papilio glaucus var. turnus, 2: $704^{1}$.

Paraphia subatomaria, 2: $753^{3}$.

Polygonia faunus, $2: 7+2^{6}$.

Schizura unicornis, 2: $705^{\circ}$.

Serica sericea, $2: 553^{3}$.
Alder, injurious insects (cont' $d$ ). leaf feeders:

tussock moth, white marked, I: $136^{9}$.

Venusia comptaria, 2: $722^{6}$.

willow leaf beetle, spotted, 2: $565^{6}$.

scale or sucking insects:

Chionaspis lintneri, $1: 173^{8}$. $227^{9}$.

Lygus monachus, $2: 728^{6}$.

Alder, black, injurious insects:

Io caterpillar, 2: $522^{3}$.

scurfy scale, 1:21 $5^{9}$.

Alder, white, leaf feeders injuring, 2: $739^{6}$.

Alder blight aphid, I: $173^{1}, 195^{8}-$ $96^{3}$.

Alder borer, $2: 430^{4}, 480^{1}-81^{2}$.

Alder flea beetle, $2: 511^{9}, 573^{4}-$ $74^{6}$.

Alder leaf beetle, 2: $509^{3}, 542^{7}-44^{2}$. aletiae, Frontina, I: $138^{8}$.

Aletis argillacea, see Alabama.

Aleurodes aceris, 2: 728?

alia, Graphiphora, 2: $704^{9}$.

Allandrus bifasciatus, $2: 73 \mathrm{r}^{4}$.

Allantus annularis, $2: 726^{\circ}$.

Allocota thyridopterigis, $1: 138^{8}$.

Allorhina nitida, 2: $719^{9}$.

Allotria elonympha, 2: $720^{2}$.

alnifolia, Clethra, $1: 215^{9}$

alnifoliae, Lachnus, 2: $750^{8}$.

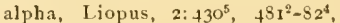
$482^{5}$.

var. cinereus, Liopus, $2: 715^{\circ}$,

Alsophila pometaria, 2: $706^{2}$.

alternata, Rhynchagrotis, $2: 704^{7}$.

alternatum, Dorcaschema, 2: $726^{6}$.

altiscuta, Pachyneuron, $\quad 1: 182^{1}$, $203^{1}$.

alutacea, Magdalis, $2: 340^{2}, 402^{7}-3^{2}$.

alutaceus, Crypturgus, 2: $753^{\circ}$.

Alydus eurinus, 2: $613^{3}$.

Aly pia octomaculata, $2: 5^{1} 2^{1}, 575^{8}$.

amasia, Catocala, 2: $705^{3}$.

amatrix, Catocala, 2: $747^{4}$.

Amauronematus azaliae, $2: 739^{5}$.

fur, 2: $741^{8}$.

luteotergum, $2: 511^{8}, 572^{7}-73^{4}$, $750^{4}$. 
Amauronematus oregonensis, 2: Amphibolips melanocera, 2:711 $1^{5}$. Andricus nigrae, 2: 71 $3^{3}$.

$7+1^{8}$.

similis, $2: 7+1^{8}$.

Ambrosia, poplar twig gall Ay in, 2: $635^{3}$.

Ambrosia beetles, $2: 335^{8}, 335^{9}$, $339^{8}-40^{5}, 394^{1}-425^{7}$.

amelanchierella, Nepticula, $2: 734^{2}$.

American bark beetle destroyer, 2: $500^{3}-I^{7}$.

American dagger moth, 2: $507^{5}$. $525^{1}$.

American lappet noth, 2: $507^{6}$, $525^{5}$.

American redstart, I: $111^{6}$.

American silk worm, 2:507 $7^{7}, 526^{1}$. americana, Adistola, $\mathbf{1}: 140^{3}$.

Apatela, 2: $507^{5}, 525^{1}$.

Camponiscus, $2: 74^{\circ}$.

Chionaspis, $1: 173^{4}, 207^{6}-8^{7}$.

Cimbex, 1: $105^{8}, 155^{7}-58^{7}$.

Epicnaptera, 2: $507^{6}, 525^{5}$.

Hemichroa, 2: $750^{6}$.

Malacosoma, see M. americana.

Schizoneura, I: $172^{5}, \mathbf{I} 77^{7}-78^{9}$.

Tenebrioides, $2: 73 \mathrm{I}^{3}$.

americanum, Platydema, 2: $497^{5}$.

americanus, Dryophthorus, $2: 752^{3}$.

Pytho, 2: $335^{4}, 339^{5}, 368^{6}-69^{5}$.

Trionymus, $2: 727^{3}$.

amica, Catocala, 2: $705^{3}$.

amicaria, Hyperitis, $2: \mathbf{7 2 2}^{4}$.

amoenus, Phymatodes, 2: $502^{4}$.

Amorbia humerusana, 2: $737^{4}$.

Anorphota orgyiae, 1: $138^{3}$.

Ampeloglypter ater, 2: $739^{9}$.

Ampelophaga choerilus, $2: 73^{4}$.

myron, 2: $739^{8}$.

versicolor, 2: $719^{5}$.

ampelopsidis, Telamona, $2: 740^{4}$. ampelopsiella, Antispila, 2: $740^{3}$.

Phyllocnistis, 2:740 8 .

Ampelopsis, see Virginia creeper.

Amphibolips badius, 2: $710^{5}$.

caroliniensis, 2: $71^{1}$.

coelebs, 2: $712^{4}$.

confluentus, $2: 618^{7}, 625^{2}, 625^{4}$.

cookii, 2: $712^{2}$.

formosa, 2: $712^{2}$.

ilicifoliae, $2: 615^{8}, 625^{5}$.

inanis, $2: 618^{7}, 625^{4}$. phellos, 2: 7129.

prunus, 2: $619^{5}, 628^{2}$.

sculpta, $2: 712^{4}$

verna, $2: 713^{8}$.

Amphion nessus, $2: 740^{1}$.

amyitor, Ceratomia, 2: $509^{7}, 546^{6}$.

amyotii, Otiocerus, 2: $717^{7}$.

Anacampsis rhoifructella, $2: 747^{8}$.

tristrigella, $2: 723^{6}$.

Anacharis suhcompressa, 2: $714^{8}$.

anaglypticus, Conotrachelus, see

C. anaglypticus.

Anagoga pulveraria, 2: $728^{3}$.

analis, Attelabus, 2: $720^{1}$.

Anamorphus pusillus, $2: 721^{\circ}$.

ananassi, Cecidomyia, $2: 755^{4}$.

Anaphes gracilis, $1: 212^{9}, 222^{4}$.

Anarta cordigera, 2: $73^{9}$.

Anaspis flavipennis, $2: 567^{1}$.

Anatis ocellata, 1: $175^{2}, 195^{2}, 199^{7}$; 2: $604^{\circ}$.

oculata, 1: $186^{2}$.

anceps, Ibalia, $2: 714^{8}$.

ancetaria, Azelina, 2: $728^{3}$.

anchora, Gaurax, I: $1 q^{6}$.

Notoxus, see N, anchora.

Ancylis cornifoliana, 2: $736^{8}$.

platanana, 2: $719^{2}$.

tineana, $2: 747^{8}$.

ancylus, Aspidiotus, I: $173^{7}, 226^{6}-$ $27^{8} ; 2: 729^{8}$.

andrei, Kermes, 2: $709^{5}$.

Andricus ashmeadii, $2: 711^{5}$.

capsulus, 2: $711^{6}$.

cicatricula, $2: 710^{7}$.

clavula, $2: 618^{4}, 624^{4}, 714^{6}$.

cornigerus, $2: 437^{8}, 45 \mathrm{I}^{6}, 6 \mathrm{I} \mathrm{8}^{3}$, $624^{3}$.

femoratus, $2: 712^{3}$.

flocci, $2: 710^{8}$.

foliaformis, $2: 710^{8}$.

fusiformis, $2.710^{8}$.

futilis, $2: 710^{8}, 715^{1}$.

gibbosus, 2: $709^{9}$.

globulus, $2: 714^{6}$.

ignotus. $2: 71 \mathrm{I}^{6}$.

incertus, 2: $71 \mathrm{I}^{5}$.

? indistinctus, 2: $710^{4}$.

lana, $2: 618^{9}, 625^{8}$.

modestus, $2: 712^{3}$. obtusilobae, 2: $709^{9}$.

operator, 2:6r $8^{2}, 622^{9}-23^{2}, 709^{8}$, $713^{3}$.

ostensackenii, 2: $713^{9}$.

palustris, $2: 714^{3}$.

papillatus, 2: $712^{8}$

patiens, $2: 713^{3}$.

pattoni, $2: 71 \mathbf{I}^{8}$.

perditor, 2: $709^{8}$.

petiolicola, 2:6189, $625^{9}, 714^{6}$.

piperoides, $2: 712^{3}$.

podagrae, $2: 623^{8}, 714^{5}, 714^{6}$.

pruinosus, $2: 7 \mathrm{II}^{8}$.

pulchellus, $2: 7 \mathrm{f}^{2}$.

pulchra, $2: 619^{4}, 627^{9}-28^{1}$.

punctatus, $2: 618^{3}, 623^{2}-24^{3}$.

pusulatoides, $2: 712^{6}$.

quercifoliae, $2: 714^{3}$.

quinque septum, 2: $711^{8}$

saccularius, $2: 712^{6}$.

scitula, $2: 7^{1} 3^{1}$.

seminator, $2: 618^{2}, 622^{1}, 622^{9}-23^{1}$.

seminosus, 2: $709^{9}$.

similus, $2: 713^{6}$.

singularis, $2: 618^{8}, 625^{7}$.

tuber, 2: $710^{4}$.

tubicola, 2: 7 II ${ }^{8}$.

utriculus, $2: 710^{x}$

ventricosus, $\cdot 2: 713^{6}$,

Androchirus fuscipes, 2: $701^{9}$.

Andromeda, injurious insects:

Datana major, 2: $739^{2}$.

Euclea delphinii, 2: $529^{2}$.

angelica, Apatelodes, 2: $727^{2}$.

anguina, Dasylophia, $2: 730^{6}$.

anguinella, Nepticula, 2: $708^{3}$.

anguinus, Patyobius, 2: $75 \mathrm{I}^{3}$.

angulifera, Callosamia, $2: 732^{3}$.

angulosa, Lophodonta, 2: $705^{7}$.

angusella, Acrobasis, 2: $71^{1}$.

angusi, Catocala, 2: $716^{7}$.

angusii, Datana, 2: $508^{6}, 535^{3}$.

angustatus, Eugnamptus, 2: $703^{8}$. $720^{5}$.

Nysius, 2: $65 \mathbf{1}^{9}, 685^{6}$.

angustiorata, Caripeta, 2: $753^{2}$.

Ania limbata, 2: $508^{1}, 530^{4}$.

Anisopteryx pometaria, 2: $547^{7}$.

Anisota rubicunda, 2: $508^{\star}, 537^{6}-$ $3^{8^{3}}$. 
Anisota senatoria, I: $25^{4}, 306^{5}-$ $10^{3} ; 2: 527^{5}, 607^{7}$.

stigma, 2: $507^{\circ}, 527^{3}$

virginiensis, 2: $7^{0} 4^{4}$.

annectens, l'ityophthorus, 2: $751^{9}$

annularis, 11lantus, 2: $726^{9}$.

annulata, Brochymena, 2: 588i$90^{3}, 590^{6}$.

l'sylla, 2: $723^{7}$.

annulipes, Aplycus, see A. annulipes.

Cecidomyia, $2: 76^{1}$.

Pimpla, 1: $138^{5}, 139^{\circ}$.

Anomala lucicola, $2: 651^{5}, 682^{6}$.

Anomalon exile, $1: 113^{2}$.

Anomoea laticlavia, 2: $730^{6}$.

antennata, Xylina, sec $\mathrm{X}$. antennata.

antennatum, Callidium, $2: 450^{3}$ $649^{8}, 660^{2}-6 x^{2}$

Eulecanium, 2: $709^{4}$.

Anthaxia aeneogaster, $2: 715^{2}$. quercata, 2: $518^{4}$.

viridicornis, $2: 724^{4}$.

viridifrons, $2: 715^{2}$.

Anthonomopsis mixtus, $2: 734^{6}$.

Anthonomus corvulus, 2: $736^{6}$.

decipiens, $2: 73 t^{5}$.

profundus, 2:719.6.

suturalis, $2: 715^{8}$.

sycophanta, 2: $7 \nmid 2^{5}$.

tessellatus, 2: $7+2^{4}$.

Anthophilax attenuatus, $2: 431^{1}$, $458^{2}-89^{2}$.

Anthrenus castaneae, 2:61 $4^{7}$. museorum, 2:61.4.

Anthribus cornutus, 2: $730^{4}$.

Antigaster mirahilis, $2: 699^{7}$.

antiopa, Euvanessa, sec $\mathbf{E}$.. antiopa.

antiopae, Entedon, 1: 161?

antiqua, Notolophus, $2: 507^{4}, 524^{3}$. $524^{8}$

Antispila ampelopsiella, 2: $740^{3}$. cornifoliella, $2: 73^{5}{ }^{8}$ nyssaefoliella, 2: $510^{5}, 555^{6}-5 \mathrm{C}^{4}$.

Ants, large black carpenter, $1: 51^{4}$, $90^{2}$.

white, $I: 51^{4}, 87^{8}-90^{1}$

anxius, Agrilus, I: $157^{4}, 28 t^{4}-87^{9}$.

Apanteles delicatus, $1: 13^{86}$.

hyphantriae, $1: 13^{5^{6}}, 145^{8}$.
Apanteles parorgyiae, $1: 138^{6}$.

Apatela afflicta, $2: 704^{5}$.

americana, $2: 507^{3}, 525^{1}$.

betulae, $2: 7+9^{3}$.

brumosa, 2: $704^{5}$.

clarescells, 2: $733^{9}$.

connecta, $2: 742^{9}$.

dactvlina, $2: 7+2^{9}$.

distans, $2: 747^{\circ}$.

falcula, 2: $723^{5}$.

funeralis, $2: 716^{6}$.

futcifera, 2: $733^{4}$.

grisea, 2: $724^{\circ}$.

hamamelis, 2: $704^{6}$.

hastulifera, 2: $750^{\circ}$.

impleta, $2: 749^{3}$.

impressa, $2: 7+3^{1}$.

innotata, 2: $716^{5}$.

interrupta, 2: $724^{\mathrm{P}}$.

lanceolaria, $2: 7+2^{4}$.

leporina, $2: 7+7^{2}$.

lepusculina, 2: $747^{2}$.

lithospila, 2: $721^{2}$.

lobeliae, $2: 704^{\circ}$.

modica, $2: 704^{6}$.

morula, 2: $724^{5}$.

noctivaga, $2: 7+7^{3}$.

oblinita, 2: $5 \mathrm{II}^{2}, 560^{1}, 7+3^{1}$.

ovata, $2: 704^{6}$.

populi, $2: 7+7^{3}$.

radcliffei, $2: 733^{5}$.

retardata, 2: $727^{7}$.

rubricoma, 2: $726^{2}$.

sperata, $2: 747^{3}$.

superans, $2: 7+9^{3}$.

viunula, 2: $724^{9}$.

xylinif ormis, $2: 7+99^{4}$.

Apatelodes angelica, $2: 727^{2}$.

torrefacta, 2: $509^{9}, 549^{2}$.

Aphelinus abnormis, I: $212^{9}$.

fuscipennis, I: $212^{7}, 214^{3}, 222^{6}$. mytilaspidis, $\quad 1: 212^{7}, \quad 222^{5}$, $231^{2}$.

Aphids, see Plant lice.

Aphis lions, 1: 154 '.

Aphis cerasicolens, $2: 732^{9}$.

cerasifoliae, $2: 732^{9}$

cornifoliae, $2: 737^{1}$.

diospyri, 2: $735^{3}$.

mali, 2: $641^{1}$.

quercifoliae, $2: 709^{3}$.
Aphis rumicis, $2: 729^{\circ}$.

snlicicola, 2: $7 \mathrm{H}^{8}$.

Aphrastus taeniatus, 2: $506^{5} .515^{8}$, $7+s^{\circ}$.

Aphrophora parallela, $2: 686^{6}$. quadrangularis, 2: 686". saratogensis, 2: $686^{5}$.

Aphycus annulipes, $1: 203^{1}$. flavus, I: Is I?

hederaceus, I: $181^{9}$.

pulvinariae, $\mathbf{1}$ : $199^{\circ}$.

apicalis, Ephistemus, 2: $491^{1}$.

Nelalopha $2: 7+7^{5}$.

apicitripunctella, Recurvaria, 2: $754^{8}$.

apiformic, Aegeria, 2: $429^{8},+72^{8}-$ $73^{3}$.

Apjon herculaneum, 2: $734^{6}$

nigrum, 2: $730^{4}$.

rostrum, 2: $730^{4}$.

segnipes, $2: 7+2^{3}$.

walshii, $2: 749^{\text {l }}$.

apionides, Phloeophagus, 2: $733^{3}$.

Aplodes bistriaria, 2: $720^{2}$.

mimosaria, 2: $706^{4}$.

A poda biguttata, 2: $529^{6}$.

$y$-inversa, 2: $529^{4}$.

appendiculatus, Gymonychus, 2: $609^{2}$.

Apple borer, flat headed, I: $261^{3}$.

round-headed, i: $51^{3}, 84^{7}-86^{9}$.

Apple plant louse, $2: 641^{1}$.

Apple tent caterpillar, $1: 2 t^{5}$; 2: $510^{2}, 550^{7}-5 \mathrm{I}^{3}, 606^{7}, 607^{5}$; bircls feeding on, $1: 28^{2}$.

Apple wood stainer, $1: 257^{6}, 287^{4-}$ $92^{5}$.

Apple worm, yellow-necked, 2: $505^{6}, 535^{4}, 535^{5}-36^{2}$.

Appletree, Phyllobaenus dislocatus beneficial to, 2: $503^{8}$.

injurious insects:

borers:

apple wood stainer, $1: 289^{6}$. $290^{5}$.

Bostrichus bicornis, 2: $721^{9}$. buprestis, divaricated, 2 : $45^{6}$.

flat-headed borer, common, I: $86^{4}, 87^{2}$. 
Appletree, inj. insects (cont'd $)$ : borers:

fruit tree bark beetle, 2: $453^{2}$.

lickory horer, banded, 1 $268^{2}$.

IIyperplatys maculatus, 2 ; $433^{1}$.

Leptostylus, prickly, 2 : $+25^{\circ}, 461^{2}$.

Leptostylus, spotted, z: $+82^{9}$

liuden borer, I: $91^{*}$.

Liopus alpha, $2: 452^{3}$.

maple and oak twig pruner, I: $6 \mathrm{I}^{3}$.

Neoclytus erytbrocephalus, I: $72^{6}$.

pigeon tremex, $1: 63^{6}$.

prionus, broad-necked, 2: $+86^{\circ}$.

twig borer, red-shouldered, 2: $442^{4}$.

twig girdler, 1: $273^{9}$.

Urographis fasciatus, 2: $435^{9}$.

flower cricket, white, $2: 603^{3}$.

leaf feeders:

American lappet moth, 2: $507^{6}, 525^{6}$

Apatela clarescens, $2: 733^{9}$. funeralis, $2: 710^{\circ}$. grisea, $2: 724^{8}$. impleta, 2: $749^{3}$. interrupta, $2: 724^{8}$. superans, 2: $749^{3}$.

apple tent caterpillar, 2 : $5 \mathrm{10}^{2}, 550^{7}$.

apple worm, yellow-necked, 2: $535^{7}$.

bag or basket worm, $1: 127^{1}$.

Basilarchia astyanax, 2 : $704^{2}$.

black walnut caterpillar, 1: $305^{4}$.

brown tail motb, 1: $164^{1}$.

Cecropia moth, 2: $539^{4}$.

Coscinoptera dominicana, 2: $737^{3}$.

Deilephila lineata, $2: 724^{6}$.

Erannis tiliaria, 2: $731^{6}$.
Appletree, inj. insects (cont' $d$ ): leaf feederw:

flannel moth, crinkled, 2 : $530^{\prime}$.

flea beetle, recl-footed, 2 , $510^{6}, 556^{4}$

forest tent caterpillar, I: $107^{3}, 110^{9}$.

hag moth caterpillar, 2: $528^{5}$.

Heterocampa guttivitta, 2 : $727^{9}$.

Heterocampa manteo, 2: $705^{\circ}$.

leaf roller, oblique banded, 2: $580^{\circ}$.

leaf roller, red-banded, 2 : $532^{2}$.

leaf roller, v-marked, 2 : $53 \mathbf{I}^{3}$.

Mineola indigenella, 2: $733^{6}$.

Morrisonia confusa, $2: 727^{\circ}$.

Orthofidonia vestaliata, 2 : $706^{4}$.

Paonias excaecatus, $2: 724^{7}$.

Papilio glaucus var. turnus, 2: $704^{1}$.

promethea moth, $2: 557^{8}$.

Pyrophila pyramidoides, 2: $704^{7}$

rose beetle, $2: 575^{\circ}$

rose leaf folder, $2: 512^{4}, 581^{4}$.

Schizura semirufescens, 2 : $7+3^{6}$.

unicornis, $2: 705^{9}$.

Scopelosoma sidus, 2: $705^{2}$.

Smerinthus jamaicensis, 2 : $724^{7}$.

Sphinx gordius, 2: $727^{1}$.

spring cankerworm, $2: 509^{7}$, $5+7^{6}$

Thecla liparops, $2: 704^{3}$.

tussock moth, white marked, I : $133^{2}, 136^{9}$

viceroy, $2: 559^{7}$.

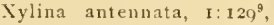
$130^{2}, 130^{3}, 13 I^{6}$

scale or sucking insects:

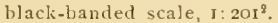

box elder plant bug, $1: 2394$.
Appletree, inj. insects (rint'ai): scale or sucking insects:

Brochymena quadripustu1:ata, 2: 59 i. $^{\circ}$

Buffalo tree hopper, 2: $592^{4}$. chinch bug, false, $2: 685^{k}$.

Eulecanium cerasifex, 2 : $728^{4}$.

oyster scale, $\mathbf{I}: 2 \mathbf{I}^{2}$.

Apricot, injurious insects:

bag or basket worm, 1: 127 $7^{1}$.

tussock moth, white marked, I: $136^{3}$.

Aquilegia canadensis, Tortrix

albicomana injuring, $2: 532^{4}$.

Aradus cinnamomeus, 2: $752^{6}$.

Arbor vitae, insects injurious to:

borers :

balsam bark borer, $2: 376^{3}$.

Dicerca tuberculata, $2: 043^{8}$, $656^{6}$.

red cedar bark beetle, 2 : $392^{l}$.

leaf feeders: $2: 755^{4}$.

bag worm, 1: $123^{8}$.

fir sawity, $2:+15^{8}$.

mite, $2: 755^{5}$

scale 3nsects: $2: 755^{5}$.

arborea, Brochymena, sie B. arborea.

arbos, Ceroptres, 2: $714^{6}$.

arcasaria, Sabulodes, $2: 750^{7}$

Archasia galeata, $2: 597^{1}$.

archippus, Basilarchia, 2:510 $559^{2}, 704^{\circ}$.

Irchips afflictana, $2: 754^{9}$.

argyrospila, $2: 508^{2}, 531^{6}$.

cerasivorana, $2: 510^{3}, 552^{1}$

fervidana, $2: 508^{2}, 530^{6}-3 \mathrm{I}^{5}, 609^{2}$. grisea, $2: 707^{6}$.

infumatana, $2: 717^{2}$.

rosaceana, $2: 512^{4}, 531^{7}, 580^{7}-8 \mathrm{I}^{2}$.

rosana, $2: 512^{4}, 58 I^{3}$.

semiferana, $2: 707^{6}$.

arcuata, Chrysopa, $\mathbf{1}: \mathbf{1 0} \mathbf{I}^{3}$

Corythuca, 2: $598^{6}-99^{7}, 720^{6}$

Drepana, 2: $7+9^{2}$

arcuatus a $\%$. coryli, Agrilus, 2 $723^{4}$.

argenteomaculatus, Stenopsis, 2: $721^{1}$. 
argentifimbriella, Lithocolletes, Ash, injurious insects (cont' $d$ ): 2: $705^{5}$.

argentinotella, Lithocolletes, 2 : $725^{5}$.

argillacea, Alabama, $1: 6^{3} ; 2: 609^{2}$. argutanus, Episimus, $2: 725^{3}$.

Argyresthia austerella, 2: $708^{\circ}$.

argyrospila, Archips, 2: 508\%, $531^{6}$.

Arhopalus fulminans, $2: 427^{6}, 4+4^{8}$.

Aristotelia rubidella, 2: $707^{6}, 707^{9}$. salicifungiella, 2:746.

armataria, Priocycla, $2: 749^{6}$.

armatus, Onychia, 2: 7 I $^{1}$.

Urosigalphus, 2: $588^{3}$.

armicollis, Magdalis, see M. armicollis.

Army worm, 1: $22^{9}, 132^{2}$.

Arotes decorus, $1: 261^{6}$.

Arsenate of lead, $\mathbf{x}: 34^{9}, 37^{4}$.

Arsenical poison, 1: $35^{1}$.

Arsenical preparations, formulas for. $1: 37^{4}-38^{2}$.

Arsilonche albovenosa, 2: $7+3^{\circ}$.

Artace punctistriga, 2: $735^{3}$.

arthemis, Basilarchia, $2: 742^{6}$.

arvensis, Dolerus, $2: 741^{9}$,

Asclera puncticollis, $2: 494^{2}$.

Asecodes albitarsis, 1: $140^{2}, 140^{4}$.

Asemum moestum, 2: $649^{4}, 659^{9}$, $66 I^{2}-62^{7}$.

Ash, beneficial insect:

Elasmocerus terminatus, 2: $501^{\circ}$.

injurious insects:

borers: $2: 726^{7}$.

ash borer, I: $51^{8}, 92^{3}$. banded, $1: 257^{2}, 279^{9}-80^{5}$. four-marked, $2: 428^{9}, 462^{5}$. ash timber beetle, I: $257^{6}$, $288^{6}$.

carpenter worm, r: $79^{9}, 83^{9}$.

lilac borer, $\mathbf{1}: \mathbf{1 0}^{3}$.

Memythrus asilipenuis, 2: $429^{1}, 464^{2}$.

Molorchus himaculatus, 2: $715^{4}$.

Obrium rubrum, 2: $428^{9}$, $463^{3}$.

powder-post beetle, white marked, $2: 483^{3}, 4^{8} 3^{8}$. rustic borer, 1: $2610^{9}$. borers:

stalk borer, $2: 429^{4}, 468^{1}$.

Stenoscelis brevis, 2: $494^{5}$.

Xyloterus politus, $1: 292^{8}$. gall insect:

ash midrib gall, $2: 620^{8}$, $632^{1}$.

leat feeders, $2: 726^{8}-27^{2}$.

Agrilus otiosus, 2: $518^{3}$.

American dagger moth, 2: $525^{3}$.

American lappet moth, 2: $507^{6}, 525^{6}$.

Apatela impleta, 2: $749^{3}$.

Apatelodes torrefacta, 2: $549^{4}$.

ash sphinx, 2: $509^{8}, 54^{2}$. wavy, $2: 509^{6}, 548^{\text {R }}$.

Cleora pampinaria, $2: 7+3^{9}$.

forest tent caterpillar, I: $110^{9}$.

hag moth caterpillar, 2: $528^{5}$.

hickory tussock moth, I: $314^{9}$.

io caterpillar, $2: 522^{3}$.

Paonias excaecatus, $2: 724^{7}$.

Papilio glaucus var. turnus, 2: $704^{\mathrm{I}}$.

Phloeophagus minor, 2: $74^{6}$.

Plagodis fervidaria, 2: $706^{5}$.

Smerinthus jamaicensis, 2: $724^{2}$.

sphinx, four-lined, $2: 509^{6}$, $5+6^{6}$.

Tischeria citrinipennella, 2: $708^{9}$.

tussock moth, white marked, I: $136^{3}$.

scale or sucking insects:

box elder plant bug, I: $239^{9}, 240^{6}$.

Eulecanium cerasifex, 2: $728^{8}$.

pruinosum, 2: $719^{7}$.

oyster scale, $\mathrm{r}: 173^{5}, 21 \mathrm{I}^{2}$.

Putram's scale, $1: 227^{4}$.

Ash, mountain, see Mountain ash.
Ash, prickly, injurious insects: 2: $729^{2}$.

Liopus fascicularis, $2: 729^{2}$, $730^{\prime}$.

Micracis suturalis, 2: $715^{9}$. orange dog, $2: 510^{4}, 554^{4}$.

Ash, white, in jurious insects: ash flower gall, $2: 620^{4}, 633^{\circ}$. Micracis suturalis, $2: 715^{\circ}$.

Ash horer, I: $51^{6}, 92^{3}$. banded, I: $257^{2}, 279^{7}-80^{5}$. four-marked, $2: 428^{9}, 462^{5}-63^{3}$.

Ash flower gall, 2: $620^{4}, 633^{6}-34^{1}$.

Ash midrib gall, 2:6203 $632^{1}-33^{5}$.

Ash sphinx, 2: $509^{8}, 548^{1}$.

wavy, 2: $509^{9}, 54^{87}-49^{9}$.

Ash timber beetle, I: $257^{5}, 288^{6}-$ $89^{4}$.

ashmeadii, Andricus, 2: $711^{5}$.

asilipennis, Memythrus, 2: $429^{\prime}$, $464^{1}$.

asopialis, Palthis, 2: $705^{6}$.

asparagi, Crioceris, $2: 608^{9}$.

Asparagus beetle, 2: $608^{9}$.

Aspen, injurious insects:

apple wood stainer, $r: 290^{5}$. poplar borer, 1: $99^{\circ}$.

asperata, Dicerca, 2: 70 ${ }^{6}$.

aspersus, Hyperplatys, 2: $74^{6}$.

asperulus, Gnathotricus, 2: $726^{8}$.

Aspidiotiphagus citrinus, $1: 212^{8}$, $222^{5}$.

Aspidiotus abietis, $2: 652^{5}, 690^{2}$. ancylus, I: $173^{7}, 226^{6}-27^{8} ; 2: 729^{8}$. comstockii, 2: $728^{7}$.

diffinis, $2: 73 I^{9}$.

juglans-regiae, $2: 719^{8}$.

perniciosus, $1: 8^{4}, 12^{6}, 38^{9}, 173^{6}$, $216^{6}-26^{5}$

rapax, 2: $728^{7}$.

ulmi, $2: 725^{6}$.

uvae, $2: 717^{9}$.

Aspidisca lucifluella, see Coptodisca.

splendoriferella, sec Coptodisca.

Aster, Typophorus canellus injuring, 2: $537^{3}$.

Aster ericoides, 2: $537^{3}$.

Asterolecanium quercicola, see A. variolosum.

variolosum, I: $25^{8}, 329^{8}-31^{7}$. 
astyanax, Basilarchia, 2: $704^{2}$. astylus, Paonias, 2: $735^{5}$.

Ataxia crypta, 2: $702^{4}$. ater, Ampeloglypter, 2: $739^{8}$.

Auletes, 2: $715^{7}$.

athasiaria, Therina, 2: $7000^{5}$.

Athous cucullatus, $2: 701^{5}$.

Atimia confusa, 2: $75 \mathrm{I}^{5}$.

atlantica, Mamestra, 2: 704'.

atomarium, Romaleum, $2: 426^{8}$,

$434^{4}$.

atomarius, Pachybrachys, 2: $730^{2}$.

at omus, Crypturgus, 2: $338^{6}, 359^{6}$ $60^{6}$.

Triachus, 2: $738^{7}$.

atra, Orsodachna, 2: $7+1^{\circ}$.

atratus, Chermes, I: $188^{\circ}$.

Elasmns, $\mathrm{x}: 140^{4}, 145^{9}$.

atricornis, Cecidomyia, 2: $746^{2}$.

atrocularis, Cecidomyia, 2: $7 \notin 6^{2}$.

Atropates collinsi, 1: $199^{6}$.

at roviolacea, Tenthredo, $2: 737^{6}$.

Attacus promethea, sec Callosamia.

Attelabus analis, $2: 720^{1}$.

bipustulatus, 2: $506^{5}, 516^{1}$.

nigripes, 2: $703^{8}$.

rhois, $2: 511^{9}, 574^{6}-75^{2}$.

attenuata, Konowia, $2: 429^{2}, 466^{5}$.

attenuatus, Anthophilax, see A. attenuatus.

Atteva aurea, 2: $735^{5}$.

Atymna castanea, 2: $721^{8}$.

inornata, 2: $721^{7}$.

augustana, Epinotia, 2: $744^{2}$.

Aulacaspis pentagona, 2: $719^{8}$. rosae, $1: 173^{8}, 225^{3}$.

Aulacomerus lutescens, 2: $568^{3}$.

Auletes ater, 2: $715^{7}$. cassandrae, $2: 735^{\top}$.

aurea, Atteva, 2: $735^{5}$.

auronitens, Lithocolletes, 2: $750^{8}$. aurora, Eros, 2: $746^{5}$.

Hyparpax, 2: $506^{\circ}, 520^{3}-2 \mathrm{I}^{1}$. austerella, Argyresthia, 2: $708^{9}$. . australasiae, Orcus, $1: 223^{3}$.

autographus, Dryocoetes, see D. autographus.

Automeris io, $2: 506^{9}, 521^{8}-22^{3}$.

aveccae, Hypothenemus, 2: $702^{6}$.

aviingrata, Odontophyes, 2: $716^{\circ}$. lavulsus, Tomicus, $z: 752^{2}$. azaliae, Amauronematus, $2: 739^{5}$.

Azalea, injurious insects:

Amauronematus azaliae, $2: 739^{4}$. Apatelodes torrefacta, 2: $549^{4}$.

Azelina ancetaria, 2:72 $33^{3}$.

azurea, Chrysobothris, $2: 429^{3}, 467^{1}$.

babayaga, Catocala, $2: 7+3^{4}$.

Baccha fascipennis, r: $186^{2}$.

bachmani, Hypatus, $2: 726^{1}$.

badia, Schizura, 2: $73^{8^{4}}$.

badiella, Tischeria, 2: $708^{8}$.

badistriga, Homohadena, $2: 7+\mathrm{I}^{1}$. balsamicola, Cecidomyia, 2: $62 \mathrm{I}^{9}$, badius, Amphibolips, 2: $710^{5}$.

Bag or basket worm, $1: 105^{5}, 123^{7}$ - baltimoralis, Bomolocha, 2: $727^{8}$. $25^{9}$.

Baileya dormitans, 2: $716^{6}$.

bajulus, Hylotrupes, $2: 649^{6}, 664^{1}$. Banded hickory borer, $1: 256^{7}$,

Balaninus caryae, $2: 5^{8} 4^{9}-85^{1}$. nasicus, $2: 512^{8}, 5^{8} 3^{8}-85^{4}$.

obtusus, 2: $723^{\circ}$.

proboscideus, 2: $512^{7}, 5^{8} 5^{4}-88^{6}$. quercus, 2: $585^{1}, 703^{9}$.

rectus, $2: 512^{7}, 585^{1}, 5^{8} 5^{5}-88^{8}$.

uniformis, 2: $5^{8} 4^{4}, 5^{8} 5^{1}, 703^{9}$.

Balm of Gilead, resistance to insect attack, $1: 47^{6}$.

in jurious insects:

clearwing, three banded, 2: $+7 \mathrm{I}^{3}$.

oyster scale, $\mathrm{I}: 173^{5}, 2 \mathrm{I \textrm {t } ^ { 2 }}$.

Saperda populnea, $2: 475^{1}$.

willow borer, mottled, $1: 10 r^{3}$, $103^{4}$.

Balsam, injurious insects: 2: $653^{2}, 693^{2}$. $339^{2}$.

borers:

ant, large black carpenter, 1: $90^{5}$.

balsam bark borer, 2: $33^{8}$, $375^{7}$.

blazed tree borer, $2: 67 \mathrm{I}^{9}$.

Buprestis maculiventris, 2: $650^{6}, 674^{5}$.

pine borer, ribbed, $2: 367^{1}$.

saw yer, 2: $360^{7}$.

spruce bark beetle, 2: $356^{7}$.

spruce timber beetle, $2: 369^{9}$.

Tomicus balsameus, $2: 354^{7}$. caelatus, 2: $354^{7}$.
Balsam, injurious insects (cont' $d)$ : leat feeders: $2: 75 t^{8}$.

balsam gall midge, $2: 65 \mathrm{I}^{8}$, $685^{2}$.

Eulia velutinana, 2: $707^{6}$.

Feralia jocosa, 2; $754^{7}$.

$79^{7}$.

Balsam gall midge, 2: $62 \mathrm{I}^{9}, 65 \mathrm{I}^{8}$, $685^{1}$.

Balsam poplar, see Poplar, balsam.

balsameus, Tomicus, see T. balsameus.

$651^{8}, 685^{1}$

Banded ash borer, $1: 257^{2}, 279^{7}-80^{5}$.

Banded buprestid, $2: 428^{6}, 45^{8}-59^{3}$.
Banded hickory borer, I: $256^{7}$, $267^{1}-68^{5}$.

Banded horntail, 2: $649^{9}, 668^{7}$.

Baptolinus longiceps, $2: 389^{6}$.

barbata, Glyptoscelis, 2: $518^{5}$.

barbatus, Serropalpus, 2: $650^{3}$, $671^{7}$.

barbita, Nagdalis, $1: 49,5 \mathrm{I}^{1}, 70^{7}$, $72^{9}, 73^{2}-75^{2}$.

barda, Selandria, 2:609 $9^{3}$.

bardus, Monopliadnus, 2: $726^{8}$.

Bark beetle, $1: 7^{3} ; 2: 729^{4}$. coarse writing, $2: 33^{8^{4}}, 345^{7}-51^{4}$, $351^{4}$.

spruce, birds feeding on, I: $28^{3}$.

Bark beetle destroyer, cloudy, 2:

Bark borers, $1: 6^{7}, 11^{9}, 35^{9}, 256^{4}-$ $57^{9}: 2: 339^{1} ;$ work of in pine, 2 : $333^{1}-36^{1}$; in trunk and wood, 2: $33^{3^{1}}$; true, $2: 33^{2}$; natural enemies, 2: $499^{4}-505^{3}$.

Baryconus oecanthi, 2: $603^{5}$.

Basal leaf gall, 2: $620^{7}, 636^{3}$.

basalis, Liodes, $2: 74^{5}$.

Scoparia, 2: $754^{8}$.

Basilarchia archippus, 2: $5 \mathrm{ro}^{9}$, $559^{\circ}, 704^{2}$.

arthemis, $2: 742^{6}$.

astyauax, 2: $704^{2}$.

basilare, Sinoxylon, $2: 427^{4}, 4+2^{2}$, $502^{4}$. 
basilis, I'ediopsis, $2: 597^{9}$. lasilona inperialis, $2: 651^{2}, 677^{6}-$ $79^{\prime \prime}$

bavistrigella, Lithocolletes, 2 : $708^{6}$.

Basket worm, 1: $123^{7}-25^{9}$.

Bassareus detritus, 2: $703^{6}$. mammifer, 2: $70^{4}, 719^{5}$.

bassettella, luclemensia, 2: $708^{2}$. bassetti, 1lolkaspis, 2: $711^{4}$.

Basswood, in jurious insects:

borers: $2: 731^{2}$.

apple wood staner, $I: 290^{6}$.

Diaperis hydni, $2: 497^{9}$.

Elater nigricollis, $2: 492^{5}$.

IJoplosia uubila, $2: 722^{3}$.

Mycetophagus flexuosus, 2: $+95^{5}$.

punctatus, 2: $495^{2}$.

Passalus, horned, $2: 492^{8}$.

Platypus composit 11s, $2: 720^{\circ}$.

I'legaderus transversus, 2: $491^{7}$.

Tenebrio tenebrioides, 2: $493^{5}$.

Triphyllus humeralis, 2 : $495^{*}$.

Xyleborus pubescens, $2: 720^{9}$. gall insects: $2: 731^{8}$.

leaf feeders: $2: 73 \mathrm{I}^{4}$.

Cistela sericea, $2: 518^{4}$. sucking insects: $2: 731^{\star}$.

batatus, Ceciclomyia, $2: 745^{4}$. Neuroterus, 2: $613^{8}, 6,24^{7}, 624^{9}$. khabdoplaga, $2: 7+5^{4}$.

l3athythrix meteori, I: $140^{3}$. pimplae, I: $140^{3}$.

Batrachedra praeangusta, $2: 744^{5}$. salicipomonella, $2: 74^{64}$.

Battle of the weak, $1: 241^{1}-52^{9}$.

Batyle suturalis, 2: $649^{5}, 663^{3}$.

Bayberry, injurions insects: 2: $735^{6}$.

leaf feeders;

Adoneta spinuloides, $2: 706 \%$.

A patelodes torrefacta, $2: 549^{4}$.

Euclea chloris, 2: $706^{\circ}$. delphinit, $2: 529^{2}, 706^{9}$. indetermina, $2: 528^{9}$.

Prolimacoules scaplaa, 2: $707^{-1}$. Sisyrosea textula, $2: 721^{4}$.

Bayberry,iujurious insects $\left(c o n l^{\prime} d\right)$ : ' Betch, injurious jusects (cont'd): leal feeder

Tortricirlia pallikla, $2: 707^{4}$.

Beautiful hickory borer, $2: 426^{\circ}$ $+3 \mathrm{I}^{4}-32^{1}$.

bedeguar, Cecidomyia, $2: 734^{9}$.

lee family, $\mathrm{I}: 10^{7}$.

Beech, scarlet winged clerid beneficial $t o, 2: 503^{1}$.

injurious insects: borers: $2: 721^{4}$.

Acanthoderes quadrigibbus, 2: $702^{4}, 715^{5}$.

Acoptus suturalis, $2: 715^{8}$.

Agrilus obsoletoguttatus, 2: $701^{7}$.

Anamorplaus pusillus, 2: $721^{9}$.

Anthophilax attenuatus, 2: $431^{1}, 438^{3}$.

Apple wood stainer, $1: 257^{\circ}$, $289^{3}$.

ash borer, four-marked, 2: $462^{9}$.

brenthian, northern, 1: $263^{8}$. buprestis, divaricated, 2: $428^{6}, 457^{6}$

Buprestis rufipes, $2: 701^{6}$.

Centrodera decolorata, 2 $429^{5}, 456^{2}$.

Ceruchus piceus, $2: 492^{7}$.

chestuut horer, two-lined, 1: $28 \mathrm{I}^{5}$.

Cratoparis lunatus, $2: 499^{2}$. Cryptorliynclus bisignatus, 2: $702^{5}$.

Dendroides canadensis, 2 : $494^{3}$.

concolor, $2: 494^{3}$.

I)itoma qualriguttata, 2 : $489^{5}$.

T)ryobius sexfasciatus, 2 : 702 '.

Elater lumeralis, $2: 492^{5}$. nigricollis, $2: 492^{5}$.

Ephistenus apicalis, $2: 49 I^{1}$. Euderces picipes, $2: 46^{l}$.

flat-headed borer, common, I: $87^{2}$.

fungous beetle, forked, 2: $498^{5}$. burers:

Goes pulverulentus, $2: 455^{3}$. Cirynoclaris quadrilineatus, $2: 460^{2}$.

IIister lecontei, 2: $491^{2}$.

1)oplocephala bicornis, 2: $49^{3}$.

Hyperplatys maculatus, 2 : $433^{2}$.

Hypulus simulator, 2: 494 '.

Laemoph]oeus testaceus, 2 : $490^{4}$.

leopard moth, $1: 7^{5}$

Leptura subhamata, $2: 675^{4}$. zebra, 2:45 I'.

Lepturges symmetricus, 2: $493^{3}$.

Melandrya striata, $2: 493^{8}$.

Ionarthrum fasciatum, 2: $751^{8}$.

Nyctobates penusylvanica, 2: $192^{3}$.

oak weevil, gray sided, 2 : $437^{5}$.

Parandra brunnea, 2: $701^{8}$.

Penthe obliquata, $2: 493^{6}$. pimelia, $2: 493^{7}$.

Plienolia grossa, $2: 496^{2}$.

pigeon tremex, $1: 63^{6}$.

Platypus compositus, 2 : $720^{9}$.

red horned borer, small, I: $209^{1}$.

Silvanus imbellis, $2: 489^{7}$

Smodicum cucujiforme, 2 : $701^{9}$.

Tenebrioides castanea, z: $492^{2}$.

Tharops ruficornis, $2: 492^{5}$.

Uliota dubius, $2: 490^{6}$.

Urographis fasciatus, 2: $+35^{\circ}$.

Xyloterus politus, I: $257^{6}$, $292^{7}$.

leaf feeders: $2: 722^{5}$,

Adoneta spinuloides, 2 : $706^{9}$.

A]ceris ferrugana, $2: 7+4^{2}$.

Anagoga pulveraria, 2: $728^{3}$.

Apatela ovata, $2: 704^{6}$. 
Beech, injurious insects $($ cont' $d)$ : Beech, blue, Cochlidion y-inversa leaf feeders:

apple worm, yellow-necked, 2: $535^{7}$.

black walnut caterpillar, I: $305^{4}$. injuring, $2: 77^{-1}$.

Beech leaf ajhis, woolly, 2: 60 $\mathbf{I}^{5}-2^{3}$. belangerella, Telphusa, $2: 750^{7}$.

bella, L'tetheisa, $2: 724^{\circ}$.

Bellamira scalaris, $2:+29^{3}, 467^{5}$.

Brachys aeruginosa, 2: 7o $3^{5}$. bellus, Callipterus, 2: $709^{3}$.

Demas propinquilinea, 2: Beneficial insects, 2: $603^{\wedge}-14^{7}$; key $7+9^{5}$.

Dichelonycha elongata, 2: Benta malanogrammos, 2: $65 \mathrm{I}^{1}$, $7 \mathrm{I6} 6^{3}$.

Euclea delphinii, 2: $529^{2}$, Benzoin, black-banderl scale in$706^{9}$. juring, $1: 201^{2}$.

Lutrapela kentaria, 2: $725^{2}$. bethunei. Xylina, $2: 73 \mathrm{I}^{\mathrm{b}}$.

Fentonia marthesia, 2: bethuniella, Lithocolletes, $2: 705^{5}$. $706^{1}$.

forest tellt caterpillar, I: lintneri injuring, $\mathbf{I}: 227^{9}$. $107^{3}$.

Heterocampa bilineata, 2 : $725^{2}$.

biundata, $2: 727^{8}$. guttivitta, $2: 727^{9}$.

Heterogenea shurtleffi, 2 : $707^{3}$.

betuleti, Orchestes, $2: 7+9^{1}$.

Hyperitis amicaria, $2: 722^{5}$. beutenmulleri, Isochaetes, $2: 722^{5}$. Ianassa lignicolor, 2: $705^{8}$. bicolor, Adelocephala, $2: 729^{7}$.

io caterpillar, $2: 522^{3}$.

Lithacodes fasciola, $2: 728^{4}$.

locust leaf miner, $1: 327^{9}$.

luna moth, $2: 527^{\text {l }}$.

maple leaf cutter, $2: 541^{5}$.

Natada nasoni, 2: $707^{\circ}$.

New York weevil, $2: 517^{8}$.

oak caterpillar, red-humped, 2: $520^{2}$.

Paraphia subatomaria, 2: $753^{3}$.

Phloeophagus minor, 2: $7+2^{5}$.

Plagodis fervidaria, 2: $706^{5}$. promethea moth, 2: $557^{8}$.

Schizura semirufescens, 2 : $7+3^{6}$.

Sisyrosea textula, 2: $721^{4}$.

sphinx. four-lined, $2: 509^{6}$, $5+6^{6}$.

scale or sucking insects: 2 : $722^{6}$.

beech leaf aphis, woolly, 2: $60 \mathrm{I}^{6}$.

Putnam's scale, $\mathbf{I}: 227^{4}$.
Dolerus, 2: $741^{9}$.

Eustrophus, 2: $73 \mathrm{I}^{4}$.

Phymatodera, 2: $393^{2}$.

Rhodites, 2: $621^{7}, 647^{8}$.

Rhynchites, 2: $518^{5}$.

bicornis, Bostrichus, 2: $701^{8}, 721^{9}$. Hoplocephala, see Il. bicornis. bicostomaculella, Gelechia, 2: $7^{\circ} 7^{9}$.

bidentata, Nerice, 2: $725^{1}$.

Tomoxia, se' T. bidentata.

bidentatus, Silvanus, $2: 721^{1}$.

bifasciatus, Allandrus, $2: 73 \mathrm{I}^{4}$.

Notoxus, sie N, bifasciatus.

bifasciella, Lithocolletes, $2: 708^{6}$.

bifidus, Telenomns, I: $145^{2}$.

bifurcus. Boletotherus, $2: 49^{5^{5}}$.

bigeminata, Hyperaspis, $1: 199^{8}$.

bigsbyana, Chrysomela, set C. bigsbyana.

biguttata, Apoda, 2: $529^{6}$. Cochlidion, 2: $707^{3}$.

biguttatus, Laemophloens, 2: $490^{2}$.

bilineata, Falcaria, 2: $7+99^{5}$.

lleterocampa, $2: 725^{2}$. bilineata, Mlacrophya, $2: 735^{3}$.

bilineatus, Agrilus, 1: $257^{\circ}, 280^{6}-$ $83^{3}$.

bimaculatus, Molorchus, $2: 715^{4}$. Tylonotus, 2: $726^{\circ}$.

bimarginata, llaltica, $2: 51 \mathrm{I}^{9}$, $573^{5}-74^{6}$.

binotata, Enchenopa, 2:50 $4^{1}-95^{2}$. 11 yeraspis, $2: 605^{4}$.

Mycetochares, $2: 48 y^{8}$.

binotatus, Copturus, 2: $730^{4}$.

biographus, Ayleborus, $2: 447^{9}$.

Biorliza forticornis, $2: 615^{6}, 619^{2}$. $626^{4}-27^{3}, 714^{7}$.

hirta, 2: $712^{9}$.

loxaulis, $2: 710^{5}$.

nigra, 2: $710^{3}$.

rubiuls, $2: 7 \mathrm{II}^{2}$.

bipunctata, Adalia, I: $174^{9}, 195^{2}$, $206^{9}: 2: 60 \mathrm{t}^{5}$.

Tetyra, 2: $753^{6}$.

bipunctatus, Elleschus, $2: 7+2^{5}$.

bipustulatus, Attelabus, 2: $506^{8}$, $516^{1}$.

Birch, injurious insects:

borers: $2: 7+5^{4}$.

alder borer, $2: 480^{4}$.

Asclera puncticollis, 2: $494^{2}$.

birch horntail, slender, 2: $429^{2},+66^{5}$.

bronze birch borer, I: $257^{4}$, $284^{9}$.

Ceruchus piceus, $2: 492^{7}$.

Chrysobothris azurea, $2:+29^{3}$, $467^{2}$.

sexsignata, $2: 721^{9}$.

Corymbites sulcicollis, $2: 492^{6}$.

Dendroides canadensis, 2: $494^{3}$.

concolor, $2: 494^{3}$.

Diaperis hydni, 2: $497^{9}$.

Gaurotes cyanipennis, $2: t^{5}$, $45 t^{6}$.

Gonotropis gibbosus, 2: $494^{4}$.

leopard moth, $1: 7^{5}$

Leptura vagans, $2: 4 \mathbf{I}^{1}$.

Nyctobates pennsylvanica, 2 : $492^{3}$.

Pityophthorus sp., 1: $257^{8}, 26^{1}$. red horned borer, $1: 257^{9}$.

small, i: $29^{5}$. 
Birch, injurious insects $\left(\operatorname{con} t^{\prime} d\right)$ : | Birch, injurious insects $\left(\operatorname{cont}^{\prime} d\right)$ : borers:

Tylonotus bimaculatus, 2: $726^{8}$.

Upis ceramboides, $2: 497^{2}$.

willow borer, mottled, I: $103^{3}$.

Xyloterus, $1: 257^{7}$.

sp., I: $293^{9}$.

politus, I: $292^{8}$.

Xyphidria provancheri 2: $429^{2},+65^{2}$

gall insects:

birch seed gall midge, 2: $621^{3}$, $6+7^{2}$.

11 amamelistes spinosus, I: $246^{9}-47^{1}$

leaf feeders: $2: 7+4^{6}-49^{8}$

Adoneta spinuloides, 2: $706^{9}$.

Alceris ferrugana, $2: 7+4^{2}$.

American dagger moth, 2: $525^{3}$.

American silk worm, 2: $526^{6}$.

Apatela brumosa, 2: $704^{5}$.

dactylina, $2: 742^{9}$.

distans, $2: 747^{2}$.

funeralis, $2: 716^{6}$.

hamamelis, $2: 704^{6}$.

interrupta, $2: 724^{*}$.

leporina, $2: 7+7^{2}$.

ovata, 2: $704^{6}$.

apple tent caterpillar, $2: 55 \mathrm{I}^{1}$.

apple worm, yellow-necked,

2: $535^{8}$.

Basilarchia arthemis, 2: $742^{6}$.

birch leaf skeletonizer, $\mathrm{I}$ : $25^{86}, 3 \times 5^{8}$.

Catocala relicta, 2: $7+3^{3}$.

Cecropia moth, 2: $539^{4}$.

Charadra deridens, $2: 704^{4}$.

Chlamys plicata, 2: $703^{6}$.

Dichelonycha elongata, 2: $716^{4}$.

elm caterpillar, spiny, I: $161^{4}$.

Eustroma testata, 2: $7.43^{8}$.

Eutrapela kentaria, 2: $72 \mathrm{~S}^{2}$.

flea beetle, black-margined, 2: $506^{4}, 515^{2}$.

forest tent caterpillar, $1: 107^{4}$, $110^{9}$ leaf feeders:

Gluphisia septentrionalis, 2: $7+7^{6}$.

Graphiphora alia, 2: $704^{9}$.

lleterocampa biundata, 2: $727^{8}$.

manteo, 2: $705^{7}$.

subrotata, 2: $716^{9}$.

umbrata, 2: $705^{8}$.

hickory caterpillar, striped, 2: $508^{6}, 535^{4}$.

Hylotoma pectoralis, 2: $5 \mathrm{II}^{2}$, $570^{9}$.

Ianassa liguicolor, 2: $705^{8}$.

io caterpillar, $2: 522^{3}$.

Lithacodes fasciola, 2: $728^{4}$.

locust leaf miner. 1: $327^{9}$.

luna moth, 2:527'.

Macaria praeatomata $\tau / t r$. bisignata, $2: 753^{2}$.

Morrisonia confusa, $2: 727^{8}$

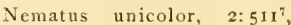
$571^{7}$.

oak caterpillar, green, $2: 52 x^{2}$.

Odontota quadrata, 2: $731^{5}$.

Paonias excaecatus, 2: $724^{7}$.

Papilio glaucus var. turnus, 2: 704'.

Paraphia subatomaria, 2: $753^{3}$.

Phigalia titea, $2: 728^{3}$.

Phloeophagus apionides, 2: $733^{3}$.

minor, $2: 7+2^{5}$

Plagodis fervidaria, 2: $706^{6}$.

Polygonia faunus, 2: $7+2^{6}$.

Priocycla armataria, $2: 749^{6}$.

Pristiphora sycophanta, 2: $5 \mathrm{IO}^{\circ}, 557^{9}$.

Prolimacodes scapha, 2: $707^{1}$. promethea moth, $2: 557^{8}$.

Pteronus latif asciatus, 2: $51 \mathrm{I}^{7}$, $572^{3}$.

Schizura ipomoeae, 2: $705^{8}$. semirufescens, $2: 7+3^{6}$. unicornis, $2: 705^{\circ}$.

Smerinthus jamaicensis, 2: $724^{7}$.

Tortricidia testacea, $2: 707^{4}$. biscolorella, Agnippe, $2: 729^{7}$.

tussock moth, white marked, bisignatus, Cryptorhynchus, 2: I: $136^{\circ}$.
Birch, injurious insects ( cont $\left.^{\prime} d\right)$ : leaf feeders:

Venusia comptaria, 2: $722^{6}$ scale or suching insects: $2: 749^{9}-$ $50^{\mathrm{l}}$

Aspidiotus rapax, 2: $728^{7}$.

birch aplaid, 2; 6019

Eulecanium pruinosum, 2: $719^{7}$.

Putnam's scale, $\mathbf{I}: 227^{5}$.

Birch, paper, Eugonia j-album injuring, $2: 7+9^{\circ}$.

, white, sec Birch.

Birch, willow, Tortricidia pallida injuring, 2: $707^{5}$.

Birch, yellow, injurious insects: borers:

Bellamira scalaris, $2: 429^{3}$ $467^{6}$.

birch bark borer, $2: 429^{4}, 468^{4}$. Xyloterus sp., $1: 294^{4}, 294^{6}$. leaf feeders:

Pristiphora sycophanta, 2: $510^{8}, 557^{9}$

tibialis, $2: 74^{6}$

Birch aphid, $2: 60 \mathbf{I}^{1}$.

Birch bark borer, 2: $429^{5}, 468^{3}-69^{3}$.

Birch borer, bronze, I: $257^{4}, 284^{6}-$ $87^{9}$

Birch horntail, slender, $2: 429^{2}$, $466^{5}$.

Birch leaf skeletonizer, 1 : $25^{7}$, $315^{8}-17^{7}$.

Birch seed gall midge, $2: 621^{4}, 647^{1}$.

Birds, relative value of certain families, 1: $29^{8}-32^{6}$; feeding on gipsy moths, $1: 27^{2}, 122^{1}$; feeding on forest tent caterpillars, I: $111^{2}, 111^{5}$; feeding on hairy caterpillars, $1: 137^{3}$; how to increase number, 1: $33^{\circ}$; insect enemies, I: $25^{4}-3 t^{5}$; probable results if insect depredations were not checked by, 1: $32^{7}$; results of increasing efficiency of, $1: 32^{9}$; value in keeping other pests under control, 1: $111^{9}$; voracity, $1: 25^{8}-26^{9}$

$702^{5}$ 
bistriaria, Aplodes, 2: $720^{2}$.

bistriatus, Paromalus, $2: 389^{7}$.

Bittersweet, injurious insects tree hopper, two marked, 2: $594^{3}$.

Zelleria celastrusella, $2: 74 \mathrm{I}^{3}$.

biundata, Ileterocampa, $2: 727^{8}$.

biustus, Leptostylus, $2: 715^{6}$.

bivittata, Neoglaphyroptera, I: $1.40^{8}$.

bivittatus, Xyloterus, $2: 335^{9}, 339^{7}$, $369^{7}-70^{9}$.

bivulnerus, Chilocorus, see C. bivulnerus.

Black-banded scale, I: $173^{3}, 200^{4}-$ $3^{7}$.

Black elm snout beetle, I: $51^{1}$, $73^{2}-75^{2}$.

Black gum, forest tent caterpillar in juring, $1: 110^{9}$.

Black-horned tree cricket, 2: $679^{3}$

$699^{1}$

Black-margined flea beetle, 2: $506^{4}, 515^{1}$.

Black scrub oak gall, 2:618 $625^{5}$.

Black walnut caterpillar, $1: 258^{8}$, $303^{5}-5^{6}$.

Blackberry bushes, injurious insects:

gall insect: rose bedegar, $2: 621^{6}, 647^{6}$. leaf feeders:

Apatelodes torrefacta, $2: 549^{4}$. Chlamys plicata, 2: $703^{6}$. Schizura unicornis, 2: $705^{9}$. scale or sucking insects: bramble flea louse, $2: 689^{1}$. rose scale, $1: 173^{8}, 228^{3}$.

Blackbird, $\mathbf{r}: 33^{3}$. crow, I: $27^{3}, 30^{9}$, III $I^{6}$.

Bladder maple gall, $2: 620^{1}, 630^{5}-$ $3 I^{3}$.

Bladdernut, Putnam's scale injuring, $1: 227^{4}$.

blancardella, Lithocalletes, 2: $708^{5}$.

blanchardi, Chrysobothris, $2: 75 \mathbf{I}^{3}$. blandella, Gracilaria, 2: $720^{2}$.

Blastothrix sericea, $1: 203^{1}$.

Blazed tree borer, 2: $650^{3}, 671^{7}$. $6 \mathrm{I}^{2}$.
Blepharida rhois, 2: $737^{3}$.

Box elder, injurious insects (cont' $d$ ) $685^{7}$.

Blue horntail, $2: 649^{9}, 669^{1}$.

Blue jays, $1: 27^{8}, 33^{3}, 6 \mathbf{1}^{1}, \mathbf{I} \mathbf{I}^{6}, \mathbf{1 2 2 ^ { 2 }}$, Box elder plant bug, $1: 174^{2},-239^{1}$, $137^{-8}, 166^{5}, 309^{6}$.

Blue pine borer, 2: $649^{3}, 660^{2}-$ Brachistes magdalis, $1: 74^{6}$.

Blueberry bushes, injurious in- brachyrus, Spathius, 2: $401^{2}$. sects:

Eulecanium kingii, $2: 739^{1}$. leaf feeders: $2: 738^{7}$.

Bluebird, $1: 32^{6}, 166^{3}$.

Bobolink, $1: 33^{2}$.

Boletophagus corticola, $2: 754^{8}$. lepressus, 2: $754^{6}$.

Bolet otherus bifurcus, $2: 49^{5}$ bolteri, Sesia, $2: 429^{6}, 470^{6}$.

Bombycidae, $1: 12^{2}$.

bombycoides, Lapara, $2: 65 \mathrm{I}^{2}$,

Bomolocha abalienalis, $2: 724^{9}$.

baltimoralis, $2: 727^{8}$. madefactalis, $2: 720^{2}$.

borealis, Harpyia, $2: 743^{5}$.

Mordella, see M. borealis.

Pontania, 2: $7+5^{6}$.

boreata, Opheroptera, 2: $725^{2}$.

Bostrichus bicornis, 2: $701^{8}, 72 \mathrm{I}^{9}$.

Bothrideres geminatus, $2: 505^{1}$.

botrana, Polychrosis, $2: 732^{3}$.

boucheanus, Dibrachys, see D. boucheanus.

Box elder, injurious insects: 2: $728^{2}-29^{1}$

borers:

Acanthoderes quadrigibbus, 2: $715^{8}$.

Ataxia crypta, 2: $702^{4}$.

Cyrtinus pygmaeus, 2: $702^{3}$.

flat-headed borer, common, I: $87^{2}$.

Leptostylus parvus, $2: 702^{4}$

Liopus variegatus, $2: 720^{7}$.

Xyloterus politus, I: $292^{8}$.

leaf feeders:

Archips semiferana, 2: $707^{6}$.

Pyrophila pyramidoides, 2: 704 .

tussock moth, white marked, I: $136^{8}$. sucking insect:

box elder plant bug, 1: $17 t^{2}$,

$$
239^{2} \text {. }
$$

$40^{\circ}$.

phymatodis, $2: 463$

Brachys aerosa, 2: $506^{3}, 512^{9}-13^{6}$.

aeruginosa, 2: $703^{5}$.

ovata, 2: $506^{3}, 513^{7}-14^{5}$.

Brachystylus acutus, 2: $735^{3}$.

Bracon sp., 2: $406^{9}$

agrilli, $1: 73^{2}$

charus, i: $87^{4}$.

erythrogaster, $1: 266^{8}$.

pectinator, $2: 391^{4}$.

pissodis, $2: 40 I^{2}$.

scolytivorus, $1: 27^{4}$.

simplex, 1: $22^{2} ; 2: 384^{6}$.

Braconidae. 1: $22^{1}$.

Brake, crinkled flannel moth injuring, 2: $530^{1}$.

Bramble flea louse, 2: $652^{4}, 688^{8}$ $89^{5}$.

brassicoides, Cecidomyia, 2: $745^{8}$.

Rhabdophaga, $2: 563^{6}, 567^{5}, 745^{7}$, $7+6^{3}$.

brendeli, Xenorhipis, 2: $70 \mathrm{I}^{7}$.

Brenthian, northern, $1: 256^{6}, 261^{8}-$ $63^{9}$.

Brephos infans, 2: $749^{7}$.

brevicornis, Ceresa, 2: $717^{6}$.

brevilineum, Physocremum, see P. brevilineum.

brevis, Stenoscelis, $2: 455^{6}, 494^{4}$.

briseis, Catocala, $2: 743^{4}$.

brizo, Thanaos, 2: $704^{8}$.

Brochymena annulata, $2: 588^{7}-90^{3}$, $590^{6}$.

arborea, 2: $59 \mathrm{I}^{1}$.

quadripustulata, $2: 588^{9}-89^{1}, 590^{4}$.

Bronchella hortaria, see Epimecis virginaria.

Bronze birch borer, I: $257^{4}, 284^{8}-$ $87^{9}$.

Brown tail moth, I: $105^{9}, 163^{9}-$ $66^{9}, 254^{1}$; birds feeding on, I: $28^{1}$. 
firceei, Mtelalupha, 2: 7\$3'

bruchus mimus. 2: $731^{\circ}$.

brumosa, Apatela, 2: $704^{3}$.

brunnea, f'slaypis, 2: $730^{3}$.

Iarandra, 2: $701^{\circ}$

brunneum, (Hothosuma, 2: $430^{\circ}$, $457^{2}-88^{\circ}$.

urunneus, Rhynculus, 2: $666^{6}, 733^{3}$

bubalus, Ceresa, 2: $59 \mathrm{r}^{\circ}-93^{\prime \prime}$.

Buceulatrix canadensisella, $\quad \mathbf{i}$ $25^{3^{7}}, 315^{8}-17^{7}$.

thuiella, $2: 755^{5}$.

trifasciella, 2: $721^{6}$.

Buck moth, 1: $250^{4}, 310^{35}-14^{7}$.

Buckeye, injurious insects:

horers:

apple wood stainer, $\mathbf{1}: 200^{6}$. Cucujus clavipes, $2:$ jort.

Xyleborus pubescens, $2: 720^{9}$.

leaf feeders:

Crepidodera aesculi, 2: $730^{3}$.

maple leaf stalk borer, 2 : $509^{2}$, $5+0^{2}$.

Proteoteras aesculana, 2: $540^{\circ}$. tussock moth, white marked,

$$
\text { 1: } 136^{\circ} \text {. }
$$

Bud gall, 2: $750^{\circ}$.

Bud moth, I: $20^{l}$.

Buffalo tree hopper, $2: 59 \mathrm{I}^{5}-93^{9}$.

Bullet gall, rough, 2:61 $5^{4}, 624$

spiny, 2:6217 $647^{*}$.

Bumelia, black-banded scale injuring, I. $20 \mathrm{I}^{2}$.

Buprestid, handed, 2: $428^{6}, 45^{n}-$ $59^{3}$.

divaricated, $2: 423^{6}, 457^{5}-58^{7}$.

golden, $2: 648^{7}, 655^{\circ}-56^{3}$

spotted, $2: 339^{6}, 390^{5}-9 \mathrm{I}^{4}$.

Buprestıdae, I: $\mathrm{II}^{\mathbf{3}}$.

Buprestis consularis, $2: 751^{8}$.

fasciata, $2: 428^{6}, 45^{4}-59^{3}$.

lineatia, $2: 751^{2}$.

maculiventris, $2: 650^{6}, 674^{4}$.

rufipes, 2: 7ol $^{6}$.

striata, $2: 644^{87}, 655^{8}-56^{7}$.

sulcicollis, $2: 75 \mathrm{I}^{2}$.

ultramarina, 2: $751^{2}$.

Burning bush, injurious insects: 2: $727^{1}$.

Butternut, Fonus tarsatorius benfficis! tu, $500^{3}$.

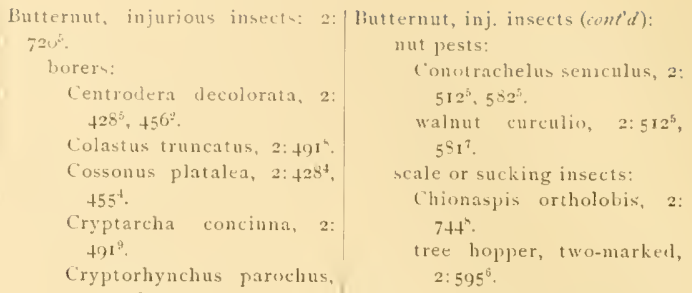
2: $494^{3}$.

Rutternut woolly worm, 2: 50$)^{7}$, $536^{2}$.

Gaurotes

hickory borer, painted, $I$ $264^{8}$.

littonbush, injurious insects:

dagger moth, smeared, 2:560\% leaf feeders, $2: 719^{4}$.

leptostylus, spotted, 2: Buttonwood, injurious insects: $422^{9}$.

Leptura vagans, $2: 4 \mathbf{1}^{1}$.

Lepturges querci, $2: 44^{4}$.

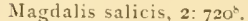

Stenoscelis brevis, $2: 494^{5}$

Tenebrio tenebrioides, 2 : $+93^{5}$.

Uliota dubius, $2: 490^{6}$.

ciliated tingis, 2: $599^{\mathrm{P}}$.

iussock moth, white-marked, 1: $136^{\circ}$.

Bythoscopus fenestratus, 2: $749^{9}$. variabilis, $2: 754^{4}$.

c-nigrum, Noctua, 2: $727^{7}$.

Cabbage butterfly, 2: $609^{1}$.

Ayleborus pubescens, 2: Cacoecia argyrospila, see Archips. 702 ?

leaf feeders:

Agrilus otiosus, 2: $518^{3}$.

black walnut caterpillar, $\mathbf{I}$ : $303^{\circ}$.

cerasivioraua, see Archips.

fervidana, sec Archips.

rosaceana, see Archips.

rosalla, sec Archips.

butternut woolly worm, 2: cacoeciae, lilachistus, 1: $140^{4}$. $508^{7}, 536^{3}$.

Cyrtolobus vau, $2: 717^{5}$. Cacoplia pullata, $2: 702^{3}$.

Eugnamptus angustatus, 2: Cacus oecanthi, 2: $603^{5}$. $703^{5}$.

collaris, $2: 716^{4}$

caelatus, Tomicus, see T. caelatus.

Caenophanes pityophthori, $2: 359^{9}$.

hickory horned devil, I: calanus, Thecla, 2:704 ${ }^{3}$. $305^{5}$.

Calaphis betulella, 2. $750^{1}$.

hickory tussock moth, I: calcarata, Saperda, $1: 49,51^{6}, 9^{81}-$ $314^{9}$.

Lithocolletes caryaefoliella, 2: $717^{4}$.

luma moth, 2: $526^{9}$. $716^{2}$

Thecla calanus, 2: $704^{3}$. ('alledapteryx dryopterata, 2: tussock moth, white mark- $73^{5}$.

ed, $1: 136^{9}$. Callichroma splendidum, $2: 735^{6}$.

Typophorus canellus, 2: Callidium aereum, $2: 428^{1}, 40^{1}$, $505^{9}, 537^{2}$ 
Cailidiun anteunatum, $2: 450^{3}$, candida, Saperda, $1: 5 I^{3}, 54^{7}-56^{2}$. $649^{3}, 660^{2}-6 \mathrm{I}^{2}$ janthinum, 2: $450^{4}, 660^{5}, 75 \mathrm{r}^{4}$.

Calligrapha scalaris, 2: $750^{5}$. lunata, $2: 575^{9}$.

calligraphus, Tomicus, see calligraphus.

Callipterus bellus, 2: $709^{3}$. betulaecolens, $2: 60 \mathrm{I}^{1}$. caryae, 2: 717 ? castanea, $2: 72 \mathrm{I}^{\mathrm{N}}$. discolor, 2: $709^{3}$. hyalinus, 2: $709^{3}$. punctatus, 2: $709^{3}$. quercifolii, 2: $709^{3}$. ulmifolii, I: $172^{4}, 176^{6}-77^{7}$.

Callirhytis tumifica, $2: 713^{2}$.

callitrichoides, Phiprosopus, 2: $740^{7}$.

Calloides nobilis, $2: 427^{6}, \quad 4+3^{7}-$ $+4^{2}$.

Callosamia angulifera, 2: $732^{3}$. prome thea, $1: 45^{5} ; 2: 510^{7}, 557^{5}$.

Calocampa curvimacula, 2: $7+3^{2}$.

Calophya nigripennis, $2: 737^{5}$.

Calosoma calidum, I: $113^{4}$. scrutator, I: $113^{4}, 146^{*}, 161^{9}$. wilcoxi, I: $113^{5}$.

calva, Limnobaris, $2: 734^{6}$.

Calymia orina, 2: $704^{9}$

cambrica, Venusia, 2:733 .

campanula, synergus, $2: 74^{4}$.

campestris, Chalcophora, $2: 722^{2}$.

Camponiscus americana, 2: $7+6^{9}$.

Camponotus herculaneus, I: $5 \mathrm{I}^{4}$, $90^{2}$.

Camptobrochis grandis, $1: 153^{9}-$ $54^{1}: 2: 614^{3}$.

Campylus denticornis, $2: 745^{4}$.

canadaria, Mlelanolophia, 2: $753^{3}$.

canadense, Eulecanium, 2: $725^{6}$.

canadeusis, Dendroides, $2+94^{2}$, $701^{9}$.

Leptura, 2: $650^{2}, 670^{5}$.

Spathins, 2: $359^{3}, 393^{3}$.

canadensisella, Bucculatrix, I: $25^{7}, 315^{8}-17^{7}$.

Canadian Leptura, 2:6502, 6705.

Canarsia ujmiarrosorella, 2: $725^{4}$.

canarsiae, Urogaster, 2: $532^{3}$.

candicans, Chaitophorus, 2: $74^{1}$. canellus, Typophorus, see T. canellus.

canescens, Tetrops, 2: $750^{3}$. caniplaga, Ellida, 2: $73 \mathrm{I}^{5}$.

T. Cankerworm, birds feeding on, $\mathbf{I}$ : $25 \%$

capraea, Eulecanium, 2: $7+4^{9}$. Neoclytus, $1: 257^{2}, 279^{7}-50^{5}$. capreana, Olethreutes, $2: 74^{5}$. capsulus, Andricus, 2: $711^{6}$. cara, Catocala, 2: $7+3^{3}$.

Carabidae, $1: 23^{4}$.

Carbolic soap wash, I: $55^{\circ}$.

Carbon bisulphid, $1: 45^{6}$.

Cardiophorus gaegates, 2: $667^{1}$.

cariniceps, I'ityophthorus, 2: $650^{6}$, $674^{1}$.

Caripeta angnstiorata, 2: $753^{2}$. divisata, 2: $754^{7}$.

Carneades scandens, $\left.2: 6 c^{2}\right)^{2}$.

carnifex, Cosmopepla, 2:6 $\mathbf{I}^{6}$.

carolina, Stagmomantis, I: $24^{3}$, $1+6^{2}, 154^{2}$.

caroliniana, I isonyclia, 2: $511^{3}$. $563^{4}-64^{7}$.

caroliniensis, Amphibolips, 2 $710^{1}$.

Carpenter bee, large, $2: 430^{7}$, $44^{1}$

Carpenter worm, $x: 7^{4}, 12^{3}, 45^{7}$, caryella, Monellia, $2: 717^{5}$.

$51^{3}, 51^{6}, 79^{4}-84^{7} ; 2: 439^{2}$. Siz caryicolum, Isodyctinm, $2: 716^{2}$. also Oak carpenter worm; Pop- Carynota mera, 2: $720^{6}$.

lar carpenter worm.

carpini, Acalyptus, $2: 7+2^{4}$. Psylla, 2: $723^{\circ}$.

Pteronus, 2: $723^{2}$.

Carpinus caroliniana, 2: $514^{9}$.

Carpocapsa pomonella, 2: $609^{2}$.

carueli, Diaspis, $\mathbf{r}: 173^{\circ}, 229^{1}$.

caryae, Acrobasis, $2: 716^{1}$

Balaninus, 2: $58 t^{9}-85^{1}$.

Callipterus, $2: 717^{8}$.

Cecidam yia, $2: 715^{2}$.

Chionaspis, 2: $717^{9}$.

Diplosis, 2: 619 $9^{7}, 628^{4}$.

Epagoge, 2: $717^{2}$.

Eulecanium, $2: 725^{6}$.

lialisidota, $1: 258^{6}, 314^{7}-15^{7}$.

Lachuns, 2: 717 '

Nicracentrus, $2: 7 \pi 7^{6}$. caryae, Monophadnus, 2: $508^{7}$, $536^{2}$.

Schizoneura, $2: 77^{9}$.

caryae-avellana, Phylloxera, 2: $718^{4}$.

caryaecaulis, Phylloxera, $1: 247^{7}$, $259^{1}, 33 \mathrm{I}^{8}-32^{9} ; 2: 6 \mathrm{I} 9^{6}$.

caryacola, Cecidomyia, 2:619 $9^{6}$. $62 S^{3}$.

caryae-fallax, Phylloxera, 2:718 caryaefoliae, Phylloxera, $2: 7^{1} 8^{5}$.

Coleophora, $2: 7 x 7^{4}$.

Lithocolletes, 2: $717^{4}$.

Nepticula, 2: $717^{4}$.

caryaefoliellus, Ypsolopnus, 2: $717^{2}$.

caryae-globuli, Phylloxera, 2: $718^{4}$.

caryae-gummosa, Phylloxera, 2: $718^{4}$.

caryae-ren, Phylloxera, 2: $71 \mathrm{~s}^{3}$.

caryae-semen, Phylloxera, 2: $718^{3}$.

caryae-septum etur. perforans, Phylloxera, 2: 7r $3^{3}$.

caryaevenae, Phylloxera, $2: 7 \mathrm{~s}^{3}$.

caryaevorella, Gelechia, $2: 717^{4}$.

caryana, Enarmonia, 2: $512^{6}$,

$583^{!}$.

caryarum, EuJecanium, 2: $717^{9}$.

Case bearers, I: $20^{2}, 106^{2}, 170^{1}-71^{9}$; 2: 706 ".

cassandrae, Auletes, $2: 738^{7}$.

cassinii, Tibicen, I: $234^{8}$.

castanea, Atymna, 2: $721 .^{1}$

Callipterus, $2: 72 \mathrm{I}^{8}$.

Orchesia, 2: $73^{4}$

Tenebrioides, $2: 492^{2}$.

castaneae, Anthrenus, see A. castaneae.

castaneacella, Lithocolletes, 2: $721^{6}$.

Tischeria, 2: $721^{6}$

castaneaefoliella, Nepticula, 2: $721^{5}$.

castaneum, Cerylon, 2: $489^{6}$.

Castastega aceriella, sie Thiodia signatana. 
Catalpa, injurious insects: Aspidiotus 11$] m i, 2: 725^{5}$. bag or basket worm, 1: $127^{2}$. leaf feeders, $2: 735^{\circ}$. lightning leaf hopper, $2: 598^{5}$.

Catalpa, hardy, resistance to insect attack, I: $47^{3}$.

catalpae, Cecidomyia, $2: 735^{\circ}$.

Ceratomia, 2: $735^{7}$.

Catapastus conspersus, $2: 729^{3}$.

Catbird, $1: 31^{8}, 11 x^{8}, 11 x^{7}, 122^{2}, 237^{8}$.

catenaria, Cingilia, $2: 706^{4}$.

Catocala amasia, $2: 705^{3}$.

amatrix, $2: 7+7^{4}$.

amica, 2: $705^{3}$.

angusi, 2: $216^{7}$.

babayaga, $2: 743^{4}$.

briseis, $2: 7+3^{4}$.

cara, $2: 7+3^{8}$.

cerogama, $2: 731^{6}$.

coccinata, 2: $705^{\circ}$.

concumbens, $2: 7+34$.

epione, $2: 705^{4}$.

flebilis, $2: 716^{7}$.

fratercula, $2: 705^{4}$.

grynea, $2: 743^{4}$.

habilis, $2: 716^{7}$.

ilia, 2: $705^{4}$.

illecta, $2: 729^{6}$.

innubens, $2: 729^{5}$.

insolabilis, $2: 716^{8}$.

judith, 2: $716^{9}$.

lacrymosa, 2: $705^{4}$.

meskei, $2: 7+7^{4}$.

minuta, 2: $729^{6}$.

neogama, 2: $719^{6}$.

obscura, 2: $716^{8}$.

palaeogama, 2: $716^{8}$.

parta, $2: 7+3^{3}$.

piatrix, 2: $719^{7}$.

polygama, 2: $705^{5}$.

var. crataegi, $2: 734^{8}$.

relicta, $2: 7+3^{8}$.

robinsonij, 2: $716^{9}$.

serena, $2: 716^{9}$.

similis, $2: 705^{5}$.

subnata, $2: 720^{2}$.

ultronia, $2: 705^{5}$.

unijuga, 2: $747^{\text {s. }}$

vidua, 2: $705^{5}$.

Catogenus rufus, $1: 26 \mathbf{I}^{8} ; 2: 489^{8}$.
Caudonia pityophthori, 2: $393^{7}$.

caulis, Acarus, 2: $720^{4}$.

cavicollis, Galerucella, $2: 510^{2}$, $550^{3}$.

cavus, Hypophloens, $2: 504^{6}$.

Cecidomyia aceris, $2: 728^{5}$.

albovittata, $2: 76^{1}$.

ananassi, $2: 755^{4}$.

annulipes, $2: 74^{1}$.

atricornis, $2: 746^{2}$.

atrocularis, $2: 746^{2}$.

balsamicola, $2: 62 \mathrm{I}^{9}, 65 \mathrm{I}^{8}, 685^{1}$.

batatus, $2: 745^{4}$.

bedeguar, $2: 734^{9}$.

betulae, see Oligotrophus.

brassicoides, $2: 7+5^{8}$.

caryae, $2: 71 \mathrm{I}^{2}$.

caryaecola, 2: $619^{\circ}, 628^{3}$.

citrina, $2: 731^{8}$.

clavula, $2: 736^{9}$.

cornuta, $2: 745^{3}$.

coryloides, $2: 745^{3}$.

cossae, $2: 718^{9}$.

cynipsea, 2: 7181.

erubescens, $2: 619^{4}, 627^{8}$.

gleditschiae, $2: 729^{8}$.

glutinosa, 2: $718^{2}$.

holotricha, 2: $619^{7}, 628^{5}$.

hordeoides, $2: 745^{3}$.

inopis, $2: 752^{9}$.

liriodendri, $2: 732^{9}$.

majulis, $2: 710^{2}$.

negundinis, $2: 723^{9}$.

niveipila, $2: 710^{9}$.

nodulus, $2: 745^{4}$.

nucicola, 2: $718^{2}$.

ocellaris, $2: 619^{9}, 629^{6}-30^{1}$.

orbitalis, $2: 74^{3}$.

pellex, $2: 620^{8}, 632^{2}-33^{6}$.

persicoides, 2: $619^{7}, 628^{7}$.

pilulae, $2: 619^{2}, 627^{4}, 717^{7}$.

pini-rigidae, $2: 340^{9}, 423^{6}-25^{7}$, $621^{9}$.

pudibunda, $2: 722^{8}$.

resinicola, $2: 340^{5}, 410^{4}-13^{3}, 424^{6}$.

robiniae, $2: 730^{6}$.

sanguinolenta, 2: $718^{1}$.

serotinae, $2: 733^{8}$.

symmetrica, $2: 710^{2}$.

tricicoides, $2: 745^{4}$.

tubicola, $2: 619^{8}, 625^{7}$.
Cecidomyia tulipiferae, 2: $732^{2}$. verruca, $2: 745^{8}$. verrucicola, 2: $620^{9}, 63 \mathrm{I}^{3}$.

Cecidomyiae catalpae, $2: 735^{\star}$.

Cecidomyjdae, $I: I I^{1} ; 2: 6 I 7^{3}$.

Cecidostiba dendroctoni, 2: $390^{\prime}$. polygraphi, 2: $390^{1}$.

Cecropia moth, 2: $505^{9}, 539^{2}$.

cecropia, Samia, 2: $508^{9}, 539^{2}$.

Cedar, injurious insects:

Atimia confusa, $2: 75 I^{5}$.

cedar tree borer, 2: $650^{8}, 675^{7}$.

red celar bark beetle, $2: 392^{1}$.

Tephroclystis miserulata, 2: $706^{2}$.

Cedar, red, see Juniper.

Cedar, white, see Arbor vitae.

Cedar birds, $\mathbf{I}_{1} \mathbf{I}^{3}$.

Cedar tree borer, $2: 650^{8}, 675^{8}-76^{2}$.

Celama triquetrana, $2: 724^{1}$.

Celastrus, Euonymus scale injuring, $1: 173^{5}, 213^{6}$.

celastrusella, Zelleria, $2: 7+\mathrm{I}^{3}$.

celsus, Xyleborus, $2: 427^{\gamma}, 46^{2}-$ $4^{8}, 504^{6}$.

celtidella, Salebria, $2: 726^{2}$.

celtidis - asteriscus, Pachypsylla, 2: $726^{3}$.

celtidis-cucurbita, Pachypsylla, 2: $726^{3}$.

celtidis-gemma, Pachypsylla, 2: $726^{3}$.

celtidis-globulus, Pachypsylla, 2: $726^{4}$.

celtidis-mamma, Pachypsylla, 2: $62 \mathrm{I}^{5}, 647^{4}$

celtidis-pubescens, Pachypsylla, 2: $726^{4}$.

celtidis-umbilicus, Pachypsylla, 2: $726^{4}$.

celtidis-vesiculum, Pachypsylla, 2: $726^{4}$.

celtifoliella, Lithocolletes, $2: 717^{6}$.

celtis, Chlorippe, 2: $725^{9}$.

Cenocoelius populator, I: $85^{8}$.

Cenopis diluticostana, $2: 707^{5}$.

pettitana, 2: $512^{3}, 579^{3}$.

reticulatana, $2: 512^{3}, 580^{1}, 707^{6}$.

centerensis, Cossus, 2: $430^{9}, 476^{1}-$ $77^{9}$.

centricola, Holcaspis, 2: $711^{9}$. 
Centrinus lineicollis, $2: 719^{5}$. Centrodera decolorata, $2: 428^{5}$, $456^{2}$.

picta, 2: $715^{5}$.

Ceophloeus pileatus abietorum, I: $29^{2}$.

ceramboides, Upis, $2: 497^{1}$.

Cerambycidae, I: $\mathbf{I I}^{5}$.

cerasi, .Iyzus, $1: 246^{7}$.

cerasicolens, Aphis, 2: $732^{9}$.

cerasifex, Eulecanium, 2: $723^{8}$.

cerasifoliae, Aphis, 2: $732^{9}$.

cerasivorana, Archips, 2: $510^{3}$, $55^{\mathrm{t}}$.

Ceratomia amyntor, $2: 509^{7}, 546^{6}$. catalpae, $2: 735^{7}$.

undulosa, 2: $509^{9}, 548^{2}-49^{2}$.

Cercopeus chrysorhoeus, 2: $72 \mathrm{I}^{2}$.

Ceresa brevicornis, $2: 717^{6}$. bubalus, 2: $59 \mathbf{1}^{5}-93^{9}$.

cerintha, Chamyris, $2: 733^{4}$.

ceragama, Catocala, 2: $731^{6}$.

Ceroptres arbos, 2: $714^{6}$.

ficus, $2: 714^{7}$.

inermis, 2: $714^{7}$.

obtusilobae, 2: 714 ?

petiolicola, 2: $714^{6}$.

Ceruchus piceus, $2: 492^{7}, 701^{3}$.

Cerura cinerea, see 11 arpyia.

occidentalis, $2: 7+3^{7}$.

scitiscripta, $2: 743^{7}$.

Cerylon castaneum, $2: 489^{6}$.

Chaitophorus aceris, I: $49,172^{3}$, $174^{2}-75^{5} ; 2: 604^{9}$.

candicans, $2: 74^{1}$.

negundinis, $2: 729^{1}$.

nigrae, $2: 74^{7}$.

pinicolens, $2: 753^{7}$.

populicola, $2: 74^{2}$.

populifoliae, $2: 77^{\circ}$.

spinosus, 2: $709^{\circ}$.

viminalis, $2: 7 H^{7}$.

Chalcid, 2: $375^{\circ}$.

Chalcididae, $1: 22^{6}$.

Chalcis ovata, $1: 127^{9}, 138^{3}$. robusta, 2: $555^{5}$.

chalcofrontella, Holcocera, 2: $754^{9}$.

Chalcophora campestris, $2: 722^{2}$.

fortis, $2: 751^{2}$.

liberta, 2: $645^{7}, 654^{8}-55^{7}$.
Chalcophora virginiensis, $2: 643^{6}$, Cherrytree, inj. insects (cont' $d$ ): $653^{8}-54^{7}, 654^{8}, 655^{1}, 655^{2}$. chalybea, IIaltica, $2: 724^{5}$. chalybeus, Orcus, 1: $223^{3}$.

Chamyris cerintha, $2: 733^{4}$.

Charadra deridens, $2: 704^{4}$.

Chariessa pilosa, 2: $49^{3}, 504^{1}$.

charus, liracon, 1: $87^{4}$.

Chauliognathus marginatus, $\mathbf{r}$ : $153^{8}$.

Checkered beetles, I: $23^{5}$.

Chermaphis laricifoliae, $2: 755^{\circ}$.

Chermes abieticolens, $2: 754^{5}$.

abiet is, $\mathbf{I}: \mathbf{1} 72^{4}, \mathbf{1} 89^{1} \rightarrow \mathbf{1}^{6}$.

atratus, $\mathbf{1}: \mathbf{1} 88^{\circ}$.

coccineus, $1: 188^{8}$.

geniculatus, I: $188^{8}$.

hamadryas, I: $138^{8}$.

lariceti, I: ISS $^{9}$.

laricis, see C. strobilobius.

pinicorticis, $\quad$ : $172^{9}, \quad 192^{7}-95^{8}$; 2: $604^{9}$.

strobilobius, $1: 172^{7}, 187^{6}-88^{9}$.

Cherry aphid, r: $2.46^{7}$.

Cherry leaf beetle, $2: 5 \mathrm{IO}^{2}, 55 \mathrm{O}^{3}$.

Cherry scallop shell moth, $2: 5 \mathrm{IO}^{3}$, $551^{3}$.

Cherry worm, ugly nest, $2: 510^{3}$, $552^{1}$.

Cherrytree, injurious insects : aphids, 1: $242^{5}$.

borers:

buprestis, divaricated, 2 : $+25^{6}, 457^{6}$.

flat-headed borer, common, I: $87^{2}$.

fruit tree bark beetle, $2: 453^{2}$.

peach bark beetle, $2: 428^{3}$, $452^{2}$.

red horned borer, small, I: $299^{2}$.

Sesia pictipes, $2: 453^{5}$.

Xyleborus pubescens, 2: $702^{7}$. flower cricket, white, $2: 603^{3}$. leaf feeders:

Apatela impleta, 2: $749^{3}$. lobeliae, $2: 704^{6}$.

apple worm, yellow-necked, 2: $535^{7}$.

Azelina ancetaria, $2: 728^{3}$.

bag or basket worm, I: $127^{1}$. leaf feeders:

Basilarchia astyanax, 2: $704^{2}$.

brown tail moth, 1: $164^{1}$.

Cecropia moth, 2: $539^{4}$.

Cenopis diluticostana, 2: $707^{5}$.

cherry worm, ugly nest, 2: $552^{3}$.

Cleora larvaria, $2: 743^{9}$.

Croesus latitarsus, 2: $74^{8}$.

Euchlaena johnsonaria, 2: $706^{6}$.

forest tent caterpillar, I: $110^{9}$.

hag moth caterpillar, 2: $528^{5}$.

Heterocampa biundata, 2 : $727^{8}$.

io caterpillar, $2: 522^{3}$.

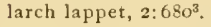

leat roller, oblique banded, 2: $580^{9}$.

Lithacodes fasciola, 2: $72^{8^{4}}$.

Odontota quadrata, $2: 731^{5}$.

Paonias excaecatus, $2: 724^{7}$.

Plagodis fervidaria, 2: $706^{5}$.

Pyrophila pyramidoides, 2: $704^{7}$.

rose beetle, $2: 575^{6}$.

saddleback caterpillar, 2: $523^{7}$.

Schizura unicornis, $2: 705^{9}$.

Sisyrosea textula, $2: 72 I^{4}$.

smerinthus jamaicensis, 2: $724^{7}$.

Thecla liparops, 2: $704^{3}$.

Tolype velleda, 2: $727^{9}$.

Tortricidia pallida, 2: $707^{5}$.

tussock moth, white marked, I: $136^{\circ}$.

viceroy, $2: 559^{\top}$.

scale or sucking insects:

Aspidiotus juglans-regiae, 2 : $719^{8}$.

Eulecanium cerasifex, $2: 72 S^{8}$.

Cherrytree, black, Ceruchus piceus injuring, $2: 492^{8}, 701^{4}$.

Cherrytree, morello, apple wood stainer injuring, $\mathbf{1}: 290^{5}$.

Cherrytree, red, Eulecanium caryae injuring, $2: 725^{6}$. 
Chervtree, wild, injurious insects:

borers: 2: $733^{1}$.

Cyrtophorus verrucosus, 2: $722^{2}$.

Parandra brunnea, 2: $701^{2}$

l'latypus compositus, $2: 720^{9}$. powder post beetle, I: $2(1) 7^{2}$.

red horned borer, small, I: $299^{1}$.

Sesia pictipes, $2:+53^{5}$.

gall insects: $2: 733^{7}$.

leaf feeders: $2: 733^{2}$.

Adoneta spinuloides, 2: $706^{\circ}$.

Apatela clarescens, $2: 733^{9}$.

Apatelodes torrefacta, $2: 549^{4}$.

apple tent caterpillar, $2: 510^{2}$, $550^{7}$.

buck moth, I: $311^{9}$.

Callosamia angulifera, $2: 732^{4}$.

Cerura scitiscripta, $2: 743^{7}$.

cherry leaf beetle, 2: $510^{2}$. $550^{4}$.

cherry seallop shell moth, 2: $5 \mathrm{IO}^{3}, 55 \mathrm{I}^{4}$.

Coptodisca saliciella, $2: 7+4^{4}$.

Crepidodera helxines, $2: 7+2^{2}$.

Cyaniris ladon, 2: $727^{6}$.

Euclea chloris, 2: $706^{3}$.

delphinii, 2: $529^{2}, 706^{9}$.

indelermina, $2: 528^{9}$.

Harpyia borealis, $2: 743^{5}$.

leaf roller, $v$-marked, $2: 531^{\circ}$

Lithocolletes blancardella, 2: $706^{6}$.

Machimia tentoriferella, 2: $708^{2}$.

Panapoda rufimargo, 2: $705^{\circ}$.

Prolimacodes scapha, $2: 707^{1}$.

promethea moth, 2: $557^{\star}$.

Schizocerus prunivorus, 2 : $734^{1}$.

Seopelosoua sidus, 2: $705^{2}$.

Serica sericea, $2: 553^{3}$.

Sisyrosea inornata, $2: 728^{3}$.

Tortricidia flexuosa, 2: $717^{2}$. testacea, $2: 707^{-4}$.

tussock moth, dark, 2: $524^{9}$.

walnut sphinx, 2: 518 ?

scale iusects:

scurfy scale, I: $215^{\circ}$. chersis, Sphinx, $2: 727^{1}$.

Chestumt, injurious insects:

borers: $2: 720^{6}$.

apple wuod stainer, $1: 290^{i}$.

brenthian, northeru, $1: 263^{\text {s }}$

Callidium aereum, $2: 42 R^{1}$, $450^{\prime}$.

Calloides nobilis, $2: 427^{6}, 4+3^{i}$.

carpenter worm, I. $84^{3}$.

Ceruchus piceus, $2: 492$.

chestnut borer, two-lined, I: $257^{3}, 280^{6}$.

chestu ut timber worm, $2: 427^{9}$, $4+9^{5}$.

Crvptorlyuchus bisignatus, 2: $702^{5}$.

Euderces picipes, $2: 427$, $4+5^{7}$.

Lupogonius vestitus, 2: $715^{7}$. flat-headed borer, common, I: $87^{2}$.

Goes debilis, 2: $702^{3}$.

hickory borer, banded, I $268^{2}$.

Hyperplatys aspersus, 2: $74^{6}$. leptostylus, spotted, $2: 452^{9}$. L.eptura zebra, $2: 450^{6}$.

maple and oak twig pruner, I: $6 \mathrm{I}^{3}$.

prionus, broad-necked, 2: $486^{7}$.

lesser, $2: 187^{6}$.

rustic borer, I: $260^{9}$.

Sesia pictipes, $2:+53^{5}$. scitula, $2: 423^{2}, 45 I^{4}$.

thunderbolt beetle, $2: 427^{6}$, $4+4^{3}$.

Thysanoes quereus, $2: 7027$.

Trograplis fasciatus, $2: 435^{\circ}$.

Xyleborus fuscatus, $2: 752^{2}$. pubescens, 2: $702^{7}$.

Xyloterus poitus, $\mathbf{I}: \mathbf{x} 92^{8}$.

leaf feeders: $2: 72 \mathrm{I}^{2}$,

Adoneta spinuloides, $2: 706^{9}$.

American dagger moth, 2 : $5 \div 5^{3}$.

Americals silk worm, 2: $526^{6}$.

Apatela hamamelis, $2: 704^{6}$. ovata, $2: 704^{6}$.

apple worm, yellow-necked, Chilocorus bivulnerus, I: $186^{1}$, 2: $535^{?}$.
Chestnut, inj. insects (cont' $d)$ :

leaf feeders:

Argyresthia austerella, 2: $708^{9}$.

Catocala pajaeogama, 2: $716^{8}$.

Datana contracta, 2: $725^{\prime}$.

Ennomos magnarius, $2: 725^{3}$. subsignarius, $2: 725^{4}$.

Euclea chloris, $2: 706^{8}$. delphinii, 2: $529^{2}, 706^{9}$.

Euguamptus angustatus, 2: $703^{t}$.

hag moth caterpillar, $2: 528^{5}$.

Heterocampa guttivitta, 2: $727^{4}$.

lleterogenea shurtleffii, 2: $707^{3}$.

Ianassa lignicolor, 2: $705^{*}$.

Kronaea minuta, 2: $707^{3}$.

Lithacodes fasciola, 2: $728^{4}$.

luna moth, 2: $526^{\circ}$.

Natada nasoni, $2: 707^{2}$.

Prolimacodes scapha, $2: 707^{1}$.

Pryophila pyramidoides, a: $704^{7}$.

Scolecocampa liburna, $2: 705^{3}$.

Thecla calanus, $2: 704^{3}$.

liparops, 2: $704^{3}$.

Therina endropiaria, 2: $706^{6}$.

Tortricidia flexuosa, $2: 717^{2}$. pallida, 2: $707^{4}$.

tussock moth, dark, 2: $524^{9}$.

Tymnes tricolor, 2: $515^{7}$.

nut pests:

acorn weevil, $2: 584^{2}$.

chestmut weevils, $2: 512^{7}, 585^{5}$. sucking insect: $2: 72 \mathrm{I}^{\text {? }}$.

Chestnut borer, two-jined, I: $257^{3}$, $280^{6}-83^{3}$.

Chestnut timber worm, $2: 427^{9}$, $449^{5}$.

Chestnut weevils, $2: 512^{7}, 5^{3} 5^{4}-88^{6}$.

Chestnut worm, $1: 7^{4}$.

chevrolatii, Otidocephalus, 2: $715^{7}$.

Chewink, $\mathbf{I}: \boldsymbol{I}_{\mathbf{x}} \mathbf{f}$.

Chickadee, I: $32^{2}, 33^{3}, 6 I^{1}$, I I I I $22^{2}, 166^{5}$.

black-capped, I: I I $^{7}$. $195^{3}, 198^{6}, 208^{7}, 216^{3}, 223^{1}, 231^{3}$. 
Chilocorus similis, $1: 223^{4}$.

Chiloneurus albicornis, I: $182^{1}$, diaspidinarum, $1: 212^{9}$.

Chimney swift, I: $137^{4}$.

Chinch bug, 2: $685^{7}$; losses caused by, I: $6^{3}$; false, $2: 65 \mathbf{1}^{3}, 685^{5}$.

chinquapin, Figites, 2: $714^{9}$.

Chion cinctus, $1: 256^{7}, 267^{1-68^{5}}$.

chionanthi, Periclista, 2: $738^{1}$.

Chionaspis americana, I: $173^{4}$, $207^{6}-8^{7}$.

caryae, $2: 717^{9}$.

corni, $2: 736^{9}$.

exonymi, 1 : $173^{5}, 213^{5}-14^{6}$.

furfura, I: $173^{6}, 214^{3}-16^{6}$. var. fulva, 2: $735^{2}$

lintnerı, $1: 173^{8}, 227^{8}-28^{2}$. ortholobis, $2: 744^{8}$.

pinifoliae, $1: 173^{9}, 229^{6}-31^{5}$.

salicis-nigrae, $2: 744^{9}$.

Chippies, I: $26^{7}$.

chiridota, Lacosoma, 2: 706?.

Chlaenogramma jasminearum, 2 : $727^{2}$.

Chlamys plicata, 2: $703^{6}$.

chloreus, Nematus, 2: $703^{2}$.

Chloridea virescens, $2: 736^{8}$.

Chlorippe celtis, 2: $725^{9}$.

clyton, 2: $725^{\circ}$.

chloris, Euclea, 2: $706^{8}$.

Parasa, 2: $529^{5}$.

choerilus, Ampelophaga, 2: $738^{4}$.

Chokecherrytree, injurious insects:

borers:

Agrilus vittaticolli', $2: 720^{7}$.

leaf feeders:

bag or basket worm, I: 127 $\mathbf{1}^{1}$.

cherry worm, ugly nest, 2 : $510^{3}, 552^{2}$.

Hylotoma macleayi, 2: $510^{1}$, $549^{7}$.

tussock moth, white marked, I : $136^{9}$.

scale insect: scurfy scale, $1: 215^{9}$.

Choragus sayi, 2: $722^{4}$.

Chramesus hicoriae, 2: $336^{5}, 336^{9}$, $427^{8}, 44^{3}, 502^{5}$.

Chrysobothris azurea, $2: 429^{3}, 467^{1}$. blanchardi, 2: $75 \mathbf{I}^{3}$.
Chrysobothris dentipes, 2: $648^{9}$, cinciunatiella, Lithocolletes, 2: $657^{4}-58^{4}$.

femorata, I: $5 \mathrm{I}^{4}, 80^{3}-87^{7}, 26 \mathrm{I}^{3}$; cinctifrons, Cixius, $2: 7 \mathrm{I} 7^{6}$. 2: $503^{4}$.

foricola, 2: $649^{1}, 657^{9}, 65^{4}, 65^{5}$.

harrisii, $2: 467^{4}, 75 \mathrm{I}^{3}$

pusilla, 2: $649^{2}, 65^{7}$.

scabripennis, 2: $753^{4}$.

scitula, 2: $701^{6}$.

sexsignata, $2: 72 \mathrm{I}^{9}$.

trinervia, 2: $75 \mathrm{I}^{3}$.

Chrysocorys erythriella, see Schreckensteinia.

Chryșomela, pine, 2: $653^{4}, 695^{1}$.

Chrysomela bigsbyana, 2:511 ${ }^{4}$, $566^{1}$.

conjuscta, $2: 747^{1}$.

multiguttata, 2: $742^{1}$.

multipuncta, 2: $566^{5}, 566^{6}$.

philaclelphica, 2: $752^{8}$.

z' $(7)$. spireae, $2: 742^{1}$

phirsa, 2: $731^{5}$.

scalaris, $2: 509^{3}, 542^{7}-44^{2}$.

Chrysomeliclae, I: $11^{6}$.

Chrysomphalus obscurus $2: 709^{6}$. smilacis, $2: 740^{\circ}$.

tenebricosus, 2: $728^{8}$.

Chrysopa, I: $14^{6}, 195^{3}$.

sp. I : $186^{2}, 23 I^{4}$.

arcuata, I: $191^{3}$.

Chrysopeleia ostryaeella, 2: $723^{\text {? }}$. purpuriella, 2: $730^{8}$.

chrysorl.ueus, Cercopeus, 2: $721^{2}$.

chrysorrhoea, Euproctis, 1: $28^{1}$. $105^{9}, 163^{8}-66^{9}, 254^{1}$.

Cicada, dog day, I: $174^{1}, 237^{8}-38^{9}$. periodical, $1: 173^{9}, 231^{6}-37^{8}$.

Cicada septendecim, see Tibicen.

tibicen, see Tibicen.

Cicada killer, 2: $603^{7}-4^{4}$.

cicadina, Massospora, $1: 237^{4}$.

cicatricula, Andricus, 2: $710^{7}$.

Cicinnus melsheimeri, $2: 706^{8}$.

Cigar case bearer, I: $171^{4}$.

ciliata, Corythuca, 2: $599^{8}-600^{4}$, $719^{3}$.

Ciliated tingis, 2: $599^{8}-600^{4}$.

Cimbex americana, I: $105^{8}, \mathbf{I}_{55^{7}-}$ $58^{7}$.

cimbicis, Phora, I: $15^{6}$.

Sarcophaga, I: $158^{4}$.
$708^{6}$.

cinctus, Chion, $1: 256^{7}, 267^{1}-68^{6}$.

Emphytus, 2: $735^{\circ}$.

cinerea, Harpyia, 2: $510^{9}, 559^{7}$.

Hetoemis, $2: 726^{6}$.

cinerella, Coleophora, $2: 747^{9}$.

cinereus, liopus, $2: 4^{8} \mathbf{r}^{7}$.

Pandeletejus, 2: $43^{6}$.

Cingilia catenaria, 2: $706^{4}$.

cingulatus, Oncicleres, I: $256^{9}$, $271^{2}-74^{4}$.

cinnamomeus, Aradus, 2: $752^{6}$.

cinnamopterum, Tetropium, see T. cinnamopterum.

Cinyra gracilipes, 2: 7o $1^{7}$.

Cistela sericea, 2: $518^{4}$.

Citheronia regalis, $1: 25^{3}, 305^{2}-6^{4}$. sepulcliralis, $2: 75^{9}$.

citrina, Cecidomyia, 2: $731^{8}$

citrinipennelia, Tischeria, 2: $708^{9}$.

citrinus, Aspidioţiphagus, see A. citrinus.

Cixius cinctifrons, $2: 717^{7}$. coloepium, 2:71 $77^{6}$. pini, $2: 753^{6}$.

Cladius isomera, $2: 7+1^{6}$. pectinicornis, $2: 735^{9}$.

Cladobius flocculosus, 2: $744^{6}$. salicis, $2: 744^{?}$.

salicti, $2: 744^{6}$.

clarescens, A patela, 2:7339.

claripennis, Euphorocera, see E. claripennis.

Spathius, 2: $389^{9}$.

clarkei, Dryophanta, 2: $7 \dot{I}^{6}, 713^{7}$.

Clastoptera, obtuse, $2: 687^{3}$. pine, $2: 686^{9}$.

Clast optera obtusa, 2: $687^{3}$. pini, 2: $686^{9}$.

proteus, 2: $59^{2}$.

clavipes, Cucujus, $2: 489^{9}-90^{2}, 701^{4}$. clavula, Andricus, 2:618 $4624^{4}$, $74^{6}$.

Cecidomyia, 2: $736^{9}$.

claypoleana, Epinotia, 2: $500^{2}$, $540^{1}-41^{2}$.

Clearwing, three banded, $2: 429^{2}$, $47 \mathrm{I}^{2}$.

clemataria, Abbotana, 2: $72 \mathrm{I}^{4}$. 
clemensella, Lithocolletes, $2: 728^{5}$. cockerelli, Eulecanium, $2: 725^{6}$. Nepticula, 2: $719^{3}$.

Cleora cribrataria, $2: 7+3^{9}, 754^{\circ}$. larvaria, $2: 7+3^{9}$. pampinaria, $2: 7+3^{9}$.

Clerid, orange-banded, $2: 502^{7}$. scarlet winged, $2: 503^{\mathrm{t}}$.

Cleridae, $1: 23^{5}$.

Clerus formicarius, $2: 500^{7}$. ichneumoneus, $1: 278^{5} ; 2: 502^{7}$. quadriguttatus, $2: 649^{8}, 666^{2}$. quadrisignatus var. nigripes, 2 : $393^{3}$.

Clethra alnifolia, I: $215^{4}$.

clethrae, Nola, $2: 739^{7}$.

Climacia, 1: $18^{\top}$.

Clisiocampa americana, see Malacosoma.

disstria, see Malacosoma.

clisiocampae, Ablerus, sic A. clisiocampae.

Clondy bark beetle destroyer, 2: $653^{2}, 693^{\circ}$.

Clover, red, locust leaf miner injuring, $1: 327^{9}$.

Clover leaf weevi], $\mathbf{1}: 18^{7}$.

clymene, Ilaploa, 2: 70 4".

Clytanthus albofasciatus, $2: 715^{5}$. ruricola, 2: $715^{5}$.

clyton, Chlorippe, $2: 725^{y}$.

Clytus pictus, see Cyllene.

Coarse writing bark beetle, 2: $338^{4}, 345^{7}-51^{4}, 351^{8}$.

coccidivora, Laetilia, I: $195^{\wedge}$.

coccinata, Catocala, $2: 705^{3}$.

coccinea, Diedrocephala, 2: $717^{7}$.

Coccinella novemnotata, $2: 652^{7}$ 691 !.

trifasciata, $2 ; 652^{8}, 69 \mathbf{I}^{5}$.

Coccinellidae, $1: 23^{7}$.

coccineus, Chermes, 1: $188^{8}$.

coccisugus, Hemisarcoptes, I: $213^{2}$.

coccois, Rhopus, I: $185^{9}$.

Cockscomb elm gall, I: $172^{6}, 186^{7}-$ $87^{6}, 247^{2} ; 2: 620^{4}$.

Codling moth, 2:609 $9^{2}$.

coelebs, Amphibolips, 2: $712^{4}$.

Coelostethus nutatus, $2: 701^{5}$.

Coenus delius, $2: 653^{6}, 697^{2}$.

coerulea, 11 ylotoma, $2: 74^{6}$.

coeruteus, Ichneumon, I: $138^{8}$.

Coffee tree, Adocephala bicolor injuring, $2: 729^{7}$.

cogitans, Eupristocerus, $2: 750^{3}$.

cognataria, 1ycia, $2: 7^{2} 8^{1}$.

Colaptes auratus luteus, I: $29^{1}$.

Colaspis brunnea, $2: 730^{3}$.

Colastus truncatus, $2: 49 \mathbf{r}^{8}$.

Coleophora caryaefoliella, $2: 717^{4}$. cinerella, $2: 747^{9}$. corylifoliella, $2: 723^{6}$. fietcherella, $\mathbf{r}: 171^{4}$. laricella, I: $106^{2}, 170^{1}-7 \mathrm{~T}^{9}$. limosipennella, I: $106^{1}, 167^{1}-68^{4}$. ostryae, $2: 722^{8}$.

pruniella, $2: 733^{\top}$. querciella, $2: 708^{3}$. rosacella, $2: 736^{3}$. rosaefoliella, $2: 736^{2}$. tiliaefoliella, 2: $731^{\text {? }}$. viburniella, $2: 738^{5}$.

Coleoptera, I: $\mathbf{I}^{3}$.

collaris, Eugnamptus, 2: $716^{5}$. Leptostylus, 2: $720^{7}$.

collinsi, Atropates, I: $199^{6}$.

coloepium, Cixius, $2: 717^{6}$.

colonus, Xylotrechus, $1: 256^{5}, 259^{2}-$ $6 \mathrm{I}^{7} ; 2: 67 \mathrm{I}^{2}$.

comptaria, Venusia, $2: 722^{6}$.

comptoniella, Acrobasis, 2: $738^{6}$.

comstockiana, Evetria, $2: 34^{5}$, $407^{8}-10^{3}, 411^{5}$.

comstockii, Aspidiotus, $2: 728^{7}$. Ephialtes, 2: $409^{9}$.

Comy's fusca, I: $199^{y}$.

concinna, Cryptarcha, $2: 491^{9}$. Schizura, 2: $743^{6}$.

concinnus, Cossonus, $2: 75 \mathbf{1}^{7}$.

concolor, Cupes, $2: 753^{7}$.

Dendroides, $2: 494^{3}$.

Saperda, $2: 429^{9}, 469^{7}, 471^{3}, 474^{1}$, $474^{9}$.

concumbens, Catocala, $2: 743^{4}$.

condita, Platagrotis, $2: 752^{9}$.

confederata, Eurycyttarus, $2: 72 I^{4}$.

confunis, Pityophthorus, $2: 75 \mathrm{I}^{9}$.

confluentus, Amphibolips, 2:6187, $625^{2}, 625^{4}$.

confusa, Atimia, $2: 75 \mathrm{I}^{5}$.

Morrisonia, $2: 727^{-8}$.

confusor, Monohammus, $2: 334^{9}-$ $35^{1}, 339^{2}, 360^{7}-63^{9}, 364^{9}$.

confusus, Hylobius, 2: $75 \mathrm{I}^{6}$. Limonius, 2: $667^{2}$.

conica, Phylloxera, 2: 7 I $8^{2}$.

conicum, Himatium, 2: $732^{1}$.

coniferarum, Lapara, $2: 753^{4}$.

Coniferous trees, enemies of, 2 : $333^{1}-425^{5}$; less destructive insects affecting, $2: 6.48^{3}-700^{3}$.

coniperda, Pityophthorus, $2: 75 \mathrm{I}^{8}$. conipositus, Platypus, $2: 720^{9}$.

conjuncta, Chrysomela, $2: 747^{1}$.

connecta, Apatela, $2: 742^{9}$.

Colopha ulmicola, $1: 172^{6}, 186^{7}-$ $87^{+} ; 247^{3} ; 2: 620^{4}$.

Colorado potato beetle, $2: 608^{9}$.

columba, Tremex, $1: 50^{7}, 54^{9}, 61^{5}-$ (i.4, $261^{4}$.

columbia, Samia, 2: $755^{2}$.

columbianus, Corthylus, 2: $702^{2}$.

Colydium lineola, $1: 292^{3}, 293^{6}$.

Coccophagus flavoscutellum, I: comma, Polygonia, $2 ; 509^{5}, 545^{6}-$ $199^{4}, 210^{2}$.

fraternus, $\mathrm{I}: \mathbf{1} 8 \mathrm{I}^{9}-8 \mathbf{2}^{1}$.

lecanii, I: $199^{2}, 203^{1}$.

coccophila, Sphaerostilba, I: $224^{2}$.

Cochlidion biguttata, $2: 707^{3}$. $y$-inversa, $2: 717^{1}$. $46^{1}$.

commelinae, Prodenia, $2: 716^{6}$.

commixtus, Leptostylus, $2: 75 \mathrm{I}^{5}$.

communis, Hymenorus, 2: 7OI'.

Melanotus, $2: 492^{6}$.

Meteorus, I: $138^{5}$.

Conotrachelus affinis, $2: 582^{7}$. anaglypticus, $2: 509^{4}, 544^{3}$. crataegi, $2: 734^{4}$. elegans, $2: 715^{8}$.

juglandis, $2: 512^{5}, 581^{6}-82^{4}$. naso, $2: 734^{4}$.

nenuphar, $2: 582^{7}, 715^{8}$. posticatus, $2: 734^{5}$. seniculus, $2: 512^{5}, 582^{5}$.

conquisitor, Pimpla, see P. conquisitor.

consimilis, Neuroterus, $2: 711^{1}$. Pityogenes, $2: 482^{6}$.

Pityophthorus, 2: $503^{7}, 737^{2}$.

consors, Pontania, $2: 745^{6}$. 
conspersus, Catapastus, $2: 729^{3}$. consularis, Buprestis, 2: $75 \mathrm{I}^{2}$.

Contact insecticides, $\mathbf{I}: 35^{5}$; formulas for, I: $35^{3}-39^{9}$.

contatella, Salebría, $2: 730^{7}$.

contracta, l)atana, $2: 725^{1}$.

Hydriomena, 2: $754^{2}$.

convergens, Xylotrechus, $2: 734^{4}$.

cookii, Amphibolips, 2: 7 I $2^{2}$.

copalina, Orthaltica, $2: 737^{3}$.

Coptocycla significa, $2: 730^{3}$.

Coptodisca juglandiella, 2: $720^{8}$.

lucifuella, $2: 717^{3}$.

ostryaefoliella, $2: 722^{b}$.

saliciella, $2: 744^{4}$.

splendoriferella, 2: $734^{8}$.

Coptotriche zelleriella, 2: $708^{9}$.

Copturodes longulus, $2: 702^{6}, 75 \mathbf{1}^{2}$.

-quercus, 2: $702^{5}$.

Copturus binotatus, 2: $730^{4}$.

coqnus var. fulvipenne, Tragidion, $2: 702^{2}$.

cordifera, Leptura, 2: $720^{7}$.

cordigera, Anarta, 2: $73^{8}$.

Coriscium albinatella, 2: $708^{8}$. cuculipennellum, $2: 727^{3}$.

corni, Chionaspis, $2: 736^{9}$.

Schizoneura, 2: $737^{1}$.

Sesia, 2: $428^{6}, 456^{2}-57^{5}$.

cornifoliae, Aphis, $2: 737^{\prime}$.

cornifoliana, Ancylis, 2: $736^{8}$.

cornifoliella, Antispila, 2: $736^{8}$.

cornigerus, Andricus, $2: 437^{8}$, $45 \mathrm{I}^{6}, 61 \mathrm{~s}^{3}, 624^{3}$.

Cornus, see Dogwood.

cornuta, Cecidomyia, 2: $745^{3}$.

cornutus, Anthribus, 2: $730^{4}$.

Passalus, 2: $492^{6}$.

corrugis, Dryophanta, 2: $714^{2}$.

Neuroterus, 2: $713^{9}$.

Corthylus columbianus, $2: 702^{\gamma}$. punctatissimns, I: $50^{8}, 65^{1}-67^{6}$; 2: $732^{5}$.

corticalis, Tenebrioides, $2: 492^{1}$, $72 \mathrm{I}^{9}$.

corticola, Boletophagus, $2: 754^{6}$. Cossonus, 2: $75 \mathrm{I}^{7}$.

Corvidae, $\mathbf{1}: 30^{6}$.

corvulus, Anthonomus, 2: $736^{6}$. corylanum, Exartema, 2: $723^{5}$. coryli, Monocesta, 2: $724^{5}$. coryli, Strophosomus, 2: $749^{\prime}$. corylifoliella, Coleophora, $723^{6}$.

Nepticula, 2: $723^{6}$.

corylisella, Gelechia, 2: $750^{5}$.

Lithocolletes, 2: $723^{5}$.

coryloides, Cecidomyia, 2: $745^{3}$.

Corylus americana, Chionaspis

lintneri injuring, $1: 227^{9}$.

corylus, Pteronus, 2: $750^{5}$.

Corymbites cruciatus, $2: 722^{1}$.

hamatus, $2: 740^{4}$.

hieroglyphicus, $2: 653^{1}, 692^{4}-93^{2}$. propola, 2: $652^{9}, 692^{5}$.

sulcicollis, $2: 492^{6}$.

vernalis, $2: 752^{6}$.

Corythuca arcuata, 2: $59^{8}-99^{7}$, Cottonworm, 2: $609^{2}$. $720^{6}$.

ciliata, $2: 599^{8}-600^{4}, 719^{3}$.

juglandis, $2: 749^{9}$.

Coscinoptera dominicana, $2: 737^{3}$.

Cosmopepla carnifex, 2:61 $1^{6}$.

Cosmophorus hopkinsii, $2: 379^{6}$, $3^{8} 9^{9}-90^{\mathrm{I}}$.

cossae, Cecidomyia, 2: $719^{2}$.

Cossidae, I: $12^{3}$.

Cossonus concinnus, $2: 751^{7}$.

corticola, $2: 75 \mathrm{I}^{7}$.

crenatus, $2: 75 \mathrm{I}^{7}$.

piniphilus, $2: 751^{8}$.

platalea, $2: 42 S^{4}, 455^{4}-56^{1}$.

Cossus centerensis, $2: 430^{2}, 47^{1}-$ $77^{9}$.

macmurtrei, see Prionoxystus. querciperda, $2: 477^{1}$.

Cosymbia lumenaria, $2: 749^{4}$.

Cotalpa lanigera, $2: 724^{5}$.

(Cottonwood, inj. insects (cont'd): gall insects:

basal leaf gall, $2: 620^{2}, 636^{4}$. poplar leaf stem gall. 2 : $620^{7}, 635^{9}$.

vagabond gall, $2: 635^{5}$.

leaf feeder:

cottonwood leaf beetle, I: $317^{4}$.

scalc or sucking insects:

Aspicliotus rapax, 2: $728^{2}$.

Buffalo tree hopper, 2: $592^{4}$.

Chionaspis ortholobis, 2: $7+4^{8}$.

Cottonwood leaf beetle, 1 ; $25^{8}$, $317^{3}-22^{2}$.

Cottony maple scale, I: $\delta^{3}, 12^{6}$, $173^{2}, 196^{3}-200^{4}$.

Crab apple, in jurious insects:

leaf feeders:

Mineola indigenella, 2: $733^{6}$.

Cranberry, red-banded leaf roller injuring, 2: $532^{3}$.

crassimana, Limosina, $\mathbf{1}: 74^{7}$.

crassipes, Pilophorus, 2: $65 \mathrm{I}^{9}$, $686^{1}$.

crassitelus, Neuroterus, 2: $710^{1}$.

crassulus, Liopus, 2: $715^{6}$.

crataegi, Conotrachelus, $2: 734^{4}$.

Nectarophora, 2: $735^{1}$.

Pseudanthonomus, 2: $733^{3}$.

Schizoneura, $2: 735^{2}$.

crataegifoliella, Nepticula, 2: $734^{7}$.

Ornix, 2: $734^{4}$.

Crataegus, see Thorn.

Cotton worm, losses caused by, Cratoparis lnnatus, $2: 499^{3}, 499^{1}$. 1: $6^{3}$.

Cratotechus orgyiae, $1: 138^{6}$.

Cottonwood, resistance to insect Creeper, black and white, 1: $111^{6}$. attacks, $1: 47^{6}$

in jurious insects:

borers:

carpenter worm, $\mathbf{1}: 80^{8}, 84^{1}$.

Hyperplatys aspersus, 2 : $746^{6}$.

poplar borer, $\mathbf{1}: 9^{7}, 99^{9}$.

Cremastus retiniae, $2: 4 \mathrm{IO}^{1}$.

crenatus, Cossonus, $2: 75 \mathrm{I}^{7}$.

Crepidodera aesculi, $2: 730^{3}$.

helxines, $2: 742^{2}$.

rufipes, $2: 510^{6}, 556^{3}$.

crepuscularia, Ectropis, 2: $743^{7}$, $749^{5}$.

poplar carpenter worm, 2: Cressonia juglandis, $2: 506^{7}, 5 \mathbf{I}^{6}-$ $476^{3}$. $19^{2}, 720^{1}$.

willow borer, mottled, $\mathbf{r}$ : $103^{6}$. cressonii, Tenthredo, 2: $74^{7}$.

cretata, Saperda, $2: 73 t^{3}$. 
cribrataria, Cleora, $2: 743^{9}, 754^{2}$. cucujiforme, Smodicum, 2: $701^{9}$, Cynipids, 2:616 $6^{2}, 616^{9}$.

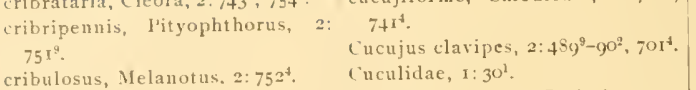

Crinkled flannel moth, 2:507 ${ }^{9}$, cuculipennellum, Coriscium, 2: $529^{7}-30^{3}$.

Criocephalus agrestis, $2: 649^{3}$, $659^{7}-60^{1}$.

Crioceris asparagi, 2: $608^{9}$.

crispata, Lagoa, 2:507 $7^{9}, 529^{6}-30^{3}$.

cristatus, Prionidus, 1: I $40^{k}, 1+6^{3}$, $324^{7}, 325^{3}$.

cristifasciella, Paralechia, 2: $707^{9}$.

crocallata, Tetracis, $2: 72 \mathrm{I}^{4}$.

Crocigrapha nurmani, 2: $704^{9}$.

Croesus latitarsus, $2: 74^{\text {h }}$.

Crows, I: $30^{6}, 111^{6}, 122^{2}, 166^{3}, 237^{2}$; voracity, $1: 26^{2}$.

cruciatus, Corymbites, 2: $722^{1}$.

crudiae, Hypothenemus, 2: $715^{9}$.

Cryphalus piceae, 2: $753^{9}$.

striatulus, $2: 376^{6}, 650^{5}, 673^{4}$.

crypta, Ataxia, 2: $702^{4}$

Cryptarcha concinna, $2: 491^{9}$.

Cryptocephalus guttulatus, 2: $703^{6}$.

leucomelas, $2: 746^{9}$

mutabilis, 2: $703^{6}$.

quadrimaculatus, $2: 653^{5}, 695^{7}$. quadruplex, $2: 724^{5}$.

schreibersii, 2: $653^{4}, 695^{4}$.

Cryptolechia quercicella, 2: $708^{1}$.

Cryptorhynchus bisignatus, 2 . $702^{5}$.

fallax, 2: $715^{8}$.

ferratus, $2: 702^{5}$.

lapathi, $\mathbf{r}: 49 ; \quad 5 \mathbf{1}^{7}, \quad 100^{4}-3^{9} ; 2$ : $469^{7}$.

minutissimus, 2: $702^{5}$.

obliquus, $2: 715^{8}, 737^{2}$.

obtentus, 2: $720^{\text {\% }}$.

parochus, $2: 494^{3}$.

tristis, $2: 702^{5}$.

Crypturgus alutaceus, 2: $753^{9}$.

atomus, $2: 338^{6}, 359^{6}-60^{6}$.

Cryptus grallator, $1: 87^{5}$.

nuncius, $\mathbf{I}: \mathbf{I}_{5} \mathrm{~S}^{3}$.

Cuckoos, I: $30^{1}, I^{3}, I I^{4}, I I I^{6}$, $122^{1}, 137^{8}, 237^{3}$.

black-hilled, $1: 27^{7}, \mathbf{1 6 6 ^ { 3 }}$.

yellow-billed, $\mathbf{1}: 27^{5}$.

$$
727^{3} \text {. }
$$

culta, Acmaeodera, 2: $715^{3}$.

cultellator, lbalia, $2: 499^{7}$.

cunea, Hyphantria, I: $\mathbf{1}+2^{9}, \mathbf{I}+3^{9}$.

Cupes concolor, 2: $753^{7}$.

cuproideus, Pteromalus, I: $13^{3^{6}}$, $139^{7}$.

Curculio, two spotted, 2: $506^{6}$, $516^{1}-17^{4}$.

Curculionidae, I: I I

Curius dentatus, $2: 702^{2}$.

Currant, injurious insects:

gall insect:

willow shoot sawfly, I: $302^{4}$.

leaf feeders:

filament bearer, $2: 50^{1}, 53^{4}$.

Priocycla armataria, 2: $7+9^{6}$.

rose leaf folder, $2: 5^{8} \mathbf{1}^{4}$.

Xylina antennata, $1: 13 \mathbf{1}^{7}$.

scale insect:

scurfy scale, $1: 215^{9}$.

Currant worms, 2: $607^{\star}$.

curvimacula, Calocampa, 2: $7+3^{2}$.

Cutworm, 2: $609^{2}$.

cyanana, Olethreutes,. 2: $5 \times 2^{3}$, $577^{6}-79^{2}$.

cyanea, Gastroidea, $2: 742^{3}$.

cyanellus, Rhynchites, 2: $567^{2}$, $7+2^{3}$.

cyaneus, Paururus, 2: $649^{9}, 669^{i}$.

cyanipennis, Gaurotes, sec 6 . cyanipennis.

cyanipes, Poecilonota, 2: $746^{6}$.

Cyaniris ladon, $2: 727^{6}$.

Cybocephalus nigritulus, $\mathbf{1}: \mathbf{2 3 \mathbf { I } ^ { 3 }}$.

cygnaei, Dendrophagus, $2: 490^{5}$.

cylindricus, Hister, $2: 350^{5}, 35 t^{7}$, $359^{4}$.

Cyllene pictus, 1: $256^{6}, 264^{1}-66^{9}$. robiniae, $\mathbf{I}: 49,5 \mathrm{I}^{6}, 93^{1}-97^{9}$.

Cymatophora pustularia, $2: 733^{5}$, $735^{9}$.

cymatophoroides, Pseudothyatira, 2: $706^{1}$.

Cynipidae, $1: 10^{7}$. cucullatus, Athous, 2: $701^{5}$.
Cynips decidua, 2:619 $39^{3}, 627^{7}$.

floccosa, 2: $7 \mathrm{Ir}^{6}$.

frondosa, 2:714.2.

juglans, 2: $710^{5}$.

nigricens, 2: $711^{6}$.

prinoides, 2:619 $9^{3}, 627^{6}$.

rugosa, 2: $713^{7}$.

strobilana, $2: 618^{6}, 625^{1}$.

vesicula, $2: 710^{7}$.

cynipsea, Cecidomyia, 2: 7181 .

Cynthia moth, $1: 45^{4}$.

cynthia, Philosamia, I: $45^{6} ; 2: 727^{6}$.

Cypress, injurious insects :

brenthian, northern, $1: 263^{\text {}}$.

Cecidomyia ananassi, 2: $755^{3}$.

tussock moth, white marked, I: $136^{9}$.

cyriades, Eulophus, 2: $577^{3}$.

Cyrtinus pygmaeus, $2: 702^{3}$.

Cyrtolohus fenestratus, $2: 597^{4}$.

valu, $2: 717^{6}$.

Cyrtoneura stabulans, $\mathbf{I}: \mathbf{1} 53^{8}$.

Cyrtophorus verrucosus, $2: 722^{2}$.

dactylina, Apatela, $2: 7+2^{9}$.

Dagger moth, smeared, 2: $5 \mathrm{II}^{2}$, $560^{l}$.

dalmanni, Habrolepis, $\mathbf{I}: 33 \mathbf{I}^{1}$.

dama, Lucanus, 2: $701^{8}$.

damon, Mitoma, 2: $740^{7}$.

Daremma undulosa, see Ceratomia.

Dark tussock moth, 2: $507^{4}$, $524^{6}$.

Darkling beetles, $1: 23^{9}-24^{1}$.

dasycerus, Ecyrus, 2: $715^{6}$.

Dasylophia anguina, 2: $730^{6}$.

Dasyneura psendacaciae, $2: 730^{5}$. serrulatae, 2: $750^{9}$.

Datana angusii, 2: $508^{6}, 535^{3}$. contracta, $2: 725^{1}$.

drexelii, 2: $739^{2}$.

integerrima, $\mathbf{1}: 25^{8}, 303^{5}-5^{6}$.

major, $2: 739^{3}$.

ministra, 2: $500^{6}, 535^{4}, 535^{6}-36^{2}$.

palmii, 2: $739^{4}$.

perspicua, $2: 737^{4}$.

dearnessi, Phenacoccus, 2: $735^{2}$.

debilis, Goes, 2: 702 ${ }^{3}$.

Spilochalcis, r: $140^{4}$.

Decatomidea polygraphi, 2: $390^{1}$. 
Decaying wood, borersin, $2: 430^{8}$ - Dendroides canadensis, $2: 494^{4}$, Dicerca punctulata, $2: 648^{8}, 656^{3}$. $31^{2}, 4^{8} 4^{8}$; inhabitants, $2: 4^{54}-\quad 701^{9}$. $94^{6}$. decemlineata, Doryphora, 2: 6089. decemmaculata, l.estodiplosis, 2 : $7+6^{3}$.

decemnotata, Xanthonia, 2: $703^{7}$. decidua, Cynips, 2: $619^{3}, 627^{7}$.

Deciduous forest trees, insects af fecting, $2: 426^{4}-30^{6}$; leaf eaters affecting, 2: $506^{1}-51^{5}$; frequenters, usually beneficial, 2: $5^{88^{7}-}$ $61.4^{9}$.

decipiens, Acanthoderes, 2: $429^{8}$, $+73^{4}$.

Anthonomus, $2: 734^{5}$.

Xylocleptes, 2: $715^{9}$.

decolorata, Centrodera, see C. de- depressus, Boletophagus, 2: $754^{6}$. colorata.

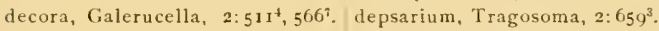

decorus, Arotes, $1: 261^{\mathrm{t}}$.

decuriella, Dioryctria, 2:68 $4^{8}$.

Deer moth, $1: 3 \mathrm{IO}^{8}$.

definita, Hemerocampa, $\mathbf{1}: 133^{3}$, Derostenus primus, $1: 328^{2}$. $134^{1} ; 2: 507^{1}, 522^{4}-23^{2}, 607^{9}$.

Definitions, $1: 8^{8}-10^{5}$.

deflorata, Ecpantheria, $2: 7+2^{8}$.

Deidamia inscriptum, $2: 740^{2}$.

Deilephila galii, 2: $736^{1}$.

lineata, $2: 724^{6}$.

Deilinia erythremaria, $2: 743^{y}$. variolaria, $2: 7+3^{8}$.

delicatus, Apanteles, $1: 138^{6}$. Macrocentrus, 2: $53 \mathrm{I}^{5}$.

delineata, Paectes, $2: 724^{3}$.

delius, Coenus, see C. delius. , delplinii, Euclea, 2: $528^{9}, 529^{5}$, ;o6 $6^{9}$.

z'ar. paenulata, Euclea, 2: $744^{1}$

I) emas propinquilinea, $2: 749^{4}$.

demotella, Acrobasis, $2: 719^{9}$.

dendroctoni, Cecidostiba, 2: $390^{1}$.

Dendroctonus, 2: $337^{5}$.

frontalis, 1: $6^{9}$.

piceaperda, $1: 6^{*}, 7^{7}: 2: 338^{7}, 379^{7}-$ $85^{9}, 693^{3}$.

pusillus, 2: $75^{3}$.

rufipennis, $2: 753^{9}$.

simplex, 2: $752^{3}$.

terebrans, $2: 333^{7}, 33^{8^{3}}, 342^{4}-45^{9}$, $357^{2}$. concolor, 2: $494^{3}$.

Dendrophagrus cygnaei, $2: 490^{5}$.

dentatus, Curius, 2: $702^{2}$.

Lachnus, $2: 744^{7}$.

Phloeosinus, 2: $336^{9}, 337^{9}, 335^{9}$, $391^{5}-93^{7}$.

denticollis, Mlyochrous, 2: $730^{2}$.

denticornis, Campylus, $2: 74^{4}$.

dentipes, Chrysobothris, 2: $644^{9}$, $657^{8}-53^{4}$.

deplanata, Phylloxera, 2: $718^{5}$.

depressa, Phylloxera, 2: $715^{5}$.

Depressaria betulella, $2: 7+9^{7}$. grotetla, 2: $723^{\circ}$.

robiniella, $2: 730^{8}$. Platycerus, 2: $722^{2}$.

Deptalia insularia, $2: 721^{3}$.

deridens, Charadra, 2: $704^{4}$.

Dermestes pulcher, $2:+31^{2},+89^{2}$.

Desmocerus palliatus, $2: 737^{7}$.

desmodioides, Pontania, 2:62 I $63^{1}$.

detracta, Mamestra, 2: $716^{6}$.

detritus, Bassareus, 2: $703^{6}$.

devia, Scopelosoma, 2 : $705^{\text {l. }}$.

Diacrisia latipennis, $2: 727^{2}$. virginica, $2: ; 20^{\circ}$.

Diaperis lydni, $2: 497^{8}-9^{81}$.

Diaphania quadristigmalis, 2: $737^{9}$.

Diapheromera femorata, 2: $508^{5}$, $533^{4}-35^{2}, 605^{9}$.

diaspidinarum, Chiloneurus, I: $212^{9}$.

Diaspis carueli, $\mathbf{1}: \mathbf{1}_{7}^{-8}, 229^{1}$. rosae, ser Aulacaspis.

tenebrosa, $2: 64^{99}, 657^{1}$.

tuberculata, $2: 645^{8}, 656^{6}$.

Dichelonycha albicollis, $2: 653^{3}$, $694^{6}$.

elongata, 2: $716^{3}$.

fuscula, $2: 703^{5}$.

subvittata, $2: 723^{4}$.

dichlocerus, Rhodites, $2: 625^{y}$, $645^{1}, 645^{2}$.

Dichrooscytus rufipennis, 2: $652^{3}$, $687^{7}-88^{1}$.

Diedrocephala coccinea, $2: 717^{7}$.

difficilis, Paromalus, $2: 389^{7}$.

diffinis, Aspidiotus, $2: 731^{9}$.

var. axillaris, llemaris, 2: $7+x^{1}$.

Diglochis omnivora, I: $166^{\circ}$.

dilutata, Epirrita, 2: $706^{2}$.

diluticostana, Cenopis, $2: 707^{5}$.

dilutus, Monophadous, 2: $703^{4}$.

dimidiata, Pheosia, 2: $747^{6}$.

dimidiatus, Phymatodes, see P. dimidiatus.

Rhizophagus, 2: $721^{9}$.

dimorphus, synergus, $2: 714^{4}$.

Dinoderus punctatus, $2: 701^{8}$.

Dioryctria abietella, $2:-752^{4}$.

decuriella, 2: $684^{8}$.

reniculella, $2: 651^{7}, 68_{4}^{1}$.

diospyri, Aphis, 2: $735^{3}$.

Diphthera fallax, 2: $738^{4}$.

diplosidis, Syntasis, $2:+12^{8}$.

Diplosis sp. 1: $140^{6}$.

caryae, $2: 619^{7}, 628^{4}$.

pini-rigidae, sec Cecidomyia. resinicola, see Cecidomyia. tritici, $1: 6^{2}$.

liptera, $I: I I^{1}, 2 I^{8}$.

I)ircaea liturata, see I’hloeotrya liturata.

Dibrachys boucheanus, I: $127^{9}-$ dineoidea, Saperda, 1:256 $269^{4}-70^{4}$. $28^{1}, 140^{1}, 140^{4}$.

Dicerca, lurid, $2: 427^{5}, 4+2^{8}-43^{6}$.

Dicerca asperata, $2: 701^{6}$. divaricata, $2: 4^{2} 8^{6}, 457^{5}-5^{87}$. Iurida, $2: 504^{3}$.

obscura z'ar. lurida, $2: 427^{5}$, $4+2^{4}-43^{6}, 499^{6}, 500^{1}$.

prolongata, 2: $77^{5}$.

Dicerca pugionata, $2: 750^{2}$. discoideus, Elater, $2: 722^{1}$.

discolor, Callipterus, 2: $709^{3}$.

dislocatus, Phyllobaenus, 2: $359^{8}$, $449^{3}, 503^{3}$.

Disonycha caroliniana, 2:51 $1^{2}$, $563^{4}-64^{7}$.

xanthomelaena, $2: 564^{6}$. Xyleborts, see X. dispar. dispar, Porthetria, see $\mathrm{I}^{\prime}$. dispar. 
dissimilis, Ilypothenemus, $2: 715^{\circ}$. Sicphanoderus, 2 : $702^{7}$.

disstria, Malacosoma, see M, disstria.

distans, Apatela, $2: 747^{2}$.

1)stenia undata, $2: 720^{7}$.

distortus, Neuroterus, 2: 7 I I $\mathrm{I}^{4}$.

1)itoma quadriguttata, $2: 459^{5}$.

divaricata. Dicera, $2: 424^{6}, 457^{5}-$ $53^{7}$.

Divaricated huprestis, $2: 428^{6}$, $457^{5}-55^{7}$.

diversilineata, Eustroma, 2: $706^{3}$.

divisata, Caripeta, $2: 754^{7}$.

1) 0 g day cicada, $1: 174^{1}, 237^{8}-38^{9}$.

Dogwood, in jurious insects:

Anthrenus castaneae, $2: 614^{5}$.

borers, $2: 73 \mathrm{G}^{\mathrm{b}}$.

Eupogonius vestitus, 2:71 $5^{7}$

leopard moth, $1: 7^{\beta^{5}}$.

Liopus punctatus, $2:+32^{5}$.

Molorchus bimaculatus, $715^{4}$.

Nenclytus erythrocephalus.

1: $72^{7}$.

wak bark beetle, minute, I: $295^{3}$.

Sesia scitula, $2: 428^{\prime \prime}, 45 I^{4}$.

sugar maple timber beetle, 1: $67^{-4}$.

gall insects:

Cecidomyia clavula, $2: 736^{9}$.

leaf feeders: $2: 736^{7}$.

Coleophora caryaefoliella, 2 : $717^{4}$.

Cyaniris ladon, 2: $727^{6}$.

forest tent caterpillar, $1:$ I I $^{9}$.

hag moth caterpillar, 2: $523^{\circ}$.

Ileterocampa biundata, 2: $727^{\text {^. }}$

subrotata, $2: 7\left[6^{9}\right.$.

Lithacodes fasciola, $2: 725^{4}$

Schizura unicornis, $2: 705^{9}$.

scale or sucking insects: $2: 730^{9}$.

Chionaspis lintneri, $\quad \mathbf{1}: 173^{n}$. $227^{9}$.

salicis-nigrae, $2: 744^{3}$.

Clastoptera proteus, $2: 508^{2}$.

dohrnii, Kaliosysphinga, 2: $750^{3}$.

Iollia hylaeus, $2: 739^{6}$.

Dolerus arvensis, $2: 74 \mathrm{r}^{9}$.
Dolerus bicolor, 2: $7+1^{9}$.

dollii, Memythrus, $2: 74^{67}$.

cominicana, Coscinoptera, $2: 737^{3}$.

l)orcas parallelus, $2: 492^{7}$.

Dorcaschema alternatum, 2: $726^{6}$. nigrum, $2: 427^{-1}, 444^{\circ}-45^{3}$. wi]dii, $2: 726^{6}$.

Dorcatoma setulosum, $2: 74^{5}$.

dormitans, Baileya, 2: $716^{6}$.

dorsalis, Acordulecera, 2: $716^{3}$.

Odontota, I: $255^{8}, 325^{1}-29^{2}$.

dorsimaculana, Phalonia, $2: 7+4^{3}$.

Doryphora decemlineata, 2: $608^{9}$.

Jorytomus mucidus, $2: 74^{6}$.

parvicollis, $2: 430^{2}, 475^{4}$.

squamosus, $2: 742^{4}$.

vagenotatus, $2: 430^{2}, 475^{7}$.

Dragonflies, 1 : $146^{\circ}$.

Trepana arcuata, $2: 749^{*}$.

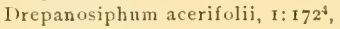
$175^{6}-76^{5}$.

tiliae, $2: 731^{9}$.

drexelii, Datana, 2: $739^{2}$.

Drosophila, I: $\mathrm{I}^{6}$.

drummondi, Melanophila, $2: 753^{\star}$.

drupiferarum, Sphinx, 2: $726^{\prime}$.

Tryobates pubescens medianus, 1: $28^{\text {* }}$.

vilosus, I: $25^{4}, 287^{4}$.

Dryolitus sexfasciatus, $2: 702^{1}, 722^{2}$.

Dryocuetes, $2: 337^{5}$.

sp., 2: $386^{7}, 429^{5}, 468^{3}-69^{3}, 673^{1}$.

affaber, $2: 752^{3}$.

autographus, $2: 336^{8}, 337^{9}, 469^{2}$, $650^{4}, 672^{5}$.

eichboffi, $2: 336^{8}, 337^{9}$.

granicollis, $2: 720^{9}, 753^{9}$.

Iryophanta clarkei, $2: 710^{6}, 713^{7}$.

corrugis, $2: 714^{2}$.

gemula, $2: 713^{\circ}$.

liberaecellulae, 2: $712^{4}$.

longicornis, $2: 711^{7}$.

pallipes, $2: 710^{5}$.

papula, 2:712.

parvula, $2: 713^{9}$.

pedunculata, $2: 712^{5}$.

polita, 2: $619^{1}, 626^{1}$.

radicola, $2: 7 \mathbf{r O}^{5}$.

1)ryophthorus americanus, $2: 752^{3}$.

dryopterata, Calledapteryx, 2: $738^{5}$. dubia, Neuroterus, 2: $710^{2}$.

dubius, Pissodes, 2: $340^{1}, 40 I^{5}$.

Thanasimus, $2: 345^{4}, 389^{8}, 500^{3}-1^{7}$.

Uliota, see U. dubius.

Dull red willow leaf beetle, 2: $5 I^{4}, 566^{6}$.

duricoria, Ilolcaspis, $2: 61 \mathrm{~S}^{4}, 624^{5}$.

Dysphaga tenuipes, 2: $715^{2}$.

Eastern pine wood stainer, 2: $371^{1}-72^{7}$.

Eburia quadrigeminata, $2: 428^{9}$, $462^{5}-63^{3}$.

Ecdytolopha insiticiana, $2: 430^{3}$, $478^{!}$.

echidna, Euchaetes, 2: $722^{4}$.

Ecpantheria deflorata, $2: 742^{8}$.

Ectropis crepuscularia, $2: 7+3^{7}$, $749^{5}$.

Ecyrus dasycerus, 2: $715^{6}$.

Edema albifrons, see Symmerista.

edwardsii, Thecla, 2: $704^{3}$.

effractana, A]ceris, $2: 744^{3}$.

egenus, Agrilus, 2: $715^{2}, 729^{9}$.

Eggs, I: $14^{3}-15^{4}$.

eichhoffi, Uryocoetes, $2: 336^{8}$, $337^{9}$.

Elachistus cacoeciae, I: $140^{4}$.

Elaphidion inerme, 2: $702^{1}$.

mucronatum, 2: $702^{2}$.

subpubescens, $2 ; 702^{2}$.

unicolor, 2: $702^{2}$.

villosum, $1: 49,50^{7}, 59^{1}-6 \mathrm{I}^{5}$.

Elasmocerus terminatus, $2: 449^{2}$, $483^{8}, 501^{8}-2^{6}$.

Elasmus atratus, I: $140^{4}, 1+5^{9}$.

Elater discoideus, $2: 722^{1}$.

humeralis, $2: 492^{5}$.

nigricollis, $2: 492^{5}, 701^{6}$.

sayi, $2: 701^{6}$.

Elder, in jurious insects: $2: 737^{6}$.

willow flea beetle injuring, 2 : $563^{7}$.

elegans, Conotrachelus, 2: $715^{8}$.

Packardia, 2: $529^{6}, 707^{2}$.

Scythropus, 2: $752^{9}$.

Ellema harrisii, see Lapara bomby. coides.

Elleschus bipunctatus, $2: 742^{6}$. ephippiatus, $2: 511^{6}, 567^{3}$.

Ellida caniplaga, $2: 731^{5}$. 
Elm, American, resistance to insect attack, $1: 47^{4}$.

injurious insects: 1: 49 . borers, 2: $724^{3}$.

ant, large black carpenter, I: $90^{4}$.

white, I: $89^{\text {'. }}$.

Anthaxia viridifrons, 2: $715^{2}$.

apple wood stainer, $\mathbf{1}: \mathbf{2 9 0 ^ { 5 }}$.

ash borer, banded, I: $257^{2}$, $2 \mathrm{SO}^{6}$.

four marked, $2: 462^{9}$.

Bostrichus bicornis, $2: 721^{\circ}$. brenthian, northern, $1: 263^{8}$. carpenter worm, I: $\mathrm{So}^{8}$. Catogenus rufus, $2: 489^{8}$.

Cucujus clavipes, $2: 490^{\prime}$.

Dendrophagus cygnaei, 2: $490^{5}$.

Dorcas parallelus, $2: 492^{7}$.

Dryobius sexfasciatus, 2: $702^{1}$.

elm borer, I: $50^{9}, 67^{9}$. dark, I: $257^{3}, 288^{2}$.

elm snout beetle, black, I: $51^{1}, 73^{2}$.

reddish, I: $5 \mathrm{I}^{2}, 75^{4}$.

Goes pulverulentus, $2: 455^{3}$.

Hister lecontei, $2: 49 \mathrm{I}^{2}$.

leopard moth, I: $78^{5}$.

linden borer, $\mathbf{I}: 9 \mathbf{I}^{5}$.

Neoclytus erythrocephalus, I: $71^{9}$.

scutellaris, $2: 715^{4}$.

Otidocephalus chevrolatii, 2: $715^{7}$.

Physocnemum brevilineum, 2: $428^{k}, 462^{1}$.

pigeon tremex, I: $50^{7}, 6 \mathbf{I}^{5}$. rustic borer, I: $260^{9}$.

saperda, red-edged, $1: 270^{6}$. Stenoscelis brevis, $2: 494^{6}$.

Tenebrioides corticalis, 2 : $492^{1}$.

twig girdler, I: $273^{7}$.

Uliota dubius, $2: 490^{6}$.

Xyloterus politus, I: $292^{8}$. gall insects:

cockscomb elm gall, I: $172^{6}$. $186^{7} ; 2: 620^{4}$
Elm, Amer., inj. insects (cont' $d)$ : Elm, Amer., inj. insects $\left(\operatorname{con} t^{\prime} d\right)$ : leaf feeders: $2: 724^{5}-25^{5}$.

Abbotana clementaria, 2: $721^{4}$.

alder leaf beetle, 2: $509^{3}$, $542^{9}$.

American dagger moth, 2: $325^{3}$.

American silk worm, 2: $526^{6}$.

A patela funeralis, $2: 716^{6}$. . impleta, $2: 749^{3}$.

apple tent caterpillar, 2: $55 \mathrm{I}^{1}$.

bag or basket worm, 1: $127^{2}$.

Basilarchia arthemis, 2: $742^{6}$.

Brachys aerosa, 2: $506^{8}$, $512^{9}$.

ovata, $2: 506^{3}$.

brown tail moth, I: $164^{\text {? }}$.

Cecropia moth, 2:539.

Charadra deridens, 2: $704^{4}$.

Chrysomela multiguttata, 2: $742^{1}$.

Dichelonycha elongata, 2: $716^{3}$.

elm case bearer, I: $106^{1}$, I $67^{2}$.

eln caterpillar, spiny, $\mathbf{I}$ : $105^{4}, 155^{9}$.

elm leaf beetle, 1: $105^{7}, 1+6^{8}$. elm leaf miner, $\mathrm{I}$ : $105^{9}, \mathbf{1} 6 \mathbf{2}^{5}$. elm saw fly, I: $105^{8}, 155^{9}$.

Erannis tiliaria, 2: $731^{6}$.

Euclea chloris, 2: $706^{9}$.

Eustroma diversilineata, : : $706^{3}$

fall webworm, I: $142^{6}$.

flannel moth, crinkled, 2: $530^{1}$.

flea beetle, black-margined, 2: $515^{4}$.

forest tent caterpillar, I: $110^{9}$.

gipsy moth, I: I20t.

Gluphisia septentrionalis, 2: $747^{6}$.

gray comma, 2: $509^{6}, 546^{2}$. hickory tussock moth, I: $3 \mathrm{I} t^{9}$.

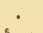

hop merchant, $2: 509^{5}, 545^{6}$. leaf feeders:

Hylotoma scapularis, 2: $509^{3}, 5+2^{2}$.

io caterpillar, $2: 522^{3}$.

leaf roller, red-banded, 2 : $532^{2}$.

v-marked, 2: $53 \mathrm{I}^{8}$.

Lycia cognataria, $2: 728^{1}$.

Metanema quercivoraria, 2: $706^{6}$.

Metrocampa praegranciaria, 2: $749^{7}$.

Odontota nervosa, 2: $703^{7}$.

Paraphia subatomaria vur. unipuncta, 2: 7064.

Phigalia titea, $2: 728^{3}$.

Plaloephagus minor, 2: $742^{5}$.

Schizura ipomoeze, 2: $705^{8}$. unicornis, 2: $705^{\circ}$.

Sisyrosea textula, $2: 721^{4}$.

sphinx, four-lined, 2: $509^{6}$, $5+6^{6}$.

spring cankerworm, 2: $509^{7}, 547^{5}$.

Tolype velleda, $2: 727^{9}$.

tussock moth, white mark. ed, I: $132^{7}, 136^{\circ}$.

violet tip, 2: $509^{5}, 544^{9}$.

scale or sucking insects: 2 : $725^{5}$.

elm bark aphid, woolly, $\mathbf{I}$ : $172^{9}$, I $92^{4}$.

elm bark louse, I: $S^{3}, 173^{3}$, $203^{8}$.

elm leaf aphid, I: $172^{4}$, $176^{7}$.

woolly, $1: 172^{5}, 177^{8}$.

elm scurfy scale, I: $173^{4}$. $207^{7}$.

maple scale, cottony, I: $173^{2}, 196^{4}, 198^{2}$

oyster scale, I: $212^{6}$.

Putnam's scale, I: $227^{4}$, $227^{5}$.

Elm, English, injurious insects, I: 49 .

Elm, European, resistance to insect attack, $1: 47^{5}$.

Elm, red, see Elm, slippery. 
Elm, Scotch, resistance to insert Enarmonia caryana, 2: $512^{6}, 5^{8} 3^{1}$. attack, $1: 47^{5}$; injurious insects, 1: + (?).

Elm, slippery, in jurious insects: loorers:

elm borer, I: $70^{5}$.

Leptura emarginata, $2: 724^{4}$.

Platypus compositus, 2: $720^{9}$.

gall insects:

elm leaf gall, red, $2: 620^{5}$, $633^{5}$.

Peinphigus ulmifusus, $1: 247^{\circ}$.

leaf feeders:

Bomolocha abalienalis, 2: $724^{9}$.

Conotrachelus anaglypticus, 2: $509^{4}, 5+4^{4}$

Monocesta coryli, $2: 724^{5}$.

Elm. white, Hister parallelus injuring, 2: $791^{3}$.

Elm bark aphid, woolly, 1: $172^{9}$, $192^{4}$

Elm bark borer, dark, 1: $28^{\circ}$.

Elm bark louse, I: $8^{3}, 8^{6}, 4^{91}$. $173^{3} \cdot 203^{7}-\tau^{6}$.

Elm borer, $r: 50^{4}, 67^{2}-71^{8}$. dark, 1: $257^{5}$.

Elm case bearer, European, I $106^{1}, 167^{-1}-6 S^{4}$.

Elm caterpillar, spiny, $1: 18^{9}, 4^{84}$, $105^{9}, 15^{8}-62^{4}, 253^{4}$.

Elm gall, cockscomb, $1: 172^{6}, 186^{7}-$ $57^{6}, 247^{2}$

Elm leaf aphirl, I: $172^{4}, 176^{6}-77^{7}$ woolly, $1: 172^{5}, 177^{7}-78^{9}$.

Elm leaf beetle, $1: 7^{9}, 8^{6}, 37^{7}, 43^{5}$, $4^{5^{3}}, 105^{7}, 1+6^{3}-55^{6} ; 2: 605^{4}, 614^{4}$.

Elm leaf gall, red, 2: $620^{5}, 633^{4}$.

Elm leaf miner, I: $105^{9}, 162^{4}-63^{8}$;

Elm sawfly, 1: $105^{8}, 155^{7}-58^{7}$.

Elm seurfy scale, 1 : $173^{4}, 207^{6}-8^{7}$.

Elm snout beetle, $1: 72^{9}$.

black, $1: 5 \mathrm{I}^{1}, 73^{2}-75^{2}$.

reddish, I: $5 \mathbf{I}^{2}, 75^{3}$.

Elm twig girdler, $1: 273^{5}$.

elongata, Hichelonycha, 2: $716^{3}$

elonympha, Allotria, 2: $720^{2}$.

emarginata, Leptura, $2: 436^{7}, 724^{4}$.

l'ericlista, 2: $703^{1}$.

Emphytus cinctus, $2: 735^{\circ}$.

Empusa grylli, I: 1 q $^{3}$. gallaesaliciana, $2: 7+6^{4}$.

prunivora, 2: $734^{7}$.

Enchenopa binotata, 2: $594^{7}-95^{7}$.

Enchodes sericea, 2: $727^{5}$.

endropiaria, Therina, 2: $706^{6}$.

English sparrow, 1 : $11^{7}, 111^{8}, 133^{6}$, $137^{5}, \mathrm{I} 66^{3}, 206^{7}, 237^{2}$.

Ennomos magnarius, 2: $725^{3}$.

subsignarius, $2: 725^{4}$.

ennucleata, Synelys, 2: $733^{6}$.

Ensign flies, $\mathbf{1}: \mathbf{2 2}^{3}$.

Entedon antiopae, I: $16 \mathbf{I}^{?}$.

Entelus onerati, 1: $7 t^{6}$.

Epagoge caryae, 2: $717^{2}$. sulfureana, $2: 730^{7}$.

Epargyreus tityrus, 2: $510^{6}, 556^{8}$ $57^{4}$.

ephemeraeformis, Thyridopteryx, I: $49,105^{5}, 123^{7}-25^{9}$.

Ephialtes comstockit, 2: $409^{9}$.

ephippiatus, Elleschus, 2:5 $\mathrm{I}^{5}$, $567^{3}$.

Orchestes, 2:567".

Ephistemus apicalis, $2: 491^{1}$.

Epicaerus imbricatus, $2: 733^{3}$.

Epicnaptera americana, 2:507 $525^{5}$.

Epimecis virginaria, $2: 747^{2}$.

Epinotia augustana, 2: $7+4^{2}$. claypoleana, 2: $509^{2}, 540^{1}-41^{2}$. pinicolana, 2: $753^{4}$.

ratzeburgiana, $2: 754^{4}$.

saliciana, $2: 7+6^{3}$.

salicicolana, $2: 7+6^{4}$.

epione, Catocala, 2: $705^{4}$.

Epipaschia superatalis, $2: 740^{5}$. zelleri, $2: 7+0^{6}$.

Epirrita dilutata, 2: $706^{2}$.

Episimus argutanus, $2: 725^{3}$.

Epithectis gallaegenitella, $707^{\circ}$.

Epizeuxis aemula, 2: $754^{2}$.

Epuraea truncatella, 2: 389 ?

Erannis tiliaria, 2: $73 \mathrm{I}^{6}$.

crectus, 11 ypothenemus, $2: 702^{?}$, $740^{\circ}$.

eremicola, Osmoderma, $2: 493^{1}$.

Eremotylus glabratum, $1: 145^{2}$. macrurus, $2: 549^{6}$.

erichsoni. Jaricolsius, $2: 751^{3}$. erichsonii, Lygaeonematus, I $254^{5} ; 2: 370^{9},+18^{8}-23^{5}$.

erinacei, Acraspis, $2: 619^{2}, 627^{5}$.

Eriocampa juglandis, 2: $720^{5}$.

Eriocampoides limacina, 2: $733^{2}$.

Eriococcus quercus, 2: $709^{6}$.

Eriophyes abrormis, $2: 620^{2}, 631^{6}-$ $32^{1}$.

acericola, 2:619 $9^{9}, 630^{2}$.

fraxiniflora, 2: $620^{4}, 633^{6}-34^{1}$

quadripes, $2: 620^{1}, 630^{6}-31^{8}$.

querci, $2: 713^{5}$.

salicicola, $2: 745^{\circ}$.

thujae, $2: 755^{6}$.

ulmi, $2: 725^{\circ}$.

Ernobius granulatus, 2: $694^{5}, 752^{5}$.

luteipennis, $2: 694^{5}, 752^{5}$.

mollis, $2: 653^{2}, 694^{3}$.

tenuicornis, $2: 752^{5}$.

Eros aurora, 2: $7+6^{5}$.

errans, IJadrobregmus, $715^{3}$.

erubescens, Cecidomyia, 2:619. $627^{8}$.

eruditus, Hypothenemus, $2: 7+0^{9}$.

erythremaria, Deilinia, $2: 7+3^{\circ}$.

erythriella, Schreckensteinia, 2: $737^{5}$.

erythrocephalus, Neoclytus, $1: 50^{\circ}$, $70^{8}, 71^{9}-73^{2}, 26 \mathrm{I}^{2}$.

erythrogaster, Bracon, I: $266^{8}$.

esurus, Syntomosphyrum, I: $1+0^{4}$.

Euchaetes echidna, 2: $722^{4}$.

Euchlaena johnsonaria, 2: $706^{6}$.

obtusaria, $2: 721^{3}$.

pectinaria, $2: 706^{6}$.

serrata, 2: $725^{\circ}$.

Enchoeca albifera, $2: 725^{2}$.

Euclea chloris, 2: $706^{8}$.

delphinii, 2: $528^{9}, 529^{5}, 706^{9}$. var. paenulata, $2: 744^{1}$.

indetermina, 2: $528^{8}, 529^{5}$.

Euclemensia bassettella, 2: $708^{2}$.

Eucoila impatiens, 2: $714^{9}$.

mellipes, 2: $714^{9}$.

pedata, $2: 714^{9}$.

stigmata, 2: $714^{9}$.

Eucosma similana, 2: $7+9^{8}$.

solicitana, $2: 7+49^{8}$.

transmissana, $2: 7+99^{8}$.

Eucrada humeralis, $2: 722^{2}$.

Fudamus tityrus, see Epargyreus. 
Eudemis vacciniana, $2: 738^{8}$.

Euderces picipes, $2: 427^{\star}, 4+5^{7}-46^{1}$. pini, $2: 751^{4}$.

Eufidonia notataria, 2: $753^{1}$.

Eugnamptus angustatns, $2: 703^{\mathrm{R}}$, $720^{5}$.

collaris, $2: 716^{5}$.

Eugonia j-album, 2: $749^{2}$.

Eulecanium antennatum, 2: $709^{4}$. canadense, $2: 725^{6}$.

capreae, $2: 7+4^{9}$.

caryae, $2: 725^{6}$.

caryarum, $2: 717^{9}$.

cerasifex, 2: $728^{8}$.

cockerelli, 2: $725^{6}$.

fletcheri, 2: $755^{6}$.

juglandifex, $2: 720^{6}$.

jnglandis, $2: 719^{3}$.

kansasense, $2: 734^{3}$.

kingii, $2: 739^{1}$.

lintneri, 2: $732^{2}$.

lymani, 2 : $709^{4}$.

maclnrarum, 2: $726^{7}$.

nigrof asciat um, I: $49,173^{3}, 200^{4}-$ $3^{7}$.

pallidior, $2: 755^{6}$.

pruinosum, 2: $719^{7}$.

pyri, 2: $7 \mathrm{I} 7^{9}$

quercifex, $2: 709^{4}$.

quercitronis, 2: $709^{4}$.

rosae, $2: 736^{3}$.

tarsale, 2: $736^{9}$.

tulipiferae, 1 : $173^{4}, 205^{*}-10^{9}$.

websteri, $2: 750^{1}$.

Eulia juglandana, $2: 717^{3}$.

ministrana, $2: 723^{5}$.

politana, $2: 65 \mathrm{I}^{5}, 68 \mathrm{I}^{8}-82^{5}$.

triferana, $2: 505^{3}, 532^{1}$.

velutinana, $2: 707^{6}$.

Eulimacodes scapha, 2: $529^{4}$.

Eulophus cyriades, $2: 577^{3}$.

Eumenidae, $1: 23^{3}$.

Eunotus lividus, I: $199^{*}$.

euonymi, Chionaspis, $1: 173^{5}, 213^{5}-$ $\mathrm{I}^{6}$.

Euonymns, injurious insects, I $173^{5} ; 2: 729^{2}$.

Euonymas scale, I: $173^{5}, 213^{5}-14^{6}$.

Euparthenos nubilis, 2: $730^{\circ}$.

Eupelmus $s p, 2:+12^{8}$.

limneriae, I: $1+0^{4}$.
Euphorocera claripennis, I: $113^{2}$, Evetria comstockiana, 2: $340^{6}$, $138^{4}, I 6 \mathbf{I}^{8}, I 66^{2}$.

Euplexia lucipara, $2: 749^{4}$.

Eupogonius pinivora, 2: $75 \mathrm{I}^{5}$. subarmatus, $2: 724^{4}$.

tomentosus, $2: 751^{5}$.

vestitus, $2: 715^{7}$.

Eupristoceras cogitans, 2: $750^{3}$.

Euproctis chrysorrhoea, $\mathbf{I}: 28^{1}$, $105^{9}, 163^{k}-66^{9}, 254^{1}$.

Eupsalis minuta, $1: 256^{6}, 261^{8}-63^{9}$. eurinns, Alydus, see 1 . eurinus.

European elm case bearer, 1 : $106^{1}$, $167^{2}-63^{4}$.

European praying mantis, I: $154^{3}$.

European willow gall midge, I: $25^{2}, 299^{4}-302^{2} ; 2: 620^{5}$.

Enrycyttarus confederata, $2: 721^{4}$.

Eurymus interior, $2: 742^{5}$.

Eurytoma sp., 2: $390^{1}, 393^{6}$.

Euschistus sp., I: $24^{4}$. fissilis, $2: 6 \mathrm{IO}^{4}$.

politus, $2: 612^{2}-13^{3}$.

servus, $1: 146^{6}$.

tristigmns, $2: 612^{3}$.

variolarius, $2: 611^{1}-12^{3}, 676^{6}, 677^{5}$.

Enstroma diversilineata, $2: 706^{3}$. testata, $2: 743^{5}$.

Enstrophns bicolor, 2: $731^{4}$. repandns, 2:667 ${ }^{5}$.

Eutettix seminurlus, 2: $749^{9}$. strobi, 2: $688^{8}$.

Enthisanotia grata, 2: $740^{2}$.

Euthyatira pudens, 2: $736^{8}$.

Eutrapela alciplsearia, $2: 728^{2}$. kentaria, $2: 72 \mathrm{~s}^{2}$.

Euura nodis, 2: $7+5^{2}$. orbitalis, $2: 7+5^{2}$. ovum, 2: $7+5^{2}$.

Euranessa antiopa, I: $31^{9}, 48^{4}, 49$, $105^{9}, 155^{8}-62^{4}, 253^{4} ; 2: 607^{*}$.

Euzophera semifuneralis, $2: 733^{\circ}$. Evacanthus acuminatus, $2: 7+4^{6}$.

Evaniidae, $1: 22^{3}$.

Evergreens, less destructive insects affecting, $2: 648^{3}-700^{3}$.

injurions insects: $2: 333^{1}-425^{5}$. bag or basket worm, I: $123^{\text {}}$, $126^{3}$.

balsam gall midge, 2:6219. pine needle gall $\mathrm{fly}, 2: 62 \mathrm{x}^{9}$.

$$
407^{8}-\mathrm{IO}^{3}, 4 \mathrm{II}^{5} \text {. }
$$

frustrana, $2: 340^{3}, 405^{2}-7^{4}, 407^{6}$. rigidana, 2: $340^{4}, 407^{-4}$.

Exartema corylanum, 2: $723^{5}$.

fagigemmaeanum, $2: 722^{8}$.

footianum, $2: 724^{2}$.

inornatanum, 2: $707^{5}$.

permundaum, 2: $723^{5}$.

versicoloranum, 2: $717^{2}$

zellerianum, $2: 749^{8}$

excaecatus, Paonias, $2: 724^{7}$.

excavata, Siobla, 2:7195.

exiguissimus, Nenroterns, $2: 710^{9}$.

exiguus, Neuroterus, 2: $71^{1}$.

exile, Anomalon, $\mathbf{I}: 113^{2}$.

eximius, Phytocoris, see P. eximins.

exitiosa, Sanninoidea, 2: $733^{1}$.

Exorista griseomicans, $1: 133^{7}$.

Explanation of "plates, I: a333a.434; 2: 757-800.

externa, Macrophya, 2: $7 \mathbf{I} 6^{3}$.

fabricii, Lophyrus, $2: 752^{6}$.

facetus, Lepturges, 2. $715^{6}$.

fagi, Phyllaphis, $2: 601^{6}-2^{3}$.

Pityophthorns, 2: $702^{6}$.

sicolytus, $2: 722^{4}$.

fagigemmeanum, lixartema, 2: $722^{6}$.

Falcaria bilineata, $2: 7+9^{5}$.

falcula, Apatela, 2: $723^{5}$.

Fall cankerworm, $2: 547^{7}$.

Fall webworm, I: $12^{2}, 105^{6}, 131^{9}$, $142^{5}-46^{7}, 253^{3} ; 2: 607^{8}, 609^{1}$.

fallax, Agrilus, 2: $725^{7}$.

Cryptorliynchns, 2: $715^{8}$.

Iiphthera, 2: $73^{4}$.

falsarius, Alcoloithus, 2: $740^{2}$.

False chincl bng, 2: $651^{9}, 685^{5}$.

False pine webworm, 2:6509 $676^{3}$.

fasciata, Luprestis, $2: 425^{6}, 45^{8}-$ $59^{3}$.

Hlolcaspis, 2: $713^{8}$.

Lyda, 2: $733^{\circ}$.

Phora, I: $\mathrm{I}+\mathrm{O}^{6}$.

Telamona, 2: $717^{\circ}$.

fasciatum, Monarthrum, 2: $751^{8}$.

fasciatus, $1 \mathrm{ps}, 2: 370^{6}$

Oecanthus, $2: 699^{5}$. 
fasciat 11s, Urographis, $2: 426^{8}, 434^{8}-\mid$ Figures and plates of $\left(\operatorname{cont}^{\prime} d\right)$ : $36^{2}, 667^{3}$

fascicularis, Hemirhipus, $\mathbf{x}: 266^{\text {h}}$. Liopus, 2: $729^{3}, 730^{1}$

fasciella, Lithocolletes, $2 \cdot 708^{6}$.

fasciola, Lithacodes, $2: 725^{4}$.

Tortricidia, $2: 529^{5}$.

fascipennis, Baccha, $1: r 86^{2}$.

faunus, Polygonia, $2: 742^{6}$.

favosus, Neuroterus, $2: 713^{\circ}$.

fayi, Saperda, I: $257^{3}, 283^{3}-84^{4}$.

femoralis, Pyrochroa, $2: 727^{6}$.

femorata, Chrysobothris, I: $5 \mathrm{I}^{4}$, $56^{3}-87^{7}, 261^{3}: 2: 503^{4}$.

Diapheromera, $2: 508^{5}, 533^{4}-35^{2}$, $605^{3}$.

femoratus, Andricus, 2: $712^{3}$.

Pachybrachys, 2: $752^{\text {s. }}$.

fenestratus, Bythoscopus, 2: $749^{\circ}$.

Cyrtolobus, 2: $597^{4}$.

Feniseca tarquithins, 1: $196^{1}$.

lentonia marthesia, 2: $706^{1}$.

Feralia jocosa, 2: $754^{7}$.

Fern, sweet, injurious insects:

borer:

Auletes ater, 2: $7 \mathbf{1} 5^{7}$.

leaf feeders:

Apion rostrum, 2: $730^{4}$.

Auletes cassandrae, 2: $738^{7}$.

Chlamys plicata, 2: $703^{6}$.

sucking insect:

Eulecanium cockerelli, 2: $725^{6}$.

ferratus, Cryptorhynchus, $2: 702^{5}$.

ferrugana, Alceris, $2: 7+1^{2}, 7+9^{k}$, $753^{3}$.

ferruginea, Lophodonta, 2: $749^{2}$. syneta, 2: $748^{9}$.

ferrugineipes, Limneria, I: $158^{4}$.

fervidana, Archips, $2: 508^{2}, 530^{6}-$ $31^{5}, 609^{2}$.

fervidaria, Plagodis, $2: 706^{5}$.

Therina, 2: $754^{2}$.

ficus, Ceroptres, 2: $714^{7}$.

Fig. white marked powder-post leetle injuring, $2: 483^{8}$.

Figites chinquapin, 2:714.

impatiens, $2: 714^{9}$.

Figures and plates of:

Ablerus clisiocampae, I: 215.

Acanthoderes decipiens, $2: 473$.
Acholla multispinosa, $2: 613$.

Adalia bipunctata, $1: a 35^{8}$.

Agrilus anxius, $1: 285$, a+1 8 .

bilineatus, 1: 282.

Agromyza aeneiventris, 2: 634 , 760.

Alaus oculatus, $\mathrm{I}: \mathrm{a}+\mathrm{I} 6$.

Alydus eurinus, 2:613.

Amphibolips confluentus, 2: 760.

ilicifoliae, 2: 760 .

Anatis ocellata, 2:604.

Andricus punctatus, 1: $a+32$, a+34.

seminator, $2: 75^{8}$.

singularis, $2: 762$.

Anisota senatoria, I: a 370 .

Anomala lucicola, 1 : a377.

Anthophilax attenuatus, $2: 488$.

Anthrenus castaneae, 2:614.

Aphrastus taeniatus, 2:515.

Aphrophora parallela, $1: a 377$.

Aphycus annulipes, I: 203.

Archasia galeata, r: a 370.

Archips fervidana, $1: a 37^{\circ}$.

Asemum moestum, 2:661.

Aspidiotiphagus citrinus, I: 2 I2.

Aspidiotus ancylus, I: a 364 .

perniciosus, 1 : a 362 .

Asterolecanium variolosum, I: a 360 .

Allacaspis rosae, I: 228, a 364 .

Automeris io, I: a424.

Balaninus nasicus, r: a 370.

Basilona imperialis, I: a37t, a.20.

Batyle suturalis, 2: $66_{3}$.

Biorhiza forticornis, $\mathbf{1}: \mathbf{a}+34$.

Boletotherus bifurcus, $2: 498$.

Brachys ovata, 2:514.

Brochymena annulata, 2: 589 . arborea, 2:59I.

Buprestis fasciata, 2:459.

maculiventris, $2: 674$.

Calitys scabra, 2: 496 .

- Callidium antennatum, 2; 660 , 752,786 .

Callipterus ulmifolii, r: a 358.

Callosamia promethea, 1:a424.

Calosoma calidum, I: 113.
Figures and plates of $\left(\operatorname{con} t^{\prime} d\right)$ :

Camponotus herculaneus, r: a 400 .

Cecidomyia caryaecola, I: $\mathbf{3} 34$. erubescens, r: a334.

holotricha, I: a 334 .

pellex, 2:632.

persicoides, I: a334.

pilulae, I: a334.

pini-rigidae, $\mathbf{~}:$ a 376 .

resinicola, $1:$ a 376 .

tubicola, 1 : a 334 .

verrucicola, $1:$ a 334 .

Centrodera decolorata, $2: 456$.

Ceresa bubalus, 2: $591,592$.

Chaitophorus? aceris, I: a358.

Chalcis ovata, 1: 128 .

Chalcophora liberta, 2: 655 . virginiensis, $2: 654$.

Chariessa pilosa, 2: 504

Chermes pinicorticis, 1. a 374 . strobilobius, I: a 372 .

Chilocorus similis, $1: 223,224$.

Chionaspis euonymi, $1: a 364$.

furfura, $1: a_{3} 62$.

pinifoliae, I: a374.

Chramesus hicoriae, $2: 446,794$, 798.

Chrysobothris dentipes, $1: a 377$.

floricola, $\mathbf{~ : ~ a ~} 376$.

pusilla, 1: a 376 .

Chrysomela bigsbyana, 2: 566 .

Chrysopa sp., I: 9377 .

Cimbex americana. 1: a 368 .

Citheronia regalis, 1 : a 354 , a424.

Clastoptera obtusa, 2: 687.

Clerus quadriguttatus, 2: 666.

Coccinella novem-notata, $2: 691$. trifasciata, 2:69I.

Coenus delius, 2:697.

Coleophora laricella, 1 : a372,

limosipennella, $\mathbf{r}:$ a.to6.

Conotrachelus anaglypticus, 2; $5+4$.

juglandis, 2: $58 \mathrm{r}$.

Corthylus punctatissimus, I: 65,66 .

Corymbites hieroglyphicus, 2: 692.

Corythuca arcuata, 2: 599 .

Cossonus platalea, 2: 455 . 
Figures and plates of (cont' $l$ ):

Cossus querciperda, $1: a+26$.

Cryphalus striatulus, $2: 673,794$.

Cryptocephalus quadrimaculatus, 2: 695 .

schreibersii, 2: 695 .

Cryptorhynchus lapathi, 1: $a_{3} 68$, a 402 .

Cyllene pictus, 1: a366. robiniae, 1: 2342 .

Cynips strobilana, r: $a+3+$.

Cyrtolobus fenestratus, 2: 597 .

Datana integerrima, $1: a 366$, a.t26.

Dendroctonus piceaperda, 2: $3^{S} 2,-j S 2,796$.

terebrans, $2: 343,34^{8}, 776$, 792,796 ,

Dibrachys boucheanus, I: 139 .

Dicerca punctulata, 2:656.

Dichelonycha albicollis, 2:694.

Diplosis caryae, 1: a 334 .

Dorcaschema nigrum, 2: 4 4.

Drepanosiphum acerifolii, I: a $35^{\circ}$.

Dryocoetes sp., 2: $468,469.794$, 708 .

autographus, 2: 469,795 .

Elaphidion villosum, r: 3336.

Elasmocerus terminatus, $2: 502$.

Enchenopa binotata, 1: a37o, 2: $75 \mathrm{~S}$,

Euderces picipes, 2: $\$+5$.

Eulecanium nigrofasciatum, I: a36o.

tulipiferae, 1: a 360 .

Eunotus lividus, I: 199.

Euproctis chrysorrhoea, $1: a+28$.

Eupsalis minuta, I: 262.

Enschistus tristigmus, $2: 612$. variolarins, 2:61I.

Euvanessa antiopa, I: a356.

Evetria comstockiana, I: $a 376$.

frustrana, 1 : $a 376$.

Galerucella decora, 2: 566 . luteola, I: a350, a.tos, +110, +12.

Gaurotes cyanipennis, $2: 454$.

Glyptoscelis pubescens, 1 : $a 376$.

Gnathotrichus materiarius, 2: $371,373,794,79^{8}$.

Goes pulchra, 1: a $35+$.
Figures and plates of (cont' $d)$ :

Gossyparia spuria, I: a335.

Habrolepis dalmanni, $1: 330$.

Halisidota caryae, I: a 366, a 426. tessellaris, I: at26.

Hamamelistes spinosus, $2: 6+3$, $64,645,646$.

Harpyia sp., I: a368. cinerea, I: a $\$ 26$.

Hemerocampa leucostigma, I: a34s.

Hemileuca maja, I: 3370 , a.26.

Holcaspis fasciata, $2: 75 \mathrm{~s}$

Hoplocephala bicornis, 2: 498 . Hormaphis hamamelidis, $I$ : a334; $2: 639,6+0,6+1,6+2,643$.

Hylesinus aculeatus, $1: 259$. opaculus, 2: 794.

Hylobius pales, $1: a 376$.

Hylurgops glabratus, 2: 665 .

Hyperaspis signata, I: 182 .

Hyperplatys maculatus, $2: 432$.

Hyphantria textor, I: 3356 .

Ibalia maculipennis, $2: 499$.

Ips quadriguttatus, 2:692. sanguinolentus, 2:602.

Janus integer, $1: 302$.

Kaliosysphinga ulmi, I: $16_{3}$.

Lebia grandis, $2: 690$.

Lepidosaphes nlini, 1: $\mathbf{3}_{362 .}$

Leptura subhamata, 2: 675 .

vagans, $2: 4+$.

zebra, $2: 450$.

Liopus alpha, 2: 451 .

Lophyrus abietis, 1:a376. lecontei, $1: 337 ;: 2: 413$.

Lyctus unipunctatus, I: 296.

Lygaeonematus erichsonii, I: a 372 .

Madarellus undulatus, $2: 479$.

Magdalis alutacea, $\mathbf{1}:$ a 377 . armicollis, $1:$ a 33 s.

barbita, 1: a 338 .

perforata, 1: a377.

Malacosoma disstria, I: $a 3+8$, a 404 .

Melalopha inclusa, 1: a368.

Melanophila fulroguttata, 2: 390.

Melasoma lapponica, 2: 565 . scripta, 1: a 368 .
Figures and plates of $\left(\cos t^{\prime} d\right)$ :

Metachroma marginalis, $2: 68_{3}$.

Neteorus hyphantriae, $1: 1+5$.

Monarthrum mali, 1: 290, 29r; 2: 794 .

Monohammus confusor, 2: 786 . scutellatus, $2: 7^{86}$.

Mordella borealis, 2:672. octopunctata, $2:+33$.

Nabis rufusculus, $2: 688$.

Neomysia pullata, 2: 605 .

Notoxus anchora, $2: 696$.

bifasciatus, $2: 696$.

Obrium rubrum, I: afI 4 .

Odontota dorsalis, I: a 25 .

Oecanthus sp., 1: a 360 .

nigricornis, 2: 699 .

niveus, $2: 602$.

pini, 2:695.

quadripunctatus, 2: 700 .

Olethreutes nimbatana, $2: 576$.

Oliarius quinquelineatus, $2: 686$.

Oncideres cingulata, I: a354.

Ormenis pruinosa, 2: 595 .

Pandeletejus hilaris, $2: 437$.

Papilio thoas, 2: 554 .

Paralechia pinifoliella, $1: a 376$.

Paratenetus punctatus, 2: 606 .

Parharmonia pini, 1: ał28.

Pemphigus populi-transversus, I: $a 358$.

rhois, $2: 758$.

tessellata, $1: a+30$.

vagabundus, $2: 762$.

Pentilia misella, $1: 222$.

Phellopsis obcordata, $2: 496$.

Phenacoccus acericola, I: $\mathbf{I S}_{3}$, I 8 , a 360 .

Phlegethontius celeus, r: a 426 .

Phloeosinus dentatus, 2:392, 393, $786,794,798$.

Phloeotribus frontalis, 2: 673 . 792.

liminaris, 2: 452, 792.

Phyllaphis fagi, 1 ; a 358 .

Phyllobaenus dislocatus, 2: 503.

Phylloxera caryaecaulis, I: a $33+$. foveola, 1: a334.

Phymatodes dimidiatus, 2:670.

Physocnemum brevilineum, 2: 462. 
ligures and plates of $\left(\operatorname{con} t^{\prime} d\right)$ :

l'bytocoris eximius, 2: 685 .

l'bytodecta pallida, 2: 55 .

Phytoptus abnormis 1 : a $33+$. quadripes, $1:$ a334.

I'ilophorus crassipes, r: a 377 .

Pimpla conquisitor, I: 112. incuisitor, 1:127, 137.

Pinipestis zimmermani, $\mathbf{1}: \mathbf{a} 37 \mathbf{7}$. Pissodes strobi, 1: a 374; 2: 790.

Pityogenes $s p ., 2: 373,374,786$, $792,794,796,798$. ponderosae, 2: 794 .

Pityophthorus sf., 2: 373, 786 . minutissimus, $1: a+16,2: 673$. 794. puberulus, 2:673.

I'lagionotus speciosus, I: a336; 2: $382,354,356,388$.

l'odisus maculiventris, 2:608. modestus, 2:610.

placidus. 2:607.

l'ogonocherus mixtus, 2:663.

Polygraphus rufipennis, $2: 382$, $387,388,794,798$.

l'ortbetria dispar, 1: a354.

l'rionoxystus robiniae, I: a $34^{2}$, a3) 8 .

Psendophilippia quaintancii, 2: 762 .

l'teronus ventralis, I: 323.

Ptilinus ruficornis, $1: 298$.

Pulvinaria acericola, 1: 179, I8I. innumerabilis, I: $197, \quad 199^{5}$, a 336 .

P'ytho americanus, 2: 788 .

khabdophaga salicis, 1: 300,301 ; 2: 670 .

Rhagium lineatum, 2: 780, 785.

Samia cecropia, 1: a 222 .

Saperda calcarata, i: a 34 .

candida, $\mathbf{r}: \bullet$

fayi, I: $23+5$.

puncticollis, 1: a 34 .

tridentata, I: a338, a39o, 392.

restita, I: a $3+4$.

Sciara ocellaris, I: a334.

Sicolytus quadrispinosus, 1: a+16, 277, 2:794.

rugulosus, 2: 794 .

Serica trociformis, 1 : a 370 .
Figures and plates of $\left(\mathrm{cont} t^{\prime} d\right)$ : sesia acerni, 1: a $3 \neq 0$. albicornis, $1:$ a 368 .

Sphecius speciosus, 2: 604.

Telea poly phemus, $1:$ a +22 .

Termes flavipes, $1: 88-89$.

Tetropium cinnamopterum, 2 660.

Thalessa lunator, 1: 64, a 384 .

Thanasimus dubius, 2: 500 .

Thelia acuminati, $1:$ a 370,2 : 595. godingi, 2: 506 .

Thiodia signatana, $x$ : 160 .

Thyridopteryx ephemeraeformis, 1 : 125 , a 350 .

Tibicen septendecim, I: $a 35^{8}$, 430 .

tibicen, 1 : a $370,430$.

Tomicus sp., 2: 790 .

balsameus, $2: 376,377,376$, $392,776,784,792,798$.

cacograpbus, $2: 353,357,780$, $792,796$.

caelatus, $2: 353, \quad 355, \quad 792$, 796.

calligraphus, $2: 346,347,34^{8}$, $764,766,768,770,772,750$. $792,796$.

integer, 2: 792, 798 .

pini, $2: 352,353,766,774,776$, $775,792,796$.

Tomoxia bidentata, $2: 44$. lineella, $2: 4+1$.

Tragosoma harrisii, 2: 659 .

Tremex columba, $1: 62$, a 34.

Trioza tripunctata, 2: 65\%.

Tropaea luna, r: a 420 .

Typophorus canellus, $2: 537$.

Uliota dubius, 2 : 490.

Urographis fasciatus, $2: 786$.

Nyleborus celsus, $2:+46,4+7$. $79+, 798$.

dispar, $2: 46,794$.

Xylina antennata, I: $a+26$.

Xylocleptes sp., $2: 460,796$.

Xylocopa virginica, $\mathbf{x}:$ a 46 .

Xyloterus sp., 2: 800 .

birittatus, $2: 370$.

lineatus, $2: 798,800$.

politus, I: 203, 2: 800 .
Figures and plates of (cont'd):

Xylotrechus colonus, I: 259.

atit.

sagittatus, 2: 663 .

undulatus, 2:671,

Xyphidria provancheri, $2: f^{6} 5$, 466.

Zeuzera pyrina, I: a 340 , a3r4, 396.

Filament bearer, 2: $508^{1}, 530^{4}$

timbricornis, Thysanoes, $2: 76^{1}$.

Finch family, $1: 3 \mathrm{I}^{1}$.

Fir, in jurious insects:

borers:

bark borers, $1: 6^{6}$.

blazed tree borer, 2:67 $\mathrm{t}^{9}$.

cedar tree borer, $2: 675^{9}$.

horntail, blue, $2: 049^{9}, 669^{2}$.

spruce timber beetle, $2: 369^{9}$.

leaf feeders:

fir sawfly, $2: 340^{8}, 415^{6}$.

Nacaria praeatomata vor. bisignata, $2: 753^{2}$.

Nepytia semiclusaria, $2: 753^{2}$.

Oligia versicolor, $2: 754^{1}$.

l'araphia subatomaria, 2: $753^{3}$.

spruce bud worm, $2: 417^{7}$.

Tottrix packardiana, $2: 75 t^{3}$.

tussock moth, white marked, I: $136^{9}$.

sucking insects:

hemlock scale, $2: 652^{6},\left(6(x)^{3}\right.$.

fir sawfly, $2: 340^{8}, 415^{b}-16^{*}$.

fissilis, Euschistus, 2:610

Fitch's oak leaf miner, 2: $505^{4}$, $533^{2}$.

fitchella, 1.ithocolletes, 2: $50 \mathrm{~m}^{4}$, $533^{2}$.

Flannel moth, crinkled, $2: 507^{y}$, $520)^{7}-30^{3}$.

Flat-headed borer, common, I : $5 \mathrm{I}^{4}, 56^{3}-87^{7}$.

Flat-headed pine borer, larger, $2: 6+5^{6}, 653^{x}-54^{7}$.

smaller, 2: $648^{7}, 654^{8}-55^{7}$.

flavedana, Platynota, $2: 551^{5}, 72 s^{4}$.

Aavicornis, Urocerus, $2: 75 \mathbf{I}^{2}$.

Aavipennis, Anaspis, 2: $567^{1}$.

Alavipes, Neuroterus, $2: 713^{4}$.

Pelecotoma, $2:-\boldsymbol{z 2}^{3}$. 
flavipes, Termes, I: $5 \mathrm{I}^{4}, 87^{8}-90^{1}$. I formosa, Amphibolips, $2: 712^{2}$. fumiferana, Tortrix, $2: 340^{8}, 416^{4}-$

flavoscutellum, Coccophagus, I: $199^{4}, 210^{7}$.

Harus, Aphycus, r: $181^{9}$.

Flea beetle, I: $150^{4}$. black-margined, 2: 506, $515^{1}$. red-footed, $2: 510^{6}, 556^{2}$.

Alebilis, Catocala, 2: $716^{7}$.

fletcherella, Coleophora, $1: 17 \mathrm{I}^{4}$.

fletcheri, Eulecanium, 2: $755^{6}$.

Alexuosa, Heterogenea, 2: $529^{6}$.

Tortricidia, $2: 717^{2}$.

fiexuosus, Mycetophagus, 2: $495^{5}$.

Flicker, I: III $^{6}$.

Flies, I; $16^{4}$.

lace-winged, $1: 14^{6}$.

two winged, $\mathbf{I}: \mathrm{I}^{1}$.

flocci, Andricus, 2: $710^{8}$.

floccosa, Cynips, 2: $711^{6}$.

flocculosus, Cladobius, 2: $7+4^{6}$.

floricola, Chrysobothris, 2: $649^{1}$, $657^{9}, 65^{4}, 65^{5}$.

Flower beetle, hermit, $2: 493^{1}$. rough, $2: 492^{9}$.

Flower cricket, 2: $653^{7}$. white, $2: 602^{3}-3$.

Flower flies, I: $24^{2}$.

fluviata, Percnoptilota, $2: 725^{3}$.

Flycatchers, I: $30^{5}$.

Foenus tarsatorius, 2: $500^{2}$.

foliaformis, Andricus, 2: $710^{8}$.

footianum, Exartema, 2: $72 \downarrow^{1}$.

forbesi, Urogaster, 2:635?.

forcata, Phylloxera, 2: $718^{5}$.

Forest products, value, $\mathbf{1}: \mathbf{2 5 5 ^ { 5 }}$.

Forest tent caterpillar, $1: 23^{8}, 25^{6}$, $4^{82}, 52^{1}, \operatorname{IO}^{3}, \operatorname{IO6}^{3}-15^{9}, 253^{5} ; 2$ : $50^{9}$; birds feeding on, 1: $28^{1}$; parasites, I: $2 \mathrm{I}^{3}$, II $2^{3}-13^{7}$; remedies, $1: 44^{7}, 113^{8}-15^{7}$.

Forest tree pests, 1: $253^{3}-332^{8}$.

Forest trees, groups of insects affecting, $1: 10^{5}-12^{7}$; insects of minor importance affecting, 2 : $426^{1}$.

Forester, eight-spotted, 2: $512^{1}$, $575^{3}$.

Forests, annual losses caused by insects, $x: 7^{7}$.

Forked fungous beetle, $2: 493^{4}$.

formicarius, Clerus, 2: $500^{7}$ forticornis, Biorhiza, 2: $61 \mathrm{~S}^{6}, 626^{4}-\quad 18^{3}$. $27^{8}, 714^{7}$.

fortis, Chalcophora, 2: $751^{2}$

Fumigation, I: $39^{9}-41^{2}$.

funeralis, Apatela, 2: $7 \mathrm{I}^{6}$.

foveata, Phylloxera, 2:6293 $79^{3} 8^{6}$. Fungous beetles, $2: 431^{3}, 494^{6}-99^{4}$. foveola, Phylloxera, 2:6198 $629^{2}$, forked, 2: $49^{5^{4}}$. $718^{5}$.

frater, Raphia, $2: 747^{1}$.

fratercula, Catocala, $2: 705^{4}$.

fraternalis, Hemichroa, $2: 703^{3}$.

fraternus, Coccophagus, 1: $181^{9}-$ furfura, Chionaspis, I: $173^{6}, 214^{7}-$ $82^{1}$.

fraxina, Podosesia, $1: 51^{5}, 92^{3}$.

fraxini, Thysanocnemus, $2: 726^{\circ}$.

fraxiniflora, Eriophyes, 2: $620^{4}$, $633^{6}-34^{1}$

fraxinifolii, Pemphigus, I: $196^{2}$; 2: $727^{3}$.

frenchii, Frontina, I: $113^{3}, 138^{4}$.

Fringe tree, injurious insects:

Periclista chionanthi, $2: 73^{1}$.

Phlegethontius rustica, 2: $737^{8}$.

Fringillidae, $\mathbf{I}: 3 \mathbf{I}^{1}$.

frondosa, Cynips, 2: $714^{2}$.

frontalis, Dendroctonus, I: $6^{9}$.

Phloeotribus, see P. frontalis.

Pityophthorus, 2: $702^{6}$.

Frontina aletiae, I: $133^{7}$.

frenchii, I: $113^{3}, 138^{4}$.

Fruit flies, $1: 14^{6}$.

Fruit insects, $2: 734^{4}$.

Fruit of deciduous forest trees, insects affecting, $2: 5 \mathrm{I} 2^{5}$.

Fruit tree bark beetle, 2: $453^{1}$.

Fruit trees, injurious insects: apple borer, round-headed, I: $5 \mathrm{I}^{3}$.

fall webworm, I: $145^{5}$.

gipsy moth, $1: 120^{3}$.

frustrana, Evetria, 2: $340^{3} .405^{2}-7^{4}$, $407^{6}$.

fugitiva, Limneria, $1: 112^{4}, 309^{7}$, $314^{3}$.

fulminans, Arhopalus, $2: 427^{6}$, $444^{3}$.

fulvescens, Theronia, I: $112^{9}-13^{1}$, $135^{\circ}$.

fulvicollis, Philonix, 2: $7 \mathrm{I}^{1}$.

fulvidorsum, Phlepsius, $2: 753^{6}$.

fulvoguttata, Melanophila, $2: 339^{6}$, $390^{5}-9 I^{4}$. fur, Amauronematus, $2: 741^{8}$.

furcifera, Apatela, 2: $733^{4}$.

furcilla, Panthea, 2:65 $\mathrm{I}^{3}, 679^{7}$ $80^{1}$.

I $6^{5}$.

var. fulva, Chionaspis, $2: 735^{2}$.

fusca, Comys, I: $199^{8}$.

Lachnosterna, 2: $753^{5}$.

fuscatus, Xyleborus, $2: 752^{2}$.

fuscipennis, Aphelinus, I: $212^{\text {? }}$ $214^{3}, 222^{6}$.

fuscipes, Androchirus, 2: $701^{9}$. Pteromalus, I: $16 \mathrm{r}^{6}$.

fuscomarginella, Tischeria, 2: $708^{8}$.

fuscotibiella, Nepticula, 2: $744^{5}$.

fuscula, Dichelonycha, 2: $703^{5}$.

fusiform maple gall, 2: $619^{9}, 630^{2}$.

fusiformis, Andricus, 2: $710^{\circ}$. Temelucha, $2: 482^{4}$.

futilis. Andricus, 2: $710^{8}, 715^{1}$. Periclistis, $2: 715^{1}$.

galeata, Archasia, 2: $597^{1}$.

Galeruca decora, see Galerucella.

luteola, see Galerucella.

Galerucella cavicollis, $2: 510^{2}$, $550^{3}$.

decora, 2: $511^{4}, 566^{7}$,

luteola, $1: 8^{1}, 48^{3}, 49,105^{7}, 146^{8}$ $55^{6} ; 2: 614^{4}$.

rufosanguinea, $2: 733^{3}$.

tuberculata, $2: 742^{2}$.

galii, Deilephila, $2: 736^{1}$

Gall berry, Apatelodes torrefacta injuring, 2: $549^{4}$.

Gall insects, I: $172^{1}, 259^{1} ; 2: 615^{1}-$ $48^{3}, 709^{8}-14^{3}, 718^{1}, 720^{4}, 726^{3}$, $731^{8}, 733^{7}, 734^{9}, 736^{9}, 742^{5}, 745^{1}-$ $46^{4}, 750^{9}, 755^{3}$; key to, I: $25^{8}$, 259; 2: $6 \mathrm{I}^{1}-2 \mathrm{I}^{9}$; alternation of generations, $2: 616^{2}$.

Gall makers, 2: $616^{8}-17^{9}$.

Gall mites, $2: 6: 7^{7}$. 
gallaegenitella, Lpithectis, 2: $707^{5}$.

gallaesaliciana, Enarmonia, 2 $7+6^{4}$

Galldies, four winged, $\mathbf{r}: 10^{7}$.

gallicola, Nematur, $2: 637^{2}$.

Podapion, 2: $75 \mathbf{I}^{6}$

Galls, on willow shoots, insects

forming, r: $25^{\mathrm{s}^{1}}$; development of, $2: 615^{3}-16^{1}$

Gargaphia tiliae, $2: 731^{9}$.

gargates, Cardioplorus, 2: $667^{1}$.

Gastroidea cyanea, $2: 742^{3}$.

Gastropacha americana, sec Epicnaptera.

Gaurax anchora, I: $140^{6}$.

Gaurotes cyanipennis, $2: 428^{4}$, $454^{6}-55^{2}$.

gazellula, Microclytus, $2: 702^{3}$.

Gelechia albisparsella, $2: 719^{3}$.

bicostomaculella, 2: $707^{9}$.

caryaevorella, $2: 717^{4}$.

corylisella, $2: 750^{8}$. .

fungivorella, see Aristotelia.

gallaegenitella, sec Epithectis.

hamameliella, $2: 724^{2}$.

pinifoliella, see Paralechia.

pseudoacaciella, $2: 730^{7}$.

querciella, see Telphusa.

quercivorella, see Recurvaria.

vernella, 2: 7081.

geminata, Packardia, 2: $529^{6}, 707^{2}$.

Tillomorpha, 2: $715^{5}$.

geminatus, 30 thrideres, $2: 505^{1}$.

Lepyrus, $2: 742^{3}$.

gemula, Jryophanta, $2: 713^{9}$.

geniculatus, Chermes, I: $155^{3}$.

gentilis, Phyllechthrus, $2: 730^{3}$.

georgica, Hyperaeschra, 2: $705^{6}$.

gibbicollis, Ptosima, $2: 730^{5}$.

gibbosa, Nadata, 2: $506^{9}, 521^{2}$.

Trichodesma, $2: 724^{4}$.

gibbosus, Andricus, $2: 709^{\circ}$.

Gonotropis, $2: 494^{4}$.

gillettei, Philonix; $2: 711^{2}$.

Gingko, resistance to insect attack, $\mathbf{I}: 47^{4}$.

Gipsy moth, I: $8^{4}, 12^{2}, 105^{4}, 116^{1}-$ $23^{7}, 254^{1}$; birds feeding on, I: $27^{7}, 28^{1}, 29^{\circ}$; enemies of cater pillar, 2: $607^{9}, 613^{2}$. glabratum, Eremotylus, I: $145^{7}$. | Gouty oak gall, $2: 618^{3}, 623^{9}-24^{3}$. glabratus, Hylurgops, $2: 649^{7}$, Gracilaria alchimiella, $2: 724^{2}$. $665^{1}-66^{2}$.

glandulella, IIolcocera, 2: $585^{2}$, $70)^{7}$.

glaucopterus, Opheltes, $\mathbf{r}: \mathbf{1} 5^{8^{3}}$.

glaucus var. turnus, Papilio, 2: $704^{1}$.

gleditschiae, Cecidomyia, 2: $729^{8}$. gledischiaeella, Mompha, $2: 729^{7}$. globosa, Liodes, $2: 77^{6}$.

globosum, Phylloxera, 2: $718^{\text {t }}$.

Globular rose gall, $2: 62 \mathrm{I}^{7}, 647^{9}-$ $45^{3}$.

globulus, Andricus, $2: 714^{5}$.

Holcaspis, 2:615 $524^{6}, 714^{4}$.

Rhodites, $2: 621^{7}, 647^{9}-45^{3}$.

Gluphisia septentrionalis, $2: 7+7^{6}$.

glutinosa, Cecidomyia, $2: 718^{2}$.

Glycobius speciosus, see l'lagionotus.

Glyptoscelis barbata, 2: $51 \mathrm{~S}^{5}$. pubescens, 2: $653^{4}, 695^{1}$.

gnaphaloides, Rhabdophaga, 2: $745^{7}$.

Gnathotricus asperulus, 2: $726^{8}$ materiarius, $2: 339^{7}, 371^{1}-72^{7}$. retusus, $2: 75 \mathrm{I}^{\mathrm{B}}$.

I godingi, Thelia, 2: $596^{3}$.

Goes debilis, 2: $702^{3}$. oculata, 2: 7 I $5^{5}$. pulchra, $2: 426^{5}, 131^{4}-321$. pulverulentus, $2: 455^{2}$. tessellata, $2: 702^{3}$. tigrina, $1: 256^{8}, 265^{6}-69^{3}$.

Golden buprestis, $2: 645^{7}, 655^{6}-56^{3}$. Golden oak scale, I: $25^{9}, 329^{3}-31^{7}$.

Gonioctena pallida, see Phytodecta.

goniphorus, Poecilocapsus, 2: $725^{7}$.

Gonodontis bypochraria, 2: $732^{6}$.

Gonotropis gibbosus, 2: $494^{4}$.

Gooseberry, injurious insects: Basilarchia astyanax, 2: $704^{2}$.: Polygona faunus, 2: $742^{6}$. rose leaf folder, $2: 512^{4}, 551^{4}$. gordius, Sphinx, 2: $727^{1}$.

Gossyparia spuria, $1: 5^{3}, f^{1}, 49$, I $73^{3}, 203^{8}-7^{6}$.

ulmi, see $G$. spuria. blandella, 2: $720^{3}$.

juglandiella, $2: 720^{3}$.

lespedezaefoliella, $2: 730^{8}$.

negundella, $2: 728^{9}$.

salicifoliella, $2: 744^{4}$.

sassafrasella, $2: 732^{6}$.

stigmatella, $2: 744^{4}, 747^{8}$.

Gracilia minuta, $2: 77^{4}$.

gracilipes, Cinyra, $2:$ 70 $^{7}$.

gracilis, Anaphes, I: $212^{9}, 222^{4}$.

Orcliesia, 2: $748^{5}$.

Pontania, $2: 7+5^{6}$.

Grackle, bronzed, I: I I I'.

grallator, Cryptus, $1: 87^{5}$.

grandis, Camptobrocbis, I: $153^{9}$ $54^{1} ; 2: 614^{3}$.

Lebia, see 1. grandis.

granicollis, Dryocoetes, 2: $720^{9}$, $753^{9}$.

granulatus, Agrilus, $2: 746^{5}$.

Ernobius, 2: $694^{5}, 752^{5}$

Grapevine, Elasmocerus termi. natus beneficial to, $2: 502^{4}$

injurious insects: borers:

Clytanthus albofasciatus, 2: $715^{5}$.

Madarellus undulatus, 2 : $430^{4}, 479^{5}$.

maple and oak twig pruner, I: $6 \mathbf{I}^{3}$.

Neoclytus erythrocephalus, I: $72^{6}$.

scutellaris, $2: 715^{4}$.

Otidocephalus chevrolatii, 2: $715^{7}$.

myrmex, 2: $715^{7}$

pine borer, lesser, $2: 662^{5}$.

powder post beetle, $1: 297^{1}$.

prionus, broad-necked, 2 : $486^{7}$.

twig borer, red-shonldered, $2: 4+24$.

flower cricket, white, $2: 603^{3}$.

leaf feeders:

Aspidiotus uvae, 2: $717^{9}$.

brown tail moth, I: $164^{2}$.

flea beetle, red-footed, 2 : $55^{6}$. 
Grapevine, inj. insects (cont'd): leaf feeders:

forester, eight-spotted, 2 $512^{1}, 575^{3}$.

rose beetle, 2: $575^{7}$.

scale or sucking insects: $239^{4}$.

chinch bug, false, $2: 655^{8}$. maple scale, cottony, I: $173^{2}, 196^{4}, 198^{2}$. tree hopper, two-marked, 2: $595^{5}$.

Grapevine beetle, light-loving, 2: $65 \mathbf{1}^{5}, 682^{6}$.

Graphiphora alia, 2: $704^{9}$.

Graphisurus pusillus, 2: $753^{3}$.

Grapholitha caryana, see Enarmonia.

Grapta comma, see Polygonia. interrogationis, sez Polygonia. progne, sie Polygonia.

graptae, Telenomus, I: $16 \mathbf{I}^{6}$.

Grasshoppers, losses caused by, I: $6^{3}$; incomplete metamorphosis, $1: 15^{6}-16^{4}$.

grata, Enthisanotia, 2: $740^{\circ}$.

gratulata, Mesoleuca, $2: 706^{3}$.

Gray comma, 2: $509^{6}, 5+6^{2}$.

Gray sided oak weevil, $2: 426^{9}$, $436^{\circ}-37^{6}$.

Green oak caterpillar, 2: $506^{4}$, $521^{1}$.

Green-striped maple worm, 2: $508^{8}, 537^{6}-38^{3}$.

gregarious, Pachynematus, $2: 7+1^{8}$, grisea, Apatela, 2: $724^{3}$.

Archips, 2: $707^{6}$.

griseomicans, Exorista, $1: 13^{3}$.

Grosbeak, rose-breasted, 1: $26^{7}$ $3 \mathrm{r}^{2}, \mathbf{1} 66^{5}$

grossa, Phenolia, 2: $49^{6}$.

- groteella, Depressaria, 2: $723^{7}$. grotei, Nylina, $1: 130^{1}, 130^{6}, 131^{1}$, $13 \mathrm{I}^{3} ; 2: 72 \mathrm{~S}^{9}$.

Ground beetles, I: $23^{4}, 320^{8}$.

Ground bird, $1: 237^{3}$.

grylli, Empusa, r: $1+6^{3}$.

grynea, Catocala, 2: $7+3^{4}$.

Grynocharis quadri-lineatus, 2: $460^{\circ}$.
Guest flies, 2: $714^{4}, 736^{5}$.

Gum, Cucujus clavipes injuring, 2: $7 \mathrm{Or}^{4}$.

guttifinitella, Lithocolletes, 2: $7+0^{6}$.

guttivitta, Heterocampa, 2: $727^{8}$.

guttulatus, Cryptocephalus, 2: $703^{6}$.

Gymonychus appendiculatus, 2: $609^{2}$.

Gypona octolineata, $2: 652^{4}, 658^{5}$.

habilis, Caţocala, 2: $716^{\circ}$.

Habrocytus thyridopterigis, I: $\mathrm{I}_{4} \mathrm{O}^{3}$.

Habrolepis dalma:ıni, $r: 33^{1}$.

Hackberry, resistance to insect attack, $1: 47^{5}$.

injurious insects:

borers: 2 : 725 .

Acanthoderes quadrigibbus, $2: 702^{4}, 715^{5}$.

Ataxia crypta, 2: $702^{4}$.

Elaphidion mucronatum, 2: $702^{2}$.

Liopus variegatus, $2: 720^{7}$. oak borer, dusty, $2: 426^{7}$, $+34^{4}$.

Scolytus fagi, 2: $722^{4}$.

Smodicun cucujiforme, 2 : $71^{9}, 71^{4}$.

gall insects: $2: 726^{3}$

hackberry nipple gall, 2 : $62 \mathrm{I}^{5}, 6+7^{5}$.

leaf feeders: $2: 725^{9}$.

elm caterpillar, spiny, $\mathbf{~}$ : I $6 \mathrm{I}^{4}$.

scale insects:

Putnam's scale, $1: 22 \%^{4}$.

Hackberry nipple gall, 2:62 $\mathrm{I}^{5}$, $647^{4}$.

Hadrobregnus errans, $2: 715^{3}$.

Hag moth caterpillar, 2: $525^{3}$.

hageni, Lithocolletes, $2: 708^{6}$.

Halisidota caryae, $1: 258^{6}, 34^{2}-$ I $5^{\circ}$.

harrisii, 2: $719^{9}$.

maculata, $2: 507^{2}, 523^{3}$.

tessellaris, 2: $507^{3}, 523^{7}-24^{2}$.

Haltica bimarginata, 2: $51^{9}, 573^{5}-$

$74^{6}$.
Haltica chalybea, $2: 724^{5}$.

hamadryas, Chermes, I: IS8*.

hamadryella, Lithocolletes, 2 : $508^{4}, 532^{5}-33^{1}$.

hamamelidis, Jormaphis, $I: 25^{1}$, 2: $616^{6}, 62 \mathrm{I}^{3}, 639^{8}-43^{4}$

hamameliella, Gelechia, 2: $72 t^{2}$.

hamamelis, Apatela, $2: 704^{6}$.

Hamamelistes spinosus, I: $246^{9}$ $47^{-1}, 251^{7} ; 2: 616^{b}, 621^{3}, 643^{4}-46^{9}$.

hamatus, Corymbites, 2: $7+0^{4}$.

Hand collecting, $1: 44^{8}-45^{5}$.

Haploa clymene, 2: $704^{4}$.

Harmonia picta, $1: 231^{4}$. pini, see Parharmonia.

Harpiphorus tarsatus, 2: $736^{7}$. versicolor, 2: $736^{7}$

Harpyia borealis, $2: 7+3^{5}$. cinerea, $2: 510^{9}, 559^{7}$. scolopendrina, $2: 7+7^{7}$.

Harris's pine hawk moth, $2: 65 \mathrm{I}^{2}$, $679^{3}$.

Harris's Prionus, 2: $649^{8}, 659^{1}$.

harrisii, Chrysobothris, $2: 467^{4}$, $75 \mathrm{I}^{3}$.

Halisidota, 2: $719^{2}$.

Tragosoma, 2: $649^{2}, 659^{1}$.

Harrisimemna trisignata, $2: 737^{8}$.

Harvest fly, $1: 174^{1}, 237^{8}-35^{9}$

hastata, Rheumaptera, $2: 749^{6}$.

hastiana, Alceris, $2: \mathrm{7H}^{3}$.

hastulifera, Apatela, $2: 70^{6}$.

Ilawthorn, injurious insects:

lleterocampa manteo, 2: $705^{\circ}$.

locust leaf miner, I: $327^{9}$.

rose leaf folder, $2: 58 \mathrm{I}^{4}$.

Hawthorn tingis, 2: $59^{56}-99^{7}$.

Hazel, in jurious insects:

borers, $2: 723^{3}$.

Otidocephalus chevrolatii, 2: $7 \mathrm{I}^{\text {h? }}$.

myrmex, 2: $715^{7}$.

sugar maple timber beetle: 1 : $67^{4}$.

flower cricket, white, $2: \cos _{3}^{3}$.

leaf feeders: $2: 723^{4}$.

Anagoga pulveraria, 2: $728^{3}$.

Apatela impressa, $2: 7+3^{1}$.

oblinita, $2: 7+3^{1}$.

Apatelodes torrefacta, 2: $5+9^{4}$. 
Hazel, inj. insects (cont' $d)$ :

leaf feeders:

Aphrastus taeniatus, 2: $515^{9}$.

apple worm, yellow-necked, 2: $535^{\circ}$.

Attelabus rhois, 2: $513^{9}, 57 t^{7}$.

Bassareus mammifer, a: $716^{4}$.

buck moth, $1: 311^{9}$.

Chlamys plicata, 2: 70 $3^{6}$.

Chrysonela multigutata, 2: $7+2^{1}$.

(ingilia catenaria, $2: 706^{5}$.

cryptocephalus mutabilis, 2: $703^{6}$.

Dichelonycha elongata, 2: $716^{3}$.

Eucosma similana, $2: 7+9^{8}$.

leaf roller, oblique banded, 2: $5300^{\circ}$.

Lycia cognataria, 2: $723^{1}$.

Monocesta coryli, 2: $724^{5}$.

Paonias excaecatus, 2: $724^{7}$.

Pyroplaila pyramidoides, 2: $704^{7}$.

rose leaf folder, 2: $5^{81^{4}}$.

Schizura unicornis, 2: $705^{9}$.

Smerintlas jamaicensis, 2 : $724^{7}$.

Thanaos icelus, $2: 7+2^{7}$.

Tortricidia flexuosa, $2: 717^{2}$.

Nanthonia villosula, $2: 703^{\top}$. nut pests: $2: 723^{i}$.

acorn weevil, 2: $58 t^{2}, 5^{8} t^{5}$. $5^{8} t^{n}$.

hebe, Phaeogenes, 1: $166^{2}$.

Ilecaholus lycti, I: $297^{7}$.

hederaceus, Aphycus, I: $15 \mathbf{I}^{9}$.

lledya signatana, I: $169^{4}$.

IIelice pallidochrella, 2: $729^{7}$.

Helicobia helicis, 1 : $14 \mathrm{O}^{5}$.

Heliophila unipuncta, $1: 22^{9}$. I $32^{1}$.

heliothidata, Sciagrapha, 2: $730^{6}$.

Helops aereus, 2: $752^{6}$.

helvalis, Phlyctaenia, 2: $7 \mathbf{H}^{1}$.

helxines, Crepidodera, $2: 7+2^{2}$.

Henaris diffinis $2 a r$. axillaris, 2 : $741^{1}$,

thysbe, 2: $73^{\circ}$.

Hemerohius, $1: 195^{3}$.

stigmaterus, $2: 653^{7}, 697^{5}$.
Hemerocampa, synopsis of larvae, I: $134^{1}$.

definita, 1: $133^{9}, 137^{1} ; 2: 507^{1}$, $522^{4}-23^{2}, 607^{9}$.

inornata, I: $134^{2}$.

leucostigma, $\mathbf{~}: 20^{*}, 44^{9}, 47^{9}-7^{1}$, 49, $105^{6}, 132^{6}-42^{5} ; 2: 522^{5}, 524^{4}$, $607^{*}, 609^{1}$.

vetusta, $\mathbf{1}: \mathbf{1} 34^{3}$.

tैư cana, 1: $134^{3}$.

llemichroa albidovariata, $2: 703^{3}$. americana, $2: 750^{6}$.

fraternalis, $2: 7033$.

laricis, 2: $755^{\circ}$.

phytophagica, 2: $703^{4}$.

Hemileuca maia, $1: 25^{5}, 310^{4}-$ It? .

Hemiptera, $1: 12^{4}, 24^{2}$.

Hemirhipus fascicularis, $\mathbf{r}: 266^{8}$.

Hem isarcoptes coccisugus, $1: 213^{2}$.

Hemiteles thyriclopterigis, I; $127^{\circ}$. townsendi, r: $140^{3}$.

Hemiock, injurious insects:

borers: 2: $75 t^{5}$.

apple wood stainer, $\mathrm{I}: 290^{6}$. balsam bark borer, $2: 376^{3}$.

huprestid, spotted, 2: $339^{5}$, $390^{6}$.

Calitys scabra, 2: $496^{4}$.

Cryphalus striatulus, 2:6736.

flat-headed borer, common, 1 : $87^{2}$.

Leptura, Canadian, 2:6706.

Leptura subhamata, $2: 650^{7}$, $675^{2}$.

Monarthrum fasciatum, 2: $75 \mathrm{I}^{\mathrm{R}}$.

Nyctobates pennsylvanica, 2: $+92^{3}$.

Phellopsis obcordata, $2: 40^{66}$. Pityobius anguinus, 2: $75 \mathrm{I}^{3}$. prionus, lesser, $2: 487^{6}$. rustic horer, I: 26I'. spruce timber beetle, $2: 369^{9}$. thunderbolt beetle, $2: 4+t^{6}$. Nyloterus politus, 1: $292^{\text {. }}$.

Xylotrechus undulatus, 2 : $650^{3}, 67 \mathrm{r}^{2}$.

leaf feeders: $2: 754^{6}$.

bag or basket worm, I: $127^{2}$.

Eufidonia notataria, 2: $753^{2}$.
Hemlock, in j. insects (cont $\left.t^{\prime} d\right)$ :

leaf feeders:

larch lappet, 2: $680^{3}$.

Melanolophia canadaria, 2 : $753^{3}$.

Nepytia semiclusaria, $2 \vdots 753^{2}$.

Selidosema umbrosarium, 2: $725^{3}$.

spruce bud worm, $2: 417^{-7}$.

scale or sucking insects:

hemlock scale, $2: 652^{6}, 690^{3}$.

l'utuan's scale, $1: 227^{5}$.

Hemlock scale, 2: $652^{6}, 690^{2}$.

Hepialus mustelina, 2: $753^{\circ}$.

herculaneum, Apion, $2: 734^{6}$.

herculaneus, Camponotus, I: $5 \mathrm{I}^{4}$, $90^{2}$.

Hermit flower heetle, 2: $493^{1}$.

Heterach thes quadrinaculatus, 2: $715^{3}$.

Heterocampa hilineata, 2: $725^{2}$.

biundata, $2: 727^{\circ}$.

guttivitta, $2: 727^{\prime \prime}$.

manteo, 2: $705^{7}$.

obliqua, 2: $705^{7}$.

subrotata, 2: $716^{9}$.

umbrata, 2: $705^{\prime}$.

Heterogenea flexuosa, $2: 529^{6}$. shurtleffii, 2: $529^{6}, 707^{3}$.

Heteropacha rileyana, 2: $729^{5}$.

Heterophleps triguttaria, 2: $727^{9}$.

Hetoemis cinerea, 2: $726^{6}$.

Hibernation, I: $19^{4}-20^{5}$.

Hickory, heneficial insects: Chariessa pilosa, 2: $504^{3}$.

Elasmocerus terminatus, 2: $502^{5}$.

Ibalia maculipennis, $2: 499^{6}$. Phyllobaenus dislocatus, 2: $503^{4}$.

Xylonomus albopictus, 2: $500^{1}$.

injurious insects:

aphids: $2: 717^{8}$.

borers: 2: $715^{2}-16^{1}$.

Acanthoderes decipiezs, 2 : $429^{8}, 473^{4}$.

quadrigibbus, 2: $702^{4}$.

Anthaxia viridicornis, 2: $724^{4}$.

apple wood stainer, $1: 290^{5}$. 
Hickory, inj. insects (cont'd): borers:

ash borer, banded, 1: $257^{\circ}$, $28 \mathrm{o}^{5}$.

four-marked, $2: 428^{9}, 462^{5}$, Calloides nobilis, $2: 427^{6}$, $4+3^{2}$.

Cryptorhynchus obtentus, 2: $720^{5}$.

Cucujus clavipes, $2:$ joI $^{4}$.

Cyrtinus pygmaeus, 2: $702^{3}$.

Dicerca asperata, 2: 7or $^{6}$.

Distenia undata, $2: 720^{7}$.

Dorcaschema nigrum, $427^{7}, 4+44^{\circ}$.

elm snout beetle, black, I: $73^{9}$.

Euderces picipes, 2: $427^{\circ}$. $445^{7}$.

Eupogonius tomentosus, 2: $751^{5}$.

flat-headed horer, common, 1: $87^{\circ}$.

Goes debilis, 2: $7 \mathrm{O}^{3}$.

hickory bark borer, 1: $257^{1}$, $275^{5}$.

hickory borer, banded, I: $256^{7}, 26 \pi^{2}$.

beautiful, $2: 426^{5}, 43 \mathrm{I}^{5}$. painted, $1: 256^{6}, 264^{4}$. tiger, $1: 256^{7}, 265^{6}$.

hickory snout beetle, I: $256^{9}, 274^{5}$.

hickory timber beetle, 2: $427^{8}, 446^{2}$.

hickory twig borer, 2: $427^{5}$, $+4^{3}$.

Hyperplatys aspersus, 2: $74^{6}$.

maculatus, $2: 433^{3}$.

Hypothenemus erectus, 2 : $702^{7}$.

leopard moth, I: $78^{5}$.

Leptura vagans, $2: 44^{1}$.

Lepturges querci, $2: 427^{2}$, $439^{8}$.

maple and oak twig pruner, I: $6 \mathbf{I}^{3}$.

Monarthrum fasciatum, 2: $751^{8}$.
Hickory, inj. insects $\left(\right.$ conf $\left.f^{\prime} d\right)$ : borers:

Nenclytus erythrocephalus, 1: $71^{9}, 72^{3}, 72^{6}$

oak borer, variable, 2 : $434^{3}$.

passalus, horned, 2: $492^{8}$.

Phymatodes varius, 2: $702^{1}$. powder post beetle, i: $2966^{\circ}$. prionus, lesser, $2: 487^{6}$.

red horned borer, small, I: $298^{7}$.

rustic borer, 1: $256^{5}, 259^{2}$. saperda, hickory, I: $256^{\times}$, $269^{4}$.

red-edged, $1: 270^{6} ; 2: 427^{7}$, $445^{4}$.

Stenosphenus notatus, 2 : $493^{2}$.

Tomoxia bidentata, $2: 427^{3}$, $441^{2}$.

lineella, $2: 427^{4}, 441^{8}$.

twig borer, red-shouldered, 2: $442^{4}$.

twig girdler, $1: 256^{9}, 271^{3}$.

Tylonotus bimaculatus, 2 : $726^{8}$.

Urographis fasciatus, 2: $435^{9}$.

Xyleborus fuscatus, $2: 752^{2}$.

Xyloterus politus, 1: $292^{4}$,

gall insects: $2: 718^{1}$.

Iiplosis caryae, 2:619?, $628^{4}$.

hickory button gail, $2: 619^{8}$, $629^{2}$.

hickory gall aphid, 1:259 $33 I^{y} ; 2: 619^{5}$.

hickory onion gall, 2:619;, $62 \mathrm{~S}^{5}$.

hickory peach gall, 2: $619^{7}$, $628^{7}$.

hickory seed gall, 2: $619^{6}$, $62 \mathrm{~S}^{3}$.

hickory tube gall, 2: $619^{8}$, $62 s^{8}$.

leaf feeders: 2: $716^{2}-18^{9}$.

Acrobasis rubrifasciella, 2: $750^{7}$.

Alsophila pometaria, 2: $706^{2}$.
Hickory, inj. insects (cont'd): leaf feeders:

American dagger moth, 2: $525^{3}$.

American silk worm, 2: $526^{6}$.

A patela brumosa, 2: $704^{6}$. lithospila, 2: $72 \mathrm{I}^{2}$.

apple worm, yellow-necked, 2: $535^{7}$.

Archips semiferana, 2: $707^{6}$.

Bassareus mammifer, 2: $719^{6}$.

black walnut caterpillar, I: $303^{9}$.

Catocala epione, 2: $705^{4}$. piatrix, 2: $719^{7}$. vidua, 2: $705^{5}$.

Conotrachelus anaglypticus, 2: $544^{6}$.

Cotalpa lanigera, $2: 724^{5}$.

Datana contracta, 2: $725^{1}$.

Ennomos magnarius, 2: $725^{3}$.

subsignarius, 2: $725^{4}$.

Erannis tiliaria, 2: $731^{6}$.

Euclea chloris, 2: $706^{8}$. itudetermina, 2: $528^{9}$.

Eugnamptus angustatus, 2: $7^{\circ} 3^{*}$.

flea beetle, black-margined, 2: $506^{4}, 515^{2}$.

forest tent caterpillar, I: I $10^{9}$.

Glyptoscelis barbata, 2: $518^{5}$

Graphiphora alia, 2: $704^{9}$.

IIeterocampa biundata, 2 : $727^{\AA}$.

umbrata, 2: $705^{6}$.

hickory caterpillar, striped. 2: $505^{5}, 535^{3}$.

hickory horned devil, I $258^{3}, 305^{7}$.

hickory tussock moth, I $255^{6}, 314^{9}$.

Laemosaccus plagiatus, 2 $703^{9}$.

leaf roller, s-marked, 2 $531^{8}$.

Lithacodes fasciola, 2: $728^{4}$. 
Iiickory, inj. insects (cont' $d$ ): leaf feeders:

Juna moth, z: $526^{9}$

Machimia tentoriferella, 2: $708^{2}$.

Nineola juglandis, $2: 719^{9}$.

Morrisonia confusa, 2: $727^{5}$.

Natada nasoni, 2: $707^{2}$.

New York weevil, $2 \vdots 517^{8}$, $518^{2}$.

Piazorhiuus scutellaris, 2: $703^{9}$.

Prolimacodes scapha, 2: $707^{\prime}$.

Pyrophila pyramidoides, 2: $704^{7}$.

Rhynchagrotis alternata, 2: $704^{7}$.

Schizura unicornis, 2: $705^{9}$.

Scopelosoma sidus, $2: 705^{2}$.

Sisyrosea inornata, $2: 723^{3}$.

textula, 2: $721^{4}$

Thecla calanus, 2: $704^{3}$.

tussock moth, dark, 2: $524^{4}$.

white marked, 1 : $136^{\circ}$.

Tymnes tricolor, 2: $515^{7}$.

walking stick, 2: $533^{9}$.

wa] nut sphinx, 2: $506^{6}, 518^{7}$.

Xanthonia villosula, 2: $703^{\top}$.

Xylina antennata, $1: 129^{9}$, $13 \mathrm{I}^{6}$.

nut pests:

acorn weevil, $2: 584^{4}$.

Conotrachelus seniculus, 2: $512^{5}, 5^{8} 2^{5}$.

hickory shuck worm, 2: $512^{6}, 583^{1}$.

wainut curculio, $2: 582^{4}$.

root feeder:

Lachnosterna fusca, 2: $753^{5}$.

scale or sucking insects: 2: $717^{5}, 717^{9}$.

Archasia galeata, 2: $597^{4}$.

Chrysumphalus obscurus, 2: 70$)^{6}$.

Eulecanium canadense, 2: $725^{6}$. caryae, $2: 725^{\circ}$.

Hickory, bitternut, hickory shuck worm injuring, $2: 583^{3}$.
Hickory, pignut, Dicerca, lurid, /Hog peanut, locust leaf miner injuring, $2: 427^{5}, 4+22^{8}-43^{5}$. injuring, $1: 327^{9}$.

II ickory bark borer, $1: 257^{2}, 275^{4}-$ Holcaspis basset1i, $2: 71 \mathrm{I}^{4}$, $79^{6} ; 2:+46^{3}, 502^{7}$.

Ilickory borers, 2: $715^{2}-16^{1}$. banded, $1: 256^{7}, 267^{1}-68^{5}$. beautiful, $2: 426^{5}, 431^{4}-32^{1}$. painted, $1: 256^{6}, 264^{1}-66^{9}$. tiger, $1: 256^{8}, 268^{6}-69^{3}$.

Hickory button gall, 2:6194. $629^{1}$.

Hickory caterpillar, striped, 2: $505^{6}, 535^{3}$.

Hickory gal] aphid, $1: 2+7^{7}, 259^{1}$ $331^{8}-32^{9} ; 2: 619^{6}$.

Hickory horned devil, 1: $25^{8}$, $305^{6}-6^{4}$.

Hickory onion gall, $2: 610^{7}, 628^{5}$.

Hickory peach gall, 2:619 $9^{9}, 628^{7}$.

Ilickory saperda, $1: 256^{8}, 269^{4}-70^{4}$.

Hickory seed gall, 2:6196 $69^{83}$.

Hickory shuck worm, 2:51 $2^{8}$, $583^{1}$.

liickory snont borer, I: $256^{9}, 274^{5}-$ $75^{3}$.

Ilickory timber beetle, $2: 427^{8}$, $+46^{2}-48^{2}$.

liickory tube gall, 2:6198, $628^{7}$.

IJickory tussock moth, I: $25^{8}$, $314^{7}-15^{7}$.

Hickory twig borer, $2: 427^{8}, 48^{8}-$ $49^{4}$.

hicoriae, Chramesus, $2: 336^{5}, 336^{9}$, $427^{4}, 44^{3}, 502^{5}$.

hieroglyphicus, Corymbites, see C. hieroglyphicus.

hilaris, Pandeletejus, $2: 426^{9}, 436^{8}-$ $37^{6}$.

llimatium conicum, 2: 7321.

hirta, Biorhiza, 2: 7 1 $2^{9}$

hirticauda, Pimpla, I: $139^{\mathbf{2}}$.

hirticeps, Pityophthorus, 2: $751^{\circ}$

hirticula, I achnosterna, 2: $716^{4}$.

Ilispa suturalis, see Odontota Jorsalis.

hispidulus, Plocamus, 2: $721^{2}$.

lispoides, Magclalis, $2: 751^{7}$.

liister cylindricus, $2: 350^{6}, 354^{7}$, $359^{4}$.

lecontei, $2:+1)^{2}$.

parallelus, $2: 359^{4}, 372^{1}, 49 r^{3}$. centricola, $2: 711^{9}$.

duricoria, $2: 618^{4}, 624^{5}$.

fasciata, $2: 713^{8}$.

globulus, $2: 618^{6}, 624^{6}, 714^{4}$.

Holcocera chalcofrontella, $2: 75 t^{9}$. glandulella, 2: $585^{2}, 709^{7}$.

Holly, injurious insects:

Harrisimemna trisignata, 2: $737^{8}$.

Schizura unicornis, 2: $705^{9}$.

Thecla liparops, 2: $704^{3}$.

holotricha, Cecidomyia, 2:6197. $623^{5}$.

HomaJomyia scalaris, $1: 1+0^{6}$.

HomaJota sp., $2: 389^{6}$.

Homoptera lunata, $2: 508^{9}, 53^{4}-$ $39^{\prime}$.

z' $(2)$. edusa, $2: 7+3^{5}$.

minerea, $2: 743^{4}$.

Honey locust, resistance to insect attack, $\mathbf{1}: 47^{3}$

in jurious insects:

borers:

ash borer, four-marked, 2: $425^{9},+62^{6}$.

Ptinidium lineatum, $2: 729^{4}$.

Nyleborus pubescens, 2: $720^{9}$.

leaf feeders, $2: 729^{4}$.

Cleora pampinaria, $2: 7+3^{9}$.

Euclea delphinii, 2: $706^{9}$.

lycia cognataria, 2: $728^{1}$.

Schizura ipomoeae, 2: $705^{\circ}$. tussock moth, white marked, $1: 136^{*}$.

scaie or sucking insects:

Agallia quadri-punctata, 2 . $595^{1}$.

Aspidiotus ancylus, 2: $729^{\circ}$.

Chionaspis ortholobis, 2: $7+4^{3}$.

Honeydew, I: $244^{4}-45^{4}$.

Honeysuck le, injurious insects:

borers, 2: $740^{9}$.

leat feeders, $2: 7+1^{1}$.

Harrisimemua trisignata, 2: $737^{9}$.
Homohadena badistriga, $2: 741^{1}$. 
Honeysuckle, inj. insects (cont'd) leal feeders:

Hemaris thy'sbe, 2: $730^{3}$.

Hop aphis, I: $2.45 \%$

Hop hornbeam, injurious insects: borer:

Mastogenius subcyaneus, 2 : $7 \mathrm{OI}$.

leaf feeders, $2: 722^{7}-23^{l}$.

Alsophila pometaria, 2: $706^{2}$.

Lithacodes fasciola, 2: $728^{4}$.

Prolimacodes scapha, $707^{1}$.

Sisyrosea textula, $2: 72 \mathrm{I}^{4}$.

Hop merchant, $2: 509^{5}, 545^{6}-46^{1}$.

hopkinsii, Cosmophorus, $2: 379^{6}$, $389^{9}-9 \mathrm{O}^{1}$.

Hoplia trifasciata, 2: $742^{2}$.

Ioplocephala bicornis, 2: $495^{2}$, $499^{2}$.

Hoplosia nubila, 2: $7 \mathbf{2 2}^{3}$.

llops, aphids injuring, $1: 2.42^{9}$.

Hoptree, injurious insects: Nepticula pteliaeella, $2: 723^{3}$. orange dog, $2: 555^{3}$.

Papilio thoas, $2: 729^{3}$.

Hoptree, red, tree hopper, twomarked, injurıng, $2: 595^{5}$.

hordeoides, Cecidomyia, 2: $745^{3}$.

Hormaphis hamamelidis, I: $25 \mathrm{I}^{1}$; 2: $616^{6}, 621^{3}, 639^{8}-43^{4}$. papyraceae, $2: 750^{1}$.

Hormiscus saltator, 2: $726^{7}$.

Hornbeam, injurious insects: borers:

Acoptus suturalis, $2: 715^{8}$.

Distenia undata, 2: $720^{7}$.

leaf feeders, $2: 723^{2}$.

apple worm, yellow-necked, 2: $535^{8}$.

Basilarchia astyanax, 2: $704^{2}$.

Heterocampa umbrata, 2: $705^{8}$.

Hyperitis amicaria, $2: 722^{5}$.

Lithocolletes corylisella, 2: $723^{6}$.

Netrocampa praegrandaria, 2: $7+9^{7}$.

Odontota quadrata, $2: 731^{5}$.

Orthofidonia vestaliata, 2: humerosana, Amorbia, $2: 737^{-4}$. jo6 $^{4}$.
Hornbeam, inj. insects (cont' $d)$ : leaf feeders:

Sierica trociformis, 2: $514^{9}$. imerinthus jamaicensis, $2:$ $724^{7}$.

Therina endropiaria, $2: 700^{6}$. II orned oak gall, 2: $618^{3}, 624^{3}$.

11orned passalus, 2: $492^{\text {r. }}$

Horntail, banded, $2: 649^{9}, 668^{7}$. blue, $2: 649^{9}, 669^{1}$.

Ilorse-chestnut, resistance to insect attack, $1: 47^{4}$.

in jurious insects: $1: 49$.

- borers:

flat-headed borer, common, I: $87^{2}$.

leopard moth, i: $78^{5}$.

leal feeders:

Apatela hamamelis, $2: 74^{6}$.

leaf roller, oblique banded, 2: $580^{9}$.

Lithocolletes guttifinitella, 2: $740^{6}$.

Selidosema umbrosarium, 2: $725^{3}$.

tussock moth, white marked, I: $105^{5}, 132^{7}, 136^{8}$

scale or sucking insects:

cicada, dog day, $1: 23 \mathrm{~s}^{3}$.

oyster scale, $1: 212^{6}$.

Huckleberry, injurious insects: borer:

sugar maple timber beetle, 1: $50^{8}, 65^{2}$.

leaf feeders:

Basilarchia astyanax, 2: $704^{2}$.

Datana drexelii, $2: 739^{2}$.

Incisalia irus, $2: .732^{8}$.

Paonias astylus, $2: 738^{8}$.

Sphinx gordius, $2: 727^{1}$.

hudsonii, Pteronus, 2: $5 \mathrm{II}^{6}, 569^{6}$ $70^{2}, 746^{8}$

Hulstea undulatella, 2: $725^{4}$.

humeralis, Elater, $2: 492^{3}$.

Eucrada, 2: $722^{1}$.

Purpuricenus, 2: $702^{2}$.

Triphyllus, $2: 495^{5}$.

var. cyanesceus, Hydnocera, 2: $653^{3}, 693^{2}-94^{2}$.

humida, Rhyssa, $2: 466^{\circ}$. liumuli, Phorodon, I: $248^{8}$.

hyaliua, Pontania, 2: $621^{2}, 638^{6}$.

hyalinus, Callipterus, $2: 709^{3}$.

l'teronus, $2: 748^{9}$.

hydni, Diaperis, 2: $497^{8}-98^{1}$.

Hydnocera humeralis var. cyanes. cens, 2: $653^{3}, 693^{2}-94^{2}$.

longicollis, 2: $723^{8}$.

pallipennis, $2: 653^{2}, 693^{5}$.

subaenea, $2: 606^{4}$.

unifasciata, $2: 721^{1}$.

verticalis, $2: 605^{8}-6^{4}$.

11 dria undulata, $2: 5 \mathrm{IO}^{3}, 55 \mathrm{I}^{4}$.

Hydriomena contracta, $2: 754^{2}$. sordidata, $2: 743^{\star}$.

11 ydrocyanic acid gas, I: $40^{1}$.

hylaeus, Dolba, $2: 739^{6}$.

11 ylastes porculus, $2: 752^{3}$.

tenuis, $2: 752^{3}$.

11 ylesinus aculeatus, $1: 257^{5}, 288^{6}$ $89^{3}$.

opaculus, $1: 257^{5}, 288^{1}$.

Hylobius confusus, $2: 751^{6}$. pales, $2: 649^{7}, 664^{4}$.

IIyloicus kalmiae, see Sphinx.

IIylotoma coerulea, 2: $74^{6}$. macleayi, $2: 510^{1}, 549^{7}-50^{3}$. pectoralis, $2: 511^{7}, 542^{3}, 570^{8}-71^{6}$, $7+4^{6}$.

scapularis, $2: 509^{3}, 542^{1}$.

11 ylotrupes bajulus, $2: 649^{6}, 664^{1}$. ligneus, $2: 650^{8}, 675^{6}-76^{2}$.

IIylurgops glabrat us, $2: 649^{7}, 665^{1-}$ $66^{2}$.

Hymenoptera, 1 : $10^{7}, 21^{8}$; parasitic, $1: 202^{9}$

Hymenorus communis, 2: $701^{9}$. obscurus, 2: $701^{9}$.

Hyparpax aurora, 2: $506^{8}, 520^{3}-21^{1}$.

IIy pat its bachmani, $2: 726^{?}$.

Hyperaeschra georgica, 2: $705^{6}$. stragula, $2: 747^{6}$.

Hyperaspidius $s p, 1: 216^{3}$.

IIyperaspis bigeminata, I: $198^{8}$. hinotata, 2: $605^{4}$. signata, I: $181^{8}, \mathbf{1} 86^{1}, 156^{3}, \mathbf{1} 98^{8}$; 2: $605^{\top}$.

$11 y$ perchiria io, see Automeris.

Ilyperitis amicaria, $2: 722^{5}$.

Hyperplatys aspersus, $2: 74^{6}$. maculatus, $2: 426^{6}, 432^{6}-33^{2}$. 
IJyphantria cunea, sec II. textor. impleta, Apatela, $2: 749^{3}$.

textor, $1: 40,105^{6}, 131^{9}, 1+2^{5}-46^{7}$, impressa, Apatela, $2: 7+3^{1}$. $253^{3}: 2: 607^{4}, 603^{1}$.

hyphantriae, Apanteles, I: $138^{6}$. $1+5^{\circ}$

Meteorus, sec M. hyphantriae.

hypochraria, (ionodontis, $2: 732^{6}$.

Hy pomolyx piuicola, 2: $751^{6}$.

IIypophloeus sp., 2: $374^{9}, 375^{2}$.

cavus, 2: $504^{6}$.

parallelus, 2: $3^{80} 9^{9},+49^{3}$.

thoracicus, $2: 350^{7}$.

Hy pothenemus aveccae, 2: $702^{6}$.

crudiate, $2: 715^{9}$.

dissimilis, $2: 715^{9}$.

erectus, $2: 702^{7}, 7+0^{9}$.

eruditus, $2: 77^{9}$.

Ianassa lignicolor, 2: $705^{8}$.

Ibalia anceps, $2: 714^{8}$.

cultellator, 2: $499^{7}$.

maculipeunis, $2: 499^{6}, 714^{8}$.

icelus, Thanaos, $2: 742^{7}$.

Ichneumon coeruleus, 1: $135^{8}$

subcyaneus, $1: 138^{\circ}, 324^{6}$.

ichneumoneus, Clerus, I: $27^{5} ; 2$ : $502^{2}$.

Ichneumonidae, $1: 2 \mathrm{I}^{9}$.

Ichthyura inclusa, see. MelaJopla.

1cteridae, I: $30^{\circ}$.

Idiocerus suturalis, 2: $597^{9}$.

ignota, Rhodites, 2: $62 r^{7}, 647^{7}$.

ignotus, Andricus, 2: $711^{6}$.

Ilex laevigata, Putram's scale injuring. $1: 227^{5}$.

verticillata, Putnam's scale injuring, $1: 227^{6}$

ilia, Catocala, 2: $705^{4}$.

ilicifoliae, Amphibolips, 2: $618^{8}$, $625^{5}$.

illecta, (atocala, 2: $729^{6}$.

imbellis, Silvanus, $2: 489^{7}$.

imbricator, Pempligus, I: $196^{2}$; 2: $722^{6}$.

imbricatus, Epicaerus, 2: $733^{2}$.

imbricornis, Prionus, 2: $456^{9}$.

impatiens, Eucoila, 2: $714^{9}$.

Figites, 2: $714^{9}$.

Imperial moth, $2: 65 \mathrm{r}^{2}, 677^{6}-79^{2}$.

imperialis, Basilona, 2:65 $\mathrm{I}^{2}, 677^{6}-$ $79^{2}$. inanis, Amphibolips, $2: 618^{7}$,

$625^{4}$.

inatomaria, Metanema, $2: 747$.

incertus, Andricus, 2:711

incipiens, Pseudanthonomus, 2: $739^{4}$

Incisalia irus, $2: 732^{8}$. niplion, 2: $752^{9}$.

incisuralis, Phora, I: $140^{5}$.

inclusa, Melalopha, 2: $5 \mathrm{II}^{2}, 560^{5-}$ $6 \mathrm{I}^{3}$.

inconspicua, Magdalis, 2: $719^{9}$.

Incurvaria acerifoliella, 2: $509^{2}$, $541^{3}, 725^{5}$.

indetermina, Euclea, 2: $528^{8}$, $529^{5}$.

indigenella, Nlineola, $2: 733^{\circ}$.

Indigo hird, I: $166^{6}$.

Indigo bunting, $\mathbf{I}: 3 \mathrm{I}^{2}$.

indistinctus, Andricus, 2: $710^{4}$.

inerme, Elaphidion, 2: $702^{1}$.

inermis, Ceroptres, 2: $7 \mathrm{I}^{7}$.

Stictocephala, 2: $652^{2}, 687^{5}$.

infans, Brephos, 2: $749^{7}$.

infensata var. biclaria, Syssaura, 2: $755^{5}$.

inferentia, Poecilostoma, 2: $750^{4}$. inficita, Marasmalus, $2: 737^{4}$.

infrequens, Isodyctium, 2: $703^{1}$.

infumatalla, Archips, 2: 7 I $7^{2}$.

Injuries caused by insects, I: $6^{1}$ $7^{7}$.

Inkberry, Dolba hylaeus injuring, 2: $739^{6}$.

innotata, Apatela, 2: $716^{5}$.

innubens, Catocala, 2: $729^{5}$.

innumerabilis, Pulvinaria, $\mathbf{~}: 8^{3}$, $12^{6}, 49,173^{2}, 196^{3}, 200^{4}$.

Ino reclusa, 2: $730^{1}$.

inopis, Cecidomyia, 2: $752^{9}$.

inornata, Atymna, 2: $72 \mathrm{I}^{7}$.

Hemerocampa, $\mathbf{1}: \mathbf{1 3} t^{2}$.

Mecas, $2: 741^{6}$.

Sisyrosea, 2: $728^{3}$.

inornatum, Exartema, 2: $707^{5}$.

Inquilines, 2: $7+6^{1}$.

inquisitor, Pimpla, see P. inquisitor.

inscriptum, Deidamia, $2: 7+0^{2}$.
Insects, aduJt, I: $19^{3}$; definitions and classification, I: $b^{b}-10^{5}$; hibernation, I: $19^{4}-20^{5}$; larvae, 1 : $16^{6}-1 S^{6}$; incomplete metamorphosis, I: $15^{6}-16^{4}$; no metamorphosis, I: $15^{5}$; complete metamorphosis, 1: $16^{4}-19^{7}$; parasitic and predaceous, $1: 20^{6}-25^{2}$ : pupa, I: $1 S^{6}-19^{4}$; transformations, $\mathbf{I}$ : $13^{n}-20^{5}$.

insiticiana, Ecclytolopha, $2: 430^{3}$, $47^{8}$ ?

insolabilis, Catocala, 2: $716^{8}$.

insolitus, Pezomachus, I: $140^{3}$.

insularia, Deptalia, $2: 72 \mathrm{I}^{3}$.

integer, Janus, $1: 25^{8}, 302^{3}-3^{7}$.

Pteronus, 2:65 17, $683^{2}, 703^{3}$.

integerrima, l)atana, $1: 25^{3}, 303^{8}-$ $5^{6}$.

interior, Eurymus, 2: 7425.

intermedia, Phylloxera, 2: $718^{6}$.

intermediata, Mesoleuca, 2: $725^{3}$.

interrogationis, Polygonia, 2:509, $5+4^{9}-45^{4}$

interrupta, Apatela, $2: 724^{8}$.

interruptus, Agrilus, $2: 7^{7}$.

inusitat umella, Ornix, 2: $734^{8}$.

lo caterpillar, 2: $506^{9}, 521^{8}-22^{3}$ :

Iphidicles ajax, $2: 735^{4}$.

Iphthinus opacus, $2:+92^{4}$.

ipomoeae, Schizura, 2: $705^{8}, 729^{5}$.

Ips fasciatus, $2: 370^{6}$.

quadriguttatus, $2: 652^{9}, 69 \mathrm{I}^{9}$, $692^{2}$.

sanguinolentus, $1: 293^{\tau} ; 2: 652^{8}$, $691^{8}-92^{2}$.

Ironwood, in jurious insects: borers:

Goes pulverulentus, $2: 455^{3}$. red horned borer, small, I: $299^{1}$.

sugar maple timber beetle, I: $67^{6}$.

leaf feeders: $2: \mathbf{7 2}^{2}$.

Apatelodes torref act a, $2: 549^{4}$.

Heterogenea shurtleffi, 2: $707^{3}$.

luna moth, 2:527.

Natada nasoni, 2: $707^{\circ}$.

walnut sphinx, $2: 506^{6}, 515^{7}$. 
Ironwood, inj. insects $\left(\operatorname{cont}^{\prime} d\right)$ : scale insect:

Eulecanium quercitronis, 2: $709^{4}$.

irregularis, Neuroterus, 2: $711^{9}$.

Priophorus, 2: $7+1^{6}$.

irrorata, Oreta, $2: 749^{5}$.

irroratus, l'hlepsius, $2: 717^{\top}$.

irus, lncisalia, 2: $732^{8}$.

Isochaetes beutenmulleri, 2: $722^{5}$.

Isodyctium caryicolum, 2: $716^{2}$.

infrequens, $2: 703^{3}$.

murtfeldtiae, $2: 7^{03^{2}}$.

subgregarium, 2: $703^{2}$.

isomera, Cladius, $2: 7+1^{6}$.

Ithycerus noveboracensis, $2: 506^{5}$, $517^{-4}-18^{5}$.

lvy, poison, injurious insects, 2: $7+0^{4}$.

leaf feeders, $2: 740^{5}$.

Madarellus undulatus, $2: 430^{4}$, $479^{5}$.

woodbine borer, $2: 430^{3}, 475^{3}$.

j-album, Eugonia, 2: $749^{\circ}$.

jamaicensis, Smerinthus, 2: $724^{7}$. janthinum, Callidium, 2: $450^{4}, 660^{5}$, $75 \mathrm{I}^{4}$.

Janus integer, $1: 25^{9^{2}}, 302^{3}-3^{7}$. jasminearum, Chlaenogramma, 2: $727^{2}$.

Jassus olitorius, 2: $597^{\circ}$.

Jays, I: $30^{6}$.

jocosa, Feralia, 2: $754^{7}$.

Jodia rufago, 2: $704^{9}$.

johnsonaria, Euchlaena, 2: $706^{5}$.

judith, Catocala, 2: $716^{7}$.

juglandana, Lulia, 2: $717^{3}$.

juglandiella, Coptodisca, $2: 720^{3}$.

Gracilaria, 2: $720^{8}$.

juglandifex, Eulecanium, 2: $720^{5}$. juglandifoliella, Nepticula, 2: $720^{4}$.

juglandis, Conotrachelus, $2: 512^{5}$, $581^{6}-82^{4}$.

Corythuca, $2: 749^{9}$.

Cressonia, 2: $506^{7}, 518^{5}-19^{2}, 720^{1}$.

Eriocampa, 2: $720^{5}$.

Eulecanium, 2: 719 ${ }^{8}$.

Nineola, 2: $719^{7}$.
Juglans alba, $2: 454^{9}$.

juglans, Cynips, 2: $710^{5}$.

juglans-regiae, Aspidiotus, 2: $719^{8}$.

Juneberry, sec Shadbush.

Juniper, injurious insects:

borers: $2: 755^{5}$.

apple wood stainer, $1: 2.90^{6}$.

Lepturges facetus, $2: 715^{6}$.

red cedar bark beetle, $2: 33 \mathrm{~S}^{4}$, $39 \mathrm{I}^{5}, 39 \mathbf{I}^{8}$.

leaf feeders, $2: 755^{8}$.

bag or basket worm, I: $127^{1}$.

Cingilia catenaria, $2: 706^{5}$.

lifdriomena contracta, 2: $754^{2}$.

Incisalia niphon, $2: 752^{9}$.

Mitoma danon, $2: 740^{2}$.

Psallus juniperi, 2: $755^{\circ}$.

Tephroclystis miserulata, 2: $706^{2}$.

scale insect:

juniper scale, $\mathrm{I}: \mathrm{I} 73^{8}, \mathbf{2 2 9 ^ { 2 }}$.

Juniper scale, $1: 173^{5}, 229^{1}$.

juniperella, Recurvaria, $2: 755^{\circ}$. juniperi, Psallus, 2: $755^{9}$.

juvenalis, Thanaos, $2: 704^{4}$.

Kaliosysphinga dohrnii, $2: 750^{3}$. ulmi, I: $105^{9}, 162^{4}-63^{7}$.

kalmiae, Sphinx, 2: $509^{8}, 54^{2}$.

kansasense, Eulecanium, 2: $734^{8}$.

kentaria, Eutrapela, 2: $72 \mathrm{~S}^{2}$.

Kermes andrei, 2: $709^{5}$.

kingii, 2: $709^{5}$.

nivalis, $2: 709^{5}$.

perryi, 2: $709^{5}$.

pettiti, $2: 709^{5}$.

pubescens, 2: $709^{5}$.

quercus, 2: $709^{5}$.

Kerosene emulsion, $1: 35^{5}, 3^{5^{8}}$.

Key, to beneficial insects, $2: 652^{8}-$

$53^{8}$; borers, $1: 50^{5}-51^{8}, 256^{4}-57^{9}$; 2: $33^{8}-40^{5}, 426^{4}-31^{2}, 648^{3}-50^{8}$; gall insects, $1: 25^{81}, 259^{1} ; 2: 618^{1}-$ $2 \mathrm{I}^{9}$; leaf feeders, $1: \log ^{3}-6^{2}, 25^{8^{2}}$; 2: $340^{5}, 506^{2}-12^{4}, \quad 650^{9}-51^{8} ;$ nut pests, 2: $512^{5}$; sucking insects, I: $172^{2}-74^{9}, 25^{8^{9}} ; 2: 651^{8}-52^{5}$.

Kingbird, $\mathrm{I}: 237^{3}$.

kingii, Eulecanium, 2: $739^{\text {}}$.

Kermes, 2: $709^{5}$. klagesi, Trichodesma, 2:715 $5^{3}$. linotty rose gall, 2:6218,6.8 2 .

Konowia attenuata, $2: 429^{2}, 466^{5}$.

Kronaea minuta, 2: $707^{3}$.

Lace-winged flies, 1: $154^{1}, 175^{2}$, $19 \mathbf{1}^{3}, 199^{9} ; 2: 653^{7}, 697^{5}$.

Lachnosterna fusca, $2: 753^{5}$.

hirticula, 2: $716^{4}$.

quercus, 2: $703^{5}$.

Lachnus abietis, $2: 75 t^{5}$.

alnifoliae, $2: 750^{8}$.

caryae, $2: 717^{y}$.

dentatus, $2: 7+4^{7}$.

laricifex, $2: 755^{3}$.

longistigua, 2: $731^{9}$.

platanicola, 2: $719^{3}$.

quercifoliae, $2: 709^{\circ}$.

salicellis, $2: 744^{7}$.

smilacis, $2: 7 \div 0^{8}$.

strobi, $2: 753^{7}$.

ulmi, $2: 725^{\circ}$.

Lacosoma chiridota, 2: 706'.

lacry'mosa, Catocala, 2: $705^{4}$.

ladon, Cyaniris, $2: 727^{6}$.

Lady beetles, $1: 23^{7}, 186^{1}, 20 t^{9}$, $2+3^{3}$.

black, I: $222^{5}$.

Chinese, $1: 223^{3}$.

fifteen-spotted, I: $175^{3}, \quad 195^{2}$, I $9^{5^{4}} ; 2: 604^{5}$.

nine-spotted, 2: $652^{7}, 691^{1}$.

spotted, I: $195^{3}$.

three-banded, $2: 652^{8}, 69^{1^{5}}$.

twice stabbed, I: $195^{3}, 19^{8^{5}}$. $208^{7}, 216^{4}, 223^{1}, 231^{3}$.

two-spotted, $1: 174^{\circ}, 195^{\circ}, 206^{9}$; 2: $60 \mathrm{I}^{5}$.

Ladybugs, 1: $320^{\circ}$.

Laemophloeus biguttatus, $2: 490^{\circ}$. testaceus, 2: $490^{3}$.

Laemosaccus plagiatus, 2: $703^{9}$.

Laetilia coccidivora, I: $195^{8}$.

laevicollis, Metachroma, 2: $703^{7}$.

laeviventris, Synergus, $2: 714^{4}$.

Lagoa crispata, 2: $507^{9}, 529^{\uparrow}-30^{3}$.

lamprosana, Pandemis, $2: 728^{4}$.

lana. Andricus, $2: 618^{9}, 625^{8}$.

lanceolaria, Apatela, $2: 7 t 2^{8}$.

Land turtle, 1: $237^{3}$.

lanigera, Cotalpa, 2: $724^{5}$. 
L.apara bombycoides, 2: $651^{2}, 679^{3}$. lateralis, Pteronus, 2: $74^{8}$. coniferarum, 2: $753^{4}$.

Iapathi, cryptorhynchus, I: 49 , $51^{7}, 100^{4}-3^{9} ; 2: 460^{7}$.

lapponica, Melasoma, 2: $511^{3}, 564^{n-}$ $65^{6}$

Larch, injurious insects: aphid: larch aphid, woolly, $1: 172^{7}$,
$187^{9}$.

borers:

llydriomena contracta, 2: $754^{2}$.

Leptura subhamata, $2: 675^{2}$.

pine bark beetle, $2: 351^{6}, 352^{3}$.

Tomicus caelatus, $2: 354^{9}$.

leaf feeders: 2: $755^{1}$.

bag or basket worm, 1: $127^{2}$.

Eufidonia notataria, $2: 753^{2}$.

hickory tussock moth, 1: $314^{9}$.

larch case bearer, $1: 106^{2}, 170^{2}$.

larch lappet, 2: $68 \mathrm{o}^{3}$.

larch sawfly, $2: 34^{8}, 41 S^{3}, 418^{5}$

Lycia cognataria, 2: $728^{1}$.

Melanolophia canadaria, 2 $753^{3}$.

Nepytia semiclusaria, $2: 753^{2}$.

Recurvaria obliquistrigella, 2: $754^{3}$.

Tephroclyst is miserulata, 2: $706^{2}$.

tussock moth, white marked, I: $136^{9}$.

sucking insect: 2: $755^{2}$.

Tetranychus telarius, 2: $755^{3}$.

Larch aphid, woolly, I: $172^{7}, 187^{6}$ $88^{9}$.

Larch case bearer, 1: $106^{2}, 170^{1}-71^{9}$.

larch lappet, 2: 65 $\mathrm{t}^{4}, 68 \mathrm{o}^{2}$.

L,arch sawfly, 1: $10^{9}, 254^{5} ; 2: 340^{9}$, $+18^{3}-23^{6}$.

laricella, Coleophora, 1: $106^{2}, 170^{1}-$ $7 \mathrm{I}^{9}$

lariceti, Chermes, 1: 1859.

laricifex. Lachnus, $2: 755^{3}$.

laricifoliae, Chermaphis, $2: 755^{2}$.

laricis, Chermes, $1: 158^{8}$.

IIemichroa, 2: $755^{2}$.

Tolype, 2: 651 $4580^{2}$.

Laricolius erichsoni, $2: 75 \mathrm{I}^{3}$.

larvaria, Cleora, $2: 7+3^{9}$.
Siaperda, $1: 270^{5}-71^{1} ; 2: 427^{7}, 445^{4}$.

laticinerea, Xylina, see $\mathrm{X}$. laticinerea.

laticlavia, Anomoea, 2: $730^{6}$.

laticollis, Prionus, $2: 430^{9}, 486^{2}-$ $87^{1}$.

latifasciatus, Pteronus, 2: $511^{8}$, $572^{3}, 74^{8^{5}}$.

latifasciella, Nepticula, 2: $721^{5}$.

latiferreanus, Melissopus, 2: $709^{?}$.

latipennis, Diacrisia, 2: $727^{2}$.

Oecanthus, 2: $603^{6}$.

latitarsus, Croesus, 2: $74^{8}$. $^{6}$.

latiusculus, Listronotus, 2: $755^{7}$.

Laurel, Eulecanium pruinosum injuring, 2: $719^{7}$.

Laurel, mountain, see Mountain laurel.

Laurel, sheep, injurious insects: Pseudanthonomus incipiens, 2: $739^{5}$.

lautus, Pityophthorus, 2: $75^{\circ}$.

Laverna gleditschiaeella, Iompha.

1.eaf eaters affecting deciduous forest trees, 2: $506^{1}-8 \mathrm{I}^{5}$.

Leaf miners, $1: 35^{9} ; 2: 705^{3}, 722^{8}$, $723^{3}, 732^{6}, 735^{5}$.

leaf rollers, $2: 707^{4}-8^{2}, 723^{6}$. oblique banded, 2:5124, $53 \mathrm{I}^{7}$, $580^{7}-8 \mathbf{1}^{2}$.

red-banded, 2: $505^{3}, 532^{1}$.

V-marked, 2: $508^{2}, 531^{6}$.

Lebia grandis, $2: 652^{7}, 690^{7}$.

lecanii, Coccophagus, r: 199. $203^{\mathrm{l}}$.

Lecanium nigrofasciatum, sie Eulecanium,

tulipiferae, see Eulecanium.

Le Conte's sawfly, $2: 340^{6},+13^{3}-14^{4}$.

lecontei, Agrilus, $2: 73^{6}$.

II ister, $2: 491^{2}$.

Lophyrus, $2: 340^{6}, 413^{3}-14^{4}$.

Magdalis, $2: 75 \mathrm{I}^{7}$.

Tachygonus, 2: $752^{8}$.

lenticularis, Rhodites, 2: $736^{4}$.

leonardi, Nelanotus, 2: $752^{5}$.

Leopard moth, 1: $S^{2}, S^{6}, 12^{3}, 45^{6}$, $51^{2}, 75^{6}-79^{4}$

Lepidosaphes ulmi, 1: $49, \quad 173^{5}$, $213^{1}-13^{5}$. leporina, Apatela, 2: $747^{2}$.

leptinoides, Schizura, 2: $716^{9}$.

Leptocoris trivittatus, $1: 17 t^{2}$, $239^{1}-40^{9}$.

Leptostylus, prickly, $2: 428^{8}$, $46 \mathrm{I}^{2}$.

spotted, 2: $430^{6}, 452^{7}$.

Leptostylus aculiferus, $2: 425^{8}$, $461^{2}$.

biustus, 2: $715^{6}$.

collaris, $2: 720^{7}$.

commixtus, $2: 751^{5}$.

macula, $2: 430^{6}, 482^{7}$.

parvus, 2: $702^{4}$.

sexguttatus, $2: 75^{5}$.

Leptura abdominalis, $2: 755^{\circ}$. canadensis, $2: 650^{2}, 670^{5}$. cordifera, $2: 720^{8}$.

emarginata, $2: 436^{7}, 724^{4}$.

nitens, 2: $702^{4}$.

proxima, 2: $727^{5}$.

subhamata, $2: 650^{7}, 675^{1}$.

vagans, $2: 427^{3}, 40^{6}-41^{1}$.

zebra, $2: 428^{2}, 450^{5}-5 \mathrm{I}^{3}, 667^{3}$.

lepturges facetus, $2: 715^{6}$.

querci, $2: 427^{2}, 439^{7}-40^{5}$.

signatus, 2: $722^{3}$.

symmetricus, 2: $493^{2}$.

lepusculina, Apatela, $2: 747^{2}$.

Lepyrus geminatus, $2: 742^{3}$.

espedezaefoliella, Gracilaria, 2: $730^{\circ}$.

Lestodiplosis decem-maculata, 2: $746^{3}$.

septem-maculata, $2: 746^{3}$.

Leucania unipuncta, see lleliophila.

leucomelas, Cryptocephalus, 2: $7+66^{9}$.

leucophaea, Olene, 2: $717^{1}$. $z^{\prime} a r$. basiflava. Olene, $2: 749^{4}$.

Leucopis nigricornis, 1 : $152^{2}$.

leucopterus, Blissus, $\quad$ : $6^{3} ; \quad$ 2: $635^{7}$.

leucostigma, 1lemerocampa see 1 I. leucostigma.

libatrix, Scoliopteryx, 2: $743^{2}$.

liberaecellulae, Dryoplianta, 2: $712^{4}$.

liberta, Chalcophora, $2: 645^{7}, 654^{8}-$ $55^{7}$. 
liburna, Scolecocampa, 2: $705^{3}$.

Light-loving grapevine beetle, a: $651^{5}, 6 \$ 2^{6}$.

Lightning leaf hopper, $2: 598^{2}$.

ligneus, Hylotrupes, 2: $650^{\circ}, 675^{6}-$ $76^{9}$.

lignicolor, Ianassa, 2: $705^{8}$. synergus, 2: $714^{5}$.

ligulellus, Ypsolophus, $2: 70^{-8}$.

Lilac, insects injurious to:

borer:

lilac borer, $1: 51^{8}, 104^{1}$.

leaf feeders: $2: 737^{\top}$.

Apatelodes angelica, 2: $\mathbf{7 2 7 ^ { 2 }}$.

ash sphinx, 2: $509^{8}, 548^{2}$.

wavy, $2: 509^{8}, 54^{8}$.

leaf roller, oblique banded, 2: $580^{9}$.

promethea moth, $2: 510^{7}, 557^{6}$.

Pyrophila pyramidoides, 2: $704^{7}$.

sphinx cliersis, $2: 727^{1}$.

Tolype velleda, $2: 727^{9}$.

scale or sucking insects:

Aspidiotus diffinis, $2: 731^{\circ}$.

Euonymus scale, $1: 213^{8}$.

Lilac borer, I: $5 \mathrm{I}^{\mathrm{s}}, \mathrm{IO}_{4}$.

limacina, Eriocampoides, 2: $733^{2}$.

limata, Pantographa, 2: $73 \mathrm{I}^{7}$.

limbata, Ania, $2: 508^{1}, 530^{5}$.

Lime-sulfur wash, $1: 39^{3}$.

Limenitis disippus, see Basilarchia archippus.

liminaris, Phloeotribus, 2: $336^{6}$, $+23^{3}, 452^{1}$.

limitata, Nyctobia, 2: $734^{2}$.

Pandenis, 2: $707^{6}$.

Limneria sp., I: $13 s^{6}$.

ferrugineipes, $I$ : $155^{4}$.

fugitiva, I: $112^{4}, 309^{7}, 314^{3}$.

lophyri, 2: $415^{2}$.

pallipes, $1: 9+5^{8}$.

valida, $1: 133^{6}$.

linueriae, Eupelmus, r: $140^{4}$.

Limnobaris calva, 2: $734^{6}$.

Limonius confusus, $2: 667^{2}$. quercinus, 2: $605^{8}$.

Limosina sp., $\mathrm{I}: \mathbf{4}+0^{6}$. crassimana, $\mathbf{I}: 74^{7}$.

limosipennella, Coleophora, I: $106^{1}, 167^{1}-68^{4}$.
Lina lapponica, see Melasoma. scripta, sez Melasoma.

Linden, resistance to insect at. tack, $I: 47^{4}$.

injurious insects: 1.49 . borers, 2: $731^{2}$.

Euderces picipes, $2: 44^{6}$. flat-headed borer, common, I: $87^{2}$.

linden borer, $1: 5 \mathrm{I}^{3}, 9 \mathrm{r}^{1}$.

Parandra brunnea, 2: $7 \mathrm{OI}^{8}$.

prionus, broad-necked, 2: $4^{56^{\top}}$.

gall insects: $2: 73 I^{9}$.

linden mite gall, 2:6202, $631^{6}$.

linden wart gall, $2: 620^{2}$, $631^{4}$.

leaf feerlers: 2: $731^{4}$.

Adoneta spinuloides, 2:706 9 .

alder leaf beetle, $2: 509^{3}$, $542^{4}$.

American dagger moth, $z$ : $525^{3}$.

American silk worm, 2: $526^{6}$.

Apatela hastulifera, $2: 750^{6}$. impleta, 2: $749^{3}$. morula, 2: $724^{9}$.

apple worm, yellow-necked, 2: $535^{7}$.

bag or basket worm, I: $\mathbf{1 2 7 ^ { 2 }}$.

Basilarchia arthemis, $2: 7.42^{6}$.

Cecropia moth, $2: 539^{4}$.

Chrysomela muitiguttata, 2: $7+2^{1}$.

Cyrtophorus verrucosus, 2: $722^{2}$.

Datana drexelii, 2: $739^{2}$.

elm saw fly, I: $1_{5} \mathrm{~s}^{1}$.

Ennomos magnarius, 2: $725^{4}$. subsignarius, $2: 725^{4}$.

Euclea chloris, 2: 706 \%

Eutrapela kentaria, $2: \mathbf{7 2}^{2}$.

forest tent caterpillar, I: $1 \mathrm{IO}^{8}$.

Heterocampa manteo, 2: $705^{\circ}$.

hickory tussock moth, I:

\begin{tabular}{c|c}
$314^{9}$. & Eulecanium, $2: 732^{7}$ \\
Lithacodes fasciola, $2: 72^{4}$. & Liodes basalis, $2: 74^{5}$.
\end{tabular}
I.inden, inj. insects (cont $d$ ): leaf feeders:

Metrocampa praegrandaria, 2: $7+9^{9}$.

Odontota nerrosa, 2: $703^{\text {? }}$.

Olene plagiata, 2: $725^{2}$.

Paonias excaecatus, $2: 724^{7}$.

Papilio glaucus var. turnus, 2: $704^{\prime}$.

Paraphia subatomaria, 2: $753^{3}$.

Prolimacodes scapla, 2: $707^{1}$.

Pyrophila pyramidoides, 2: $704^{7}$.

Schizura ipomoeae, 2: $705^{9}$.

Sisyrosea textula, 2: $72 \mathrm{I}^{4}$.

sphinx, four-lined, 2: $509^{6}$, $5+6^{6}$.

Strongylogaster piuguis, 2: $7+5^{7}$.

Tortricidia testacea, 2: $707^{4}$.

tussock moth, white marked, $1: 105^{5}, 132^{7}, 136^{8}$.

scale or sucking insects: 2: $731^{8}$.

black-banded scale, I: 20 I $^{2}$. Eulecanium capreae, 2: $744^{9}$.

oyster scale, $\mathbf{I}: \mathbf{2} \mathbf{I} \mathbf{2}^{6}$.

Putnam's scale, $1: 227^{4}$.

Linden, European, resistance to insect attack, I: $47^{3}$; injurious insects, $1: 49$.

Linden borer, $1: 5 \mathbf{I}^{5}, 91^{1}-92^{2}$.

Linden mite gall, $2: 620^{2}, 631^{6}-32^{1}$.

Linden wart gall, $2: 620^{2}, 631^{3}$.

Lindera odorifera, Chionaspis liutneri injuring, $1: 227^{9}$.

lineata, Buprestis, $2: 751^{2}$.

Deilephila, 2: $724^{6}$.

lineatum, Ptinidium, 2: $729^{4}$.

Rhagium, 2: $335^{3}, 339^{5}, 349^{5}$, $366^{5}-68^{5}, 665^{3}$.

lineella, Tomoxia, sec T. lineella.

lineicollis, Centrinus, $2: 719^{5}$.

lineola, Colydium, $1: 292^{3}, 293^{6}$.

lintneri, Chionaspis, $1: 173^{9}, 227^{\circ}-$ $23^{2}$

Eulecanium, 2: $732^{7}$.

Liodes basalis, $2: 74^{5}$. 
Liodes globosa, $2: 748^{3}$.

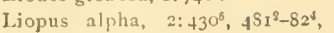
$432^{h}$.

sar. cinereus, $2: 715^{\circ}$.

cinereus, $2: 451^{7}$.

crassulus, 2: $715^{6}$.

fascicularis, $2: 729^{3}, 730^{1}$.

punctatus, $2:+26^{5}, 432^{2}$.

variegatus, $2: 720^{7}, 730^{1}$.

liparops, Thecla, 2: $704^{3}$.

Liquidambar, leaf feeders injuring, $2: 72 t^{2}$.

liquidambarisella, Phyllocnistis, 2: $735^{6}$.

liriodendiri, Cecidomyia, $2: 732^{2}$. Nectarophora, 2: $732^{4}$.

liriodendronella, Phyllocnistis, 2: $732^{3}$.

Listronotus latiusculus, $2: 755^{7}$.

I.itargus tetraspilotus, $2: 74^{1^{9}}$.

Literature relating to forest entomology, $1: 12^{7}-13^{8}$.

Lithacodes fasciola, 2: $728^{4}$.

Lithocolictes aceriella, 2: $728^{4}$. aeriferella, 2: $70 \$^{4}$. albanotella, 2: $705^{4}$. argentifimbriella, $2: 708^{\circ}$. argentinotella, $2: 725^{5}$. auronitens, $2: 75^{8}$. basistrigella, 2: $705^{6}$. betliuniella, $2: 708^{5}$. bifasciella, 2: $708^{6}$. blancardella, 2: $705^{5}$. caryaefoliella, $2: 717^{4}$. castaneaeclla, $2: 721^{6}$. celtifoliella, 2: $717^{6}$. cincisnatiella, 2:7086. clemensella, $2: 728^{5}$. corylisella, $2: 723^{5}$. fasciella, 2: $708^{6}$. fitchella, $2: 505^{4}, 533^{2}$. guttifuitella, 2: $7+0^{6}$. hageni, $2: 708^{6}$. hamadryella, $2: 508^{4}, 532^{8}-33^{1}$. lucetiella, $2: 731^{\circ}$. lucidicostella, $2: 725^{5}$. morrisella, $2: 730^{\circ}$. obscuricostella, $2: 723^{\text {' }}$. obstrictella, 2: 708?. ostensackenella, 2: $730^{9}$. ostryaefoliella, $2: 722^{9}$.
Lithocolletes populiella, $2: 7+7^{-9}$. quercialbella, 2: 7os?. robiniella, $2: 730^{9}$. salicifoliella, $2: 7+4^{5}$. tiliacella, $2: 73 \mathrm{I}^{7}$. tritaeniella, $2: 722^{9}$. tubiferella, $2: 705^{7}$. uhlerella, $2: 730^{9}$. ulmella, 2: $725^{6}$.

lithospila, Apatela, 2:721 . liturata, Phloeotrya, 2: $493^{9}-94^{1}$. livens, J'achybrachys, $2: 7+2^{1}$.

Livia vernalis, $2: 753^{6}$.

lividus, Eunotus, see E. lividus.

lixaria, Racheospila, 2: $738^{6}$.

Lobed oak gall, 2:618 $8^{6}, 625^{1}$.

lobeliae, Apatela, 2: $704^{6}$.

Lochites sp., 2: $390^{1}$.

Locust, injurious insects: $1: 49$. borers, 2: $729^{9}-30^{1}$.

Agrilus egenus, $2: 715^{2}$. politus, $2: 7+1^{4}$. apple wood stainer, $1: 290^{6}$. carpenter worm, I: $5 \mathbf{I}^{3}, 79^{5}$, $83^{3}$.

Cucujus clavipes, $2: 701^{4}$.

Cyrtinus pygmaeus, $2: 702^{3}$.

Ecyrus dasycerus, 2: $715^{6}$.

Leptostylus commixtus, $75 \mathrm{I}^{\mathrm{5}}$.

Liopus alpha, $2: 4^{82^{3}}$. var. cinereus, $2: 715^{6}$. variegatus, $2: 720^{8}$.

locust borer, 1: $51^{5}, 93^{1}$. locust twig borer, $2: 430^{2}$, $47^{8}$.

maple and oak twig pruner, r: $6 I^{3}$.

Neoclytus erytlirocephalus, I: $72^{8}, 72^{6}$.

powder post beetle, I: $297^{2}$.

leaf feeders: $2: 730^{\circ}$.

Adoneta spinuloides, 2: $706^{9}$. apple worm, yellow-necked, 2: $535^{8}$.

bag or basket worm, I: $127^{2}$.

Bassareus mammifer, $2: 719^{8}$.

black walnut caterpillar, I: $305^{4}$.

Catocala vidua, 2: $705^{5}$.

Ecpantheria deflorata, $2: 7+2^{8}$.
Locust, injurious insects (cont' $d$ ): leaf feeders:

flea beetle, red-footed, $2: 510^{6}$, $55^{3}$.

forest tent caterpillar, I: IIO 8 . IIeterogenea shurtleffii, 2: $707^{3}$.

io caterpillar, $2: 522^{3}$.

locust leaf folder, 2: $510^{6}$, $556^{8}$.

locust leaf miner, I: $25^{8}, 325^{9}$.

Plocamus hispidulus, 2: $721^{2}$.

Pyrrhia umbra var. exprimens, 2: $737^{3}$.

Schizura unicornis, 2: $705^{9}$.

scale or sucking insects:

Aspidiotus jugians-regiae, 2: $719^{8}$.

tree hopper, two-marked, 2: $595^{6}$.

Locust, black, resistance to insect attack, $1: 47^{6}$.

injurious insects:

borers: $2: 729^{9}-30^{1}$.

leaf feeders: $2: 730^{2}$.

Nicracis suturalis, $2: 715^{\circ}$.

Locust, water, Putnam's scale injuring, $1: 227^{4}$.

Locust, yellow, Ilyperplatys mac. ulatus injuring, $2: 433^{1}$.

Locust borer, , I: $51^{6}, 93^{1}-97^{9}$.

Locust leaf folder, $2: 510^{6}, 556^{7}-$ $57^{4}$.

Locust leaf miner, I: $25^{8}, 325^{1}-$ $29^{2}$.

Locust twig borer, $2: 430^{3}, 47^{1}$.

logiana, Alceris, $2: 733^{6}$.

logiana var. viburnana, Alceris, 2: $744^{2}$.

lombardae, Pteronus, $2: 746^{9}$.

London purple, I: $34^{9}-35^{1}, 37^{9}$.

Long sting, lunate, $1: 63^{2}, 261^{5}$.

longiceps, Baptolinus, 2: $389^{6}$.

longicollis, Jydnocera, $2: 723^{6}$.

longicornis, Dryophanta, 2:7II'.

longipes, Melanophila, 2: $753^{8}$.

Rliopalophora, 2: $731^{2}$.

longistigma, Lachnus, 2: $73 \mathbf{1}^{9}$.

longulus, Copturodes, $2: 702^{8}, 751^{7}$. lophanthae, Scymnus, i: $223^{3}$.

Lophoderus triferana, see Eulia. 
Lophodonta angulosa, 2: $705^{7}$. ferruginea, $2: 7+9^{2}$.

lophyri, Limneria, 2: $415^{\circ}$.

Lophyrus abbotii, $2: 340^{7}, 4^{1} 4^{4}-15^{5}$. abietis, $2: 340^{\circ}, 415^{5}-16^{4}$. fabricii, 2 : $752^{6}$.

lecontei, $2: 340^{6}, 413^{3}-14^{4}$. pinetum, $2: 752^{\%}$.

pini-rigidae, $2: 752^{7}$.

lorata, Sabulodes, 2: $754^{7}$.

loxaulis, Biorhiza, 2: $710^{5}$.

Loxostege obliteralis, $2: 609^{3}$.

Lucánus dama, 2: $701^{8}$.

lucetiella, Litlocolletes, 2: $73 \mathrm{I}^{7}$.

lucicola, Anomala, $2: 651^{5}, 632^{6}$.

lucidicostella, Lithocolletes, 2 $728^{5}$.

lucifluella, Coptodisca, $2: 717^{3}$.

lucipara, Euplexia, 2: $749^{4}$.

lugubris, Triptogon, $2: 740^{1}$.

Xyletinus, 2: $731^{3}$.

lumenaria, Cosymbia, 2: $749^{4}$.

luna, Tropaea, $2: 507^{7}, 526^{7}-27^{3}$.

Luna moth, 2: $507^{7}, 526^{7}-27^{3}$.

lunata, Calligraphus, $2: 575^{\circ}$.

Homoptera, 2: $508^{9}, 53^{4}-39^{2}$. var. edusa, Homoptera, 2: $743^{5}$.

Lunate long sting, $1: 63^{9}, 261^{5}$.

lunator. Thalessa, $1: 63^{2}, 64,261^{5}$. lunatus, Cratoparis, $2: 49^{8^{3}}, 499^{1}$.

lunifera, Pheocyma, $2: 753^{1}$.

Luperodes meraca, $2: 723^{9}$.

luriả, Dicerca, 2: $504^{3}$.

luscitiosa, Sphinx, 2: $74^{8}$.

Iuscus, Neoclytus, 2: $715^{4}$.

luteata, Tephroclystis, $2: 754^{9}$.

luteipenuis, Ernobius, 2: $694^{5}$, $752^{5}$.

luteola, Galerucella, see G. Iuteola. luteotergum, Amauronematus, 2: $511^{6}, 572^{7}-73^{4}, 750^{4}$.

lutescens, Aulacomerus, 2: $568^{8}$.

Lycia cognataria, 2: $728^{1}$. ursaria, $2: 747^{7}$.

lycti, Hecabolus, I: $297^{i}$.

Lyctus parallelopipedus, $2: 430^{7}$, $483^{2}, 501^{9}$.

unipunctatus, $1: 257^{8}, 296^{4}-99^{3}$, $4^{8} 3^{3}, 483^{5}$.

Lyda $s p ., 2: 650^{9}, 676^{3}$. fasciata, $2: 733^{2}$.
Lygaeonematus erichsonii, I: $254^{5} ; 2: 340^{4}, 410^{3}-23^{5}$.

Lygus monachus, 2: $725^{5}$.

lymani, Eulecanium, 2: $709^{4}$.

Lymexylon sericeum, $2:\left\{27^{9}, 449^{5}\right.$.

Lysitermus scolyticida, $1: 273^{4}$.

Macaria praeatomata, $2: 73^{\circ}$. var. bisignata, 2 : $753^{2}$.

Machimia tentoriferella, 2: $708^{2}$.

macleayi, llylotoma, 2: $510^{1}, 5+9^{7}-$ $50^{3}$.

unaclurae, Pulvinaria, 2: $737^{5}$.

maclurarum, Eulecanium, $2: 726^{7}$.

macnurtrei, Prionoxystus, $2: 42 \tau^{2}$, $439^{1}, 477^{4}$.

Macratria murina, $2: 7+2^{3}$.

Macrobasis unicolor, $2: 730^{5}$.

macrocarpae, Philonix, 2: $713^{5}$.

Macrocentrus delicatus, $2: 531^{5}$. solidaginis, $2: 531^{5}, 553^{2}$.

Macrodactylus subspinosus, 2: $512^{2}, 575^{6}$.

Macrophya bilizeata, $2: 735^{3}$. externa, $2: 716^{3}$.

mixta, $2: 73 \mathrm{~S}^{3}$.

trisyllaba, 2: $737^{\circ}$.

macrurus, Eremotyius, 2: $549^{6}$.

macula, Leptostylus, $2: 430^{6}, 482^{7}$.

maculata, Halisidota, $2: 507^{2}, 523^{3}$. Megilla, I: $195^{3}, 320^{7}$.

maculatus, Hyperplatys, see H. maculatus.

maculipennis, Ibalia, see I. maculipenuis.

maculiventris, Buprestis, see $B$. maculiventris.

Podisus, 2: $608^{5}-9^{8}$.

Madarellus undulatus, $2: 430^{4}$, $479^{5}$.

Madarus undulatus, see Madarellus.

madefactalis, Bomolocha, 2: $720^{\circ}$.

Magdalis alutacea, $2: 340^{2},-102^{7}-3^{2}$. armicollis, $1: 49,51^{2}, 70^{8}, 72^{9}$, $74^{5}, 75^{3}$.

barbita, I: $49,51^{1}, 70^{7}, 72^{9}, 73^{2}-$ $75^{2}$.

hispoides, 2: $75 \mathrm{I}^{7}$.

inconspicua, 2: $719^{\circ}$.

lecontei, 2: $751^{?}$.
Magdalis olyra, I: $256^{9}, 274^{5}-75^{3} ; 2$ : $503^{4}$ perforata, $2: 340^{2}, 402^{3}$.

salicis, $2: 720^{*}$.

magdalis, Brachistes, I: $74^{6}$.

magnarius, Ennomos, 2: $725^{3}$.

Magnolia, injurious insects:

Platypus compositus, $2: 720^{9}$.

Ayleborus pubescens, 2: $7^{\mathrm{O} 2}$, $720^{9}$.

Xyloterus politus, I: $292^{5}$.

maia, Ilemileuca, 1: $25^{5}, 310^{4}-14^{7}$.

Maia moth, I: $25^{5}, 310^{3}-14^{7}$.

majalis, Neuroterus, 2: $710^{9}$.

major, Latana, 2: $739^{3}$.

majulis, Cecidomyia, 2: $710^{2}$.

malachitana, Olethreutes, $2: 735^{3}$.

Milacosoma americana, I: $24^{5}, 28^{2}$; 2: $510^{2}, 550^{7}-51^{3}, 606^{7}, 607^{5}$.

disstria, $1: 21^{3}, 23^{3}, 25^{6}, 28^{2}, 48^{8}$, $49, \quad 52^{1}, \quad 105^{3}, \quad 106^{3}-15^{9}, \quad 253^{3}$; 2: $550^{9}$.

malanogrammos, Benta, 2: $65 \mathrm{I}^{1}$, $676^{7}-77^{5}$.

mali, Aphis, $2: 6 \uparrow^{1}$.

Nonarthrum, I: $257^{6}, 289^{4}-92^{5}$; 2: $336^{5}$.

malifoliella, Tischeria, $2: 734^{9}$.

malus, Tyroglyphus, $1: 213^{1}$.

Nlamestra atlantica, 2: $704^{8}$.

detracta, 2: $716^{6}$.

picta, 2: $608^{8}$.

mammifer, Bassareus, 2: $716^{4}, 719^{6}$.

manteo, Heterocampa, 2: $705^{7}$.

mantis, Europenn, 1: $25^{1}$.

southern praying, $1: 24^{9}$.

Mantis carolina, see Stagmoman. tis.

religiosa, 1: $25^{1}, 154^{3}$.

Manufactured wood, borers in, 2: $430^{6}-31^{2}, 483^{1}-99^{4}$.

Maple, scarlet winged clerid beneficial to, 2: 503'.

injurious insects:

borers: $2: 727^{4}$.

ants, white, I: $89^{2}$.

apple wood stainer, I: $290^{5}$. Bellamira scalaris, $2: \downarrow^{2} 9^{3}$, $467^{6}$.

buprestid, banded, $2: 4^{28^{\circ}}$, $458^{9}$. 
Maple, inj. insects (ront' $d$ ): borers:

buprestid, divaricated, 2: $428^{6}, 457^{6}$.

carpenter wornı, $1: 51^{*}, 79^{5}$, $83^{3}$.

Cerylon castaucum, $2: 489^{7}$.

Chalcopliora campestris, 2 : $722^{2}$.

Colastus truncatus, $2: 491^{8}$.

Cratoparis lunatus, $2: 499^{2}$.

Cryptarcha concinna, 2: $471^{9}$.

Cryptorhynchus obtentus, 2: $720^{8}$.

Cucujus clavipes, $2: 701^{4}$.

Dendroides canadensis, 2: $494^{3}$.

concolor, 2: $494^{3}$.

Dicerca pugionata, 2: $750^{2}$.

Dryobius sexfasciatus, 2 : $702^{1}$.

Elater bumeralis, $2: 492^{5}$. nigricollis, $2: 492^{5}$.

fungous bectle, forked, 2 : $498^{5}$.

Gonotropis gibbosus, 2: $494^{4}$.

Hister lecontei, $2: 49 \mathbf{I}^{2}$.

lloplocephala bicornis, 2: $49 \mathrm{~s}^{2}$.

Hyperplatys maculatus, 2 : $+33^{1}$.

Laemopbloeus biguttatus, 2: $490^{2}$.

testaceus, 2: $400^{3}$.

leopard moth, $1:-8^{5}$.

Leptostylus, prickly, 2: $428^{\circ}$, $46 \mathrm{I}^{2}$.

Liopus variegat 1 , $2: 720^{7}$.

maple sesian, $1: 50^{6}, 56^{7}$, $58^{3}$.

maple twig pruner, I: $50^{\circ}$, $59^{2}$.

Melandrya striata, 2: $493^{8}$.

Molorclus bimaculatus, 2 : $715^{4}$.

Mordella loreatis, 2: $650^{4}$, $672^{2}$.

Phloeotrya liturata, 2: $493^{9}$. simulator, 2: $474^{1}$
Maple, inj. insects (cont' $d)$ : borers:

pigeon trentex, $\mathbf{I}: 50^{7}, 6 \mathbf{I}^{5}$.

Proteoteras aesculanum, 2: $725^{8}$.

Purpuricenus humeralis, 2: $702^{4}$.

red borned burer, $1: 257^{9}$. small, r: $29^{8^{5}}, 299^{1}$.

Sesia corni, $2: 428^{6}, 456^{7}$.

Silvanus imbellis, $2: 489^{7}$.

stalk borer, $2: 429^{4}, 468^{2}$.

Stenocelis brevis, $2: 494^{6}$.

Synchroa punctata, $2: 666^{9}$.

Uliota dubius, $2: 490^{6}$.

Urographis fasciatus, 2: $435^{9}$.

leaf feeders: $2: 727^{5}-28^{6}$.

American dagger moth, a: $525^{3}$.

American silli worm, 2: $526^{6}$.

Apatela impleta, $2: 749^{3}$.

bag or basket worm, $1: 127^{2}$.

brown tail moth, I: $164^{1}$, $254^{3}$.

Cecropia moth, $2: 539^{4}$.

Cenopis reticulatana, 2: $707^{5}$.

Chrysomela bigsbyana, z: $566^{5}$.

Cleora pampinaria, $2: 743^{9}$.

Demas propinquilinea, 2 : $749^{5}$.

Lictropis crepuscularia, 2 : $7+3^{3}$.

elm saw fly, 1: $15^{1}$.

linnomos magnarius, 2: $725^{4}$.

subsignarius, $2: 725^{4}$.

Eulia velutinana, $2: 707^{6}$.

filament bearer, $2: 508^{1}$, $530^{4}$.

forest tent caterpillar, I: $105^{8}, \operatorname{IO6}^{3}, 110^{8}, 253^{8}$.

gipsy moth, I: $120^{4}$.

Gracilaria alcbimiella, z: $724^{2}$.

lleterocampa subrotata, 2: $716^{9}$.

io caterpillar, $2: 522^{3}$.
Maple, inj. insects $\left(\right.$ cont' $\left.^{\prime} d^{\prime}\right)$ :

leaf feeders.

maple leaf cutter, 2:509 $54 r^{3}$.

maple leaf stalk borer, 2 : $509^{2}, 540^{\circ}$.

maple spanworn, large, 2: $509^{1}, 539^{6}$.

maple trumpet skeletonizer, I: $106^{2}, 168^{5}$.

maple worm, green-striped, 2: $505^{5}, 537^{7}$.

semilooper, 2: $508^{*}, 53^{8^{5}}$.

oak caterpillar, green, 2 : $521^{7}$.

red-humped, $2: 519^{5}+520^{2}$.

Opheroptera boreata, $\mathbf{2 :}$ $725^{2}$.

Priocycla armataria, $2: 749^{\hbar}$.

Prolimacodes scaplia, 2: $707^{1}$.

promethea motl, $2: 557^{8}$,

Pyrophila pyramidoides, 2: $704^{7}$.

Schizura ipomoeae, $2: 705^{8}$. semirufescens, $2: 743^{6}$.

Sisyrosea textula, $2: 721^{4}$.

Stenopsis argenteomaculatus, $2: 721^{2}$.

Tortricidia pallida, $2: 707^{4}$.

tussock moth, white marked, I: $105^{5}, 132^{7}$.

scale or sucking insects:

Aspidiotus juglans-regiae, 2: $719^{8}$.

black-banded scale, $1: 173^{8}$, $201^{2}$.

Buffalo tree hopper, 2: $592^{4}$. cicada, dog day, $\mathbf{~}: 238^{3}$.

Eulecanium canadense, 2: $725^{6}$.

hemlock scale, $2: 652^{6}, 690^{2}$.

Putnam's scale, $1: 227^{4}$.

Maple, ash-leaved, Xyloterus politus.injuring, $1: 292^{8}$.

Maple, hard, maple borer, whitehorned, injuring, $2: 128^{7}, 459^{4}$.

Maple, Norway, resistance to insect attack, I: $47^{5} ;$ lady beetle, fifteen-spotted, beneficial to, 2: $604^{9}$. 
Maple, Norway (cont'd):

injurious insects:

black-banded scale, I: $20 \mathbf{1}^{1}$.

Chaitophorus aceris, I: 49 , $172^{3}, 174^{2}$.

maple scale, cottony, I: $198^{2}$.

tussock moth, white marked, I: $136^{8}$.

Maple, red, resistance to insect attack, I: $47^{3}$.

injurious insects:

black-banded scale, 1: $20 \mathbf{1}^{2}$. imperial moth, 2: $679^{1}$.

maple leaf gall, ocellate, 2: $619^{9}, 629^{7}$.

Nyloterus politus, I: $292^{x}$.

Maple, soft, resistance to insect attack, $\mathbf{1}: 47^{1}$.

injurious insects: $1: 49$. aphid:

maple aphid, painted, I: $172^{4}, 175^{7}$.

borers:

Acamptus rigidus, 2: $727^{5}$.

flat-headed borer, common, I: $87^{2}$.

maple sesian, $1: 50^{6}, 58^{3}$.

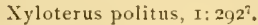

gall insects:

maple gall, bladder, $2: 620^{1}$, $630^{6}$.

leaf feeders:

forest tent caterpillar, I: $4^{8^{2}}$.

leaf roller, red-banded, 2 : $532^{2}$.

v-marked, 2: $531^{8}$.

maple worm, green-striped, 2: $537^{8}$.

tussock moth, white marked, I: $136^{8}$.

Xylina antennata, $\mathbf{I}: \operatorname{IO}^{5}$, $129^{2}$.

scale or sucking insects:

black-banded scale, I: $173^{3}$, $200^{6}$.

maple scale, cottony, $1: 8^{8}$, $173^{2}, 196^{4}$.

woolly maple leaf aphid, 2 : $600^{6}$.
Maple, sugar, resistance to insect attack, $1: 47^{6}$.

injurious insects: $1: 49$.

borers:

maple borer, sugar, I: $50^{5}$, $51^{\text {n. }}$

white-horned, $2: 459^{5}$.

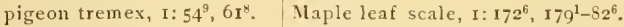

Platypus compositus, 2: Maple leaf stalk borer, 2: $509^{2}$, $720^{9}$.

rustic borer, $\mathbf{I}: 260^{9}$.

sugar maple timber beetle, I: $50^{6}, 65^{2}$.

Xylocleptes sp., $2: 428^{7}$, $460^{4}$.

Xyloterus politus, $\quad \mathrm{I}: 292^{8}$, $293^{7}$.

gall insects:

maple gall, fusiform, 2: $619^{9}, 630^{3}$.

leaf feeders:

apple tent caterpillar, 2: $55 \mathrm{I}^{1}$.

forest tent caterpillar, I: $48^{2}, 5^{2^{1}}, 1$ I $\mathrm{O}^{2}$.

hag moth caterpillar, 2: $528^{6}$.

maple trumpet skeletonizer, $r: 168^{6}$.

maple worm, green-striped, 2: $537^{9}$.

scale insects:

black-banded scale, I: $200^{5}$.

maple leaf scale, I: $172^{6}$, $179^{2}$.

maple Phenacoccus, I: $172^{6}$, I $82^{7}$.

maple scale, cottony, I: $\mathrm{Ig}^{2}$.

oyster scale, $1: 212^{6}$.

Maple, swamp, oyster scale injuring, $1: 212^{6}$.

Maple, sycamore, resistance to insect attack, I: $47^{5}$.

Mlaple and oak twig pruner, I: $50^{7}$, $59^{1}-6 \mathbf{r}^{5}$.

Maple aphid, painted, $1: 172^{4}$, $175^{6}-76^{5}$.

Naple borer, sugar, $50^{5}, 51^{8}-56^{7}$. white-horned, $\quad 2: 428^{7}, \quad 459^{8}-$ $60^{1}$.
Maple gall, bladder, 2:6201, 630 $31^{3}$.

fusiform, 2: $619^{9}, 630^{2}$.

1laple leaf aphid, woolly, 2:6005.

Maple leaf cutter, 2: $509^{2}, 541^{3}$.

Maple leaf gall, ocellate, $2: 6 \mathbf{I}^{9}$, $629^{6}-30^{1}$ $540^{1}-41^{2}$.

Vlaple Phenacoccus, I: $I 72^{6}, I 82^{7}-$ $86^{6}$

Waple scale, cottony, $1: 8^{3}, 12^{6}$, $173^{2}, 196^{3}-200^{4}$.

Naple sesian, $\mathrm{I}: 50^{6}, 56^{7}-58^{9}$.

dlaple spanworm, large, 2: $509^{1}$, $539^{5}$.

Maple trumpet sheletonizer, I $106^{2}, 168^{4}-69^{9}$.

Maple worm, $1: 52^{1}, 106^{3}-15^{9}$. green-striped, 2: $508^{8}, 537^{6}-38^{3}$. semilooper, 2: $505^{9}, 53^{8^{4}-39^{1}}$.

Marasmalus inficita, $2: 737^{4}$. ventilator, $2: 737^{4}$.

Marbled sawyer, $2: 339^{4}, 366^{\circ}$.

margaritusa var. saucia, Peridroma, 2: 704.

Marginal foll gall, 2: $619^{4}, 627^{8}$.

marginalis, Netachroma, 2:65 $\mathrm{I}^{6}$, $682^{8}-83^{2}$.

Systena, 2: $506^{4}, 515^{1}$.

marginatus, Chauliognathus, I: $153^{\mathrm{b}}$.

marlattii, Pteronus, $2: 750^{5}$.

Marmara salictella, 2: $744^{5}$.

marmoratus, Nonohammus, 2 :

marthesia, Fentonia, 2: 706 1 .

Martins, $1: 26^{7}$.

Marumba molesta, 2: $742^{8}$

Maryland yellowthroat, $1: 26^{4}, 27^{4}$.

Mastogenius subcyaneus, $2: 701^{8}$.

materiarius, Fnathotrichus, see G. materiarius.

maximella, Nepticula, 2; $719^{3}$.

May apple, 2:625.

Mealy rose gall, 2:621 ${ }^{7}, 647^{7}$.

Ilecas inornata, $2: 74 \mathrm{I}^{5}$.

media, Periclista, 2: $702^{9}$.

Megachile optiva, $2: 728^{6}$. $339^{4}, 36 \mathbf{r}^{6}, 366^{1}$. Massospora cicadina, I: $237^{4}$. 
Megalupyge percularis, $2: 726^{2}$. Megilla maculata, $1: 195^{3}, 320^{7}$.

Melalopha albosigma, $2: 7+7^{4}$. apicalis, $2: 7+7^{\circ}$

hrucei, $2: 7+3^{\text {s. }}$.

inclusa, $2: 5 \mathbf{I}^{2}, 560^{5}-6 \mathrm{I}^{3}$.

strigosa, $2: 747^{5}$.

Melandrya striata, $2: \$ 93^{\circ}$.

Melanerpes erythrocephalus, I: $29^{1}$.

Nelanobracon simplex, I: $70^{7}$, $261^{6}$.

melanocera, Amphibolips, 2: $711^{5}$.

Melanolophia canadaria, 2: $753^{3}$.

Melanophila aeneola, 2: $751^{3}$.

drummondi, 2: $753^{*}$.

fulvoguttata, $2: 339^{6}, 390^{5}-91^{4}$.

longipes, $2: 753^{8}$.

Nelanotus communis, $2: 492^{6}$. cribulosus, 2: $752^{4}$.

leonardi, 2: $752^{5}$.

Melasis pectinicornis, 2: $701^{5}$.

Ilelasoma laрроліса, 2: $511^{3}, 564^{5}-$ $65^{6}$.

scripta, 1: $258^{7}, 317^{8}-22^{2} ; 2: 564^{9}$, $565^{7}$.

tremulae, $2: 565^{7}$.

Melinna modesta, $2: 753^{6}$. pumila, 2: $735^{1}$.

melinus, Uranotes, $2: 734^{7}$.

Melissopus latiferreanus, 2: $709^{\text {? }}$.

mella, Tachina, I: $113^{3}, 133^{4}$, $139^{\circ}$.

melleus, Nesochorus, I: $15^{8^{4}}$.

mellipes, Eucoila, 2: $714^{9}$.

Melons, Euschistus variolarius injuring, 2:611 ${ }^{9}$.

melsheimeri, Cicinnus, $2: 706^{\text {}}$.

Memythrus asilipennis, $2: 429^{1}$, $464^{1}$.

dollii, 2: $7+6^{7}$.

simnlans, $2: 427^{1}, 43^{8^{3}}$.

tricinctus, $2: 429^{7}, 471^{1}$.

mendax, synergus, $2: 714^{5}$.

mendicus, Pteronus, 2:5 $\mathrm{II}^{2}, 56 \mathrm{I}^{4}-$ $62^{3}, 741^{7}$.

Menesta tortriciformella, $2: 723^{\text {? }}$. mera, Carynota, 2: $720^{6}$.

meraca, Luperodes, 2: $723^{9}$. Neroptera pravella, $2: 7+t^{1}$. meshei, Catocala, $2: 747^{4}$.
Nesochorus agilis, $1 ; 13 \mathrm{I}^{4}$.

melleus, I: $15^{8^{4}}$.

Mesoleuca gratulata, 2: $706^{8}$. intermediata, $2: 725^{3}$.

ruficillata, $2: 749^{5}$.

truncata, $2: 750^{6}$.

vasaliata, $2: 754^{5}$.

Metachroma laevicollis, 2: $703^{\text {? }}$. marginalis, $2: 65 \mathrm{I}^{6}, 652^{8}-83^{2}$. pallida, 2: $703^{7}$.

quercata, 2: $703^{\circ}$.

metallicus, Tridymus, I: $30 \mathrm{I}^{\mathrm{k}}$.

Netamorphism of insects, I: $13^{8}$ $20^{5}$.

Metanema inatomaria, 2: $747^{8}$. quercivoraria, $2: 706^{6}$. textrinaria, 2: $706^{7}$.

metasternalis, Tymues, $2: 734^{6}$. meteori, Bathythrix, I: I $40^{3}$.

Meteorus communis, $1: 138^{5}$. hyphantriae, I: $131^{9}, 138^{5}, 145^{9}$.

Metrocampa praegrandaria, 2: $749^{2}$.

Mlicracis aculeata, 2: $715^{\circ}$.

opacicollis, $2: 702^{7}$.

rudis, $2: 725^{8}$.

saturalis, $2: 715^{\circ}$.

Microcentrus caryae, $2: 717^{6}$.

Microclytus gazellula, 2: $702^{3}$.

microgaster, Smicra, $1: 74^{6}$.

Microgasters, I: $22^{2}$.

Micromus montanus, $2: 653^{7}, 697^{8}$.

Midges, gall-making, $\mathbf{I}: \mathbf{I}^{1}$.

milberti, Aglais, $2: 7+2^{6}$.

Miminae, $I: 3 I^{8}$.

mimosaria, Aplodes, $2: 706^{4}$.

mimus, liruchus, $2: 731^{2}$.

Mineola indigenella, $2: 733^{6}$. juglandis, 2: $719^{7}$.

minerea, flomoptera, $2: 743^{4}$.

ministra, Datana, $2: 505^{6}, 535^{4}$. $535^{6}-36^{2}$.

ministrana, Fülia, 2: $723^{5}$.

minor, Phloeophagus, $2: 722^{4}, 742^{5}$.

minuscula var. phylla, Roeselia, 2: $706^{7}$.

minuta, Alceris, $2: 738^{9}$.

Catocala, 2: $729^{6}$.

Eupsalis, $1: 256^{6}, 26 \pi^{8}-63^{9}$.

Gracilia, $2: 745^{4}$.

Kronaea, 2: $707^{3}$. minuta, Phora, I: $158^{5}$.

minutissimus, Cryptorhynchus, 2: $702^{5}$.

Pityophthorus, see P. minutissimus.

minutus, Neuroterus, $2: 710^{6}$.

Zygomicros, 2: $702^{6}$.

mirabilis, Antigaster, 2: $699^{7}$.

misella, Pentilia, sec $P$. misella.

miserulata, Tephroclystis, 2: $706^{2}$.

Misogada unicolor, $2: 719^{2}$.

Mite. $2: 755^{2}, 755^{5}$.

Mitoma damon, 2: $740^{7}$.

mixta, Macrophya, $2: 735^{3}$.

mixtus, Anthonomopsis, $2: 734^{6}$.

l'ogonocherus, $2: 649^{8}, 663^{8}$.

Mniotiltidae, $1: 3 \mathrm{I}^{5}$.

modesta, Marumba, $2: 742^{9}$.

Melinna, $2: 753^{6}$.

modestus. Andricus, 2: $712^{3}$.

Placidus, see $\mathrm{P}$. modestus.

modica, Apatela, $2: 704^{6}$.

moesta, Saperda, $2: 471^{6}, 474^{3}, 746^{8}$.

moestum, Asemum, 2: $649^{4}, 659^{9}$, $66 I^{2}-62^{7}$.

moffatiana, Scopelosoma, $2: 723^{9}$. mollis, Ernobius, 2: $653^{3}, 694^{3}$.

molochinus, Quedius, I: $153^{7}$.

Molorchus bimaculatus, $2: 7$ I $5^{4}$.

Mompha gleditschiaeella, $2: 729^{7}$.

Monachus saponatus, $2: 750^{b}$.

monachus, Lygus, $2: 728^{6}$.

Monarch butterfly, I: $19^{1}$.

Monarthrum fasciatum, $2: 751^{8}$. mali, I: $257^{6}, 289^{4}-92^{5} ; 2: 336^{6}$.

Nonellia caryella, $2: 717^{8}$.

Monocesta coryli, $2: 724^{5}$.

Monohammus confusor, $2: 334^{9}-$ $35^{1}, 339^{2}, 360^{7}-63^{9}, 364^{9}$.

marmoratus, $2: 339^{4}, 36 \mathrm{I}^{6}, 366^{2}$.

notatus, $2: 36 \mathrm{r}^{6}$.

scutellatus, $2: 339^{3}, \quad 36 I^{6}, 362^{1}$, $364^{1}$.

titillator, $2: 339^{3}, 365^{1}$.

IIonophaduus bardus, $2: 726^{8}$.

caryae, $2: 505^{7}, 536^{2}$.

dilutus, 2: $703^{4}$.

tiliae, $2: 731^{5}$.

Nonostegia quercusalbae, 2: $703^{4}$. quercuscoccineae, $2: 703^{4}$.

rosae, $2: 735^{9}$. 
montanus, Micromus, $2: 653^{7}, 697^{8}$. monticola, Telamona, $2: 59^{67}$.

Moodna pelviculella, $2: 7+9^{7}$.

Mordella borealis, 2: $650^{4} \cdot 672^{1}$. octopunctata, $2: 426^{6}, 433^{2}$. Norning glory leaf cutter, $2: 609^{2}$. morrisella, Lithocolletes, 2: $730^{9}$. morrisii, Acanthoderes, $2: 732^{1}$. morrisoni, Scopelosoma, 2: $705^{1}$. Morrisonia confusa, $2: 727^{5}$. morula, Apatela, 2: $724^{8}$.

Mottled willow borer, I: $8^{6}, 5 \mathrm{I}^{7}$, $100^{4}-3^{9} ; 2:+69^{7}$.

Mountain ash, injurious insects: 2: $733^{8}$.

borers:

apple borer, round-headed, $\mathbf{I}$ : $5 \mathrm{I}^{3}, 8 t^{8}$.

flat-headed borer, common, I: $87^{2}$.

leaf feeders:

Apatela superans, 2: $7+9^{8}$.

Apple tent caterpillar, 2: $55 \mathrm{I}^{2}$.

Typophorus canellus, $2: 508^{8}$, $537^{2}$.

scale insects:

Putnam's scale, $1: 227^{5}$.

scurfy scale, I: $215^{8}$

Mountain laurel, injurious insects:

Agrilus vittaticollis, 2: $720^{\circ}$.

ash sphinx, 2: $509^{8}, 54^{2}$.

Nourning cloak butterfly, I: $160^{9}$.

mucida, Perothops, 2: $722^{1}$.

mucidus, Dorytomus, 2: $74^{67}$.

mucronatum, Elaphidion, 2: $702^{2}$.

Nulberry, injurious insects:

borers: $2: 726^{5}$.

painted hickory borer, $1: 204^{8}$, $266^{8}$.

Phloeotribus frontalis, 2: $725^{2}$. red-shouldered twig borer, 2 : $+42^{4}$.

multicolor, Taxonus, 2: $74^{8}$.

multiguttata, Chrysomela, $2: 72^{2}$. multipuncta, Chrysomela, $z: 566^{5}$, $566^{6}$.

multispinosa, Acholla, 2: $613^{6}+54^{2}$.

Rhodites, 2: $736^{4}$.

muricatulus, Neoclytus, $2: 75 \mathrm{I}^{4}$.

murina, Macratria, $2: i+2^{3}$. murtfeldtiae, Isodyctium, 2: $703^{2}$. nenuphar, Conotrachelus, 2: $582^{7}$, museorum, Anthrenus, 2: $6 \mathrm{I}_{4}^{9}$. $715^{8}$.

mustelina, Hepialus, $2: 753^{9}$. Neoclytus capraea, 1: $257^{2}, 279^{7}-$ Schizura, 2: $736^{1}$.

mutabilis, Cryptocephalus, 2: erythrocephalus, I: $50^{9}, 70^{8}, 71^{9}-$ $703^{6}$.

mutica, Saperda, 2: $429^{3}, 469^{3}$.

muticus, Scolytus, 2: $725^{8}$.

Mycetochares binotata, $2: 489^{6}$. nigerrima, $2: 723^{5}$.

Nycetophagus flexuosus, $2: 495^{6}$. pini, $2: 752^{4}$.

punctatus, $2: 475^{1}$.

Ifycetophilidae, $2: 6 I 7^{5}$. Iyochrous denticollis, $2: 730^{2}$.

myops, Paonias, 2: $733^{3}$.

Myrica, Sphinx gordius injuring, 2: $727^{1}$.

myrmex, Otidocephalus, 2: $715^{7}$.

myron, Ampelophaga, 2: $739^{\natural}$.

mytilaspidis, Aphelinus, $1: 212^{7}$, $222^{5}, 231^{2}$.

Tetranychus, $1: 14^{8}$.

Mytilaspis pomorum, see Lepidosaphes ulni.

Myzus achyrantes, I: $2+9^{6}$. cerasi, $1: 2+66^{3}$.

Nabis rufusculus, $2: 652^{3}, 688^{2}$.

Nacophora quernaria, 2: $734^{\circ}$.

Nadata gibbesa, $2: 506^{9}, 52 \mathrm{I}^{2}$.

Nantucket pine moth, 2: $340^{3}$, $405^{2}-7^{4}$.

nasicus, Balaninus, $2: 512^{6}, 5^{8} 3^{8}-$ $85^{4}$.

naso, Conotrachelus, $2: 734^{4}$.

Natada nasoni, 2: $529^{7}, 707^{2}$.

nebulosus, Khodites, $2: 730^{4}$.

Nectarophora crataegi, $2: 735^{1}$.

liriodendri, $2: 732^{4}$.

negundella, Gracilaria, 2: $728^{9}$.

negundinis, Cecidomyia, 2: $725^{9}$. Chaitophorus, 2: $729^{1}$.

nematicida, Pteromalus, $2: 423^{1}$.

Nematocampa filimentaria, see Ania limbata.

Nematus chloreus, 2: 703? erichsonii, see Lygaconematus. gallicola, $z: 637^{2}$. unicolor, $2: 511^{7}, 57 \mathrm{I}^{6}-72^{2}$.

Nemoria subcroceata, 2: $706^{3}$.

$$
73^{2}, 261^{2} \text {. }
$$

luscus, $2: 715^{4}$.

muricatulus, $2: 75 \mathrm{r}^{4}$.

scutellaris, $2: 715^{4}$.

Neoforus petitii, 2: $727^{3}$.

neogana, Catocala, $2: 719^{6}$.

Neoglaphyroptera bivittata, I: I $40^{6}$.

Neomysia pullata, 2: $605^{1}$.

Nepticula amelanchierella, 2: $734^{2}$.

anguinella, $2: 708^{3}$.

caryaefoliella, $2: 717^{4}$.

castaneaefoliella, 2: $72 \mathrm{I}^{5}$.

clemensella, $2: 719^{3}$.

corylifoliella, $2: 723^{6}$.

crataegifoliella, $2: 734^{8}$.

fuscotibiella, $2: 7+4^{5}$.

juglandifoliella, 2: $720^{4}$.

latifasciella, $2: 72 \mathbf{I}^{5}$.

maximella, $2: 719^{3}$.

nyssaeella, $2: 735^{7}$.

platanella, 2: $719^{2}$.

platea, 2: $708^{4}$.

prunifoliella, 2: $733^{7}$.

pteliaeella, $2: 723^{3}$.

quercicastanella, 2: $708^{4}$.

quercipulchella, 2: $708^{3}$.

rosaefoliella, $2: 736^{2}$.

saginella, 2: $705^{3}$.

serotinacella, $2: 733^{7}$,

virginiella, $2: 722^{9}$.

Nepytia semiclusaria, 2: $753^{2}$.

Nerice bidentata, $2: 725^{1}$.

nervosa, Odontota, 2: $703^{7}$.

nessus, Amphion, 2: $740^{1}$.

Neuroterus affinis, $2: 713^{8}$.

batatus, 2: $618^{5}, 624^{7}, 624^{9}$.

consimilis, 2: $7 \mathrm{II}^{1}$.

corrugis, $2: 713^{9}$.

crassitelus, 2: $7 \mathrm{IO}^{1}$.

distortus, $2: 71 I^{4}$.

dubia, 2: $710^{2}$.

exiguissinus, $2: 710^{9}$.

exiguus, 2 : $710^{1}$. ostryaefoliella, $2: 722^{8}$. 
$8+6$

Veuroterus farosus, 2: $713^{2}$.

flavipes, 2: $73^{4}$.

irregularis, 2: $7 \mathrm{I}^{9}$.

majalis, $2: 710^{9}$.

minutus, 2: $7 \mathbf{1 0}^{6}$

uigrtm, 2: $713^{5}$.

noxiosus, 2:61 $\mathrm{h}^{5}, 624^{9}, 711^{4}$

pallidus, $2: 712^{5}$.

pallipes, 2: $710^{9}$.

perminimus, 2: $710^{9}$.

pigra, 2: $73^{3}$.

rileyi, $2: 712^{7}$.

umbilicatus, 2:619 $9^{3}, 627^{9}$.

vernus, 2: $713^{4}$.

verrucarum, $2: 711^{9}$.

New Jersey tea, Cryptocephalus quadrimaculatus injuring, 2: $(x) 5^{-9}$.

New Lork weevil, 2: $506^{6}, 517^{4}-1 S^{5}$.

Nezara pennsylvanica, $2: 717^{5}$.

niger, Acraspis, $2: 7 \mathrm{II}^{2}$

Orchestes, 2: $567^{2}, 7+2^{4}$.

Pytho, 2: $751^{6}$.

nigerrima, Mycetochares, $2: 723^{8}$.

nigra, Biorhiza, 2: $710^{3}$.

nigrae, Andricus, 2: $713^{3}$.

Chaitophotus, $2: 7+4^{7}$.

nigricens, Cynips, 2: 7 II $^{6}$.

nigriceps, Phora, $3: 1+0^{5}$.

nigricollis, Elater, $2: 492^{5}$, $701^{6}$.

l'hilonix, 2: $71 \mathrm{I}^{2}$.

nigricornis, leucopis, r: $182^{2}$.

Oecanthus, 2: $698^{6}, 609^{1}$.

nigripennis, Caloplyaa, $2: 737^{5}$.

nigripes, Attelabus, 2: $703^{8}$.

nigritulus, Cybocephalus, $1: 231^{3}$.

nigrofasciatum, Eulecanium, I:

49. $173^{3}, 200^{4}-3^{7}$.

nigrum, .1pion, 2: $730^{4}$.

Ilorcaschema, s\% higrum.

Neuroterus, $2: 713^{5}$.

nimbatana, Oletlireltes, 2: $5 \mathrm{r}^{2}$, $576^{!}$.

niphen, lncisalia, 2: $752^{9}$.

nitela, l'apaipema, $2: 429^{4}, 4^{608}$ ?

nitens, I.eptura, $2: 702^{4}$.

nitilli, Allorbina, $2: 7 \mathbf{m})^{9}$.

nivalis, Kermes, 2: $709^{5}$.

niveana, Alceris, $2: 749^{8}$.

niveigullana, Olethreutes, $2: 724^{1}$.

niveipila, cecienmyi.1, 2, ;
AEW YORK STATE MUSEUM

niveus, Oecanthus, 2: $602^{3}-3^{7}, 699^{4}$.

nolilis, Calloides, $2: 427^{6},+43^{3}-$ $+4^{2}$.

noctivaga, Apatela, $2: 747^{3}$.

Noctua c-nigrum, 2: $727^{?}$.

Vodonota puncticollis, 2: $730^{3}$, $735^{9}$.

tristis, $2: 730^{3}, 742^{3}$.

nodosus, Acanthocinus, 2: $75 \mathrm{I}^{5}$.

nodulus, Cecidomyia, $2: 7+5^{4}$.

nodus, Eunra, $2: 745^{2}$.

Nola clethrae, $2: 739^{\circ}$.

ovilla, 2: $706^{7}$.

normani, Crocigrapha, 2: $704^{9}$.

Northern Brenthian, I: $256^{6}, 26 x^{8}-1$ $63^{9}$.

notataria, Eufidonia, $2: 753^{1}$.

notatus, Coelostethus, $2: 701^{5}$.

Monohammus. $2: 36 \mathrm{I}^{6}$.

Stenosphenus, $2: 493^{2}, 715^{4}$.

Nothus varians, $2: 734^{5}$.

Notolophus antiqua, $2: 507^{4}, 524^{3}$, $524^{8}$

definita, se' Hemerocampa.

leucostigma, sec Hemerocampa.

Notoxus anchora, 2: $653^{6}, 696^{6}-97^{1}$.

bifasciatus, $2: 653^{5}, 696^{1}$.

noveboracensis, It hycerus. 2: $506^{6}$. $517^{4}-16^{5}$.

novemnotata, Coccinella, 2: $652^{\circ}$. $60 \mathrm{I}^{1}$.

noxiosus, Veuroterus, $2: 619^{5}, 624^{\prime \prime}$. $711^{4}$.

Noxious oak gall, 2:6155, $624^{9}$.

nulifer, Phyllotrox, $2: 567^{8}$.

nubila, Iloplosia, 2: $722^{8}$.

nubilis, Fuparthenos, $2: 730^{6}$.

unbilus, Thanasimus, $2: 3^{8} 4^{6}, 653^{*}$, $603^{2}$.

ntcicola, Cecidomyia, 2: $713^{1}$.

unucius, Cryptus, I: $155^{3}$.

Nut pests, 2:723\%; key to, 2:512:

Nutliatches, I: $32^{2}$, I I I ${ }^{3}$, I I I $\mathbf{I}^{6}, \mathrm{I}_{1} \mathbf{I}^{4}$

Nyctohates penusylvanica, $\left.2: f^{1}\right) 2$

Nyctobia limitata, $2: 73 t^{2}$.

Xymphs, use of term, $\mathbf{1}: 15^{7}$.

Xysius angustatus, $2: 65 \mathrm{r}^{\circ}, 6.55^{\circ}$.

uyssae, Phylloxera, 2: $735^{\circ}$.

nysuacella, Nepticula, 2: $735^{7}$.

nysatefoliella, Antispila, 2: 501 . $555^{6}-56^{\circ}$.
Oak, Ips quadriguttatus on, 2: $692^{4}$.

beneficial insects:

Bothrideres geminatus, 2 . $505^{\prime}$.

Chariessa pilosa, 2: 5044.

Hydnocera verticalis, 2: $605^{9}$. injurious insects:

aphids: $2: 709^{2}$.

borers: 2 : $701^{4}-2^{8}$.

Acanthoderes quadrigib. bus, $2: 702^{4}, 715^{6}$.

apple wood stainer, $1: 290^{5}$. ash borer, four-marked, 2 : $+62^{9}$.

Brenthian, northern, I: $256^{6}, 261^{9}$.

Calloides nobilis, $2: 427^{6}$, $+43^{\top}$.

carpenter worm, I: $7^{4}, 5 \mathrm{I}^{2}$, $79^{5}, 83^{9}$.

Ceruchus piceus, 2: $70 \mathbf{I}^{8}$.

chestnut borer, two-lined, I: $257^{3}, 250^{6}$

chestnut timber worm, 2 : $+27^{9}, 449^{5}$.

Cyrtophorus verrucosus, 2: $722^{2}$.

Dendroides canadensis, 2: $494^{3}$.

concolor, $2: 494^{3}$.

Dermestes pulcher, $2: 43 I^{2}$, $489^{3}$.

I)icerea pugionata, $2: 750^{2}$.

I)ysphaga tenuipes, 2: 7 $15^{7}$.

flat-headed borer, common, I: $87^{2}$.

Gaurotes cyanipennis, 2: $+28^{4},+54^{6}$.

hickory borer, banded, $\mathbf{I}$ : $268^{2}$.

tiger, $1: 2566^{7}, 268^{6}$.

hickory snout borer, r: $275^{2}$.

hicliory timber beetle, 2 : $427^{8},+46^{2}$.

11 yerplatys maculatus, 2 : $426^{6},+32^{6}, 433^{1}$.

llypothenemus crudiae, 2 : $7 \mathrm{I}^{9}$.

leopard moth, i: $78^{5}$.

leptostylus, prickly, $2: 461^{8}$. 
Oak, inj. insects $\left(\operatorname{con} t^{\prime} d\right)$ : borers:

leptostylus, spotted, 2: $48 z^{9}$.

Leptura subhamata, 2:675 ${ }^{3}$. zebra, $2: 45 x^{1}$.

Lepturges querci, $2: 427^{2}$, $439^{8}$.

Liopus punctatus, $2: 426^{5}$, $432^{2}$.

Micracis suturalis, $2: 715^{9}$.

Monarthrum fasciatum, 2: $75 \mathrm{I}^{8}$.

Mordella octopunctata, 2: $433^{5}$.

oak bark beetle, minute, I: $295^{2}$.

oak borer, dusty, $2: 426^{7}$, $434^{4}$.

variable, $2: 433^{8}$.

oak twig pruner, I: $50^{6}$, $59^{2}$.

oak weevil, gray sided, 2 : $426^{9},+36^{8}$.

pigeon tremex, $1: 63^{6}$.

pine borer, lesser, 2: 66 $2^{5}$.

Pity ophthorus querciperda, 2: $702^{6}$.

Platypus quadridentatus, 2: $720^{9}$.

powder post beetle, $1: 296^{9}$.

prionus, broad-necked, 2: $4^{86^{7}}$.

lesser, $2: 487^{6}$.

red horned borer, small, I: $29^{\mathrm{S}}$.

rustic borer, I: $256^{5}, 259^{2}$.

Sesia rubristigma, 2: $426^{9}$, $437^{7}$.

Stenopsis argenteomaculatus, 2: $721^{1}$.

Stenosphenus notatus, 2: $493^{2}$.

thunderbolt beetle, $2: 427^{6}$, $4+4^{3}$.

twig girdler, $1: 273^{9}$.

Urographis fasciatus, 2: $426^{8}, 434^{8}, 435^{9}$.

Xyleborus fuscatus, $2: 752^{2}$.

Xyloterus politus, I: $257^{6}$, $292^{4}$.
Oak, in j. insects (cont' $d$ ):

bud feeders:

Namestra detracta, $2: 7 \mathrm{I}^{\circ}$.

flower cricket, white, $2: 603^{3}$.

gall insects, $2: 617^{4}, 709^{8}-14^{3}$.

Biorhiza hirta, 2: $7 \mathbf{I} 2^{9}$.

marginal fold gall, 2: $619^{4}$, $627^{9}$.

oak apple, large, $2: 618^{7}$.

larger empty, 2:6I ${ }^{7}$

oak leaf stalk gall, $2: 618^{9}$ $625^{9}$.

woolly oak gall, $2: 623^{2}$.

leaf feeders, $2: 702^{8}-8^{9}$.

Acordulecera dorsalis, 2: $716^{3}$.

Agrilus otiosus, 2: $518^{3}$.

Alceris ferrugana, $2: 744^{2}$.

American dagger moth, 2: $525^{3}$.

American lappet moth, 2: $507^{6}, 525^{6}$.

American silk worm, 2: $526^{6}$.

Apatela impleta, 2: $749^{3}$.

interrupta, $2: 7^{2} 4^{8}$.

lithospila, 2: $72 \mathrm{I}^{2}$.

apple tent caterpillar, 2: $55 \mathrm{I}^{1}$.

apple worm, yellow-necked, 3: $535^{7}$.

hag or hasket worm, I: $127^{2}$.

black walnut caterpillar, $\mathbf{~ : ~}$ $305^{4}$.

Brachyos aerosa, 2: $5063^{3}, 512^{9}$, brown tail moth, $1: 164^{1}$. buck moth, I: $25^{5}, 310^{4}$. Cenopis pettitana, 2: $5 \mathbf{r 2}^{3}$, $579^{3}$.

reticulatana, $2: 512^{3}, 580^{1}$.

Cistela sericea, $2: 5 \mathbf{1}^{84}$.

Copturus binotatus, 2: $730^{4}$.

Coscinoptera dominicana, 2: $737^{3}$.

Cotalpa lanigera, $2: 724^{5}$.

curculio, two spotted, 2: $506^{3} \cdot 516^{2}$

Datana contracta, $2: 725^{1}$.

)emas propinquilinea, $\mathbf{2}$ : $749^{4}$.

Dichelonycha elongata, 2 : $7 \mathrm{I} \mathrm{f}^{3}$.
Oak, inj. insects (cont'd $)$ :

leaf feeders:

Erannis tiliaria, 2: $731^{6}$.

Euclea delphinii, 2: $529^{2}$.

indetermina, $2: 528^{9}$.

Eutrapela kentaria, 2: $728^{2}$.

filament bearer, $2: 508^{1}, 530^{4}$.

flannel moth, crinkled, 2 : $530^{1}$.

flea beetle, black-margined, 2: $506^{4}, 515^{2}$.

forest tent caterpillar, I: $107^{A}, 110^{6}, 110^{9}$.

gipsy moth, I: $120^{4}$.

Glyptoscelis barbata, 2: $518^{5}$.

hag moth caterpillar, $2: 525^{5}$.

Heterocampa guttivitta, 2 : $727^{8}$.

Hyparpax, rosy, 2: $506^{\Uparrow}$, $520^{4}$.

Hyperitis amicaria, 2: $722^{5}$. imperial moth, $2: 677^{\circ}$.

io caterpillar. 2: $506^{9}, 522^{3}$.

Isochaetes beutenmulleri, 2: $722^{5}$.

leaf roller, red-bauded, 2 : $532^{2}$.

V-marked, 2: $508^{2}, 53 \mathrm{I}^{7}$, $531^{8}$.

Lithacodes fasciola, 2: $72 \mathrm{~S}^{4}$.

Lithocolletes argentinotella, $2: 725^{5}$.

castaneaeella, 2: $721^{6}$.

locust leaf miner, I: $327^{\circ}$.

luna moth, 2.526.

maple worm, semilooper, 2: $503^{9}, 538^{5}$.

Metrocampa praegrandaria, 2: $749^{7}$.

Morrisonia confusa, 2: $727^{8}$.

New lork weevil, 2:51 $7^{8}$, $518^{2}$.

oak caterpillar, green, 2 : $506^{8}, 52 \mathrm{I}^{2}$.

red-liumped, 2: 5067, $519^{3}$. yellow striped, $1: 25^{5^{4}}$. $306^{5}$.

oak leaf miner, Fitch's, 2: $533^{2}$

white-blutch, 2. $508^{4}, 532^{8}$. 
Oak, inj. insects (cont $d$ ' $)$ :

leaf feeclers:

oak leaf roller, $2: 505^{3}, 532^{6}$.

oak tussock caterpillar, 2: $523^{3}$.

Orlontota quadrata, 2: $731^{5}$.

Olene leucophaea, $2: 717^{1}$.

Paonias excaecatus, 2: $724^{7}$.

promethea moth, $2: 557^{8}$.

saddleback caterpillar, 2: $523^{7}$.

Sisyrosea textula, 2: $72 \mathrm{I}^{4}$.

Smerinthus jamaicensis, 2 : $724^{7}$.

spiny oak worm, 2: $507^{8}$, $527^{4}$.

spruce sawfly, $2: 683^{9}$.

Strongylogaster pinguis, 2 $74^{5}$.

Tacbygonus lecontei, 2: $752^{5}$.

Tischeria castaneaeella, 2: - $72 \mathrm{r}^{6}$.

Tolype velleda, $2: 727^{9}$.

Tortricidia flexuosa, $2: 717^{2}$.

Tortrix albicomana, $2: 532^{4}$.

tussock moth, dark, 2: $524^{9}$.

definite-marked, $2: 507^{-1}$, $522^{4}$.

white marked, I: $136^{9}$

viceroy, $2: 559^{7}$.

walking stick, $2: 535^{1}$.

Xylina antennata, $1: 131^{5}$.

nut pest:

acorn weevil, 2: $512^{6}, 583^{9}$.

scale or sucking insects: 2 : $709^{1}, 709^{4}$.

cicada, dog day, $1: 238^{3}$.

Eulecanium cerasifex, 2: $728^{8}$.

cockerelli, $2: 725^{6}$.

golden oak scale, r: $255^{9}$, $329^{4}$.

hawthorn, tingis, 2: $598^{\text {? }}$.

Putnam's scale, $\mathbf{s}: 227^{4}$.

Oak. black, injurious insects: borers:

oak carpenter worm, lesser, 2: $427^{2}, 439^{2}$.

Plyymatodes varius, 2: $702^{1}$.

Platypus compositus, $2: 720^{\circ}$.
Oak, black, inj, insects (cont' $d)$ : borers:

Sesia scitula, $2: 451^{6}$.

Urographis fasciatus, $2: 435^{6}$.

Ayleborus pubescens, $2: 720^{\circ}$.

gall insects:

Andricus scitula, 2: $713^{1}$.

oak plum gall, 2:6252.

leaf feeders:

Isodyctium murtfeldtiae, 2: $703^{2}$.

Lithocolletes obstrictella, 2: $70^{87}$.

Monostegia quercuscoccineae, 2: $703^{4}$.

Periclista subtruncata, 2 $702^{9}$.

Telphusa qquercinigracella, 2: $707^{7}$.

Tiscberia tinctoriella, 2: $721^{7}$. scale insect:

Eulecanium quercitronis, 2: $709^{4}$.

Oak, black jack, injurious insects: Andricus operator, 2: $713^{3}$.

oak gall, borned, 2: $624^{4}$.

oak leaf gall, warty, $2: 627^{4}$.

Oak, burr, resistance to insect attack, $\mathbf{r}:+7^{6}$.

injurious insects:

gall insects: 2: $713^{4}$.

Lachnosterna hirticula, 2; $716^{4}$.

leaf roller, oblique banded, 2 : $580^{9}$.

Oak, chestnut, injurious insects:

Neuroterus rileyi, 2: $712^{7}$.

oak bullet gall, $2: 62 t^{7}$.

Oak, chinquapin, injurious insects:

gall insects, 2: 7 $\mathbf{I}^{\mathbf{1}}$.

Oak, dwarf, black scrub oak gall injuring, 2: $61 \mathrm{~s}^{8}, 625^{6}$.

Oak, dwarf chestnut, injurious insects:

oak fig gall, $2: 626^{5}$.

oak gall, spiny, 2:619 ${ }^{3}, 627^{6}$.

@ak, Fnglish, Putnam's scale injuring, $\mathbf{I}: 227^{5}$.

Oak, jack, Xyleborus pubescens injuring, $2: 720^{\circ}$.
Oak, laurel, injurious insects: Gelechia vernella, 2: $705^{1}$. Tmetocera ocellana, 2: $707^{5}$. Oak, pin, injurious insects: Andricus palustris, $2: 714^{3}$. oak gall, horned, 2:62 $t^{4}$. oak leaf gall, warty, $2: 627^{4}$. Putnam's seale, I: $227^{5}$.

Oak, post, injurious insects: gall insects: $2: 7 \mathrm{~m}^{7}$.

oak bullet gall, 2: $624^{5}$. oak leaf bullet gall, 2:619', $626^{2}$.

Phylloxera rileyi, $2: 7 \mathrm{I}^{3}$.

Oak, red, resistance to insect attack, $1: 47^{4}$.

injurious insects: $1: 49$. borers:

Memythrus simulans, 2: $427^{-1}, 438^{4}$.

oak bark beetle, 1: $257^{2}$.

Sesia scitula, $2: 45 \mathrm{I}^{6}$.

Synchita obscura, $2: 70 I^{4}$.

gall insects: 2 : 712 .

oak apple, large empty, 2: $625^{4}$.

oak flower gall, $2: 619^{4}, 627^{9}$. oak gall, gouty, $2: 618^{3}, 623^{3}$. oak leaf apple, 2: $618^{8}, 625^{7}$. oak leaf gall, warty, $2: 627^{4}$. oak leaf seed gall, 2: $619^{3}$, $627^{7}$.

oak plum gall, 2:6282. scale insect:

Kermes kingii, 2: $709^{5}$.

Oak, scarlet, resistance to insect attack, $1:+7^{4}$.

injurious insects:

gall insects: 2: 7126.

Jryophanta papula, 2: 7124. oak apple, larger empty, 2 : $625^{4}$.

Oak, scrub, beneficial insects:

cidada killer, 2: $603^{\circ}$.

IIydnocera subaenea, 2: $606^{3}$. IIyperaspis binotata, 2: $605^{3}$.

in jurious insects: borers:

I.eptura vagans, $2: t 27^{3}$, $4+0^{6}$. 
Oak, scrub, inj. insects (cont' $d)$ : borers:

- Typocerus velutinus, 2: $426^{8}, 436^{2}$. gall insects: $7 \mathrm{I}^{6}$.

bullet gall, rough, $2: 624^{5}$. oak fig gall, 2:6192, 6264.

oak gall, black scrub, 2 : $6 \mathrm{I} 5^{8}, 625^{6}$.

horned, $2: 62 t^{4}$.

oak leaf bullet gall, $2: 6 \mathrm{I} 9^{1}$, $626^{\circ}$.

oak leaf gall, warty, 2: $627^{4}$.

leaf feeders:

Anthaxia quercata, 2: $518^{4}$.

Aphrastus taeniatus, $2: 506^{5}$, $515^{8}$.

Archips fervidana, 2: $508^{2}$ $530^{6}$.

Attelabus nigripes, $2: 703^{8}$.

Brachys ovata, 2: $506^{3}, 513^{7}$.

Cryptocephalus quadrimaculatus, 2: $695^{9}$.

Eugnamptus collaris, 2: $716^{5}$.

Metachroma quercata, 2: $703^{7}$.

Rhynchites aeratus, $2: 703^{8}$. bicolor, 2: $5 \mathrm{IS}^{5}$.

rose beetle, $2: 575^{b}$.

Serica trociformis, 2: $506^{3}$, $514^{6}$.

Thanaos brizo, 2: $704^{3}$.

Tymnes tricolor, 2:5064, 5 i $5^{5}$.

nut pest:

acorn weevil, $2: 584^{\mathrm{I}}$.

sucking insects:

Alydus eurinus, 2:61 $3^{5}$.

Archasia galeata, 2: $597^{2}$.

Cyrtolobus fenestratus, 2: $597^{7}$.

Euschistus fissilis, 2:610

Jassus olitorius, 2: $597^{8}$.

Kermes perryi, 2: $709^{5}$.

lightning leaf hopper, 2: $598^{5}$.

Telamona monticola, 2: $596^{8}$.

Thelia godingi, $2: 596^{6}$.
Oak, swamp, gall insects injur-|Oak, white, inj. insects (cont' $d$ ): ing, $2: 7 \mathrm{II}^{3}$.

Oak, swamp chestnut, Andricus papillatus injuring, 2:712 .

Oak, turkey scrub, Andricus quercifoliae injuring, 2: $7 \mathrm{I}^{3}$.

Oak, white, resistance to insect attack, $1: 47^{6}$

injurious insects:

borers:

Chrysobothris scitula, 2: $701^{6}$.

Cinyra gracilipes, 2: 7017.

Elaphidion subpubescens, 2: $702^{2}$.

Goes debilis, 2: $702^{3}$.

Leptura emarginata, $2: 436^{7}$.

Sandalus petrophya, 2: $701^{5}$.

Tillomorpha geminata, 2: $715^{5}$.

Typocerus zebratus, $2: 702^{4}$.

Xyleborus pubescens, 2: $720^{\circ}$.

gall insects: $2: 710^{3}-11^{3}$.

bullet gall, rough, $2: 62 t^{6}$ -

oak bullet gall, $2: 6 \mathbf{1}^{4}, 624^{7}$. Oak button gall, $2: 619^{3}, 627^{7}$.

oak button gall, $2: 6 \mathrm{Ig}^{3}$, $627^{8}$.

oak fig gall, $2: 6 \mathrm{I} 8^{6}, 6 \mathbf{I} 9^{2}$, $626^{4}$

oak hedgehog gall, 2: $6 \mathbf{1} 9^{2}$, $627^{5}$.

oak potato gall, $2: 61 \mathrm{~S}^{5}, 624^{2}$. oak tip gall, $2: 618^{3}, 624^{5}$.

oak wool gall, $2: 615^{9}, 625^{8}$. wool sower, $2: 618^{2}, 622^{2}$.

leaf feeders:

brown tail moth, $1: 254^{3}$.

Exartema inornatanum, 2: $707^{5}$.

Isodyctium infrequens, 2: $703^{1}$.

subgregarium, 2: $703^{9}$.

Monostegia, quercuscoccineae, 2: $703^{4}$

Periclista albicollis, 2: $702^{8}$. media, $2: 7^{\circ} 2^{9}$

purpuridorsum, 2: $702^{9}$.

Psaphidia thaxterianus, 2 : $704^{8}$.

walking stick, 2: $533^{9}$. scale or sucking insects:

Eulecanium canadense, 2 : $725^{6}$.

Kermes andrei, 2: $709^{5}$. nivalis, 2: $709^{5}$.

Sphaerococcus sylvestris, 2 : $709^{6}$.

Oak, white swamp, injurious in. sects:

oak gall, lobed, $2: 618^{6}, 625^{1}$. noxions, 2:6185, $624^{9}$.

Oak, willow, Amphibolips phellos injuring, 2: $712^{\text {x. }}$

Oak, yellow, resistance to insect attack, $1: 47^{4}$.

Oak apple, 2: $710^{1}$

large, $2: 618^{7}, 625^{2}, 625^{4}$.

larger empty, 2:61 $3^{7}, 625^{4}$.

Oak bark beetle, I: $257^{7}$.

minute, $1: 295^{1}$.

Oak borers, 2: $701^{4}-2^{8}$.

dusty, $2: 426^{8}, 434^{4}$.

variable, $2: 426^{7}, 433^{7}-34^{3}$.

Oak carpenter worm. lesser, 2: $427^{2}, 439^{1}$.

Oak caterpillar, green, 2: $506^{9}$, $521^{1}$.

red-humped, 2: $506^{7}, 5 \mathrm{Ig}^{2}-20^{2}$.

senatorial, $2: 607^{7}$.

yellow-striped, I: $25^{4}, 306^{4}-\mathrm{IO}^{3}$. Oak fig gall, 2:61 $\mathrm{s}^{6}, 619^{2}, 626^{4}-27^{3}$.

Oak flower gall, $2: 619^{4}, 627^{9}-28^{1}$.

Oak galls, 2: $709^{8}-\mathrm{I}_{4}^{3}$.

black scrub, $2: 618^{5}, 625^{5}$.

gouty, 2: $618^{3}, 623^{2}-24^{3}$.

horned, $2: 618^{3}, 624^{3}$.

lobed, $2: 61 \mathrm{~s}^{6}, 625^{1}$.

noxious, 2: $618^{3}, 624^{9}$.

spiny, $2: 619^{3}, 627^{6}$.

woolly, $2: 61 \mathrm{~S}^{2}, 622^{9}-23^{2}$.

Oak hedgehog gall, 2:6192, $627^{5}$.

Oak leat apple, 2:6I8 $625^{7}$.

Oak leaf bullet gall, 2: $619^{1}, 626^{1}$.

Oak leaf feeders, $2: 702^{8}-3^{4}$.

Oak leaf gall, warty, 2:619 $2,627^{4}$.

Oak leaf miner, Fitch's, 2: $508^{4}$, $533^{2}$.

white-blotch, 2: $508^{4}, 532^{7}-33^{1}$. 
Oak luat ruller, $2: 508^{3}, 52^{\circ}$. Oak leaf scel gall, $2: 619^{3}, 627^{7}$. Oak leaf-stalk gall, $2: 618^{9}, 625^{9}$. ()ak plum gall, $2: 619^{5}, 628^{?}$. ()ak potato gall, 2: $6 \mathbf{r}^{5}, 624^{7}$. Oak scale, golden, $1: 25^{39}, 329^{3}-$ $3 x^{7}$.

Oak tip gall, $2: 6 \mathbf{1}^{4}, 624^{4}$.

Oak tussock caterpillar, 2: $507^{2}$, $5 \div 3^{2}$.

Oak twig pruner, sec Maple and oak twig pruner.

Oak weevil, gray sicled, $2: 426)^{7}$, $+36^{8}-37^{6}$.

Oak wool gall, 2:6r59, $625^{\text {* }}$.

Oak worm, orange-striped, $2: 527^{5}$. spiny, 2: $50^{-8}, 527^{3}$.

obcordata, Jhellopsis, see P. obcordata.

Oberea ocellata, $2: 493^{3}$.

ruficollis, $2: 732^{5}$.

schaumii, $2: 493^{3}$.

tripunctata $2(\pi)$. mandarina, 2 : $7+6)^{7}$.

obesus, Nyleborus, 2: $722^{4}$.

oblinita Apatela, 2: $5 \mathrm{I}^{2}, 560^{1}$, Odontophyes avingrata, 2:7102. $7+3^{1}$.

obliqua, Heterocampa, 2: $705^{7}$.

Saperda, $2: 430^{4}, 480^{1}-31^{2}$.

obliquata, Penthe, $2: 493^{6}$.

Oblique banded leaf roller, 2: $512^{4}, 531^{7}, 530^{7}-81^{2}$.

obliquistrigella, Recurvaria, 2: $754^{3}$.

obliquus, Cryptorlynchus, 2: $715^{8}$, oecanthi, Baryconus, $2: 603^{6}$. $737^{2}$.

obliteralis, Loxostege, 2: $609^{3}$.

Obrium rubrum, $2:+28^{9},+63^{3}$.

olscura, (atocala, 2: 7 I6".

Synchita, 2: 7or'.

w\%. lurida, Dicerca, $2: 427^{5}$. $4+2^{8}-43^{6}$

obscuricustella, Lithocolletes, 2: $723^{1}$.

obscurus, Adoxus, 2: $739^{x}$.

Chrysomphalus, 2: $709^{6}$.

Hymenorus, 2: 7019 .

obsoletoguttatus, Agrilus, 2: 701?

obsoletus, Acanthosinus, 2: $649^{4}$, $662^{7}$.

obstrictella, lithocolleter, $2: 7 ; 2^{7}$. ohtentus, Cryptorhynchus, $2: 720^{8}$

ohtusa, Clastoptera, 2: $687^{3}$.

obtusaria, Euchlaena, 2: $721^{3}$.

Ubtuse clastoptera, $2: 687^{3}$.

obtusilobae, Aegilips, 2: $715^{3}$.

Andricus, $2:$;oy 9 .

Ceroptres, 2: $714^{7}$.

obtusus, Balaninus, 2: $723^{*}$.

occidentalis, Cerura, $2: 7+3^{7}$.

ocellana, Tmetocera, 2: $707^{5}$.

ocellaris, Cecidomyia, 2:6199. $629^{6}-30^{1}$.

ocellata, Anatis, 1: $175^{2}, 195^{2}, 199^{7}$; 2: $604^{5}$.

()herea, $2: 493^{3}$.

Ocellate maple leaf gall, $2: 619^{9}$, $629^{6}-30^{1}$

octolineata, Gypona, 2: $652^{4}, 688^{5}$. octomaculata, Aly pia, 2: $512^{1}, 575^{3}$. octopunctata, Mordella, see M. octopunctata.

oculata, Anatis, I: $186^{2}$.

Goes, 2: $715^{5}$.

oculatus, Alaus, $2: 430^{8}, 485^{1}-86^{1}$.

Odontophyes aviingrata, 2: $716^{2}$. $29^{2}$.

nervosa, 2: $703^{7}$.

quarlrata, 2: $731^{5}$.

odontotae, Spilochalcis (Smicra), I: $328^{1}$.

Trichogramma, I: $328^{\circ}$.

odoratus, Pteronus, 2: $511^{3}, 562^{3}-$ $63^{4}, 7+r^{7}$.

Cacus, $2: 603^{5}$.

()ecanthus fasciatus, $2: 699^{5}$.

latipennis, 2: $603^{6}$.

nigricornis, 2: $69^{86}, 609^{1}$.

niveus, $2: 602^{3}-3^{7}, 699^{4}$.

pini, $2: 69^{9}$.

quadripunetatus, 2: $699^{9}-700^{4}$.

Oeme rigida, $2: 755^{7}$.

Ohio buckeye, leopard moth injuring, $1: 75^{5}$.

Olene achatina, 2: $507^{-4}, 524^{7}$.

leucophaea, 2: $\left\lceil\mathrm{I}^{\top}\right.$.

var. basillava, $2: 749^{4}$.

plagiata, 2: $725^{2}$.

()ethreutes capreana, $2: 7+1^{5}$. cyanana, $2: 512^{3}, 5 ; 7^{-1 i}-79^{2}$.
Olethreutes malachitana, $2: 735^{3}$. nimbatana, $2: 512^{2}, 576^{1}$. niveiguttana, 2: $724^{1}$.

Oliarius quinqquelineatus, 2: $652^{1}$, $686^{2}$.

Oligia versicolor, $2: 75 t^{1}$.

Oligotrophus betulae, $2: 62 \mathrm{I}^{4}$, $647^{1}$.

olitorius, Jassus, 2: $597^{8}$.

Olive, black-banded scale injuring, 1: $201^{2}$.

olyra, Magdalis, $1: 256^{9}, 277^{6}-75^{3}$; 2: $503^{4}$.

omnivora, Diglochis, I: $166^{2}$.

Oncideres cingulatus, $1: 256^{\circ}, 271^{2}-$ $74^{4}$.

onerati, Entelus, I: $74^{5}$.

oneratus, Synergus, $2: 714^{5}$.

Onychia armatus, $2: 715^{1}$. quinquelineata, $2: 75^{1}$.

opacicollis, Micracis, $2: 702^{7}$. opaculus, 11 ylesinus, I: $257^{5}, 288^{1}$. opacus, 1phthimus, 2: $492^{4}$.

operator, Andricus, $2: 618^{2}, 622^{9}-$ $23^{8}, 709^{8}, 713^{3}$.

opercularis, Megalopyge, 2: $726^{2}$.

Opheltes glaucopterus, $\mathrm{i}: 15 \mathrm{~s}^{8}$.

Opheroptera boreata, 2: $725^{2}$.

Ophion, 1. $21^{8}$. glabratum, sec Eremotylus. optiva, .legachile, $2: 725^{6}$.

Orange, injurious insects: borers:

apple wood stainer, $\mathbf{I}: 290^{5}$.

Dorcaschema alternatum, 2: $726^{6}$.

Elaphidion inerme, 2: $702^{1}$.

IIyperplatys maculatus, 2: $+33^{1}$.

Leptostylus hiustus, $2: 715^{6}$. maple and oak twig pruner, I: $6 \mathrm{I}^{3}$.

powder post beetle, 1: $297^{1}$.

twig borer, I: $273^{9}$.

leaf feeders:

orange dog, $2: 555^{3}$.

Papilio thoas, 2: $729^{3}$.

scale insects:

Euonymus scale, $\mathrm{r}: \mathbf{2 1} \mathbf{4}^{2}$.

Orange, osage, injurious insects: 2: $726^{6}$. 
Orange, usage, inj. insects (cont' $d$ ): borers:

Dorcaschema wilkii, $2: 726^{6}$. leptostylus, prickly, 2: $46 \mathrm{I}^{3}$.

leaf feeders:

bag or basket worm, I: $127^{2}$.

Cenopis reticulatana, 2: $707^{5}$.

scale or sucking insects:

Pulvinaria maclurae, 2: $737^{5}$.

Putnam's scale, $1: 227^{4}$.

Orange-banded clerid, 2: $502^{7}$.

Orange buttertly, r: $196^{1}$.

Orange dog, 2: $510^{4}, 554^{3}-55^{6}$.

orbitalis, Cecidomyia, $2: 746^{3}$.

Euura, 2: $745^{2}$.

Orchesia castanea, $2: 731^{4}$. gracilis, $2: 745^{5}$.

Orchestes betuleti, $2: 749^{1}$. ephippatus, $2: 567^{2}$.

niger, $2: 567^{2}, 742^{4}$

pallicornis, $2: 742^{4}$.

rufipes, $2: 7+2^{4}$.

salicis, $2: 7+2^{4}$.

Orcus australasiae, $1: 223^{8}$. chalybeus, $1: 223^{3}$.

oregonensis, Amauronematus, 2 : $7+1^{8}$.

Oreta irrorata, 2: $749^{6}$. rosea, $2: 749^{6}$.

Orgyia antiqua, see Notolophus. definita, see Hemerocampa. dispar, see l'orthetria. leucostigma, se Hemerocampa. orgyiae, Amorphota, 1: $133^{5}$. Cratotechus, I: $135^{6}$.

Telenomus, I: $13^{8^{6}}$.

orina, Calymnia, $2: 704^{9}$.

Orioles, 1: $30^{9}, 33^{3}$, II $^{2}, 237^{3}$.

Baltimore, I: $27^{8}, 30^{9}, 111^{6}, 122^{2}$, $137^{8}, 166^{3}$.

Ormenis pruinosa, $2: 596^{b^{2}}$.

Ornix acerifoliella, see Tischeria. crataegifoliella, $2: 734^{2}$. inusitatumella, $2: 734^{8}$. quadripunctella, $2: 734^{\circ}$. Orsorlachna atra, 2: $741^{9}$.

Orthaltica copalina, $2: 737^{3}$.

Orthofidonia vestaliata, 2: $706^{4}$. ortholobis, Chionaspis, $2: 744^{2}$.

Orthoptera, 1: $24^{n}$.
|Orthosoma brunneum, 2: $430^{9}$. | Packardia geminata, 2: 529, $707^{7}$. $487^{2}-85^{2}$.

Oryssus sayi, 2: $727^{4}$. terminalis, $2: 727^{4}$.

Osmoderma eremicola, 2: $493^{1}$. Painted hickory borer, 1: $256^{6}$, scabra, 2: $492^{9}$.

packardiana, Tortrix, 2: $754^{3}$.

Paectes delineata, 2: $724^{3}$.

pygmaea, 2: $724^{3}$. $264^{1}-66^{3}$.

ostensackenella, Lithocolletes, 2: Painted mapie aphid, r: $172^{4}, 175^{6}-$ $730^{9}$.

ostensackenii, Andricus, $2: 713^{\circ}$. palaeogama, Catocala, $2: 716^{8}$

ostryae, Coleophora, 2: $722^{8}$. Pale tussock caterpillar, 2:507 ${ }^{3}$,

Pteronus, 2: $722^{7}$.

$523^{7}-2 t^{2}$.

ostryaeella, Chrysopeleia, 2: $723^{1}$. Paleacrita vernata, 2: $509^{7}, 547^{5}$.

ostryaefoliella, Coptodisca, 2: l'ales weevil. 2: $649^{\circ}, 664^{4}$. $722^{8}$.

Lithocolletes, $2: 722^{9}$.

Nepticula, $2: 722^{*}$.

Otacustes periliti, $\mathbf{1}: \mathbf{1}+\mathrm{O}^{3}$.

Otidocephalus chevrolatii, $2: 715^{7}$. pallida, Netachroma, $2: 703^{7}$. myrmex, 2: $715^{\text {? }}$.

Otiocerus amyotii, 2: $717^{7}$.

otiosus, Agrilus, 2: $502^{4}, 518^{3}, 729^{9}$.

ovata, Apatela, 2: $704^{6}$.

Brachys, see B. ovata.

Chalcis, sec C. ovata.

ovatus, Pterocolıs, 2: $703^{9}$.

ovilla, Nola, 2: $706^{7}$.

ovum, Euura, 2: $745^{\circ}$.

Ow beetle, $2: 430^{\circ}, 485^{1}-86^{1}$.

Oxyptilus tenuidactylus, $2: 754^{2}$.

Oyster scale, $1: 173^{5}, 211^{1-1} 3^{5}$.

Pachybrachys a tomarius, $2: 730^{2}$. femoratis, $2: 752^{8}$.

livens, $2: 74^{1}$.

tridens, $2: 740^{5}, 7+2^{2}$.

Pachylobius picivorus, 2: $751^{6}$.

Pachyneuronsp. I: $1 \$ 6^{3}$. a)tiscuta, 1: $182^{1}, 203^{1}$.

Pachypsylla, 2:61 $7^{6}$.

celtidis-asteriscus, $2: 726^{3}$. celtidis-cucurbita, $2: 726^{3}$. celtidis-gemma, $2: 726^{3}$. celtidis-globulus, $2: 726^{4}$.

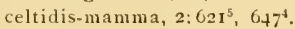
celtidis-pubescens, 2: $726^{4}$. celtidis-umbilicus, $2: 726^{4}$. celtidis-vesiculum, 2: $726^{4}$. venusta, $2: 726^{5}$.

Pachyscelus purpureus, 2: $715^{3}$.

Packardia elegans, $2: 529^{6} .707^{\circ}$. pales, 1lylobius, $2: 649^{7}, 664^{4}$.

palliatus, I)esmocerus, $2: 737^{7}$.

pallicornis, Orchestes, $2: 742^{4}$.

tania, $2: 7+\mathrm{I}^{7}$

Plyytodecta, 2: $510^{8}, 55^{6}$

Tortricidia, $2: 529^{4}, 707^{4}$.

pallidior, Eulecanium, 2: $755^{6}$.

pallidochrella, Jlelice, $2: 729^{7}$.

pallidum, Pliyton, 2: $715^{3}$.

pallidus, Neuroterus, $2: 712^{5}$.

Spathius, $2: 359^{3}$.

pallipennis, Hydnocera, 2: $653^{2}$, $693^{5}$.

pallipes, Iryophanta, 2: $7 \mathrm{IO}^{5}$.

Limneria, I: $145^{\circ}$.

Neuroterus, 2: $710^{9}$.

pallorana, Tortrix, 2: $733^{6}$.

Palm warbler, $1: 26^{5}$.

$\mathrm{Pa}$ metto, oak borer, dusty, injuring, $2: 434^{4}$.

palmii, Datana, 2: $739^{4}$.

Palthis asopialis, $2: 705^{6}$.
palustris, Andricus, 2: $7 \mathrm{I}_{4}$

Pammegischia xiphydriae, $2: 466^{4}$.

pampinaria, Cleora, $2: 743^{9}$.

Panapoda rnfimargo, 2: $705^{5}$.

Pandeletejus cinereus, $2: 436^{9}$. hilaris, $2: 426^{9}, 436^{8}-37^{6}$.

Pandemis lamprosana, $2: 725^{4}$. limitata, $2: 707^{6}$.

pandorus, Pholus, 2: $739^{9}$.

Panthea acronyctoides, 2: $754^{9}$. furcilla, 2: $65 \mathrm{I}^{3}, 679^{7}-80^{3}$.

Pantographa limata, 2: $73 \mathbf{I}^{7}$.

Paonias astylus, $2: 738^{\circ}$.

excaecatus, $2: 724^{7}$

myops, 2: $733^{3}$. 
Papaipema nitela, $2: 429^{4}, 403^{3}$. Papilio glaucus var. turuus, 2: $704^{1}$.

rutulus, 2: $750^{6}$

thoas, $2: 510^{4}, 554^{3}-55^{6}, 729^{3}$.

troilus, $2: 732^{6}$.

papillatus, Andricus, 2: $712^{R}$. papula, Dryophanta, 2:7124. papyraceae, Hormaphis, $2: 750^{3}$.

Paralechia cristifasciella, 2: $707^{9}$. pinifoliella, 2:65 $\mathrm{r}^{4}, 68 \mathrm{r}^{1}$.

Parallel spittle insect, 2: $686^{6}$. parallela, A phrophora, 2: $686^{6}$.

parallelopipedus, lyctus, $2: 430^{6}$, $4^{8} 3^{2}, 501^{9}$.

parallelus, Dorcas, $2: 492^{7}$. Hister, $2: 359^{4}, 372^{1}, 491^{3}$. Hypophloeus, 2: $3^{80} 9^{7}, 449^{2}$.

Parandra brunnea, 2: $70 \mathbf{I}^{8}$.

Paraphia suhatomaria, $2: 753^{8}$. var. unipuncta, 2: $706^{4}$.

Parasa chloris, $2: 529^{3}$.

Parasites or natural enemies, 1 : $20^{6}-25^{2} ; 2: 714^{4}-15^{1}$.

Paratenetus punctatus, : : $606^{4}$.

Parharmonia pini, 2: $33^{8^{2}}, 341^{1-}$ $+2^{4}$.

Paridae, I: $32^{2}$.

P'aris green, $1: 34^{9}, 37^{9}$.

parochus, Cryptorlyynchus, $2: 494^{8}$.

Paromalus bistriatus, $2: 389^{7}$. difficilis, $2: 359^{7}$.

Parorgyia acliatina, sei Olene. parorgyiae, Apanteles, I: $13^{8^{6}}$. parta, Catocala, 2: $743^{2}$.

parvicollis, Dorytomus, 2: $430^{1}$, $475^{4}$.

parvula, Dryophanta, 2: $713^{9}$. parvus, Leptostylus, 2: $702^{4}$.

Passalus cornutus, 2: $492^{2}$. patiens, Andricus, $2: 713^{8}$. pattoni, Andricus, 2: $711^{8}$. Paururus cyaneus, 2: $649^{9}, 669^{1}$. Pawpaw, injurious insects:

Aphrastus taeniatus, $2: 515^{9}$.

1 phidicles ajax, 2: $735^{4}$.

Peach bark leetle, $2: 428^{3}, 452^{1}$.

Peachtree, injurious insects: borers:

buprestis, divaricated, $2: 428^{6}$, $457^{6}$.
Peachtree, inj. insects $\left(\operatorname{con} t^{\prime} d\right)$ : borers:

flat-headed borer, common, I: $87^{2}$.

fruit tree bark beetle, $2: 453^{2}$. maple and oak twig pruner, I: $6 \mathbf{r}^{3}$.

peach bark beetle, $2 ; 428^{8}, 452^{2}$. Sesia pictipes, $2: 453^{5}$.

$\mathrm{t}$ wig borer, red-shouldered, $2: 4+2^{4}$.

twig girdler, 1: $273^{\circ}$.

flower cricket, white, $2: 603^{3}$.

leaf feeders:

brown tail moth, 1: $164^{1}$.

forest tent caterpillar, I: $I I^{8}$.

Mineola indigenella, 2: $733^{6}$.

promethea moth, $2: 557^{\circ}$.

rose beetle, $2: 575^{7}$.

Scopelosoma sidus, 2: $705^{2}$,

walking stick, 2: $534^{2}$.

Xylina antennata, $1: 130^{3}$, I $3 I^{6}$.

scale or sucking insects:

black-banded scale, $1: 200^{7}$.

box elder plant bug, $1: 239^{4}$.

Eulecanium canadense, 2 : $725^{6}$.

cerasifex, $2: 728^{8}$

cockerelli, $2: 725^{6}$.

Enschistus variolarius, 2: 6121.

Putnam's scale, I: $227^{4}$.

Peartree, beneficial insects:

Chariessa pilosa, 2: 504 .

injurious insects:

borers:

buprestis, divaricated, 2 : $45^{8^{6}}$.

flat-headed borer, common, 1: $87^{2}$.

maple and oak twig pruner, I: $6 \mathrm{I}^{3}$.

Neoclytus erythrocephalus, I: $72^{3}$.

pigeon tremex, $\mathbf{1}: 63^{6}$.

twig girdler, 1: $273^{9}$.

Urographis fasciatus, 2: $435^{9}$.

leaf feeders:

apple worm, yellow-necked, 2: $535^{7}$.
Peartree, inj. insects $\left(\right.$ cont $\left.t^{\prime} d\right)$ :

leaf feeders:

bag or basket worm, 1 : $127^{\mathbf{1}}$.

brown tail moth, $1: 164^{1}$.

cecropia moth, $2: 539^{4}$.

Cenopis reticulatana, 2 : $707^{5}$.

Erannis tiliaria, 2: $73 \mathrm{I}^{6}$.

forest tent caterpillar, I: $107^{3}$.

rose beetle, $2: 575^{7}$.

tussock moth, white marked, $1: 136^{\circ}$.

Xylina antennata, $1: 131^{8}$.

scale or sucking insects:

Eulecanium cerasifex, 2: $729^{5}$.

cockerelli, $2: 725^{6}$.

oyster scale, $1: 2 \mathbf{I}^{2}$.

Putnam's scale, $1: 227^{5}$.

Peas, injurious insects:

aphids, $1: 242^{7}$.

Xylina antemnata, I: $13 \mathbf{I}^{7}$.

Pecan, twig girdler injuring, $\mathbf{~}$ : $273^{8}$.

pectinaria, Euchlaena, 2: $706^{6}$.

pectinator, Bracon, 2: $391^{4}$.

pectinicornis, Cladius, $2: 735^{\circ}$.

Melasis, $2: 701^{5}$.

pectoralis, Hylotoma, $2: 511^{7}, 542^{3}$. $570^{8}-71^{6}, 74^{8^{6}}$.

pedalis, Pimpla, I: $1 \mathbf{I}^{8}$.

pedata, Eucoila, 2: $714^{9}$.

Tediopsis basilis, $2: 597^{9}$.

trimaculata, $2: 732^{9}$.

viridis, $2: 744^{6}$.

pedunculata, Dryophanta, $2: 712^{5}$.

Pelecotoma flavipes, $2: 722^{3}$.

pellex, Cecidomyia, 2:6203 $632^{2}-$ $33^{5}$.

pellucidaria, Therina, $2: 753^{1}$.

pelviculella, Moodna, $2: 749^{7}$.

Pemphigus acerifolii, 2: $600^{5}$.

aceris, $2: 600^{8}, 728^{7}$.

fraxinifolii, 1 : $196^{2} ; 2: 727^{3}$.

imbricator, 1 : $196^{2} ; 2: 722^{6}$.

popularius, $2: 748^{2}$.

populicaulis, $2: 620^{7}, 636^{3}, 748^{3}$.

populi-globuli, $2: 748^{2}$.

populimonilis, $2: 743^{2}$.

populiramulorum, $2: 748^{2}$. 
$247^{4} ; 2: 620^{7}, 635^{8}-36^{8}$ pseudobyrsa, $2: 74^{3}$. rhois, $1: 247^{7} ; 2: 621^{5}, 647^{3}$. tessellatus, $\mathrm{I}: 173^{1}, \mathrm{I} 95^{8}-96^{3}$. ulmifusus, $1: 247^{8} ; 2: 620^{5}, 633^{4}$. vagabundus, $2: 620^{6}, 635^{3}$.

penicellatus, Pogonocherus, 2: $737^{2}$.

penusylvanica, Nezara, 2: $717^{5}$. Nyctobates, $2: 472^{3}$.

pentagona, Aulacaspis, $2: 7 \mathrm{I} 9^{6}$.

Pentatomidae, $1: 2 t^{3}$.

Pentlue obliquata, $2: 493^{6}$. pimelia, 2: $+93^{\text {? }}$.

Penthina cyanana, see Olethreutes. nimbatana, see Olethreutes.

l'entilia misella, I: $222^{9}$.

l'epperidge tree, see Sour gum. Percnoptilota fluviata, $2: 725^{3}$. perditor, Andricus, 2: $709^{8}$. perforata, Magdalis, 2: $340^{2}, 402^{3}$.

Periclista albicollis, $2: 702^{8}$. chionanthi, $2: 73^{3}$. emarginata, 2: $703^{1}$. media, 2: $702^{9}$. purpuridorsum, 2: $702^{9}$ subtruncata, 2: $702^{9}$.

Periclistis futilis, $2: 715^{1}$. semipiceus, 2: $736^{5}$. sylvestris, $2: 736^{5}$.

Peridroma margaritosa vor. saucia, 2: $704^{\circ}$.

Perilampus, $2: 406^{9}-7^{1}$. periliti, Otacustes, I: $14^{x}$.

l'erimegatoma variegatum, $1: 1.40^{7}$.

Periodical cicada, I: $173^{9}, 231^{5}$ $37^{4}$.

Perissopterus pulchellus, 1: $208^{6}$, $231^{2}$.

perminimus, Neuroterus, $2: 7 \mathrm{rO}^{9}$. permundanum, Exartema, 2: $723^{5}$. permutana, Alceris, 2. $744^{3}$.

perniciosa, Playlloxera, 2: $7 \mathrm{r}^{8}$.

perniciosus, Aspidiotus, I: $8^{4}, \mathbf{I} 2^{6}$, $35^{9}, 173^{6}, 216^{6}-26^{5}$.

Perothops mucirla, 2: 722 . perryi, Kermes, 2: $709^{5}$.

persicoides, Cecidomyia, 2: $619^{7}$, $628^{7}$. populi-venae, $2: 7 t^{3}$.

$735^{2}$.

borers:

twig borer, red-shouldered, 2 :

$+42^{4}$

twig girdler, $1: 273^{\circ}$.

leaf feeders:

Catocala piatrix, $2: 719^{7}$.

Cenopis reticulatana, 2: $707^{5}$.

Gonodontis hypochraria, 2: phlogosaria, I'lagodis, 2: $733^{5}$. $732^{6}$,

minor, $2: 722^{4}, 742^{5}$.

P'hloeosinus dentatus, $2: 336^{9}, 337^{7}$, $335^{9}, 391^{3}-93^{7}$.

Phloeotribus frontalis, 2: $336^{6}$, $725^{8}$.

liminaris, $2: 336^{6},+25^{3},+52^{1}$.

Phloeotrya liturata, $2: 493^{\circ}$.

simulator, $2: 494^{1}$.

Phlyctaenia helvalis, $2: 7+4^{1}$.

lleterocampa maiteo, $2: 705^{7}$. I'hohetron pithecium, 2: $528^{3}, 529^{4}$.

hickory horned devil, I: $305^{\circ}$. l'hoebe, I: $137^{*}$.

persius, Thanaos, $2: 7+2^{7}$.

perspicua, Datana, 2: $737^{4}$.

Pholus achemon, 2: $739^{8}$. pandorus, $2: 739^{\circ}$.

petiolicola, Andricus, $2: 618^{9}, 625^{9}$, Phora agarici, $1: 140^{6}$. $714^{6}$.

Ceroptres, 2: $71^{6}$

petitii, Neoforus, $2: 727^{3}$.

petrophya, Sandalns, $2: 7^{\circ} 1^{3}$.

pettitana, Cenopis, $2: 512^{3}, 579^{3}$.

pettiti, Kermes, $2: 709^{5}$.

pezomachoides. Acraspis, $2: 714^{8}$. Phorodon bumuli, $1: 243^{7}$.

Pezomachus insolitus, I: $140^{3}$.

Phaeogenes hebe, I: $166^{\circ}$.

Phalonia dorsimaculana, $2: 744^{3}$.

rutilana, 2: $755^{\circ}$.

I'hellopsis obcordata, $2: 496^{6}$.

phellos, Amphibolips, 2: $712^{9}$.

Phenacoccus acericola, $1: 49,172^{6}$, $182^{7}-56^{6}$.

dearnessi, $2: 735^{2}$.

Plienolia grossa, 2: $49^{1}$.

Pheocyma lunifera, 2: $753^{1}$.

Pheosia dimidiata, $2: 747^{6}$.

Phigalia titea, 2: $728^{3}$.

philadelphica, Chrysomela, 2: Phyllotreta picta, 2: $716^{4}$ $752^{x}$.

var: spireae, Chrysomela, 2: $7+2^{3}$

Philonix fulvicollis, 2: $7 \mathrm{II}^{1}$.

gillettei, 2: $7 \mathrm{II}^{2}$.

macrocarpae, $2: 713^{5}$.

nigricollis, $2: 7 \mathrm{II}^{2}$.

villosus, 2: $713^{5}$.

Philosamia cynthia, $1: 45^{5} ; 2: 727^{6}$.

Phiprosopus callitrichoides, 2: $7+0^{7}$.

Phlegethontius rustica, 2: $737^{8}$
Phlepsius fulvidorsum, 2: $753^{6}$.

irroratus, 2: $717^{7}$. cimbicis, $\mathrm{I}: 153^{5}$.

fasciata, $1: 1+10^{6}$

incisuralis, I: $140^{6}$.

minuta, $\mathbf{I}: 15 \mathrm{~s}^{3}$

nigriceps, $1: 1+0^{5}$.

setacea, I: $158^{5}$.

Phyllaphis lagi, 2: $601^{5}-2^{3}$.

Phyllechithrus gentilis, 2: $730^{8}$.

Phyllobaenus dislocatus, 2: $389^{8}$, $449^{3}, 503^{3}$.

Phyllocnist is ampelopsiella, 2: $740^{3}$.

liquidambarisella, $2: 735^{6}$.

liriodendronella, 2: $732^{3}$.

populiella, $2: 747^{9}$.

smilacissella, $2: 740^{7}$.

Phyllodecta vulgatissima, $2: 7+2^{2}$.

Phylloecus flaviventris, see Janus integer.

Phyllotrox nubifer, 2: $567^{8}$.

Phylloxera caryae-avellana, 2: $718^{4}$.

caryaecaulis, $1: 247^{7}, 259^{1}, 331^{8}-$ $32^{9} ; 2: 619^{6}$.

caryae-fallax, $2: 7 \mathrm{I}^{4}$.

caryae-foliae, $2: 718^{5}$

caryae-globuli, 2: $718^{4}$.

caryae-gummosa, $2: 715^{4}$.

caryae-ren, $2: 718^{3}$.

caryae-semen, $2: 7 \mathrm{I}^{\mathrm{S}^{3}}$.

caryae-septum a't 2: 7 I $8^{3}$.

carvaevenae, $2: 718^{3}$. 
Phylloxera conica, $2: 713^{2}$. deplanata, 2: $715^{3}$.

depressa, $2: 715^{\circ}$

forcati, $2: 7 \mathrm{Is}^{5}$.

foveata, 2: $620 ;$.

foveula, 2:610\%, 620 $2,718^{5}$.

glohosum, 2: $718^{6}$.

intermedia, 2: $718^{7}$.

nyssac, $2: 735^{\circ}$.

perniciosa, $2: 715^{8}$.

picta, 2: $718^{7}$.

pilosula, 2: $7 \mathbf{r S}^{7}$.

popularia, $2: 745^{3}$.

prolifera, $2: 74^{3}$.

quercet $i, 2:-\mathbf{I r}^{3}$.

rileyi, $2: 710^{2}, 711^{3}$.

rimosalis, $2: 718^{\circ}$.

salicicola, 2: $745^{\star}$.

spinosa, $2: 718^{8}$.

spinuloida, $2: 718^{4}$.

subelliptica, $2: 715^{9}$.

symmetrica, $2: 718^{9}$.

Phymatodera bicolor, 2: $393^{2}$.

Phymatodes amoenus, 2: $502^{4}$.

dimidiatus, $2: 650^{2}, 669^{7}-70^{6}$.

variabilis, $2: 426^{7}, 433^{7}-34^{3}$.

varius, $2: 702^{1}$.

phymatodis, Brachistes, 2: $463^{\circ}$

Physcus varicornis, I: $208^{6}, 227^{7}$.

Physocnemum brevilineum, 2: $4^{28^{8}}, 4^{62^{1}}$.

Phytocoris eximius, 2: $65 \mathrm{I}^{9}, 685^{5}$. Pliytodecta pallida, 2: $510^{8}, 55^{6}$.

Phyton pallidum, 2: $715^{3}$.

'Phytonomus punctatus, $1: 15^{\text {'. }}$

phytophagica, Iemichroa, 2: $703^{\sharp}$.

Phytoptus, see Erioplyyes.

piatrix, Catocala, 2: $719^{7}$.

Piazorhinus pictus, $2: 703^{9}$.

scutellaris, $2: 703^{4}$.

piceae, (ryphalus, $2: 753^{9}$.

piceaella, Recurvaria, $2: 754^{3}$.

piceaperda, Dendroctonus, I: $6^{\mathrm{m}}$, $7^{1} ; 2: 33^{9}, 379^{7}-55^{9}, 693^{3}$.

piceus, Ceruchus, $2: 492^{7}, 701^{5}$.

Picidae, $1: 30^{3}$.

picipes, Euderces, see F:. picipes,

Rhaldopterus, $2: 731^{5}$.

picivorus, Pachylolius, 2: $751^{6}$.

Picoides americanus. $1: 28^{9}$.

arcticus, $1: 28^{9}$. picta, Centrodera, 2: $715^{5}$.

Harmonia, $1: 231^{4}$.

Mamestra, 2: $608^{4}$.

l'hyllotreta, 2: $716^{4}$.

Pliglloxera, 2: 7157.

pictipes, tiesia, $2: 428^{3}, 453^{4}-54^{5}$.

pictus, Cyllene, $1: 256^{6}, 264^{1}-66^{9}$.

P'iazorhinus, $2: 703^{9}$.

Picus villosus, $2: 454^{1}$.

Pieris rapae, 2: 609 ?

Pigeon tremex, I: $50^{7}, 54^{9}, 6 \mathbf{I}^{5}-64$, $26 \mathrm{I}^{*}$.

piger, Trichius, $2: 735^{\circ}$.

pigra, Neuroterus, 2: $713^{3}$.

pileatus abietorum, Ceophloeus, I: $29^{2}$.

Pilophorus crassipes, 2: $651^{9}, 686^{1}$.

pilosa, Chariessa, sec C. pilosa.

pilosula, Phylloxera, 2: $715^{7}$.

pilosus, Rhinomacer, 2: $667^{5}$.

pilulae, Cecidomyia, $2: 619^{2}, 627^{4}$ $714^{7}$.

pimelia, Penthe, 2: $493^{7}$.

Pimpla, 1: $2 x^{3}$.

annulipes, $1: 139^{6}, 139^{7}$.

conquisitor, $1: 112^{8}, 127^{8}, 138^{5}$, $139^{7} ; 2: 417^{2}-18^{1}$.

hrticauda, r: $130^{3}$.

inquisitor, $1: 112^{9}, 127^{8}, 138^{2}$, $139^{7}, 140^{1}$.

perialis, I: I I $2^{5}$

pimplat, Bathythrix, I: $140^{3}$.

l'ine, beneficial insects:

11 yinocera subaenea, $2: 60 t^{3}$.

1Iyperaspis binotata, 2: $605^{6}$.

injurious insects, $2: 339^{1}$.

borers: $2: 751^{1}-52^{4}$.

ants, white, 1: $87^{9}$.

apple wood stainer, $1: 200^{6}$.

bark beetle, $1: 7^{3}$.

hark borers, $2: 333^{1}-3 r^{1}$.

liatyle suturalis, $2: 649^{6}$, $663^{3}$.

buprestis, golden, $2: 645^{7}$, $655^{\circ}$

Callidium aereum, $2: 450^{4}$.

Cardiophorus gargates, 2: $667^{1}$

cedar tree borer, 2:675?.

Chrysobothris scabripenuis, $2: 753^{8}$.
Pine, inj. insects (cont'd):

borers:

Clerus quadriguttatus, $\boldsymbol{z}$ : $649^{3}, 666^{3}$.

coarse writing bark beetle, 2: $33^{x^{4}}, 345^{\circ}, 351^{8}$

Criocephalus agrestis, 2: $649^{2}, 659^{3}$.

Dicera tuberculata, 2: $645^{8}$, $656^{6}$.

Dryocuetes autographus, 2: $672^{7}$.

eastern pine wood stainer, 2: $339^{7}$.

IIister lecontei, $2: 401^{2}$. parallelus, $2: 491^{4}$.

IIylotrupes bajulus, $2: 649^{6}$, $664^{2 .}$.

Leptura zebra, 2:45 I'.

Melanophila longipes, 2: $753^{8}$.

Melanotus communis, 2: $492^{6}$.

Nantucket pine moth, 2: $340^{3}$.

Neoclytus erythrocephalus, I: $73^{1}$.

pales weevil, $2: 649^{6}, 664^{5}$.

pine bark beetle, $2: 33^{4}$, $35 I^{5}, 352^{3}$.

pine borer, blue, $2: 679^{8}$, $660^{2}$

larger flat-headed, $2: 64 S^{6}$, $653^{x}$.

lesser, 2: $049^{3}, 661^{3}$.

ribbed, $2: 339^{4}, 366^{6}$.

pine Hylurgops, $2: 649^{7}, 665^{2}$.

pine tip moth, 2: $404^{4}$.

pine weevil, white, $2: 339^{9}$, $397^{2}$.

pitch mass borer, 2: $33^{2}$, $3+1^{2}$.

pitch midge, $2: 340^{6}$.

pitch pine Retinia, $2: 340^{4}$.

Pityobius anguinus, 2: $75 \mathbf{I}^{3}$.

prionus, broad-necked, 2: $456^{7}$.

Harris's, $2: 649^{2}, 659^{2}$.

lesser, $2: 4^{8} 7^{6}$.

Pytho americanus, 2: $368^{6}$ 6()$^{5}$. 
Pine, iuj. insects (con' $\left.d^{\prime}\right)$ : borers:

Rhyncolus brunneus, 2: $666^{6}$.

sawyer, 2: $360^{7}$.

Scymnus tenebrosus, $2: 666^{9}$.

spruce bark beetle, $2: 3^{56}$. minute, $2: 338^{6}, 359^{7}$.

Tenebrioides castanea, 2 : $492^{2}$.

tickler, 2: $365^{2}$.

Tomicus, southern, 2: $335^{6}$, $35^{\top}$.

Tomicus caelatus, $2: 33 \mathrm{~S}^{5}$, $354^{3}$.

turpentine bark beetle, 2 : $33^{3}, 342^{5}$.

Urocerus, white-horned, 2: $665^{5}$.

Urographis fasciatus, 2: $426^{x},+34^{*}$.

Xylotrechus sagittatus, 2: $649^{4}, 663^{1}$.

gall irsect:

pine needle gall $\mathrm{fl} y, 2: 340^{9}$.

leaf feeders: $2: 752^{\mathbf{6}}$.

Amorbia humerosana, 2: $737^{4}$.

bag or basket worm, $1: 127^{2}$.

Brachys ovata, 2: $514^{4}$.

Cingilia catenaria, $2: 706^{5}$.

Cistela sericea, 2: $518^{6}$.

Dichelonycha albicollis, 2: $694^{6}$.

elongata, 2: $716^{4}$.

Epagoge sulfureana, 2: $730^{7}$.

fir sawfly, $2: 3+0^{8}$.

Hydriomena contracta, 2 : $754^{2}$.

larch lappet, $2: 65 \mathrm{I}^{3}, 680^{3}$.

Melanolophia canadaria, 2: $753^{3}$.

Oligia versicolor, $2: 754^{1}$.

pine hawk moth, IIarris's, 2: $65 \mathrm{I}^{2}, 679^{3}$.

pine leaf miner, $2: 65 \mathrm{r}^{4}$, $68 \mathrm{I}^{2}$.

pine sawfly, Abbott's, 2 : $3+0^{7}$.

pine tufted caterpillar, white, $2: 65 \mathrm{I}^{3}, 679^{8}$.
Pine, inj. insects (cont' $d$ ):

leaf teeders:

pine webworm, 2: $65 \mathrm{I}^{2}, 676^{7}$. false, $2: 650^{3}, 676^{3}$.

promethea motli, $2: 557^{\circ}$.

sawlly, Le Conte's, $2: 340^{6}$, $4 \sqrt{4}$.

Therina athasiaria, $2: 706^{5}$. root feeder:

Lachnosterna fusca, 2: $753^{5}$.

scale or sucking insects: 2 : $753^{5}$.

cicada, dog day, $1: 23^{3}$.

clastoptera, pine, $2: 657^{1}$.

Eutettix strobi, 2: $685^{5}$.

hemlock scale, $2: 652^{6}, 690^{3}$.

Phlepsins fulvidorsum, 2: $753^{6}$.

pine bark aphid, I: $172^{9}$, I $92^{5}$,

pine jeaf scale, 1 : $173^{9}, 229^{6}$.

ring-legged tree bug, 2: $5^{55^{9}}$.

spittle insects, $2: 652^{2}, 686^{4}$.

Pine, hard, insects on:

Coenus delius, 2: $697^{3}$.

Corymbites hieroglyphicus, 2: $692^{9}$.

propola, $2: 692^{7}$.

Ips quadriguttatus, $2: 692^{4}$.

Notoxus anchora, 2: $696^{6}$.

bifasciatus, $2: 696^{2}$.

Rhinomacer pilosus, 2: $667^{5}$.

tree cricket, black-horned, 2 : $699^{3}$.

four-spotted, 2: $6099^{9}$.

beneficial insects:

Hydnocera humeralis var. cyanescens, $2: 693^{8}$.

pallipennis, 2: $693^{6}$.

lace-winged fly, 2: $697^{6}$.

lady beetle, fifteen-spotted, 2: $604^{6}$.

nine-spotted, $2: 69 I^{2}$.

three-banded, $2: 69 \mathrm{I}^{7}$.

Lebia grandis, $2: 690^{\circ}$.

Nicromus montanus, 2: $697^{9}$. pine tree cricket, $2: 698^{2}$.

sucking insects:

Acholla multispinosa, 2: $613^{9}$.
Pine, hard (cont' $d)$ :

beneficial insects:

sucking insects:

Camptobrochis grandis, 2: $614^{2}$.

Euschistus fissilis, 2:6 $1 \mathrm{IO}^{5}$. politus, $2: 6 \mathrm{I} 2^{9}$. tristigmus, $2: 612^{4}$.

Podisus placidus, 2: $607^{2}$, $607^{6}$.

injurious insects:

borers:

Chrysobothris dentipes, 2: $648^{9}, 657^{9}$.

floricola, $2: 649^{1}, 65^{5}$. pusilla, 2: $649^{\mathrm{i}}, 65^{7}$.

coarse writing bark beetle, 2: $35 t^{8}$.

Limonius confusus, 2: $667^{\circ}$.

Mlagdalis alutacea, 2: $402^{9}$. perforata, 2: $102^{4}$.

Nantucket pine moth, 2: $405^{4}$.

Pales weevil, 2: $664^{6}$.

pine borer, larger flatheaded, $2: 65 t^{9}$.

ribbed, 2: $366^{7}$.

smaller flat-headed, 2: $6+8^{7}, 654^{9}$.

pine Hylurgops, 2: $665^{3}$.

pine tip moth, $2: 340^{2}, 403^{3}$. pitch pine retinia, 2: $407^{4}$.

pitch twig moth, 2: $340^{4}$, $407^{5}$.

Pogonocherus mixtus, 2: $6+9^{5}, 663^{8}$.

sawyer, white spotted, 2 : $364^{2}$.

tickler, 2: $365^{3}$.

Tomicus, southern, $2: 35 t^{9}$, $356^{8}$.

Tomicus caelatus, $2: 354^{8}$,

leaf feeders:

Abbott's pine sawfly, 2: $414^{5}$.

Chrysomela bigsbyana, 2: $5 \mathrm{II}^{4}, 566^{2}$.

Cryptocephalus quadrimaculatus. 2: $605^{7}$. schreibersii, 2: $695^{5}$.

Ernobius mollis, 2: $694^{3}$. fir sawfly, $2: 415^{6}$. 
Pine, hard, inj. insects (cont'a): leaf feeders:

grapevine beetle, light-loving, 2:651 $652^{6}$.

Metachroma marginalis, 2 : $651^{6}, 682^{9}$.

pine chrysomela, 2: $605^{\circ}$.

rose beetle, 2: $575^{\circ}$.

sucking insects:

bramble tlea louse, 2: $652^{4}$, $685^{9}$.

Brochymena quadripustulata, 2: $590^{4}$.

clastoptera, obtuse, $2: 687^{2}$.

Dichrooscytus rufipennis, 2: $652^{9}, 657^{\circ}$.

false chinch bug, $2: 65 \mathrm{I}^{9}$, $685^{8}$.

Gypona octolineata, $2: 652^{4}$, $688^{6}$.

hemlock scale, $2: 690^{4}$.

Nabis rufusculus, 2: $652^{3}$, $688^{2}$.

Oliarius quinquelineatus, 2 : $652^{1}, 686^{3}$

Phytocoris eximius, 2: $651^{9}$, $685^{9}$.

Pilophorus crassipes, 2: $651^{9}, 686^{9}$.

spittle insect, parallei, 2 : $686^{7}$.

quadrangular, 2: $686^{8}$.

Stictocephala inermis, 2 : $652^{2}, 687^{5}$.

Pine, pitch, injurious insects: borers:

Dicerca punctulata, 2:645*, $656^{4}$.

pine borer, ribbed, 2: $367^{1}$. pitch midge, $2: 4 \mathrm{IO}^{5}$.

leaf feeders:

fir sawfly, $2: 415^{6}$.

pine needle gall fly, 2 : $+23^{6}$.

sucking insect:

pine scale, woolly, $2: 652^{5}$, $689^{7}$.

Pine, scrub, Cecidomyia inopis injuring, 2: $752^{9}$.

Pine, southern yellow, pine scale, Pine hawk moth, Harris's, $2: 65 \mathrm{I}^{2}$,

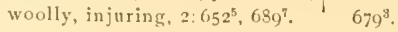
2: $500^{5}$.

Euschistus variolarius, 2:61 $\mathrm{I}^{2}$. injurions insects:

borers:

Acanthosinus obsoletus, 2: $649^{4}, 662^{8}$.

balsam bark borer, 2:376 ${ }^{2}$. coarse writing bark beetle, 2: $354^{y}$.

I)icerca tenebrosa, 2:6.48 $657^{2}$.

Eustrophus repandus, 2: $667^{5}$.

pine bark beetle, $2: 354^{8}$. pine borer, ribbed, $2: 366^{7}$. pine Hylurgops, 2: $665^{7}$.

pine wood stainer, eastern, 2: $371^{2}$.

Pissodes affinis, $2: 402^{2}$.

Pityogenes $s p ., \mathrm{b}, 2: 374^{8}$.

Pityophthorus sp., 2: $372^{8}$.

sawyer, white spotted, 2 : $364^{2}$.

tickler, $2: 365^{3}$.

Tomicus, southern, $2: 357^{1}$.

Tomicus caelatus, $2: 354^{8}$.

leaf feeders:

Abbott's pine sawfly, 2: $414^{5}$.

Eulecanium pyri, 2: $717^{9}$.

imperial moth, $2: 65 \mathrm{I}^{2}, 677^{6}$.

pine tube builder, 2: $65 \mathrm{t}^{5}$, $681^{9}$.

Pine, yellow, tickler injuring, 2: $365^{5}$.

Pine bark aphid, $\mathbf{1}$ : $172^{9}, 192^{7}-95^{8}$.

Pine bark beetle, $2: 334^{4}, 33^{4}, 35^{4}$ $54^{2}$.

Pine borer, blue, $2: 649^{3}, 660^{2}-6 \mathbf{x}^{2}$. larger flat-headed, $2: 648^{6}, 653^{\text {R }}$ $54^{7}$.

lesser, $2: 649^{4}, 661^{2}-62^{7}$.

ribbed, $2: 339^{5}, 366^{5}-68^{5}$.

smaller flat-headed, $2: 648^{7}, 654^{8}-$ $55^{7}$.

Pine Chrysomela, 2: $653^{4}, 695^{1}$.

Pine clastoptera, 2: $686^{9}$.
Pine, white, beneficial insects: | P'ine Hylurgops, 2: $649^{7}, 665^{1}-66^{2}$. American bark beetle destroyer, I'jne leaf miner, $2: 65 \mathrm{I}^{4}, 68 \mathrm{I}^{1}$.
Pine lcaf scale, $1: 173^{9}, 229^{6}-31^{5}$.

Pine moth, Nantucket, $2: 340^{3}$, $405^{3}-7^{4}$.

Pine needle gall fly, $2: 340^{9}, 423^{6}-$ $25^{7}, 621^{9}$.

Pine sawfly, Abbott's, $2: 340^{7},+14^{4-}$ $15^{5}$.

Pine sawyer, $2: 334^{9}$.

Pine scale, woolly, $2: 652^{5}, 659^{6}$ $90^{1}$.

Pine tip moth, $2: 340^{3}, 403^{2}-5^{2}, 409^{6}$.

l'ine tree cricket, $2: 698^{1}$.

Pine tube builder, $2: 651^{5}, 681^{8}-82^{5}$.

Pine tufted caterpillar, white, 2 : $651^{3}, 679^{7}-80^{1}$.

Pine twig moth, $2: 41 \mathrm{I}^{6}$.

Pine webworm, 2: $651^{1}, 676^{1}-77^{5}$. false, $2: 650^{9}, 676^{3}$.

Pine weevil, white, $2: 339^{9}, 397^{1}-$ $401^{2}, 402^{1}, 402^{5}, 402^{9}$.

Pine wood stainer, eastern, $2: 339^{7}$, $371^{1}-72^{7}$.

pinetum, Jophyrus, $2: 752^{7}$.

pinguidorsum, I'teronus, $2: 748^{9}$.

pinguis, Strongylogaster, $2: 745^{7}$.

pini, Cixius, $2: 753^{6}$.

Clastoptera, $2: 686^{9}$.

Fuderces, 2: $75 \mathrm{I}^{4}$.

Mycetophagus, 2: $752^{4}$.

Oecanthus, see O. pini.

Parharmonia, 2: $338^{2}$.

Tomicus, see T. pini.

pinicola, Iyponolyx, 2: $751^{6}$.

l'olygnatus, $2: 412^{\gamma}$.

Schizoneura, 2: $753^{6}$.

pinicolana, Epinotia, 2: $753^{4}$.

pinicolens, Chaitophorus, 2: $753^{7}$.

pinicorticis, Chermes, 1 : $172^{9}, 192^{1}-$ $95^{8}: 2: 604^{9}$.

pinifoliae, Chionaspis, $1: 173^{9}$, $229^{6}-3 \mathrm{r}^{5}$.

pinifoliella, Paralechia, 2: $65 \mathrm{I}^{4}$, $68 I^{1}$.

Pinipestis zimmermani, $2: 340^{3}$, $403^{3}-5^{2}, 409^{6}$.

piniphilus, Cossonus, 2: $751^{8}$.

pini-rigidae, Cecidomyia, $2: 340^{\circ}$, $423^{6}-25^{7}, 621^{9}$.

Lophyrus, 2: $752^{7}$. 
pinivora, Eupogonius, $2: 75^{6}$.

Pinus sylvestris, 2: $68 \mathrm{~S}^{1}$.

piperoides, Andricus, $2: 7 \mathbf{1} \mathbf{2}^{3}$.

Pissodes affinis, 2: $340^{1}, 401^{7}, 402^{1}$. dubius, $2: 340^{1}$, $401^{5}$.

strobi, 2: $339^{9}, 397^{1}-401^{2}, 402^{1}$, $402^{5}, 402^{9}$.

pissodis, Bracon, 2: $40 \mathrm{I}^{2}$.

pisum, Pontania, 2: $620^{9}, 637^{4}$.

Pitch mass borer, 2: $338^{2}, 3+1^{1}-$ $42^{4}$.

Pitcl midge, 2: $340^{5},+10^{4}-13^{2}$.

Pitch pine retinia, 2: $340^{4}, 407^{4}$.

Pitch twig moth, 2: $340^{5}, 407^{8}-10^{3}$.

pithecium, Phobetron, 2: $528^{3}$, $529^{4}$.

Pityobius anguinus, 2: $75 \mathbf{I}^{3}$.

Pityogenes, $2: 337^{5}, 339^{8}$.

sp., 2: $375^{2}, 376^{6}$.

st. a, $2: 374^{3}$.

sp. b, $2: 374^{7}-75^{6}$.

consimilis, $2: 482^{5}$.

plagiatus, $2: 752^{2}$.

sparsus, $2: 752^{2}$.

pityophthori, Caenophanes, 2: $389^{9}$.

Caudonia, 2: $393^{7}$.

Pityophthorus, $2: 339^{3}$.

sp., I: $257^{8}, 296^{1} ; 2: 372^{7}-74^{2}, 49 \mathrm{I}^{4}$.

annectens, $2: 75 \mathrm{I}^{9}$.

cariniceps, $2: 650^{6}, 674^{1}$.

confinis, $2: 751^{9}$.

coniperda, $2: 75 \mathrm{I}^{8}$.

consimilis, $2: 503^{\circ}, 737^{2}$.

cribripennis, $2: 751^{9}$.

fagi, 2: $702^{6}$.

frontalis, $2: 702^{6}$.

hirticeps, $2: 75 \mathrm{I}^{9}$.

lautus, $2: 75 x^{9}$.

minutissimus, I: $257^{7}, 295^{1}$.

plagiatus, $2: 752^{1}$.

puberulus, 2: $75^{1}$.

pulchellus, $2: 752^{1}$.

pulicarius, $2: 751^{8}$.

pullus, 2: $751^{8}$.

querciperda, 2: $7 \mathrm{O}^{6}$.

sparsus, $2: 752^{1}$.

tuberculatus, $2: 753^{9}$.

placidus, Podisus, see P. placidus.

plagiata, Olene, $2: 725^{2}$. plagiatus, Laemosaccus, 2: 7o3 9 Pityogenes, 2: $752^{2}$.

Pityophthorus, 2: $752^{1}$.

Plagionotus speciosus, $1: 49,50^{5}$, $51^{6}-56^{7} ; 2: 443^{x}$.

Plagodis fervidaria, 2: $706^{5}$. phlogosaria, 2: $733^{5}$.

planatus, Silvanus, $2: 73 \mathrm{r}^{3}$.

Plane tree, American, resistance to insect attack, $1: 47^{5}$.

Plane tree, oriental, resistance to insect attack, I: $47^{5}$.

Plant galls, see Gall insects.

Plant lice, I: $7^{5}, 12^{4}, 35^{5}, 36^{2}, 172^{1}$, $24 \mathrm{I}^{2}-52^{9} ; 2: 615^{9}-16^{1}, 6 \mathbf{1} 6^{6}, 709^{2}$, $717^{8}, 74^{2}, 750^{8}, 753^{6}, 754^{5}, 755^{2}$; parasites, 2: $604^{6}, 697^{5}$.

Platagrotis condita, 2: $75^{2}$.

platalea, Cossonus, see C. platalea. platanana, Ancylis, 2: $719^{2}$. platanella, Nepticula, 2: $7 \mathbf{1} 9^{2}$. platanicola, Lachnus, 2: $719^{3}$. platea, Nepticula, $2: 708^{4}$.

Plates, explanation of, I: a333a.434; $2: 757-800$. See also Fig. ures and plates.

Plathypena scabra, $2: 7+7^{4}$.

Platycerus depressus, $2: 722^{2}$. quercus, $2: 722^{2}, 727^{6}$.

Platydema americanum, 2: $497^{5}$. ruficorne, $2: 497^{3}, 497^{6}$. subcostatum, 2: $497^{7}, 667^{4}$.

Platynota flavedana, $2: 581^{5}, 728^{4}$. sentana, $2: 738^{5}$.

Platynus punctiformis, $1: 153^{7}$.

Platypus compositus, $2: 720^{9}$. quadridentatus, $2: 720^{9}$.

plebeia, Sphinx, $2: 74 \mathrm{r}^{2}$.

Plectrodera scalator, 2: $74^{66}$.

Plegaderus transversus, $2: 49 I^{7}$.

Plemyria hastata, see Rheumaptera.

plicata, Chlamys, 2: $703^{6}$.

Plocamus hispidulus, 2: $721^{2}$.

Plocetes ulmi, 2: $72 t^{6}$.

Plochionus timidus, I: $14^{6{ }^{1}}$.

Plum curculio, 2: $58 \mathrm{I}^{7}$.

Plumtree, injurious insects: borers:

buprestid, divaricated, 2: $45^{8^{6}}$
Plumtree, inj. insects (cont' $d$ ):

borers:

flat-headed borer, common, 1: $87^{2}$.

fruit tree bark beetle, $2: 453^{2}$.

hick ory borer, banded, $1: 268^{\text {t }}$.

Liopus punctatus, $2: 432^{5}$.

maple and oak twig pruner, 1: $61^{3}$.

peach bark beetle, $2: 423^{3}, 452^{2}$. Sesia pictipes, $2: 42 S^{3}, 453^{4}$.

leaf feeders:

Adoneta spinuloides, 2: $706^{9}$.

Apatela brumosa, 2: $704^{5}$.

bag or basket worm, I: $127^{1}$.

Basilarchia archippus, 2: $704^{2}$. astyanax, 2: $704^{2}$.

brown tail moth, I: $164^{1}$.

Coscinoptera dominicana, 2: $737^{3}$.

Deilephila lineata, $2: 724^{6}$.

forest tent caterpillar, I: $\mathrm{IO}^{3}$, $110^{8}$.

hag moth caterpillar, $2: 528^{5}$.

Hemaris thyshe, 2: $738^{3}$.

larch lappet, 2: $68 \mathrm{o}^{3}$.

luna moth, 2: $527^{\text {? }}$.

Nineola indigenella, 2: $733^{6}$.

Paonias excaecat us, 2: $724^{7}$.

Papilio glacus var. turnus, 2 : $704^{1}$.

promethea moth, $2: 557^{\circ}$.

rose beetle, $2: 575^{\circ}$.

Schizura unicornis, 2: $705^{9}$.

Sisyrosea textula, 2: $721^{4}$.

Smerinthus jamaicensis, 2: $724^{7}$

Strymon titus, 2: $733^{4}$.

Thecla liparops, $2: 704^{3}$.

tussock moth, white marked, 1: $136^{8}$.

viceroy, $2: 559^{7}$.

Xylina antennata, $I: 13 I^{7}$.

scale or sucking insects:

Aspidiotus juglans-regiae, 2: $719^{8}$.

black-banded scale, I: $20 \mathbf{I}^{1}$, $20 I^{3}$.

box elder plant bug, $x: 239^{4}$.

Brochymena quadripustulata, 2: $590^{8}$. 
Plumtree, inj. insects (wnt'd ): scale or sucking insects:

J. ulecanium capreac, $2: 74^{\circ}$. crasifex, 2: $728^{*}$. cockerelli, $2: 725^{6}$. juglandis, $2: 71)^{9}$. ring-legged tree bug, 2 $500^{\prime}$.

Plumtree, sugar, green oak caterpillar injuring, $2: 52 \mathrm{I}^{7}$.

Plumtree, wild, injurious insects: Jeaf feeders, $2: 732^{7}$.

Calligrapha scalaris, $2: 750^{5}$ Clilorippe clyton, 2: $725^{9}$. Euclea chloris, $2:-706^{9}$. Paonias myops, 2: $733^{4}$. Papilio troilus, $2: 732^{6}$. tussock moth, white marked, I: $136^{9}$.

sucking insects: $2: 732^{9}$. pmirsa, ('hrysomela, 2: $73 \mathrm{I}^{5}$. pocularis, Prionus, $2: 75 \mathrm{I}^{4}$. podagrae, Andricus, $2: 623^{8}, 714^{5}$, $714^{6}$.

Podapion gallicola, $2: 75 \mathrm{I}^{6}$. polisi, Telenomus, $2: 609^{3}$.

Trissolcus, $2: 60 t)^{3}$.

Podisus $s p .$, I: $24^{4}$.

maculiventris, $2: 605^{5}-9^{2}$. modestus, 2: 610 1 .

placidus, $1: 24^{5}, 113^{5}, 161^{9}, 309^{7}$; 2. $53 I^{5}, 55 I^{2}, 60_{1}^{-1}-3^{4}$.

serieventris, $1: 113^{6}, 161^{9}, 166^{3}$.

spinosus, I: 1. $6^{1}$, I $53^{\prime} ; 2: 5+3^{9}$, $608^{7}$.

Podosesia fraxina, $\mathrm{I}: 5 \mathrm{I}^{5}, 92^{3}$. syringae, I: $5 \mathrm{I}^{\mathrm{k}}, \mathrm{IO}^{1}$.

Joecilocapsus goniphorus, $2: 728^{7}$.

Joecilonota cyanipes, $2: 76^{\circ}$.

Poecilostoma inferentia, $2: 750^{4}$.

logonocherus mixtus, 2: $649^{6}$, $663^{x}$.

penicellatus, $2: 737^{\circ}$.

Poison ivy, sei Jvy, poison.

polita, 1)ryoplyanta, $2: 61()^{1}, 626^{1}$. politana, Eulia, 2: $65 \mathrm{I}^{5}, 6.81^{8}-32^{5}$.

politus, Agrilus, $2: 729^{9}, 7+1^{4}$.

luschistus, 2: $612^{2}-13^{3}$.

'somus, $2: 720^{9}$.

Xyloterus, sic X. politus.

I'olychrosis botrana, 2: $732^{2}$. polygama, Catocala, 2: $705^{5}$. E'ar. crataegi, Catocala, $2: 734^{6}$.

'olygnotus pinicola, $2: 412^{4}$. salicicola, $1: 30 \mathrm{r}^{8}$.

Polygonia comma, 2: $509^{5}, 545^{6}-$ $4^{2,1}$.

faunus, $2: 7+2^{6}$.

interrogationis, $2: 509^{5}, 5+4^{9}-45^{4}$. prognt, 2: $509^{6}, 546^{8}$.

polygraphi, Cecidostiba, 2: $390^{1}$. Decatomidea, $2: 390^{1}$.

Polygrapluus rufipenuis, $2: 33 \mathrm{~s}^{8}$, $354^{4}, 376^{7}, 356^{1}-90^{4}, 503^{7}, 673^{2}$.

polyphemus, Telea, $2: 507^{7}, 526^{1}$.

pometaria, Alsopliila, $2: 706^{3}$.

Inisopteryx, 2: $547^{7}$.

pomonella, Carpocapsa, 2: $609^{2}$.

pomum, Pontania, 2: $620^{9}, 636^{9}-$ $37^{3}$.

Salix, 2:636 $637^{9}$.

l'ontania borealis, $2: 745^{6}$,

consors, $2: 7+5^{6}$.

desmodiuides, 2: $621^{1}, 638^{1}$.

gracilis, $2: 7+5^{6}$.

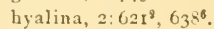

pallicornis, 2: $7+I^{3}$.

pisum, 2: $620^{\circ}, 637^{4}$.

pomum, 2:620, $6366^{7}-37^{3}$.

populi, $2: 7466^{8}$.

robusta, 2: $746^{3}$.

terminalis, $2: 745^{7}$.

Poplar, injurious insects, $1: 49$. borers: $2: 746^{3}$.

Acanthoderes decipiens, 2 : $+29^{8},+73^{4}$.

Aegeria apiformis, $2: 429^{4}$, $472^{\circ}$

tibialis, $2: 429^{7}, 472^{2}$.

bronze birch borer, $1: 287^{3}$.

buprestid, banded, $2: 459^{3}$.

carpenter worm, I: $\mathrm{So}^{4}, 84^{3}$.

clearwing, three banded, 2 : $47 \mathrm{I}^{2}$.

Cossonus platalea, $2: 428^{4}$, $455^{4}$.

Dorytomus parvicollis, 2: $430^{\prime}, 475^{4}$.

vagenotatus, $2: 430^{2}, 475^{2}$.

Hyperplatys maculatus, 2 : $+33^{1}$.

linden borer, r: $91^{9}$.
Poplar, inj. insects (cont' $d)$ : borers:

Mecas inornata, $2: 741^{4}$.

Jycetochares binotata, 2: $489^{6}$.

Oberea schaumii, $2: 493^{3}$. poplar borer, I: $5 \mathrm{I}^{6}, 0 \mathrm{~S}^{1}$.

poplar carpenter worm, 2: $430^{2}, 46^{2}$.

prionus, broad-necked, 2: $456 ?$.

Saperda concolor, $2: 429^{4}, 474^{1}$. stenopsis argenteomaculatus, 2: $721^{2}$.

Stenoscelis brevis, $2: 494^{6}$.

Tritoma tboracica, $2: 494^{3}$.

willow borer, mottled, $1: 5 \mathrm{r}^{7}$, roos.

willow shoot sawfly, I: $302^{5}$.

Nyloterus sp., I: $257^{7}, 294^{*}$.

gall insects:

Pemphigus populi-transversus, $1: 247^{5}$.

poplartwig gall, $2: 620^{5}, 634^{3}$. vagabond gall, $2: 620^{6}, 635^{5}$.

leaf feeders: $2: 746^{7}-47^{9}$.

American dagger moth, 2: $525^{3}$.

American silk worn, $2: 526^{6}$,

Apatela impleta, $2: 749^{3}$.

apple tent caterpillar, $2: 55 \mathrm{I}^{2}$.

bag or basket worm, $r: 127^{2}$.

Basilarchia archippus, $2: 704^{9}$. arthemis, $2: 7+2^{6}$.

Brachys aerosa, 2: $513^{4}$.

Catocala cara, $2: 7+3^{3}$.

parta, $2: 743^{2}$.

relicta, $2: 7+3^{3}$.

Cecropia moth, 2: $539^{5}$.

Cerura scitiscripta, $2: 7+3^{7}$.

Cleora cribrataria, $2: 743^{\circ}$, $754^{\circ}$.

Cotalpa lanigera, 2: $724^{5}$.

cottonwood leaf beetle, I: $255^{7}, 317^{8}$.

Crepidodera helxines, $2: 742^{2}$. dagger moth, smeared, $2: 5 \mathbf{I r}^{2}$, $560^{2}$.

Deilinia erythremaria, $2: 7+3^{8}$.

Ectropis crepuscularia, 2: $7+3^{3}$. 
Poplar, inj. insects (iont' $d$ ): leaf feeders:

Elleschus bipunctatus, $2: 7+2^{5}$. elm caterpillar, spiny, I: $105^{\circ}$, $155^{9}$.

elm sawfly, I: $105^{5}, 155^{7}$.

Euchlaena pectinaria, 2: $706^{6}$.

Eustroma testata, $2: 7+3^{*}$.

forest tent caterpillar, $1: \mathbf{1 0 7}^{-4}$, 110 .

Harpyia borealis, $2: 7+3^{5}$. cinerea, $2: 510^{9}, 559^{3}$.

io caterpillar, $2: 522^{3}$.

leaf roller, oblique banded, $2: 530^{\circ}$.

If arumba modesta. $2: 742^{8}$.

Melasoma tremulae, $2: 565^{\circ}$.

Metachroma pallida, 2: $703^{\dagger}$.

Metanema quercivoraria, 2: $706^{6}$.

Metrocampa praegrandaria, 2: $749^{\circ}$.

oak tussock caterpillar, 2 $523^{3}$.

Paonias excaecatus, 2: $724^{;}$.

Papilio glaucus arar. turnus, 2 $704^{\prime}$.

thoas, 2: $729^{3}$.

Phlyctaenia helvalis, s: $\mathrm{iH}^{1}$.

Phyllodecta vulgatissima, 2: $742^{8}$.

poplar leaf beetle, $2: 510^{5}$, $555^{6}$.

poplar sawfly, $2: 511^{6}, 565^{2}$.

poplar tent maker, $2: 5 \mathrm{II}^{2}$, $560^{6}$.

Proleucoptera albella, 2: $7+4^{5}$.

promethea moth, $2: 557^{\circ}$.

Pteronus hudsonii, 2: $51 \mathrm{r}^{6}$, $569^{7}$.

vertebratus, $2: 511^{6}, 570^{3}$.

Pyrophila pyramidoides, 2: $704^{7}$.

Schizura semirufescens, 2 : $7+3^{6}$.

unicornis, 2: $705^{\circ}$.

Serica trociformis, 2: $514^{7}$.

Smerinthus jamaicensis, 2: $724^{7}$.

Thanaos icelus, $2: 7+2^{\top}$. persius, $2: 742^{7}$.
Poplar, inj. insects (cont' $d$ ):

leaf feeders:

tussock moth, white marked, populimonilis, l'emphigus, $2: ; 45^{9}$. I: $136^{9}$.

viceroy, 2: $510^{9}, 559^{2}$.

webworm, fall, $\mathrm{I}: \mathrm{I}+2^{6}$.

willow leaf beetle, spotted, 2: $565^{3}$.

willow slug, yellow spotted, I: $25^{5}, 322^{3}$.

Xanthonia villosula, 2: 'о03'.

Aylina antennata, $1: 129^{9}$.

scale or sucking insects: $2: 74^{3 !}$.

Chionaspis ortholobis, 2: $7+4$ '.

salicis-nigrae, $2: 74^{9}$.

Eulecanium capreae, $2: 7+4^{9}$.

Idiocerus suturalis, $2: 597^{9}$.

oyster scale, I: $2 I^{4}$.

Pediopsis basilis, 2: $597^{-9}$.

Poplar, balsam, Saperda populnea injuring, $2: 429^{\circ}, 474^{5}$.

Poplar, lombardy, Proleucoptera albella injuring, $2: ;+i^{-9}$.

Poplar, silver-leaved, Proleucoptera albella injuring, $2: 7+7^{9}$.

Poplar, yellow, apple wood stainer injuring, $1: 290^{6}$.

Poplar borer, $\mathrm{I} ; 5 \mathrm{I}^{6}, 9^{51}-100^{3}$.

Poplar carpenter worm, $2: 430^{\circ}$, $47^{1}-77^{9}$.

Poplar leaf beetle, 2: $510^{8}, 55^{5}$.

Poplar leaf stem gall, 2:6207, $635^{\circ}-$ $36^{3}$.

Poplar sawfly, 2: $5 \mathrm{II}^{6}, 56^{61}-69^{5}$.

Poplar tent maker, $2: 5 \mathrm{II}^{2}, 560^{5}-$ $6 \mathrm{I}^{3}$.

Poplar twig gall fly, $2: 620^{6}, 634^{1-}$ $35^{3}$.

popularia, Phylloxera, $2: 74^{3}$.

popularius, Pemphigus, $2: 745^{2}$.

populator, Cenocoelius, $1: 55^{8}$.

populi, Apatela, $2: 7+7^{3}$.

Pontania, 2: $7+6^{5}$.

populicaulis, Pemphigus, 2: $620^{\circ}$, $636^{3}, 74^{\mathrm{s}^{3}}$.

populicola, Chaitophorus, 2: $7+3^{\circ}$.

populiella, Lithocolletes, $2: 747^{9}$. Phyllocnistis, $2: 7+7^{9}$.

populifoliae, Chaitophorus, 2: $74^{2}$. populi-globuli, l'emphigus, 2: it?:

populiramulurum, l'emphigus, 2 : $7+$ r.

populi-transversus, Pemphigus, r: $247^{4} ; 2: 620^{\circ}, 635^{\circ}-36^{3}$.

populi-venae, l'emphigus, $2: 74^{3}$. populnea, Saperda, $2: 429^{9}, 474^{6}-$ $75^{3}$.

Populus candicans, $2: 47 I^{2}$. porculus, Hylastes, $2: ; 52^{3}$.

Porthetria dispar, I: $\varsigma^{4}, 23^{1}, 30^{6}$, 49, $105^{4}, \operatorname{1r} 6^{1}-23^{3}, 254^{1} ; 2: 607^{-9}$.

posticatus, Conotrachelus, $2: 734^{5}$.

Potato beetle, parasites, 2. $600^{9}$.

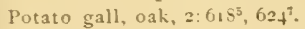

Potatoes, false chinch bug injuring, $2: 685^{\circ}$. $296^{3}-9 s^{3} ; 2: 4^{2} 3^{3}$.

white marked, $2: 430^{\circ}, 4^{\S} 3^{1}$.

praeangusta, Batrachedra, $2: 74^{5}$.

praeatomata, Macaria, 2: $730^{9}$. iur. bisignata, Macaria, 2: $753^{\circ}$.

praegrandaria, Metrocampa, 2: $7+9^{\circ}$.

pravella, Meroptera, $2: 7 H^{2}$.

Praying mantis, I: $146^{2}, 154^{2}$.

European, 1: $15 t^{3}$.

southern, I: $2 t^{9}$.

Predaceous insects, $1: 20^{6}-22^{2}$.

Prickly Leptostylus, $2:+25^{2}, 46 \mathrm{r}^{2}$,

primus, Derostenus, r: $32 \mathrm{~S}^{2}$.

prinoides, Cynips, $2: 619^{3}, 627^{6}$.

Priocycla armataria, $2: 7+9^{6}$.

Prionidus cristatus, $1: 140^{3}, 1+6^{3}$, $324^{7}, 328^{3}$.

Prionomerns calceatus, $2: 732^{6}$.

Prionoxystus macmurtrei, $2:+27^{9}$, $439^{2}, 47 \pi^{-4}$.

robiniae, $\mathrm{I}: 45^{7}, 40,5 \mathrm{I}^{3}, 5 \mathrm{I}^{6}, 79^{4}-$ 8f; $2: 439^{*}, 477^{4}$.

Prionus, broad-necked, $2: 430^{\circ}$, $+86^{2}-87^{-1}$.

IIarris's, 2: $649^{2}, 659^{1}$.

Prionus imbricornis, $2: 4 \$ 6^{\circ}$. laticollis, $2: 430^{9}, 4=6^{9}-57^{-1}$. pocularis, 2: $75 \mathrm{I}^{4}$.

Priophorus irregularis, $2: 74^{6}$.
Powder post beetle. $1: 7^{5}, 25 \%$,

lesser, $2: 430^{9}, 407^{2}-65^{\circ}$. 
Pristiphora sycophanta, 2: $510^{8}$, Pseudanthonomus crataeri, 2:|puberulus, Pityophthorus, see P. $55 i^{-5}-5 h^{5}, 7+1^{6 i}$ tibialis, $2: 74^{8}$.

Privet, injurious insects: a<h sphinx, wavy, 2: $509^{5}, 54^{84}$. I) iaphania quadristigmalis, 2 2: $737^{9}$.

proboscicleus, Balaninus, 2: $512^{7}$, $5^{8} 5^{5}-8.3^{6}$.

Proctotrypidae, $1: 22^{6}$.

Prodenia commelinae. $2: 716^{6}$. profundus, Anthonomus, $2: 719^{6}$. progne, Polygonia, 2: $509^{6}, 5+6^{2}$.

Proleucoptera albella, 2: $744^{5}$ $7+7^{9}$. smilaciella, 2: $740^{8}$.

prolifera, l'hylloxera, 2: $74^{8}$. Prolimacodes scapha, 2: $707^{1}$. prolongata, Dicerca, 2: $7 \neq 6^{5}$.

Promethea moth, $1: 45^{4} ; 2: 510^{7}$, $557^{5}$.

promethea, Callosamia, $\mathbf{r}: 45^{5} ; 2$ : $510^{7}, 557^{3}$.

propinquilinea, Demas, 2: $7+9^{4}$.

propola, Corymbites, $2: 652^{9}, 692^{5}$.

I'roteoteras aesculana, $2: 540^{4}$, $5+0^{7}, 725^{8}$.

proteus, Clastoptera. 2: $59^{8^{2}}$.

protumnusalis, Zanclognatha, 2: $705^{6}$.

provancherł, Xyphidria, see X. provancheri.

proxima, Leptura, 2: $727^{5}$.

prudens, Trypanisma, 2: $707^{8}$.

pruinosa, Ormenis, 2: $598^{2}$.

pruinosella, Tischeria, 2: $708^{8}$

pruinosum, lulecanium, 2: 7 I9 $^{7}$.

pruinosus, Andricus, 2: $7 \mathrm{Tt}^{8}$.

pruniella, Coleophora, 2: $733^{7}$.

prunifoliclla, Nepticula, 2: $733^{7}$.

pruniramiella, Aylestia, $2: 73 \mathrm{I}^{1}$.

prunivora, Enarmonia, 2: $734^{\top}$.

prunivorus, Schizocerus, $2: 734^{1}$.

Prunus, l'utmam's scale injuring, I: $227^{5}$.

prunus, Amphiholips, $2: 6 \mathbf{1} 9^{5}$, $624^{2}$

Psallus juniperi, 2: $755^{9}$.

Psaphiclia thaxterianus, 2: $704^{8}$.

Psenocerus supernotatus, 2: $736^{6}$.

pseudacaciae, Dasyneura, 2: $730^{5}$.

$733^{3}$.

incipiens, 2: $739^{5}$.

pseudoacaciella, Gelechia, 2: $730^{7}$.

pseudobyrsa, Pemphigus, 2: $74^{3}$.

Pseudococcus aceris, see Phenacoccus acericola.

Pseudophilippia quaintancii, 2: $652^{5}, 689^{6}-90^{1}$.

I'seudothyatira cymatophoroides, 2: $703^{1}$

Psocus rufus, $2: 74 t^{9}$.

I'somus politus, 2: $726^{9}$.

P'sylla annulata, 2: $72 \mathrm{~S}^{7}$. carpini, $2: 7^{2} 3^{\circ}$.

Psyllidae, 2:61 $7^{6}$.

Psysostegania pustularia, 2: $728^{1}$. pteliacella, Nepticula, $2: 723^{3}$.

Pteris aquilina, 2: $530^{1}$.

Pterocolus ovatus, 2: $703^{9}$.

Pteromalus st., 2: $393^{6}$. cuproideus, 1: $13^{8^{6}}, 139^{7}$. fuscipes, $\mathbf{1}: \mathbf{1 6} \mathbf{1}^{6}$. nematicida, $2: 423^{1}$. puparum, $\mathrm{I}: 16 \mathrm{I}^{7}$ vancssae, $1: 113^{9}, 161^{7} ; 2: 555^{8}$.

Pteronus carpini, 2: $723^{2}$

corylus, $2: 750^{5}$.

hudsonii, 2: $5 \mathbf{I I}^{6}, 569^{6}-70^{2}, 746^{8}$. hyalinus, $2: 74^{9^{9}}$,

iinteger, $2: 65 \mathrm{r}^{7}, 6 \varepsilon 3^{2}, 703^{3}$.

?lateralis, $2: 74^{8}$

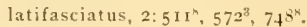
lombardae, $2: 746^{9}$.

marlattii, $2: 750^{\circ}$.

mendicus, $2: 511^{2}, 561^{4}-62^{3}, 7+1^{7}$. odoratus, 2: $5 \mathrm{II}^{3}, 562^{3}-63^{4}, 74 \mathrm{I}^{7}$. ostryae, $2: 722^{7}$

pinguidorsum, 2: $74^{9}$.

quercus, $2: 703^{3}$.

ribesii, $2: 607^{8}$.

thoracicus, $2: 510^{4}, 553^{3}-54^{3}, 732^{8}$. trilineat us, $2: 730^{2}$.

ventralis, I: $25^{8}, \quad 322^{2}-24^{9} ; \quad 2$ : $7+66^{9}$.

vertebratus, $2: 511^{6}, 570^{2}$.

Ptilinus ruficornis, $\mathbf{I}: 257^{9}, 208^{3}-$ $99^{3} ; 2: 4^{98^{4}}$.

Ptinidium lineatum, 2: $729^{4}$. l'tosima gibbicollis, $2: 730^{6}$. puberulus.

pubescens, Glyptoscelis, 2:6534. $695^{1}$.

Kermes, $2: 709^{6}$.

Xyleborus, 2: $396^{2}, 702^{7}, 720^{9}$.

pudens, Euthyatira, 2: $736^{\circ}$

pudibunda, Cecidomyja, $2: 722^{8}$.

pugionata, Dicerca, 2: $750^{2}$.

pulchellus, Andricus, 2: $7 \mathrm{I}^{2}$.

Perissopterus, I: $205^{6}, 23 \mathrm{I}^{2}$.

Pityophthorus, 2: $752^{1}$.

pulcher, Dermestes, $2: 431^{2}, 45 q^{2}-$ $91^{2}$.

pulchra, Andricus, 2:6194 $627^{9}$ $23^{\prime}$.

Goes, $2: 426^{5}, 431^{4}-32^{1}$.

pulicarius, Pityophthorus, $2: 751^{\mathrm{k}}$.

pullata, Cacoplia, 2: $702^{3}$.

pullata, Neomysia, see N. pullata.

pullus, Pityophthorus, 2: $751^{\circ}$.

pulveraria, Anagoga, 2: $728^{3}$.

pulverulentus, Goes, $2: 455^{2}$.

Pulvinaria acericola, $1: 172^{6}, 179^{1}-$ $82^{6} ; 2: 729^{1}$.

innumerabilis, $1: 8^{3}, 12^{6}, 49,173^{2}$, $19^{6}-200^{4}$.

maclurae, $2: 737^{5}$.

tiliae, $2: 731^{9}$.

pulvinariae, Aphycus, I: $199^{8}$.

pumila, Melinna, 2: $735^{1}$.

punctata, Synchroa, 2: $666^{8}$.

punctatissimus, Corthylus, I: $50^{8}$, $65^{1}-67^{6} ; 2: 732^{5}$.

punctatus, Andricus, $2: 018^{3}, 623^{2}-$ $24^{3}$.

Callipterus, 2: $709^{3}$.

Dinoderus, 2: $701^{8}$.

Liopus, 2: $426^{5}, 432^{2}$.

Mycetophagus, $2: 495^{\circ}$.

Paratenetus, see P. punctatus.

Plyytonomus, I: 18 ?

puncticollis, Asclera, 2: $494^{2}$.

Nodonota, 2: $730^{3}, 735^{9}$.

Saperda, $2: 430^{3}, 478^{8}-79^{5}, 479^{9}$.

punctiformis, Platynus, I: $153^{7}$.

punctistriga, Artace, 2: $735^{3}$.

punctuJata, Dicerca, see D. punctulata.

Pupal stage, I: $18^{8}-10^{7}$.

puparum, Pteromalus, I: $16 \mathbf{I}^{7}$. 
purpureus, Pachyscelus, 2: $715^{3}$. quadripes, Eriophyes, 2:6201, quercivoraria, Mletanema, $2: 706^{6}$. \begin{tabular}{l|l|l} 
Purpuricenus humeralis, $2: 702^{2}$ & . $630^{6}-31^{3}$. & quercivorella, Recurvaria, 2:
\end{tabular} purpuridorsum, Periclista, 2: 202 $2^{9}$. quadripunctata, Agallia, 2: $598^{1}$. $707^{7}$. purpuriella, Chrysopeleia, 2: $730^{\circ}$. quadripunctatus, Oecanthus, 2: Quercus, see Oak.

pusilla, Chrysobothris, $2: 649^{2}, 1699^{9}-700^{4}$. $65^{7}$.

pusillus, Anamorphus, 2: $72 \mathbf{1}^{9}$.

Dendroctonus, $2: 752^{3}$.

Graphisurus, 2: $753^{\circ}$.

pustularia, Cymatophora, 2: $733^{5}$, $735^{9}$.

Psysostegania, 2: $72 \$^{1}$. pusulatoides, Andricus, $2:-712^{6}$. Putnam's scale, 1 : $173^{7}, 226^{6}-27^{5}$. pygmaea, Paectes, 2: $724^{3}$. pygmaeus, Cyrtinus, 2: $702^{3}$. pyramidoides, Pyroplila, $2: 704^{7}$. Pyrausta thestialis, $2: 739^{7}$. pyri, Eulecanium, 2: $717^{9}$. Sesia, $2: 451^{5}$.

pyrina, Zeuzera, see Z. pyrina. Pyrochroa femoralis, 2: $727^{5}$. Pyrophila pyramidoides, $2: 704^{7}$. Pyrrhia umbra var. exprimens, 2: $737^{3}$.

Pytho americanus, $2: 335^{4}, 339^{5}$. $368^{6}-69^{5}$. niger. $2: 751^{6}$.

Quadrangular spittle insect, 2: $686^{8}$.

quadrangularis, Aphrophora, 2: $686^{5}$.

quadrata, Odontota, 2: $731^{5}$.

quadridentatus, Platypus, $2: 720^{\circ}$.

quadrigeminata, Eburia, $2: 428^{9}$, $462^{5}-63^{3}$.

quadrigibbus, Acanthoderes, 2: $702^{4}, 715^{5}$.

Tachypterus, 2: $73 t^{4}$.

quadriguttata, Ditoma, $2: 489^{5}$.

quadriguttatus, Clerus, see C. quadriguttatus.

quadriguttatus, Ips, see I. quadriguttatus.

quadrilineatus, Grynocharis, 2: $460^{2}$.

quadrimaculatus, Cryptocephalus, see C. quadrimaculatus.

Heterachthes, $2: 715^{3}$.

Xylotrechus, 2: $722^{3}$.

quadripunctella, Ornix, $2: 734^{2}$.

quadripustulata, Brochymena, 2: $585^{9}-89^{1}, 590^{4}$.

Winthemia, $1: 132^{1}, 13^{7}$.

quadrisignatus, Clerus, $2: 393^{3}$.

quadrispinosus, Scolytus, see S. quadrispinosus.

quadrustigmalis, Diaphania, 2: $737^{9}$.

quadruplex, Cryptocephalus, 2: $724^{5}$.

quaintancii, Pseudophilippia, 2: $652^{5}, 689^{6}-90^{7}$

Quedius molochinus, I: $153^{7}$.

quercata, Anthaxia, $2: 513^{4}$.

Metachroma, 2: $703^{7}$.

querceti, Phylloxera, 2: $71 \mathbf{I}^{3}$.

querci, Eriophyes, $2: 713^{5}$.

Lepturges, $2: 427^{2}, 439^{7}-40^{5}$.

Schizoneura, 2: $709^{2}$.

Telamona, 2: $596^{\circ}$.

quercialbella, Lithocolletes, 2: $708^{7}$.

quercicastanella, Nepticula, 2: $708^{3}$.

qquercicella, Cryptolechia, z: 708 '.

quercicellus, Ypsolophus, 2: $707^{5}$.

quercicola, Wollastonia, $2: 747^{2}$.

querciella, Coleophora, 2 : $\mathbf{j}^{3} 8^{3}$.

Telphusa, 2: 707?.

quercifex, Eulecanium, 2: $709^{4}$.

quercifoliae, Andricus, $2: 7 \mathrm{I}^{3}$.

Aphis, $2: 709^{3}$.

Lachnus, 2: 709".

quercifoliana, Tortrix, 2: $508^{3}$. quinqueseptum, Andricus, 2: $711^{8}$. $532^{6}$.

quercifolii, Callipterus, $2: 709^{3}$.

quercinigracella, Telphusa, 2: $707^{-1}$.

quercinus, Limonius, $2: 605^{8}$.

querciperda, Cossus, $2: 477^{1}$.

Pityophthorus, 2: $702^{6}$.

quercipulchella, Nepticula, 2: $708^{3}$.

Quercitron bark borer, $2: 434^{9}$.

quercitronis, Eulecanium, 2: $709^{4}$. quercus, Balaninus, $2: 585^{1}, 703^{\circ}$.

Copturodes, 2 : $702^{5}$.

Eriococcus, 2: $709^{\circ}$.

Kermes, 2: $709^{6}$.

Lachnosterna, 2: $703^{5}$.

Platycerus, 2: $722^{2}, 727^{6}$.

Pteronus, 2: $703^{3}$.

Thysanoes, 2: $702^{7}$.

quercusalbae, Mlonostegia, 2: $73^{4}$.

quercuscoccineae, Monostegia, 2: $703^{4}$.

quernaria, Nacophora, 2: $734^{7}$.

Quince, injurious insects:

borers:

maple and oak twig pruner, I: $6 \mathrm{r}^{3}$.

twig girdler, $1: 273^{9}$.

leaf feeders:

apple worm, yellow-necked, 2: $535^{\top}$.

bag or basket worm, 1: $127^{1}$.

brown tail moth, I: $16+$ '.

Mineola indigenella, 2: $733^{6}$.

Papilio glaucus var. turnus, 2: $704^{1}$.

tussock moth, white marked, 1: $136^{9}$.

Xylina antennata, I: $131^{7}$.

scale insects

San José scale, 1: $173^{6}, 216^{\circ}$.

scurfy scale, $1: 173^{6}, 214^{9}$.

quinquelineata, Onychia, 2: 71 $5^{3}$.

quinquelineatus, Oliarius, see $\mathrm{O}$. quiuquelineatus.

Rachiospila lixaria, 2: $73^{6}$.

radcliffei, Apatela, $2: 733^{5}$.

radicola, Dryophanta, 2: $710^{6}$

radicum, Rhodites, $2: 62 I^{6}, 647^{5}$, $736^{5}$.

Radishes, chinch bug, false, injuring, 2: $685^{8}$.

rapae, Pieris, 2: $609^{1}$.

rapax, Aspidiotus, 2: $728^{7}$.

Raphia frater, $2: 747^{\mathrm{I}}$. 


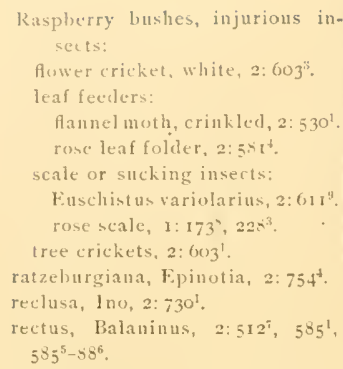

Recurvaria apicitripunctella, 2: $754^{\circ}$.

juniperella, $2: 755^{\circ}$.

obliquistrigella, $2: 754^{3}$.

piceaella, 2: $754^{5}$.

quercivorella, $2: 707^{7}$.

robiniella, $2: 730^{\circ}$,

thujaella, $2: 755^{5}$.

Ked-banded leaf roller, 2: $508^{3}$, $532^{1}$.

Red cedar bark beetle, $2: 335^{y}$, $39 \mathbf{1}^{5}-93^{7}$.

Red-edged saperda, $1: 270^{5}-71^{1} ; 2$ : $427^{7},+45^{4}$.

Red elm leaf gall, 2: $620^{5}, 633^{4}$.

Red-footed flea beetle, 2: $5 \mathrm{JO}^{6}$, $55^{2}$.

Red horned borer, small, I: $257^{4}$, $299^{3}-99^{3}$.

Red-humped oak caterpillar, 2: $506^{7}, 519^{2}-20^{2}$.

Red-shouldered twig borer, 2: $4+2^{4}$.

Red spider, Californian, $1: 14^{z}$.

Redbud, injurious iusects: $2: 731^{1}$. borers:

Dysphaga tenuipes, $2: 715^{7}$. Ecyrus dasycerus, $2: 715^{6}$.

Elaphidion unicolor, 2: $702^{2}$.

Lepturges querci, $2:+40^{3}$. signatus, $2: 722^{3}$.

Micracis suturalis, $2: 7 \mathrm{I} 5^{\circ}$.

l'hyton pallidum, 2: $715^{3}$.

leaf feeder:

Ptosima gibbicollis, $2: 730^{5}$.

kedaish elm snout beetle, $1: 51^{2}$, $75^{3}$.
Redistart, I: $27^{-4}, 166^{5}$.

Imerica $11,1: 111^{\hbar}$.

reductella, Tlascala, $2: 729^{3}$.

keduriidat, I: 24 .

regalis, Citheronia, $1: 258^{3}, 305^{7}-60^{4}$.

relicta, Catoca]a, $2: 7+3^{3}$.

religiosa, Mantis, $1: 25^{1}, 154^{3}$.

Remedies and preventives for:

aller blight aphid, I: $196^{2}$.

aliler leaf beetle, $2: 544^{2}$.

apple borer, round-headed, 1 :

$$
85^{9}-866^{2} \text {. }
$$

bag or basket worm, 1: 125'.

birch aphid, 2: (rot.

biting and sucking insects, 1 $34^{*}-46^{3}$.

black-banded scale, I: $203^{4}$.

boters, $1: 45^{5}-40^{3}$.

box elder plant bug, I : $240^{5}$.

bronze birch horer, $\mathbf{1}: 287^{6}$.

brown tail moth, $1 ; 166^{8}$.

carpenter worm, I: $45^{7}, 84^{2}$.

Chaitophorus ? aceris, 1: $175^{3}$.

chestnut borer, two-lined, I: $282^{9}-83^{2}$.

chestmut weevil, $2: 585^{4}$.

cicada, periodical, $\mathbf{1}: 237^{4}$.

cuarse writing bark betle, 2 : $350^{9}-5 I^{2}$.

cottonwood leaf beetle, I: $320^{9}-$ $21^{9}$.

cynthia moth, $1:+5^{4}$.

elm bark aphid, woolly, I: $192^{6}$.

elu bark louse, 1: $207^{2}$.

elm borer, 1 : $70^{9}-71^{7}$.

elm leaf aphid, $1: 177^{6}$.

elm leaf beetle, $1: 37^{7}, 43^{8}, 154^{4-}$ $55^{8}$.

elm sawfly, $1: 15^{8^{6}}$.

elm snout beetle, black, r: $74^{x}$.

Euonymus scale, I: $214^{4}$.

European elm case bearer, I: $168^{3}$.

European willow gall midge, 1: $301^{\circ}-2^{2}$.

fall webworm, I: $146^{4}$.

flat-headed borer, common, I: $s 7^{5}$.

forest tent caterpillar, $1: 44^{7}$, $113^{8}-15^{7}$.

forest tree pests, $1: 254^{6}$.
Remedies, etc. (cont'd):

forester, eight spotted, $2: 575^{4}$.

gipsy moth, I: $122^{3}-23^{4}$.

golden oak scale, $1: 331^{3}$.

lickory bark borer, I: $278^{6}-79^{4}$.

hickory borer, banded, I: $268^{4}$.

larch case bearer, $1: 17 \mathbf{I}^{7}$.

larch sawfly, $2: 423^{3}$.

leaf feeders, $1: 37^{9}$.

leopard moth, $1: 45^{6}, 78^{6}-79^{3}$.

linden borer, $1: 92^{\mathrm{t}}$.

locust borer, I: $97^{7}$.

locust leaf miner, $1: 328^{8}-29^{1}$.

lucust twig borer, $2: 478^{7}$.

maple and oak twig pruner, $\mathbf{r}$

$61^{3}$.

maple borer, sugar, $1: 54^{9}-56^{6}$.

maple leaf cutter, $2: 541^{9}$.

maple leaf scale, $1: 132^{4}$.

maple phenacoccus, $1: 186^{4}$.

maple scale, cottony, 1: $199^{9}-$ $200^{3}$.

maple sesian, $1: 5^{4}$.

maple stalk borer, $2: 540^{9}-41^{2}$.

maple trumpet skeletonizer, I: $169^{9}$.

Nantucket pine moth, 2: $407^{-1}$.

orange dog, $2: 555^{5}$.

oyster scale, $1: 213^{3}$.

peach bark beetle, $2: 452^{9}$.

pigeon tremex, $1: 63^{7}$.

pine bark aphid, I: $195^{4}$.

pine bark beetle, $2: 353^{9}$.

plant lice, $1: 35^{6}$.

poplar borer, I: $100^{2}$.

poplar carpenter worm, $2: 477^{8}$.

poplar leaf beetle. $2: 55^{5^{9}}$.

powder-post beetle, I: $297^{7}-98^{2}$.

white marked, $2: 483^{9}$.

I'rionus, broad-necked, $2: 486^{9}-$ $37^{2}$.

promethea moth, $1: 45^{4}$.

rose beetle, $2: 575^{8}$.

rose leat hopper, 1: $192^{1}$.

rose scale, $\mathbf{1}: 226^{9}$.

rosebud worm, $2: 577^{4}$.

San José scale, 1: $35^{9}, 224^{9}-26^{3}$.

saperda, hickory, 1: $270^{3}$.

sawyer, $2: 363^{\circ}$.

white spotted, 2: $364^{9}$.

scale insects, $1: 35^{6}, 39^{3}, 39^{9}$. 
Remedies, etc. $\left(\operatorname{cont}^{\prime} d\right)$ : scurfy scale, $1: 216^{4}$. spiny elm caterpillar, 1 : $162^{1}$. spring cankerworm, $2: 547^{9}$. spruce destroying beetle, 2: $3^{5} 5^{2}$.

spruce gall aphid, I: I9I $^{5}$. thorn limb borer, I: $254^{6}$. tuliptree scale, $1: 210^{8}$. tussock moth, $1: 44^{9}$.

white marked, $1: 1+0^{9}-42^{3}$ : twig girdler, I: $274^{2}$. walking stick, 2: $535^{2}$. wiltow borer, mottled, 1: $103^{6}$. willow leaf beetle, spotted, 2: $565^{6}$.

willow shoot sawfly, I: $303^{5}$. willow slug, yellow spotted, I: $324^{7}$.

woolly beech leaf aphis, 2: 602? Xylina antennata, I: $132^{2}$.

Remedies and preventives for insect depredations:

arsenate of lead, $1: 34^{9}, 37^{4}$. arsenical poisons, $1: 35^{1}$. birds, $1: 25^{4}-34^{5}$.

carbolic soap wash, $\mathbf{I}: 55^{2}$. carbon bisulphid, $1: 45^{6}$. contact insecticides, $1: 35^{5}, 38^{3}-$ $39^{9}$.

fumigation, $1: 39^{9}-41^{2}$. hand collecting. I: $44^{8}-45^{5}$. hydrocyanic acid gas, $1: 40^{2}$. kerosene emulsion, $1: 35^{6}, 35^{3}$. lime-sulfur wash, I: $39^{3}$. london purple, $1: 34^{9}-35^{1}, 37^{9}$. paris green, I: $3 t^{9}, 37^{9}$. spraying, $1: 41^{2}-44^{2}$ useless, I: $36^{6}-37^{2}$. whale oil soap, $1: 35^{6}, 35^{9}$. remota, Tenthredo, $2: 74^{7}$. reniculella, Dioryctria, $2: 65 \mathbf{I}^{7}$, $634^{2}$.

repandus, Eustrophus, 2: $667^{5}$.

resinicola, Cecidonyia, $2: 340^{6}$, $410^{4}-13^{2}, 424^{6}$.

retardata, Apatela, $2: 727^{-i}$.

reticulatana, Cenopsis, 2:5123, $580^{1}, 707^{5}$.

Retinia, pitch pine, $2: 340^{4}, 407^{4}$.

Retinia comstockiana, see Evetria.
Retinia frustrana, sec livetria. rigidana, set Evetria.

retiniae, Cremast ts, 2: $410^{1}$. retusus, Gnathotrichus, 2: $751^{8}$.

Rhabdophaga batatas, $2: 745^{4}$.

brassicoides, $2: 563^{6}, 567^{5}, 745^{7}$, $7+6^{3}$.

guaphaloides, $2: 7+5^{7}$.

rhodoides, $2: 7+5^{5}$.

rigidae, $2: 620^{8}, 636^{6}$.

salicis, $\mathbf{I}: 253^{2}, 299^{5}-302^{2} ; 2: 620^{4}$.

siliqua, 2: $7+5^{5}$.

strobiliscus, $2: 745^{8}, 746^{2}$.

strobiloides, $2: 621^{2}, 639^{1}, 74^{1}$ $746^{2}, 746^{3}$.

Rhabdopterus picipes, $2: 731^{5}$.

Rhagium lineatum, $2: 335^{3}, 339^{5}$, $3+9^{5}, 366^{5}-68^{5}, 665^{3}$.

Rheumaptera hastata, $2: 749^{6}$.

Khinomacer pilosus, 2: $667^{5}$.

Rhinosimus viridiaeneus, $2: 74^{5}$.

Khizophagus dimidiatus, 2: $721^{9}$.

Rhodites bicolor, $2: 621^{7}, 647^{8}$.

dichlocerus, $2: 621^{8}, 645^{1}, 648^{2}$.

globulus, $2: 621^{3}, 647^{9}-48^{8}$.

ignota, $2: 621^{7}, 6+7^{7}$.

lenticularis, $2: 736^{4}$.

multispinosa, 2: $736^{4}$.

nehulosus, $2: 736^{4}$.

radicum, $2: 621^{6}, 647^{5}, 736^{5}$.

rosae, $2: 621^{6}, 647^{6}$.

verna, $2: 621^{8}, 645^{2}$.

rhoditiformis, synergus, $2: 714^{6}$.

rhodoides, Rhabdophaga, $2: 745^{5}$.

rhoifructella, Anacampsis, $2: 747^{8}$.

rhois, Attelabus, 2: $511^{9}, 574^{6}-75^{2}$.

Blepharida, $2: 737^{3}$.

Pemphigus, I: $247^{7} ; 2: 621^{5}, 647^{3}$.

Rhopalophora longipes, 2: $731^{\circ}$.

Rhopus coccois, I: $185^{9}$.

Rhus glabra, $2: 647^{4}$. typhina, $2: 647^{-4}$.

Rhychagrotis alternata, 2: 704:

Rhynchites aeratus, $2: 703^{\star}, 7 I 6^{5}$. bicolor, $2: 518^{5}$.

cyanellus, $2: 567^{2}, 742^{3}$.

Rhyncholophus sp., I: $140^{\circ}$

Rhyncolus brunneus, 2: $666^{6}, 733^{3}$.

Rhyssa humida, $2: 466^{6}$.

Ribbed pine borer, $2: 335^{3}, 339^{5}$, $366^{5}-63^{5}$. ribesii, Pteronus, 2: $6 \pi^{\circ}$

rigida, Oeme, 2: $755^{\top}$.

rigidae, Rhabdophaga, $2: 620^{\circ}$, $636^{6}$.

rigidana, Evetria, 2: $340^{4}, 407^{4}$.

rigidus, Acamptus, 2: $727^{5}$.

rileyana, Heteropacha, 2: $729^{5}$.

rileyi, Neuroterus, $2: 712^{i}$.

l'hylloxera, 2: $7 \mathrm{IO}^{2}, 7 \mathrm{II}^{3}$.

Schizoneura, I: $172^{9}, 192^{4}$.

rimosalis, Phylloxera, 2:718

Ring-legged tree bug, 2: $588^{7}-90^{3}$.

Robber fly, 1: $146^{2}$.

robiniae, Cecidomyia, 2: $730^{5}$. Cyllene, $1: 49,51^{6}, 93^{1}-97^{9}$.

Prionoxystus, see P. robiniae,

Spermophagus, 2: 73 $\mathbf{I}^{1}$

robiniella, Depressaria, 2: $730^{\circ}$.

Lithocolletes, 2: $730^{9}$

Recurvaria, 2: $730^{8}$.

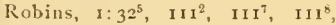
I $22^{12}, 137^{7}, 166^{5}, 237^{2}, 309^{6}$; voracity, I: $26^{2}$; daily food, $1: 26^{\text {r }}$.

robinsonii, Catocala, 2: $716^{9}$.

robusta, Chaicis, 2: $555^{5}$.

Pontania, 2: $746^{6}$.

Roeselia minuscula var. phylla, 2: $706^{7}$.

Romaleum atomarinm, $2: 426^{5}$, $434^{4}$.

rufulum, 2: $702^{1}$.

simplicicollis, $2: 75 \mathrm{I}^{4}$.

Root feeder, $2: 753^{5}$.

rosaceana, Archips, 2: $512^{4}, 531^{7}$. $550^{2}-81^{2}$

rosacella, Coleophora, 2: $736^{3}$.

rusae, Aulacaspis, $1: 173^{8}, 228^{3}$.

Eulecanium, 2: $736^{3}$.

Monostegia, 2: $735^{9}$.

Rhodites, 2: $621^{6}, 647^{6}$.

Typhlocyba, I: $172^{\wedge}, 191^{2}-92^{3}$.

rosaefoliella, Coleophora, $2: 736^{9}$.

Nepticula, 2: $736^{2}$.

rosana, Archips, 2: $512^{4}, 58 \mathrm{I}^{3}$.

Rose bedegar, 2: $621^{6}, 6.47^{6}$.

Rose beetle, 2: $512^{2}, 575^{6}$.

Rose gall, giobular, 2: $621^{7}, 647^{9}-$ $45^{3}$.

knotty, $2: 621^{8}, 643^{2}$.

long, 2: 621 $64^{6}, 68^{1}$.

mealy, $2: 621^{7}, 647^{7}$. 
Rose leat folder, 2: $512^{4}, 5 I^{3}$. lose leaf hopper, $1: 172^{6}, \mathbf{I} 9 \mathrm{I}^{i}-92^{3}$. kose leaf rollers, $2: 577^{n}, 579^{3}, 580^{2}$. $5^{80} 0^{7}, 581$

Rose leaf tier, $2: 512^{3}, 577^{5}-79^{3}$.

Rose root gall, $2: 62 \mathrm{I}^{6}, 647^{3}$.

Rose scale, $1: 173^{8}, 225^{2} ; 2: 736^{n}$

rosea, Oreta, 2: $749^{6}$.

Rosebud worm, 2: $512^{2}, 576^{1}-77^{5}$.

Rosebushes, injurious insects:

borer:

twig girdler, $\mathbf{x}: 273^{9}$.

gall insects, $2: 617^{9}, 736^{4}$.

rose bedegar, $2: 62 \mathrm{r}^{6}, 647^{6}$.

leaf feeders: $2: 735^{8}-36^{3}$.

Alceris permutana, $2: 744^{3}$.

apple tent eaterpillar, $2: 55 \mathrm{I}^{1}$.

brown tail moth, r: $164^{2}$.

buck moth, I: $3 I^{\text {? }}$.

Calligraphus lunata, 2: $575^{\circ}$.

Cenopis pettitana, $2: 512^{3}$, $579^{3}$.

reticulatana, $2: 512^{3}, 580^{1}$.

Deilephila lineata, $2: 724^{6}$.

forest tent caterpillar, I: II $0^{9}$.

leat roller, oblique banded, 2: $512^{4}, 550^{7}$.

red-banded, $2 ; 532^{2}$.

v-marked, 2: $531^{8}$.

maple worm, semilooper, 2: $508^{9}, 538^{5}$.

Platynota flavedana, 2: $728^{4}$. rose beetle, 2: $512^{1}, 575^{6}$.

rose bud worm, 2:512 $576^{2}$.

rose leaf folder, $2: 512^{4}, 581^{3}$.

rose leaf tier, $2: 512^{2}, 577^{5}$.

Schizura unicornis, 2: $705^{\circ}$.

Tortrix albicomana, 2: $532^{4}$, $707^{6}$.

tussock moth, white marked, I: I $_{36} 6^{9}$.

Xylina antennata, $1: 130^{4}$.

scale or sucking insects:

rose leaf hopper, $I$ : $172^{8}, 19 \mathbf{1}^{2}$. rose scale, I: $173^{8}, 228^{3} ; 2: 736^{3}$.

Rosebushes, wild, injurious insects:

gall insects:

bullet gall, spiny, $2: 62 \mathrm{x}^{7}, 647^{9}$. rose gall, globular, $2: 62 \mathrm{I}^{\dagger}$, $647^{9}$
Rosehushes, inj. insects (cont $d)$ : ruricola, Clytanthus, $2: 715^{5}$ gall insects: rose gall, knotty, $2: 621^{8}$, $65^{2}$

long, $2 ; 62 \tau^{\circ}, 6+8^{\circ}$.

mealy, $2: 62 \mathrm{r}^{7}, 647^{7}$.

rose root gall, $2: 621^{6}, 647^{5}$.

leaf feeder:

rose leaf folder, $2: 512^{4}, 58 \mathrm{I}^{4}$. rostrum, Apion, $2: 730^{4}$.

Kosy IIyparpax, 2: $506^{8}, 520^{3}-2 \mathrm{~L}^{1}$.

Rough bullet gall, 2: $613^{4}, 624^{5}$.

Round-headed apple borer, $1: 5 \mathrm{I}^{3}$, $84^{7}-56^{8}$.

rubicunda, Anisota, 2: $506^{8}, 537^{6}-$ $35^{3}$.

rubidella, Aristotelia, $2: 707^{6}, 709^{9}$. rubinus, Biorhiza, 2: $71^{2}$.

rubricoma, Apatela, 2: $726^{2}$.

rubrifasciella, Acrobasis, $2: 750^{7}$.

rubristigma, Sesia, $2: 426^{9}, 437^{7}-38^{3}$.

rubrum, Obrium, $3: 428^{4}, 463^{3}$.

Rubus, Cryptocephalus quadrinaculatus injuring, $2 ; 695^{\circ}$.

rudis, Micracis, $2: 725^{\mathrm{K}}$

rufago, Jodia, 2: $704^{\circ}$.

ruficillata, Mesoleuca, $2: 719^{5}$.

ruficollis, Oberea, $2: 732^{6}$.

ruficorne, Platydema, $2: 497^{3}, 497^{6}$. Salicifungiella, Aristotelia, $2: 746^{4}$.

ruficornis, T'tilinus, I: $257^{9}, 29 s^{3}-$ salioipomonella, Batrachedra, 2: $99^{3} ; 2: 4^{88^{4}}$

Tharops, $2: 492^{5}$.

rufimargo, Panapoda, $2: 705^{5}$.

rufipennis, Dendroctonus, $2: 753^{9}$.

1)ichrooscytus, $2: 652^{3}, 657^{7}-88^{1}$.

Polygraphus, see P. rufipennis.

rufipes, Buprestis, 2: $701^{6}$.

Crepidodera, 2: $510^{6}, 556^{3}$.

Orchestes, 2: $742^{4}$.

Trichacis, $2: 585^{2}$.

rufosanguinea, Galerucella, 2: $733^{3}$.

rufulum, Romaleum, $2: 702^{1}$.

rufus, Catogenus, $I: 26 I^{3} ; 2: 489^{*}$. Psocus, 2: $744^{9}$.

rufusculus, Nabis, see N, rufusculus.

rugosa, Cynips, 2: 71 $3^{\uparrow}$.

rugulosus, Scolytus, $2: 336^{6},-153^{1}$, $50 y^{8}$.

rumicis, Aphis, $2: 729^{9}$.
Rustic borer, I : $256^{5}, 259^{2}-6 \mathrm{I}^{7}$.

Rusty tussock motl, $2: 507^{4}, 524^{8}$, $524^{5}$.

rutilaha, Phalonia, $2: 755^{8}$.

rutulus, Papilio, 2: $750^{6}$

Sabulodes arcasaria, $2: 750^{7}$.

lorata, $2: 754^{7}$

transversata, $2: 509^{3}, 539^{5}$.

saccularius, Anclrieus, 2: $712^{6}$.

Saddleback caterpillar, 2: 5286. saginella, Nepticula, 2 : job $^{3}$.

sagittatus, Nylotrechus, see X. sagittatus.

Salebria celtidella, $2: 726^{\circ}$. contatella, $2: 730^{\circ}$.

salicellis, Lachnus, $2: 744^{7}$.

saliciana, Epinotia, $2: 746^{3}$.

salicicola, Aphis, $2: 7+4^{8}$.

Eriophyes, $2: 745^{9}$.

Phylloxera, $2: 745^{3}$.

Polygnotus, $\mathbf{1}: 301^{\mathrm{k}}$.

salicicolana, Epinotia, 2: $74^{6^{4}}$.

saliciella, Coptodisca, $2: 7+4^{4}$.

salicifoliella, Ciracilaria, $2: 744^{4}$.

Lithocolletes, $2: 744^{5}$.

$74^{4}$

salicis, Cladobius, $2: 744^{7}$.

Nagdalis, 2: $720^{8}$.

Orchestes, $2: 742^{4}$.

Rhabdophaga, 1: $258^{2}, 299^{5}-302^{9}$; 2: $620^{\circ}$.

Siphocoryne, $2: 744^{8}$.

Tridymus, I: $30 \mathbf{I}^{7}$.

salicis-nigrae, Chionaspis, $2: 744^{9}$.

salictella, Narmara, 2: $741^{5}$.

salicti, Cladobius, $2: 744^{6}$.

Salix pomum, 2: $636^{9}, 637^{9}$.

saltator, 1lormiscus, $2: 726^{7}$.

Samia cecropia, $2: 508^{9}, 539^{2}$.

columbia, $2: 755^{2}$.

cynthia, see Philosamia.

San José scale, $\mathbf{3 :} 8^{4}, 8^{6}, 12^{6}, 38^{9}$, $173^{6}, 216^{6}-26^{5}$.

Sandalus petroplyya, $2: 701^{5}$.

sanguineus, Thaneroclerus, 2: $370^{7}, 503^{1}$. rustica, Phlegethontius, $2: 737^{8}$. 
sanguinolenta, Cecidonyia, 2: Sassafras, inj. insects (cont' $d$ ): 7rs'.

sauguinolentus, Ips, see I. sanguinolentus.

Samninoidea exitiosa, $2: 733^{1}$.

Siaperda, hick ory, $1: 256^{8}, 269^{4}-70^{4}$. red-edged, $1: 270^{5}-71^{1} ; 2: 427^{7}$, $445^{4}$.

saperda calcarata, $\mathrm{I}: 49,5 \mathrm{I}^{\mathrm{b}}, 9^{8^{1}-}$ $100^{3}$.

candida, $I: 51^{3}, 84^{7}-86^{2}$.

concolor, $2: 429^{9}, 469^{7}, 47 \mathrm{I}^{3}, 474^{1}$ $474^{9}$.

cretata, $2: 734^{3}$.

discoidea, $1: 256^{8}, 269^{4}-70^{4}$. fayi, $1: 257^{3}, 283^{3}-84^{8}$.

lateralis, $\mathrm{I}: 270^{5}-7 \mathrm{I}^{1} ; 2: 427^{7}, 445^{4}$. moesta, $2: 471^{6}, 474^{7}, 74^{66}$. mutica, $2: 429^{5}, 469^{3}$.

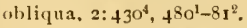
populnea, $2: 429^{9}, 474^{6}-75^{3}$. puncticollis, $2: 430^{3}, 478^{8}-79^{8}$, $+79^{9}$.

tridentata, $1: 49,50^{9}, 67^{7}-71^{8}, 74^{6}$. tulari, $2: 474^{7}$.

vestita, $1: 49,51^{5}, 91^{1}-9 z^{2}$.

saperdoides, Xylopinus, 2: $703^{\circ}$.

siponatus, Monachus, 2: $750^{5}$.

Sapsucker, yellow-bellied, 1 : $1 \mathrm{II}^{6}$. iaratoga spittle insect, $2: 686^{5}$.

raratogensis, Aphrophora, 2: $686^{5}$. sircophaga sp., I: $140^{5}$.

cimbicis, 1 : $153^{4}$.

Sassafras, injurious insects:

borers: $2: 732^{5}$.

maple and oak twig pruner, I: $6 \mathbf{I}^{3}$.

Vicracis suturalis, $2: 715^{9}$.

utgar maple timber beetle, I: $67^{4}$.

leaf feeders: $2: 732^{5}$.

Abbotana clementaria, 2: $721^{4}$.

Apatelodes torrefacta, $2: 549^{4}$.

Callosamia angulifera, $2: 732^{2}$.

Coscinoptera dominicana, 2: $737^{3}$.

Graphiphora alia, 2: $704^{9}$. hag moth caterpillar, $2: 528^{\text {b. }}$. io caterpillar, 2: $5 \mathbf{2 2}^{3}$.

Olethreutes niveiguttana, 2: $724^{1}$ leaf feeders:

Papilio glaucus $\approx n \%$ turnus, 2: $704^{1}$.

Platynota flavedana, 2: $728^{4}$. promethea moth, 2: $557^{8}$.

scale insect:

Eulecanium lintneri, 2: $732^{7}$. sassafrasella, Gracilaria, $2: 732^{6}$.

Sawtlies, $1: 10^{7}, 25^{2} ; 2: 607^{6}, 609^{8}$, $702^{8}-3^{4}, 7+1^{7}$.

Abbott's pine, 2: $340^{\circ}$.

fir, $2: 340^{8}, 4^{1} 5^{6}-16^{4}$.

larch, $1: 10^{3}, 254^{5} ; 2: 340^{9}, 418^{3}-$ $23^{5}$.

Le Conte's, $2: 340^{6}$.

Sawyers, $2: 339^{1}, 339^{2}, 360^{7}-63^{9}$.

marbled, $2: 339^{4}, 366^{1}$.

white spotted, $2: 339^{3}, 364^{1}$.

sayi, Choragus, $2: 722^{4}$.

Elater, 2: $7^{\circ}{ }^{\circ}$.

Oryssus, $2: 727^{4}$.

scabra, Calitys, see C. scabra.

Ostuoderma, 2: $492^{9}$.

Plathypena, $2: 747^{4}$.

scabricollis, Xyloterus, $2: 72^{2}$.

scabripennis, Chrysobothris, 2 $753^{8}$.

scalaris, Bellamira, $2: 429^{3}, 467^{5}$.

Calligrapha, 2: $750^{5}$.

Chrysomela, 2: $509^{3}, 542^{i}-44^{2}$.

Homalomyia, I: $140^{6}$.

scalator, Plectrodera, $2: 746^{6}$.

Scale insects, $1: 7^{5}, 12^{5}, 35^{6}, 172^{8}$; 2: $709^{4}, 717^{9}, 719^{7}, 729^{8}, 732^{7}, 734^{2}$, $739^{1}, 744^{8}, 755^{5}$; remedies, $1: 39^{3}$, $39^{\circ}$.

scandens, Carneades, 2: $609^{2}$.

scapha, Eulimacodes, 2: $529^{4}$.

Prolimacodes, 2: $707^{1}$.

scapularis, IIylotoma, $2: 509^{3} \cdot 542^{1}$.

Scarlet winged clerid, $2: 503^{1}$.

schalleriana, Alceris, $2: 7+4^{2}$.

schaumii, Oberea, 2: $493^{3}$.

Toxot us, 2: $722^{3}$.

Schizocerus prunivorus, $2: 734^{1}$.

Schizonetra americana, $1: 172^{6}$, $177^{7}-78^{9}$

caryae, $2: 717^{\circledR}$.

corni, $2: 737^{1}$.

crataegi, 2: $735^{2}$.
Schizoneura pinicola, $2: 753^{6}$.

querci, 2: $709^{2}$.

rileyi, 1 : $172^{9}, 192^{4}$.

Schizura badia, $2: 738^{4}$.

concinna, $2: 7+3^{6}$.

ipomoeae, $2: 705^{8}, 729^{5}$.

leptinoides, 2: $716^{9}$.

mustelina, $2: 736^{1}$.

semirufescens, $2: 7+3^{6}$.

unicornis, 2: $705^{9}$.

schlaegeri, Stenoma, 2: 7081.

Schreckensteinia erythriella, 2: $737^{5}$.

schreibersii, Cryptocephalus, see C. schreibersii.

Sciagraphia heliothidata, 2: $730^{6}$.

Sciapteron simulans, see Memythrus.

tricincta, sie Nemythrus.

Sciara ocellaris, see Cecidomyia. tilicola $2: 731^{8}$.

scitiscripta, Cerura, $2: 7+3^{2}$.

scitula, Andricus, 2: $7^{1} 3^{1}$.

Chrysobothris, $2: 701^{6}$.

Sesia, $2: 428^{2}, 4 x^{3}$.

Scolecocampa liburna, 2: $705^{3}$.

Scoliopteryx libatrix, $2: 743^{2}$.

scolopendrina, Harpyia, 2: $747^{7}$.

scolyticida, Lysitermus, I: $275^{4}$.

Scolytidae, $1: 11^{9}, 12^{9}-13^{1}$.

Scolytids, certain structures of, 2: $336^{2}-37^{9}$.

scolytivorus, Bracon, I: $275^{4}$.

Scolytus fagi, $2: 722^{4}$.

muticus, 2: $725^{8}$.

quadrispinosus, $1: 257^{2}, 275^{4}-79^{6}$ :

2: $336^{6}, 446^{3}, 502^{7}, 504^{6}, 505^{2}$.

rugulostts, $2: 33^{6} ; 2: 453^{1}, 503^{x}$.

Scoparia basalis, $2: 754^{8}$.

Scopelosoma devia, 2: $705^{2}$.

moffatiana, $2: 723^{9}$.

morrisoni, 2: $705^{1}$.

sidus, $2: 705^{2}$.

tristigmata, $2: 705$

walkeri, 2: $705^{2}$.

Scotobates calcaratus, $2: 493^{4}$.

scripta. Mlelasoma, I: $253^{7}, 317^{8}-$ $22^{2} ; 2: 564^{9}, 565^{7}$.

scrutator, Calosoma, I: $113^{4}, 146^{2}$, $16 \mathrm{r}^{9}$.

sculpta. Amphibolips, $2: 7 \mathrm{r}^{4}$ 
ficurfy scale, 1 : $173^{6}, 207^{6}-8^{4}, 214^{7}-1$ $16^{\mathrm{b}}$.

scutellaris, Neoclytus, $2: 715^{4}$. Piazorhinus, 2: $703^{\circ}$.

scutellatus, Monohammus, 2: $339^{3}$, $36 \mathbf{1}^{6}, 362^{1}, 364^{1}$.

Scymnus sp., I: $231^{3}$.

lophanthae, $1: 223^{3}$.

tenebrosus, 2: $666^{\circ}$.

Scythropus elegans, 2: $752^{9}$.

segnipes, Apion, 2: $742^{3}$.

Selandria barda, 2: $609^{3}$.

Selidosema umbrosarium, $2: 725^{3}$.

semen, Acarus, 2: $7+5^{9}$.

semiclusaria, Nepytia, 2: $753^{2}$.

semiferana, Archips, 2: $707^{5}$.

semaifuneralis, Euzophera, 2: $733^{\circ}$.

Semilooper maple worm, 2: $500^{9}$,

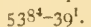

seminator, Andricus, $2: 618^{2}, 622^{1}$, $622^{9}-23^{1}$.

seninosus, Andricus, 2: $709^{9}$.

seminudus, Eutettix, 2: $749^{9}$.

semipiceus, Periclistis, 2: $736^{5}$.

semirufescens, Schizura, $2: 7+3^{6}$.

senatoria, Anisota, $1: 25^{84}, 306^{5}$ io ${ }^{3} ; 2: 527^{5}, 607^{7}$.

seniculus, Conotrachelus, 2: $512^{5}$, $5^{82^{5}}$.

sentana, Platynota, $2: 738^{5}$.

septem-maculata, Lestodiplosis, 2: $7+5^{5}$.

septendecim, Tibicen, 1: $173^{9}$, $231^{5}-37^{8}$.

septentrionalis, Gluphisia, $2: 747^{6}$. sepulchralis, Citheronia, 2: $752^{9}$.

serena, Catocala, 2: $716^{9}$.

Serica sericea, $2: 553^{2}$. trociformis, 2: $506^{4}, 514^{5}$.

sericea, 13lastothrix, $\mathbf{I}: 203^{1}$.

Serica, 2: $553^{\circ}$.

Cistela, 2: $518^{4}$.

Enchodes, 2: $727^{5}$.

vericeum, Lymexylon, $2: 427^{9}, 449^{5}$. serieventris, Podisus, I: $113^{8}, 161^{9}$, I $66^{3}$.

serotinae, Acarus, $2: 733^{8}$.

Cecidomyia, $2: 733^{8}$.

serotinaeella, Nepticula, 2: $733^{7}$.

serrata, Euchlaena, 2: $72^{9}$.

Serropalpus barbatus, $2: 650^{3}, 67 \mathrm{r}^{7}$. serrulatae, Dasyneura, 2: $750^{\circ}$. servus, Euschistus, I: $146^{1}$. Sesia acerni, $1: 49,50^{6}, 56^{9}-58^{9}$. albicornis, $2: 429^{6}, 469^{6}-70^{4}$. bolteri, 2: $429^{6}, 470^{6}$. corni, 2: $428^{6}, 45^{6}-57^{5}$. pictipes, $2: 4^{25^{3}}, 453^{4}-54^{5}$. pyri, $2: 45^{5}$. rubristigma, $2: 426^{9}, 437^{7}-38^{3}$. scitula, 2: $428^{2}, 451^{3}$.

Sesiidae, $\mathbf{I}: \mathbf{1} 2^{3}$.

setacea, Phora, 1: $15^{8^{5}}$.

setulosum, Dorcatoma, 2: $748^{5}$.

sexfasciatus, Dryobius, 2: $702^{1}$, $722^{2}$.

sexguttatus, Leptostylus, 2: $75 \mathbf{I}^{6}$.

sexsignata, Chrysobothris, 2: $721^{9}$.

Shadbush, injurious insects:

borers:

Agrilus vittaticollis, $2: 720^{7}$.

apple borer, round-headed, I: $5 I^{3}, 84^{8}$.

Molorchus bimaculatus, 2: $715^{4}$.

Sesia pictipes, $2: 453^{b}$.

leaf feeders: $2: 734^{1}$. apple tent caterpillar, $2: 55 \mathrm{I}^{1}$. Odontota quadrata, 2: $731^{5}$.

Pteronus thoracicus, 2: $510^{4}$, $553^{4}$.

scale insects:

Eulecanium kansasense, 2: $734^{2}$.

scurfy scale, $1: 215^{9}$.

Shade tree pests, more important, I: $50^{1}-240^{9}$; annual losses caused by, $1: 7^{6}-8^{7}$.

Shellbark, hickory onion gall injuring, $2: 628^{5}$.

shurtleffi, IJeterogenea, 2:5296, $707^{3}$.

Sibine stimulea, $2: 528^{6}, 529^{4}$.

sidus, Scopelosoma, 2: $705^{\circ}$.

signata, IHyperaspis, see H. signata.

signatana, lledya, $1: 169^{4}$.

Thiodia, 1: $106^{9}, 168^{4}-69^{9}$.

signatus, Lepturges, 2: $\mathbf{7 2 2}^{3}$.

significa, Coptocycla, 2: $730^{\circ}$.

siliqua, Rlıabdophaga, 2: $745^{8}$.

silkworm, 1: 18?
Silvanus bidentatu〉, 2: 72I'. imbellis, $2: 489^{7}$. planatus, $2: 73 \mathrm{I}^{3}$. surinamensis, $1: 295^{\circ}$.

Silverfish, $1: 15^{5}$.

similana, Eucosma, 2:7498.

similis, Amauronematus, $2: 7+1^{8}$. Catocala, 2: $705^{5}$. Chilocorus, I: $223^{4}$.

simillinus, Spathius, 1:282.

similis, Andricus, $2: 713^{6}$.

simplex, Bracon, I: $22^{2} ; 2: 384^{5}$. Dendroctonus, 2: $752^{3}$.

Melanobracon, 1: $70^{7}, 261^{6}$.

simplicicollis, Romaleum, $2: 75 \mathrm{r}^{3}$. simulans, Memythrus, $2: 427^{1}+3{ }^{2}$. simulator, Phloeotrya, 2: $494^{1}$.

singularis, Andricus, 2: $615^{4}, 625^{7}$.

Sinoxylon basilare, $2: 427^{4}, 42^{2}$, $502^{4}$.

sinuatus, Agrilus, 2: $504^{4}$.

Siobla excavata, $2: 719^{4}$.

Siphocoryne salicis, $2: 7^{\circ} 4^{*}$.

Sisyrosea inornata, 2: $728^{3}$. textula, $2: 529^{4}, 721^{4}$.

Slender birch horntail, 2: $429^{\circ}$, $466^{6}$.

Slug caterpillars, $2: 507^{9}, 527^{5}-2 y^{9}$;

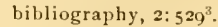

Smeared dagger motli, $2: 511^{2}$, $560^{\prime}$.

Smerinthus jamaicensis, $2: 724^{7}$.

Smicra microgaster, I: $74^{\text {i. }}$. odontotae, see Spilochalcis (Sinicra) odontotae.

smilaciella, Proleucoptera, 2: $74^{\circ}$. smilacis, Chrysomphalus, 2: $740^{4}$. Lachnus, $5: 740^{8}$.

smilacisella, Phyllocnistis, 2: $740^{7}$. smilax, injurious insects:

leaf feeders: $2: 7+0^{6}$. sucking insects: $2: 740^{\circ}$.

smodicum cucujiforme, 2: $701^{9}$, $741^{4}$.

Snow fleas, $1: 15^{5}$.

Snowberry, injurious insects: leaf feeder:

Hemaris thysbe, $\boldsymbol{2}: 738^{3}$.

Snowy tree cricket, 2: $699^{4}, 699^{6}$.

Soja beans, locust leaf miner injuring, I: $327^{9}$. 
Soldier bug, 1: $166^{3}, 309^{3}: 2: 607^{1-}$ $13^{3}, 676^{\circ}, 677^{3}$.

spined, I: $146^{1}$.

solicitana, Eucosma, 2: $749^{4}$.

solidagini $4,1 / a c r o c e n t r u s, 2: 53 \mathrm{I}^{5}$, $553^{2}$.

sordidata, Hydriomena, $2: 7+3^{\circ}$.

Sour gum, injurious insects: 2: $735^{6}$.

borer:

Acanthoderes morrisii, 2: $732^{1}$.

leaf feeders:

Adoneta spinuloides, 2: $700^{y}$.

Ampeloplraga choerilus, 2: $73 \mathrm{~S}^{4}$.

Euclea delphinii, $2: 529^{2}, 706^{3}$.

forest tent caterpillar, 1 : $110^{9}$. sour gum case cutter, 2: $510^{5}$, $555^{6}-56^{2}$.

Siour gum case cutter, 2: $510^{5}$, $555^{6}-56^{\circ}$.

Southern praying mantis, $1: 24^{9}$.

fouthern Tomicus, 2: $338^{6}, 36^{6}-$ $59^{6}$.

Spanworms, 2: $706^{2}, \quad 720^{2}, 72 \mathbf{1}^{3}$, $727^{9}, 728^{1}, 730^{6}, 731^{6}, 733^{5}, 733^{9}$, $734^{7}, 73^{9}, 7+3^{7}, 7+3^{9}, 7+7^{7}, 7+9^{6}$, $749^{7}, 750^{7}, 753^{1}, 753^{2}, 753^{3}, 754^{7}$, $754^{9}, 755^{8}$.

Sparrow, 1:237 .

chipping, 1 : $111^{3}, 111^{5}, 111^{8}, 122^{2}$.

English, 1: $111^{7}, 111^{8}, 137^{8}, 166^{8}$. $237^{2}$; effect on local fauna, 1: $133^{6}$.

Sparrow family, I: $31^{1}$.

sparsus, Pityogenes, 2: $752^{2}$.

Spathius brachyrurus, $2:$ for $^{2}$.

canadensis, $2: 359^{3}, 393^{8}$.

claripennis, $2: 389^{9}$.

pallidus, $2: 359^{3}$.

simillimus, $1: 282$.

tomici, 2: $379^{6}$.

trifasciata, $1: 278^{3}$.

unifasciatus, $1: 27^{4}$.

speciosus, Plagionotus, $I: 49,50^{5}$, $51^{8}-56^{7} ; 2: 443^{8}$.

Sphecius, 2: $603^{8}-4^{4}$.

sperata, Apatela, $2: 747^{3}$.

Spermophagus robiniae, $2: 73 \mathrm{I}^{1}$.

Sphaerococcus sylvestris, 2: $709^{6}$.
Tphaerostilba coccophila, I: $\mathbf{2 2 4 ^ { 2 }}$. Sphecins speciosus, $2: 603^{8}-4^{4}$. sphecodına abbotii, $2: 739^{9}$.

Sphinx, ash, $2: 509^{8}, 54^{1}$. four-lined, 2: $509^{7}, 546^{5}$. wavy ash, $2: 509^{9}, 54^{7}-49^{2}$.

Sphinx chersis, $2: 727^{1}$. drupiferartm, 2: $726^{1}$. gordius, $2: 727^{1}$. kalmiae, $2: 509^{3}, 54^{8}$. luscitiosa, $2: 7+2^{5}$. plebeia, $2: 7 \boldsymbol{t}^{2}$.

Splnyrapicus varius, $1: 28^{9}$. spicebush, injurious insects: Amorbia humerosana, 2: $737^{4}$. Papilio troilus, 2: $732^{6}$.

Tetracis crocallata, $2: 72 \mathrm{I}^{4}$. Spilochalcis debilis, I: $1.40^{4}$. (Smicra) odontotae, $1: 328^{1}$. Spined soldier bug, $1: 146^{1} ; 2: 605^{4}-$ $9^{\text {*. }}$

spinosa, Phylloxera, 2: $718^{x}$.

spinosus, Chaitophorus, 2: $709^{2}$.

Hamamelistes, I: $2.46^{9}-47^{1}, 25 \mathbf{I}^{7}$; 2: $616^{6}, 621^{3}, 643^{3}-46^{9}$.

Podisus, 1: $146^{1}, 153^{8} ; 2: 543^{9}$, $608^{7}$.

spinuloida, Phylloxera, 2: $718^{*}$.

spinuloides, Adoneta, 2: $529^{5}$, $706^{9}$.

Spiny bullet gall, 2:621 $747^{8}$.

Spiny elm caterpillar, $\mathbf{x}: 18^{9}, 4^{8^{4}}$, $105^{9}, 15^{8^{8}-62^{4}}, 253^{4} ; 2: 607^{8}$.

Spiny oak gall, $2: 619^{3}, 627^{6}$.

Spiny oak worm, $2: 507^{\mathrm{s}}, 527^{6}$.

Spiny witch-hazel gall, $2: 62 \mathbf{I}^{3}$, $643^{4}-4^{9}$.

Spittle insects, $2: 652^{2}, 686^{4}-87^{4}$.

splendidum, Callichroma, $2: 735^{6}$.

splendoriferella, Coptodisca, 2: $734^{8}$.

Spotted buprestid, $2: 339^{6}, 390^{5}-$ $9 \mathrm{I}^{4}$.

Spotted Leptostylus, $2: 430^{6}, 482^{7}$.

Spotted willow leaf beetle, 2 : $511^{3}, 564^{8}-65^{6}$.

Spraying, proper apparatus, I: $43^{2}-44^{8}$; cost of, $1: 4^{8}-43^{2}$; directions for, $1: 4 \mathrm{I}^{2}$.

Spring cankerworm, 2: $509^{7}$, $5+7^{4}$.
Spruce, beneficial insects:

American bark beetle destroyer, 2: 50I $^{3}$.

cloudy bark beetle destroyer, 2: $653^{2}, 693^{3}$.

injurious insects: $2: 339^{1}$.

borers: $2: 753^{7}$.

apple wood stainer, $1: 257^{6}$. $289^{5}$.

balsam bark borer, 2: $376^{2}$.

bark borers, $1: 6^{6}$.

blazed tree borer, $2: 650^{3}$. $67 \mathrm{r}^{9}$.

buprestid, spotted, $2: 339^{5}$. $390^{5}$.

buprestis, golden, $2: 645^{7}$. $655^{\circ}$.

cedar tree borer, 2: $675^{\circ}$.

Chrysobothris trinervia, 2: $75^{1^{3}}$.

Cossonus corticola, 2: $75 \mathbf{I}^{7}$.

Criocephalus agrestic, 2: $660^{1}$.

Cryphalus striatulus, a: $650^{5}, 673^{4}$.

Dendroctonus pusillus, 2: $75^{3}$.

Dicerca tenebrosa, 2: $657^{\circ}$.

Dorcaschema nigrum, 2: $445^{3}$.

Dryocoetes sp., 2: 6732. affaber, $2: 752^{3}$.

autographus, $2: 650^{4}, 672^{6}$.

tlat-headed borer, common, 1: $87^{2}$.

Hister parallelus, $2: 491^{4}$.

horntail, banded, 2: $649^{9}$. $668^{8}$.

blue, $2: 649^{9}, 669^{2}$.

Hylotrupes bajulus, 2: $664^{2}$.

Leptura, Canadian, 2: $650^{2}$. $670^{6}$.

Mordella borealis, 2: $650^{4}$. $672^{2}$.

Phymatodes dimidiatus, 2: $650^{2}, 669^{2}$.

pine bark beetle, 2: $35 \mathrm{r}^{6}$. pine borer, lesser, 2: $662^{5}$.

pine wood stainer, eastern, 2: $371^{3}$.

Pissodes dubius, 2: $401^{5}$. 
Spruce, inj. insects $\left(i n t^{\prime} d\right)$ :

borers:

Pityojthorns pulchellus, 2: $752^{1}$,

sawyer, 2: $360^{\circ}$.

spruce bark beetle, $2: 33^{6}$, $354^{8}, 3^{86^{2}}$. minute, $2: 338^{6}, 359^{7}$.

spruce clest roying beetle, 2 : $33^{8}, 379^{4}$.

Tetropium cinnamopternm, 2: $650^{3}, 669^{4}$.

'Tomicus caclatus, 2: $354^{\text {". }}$.

Urocerus, white-horned, 2 : $649^{8}, 667^{6}$.

Xylotrechus undulatus, 2: $650^{3}, 671^{2}$.

gall insects:

spruce gall aphid, i: $172^{8}$, $159^{2}$.

leaf feeders: $2: 754^{1}$.

Alceris hastiana, $2: 7+44^{3}$.

bag or basket worm, $\mathrm{I}: \mathbf{1 2} 7^{2}$.

Feralia jocosa, 2: $754^{7}$.

fir sawfly, 2. $340^{\natural}, 415^{6}$.

Nlelanolophia canadaria, 2: $753^{3}$.

Nepytia semiclusaria, 2: $753^{2}$.

Paraphia subatomaria, 2: $753^{3}$.

pine chrysomela, 2: $695^{4}$.

l'agodis fervidaria, 2: $706^{5}$.

Scytbropus elegans, 2: $752^{9}$.

spruce bad worm, 2: $340^{\circ}$, $416^{5}$.

spruce cone worm, $2: 65 \mathrm{I}^{7}$, $634^{2}$.

spruce sawtly, 2: $651^{6}, 683^{3}$.

tussock moth, white marked, $x \cdot 136^{\circ}$.

sucking insects: $2: 754^{4}$.

Spruce, black, Phyllobaenus dis-

locatus beneficial to, 2: $503^{7}$.

injurious insects:

borers:

Crypturgus alutaceus, 2* $753^{2}$.

Iryococtes granicollis, 2 $753^{\circ}$.

Pytho niger, 2: $751^{6}$.
Spruce, black, inj. insects (cont' $d$ ): | Stepbanoderus dissimilis, $2: 702^{2}$. borers: Stethobaris tubulatus, 2: $734^{6}$.

spruce timber beetle, 2: Stictocephala inermis, $2: 652^{2}$, $369^{9}$. $687^{5}$.

spruce wood engraver, 2: stigma, Anisota, 2: $507^{8}, 527^{3}$. $650^{6}, 674^{2}$. Stigmata, Eucoila, 2: $714^{\circ}$.

Xestobium squalidum, 2: stigmatella, Gracilaria, 2.744, $753^{8}$.

Xyloterus politus, I: $202^{8}$. stigmaterus, 11 emerobius, $2: 653^{7}$, leaf feeder:

Recurvaria piceaella, 2: stimulea, Sibine, $2: 528^{6}, 529^{4}$. $754^{3}$.

Spruce, Norway. in jurious insects: Crypturgus alutaceus, $2 \cdot 753^{\circ}$. pine weevil, white, $2: 397^{6}$.

turpentine bark beetle, $2343^{3}$.

spruce, red, spruce wood engraver injuring, $28650^{6}, 674^{4}$.

Spruce bark beetle, $1: 6^{7} ; 2.33^{8^{8}}$, $356^{1}-90^{4}$; birds feeding on, 1 : $28^{3}$.

minute, $2^{\cdot} 33^{8}, 359^{6}-60^{6}$

Spruce bark borer, $2: 673^{2}$.

Spruce bud worm, $2 \cdot 340^{8}, 416^{8}-18^{3}$. Spruce cone worm, $2: 651^{7}, 684^{1}$.

Spruce destroying beetle, $2: 33^{8}$, $379^{i}-85^{9},(\kappa) 3^{2}$.

Spruce gall aphid, $\mathrm{J}: 172^{\mathrm{F}}, 189^{1}-91^{6}$. Spruce sawfly, $2: 651^{2}, 683^{2}$.

Spruce timber beetle, $2: 339^{7}, 369^{9}-$ $70^{\circ}$.

Spruce woorl engraver. 2.650, $674^{1}$.

spuria, Gossyparia, I: $8^{3}, 4^{k^{1}}, 49$. $173^{3}, 203^{3}-7^{6}$.

squalidum, Nestobium, 2: $753^{\mathrm{k}}$.

squamosus, Dorytomus, 2: $74^{4}$.

Sqquaw-buckleberry, Datana palmii injuring, 2: $739^{3}$.

stabulans, Cyrtoneura, 1: $153^{8}$.

Stagmomantic carolina, $1 \cdot 24^{9}$, $146^{2}, 154^{2}$.

Stalk borer, $2: 429^{4}, 468^{1}$.

Steganoptycha claypoleana, see Epinotia.

Stenoma scblaegeri, $2: 708^{1}$.

Stenomesius sp., 2: $410^{2}$.

Stenopsis argenteomaculatus, 2: $721^{\prime}$.

Stenoscelis brevis, $2: 455^{\circ}, 494^{4}$.

vienophenus notatus, $2: 493^{8}, 715^{4}$ stragula, 11 y peraeschra, $2: 747^{6}$.

Strawberry bushes, injurious insects:

Euschistus variolarius, 2:6122. filament bearer, $2: 530^{5}$. Typopborus canellus, $2: 537^{8}$. striata, Buprestis, $2: 648^{7}, 655^{8}-56^{7}$. Melandrya, 2: $493^{\text {r }}$.

striatulus, Cryphalus, see C. striatulus.

strigosa, Mlelalopha, 2: $747^{5}$.

Striped cottonwood beetle, $2: 564^{9}$.

Striped bickory caterpillar, 2: $508^{6}, 535^{8}$.

strobi, Eutettix, 2: $688^{N}$.

Lachnus, 2: $753^{\text {7 }}$.

Pissodes, 2: $339^{9}, 397^{1}-401^{2}, 402^{1}$, $402^{6}, 402^{9}$.

strobilana, Cynips, $2: 618^{6}, 625^{1}$.

strobiliscus, Rbabdophaga, 2: $7+5^{4}, 7.46^{2}$.

strobilobiu, Chermes, 1,1727, $187^{6}-88^{9}$

strobiloides, Rhabdophaga, 2: $621^{2}, 639^{1}, 746^{1}, 746^{2}, 746^{3}$.

Strongylium terninatum, 2: $703^{\circ}$.

Strongylogaster pinguis, $2: 74^{8}$.

Stropbosomus coryli, 2: $749^{1}$.

Strymon titus, $2: 733^{4}$.

subaenea, Hydnocera, 2: $606^{4}$.

subarmatus, Eupogonius, 2: $724^{4}$.

subatomaria, Paraphia, 2: $753^{3}$. $706^{4}$. subcostatum, Platydema, 2:497, $667^{4}$.

subcroceata, Nemoria, z: $706^{3}$.

subcyaneus, Ichneumon, I: $13^{8}$, $324^{6}$. var, unipuncta, Yarapbia, 2:

subcompressa, Anacbaris, 2: $714^{8}$. 
subcyancus, Mastogenius, 2: $701^{8}$. subelliptica, Phylloxera, 2: $71 \mathrm{I}^{9}$. suhgregarium, Isodyctium, 2: $7^{\circ} 3^{\circ}$. subhamata, Leptura, $=: 650^{7}, 675^{1}$. subnata, Catocala, 2: $720^{9}$. subpubescens, Elaphidion, 2: $7 \mathrm{O}^{2}$. subrotata, Heterocampa, 2: $716^{\circ}$. subsignarius, Ennomos, $2: 725^{4}$.

subspinosus, Macrodactylus, 2: $512^{2}, 575^{6}$.

subtruncata, Periclista, 2: $702^{9}$.

subvittata, Dichelonycha, 2: $723^{4}$.

sugar maple borer, 1: $50^{5}, 51^{6}-56^{7}$; $2: 443^{8}$.

Sugar maple timber beetle, 1: $50^{8}$, $65^{1}-67^{6}$.

sulcicollis, Buprestis, 2: $75 \mathrm{I}^{\circ}$.

Corymbites, $2: 492^{6}$.

sulfureana, Epagoge, 2: 7307.

Sumac, Phyllobaenus dislocatus beneficial to, 2: $503^{8}$.

injurious insects:

borers: $2: 737^{\circ}$.

Gaurotes cyanipennis, 2: $454^{9}$.

Hyperplatys maculatus, 2: $433^{3}$.

leptostylus, spotted, $2: 482^{9}$.

Liopus alpha, $2: 430^{5}, 481^{2}-$ $82^{4}$.

maple and oak twig pruner, I. $6 \mathrm{I}^{3}$.

Oberea ocellata, $2: 493^{3}$. ruficollis, $2: 732^{5}$.

l'ityogenes similis, $2: 482^{5}$. woodbine borer, $2: 430^{3}$, $478^{8}$.

flower cricket, white, $2: 603^{3}$. gall insects:

Pemphigus rhois, $1: 247^{\hbar}$.

sumac tomato gall, $2: 621^{4}$, $647^{3}$.

leaf feeders, $2: 737^{\circ}$.

Anacampsis rhoifructella, 2: $747^{8}$.

apple worm, yellow-necked, 2. $535^{8}$.

Attelabus analis, 2: $720^{1}$. rhois, a: $511^{9}, 574^{7}$.

Copturus binotatus, $2: 730^{4}$.

Episimus argutanus, 2: $725^{3}$.
Sumac, inj. insects (iont'd):

leaf feeders:

hickory horned devil, I: $305^{8}$.

hickory tussock moth, I: $314^{9}$.

Jeaf roller, oblique banded, 2: $580^{9}$.

Lepturges signatns, $2: 722^{3}$.

Nodonota puncticollis, 2: $730^{3}$.

Pachybrachys tridens, 2: $742^{2}$.

Tetracis crocallata, $2: 72 \mathrm{I}^{4}$. sucking insects: $2: 737^{5}$.

Sumac tomato gall, $2: 62 \mathbf{1}^{5}, 647^{3}$.

Sunflower, poplar twig gall fly injuring, $2: 635^{3}$.

superans, Apatela, 2: $749^{3}$.

superatalis, Epipaschia, 2:740 .

supernotatus, Psenocerus, 2: $736^{6}$.

Supple jack, powder post beetle injuring, $1: 296^{9}$.

surinamensis, Silvanus, 1: $295^{\circ}$.

suturalis, Acoptus, 2: $715^{8}$.

Anthonomus, 2: $715^{9}$.

Batyle, 2. $649^{5}, 663^{3}$.

Idiocerus, 2: $597^{9}$.

Micracis, 2: $715^{\circ}$.

Sweet fern, see Fern, sweet.

Sweet gale, injurious insects:

Melanolophia canadaria, $2: 753^{3}$.

Rheumaptera hastata, $2: 749^{6}$.

Sweet gum, injurious insects:

borers:

Leptostylus, prickly, 2: $46 \mathrm{I}^{8}$.

leaf feeders:

forest tent caterpillar, I: $110^{9}$.

Gluphisia septentrionalis, 2 . $747^{6}$.

luna moth, 2: $526^{9}$.

Phyllocnistis liquidambarisella, $2735^{5}$.

Prolimacodes scapha, 2: $707^{-1}$. Sycamore, injurious insects.

borers:

Chalcophora campestris, 2. $722^{2}$.

Hat-headed borer, common, 1: $87^{2}$.
Sycamore, in j. insects (cont'd):

borers:

leptostylus, prickly, 2: $46 \mathrm{I}^{\circ}$.

pigeon tremex, $1: 63^{6}$.

powder post beetle, I: $297^{\prime}$.

leaf feeders: 2: $719^{1}$.

American dagger moth, 2: $525^{3}$.

bag or basket worm, I: $127^{2}$.

Chlamys plicata, 2: $703^{5}$.

Eugnamptus angustatus, 2: $703^{8}$.

Tortricidia pallida, $2: 707^{4}$.

tussock moth, white marked, I: $136^{9}$.

scale or sucking insects:

black-banded scale, $1: 20 \mathbf{1}^{2}$. ciliated tingis, 2: $600^{1}$.

sycophanta, Anthonomus, 2: $742^{5}$.

Pristiphora, 2: $510^{8}, \quad 557^{3}-53^{\circ}$. $741^{6}$.

sylvestris, Periclistis, $2: 736^{5}$.

Sphaerococcus, 2: $709^{6}$.

Symmerista albifrons, 2: 506?, $519^{3}-20^{2}$.

symmetrica, Cecidomyia, $2: 710^{2}$.

Phylloxera, 2: $718^{9}$.

symmetricus, Lepturges, 2: $493^{2}$.

Sympiezus uroplatae, 1: $328^{8}$.

Syuchita obscura, 2: 7ort.

Synchroa punctata, 2: $666^{6}$.

Synelys enucleata, 2: $733^{6}$.

Synergus albipes, $2: 714^{4}$.

campanula, 2:714 4

dimorphns, $2: 714^{4}$.

laeviventris, $2: 7 \mathrm{I}_{4}^{4}$.

lignicolor, $2.714^{5}$.

mendax, $2714^{5}$.

oneratus, $2: 714^{6}$.

rhoditiformis, $2: 714^{6}$.

Syneta ferruginea, $2: 74^{9}$.

Syntasis diplosidis, $2: \downarrow 12^{6}$.

Syntomosphyrum esurus, I: $140^{4}$.

syringae, Podosesia, I. $51^{8}, 104^{1}$.

Syrphidae, $1: 24^{2}$.

Syrphus flies, $\mathbf{x}: 175^{\circ}$.

Syssaura infensata var. biclaria, $z$ $755^{8}$.

Systena marginalis, $2: 506^{4}, 515^{1}$. taeniata, 2, $703^{6}$. 
Tachina fly, red-tailed, $1: 132^{1}$. | tentoriferella, Machimia, 2: $703^{2}$. Tachina mella, I: $113^{3}, 133^{4}, 139^{2}$. tenuicornis, Eruobius, $2: 752^{5}$.

Tachinidae, 1: 22 ?

Tachygonus lecontei, $2: 75^{x}$.

Tachypterus quadrigibbus, $734^{4}$.

taeniata, Systena, 2: $703^{5}$.

taeniatus, Aphrastus, see A. taeniatus.

Tamarack, see Larch.

Tan bark, variable oak borer injuring, 2: $426^{3}, 433^{8}$.

Tanagers, $1: 3 \mathbf{1}^{3}, 33^{3} ;$ voracity, $\mathbf{x}$ : $26^{3}$.

scarlet, $1: 27^{3}, 111^{6}, 166^{5}$.

Tanagridae, $1: 31^{3}$.

tarquinius, Feniseca, 1: $196^{1}$.

tarsale, Eulecanium, 2: $736^{\circ}$.

tarsatorius, Foenus, 2: $500^{2}$.

tarsatus, Harpiphorus, 2: $73^{\circ}$.

Taxonus multicolor, 2: $748^{8}$.

Telamona ampelopsidis, $2: 740^{4}$.

fasciata, 2: $717^{6}$.

monticola, 2: $596^{7}$.

querci, 2: $596^{9}$.

telarius, Tetranychus, $2: 755^{\circ}$.

Telea polyphemus, $2: 507^{7}, 526^{2}$.

Telenomus bifidus, I: $1+5^{7}$.

graptae, 1: $161^{6}$.

orgyiae, $\mathbf{x}: 138^{6}$.

podisi, 2: $609^{3}$.

Telphusa belangerella, 2: $750^{\circ}$. querciella, 2: $707^{7}$.

quercinigracella, $2: 707^{7}$.

Temeluclia fusiformis, $2: 4^{82^{4}}$.

tenebricosus, Chrysomphalus, 2 $725^{\circ}$.

Tenebrio tenebrioides, 2: $493^{5}$.

Tenebrioides americana, $2: 73 x^{3}$. castanea, 2: $492^{\circ}$.

corticalis, $2: 492^{1}, 721^{9}$.

tenebrioides, Tenebrio, $2: 493^{5}$.

Tenebrionidae, $1: 23^{9}-24^{1}$.

tenebrosa, Dicerca, 2: $644^{\circ}, 657^{1}$.

tenebrosus, Scymnus, 2: $666^{\circ}$.

Tent caterpillar, 1: $14^{9}, 19^{9}$.

Tenthredinidae, I: $10^{7} ; \quad 2: 616^{9}$, $617^{1}$.

Tenthredo atroviolacea, $2: 737^{6}$.

cressonii, $2: 74^{8}$

remota, $2: 77^{87}$. tenuidactylus, Oxyptilus, $2: 754^{2}$

tenuipes, Dysphaga, 2: $715^{7}$.

2: tenuis, 11 ylastes, $2: 752^{8}$.

Tephroclystis luteata, $2: 754^{9}$. miserulata, 2: $706^{2}$.

Teras hastiana, set Alceris.

terehrans, Dendroctonus, see D. terebrans.

Termes flavipes, $1: 51^{4}, 87^{8}-90^{1}$.

terminalis, Oryssus, 2: $727^{4}$.

Pontania, 2: $745^{7}$.

terminatum, Strongylium, 2: $703^{8}$.

terminatus, Elasmocerus, see E. terminatus.

tessellaris, Halisidota, 2: $507^{8}$, $523^{7}-24^{2}$.

tessellata, Goes, 2: $7 \mathrm{O}^{3}$.

tessellatus, Anthonomus, 2: $742^{4}$. Pemphigus, 1: $173^{1}, 195^{8}-96^{3}$.

testacea, Tortricidia, 2: $529^{6}, 707^{4}$. testaceus, I,aemophloeus, $2: 490^{3}$.

testata, Eustroma, 2: $7+3^{8}$.

Tetracis crocallata, $2: 72 x^{4}$.

Tetranychus mytilaspidis, $1: 14^{8}$. telarius, $2: 755^{3}$.

tetraspilotus, Litargus, 2: $74^{9}$.

Tetratoma truncorum, $2: 731^{3}$.

Tetropium cinnamopterum, 2: $650^{1}, 669^{4}$.

Tetrops canescens, 2: $750^{3}$.

Tetyra bipunctata, $2: 753^{6}$.

textor, Hyphantria, see H, textor.

textrinaria, Metanema, 2: 706?.

textula, Sisyrosea, 2:529, $721^{4}$.

Thalessa, $1: 21^{8}$.

lunator, $1: 63^{2}, 64,261^{6}$.

Thanaos brizo, 2: $704^{3}$.

icelus, $2: 742^{7}$.

juvenalis, $2: 704^{4}$.

persius, $2: 742^{7}$.

Thanasimus dubius, $2: 345^{4}, 389^{8}$, $500^{3}-1^{7}$.

nubilus, $2: 384^{5}, 653^{2}, 693^{\circ}$. trifasciatus, $2: 389^{8}$.

Thaneroclerus sanguineus, $2: 370^{7}$, $503^{1}$.

Tharops ruficornis, $2: 492^{5}$.

thaxterianus, Psaphiclia, 2: $704^{8}$.

Thecla acadica, 2: $742^{7}$.
Thecla calauus, $2: 704^{3}$. edwardsii, 2: $704^{3}$.

liparops, 2: $704^{3}$.

Thelia acuminata, 2: $595^{8}-96^{2}$. godingi, 2: $596^{3}$. univittata, 2: $709^{1}$.

Therina athasiaria, 2: $706^{6}$. endropiaria, 2: $706^{6}$. fervidaria, $2: 754^{2}$. pellucidaria, $2: 753^{2}$.

Theronia fulvescens, I: $112^{9}-13^{1}$, $138^{6}$.

thestialis, Pyrausta, 2: $739^{7}$.

Thiodia signatana, $1: 106^{2}, 168^{4}-$ $69^{9}$.

thoas, Papilio, 2: $510^{4}, 554^{3}-55^{4}$, $729^{3}$.

thoracica, Tritoma, $2: 494^{8}$.

thoracicus, Hypophloeus, 2: $359^{7}$. Pteronus, 2: $510^{4}, 553^{3}-54^{3}, 732^{8}$.

Thorn, injurious insects:

borers:

Agrilus vittaticollis, 2: $720^{\circ}$. leaf feeders:

Anthonomus profundus, 2: $719^{6}$.

apple tent caterpillar, 2: $551^{1}$, Basilarchia astyanax, $2: 704^{2}$.

black walnut caterpillar, I: $305^{4}$.

Catocala polygama, 2: $705^{5}$.

Crepidodera helxines, $2: 7+22$.

Hemaris thysbe, $2: 738^{8}$.

Lithocolletes blancardella, 2: $705^{6}$.

Paonias myops, 2: $733^{4}$.

Papilio glaucus var. turnus, 2: $704^{1}$.

Schizura unicornis, $2: 7^{\circ} 5^{\circ}$.

Sphecodina abbotii, 2: $739^{\circ}$.

Thecla calanus, $2: 704^{3}$.

liparops, 2: $704^{8}$.

scale or sucking insects: black-banded scale, 1: $201^{2}$. hawthorn tingis, $2: 598^{7}$.

Thorn, black, Episimus argutanus injuring, $2: 725^{3}$.

Thorn, wild, injurious insects: borer: $2: 734^{3}$. thorn $\operatorname{limb}$ borer, $1: 257^{8}$.

fruit insects, 2: $734^{4}$. 
Thorn, wild, inj. insects $($ cont $d)$ : | Timber ash, $1: 257^{5}, 288^{6}-89^{4}$. gall insect:

Cecidomyia bedeguar, $2: 734^{\circ}$. leaf feeder: $2: 734^{5}$.

Pseudanthonomus crataegi, 2: $733^{3}$.

sucking insects: $2: 735^{!}$.

Thorn limb borer, $1: 257^{3}, 283^{3}-$ $84^{8}$.

Thornapple, round-headed apple borer injuring, $I: 51^{3}, 84^{8}$.

Thrasher, brown, $1: 3 I^{\mathrm{k}}$.

Thrushes, 1: $32^{4}, 237^{3}$.

mocking, I: $3 \mathbf{I}^{8}$.

wood, 1: $111^{6}$.

thuiella, Bucculatrix, $2: 755^{5}$.

thujae, Eriophyes, $2: 755^{6}$.

thujaella, Recurvaria, 2: $755^{5}$.

Thunderbolt heetle, $2: 427^{6}, 444^{2}$.

thyridopterigis, Allocota, I: $135^{8}$.

llabrocytus, $x: 140^{3}$.

llemiteles, 1: $127^{\circ}$.

Thyridopteryx ephemeraeformis, I: $49,105^{5}, 123^{7}-28^{9}$.

Thysanocnemus fraxini, $2: 726^{\circ}$.

Thusanoes fimbricornis, $2: 716^{1}$. quercus, $2: 702^{7}$.

Thysanura, I: $15^{5}$.

thyshe, Hemaris, $2: 73^{\circ}$

tibialis, Aegeria, $2: 429^{7}, 472^{1}$.

P'ristiphora, $2: 748^{6}$.

Tibicen cassinii, I: $234^{8}$. septendecim, 1: $173^{9}, 23 \mathrm{r}^{5}-37^{b}$. tibicen, 1: $174^{1}, 237^{\circ}-38^{9}$.

Tickler, 2: $339^{3}, 365^{1}$.

Tiger beetles, I: $320^{\circ}$.

liger hickory borer, $1: 256^{8}, 268^{6}-$ $60^{3}$.

tigrina, (ioes, $1: 256^{\circ}, 268^{6}-69^{3}$.

tiliacella, Lithocolletes, $2: 731^{7}$. tiliae, Drepanosiphum, 2: 731'.

Ciargaphia, 2: $73 \mathrm{I}^{9}$.

II onophadnus, $2: 731^{5}$.

l'ulvinaria, 2: 731'.

tiliaefoliella, Coleophora, $2: 731^{7}$.

tiliaria, Erannis, 2: $733^{6}$.

tilicola, Sciara, $2: 731^{8}$.

Tillomorpha geminata, 2:715 .

Timber, losses caused by insects, I: $7^{8}$.

Timber beetles, $1: 7^{8}$. hickory, $2: 427^{5}, 44^{2}-4^{8}$.

spruce, $2: 339^{7}+369^{7}-70^{9}$.

sugar maple, $x: 50^{8}, 65^{1}-67^{6}$.

Timber worms, $1: 7^{4}$.

chest 11 t, $2:+27^{9}, 4+9^{5}$.

timidus, Plochionus, $1: 146^{1}$.

tinctoriella, Tischeria, 2:7217.

tineana, Ancylis, $2: 747^{\circ}$.

Tingis, ciliated, $2: 599^{8}-600^{4}$. hawthorn, 2: $59^{8^{6}-99^{8}}$.

Tischeria acerifoliella, see Incurvaria.

hadiiella, 2: $708^{8}$.

castaneaeella, $2: 721^{6}$.

citrinipennella, 2: $708^{9}$.

[uscomarginella, 2: $708^{8}$.

malifoliella, $2: 734^{9}$.

pruinosella, 2: $708^{8}$.

tinctoriella, $2: 721^{7}$.

titea, Phigalia, 2: $728^{3}$.

titillator, Nonohammus, 2: $339^{3}$, $365^{1}$.

Titmice, I: $32^{z}$.

Tits, $\mathrm{r}: \mathbf{1 9}^{4} \mathrm{I}^{4}$.

blue, $1: 213^{5}, 331^{3}$.

long tailed, $1: 213^{3}, 331^{3}$.

titus, Strymon, 2: $733^{4}$.

tityrus, Epargyreus, 2: $510^{6}, 55^{8}-$ $57^{4}$.

Tlascala reductella, $2: 729^{5}$.

Tmetocera ocellana, 2: $707^{5}$.

Tobacco plants, Euschistus variolarius injuring. $2: 612^{2}$.

Tolype laricis, $2: 65 \mathrm{I}^{4}, 680^{2}$. vellerla, $2: 727^{9}$.

Tomatoes, Euschistus variolarius injuring, 2:61 $2^{1}$.

tomentosus, Eupogonius, 2: $75 \mathrm{I}^{5}$.

tomici, Spathius, $2: 379^{6}$.

Tomicus, $1: 23^{6} ; 2: 336^{9}$.

avulsus, $2: 752^{2}$.

lralsameus, $2: 33^{9}, 354^{7}, 374^{6}$, $375^{2}, 375^{2}-79^{7}, 386^{7}, 389^{1}, 673^{8}$. cacographus, $2: 334^{6}, 33^{6}, 342^{8}$, $354^{8}, 356^{7}-59^{6}, 374^{9}$.

caelatus, $2: 338^{3}, 354^{2}-56^{6}, 374^{6}$, $376^{7}$.

calligraphus, $2: 334^{1}, 33^{4}, 34^{\natural}$, $345^{7}-5 r^{4}, 35 x^{8}, 354^{8}, 35^{6}, 35^{8}$, $75^{3}$.
Tomicus, pini, $2: 334^{7}, 33^{4}, 35 x^{4}-$ $54^{2}, 354^{8}, 359^{1}, 376^{6}$.

xylographus, $2: 355^{8}$.

Tomicus, southern, 2: $33^{6}, 36^{6}$ $59^{6}$.

Tomoxia bidentata, I: $26 \mathrm{I}^{2} ; 2$ : $427^{3}, 44^{1}, 42^{1}$.

lineella, $2: 427^{4}, 441^{2}, 441^{7}-42^{2}$.

torrefacta, Apatelodes, 2: $509^{\circ}$, $549^{2}$.

Tortricidia fasciola, $2: 529^{5}$.

flexuosa, 2: $717^{2}$.

pallida, $2: 529^{4}, 707^{4}$.

testacea, 2:5296 $707^{4}$.

tortriciformella, Menesta, 2: $723^{7}$.

Tortrix albicomana, $2: 532^{4}, 707^{6}$.

fumiferana, $2: 3+0^{8}, 416^{4}-18^{3}$.

packardiana, $2: 754^{3}$.

pallorana, 2: $733^{6}$.

politana, see Eulia.

quercifoliana, $2: 508^{3}, 532^{8}$.

Towhee, $1: 27^{6}, 31^{2}, 111^{7}$.

townsendi, IIemiteles, $1: \mathbf{r}_{4} \mathrm{O}^{3}$.

Toxotus schaumii, 2: $7^{22^{3}}$.

Tragidion coquus var. fulvipenue, $2: 702^{9}$.

Tragosoma depsarium, 2: $659^{3}$. harrisii, 2: $649^{2}, 659^{1}$.

Transformations of insects, $1: 13^{8}-$ $20^{5}$.

transmissana, Encosma, 2: $749^{8}$.

transversata, Sabulodes, 2: $509^{1}$, $539^{5}$.

transversus, Plegaderus, $2: 491^{\circ}$.

Tree creeper, $1: 213^{3}$.

Tree crickets, 2: $603^{1}, 653^{7}$. black-horned, $2: 699^{1}$.

four-spotted, $2: 699^{9}-700^{4}$.

suowy, 2: $699^{4}, 699^{6}$.

Tree hopper, 2: $709^{1}, 740^{8}$.

Buffalo, 2: $59 \mathrm{r}^{\mathrm{i}}-93^{9}$.

two-marked, 2: $594^{2}-95^{7}$.

Tree of lleaven, resistance to insect attack, I: $47^{3}$.

Atteva aurea injuring, $2: 735^{4}$.

Trees, selection and planting, $I$ : $46^{3}-49$; resistance of certain to insect in jury, $1: 46^{6}$; massing of, I: $47^{2}-48^{5}$.

Trefoil, two-marked tree hoppe: injuring, 2: $595^{5}$. 
Tremex $p ., 2:+(y)^{7}$.

columba, $x: 50^{2}, 54^{9}, 61^{6}-64,26 t^{4}$.

tremulae, Nelasoma, 2: $565^{7}$.

Triacius atomus, 2: $73^{5^{2}}$.

triangulifer, Urographis, 2: $435^{2}$, $725^{\wedge}$.

Trichacis rufipes, $2: 5^{8} 5^{\circ}$.

Trichiocampus viminalis, $2: 511^{6}$, $568^{1}-6 g^{5}$.

!richius piger, $2: 735^{9}$.

Trichodesma gibloosa, 2: $724^{4}$.

klagesi, 2: $715^{3}$.

Trichogramma odontotae, $1: 32^{82}$.

tricincta, Typhlocyba, $2: 725^{3}$.

tricinctus, Memythrus, 2: $429^{7}$, $47 \mathrm{r}^{1}$.

tricolor, Tymnes, 2: $506^{4}, 515^{5}$.

tridens, Pachybrachys, 2: $740^{5}$, $7+2^{9}$.

tridentata, Saperda, $1: 49,50^{9}$, $67^{7}-71^{8}, 74^{6}$.

Tridymus metallicus, $\mathrm{r}: 301^{8}$. salicis, $\mathbf{I}: 30 \mathbf{I}^{7}$.

trifasciata, Coccinella, 2:652 $69 \mathrm{I}^{5}$.

Iloplia, 2: $74^{22}$.

Spathina, $1: 278^{3}$.

trifasciatus, Thanasimus, $2: 389^{8}$. trifasciella, liucculatrix, $2: ; 2 r^{5}$.

triferana, Eulia, 2: $508^{3}, 532^{1}$.

triguttaria, IIeterophleps, $2: 727^{9}$.

trilineatus, Pteronus, $2: 730^{\circ}$.

trimaculata, Pediopsis, 2: $732^{\prime \prime}$.

trinervia, Chrysobothris, 2: $751^{3}$.

trinotellus, Ypsolophus, 2: $723^{\text {? }}$.

Trionymus americanus, 2: $727^{3}$.

Trioza tripunctata, $2: 652^{5}, 6 n 8^{8}$ $89^{5}$.

Triphyllus humeralis, $2: 495^{\text {h }}$.

Triptogon lugubris, 2: $740^{\mathrm{k}}$.

tripunctata, Trioza, $2: 652^{5}, 685^{*}-$ $80^{5}$.

i' $7 \%$, mandarina, ()berea, $2: 74^{\circ}$. triquetrana, ('elama, $2: 7^{2} t^{\prime}$.

irisignata, 11arrisimemna, 2: $737^{8}$.

Trissolcus podisi, $2 ;(60)^{3}$.

tristigmata, Scopelosoma, 2. $705^{2}$.

tristigmus, Euschistus, see li. tristignus.

tristis, Cryptorlynchus, 2: $702^{5}$.

Nodounta, 2. $730^{3} \cdot 7+2^{3}$. tristrigella, Anacampsis, 2: $723^{6}$.

trisyllaba, Macrophya, 2: $737^{7}$.

tritaeniella, Lithocolletes, $2: 722^{\circ}$. tritici, 1)iplosis, I: $6^{2}$.

triticoides, Cecidomyia, 2: $745^{4}$.

Tritoma thoracica, $2: 494^{8}$.

trivittatus, Leptocoris, $1: 174^{2}$. $239^{1}-40^{\circ}$.

Trochilium apiformae, sec Aegeria apiformis.

tibiale, see Aegeria tibialis.

trociformis, Serica, 2: $506^{4}, 514^{5}$.

Troglodytidae, $1: 32^{1}$.

troilus, Papilio, 2: $732^{6}$.

Trombidium sp., $1: 113^{6}$.

Tropaea luna, 2: $507^{7}, 526^{8}-27^{3}$.

Trumpet vine, Sphinx plebeia injuring, $2: 741^{2}$.

truncata, Mesoleuca, 2: $750^{6}$.

truncatella, Epuraea, 2: $389^{7}$.

truncatus, Colastus, $2: 491^{8}$.

truncorum, Tetratoma, 2: $731^{8}$.

Trypanisma prudens, $2: 707^{\circ}$.

Trypetidae, $2: 6 \mathbf{1} 7^{3}$.

tuber, Andricus, 2: $710^{4}$.

tuberculata. Dicerca, 2:648 $64,656^{6}$.

Galerucella, 2: $7+2^{2}$.

tuberculatus, l'ityophthorus, 2: $753^{\circ}$.

tubicola, Andricus, 2: $711^{\text {" }}$.

Cecidomyia, $2: 619^{8}, 628^{7}$

tubiferella, lithocolletes, $2: 708^{7}$.

tubulatus, Stetlobaris, $2: 734^{6}$.

tulari, Saperda, $2: 474^{7}$. .

Tulip aphid, $2: 732^{4}$.

Tuliptree, resistance to insect attack, $x:-17^{3}$.

injurious insects: aphid:

Nectarophora liriodendri, 2: $732^{4}$.

lorers: $2: 732^{1}$.

apple wool stainer, $x: 2(y)^{6}$.

Chalcophora cainpestris, 2 : $722^{2}$.

Ficyrus dasycerus, 2: $715^{6}$.

leptostylus, prickly, $2: 46 \mathrm{r}^{9}$.

Neoclytus erythrocephalus, 1: $72^{6}$.

Tylonotus limaculatus, 2: $726^{6}$.
Tuliptree, inj. insects (cont'd): leaf feeders: $2: 732^{2}$.

l'apilioglaucus var. turnus, 2: 704 '.

promethea moth, $2: 557^{\text {* }}$.

scale insects:

Chionaspis salicis-nigrae, 2: $7+4^{9}$.

tuliptree scale, $\mathbf{1}: 173^{4}, 208^{9}$.

tulipiferae, Cecidomyia, $2: 732^{2}$

Eulecanium, $\mathrm{r}: 173^{4}, 208^{8}-10^{6}$.

Tuliptree scale, $1: 173^{4}, 208^{8}-10^{\circ}$.

Iumifica, Callirhytis, 2: $713^{3}$.

Turdidae, $1: 32^{4}$.

Turnips, false chinch bug injuring, 2: $685^{8}$.

Turpentine bark beetle, $2: 33^{3}$, $3+2^{4}-45^{?}$.

Tussock caterpillar, oak, 2: 507, $523^{2}$.

pale, $2: 507^{3}, 523^{7}-24^{2}$.

Tussock moth, dark, 2: $507^{4}, 524^{4}$. definite-marked, 2:507, $522^{4}-$ $23^{2}$.

hickory, I: $25^{8}, 314^{7}-15^{9}$.

rusty, $2: 507^{4}, 524^{2}, 524^{R}$.

white marked, $1: 12^{2}, 14^{\circ}, 19^{\circ}$, $20^{8}, 44^{9}, 47^{9}, 105^{6}, 132^{6}-42^{5} ; 2:$ $522^{5}, 524^{4}, 607^{8}, 609^{1}$.

Twig borers, $x: 35^{9} ; 2: 339^{8}-40^{6}$, $719^{9}$.

hickory, $2: 427^{8}, 44^{3^{2}-49^{4}}$.

locust, $2: 430^{3}, 47^{1}$.

red-shouldered, $2:+27^{4}, 42^{2}$.

Twig galls, $2: 7+5^{1}$.

Twig girdler, $1: 256^{9}, 27 \mathrm{I}^{2}-74^{4}$.

Tylonotus bimaculatus, $2: 726^{8}$.

Tymnes metasternalis, $2: 734^{6}$.

tricolor, 2: $506^{4}, 515^{5}$.

violaceus, 2: $7 \mathrm{I}^{4}$.

Typhlocyla rosae, $1: 172^{\mathrm{x}}, 19 \mathbf{1}^{7}-172^{2}$. tricincta, 2: $725^{\circ}$.

Typocerus velutinus, $2: 426^{8}, 431^{3}$. zebratus, $2: 702^{4}$.

Typophorus canellus, $2: 50 \AA^{8}, 537^{-1}$.

Tyrannidae, $\mathbf{r}: 30^{5}$.

'yroglyphus malus, I : $213^{\prime}$ '.

Ugly nest cherry worm, 2:510", $522^{1}$.

uhlerella, Lithocolletes, 4: 730'. 
Uliota dubius, 2: $490^{\circ}$.

ulnella, Lithocolletes, $2: 725^{6}$.

ulmi, Aspidiot us, 2: $725^{6}$.

Eriophyes, 2: 725 ?

Kaliosysphinga, I: $105^{9}, 162^{4}-$ $63^{7}$.

Lachnus, 2: $725^{6}$.

Lepidosaphes, I: $49,173^{5}, 211^{1}-$ $13^{6}$.

Plocetes, 2: $724^{5}$.

ulmiarrosorella, Canarsia, $2: \mathbf{7 2}^{4}$. ulmicola, Colopha, 1: $172^{6}, 186^{7}-$ $87^{6}, 247^{3} ; 2: 620^{4}$.

ulmifolii, Callipterus, I: $172^{4}$, $1 ; 6^{6}-77^{2}$.

nlmifusus, Pemphigus, I: $247^{8} ; 2$ : $620^{5}, 633^{4}$.

ultramarina, Buprest is, 2: $75 \mathrm{I}^{2}$.

ultronia, Catocala, 2: $705^{5}$.

umbilicatus, Neuroterus, 2:619 $9^{3}$, $627^{7}$.

umbra var. exprimens, Pyrrhia, 2: $737^{3}$.

umbrata, Ifeterocampa, 2: $705^{\text {\% }}$.

umbrosarium, Selidosema, 2: $725^{3}$.

undata, I)istenia, 2: $720^{\circ}$.

undulata, Hydria, 2: $5 \mathbf{1 0}^{3}, 55 \mathrm{I}^{4}$.

undulatella, Hulstea, $2: 725^{4}$.

undulatus, Madarellus, sie MI. undulatus.

undulatus, Xylotrechus, see X. undulatus.

undulosa, Ceratomia, 2: $509^{9}, 54^{7}-$ $49^{2}$.

unicolor, Elaphidion, 2: 702².

IJacrobasis, 2: $730^{5}$.

Misogada, 2: $719^{3}$.

Nematus, 2: $511^{7}, 571^{5}-72^{2}$. unicornis, Schizura, 2: $705^{9}$. unifasciata, Hydnocera, 2: $72 \mathrm{I}^{1}$. unifasciatus, Spathina, $1: 27^{4}$.

uniformis, Halaninus, $2: 584^{4}, 585^{2}$, $73^{3}$.

unijuga, Catocala, 2: $747^{4}$.

unipuncta, Heliophila, 1: $22^{9}, 132^{1}$.

unipunctatus, Lyctus, 1: $257^{8}$, $296^{4}-98^{3} ; 2: 4^{8} 3^{3}, 483^{5}$.

univittata, Thelia, 2: $709^{1}$.

Upis ceramboides, $2: 497^{1}$.

Uranotes melinus, $2: 734$ ?
Urocerus, white-horned, 2: $649^{3}$, | velutinus, Typocerus, $2: 426^{8}, 436^{4}$. $667^{5}-68^{7}$.

ventilator, Harasmalus, $2: 737^{4}$.

Urocerus abdominalis, 2: $649^{4}$, ventralis, Pteronus, $1: 258^{8}, 322^{2}-$ $665^{8}$.

albicornis, $2: 649^{8}, 667^{5}-68^{7}, 668^{4}$.

flavicornis, $2: 75 \mathrm{I}^{2}$.

Urogaster canarsiae, $2: 532^{3}$.

forbesi, $2: 635^{2}$.

Urographis fasciatus, $2: 426^{8}, 434^{8}-$ $36^{2}, 667^{8}$

triangulifer, $2: 435^{2}, 725^{8}$.

uroplatae, Sympiezus, I: $328^{\circ}$.

Urosigalphus armatus, 2: $588^{3}$.

ursaria, Lycia, 2: $747^{2}$.

Utetheisa hella, 2: $724^{8}$.

utriculus, Andricus, 2: $710^{8}$.

uvae, Aspidiotus, 2: $717^{9}$.

V-marked leaf roller, 2: $508^{2}, 531^{6}$. vacciniana, Eudemis, $2: 73^{8}$.

Vaccinium, black-banded scale injuring, $\mathbf{x}: 201^{2}$.

Vagahond gall, 2: $620^{5}, 635^{3}$.

vagabundus, Pemphigus, $2: 620^{6}$, $635^{3}$.

vagans, Leptura, see I. vagans.

vagenotatus, Dorytomus, $2: 430^{8}$. $475^{7}$.

valida, Limneria, I: $13^{6}$.

Vanessa antiopa, see Euvanessa.

vanessae, Pteromalus, 1: $113^{3}$, $161^{7} ; 2: 555^{5}$.

variabilis, Bythoscopus, 2: $754^{4}$.

Phymatodes, 2: $426^{7}, 433^{7}-34^{7}$.

variana, Alceris, $2: 754^{3}$.

varians, Nothus, $2: 734^{5}$.

Zeugophora, 2: $746^{6}$.

varicornis, Pliyscus, 1: $208^{6}, 227^{7}$.

variegatum, Perimegatoma, I: $140^{\circ}$.

variegratus, Liopus, $2: 720^{7}, 730^{1}$.

variolaria, Deilinia, $2: 743^{8}$.

variolarius, Euschistus, sie E. variolarius.

variolosum, Asterolecanium, I: $25^{8}, 329^{3}-31^{7}$.

varius, Phymatodes, $2: 702^{1}$.

vasaliata, Mesoleuca, 2: $754^{8}$.

vau, Cyrtolobus, 2: $717^{5}$.

velleda, Tolype, $2: 727^{9}$.

velutinana, Eulia, 2: $707^{6}$.

$$
24^{9} ; 2: 746^{2} \text {. }
$$

ventricosus, Andricus, 2: $713^{5}$.

Venusia cambrica, 2: $733^{2}$.

comptaria, 2: $\mathbf{7 2 2 ^ { 6 } \text { . }}$.

venust a, Pachypsylla, 2: $726^{5}$.

verna, Amphibolips, 2: $713^{\circ}$.

Rhodites, 2:62 $\mathrm{I}^{\mathrm{s}}, 648^{2}$.

vernalis, Corymbites, $2: 752^{5}$.

Livia, $2: 753^{6}$.

vernata, Paleacrita, $2: 509^{7}, 547^{6}$.

vernella, Gelechia, 2: 7081.

vernus, Neuroterus, $2: 713^{4}$.

verruca, Cecidomyia, $2: 745^{\circ}$.

verrucarum, Neuroterus, 2: $7 \mathrm{rr}^{9}$.

verrucicola, ('ecidonyia, 2: $620^{3}$, $63 \mathrm{I}^{3}$.

verrucosus, Cyrtophorus, 2: $722^{2}$.

versicolor, Ampelophaga, 2: $719^{6}$.

Harpiphorus, 2: $736^{7}$.

Oligia, 2: $754^{1}$.

versicoloranum, Exartema, 2: $717^{2}$.

vertebratus, Pteronus, 2: $511^{4}$, $570^{2}$.

verticalis, Hydnocera, 2: $605^{\circ}-6^{4}$.

vesicula, Cynips, 2: $710^{7}$.

vestaliata, Orthofidonia, 2: $706^{4}$.

vestita, Sa perda, $1: 49,51^{5}, 91^{1}-92^{2}$. vestitus, Eupogonius, 2: 71 $5^{7}$.

vetusta, Hemerocampa, $1: 134^{3}$.

viburniella, Coleophora, $2: 73^{5}$.

Viburnum, injurious insects:

Apatelodes torrefacta, 2: $549^{4}$.

Cyaniris ladon, $2:-727^{\circ}$.

lleterocampa guttivitta, 2: 7274.

leaf feeders: $2: 738^{2}$.

Viburnum lantanoides, Chionaspis lintneri injuring, $1: 227^{9}$.

Viceroy, 2: $510^{9}, 559^{1}$.

vidua, Catocala, 2: $705^{5}$.

villosula, Xanthonia, 2: $703^{7}$.

villosum, Elaphidion, I: $49,50^{\circ}$, $59^{1}-61^{5}$

villosus, Philonix, 2: $713^{5}$.

viminalis, Chaitophorus, $2: 744^{7}$.

Trichiocampus, 2: $511^{6}, 568^{1}-69^{4}$.

vinnula, Apatela, 2: $724^{2}$.

violaceus, Tymnes, 2: 7164. 
Violet tip, 2: $509^{b}, 544^{8}-45^{4}$.

Vireonidae, $1: 31^{4}$.

Vircos, $1: 26^{7}, 31^{4}, \mathrm{III}^{4}, \mathrm{III}^{6}, \mathrm{III}^{7}$, $122^{2}$.

red-eyed, $1: 27^{4}, 27^{5}, 27^{2}, 166^{5}$.

yellow-throated, $1: 166^{3}$.

virescens, Chloridea, $2: 736^{2}$.

virginaria, Foimecis, $2: 747^{7}$.

Virginia creeper. injurions iusects:

borers:

Vladarellus undulatus, $2:+3 \mathrm{O}^{4}$, $479^{5}$.

woodbine horer, $2: 478^{9}$.

leaf feeders: $2: 739^{7}-40^{3}$.

forester, eight-spotted, 2: $512^{1}, 575^{3}$.

sucking insects:

hox elder plant bug, $\mathbf{1}: 240^{6}$.

Telamona monticola, 2: $596^{8}$.

tree hopper:

Telamona ampelopsidis, 2: $740^{3}$.

virginica, liacrisia, 2: $720^{6}$.

Xylocopa, $2: 430^{\circ}, 484^{2}$.

virginiella, Nepticula, 2: $\mathbf{7 2 2}^{4}$.

virginiensis, Anisota, 2: $704^{4}$.

(halcophora, 2: $645^{6}$. $653^{3}-54^{7}$, $654^{4}, 655^{1}, 655^{2}$.

viridiaeneus, khinosimus, $2: 748^{5}$. viridicornis, Anthaxia, $2: 724^{4}$. viridifrons, Anthaxia, 2: $715^{\circ}$.

viridis, l'ediopsis, $2: 7+4^{6}$.

vittaticollis, Agrilus, 2: $7200^{\circ}$.

vulgatissima, Phyllodecta, $2: 74^{2}$.

walkeri, Scopelosoma, 2: 705".

Walking stick, 2: $508^{5}, 533^{4}-35^{2}$, bon?

Walnut, injurious insects:

borers:

Dysphaga tenuipes, $2: 715^{7}$.

Eupogonius vestitus, 2: $715^{7}$.

Hetoem is cinerea, 2: $726^{5}$.

hickory borer, painted, I: $264^{6}$.

tiger, $1: 268^{7}$.

leoparil moth, i: $78^{6}$.

leptostylus, spotted, $2: 482^{\circ}$.

Molorchus himaculatus, 2: $715^{4}$.
Walnut, inj. insects $\left(\operatorname{cont}^{\prime} d\right)$ : borers:

oak borer, dusty, $2: 426^{2},+34^{4}$. prionus, lesser, $2: 487^{8}$.

saperda, hickory, I: $269^{\circ}$.

leaf feedits: $2: 719^{5}$.

Apatela impleta, 2: $749^{3}$.

apple worm, yellow-necked, 2: $535^{7}$.

black walnut caterpillar, I: $305^{4}$.

Catocala habilis, $2: 716^{\circ}$.

lacrymosa, 2: $705^{4}$.

Conotrachelus anaglypticus, 2: $544^{7}$.

Demas propinquilinea, $2: 749^{5}$.

Eulia juglandana, 2: $717^{3}$.

forest tent caterpillar, $1: 110^{9}$. Walnut curculio, $2: 512^{5}, 581^{6}-32^{4}$.

Ieterocampa manteo, 2: 705 ${ }^{7}$. Walnut sphinx, 2: $506^{7}, 518^{67}-19^{5}$.

hickory caterpillar, striped, walshii, Apion, 2: $749^{1}$. 2: $508^{5}, 535^{4}$.

hickory tussock moth, I: 3 I $^{8}$.

1.achuus caryae, $2: 717^{8}$.

luna moth, 2: $526^{\circ}$.

Pyrophila pyramidoides, 2: $704^{7}$.

Thecla calanus, 2: $704^{3}$.

nut pests:

walnut curculio, $2: 512^{3}, 581^{7}$.

scale or sucking insects: $2: 719^{7}$.

Aspidotus rapax, $2: 723^{\top}$.

Eulecanium cockerelli, 2: $725^{6}$.

Walnut, black, injurious insects: 2: $719^{9}$.

borers: $264^{7}$.

Vicracis suturalis, $2: 715^{\circ}$.

Tylonotus bimaculatus, $726^{\mathrm{b}}$.

yall insects: $2: 720^{4}$.

leaf feeders: $2: 720^{1}$.

American silk worm, 2: $526^{\circ}$.

black waluut caterpillar, 1: $25^{3}, 303^{8}$.

Callipterus caryae, $2: 717^{8}$.

Catocala inuubens, $2: 720^{5}$.

lacrymosa, $2: 705^{4}$.

palaeogama, $2: 716^{8}$.

vidua, $2: 705^{5}$.
Walnut, black, inj. insects $\left(\operatorname{con} t^{2} d\right)$ : leaf feeders:

Heterocampa umbrata, 2: $705^{8}$.

hickory horned devil, I: $305^{8}$. Lithocolletes caryaefoliella, $2: 717^{4}$.

Olgia versicolor, $2: 754^{\prime}$.

Schizoneura caryae, $2: 717^{\circ}$.

Schizura leptinoides, $2: 716^{9}$.

tussock moth, white marked, I: $136^{2}$,

walnut sphinx, 2: $506^{6}, 518^{7}$.

scale iusect:

scurfy scale, I: $215^{y}$.

alnut, white, Cossonus platalea

injuring, $2: 455^{\circ}$,

Warblers, 1: $26^{5}, 31^{5}, 33^{3}$.

hlack and white, 1: $111^{7}, 166^{5}$.

chestnut-sided, $1: 166^{5}$.

Nashville, 1: $27^{2}$.

yellow, I: $2 \mathbf{7}^{2}, \mathbf{I} \mathbf{I} \mathbf{I}^{\top}$.

Warty oak leaf gall, $2: 619^{2}, 627^{4}$.

Wiasps, 1: $23^{3}$.

Water beech, sugar maple timber beetle injuring, 1: $67^{6}$.

Wavy ash sphinx, 2: $509^{9}, 54^{8^{7}-49^{2}}$. Waxwing, cedar, I: III ${ }^{7}$.

websteri, Eulecanium, $2: 750^{1}$.

Webworm, 2: $609^{2}$.

fall, I: $12^{2}, 105^{6}, 131^{9}, 142^{5}-46^{7}$, $253^{3}$.

pine, 2:651 $1,676^{7}-77^{3}$.

Meevils, $1: 1 \mathrm{I}^{8} ; 2: 720^{\circ}$.

Whale oil soap, I: $35^{6}, 38^{9}$. I: $6^{2}$.

Wheel bug, I: $140^{k}, 146^{3}, 324^{7}$, $325^{3}$.

Whip-poor-wills, $1: 137^{8}$.

White-blotch oak leaf miner, 2: $508^{4}, 532^{7}-33^{1}$.

White flower crickets, $1: 24^{6} ; 2$ : $602^{3}-3^{7}$.

White-horned maple borer, 2: $428^{7}, 459^{3}-60^{1}$.

White-horned Urocerus, 2: $649^{8}$, $667^{6}-68$ ?
Wheat midge, losses caused by, 
White marked powder post beetle, $2: 430^{7}, 483^{1}$.

White markerl tussock moth, I: $12^{2}, 14^{9}, 14^{4}, 20^{4}, 44^{9}, 47^{9}, 105^{6}$, $132^{6}-42^{3} ; 2: 522^{5}, 524^{4}, 607^{8}, 609^{1}$.

White pine tufted caterpillar, 2 : $65 \mathrm{I}^{3}, 679^{7}-80^{1}$.

White pine weevil, I: $7^{5} ; 2: 339^{9}$, $397^{1}-401^{2}, 402^{1}, 402^{5}, 402^{9}$.

White spotted sawyer, 2: $339^{3}$, $364^{1}$.

wilcoxi, Calosoma, $1: 113^{5}$.

wildii, Dorcaschema, 2: $726^{6}$.

Willow, in jurious insects: $1: 49$.

borers: $2: 74 \mathrm{r}^{4}$.

Aegeria apiformis, $2: 429^{8}$, $472^{x}$.

tibialis, $2: 429^{7}, 472^{2}$.

Agrilus politus, 2: $729^{\circ}$.

Anthaxia viridicornis, $2: 724^{3}$.

bronze birch horer, $1: 285^{7}$, $287^{3}$.

carpenter worm, I: 84 '.

Ceruchus piceus, $2: 492^{7}$.

clearwing, three banded, 2: $429^{2}, 471^{2}$.

Lucanus dama, 2: $70 \mathbf{I}^{8}$.

Micracis suturalis, $2: 715^{9}$.

l'lectrodera scalator, 2: $746^{6}$.

J'ngonocherus mixtus, $2: 649^{5}$. $663^{8}$.

Saperda mutica, 2: $429^{5}, 469^{4}$. Sesia albicornis, 2: $429^{6}, 469^{6}$. holteri, $2: 429^{6}, 470^{5}$.

Stenopsis argenteomaculatus, 2: $72 \mathrm{I}^{2}$.

Sitenoscelis brevis, $2: 494^{5}$.

Tenebrio tenebrioides, $493^{5}$.

Tenebrioides corticalis, 2: $492^{1}$.

willow borer, mottled, I: $5 \mathrm{I}^{7}$, $100^{4}$.

wiNow shoot sawtly, I: $25^{8^{2}}$, $302^{5}$.

flower cricket, white, $2: 603^{3}$.

gall insects, 2: $617^{9}, 745^{1}-46^{4}$.

European willow gall midge, I: $25^{1}, 299^{5}$.

Pontania desmodioides, 2: $625^{2}, 6381$.
Willow, inj. insects (cont' $d$ ): gall insects:

Pontania hyalina, 2: $62 \mathrm{I}^{2}, 635^{6}$. pisum, $2: 620^{9}, 637^{5}$.

willow apple gall, $2: 620^{\circ}$, $636^{\circ}$.

willow club gall, $2: 620^{8}, 636^{5}$. willow cone gall, $2: 62 \mathrm{I}^{2}, 639^{\circ}$. willow gall midge, European, 2: $620^{8}$,

leaf feeders: $2: 74 \mathrm{I}^{3}-44^{5}$.

Abbotana clementaria, 2: $72 \mathrm{I}^{4}$.

Adoneta spinuloides, 2: $706^{\circ}$.

Alceris hastiana, $2: 744^{3}$.

alder leaf beetle, $2: 509^{3}, 5+2^{8}$.

American silk worm, 2: $526^{6}$.

Anagoga pulveraria, 2: $728^{3}$.

Anaspis flavipennis, 2: $567^{1}$.

Apatela brumosa, 2: $704^{5}$.

distans, $2: 747^{\circ}$.

grisea, $2: 724^{8}$.

A patelodes torrefacta, 2: $549^{4}$. apple tent caterpillar, $2: 55^{2}$. bag or basket worm, I: $27^{2}$.

Basilarchia archippus, 2: $70^{2}$. black walnut caterpillar, 1: $305^{4}$.

buck moth, I: $311^{9}$.

Catocala vidua, 2: $705^{5}$.

Cecropia moth, 2: $539^{5}$.

cherry scallop shell moth, 2 : $551^{6}$.

Chrysomela bigsbyana, 2: $51 \mathrm{I}^{4}, 566^{2}$. philadelphica, 2: 752 "

Corythuca ciliata, 2: $719^{3}$.

cottonwood leaf beetle, I:

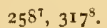

dagger moth, smeared, 2: $5 \mathrm{II}^{1}$, $560^{2}$.

Dichelonycha elongata, 2: $716^{4}$.

Elleschus ephippiatus, 2: $511^{5}, 5^{6} 7^{3}$.

eln caterpillar, spiny. 1: $105^{8}$, $158^{9}$.

elm sawfly, I: $105^{b}, 155^{*}$.

Epagoge sulfureana, 2: $730^{7}$.

forest tent caterpillar, I: I $10^{\circ}$.
Willow, inj. insects (cont' $d$ ):

leaf feeders:

Gluphisia septentrionalis, 2 : $747^{6}$.

Gracilaria stigmatella, 2: $747^{8}$.

Harpyia cinerea, 2: $5 \mathrm{JO}^{\circ}, 559^{4}$.

Heterocampa biundata, 2: $727^{5}$.

Hyperaeschra stragula, 2: $747^{6}$.

lung moth, 2: $527^{3}$.

Lycia cognataria, 2: 728 .

maple worm, semilooper, 2: $508^{9}, 538^{5}$.

Melalopha albosigma, $2: 747^{5}$. apicalis, $2: 747^{5}$.

Melasoma tremulae, 2: $565^{6}$

Metanema quercivoraria, 2: $706^{6}$.

Metrocampa praegrandaria, 2: $749^{7}$.

Morrisonia confusa, $2: 727^{8}$.

oak tussock caterpillar, 2 : $523^{3}$.

Orchestes ephippiat us, $2: 567^{2}$. niger, 2: $567^{2}$.

Paonias excaecatus, $2: 724^{\circ}$.

Pheosia dimidiata, $2: 747^{6}$.

poplar leaf beetle, 2: $510^{8}$, $55^{8}$.

poplar sawfly, $2: 569^{1}$.

poplar tent maker, 2: $511^{2}$, $560^{6}$.

Pristiphora sycophanta, 2: $510^{8}, 557^{9}$

tibialis, $2: 74^{6}$.

Pteronus mendicus, 2: $5 \mathrm{II}^{2}$, $56 \mathrm{I}^{4}$.

odoratus, 2:5 II $\mathrm{I}^{3}, 562^{4}$.

Pyrophila pyramidoides, 2: 704 .

Raphia frater, $2: 74{ }^{\prime}$.

Rhynchites cyanellus, 2;567\%.

Schizura unicornis, 2: $705^{\circ}$.

smerinthus jamaicensis, 2: $724^{7}$.

Thecla liparops, 2: $704^{3}$.

tussock moth, white marked, 1: $136^{\circ}$.

viceroy, $2: 510^{9}, 559^{\circ}$.

webworm, fall, $r: 142^{5}$. 
Willow, inj. insects (cont'd):

leaf feeclers:

willow thea beetle, 2: $5 \mathbf{1 1}^{3}$, $5^{6} 3^{5}$.

willow leaf heetle, dull red, 2: $511^{4}, 566^{8}$.

spotted, 2: $511^{8}, 564^{9}$.

willow slug, yellow spotted, I: $25^{8^{8}}, 322^{3}$.

Psocus rufus, $2: 744^{9}$.

scale or sucking insects: 2: $7+4^{6}$.

Aspidiotus rapax, 2: $728^{7}$.

Brochymena arborea. 2:591 ${ }^{8}$. quadripustulata, 2: $590^{4}$.

Buffalo tree hopper, $2: 592^{3}$.

Chionaspis lintneri, I: $227^{9}$.

Eulecanium caryae, $2: 725^{6}$.

Melinna pumila, $2: 735^{1}$.

oyster scale, $I: 212^{6}$.

l'utnam's scale, $1: 227^{4}$.

Willow, European, cottonwood

leaf beetle iujuring, I: $318^{\prime}$.

Willow apple gall, 2: $620^{9}, 636^{\top}-$ $3 i^{-2}$.

Willow borer, mottled, $x: 8^{8}, 51^{7}$, $100^{4}-3^{9} ; 2: 469^{7}$.

Willow club gall, $2: 620^{8}, 636^{5}$.

Willow cone gall, 2: 621 ${ }^{\circ}, 639^{\prime}$.

Willow flea beetle, $2: 511^{3}, 563^{4}$ $64^{7}$.

Willow gall midge, European, 1: $258^{9}, 299^{4}-302^{2} ; 2: 620^{y}$.

IVillow galls, $2: 745^{1}-46^{5}$.

Willow leaf beetle, dull red, 2 $51^{4}, 566^{6}$.

spotted, 2: $5 \mathrm{II}^{3}, 564^{4}-65^{6}$.

IVillow shoot sawfly, $1: 25 x^{2}, 302^{2}-$ $3^{\mathrm{T}}$.

Willow slug, yellow spotted, lo: $25^{8}, 322^{2}-24^{9}$.

Winterberry, injurious insects: leaf feeder:

Schizura unicornis, 2: $705^{9}$.

Winthemia f-pustulata, $1: 132^{1}$, $13^{87}$.

Wisteria, $t$ wo-marked tree hopper injuring, 2: $595^{6}$.

Witch-hazel, injurious insects: lyorer: $2: 723^{\circ}$.

Jeptostylus, spotted, $2: 482^{9}$
Witch-hazel, inj. Insects (cont'd'): gall insects:

witch-hazel cone gall, $2: 621^{2}$, $639^{9}$.

witch-hazel gall, spiny, 2 : $621^{3}, 6+3^{4}$.

leaf feeders: $2: 723^{9}-24^{2}$.

Adoneta spinuloides, $2: 706^{9}$.

American silk worm, 2: $526^{\circ}$.

Apatela hrumosa, 2:70.5

apple tent caterpillar, $2: 55^{\mathbf{I}^{1}}$.

Datana drexelii, $2: 739^{2}$.

Episimus argutanus, $2: 725^{3}$.

hag moth caterpillar, $2: 528^{6}$.

Heterocampa biumdata, 2: $727^{8}$.

subrotata, 2: $716^{4}$.

Prolimacodes scapha, 2: $7^{07^{1}}$.

Schizura ipomoeae, $2: 705^{9}$.

Tortricidia pallida, $2: 7^{0} 7^{4}$.

Witch-hazel cone sall, 2: $62 \mathrm{I}^{3}$, $639^{8}-43^{4}$.

Witch-hazel gall, spiny, 2: $62 \mathrm{I}^{3}$, $643^{4}-46^{9}$.

Wollastonia quercicola, $2: 7+7^{1}$.

Wood borers, $1: 7^{3}, 1 \mathrm{t}^{9}, 35^{9}, 256^{4}-$ $57^{9} ; 2: 339^{1}$.

long-horned, $I: 7^{4}$.

smaller, $2: 339^{6}$.

Woodbine, injurious insects:

Eustrona diversilineata, 2: $706^{2}$. woodbine borer, $2: 430^{3}, 47^{8}$.

Woodbine borer, $2: 430^{8}, 478^{8}-79^{5}$.

Woodpeckers, $1: 28^{9}, 30^{4}, 54^{6}, 58^{4}$, $85^{8}, 284^{5}, 287^{4} ; 2: 3^{5} 4^{4}, 453^{3}$, $450^{4}$; activity, $1: 29^{2}$; common and scientific names, $1: 28^{6}$. downy, $1: 6 \mathrm{I}^{\mathrm{t}}$.

hairy, $2: 45 t^{1}$

Wool sower, 2: $615^{2}, 622^{1}, 622^{9}$

Woolly beech leaf aphis, $2: 601^{5}-2^{3}$.

Woolly elm hark aphid. I: $172^{9}$, $192^{4}$.

Woolly elm leaf aphid, $1: 172^{5}$, I $77^{7}-73^{9}$.

Woolly larch aphid, I: $172^{7}, 187^{6}-$ $88^{9}$.

Woolly maple leaf aphid, $2: 600^{5}$.

Woolly oak gall, 2: $618^{2}, 622^{9}-23^{2}$.

Woolly pine scale, $2: 652^{6}, 689^{6}-$ $93^{2}$.
II ren, 1: $32^{1}$. golden-crested, I: I9I. house, $1: 26^{8}$

xanthomelaena, Jisonycha, 3 $564^{6}$.

Xanthonia decemnotata, 2: $703^{7}$. villosula, 2: $703^{\text {? }}$.

Xenorhipis hrendeli, $2: 701^{7}$.

Xestobium squalidum, $2: 753^{8}$.

xiphydriae, l'ammegischia, $2: 466^{4}$.

Ayleborus, 2: $337^{\top}$.

biographus, $2: 4+7^{9}$.

celsus, $2: 427^{8},+4^{9}-48^{2}, 504^{4}$.

dispar, $2: 446^{6}$.

fuscatus, $2: 752^{2}$.

obesus, $2: 722^{4}$.

pubescens, $2: 396^{9}, 702^{7}, 720^{\circ}$.

Xylestia pruniramiella, $2: 731^{\prime}$.

Xyletinus Jugubris, $2: 731^{3}$.

Xylina antennata, $I: 49, I 05^{\circ}$. $129^{1}-32^{6}$.

bethunei, $2: 731^{6}$.

grotei, I: $130^{1}, 130^{6}, 131^{1}, 131^{2}$ : 2: $728^{9}$.

laticinerea, $1 ; 130^{1}, 130^{\circ}, 131^{1}$. $13 r^{3}$.

xyliniformis, Apatela, $2: 740^{4}$.

Xylocleptes, $2: 336^{9}$.

sp., $2: 428^{7}, 460^{8}$.

decipiens, $2: 715^{9}$.

Xylocopa virginica, $2: 430^{7}, 4^{5} 4^{9}$.

xylographus, Tomicus, $2: 355^{8}$.

Aylonomus albopictus, $2: 500^{1}$.

Xylopinus saperdoisles, $2: 703^{*}$.

Xyloterus, 2: $337^{7}$.

sp., I: $257^{\top}, 203^{9}-94^{4}$.

bivittatus, $2: 335^{\circ}, 339^{\circ}, 3(6)^{3}-$ $70^{9}$.

politus, $1: 257^{6}, 292^{5}-93^{*}$.

scabricollis, $2: 752^{2}$.

Aylotrechus colonus, $1: 256^{6}, 25 y^{2}-$ $6 \mathrm{I}^{7}: 2: 67 \mathrm{I}^{\circ}$.

contergens, $2: 734^{4}$.

(uadriuaculatus, $2: 722^{3}$.

sagittatus, $2: 649^{6}, 663^{1}$.

undulatus, $2: 650^{\circ}, 67 \mathrm{I}^{1}$.

Xyphidria albicornis, $2: 428^{3}, 459^{8}-$ $60^{1}, 406^{4}$.

provancheri, $2: 429^{3}, 459^{\circ}, 465^{1}-$ $66^{4}$. 


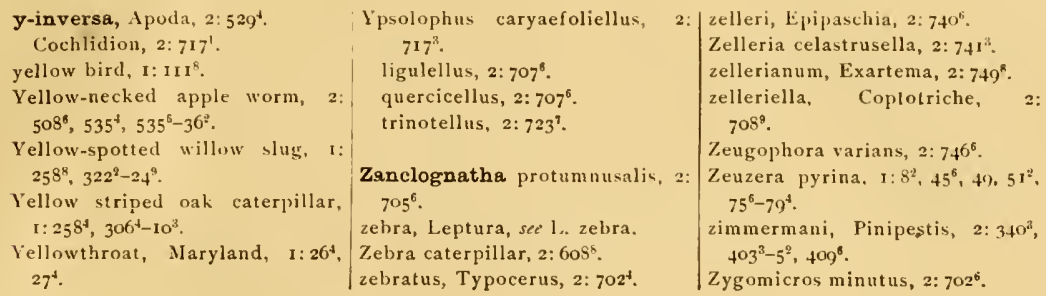

\section{ERRATA}

Page 74, line 12 from bottom, for E n telus, read Eutelus.

Page 105, line 3 from bottom, for Kaliosyphinga, read Kaliasysphinga.

Page 162, line 15, for Kaliosyphinga, read Kaliosysphinga.

Page ${ }_{16}$, legrend, figure 23 , for $\mathrm{K}$ a lios yph inga, read Kaliosysphinga.

Page 163 , line 7 from bottom, for 257 , read $23 \%$.

Page 214 and 229; for Comstock, J. A., read Comstock, J. H.

Page 233 , line 4 from bottom, for Emily G., read Emily L.

Page $\mathbf{2 3 9}$, line 3 , for Leptocorus, read Leptocoris.

Page 278 , line 11 , for $S p a t h$ in a, read $S$ pathius.

Page 3or, line 6 from bottom, for Polygonotus, read Polyg$110 \mathrm{t} 11 \mathrm{~s}$. 



$$
\begin{aligned}
& \text { PFOPERT OF } \\
& \text { Z P. METCALF }
\end{aligned}
$$




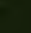

